\title{
THE CONSTRUCTION
}

\author{
OF
}

\section{HADRIAN'S WALL}

\author{
PETER ROBERT HILL
}

The copyright of this thesis rests with the author. No quotation from it should be published without his prior written consent and information derived from it should be acknowledged.

DOCTOR OF PHILOSOPHY

UNIVERSITY OF DURHAM

DEPARTMENT OF ARCHAEOLOGY

2003

$18 \mathrm{JUn} 200 \mathrm{~g}$ 


\section{ACKNOWLEDGEMENTS}

The writer gratefully acknowledges the assistance of many friends and colleagues who have offered information and comment.

He is especially grateful to his supervisors: initially Professor M. Millett and then, jointly, Professor A.J. Price and Dr. B. Dobson 


\section{CHAPTER 3 THE NATURE OF THE COUNTRYSIDE}

\section{AND ITS GEOLOGY}

$\begin{array}{lll}3.1 & \text { Topographical description } & 40\end{array}$

3.2 Geological description of the line 43

3.3 Climate 44

$3.4 \quad$ Flora 45

\section{CHAPTER 4 CONCEPT, DESIGN, AND SURVEY}

$\begin{array}{lll}4.1 & \text { Concept } & 51\end{array}$

4.2 The design of the Wall and its components 52

4.2.1 Introduction 53

4.2.2 The foundations and footings 54

Broad Wall foundations $\quad 56$

Narrow Wall foundations $\quad 58$

Intermediate Wall foundations $\quad 59$

Footings $\quad 59$

4.2.3 The design of the curtain wall 60

4.2.4 Broad, Narrow and Intermediate Walls compared 64

4.2.5 Milecastles and milefortlets 65

Milecastle gateways $\quad 72$

4.2.6 Comparisons with Antonine Wall fortlets 75

4.2.7 The purpose of the milecastles 76

$\begin{array}{lll}4.2 .8 & \text { Turrets } & 79\end{array}$

4.2.9 Comparison with the African frontier 83

4.2.10 Forts 86

4.3 Materials used in building the Wall 88

4.4 Render and limewash 91

4.5 The ditch 96

$\begin{array}{lll}4.6 & \text { The Vallum } & 97\end{array}$ 
$4.7 \quad$ Surveying $\quad 99$

4.7.1 The general line of the Wall 99

4.7.2 Positioning of milecastles and turrets 105

CHAPTER 5 QUARRYING

$\begin{array}{lll}5.1 & 107\end{array}$

$\begin{array}{lll}5.2 & \text { Overview of stone and quarries } & 109\end{array}$

5.3 Types of walling and surface finishes 115

$\begin{array}{lll}\text { 5.3.1 Ashlar } & 115\end{array}$

$\begin{array}{lll}5.3 .2 & \text { Block-in-course } & 118\end{array}$

$\begin{array}{lll}5.3 .3 & \text { Rubble } & 119\end{array}$

5.4 Methods of quarrying 122

$\begin{array}{lll}5.5 & \text { Quarry dressing } & 137\end{array}$

$\begin{array}{lll}5.6 & 139\end{array}$

CHAPTER 6 WORKING STONE: TOOLS AND METHODS

6.1 Tools 143

6.1.1 Tools of direct percussion 145

6.1.2 Tools of indirect percussion 149

6.2 Sharpening tools 156

6.2.1 Fire-sharpening and reforging of tools 157

$\begin{array}{lll}6.3 & \text { Working stone } & 158\end{array}$

6.3.1 Squared rubble 159

$\begin{array}{lll}\text { 6.3.2 Gate piers and voussoirs } & 161\end{array}$

6.3.3 Inscriptions 163

6.4 Setting-out and templets 165

6.4.1 Setting-out 166

6.4.2 Templets 169

6.5 Orientation of the stone 169

$\begin{array}{lll}\text { 6.6 Working stone from Roman quarries } & 171\end{array}$ 


\section{CHAPTER 7 HOISTING}

$\begin{array}{lll}7.1 & \text { Types of lifting tackle } & 175\end{array}$

$\begin{array}{lll}7.2 & \text { Ropes } & 181\end{array}$

7.3 The capacity and use of lifting tackle 181

$\begin{array}{lll}7.4 & \text { Attachment to the crane } & 189\end{array}$

$\begin{array}{lll}7.4 .1 & \text { Nippers and dogs } & 189\end{array}$

$\begin{array}{lll}\text { 7.4.2 Lewises } & 191\end{array}$

CHAPTER 8 LIME, SAND, AND MORTAR

$\begin{array}{lll}8.1 & \text { Lime } & 198\end{array}$

8.2 Pozzolanic additives 204

$\begin{array}{lll}8.3 & \text { Sand } & 205\end{array}$

8.4 Water 206

$\begin{array}{lll}8.5 & \text { Mortar mixes } & 207\end{array}$

8.6 Transport to the site 209

\section{CHAPTER 9 SCAFFOLDING}

$\begin{array}{lll}9.1 & \text { Definitions } & 210\end{array}$

9.2 The need for scaffolding 213

9.3 Scaffolding in Roman Britain 215

9.4 Scaffolding elsewhere in the Roman empire 220

9.5 The evidence for scaffolding along the Wall 221

9.6 The use of scaffolding on Hadrian's Wall 224

9.6.1 The probable nature of the scaffolding 224

\section{CHAPTER 10 TRANSPORT}

$\begin{array}{lll}10.1 & \text { Introduction and road construction }\end{array}$

10.2 Materials to be transported 233

$10.3 \quad$ Methods of transport 236 
10.3.1 Man carrying 236

10.3.2 Pack transport 238

10.3.3 Loading of pack animals 242

$\begin{array}{lll}\text { 10.3.4 Wheeled transport } & 247\end{array}$

10.3.5 Types and capacities of wheeled transport 247

10.4 Access roads 255

10.5 The Military Way 259

\section{CHAPTER 11 BUILDING OPERATIONS}

$11.1 \quad$ Preparation of the ground 264

$11.2 \quad$ Foundations and footings 265

11.2.1 Laying the foundations 265

11.2.2 Laying the footings 265

$\begin{array}{lll}11.3 & \text { The curtain wall } & 269\end{array}$

11.4 The milecastles $\quad 272$

$\begin{array}{lll}\text { 11.4.1 } & \text { Milecastle walls } & 272\end{array}$

11.4.2 Milecastle gateways 274

$\begin{array}{lll}11.5 & \text { Turrets } & 281\end{array}$

11.6 Forts 284

11.6.1 Interval towers 285

11.6.2 The gateways 285

11.7 Specialisation 288

$\begin{array}{lll}11.8 & \text { The ditch and Vallum } & 288\end{array}$

\section{CHAPTER 12 ORGANISATIONAL ASPECTS OF THE WORK}

12.1 The building season and the working week 291

12.2 The labour force 294

12.2.1 The evidence of inscriptions 294

12.2.2 Inscriptions from the Wall and forts 295

$\begin{array}{lll}\text { 12.2.3 The Vallum } & 299\end{array}$ 
$\begin{array}{lll}\text { 12.2.4 The ditch } & 304\end{array}$

12.2.5 Other auxiliary and native involvement 304

12.2.6 The size of the legionary labour force 305

12.3 Horizontal building and centurial lengths 313

$12.4 \quad$ Rate of building 320

12.4.1 Speed of fixing 321

12.4.2 Speed of quarrying and dressing 324

12.4.3 Speed for foundations, milecastles, and turrets 327

12.4.4 Rate for building a 'legionary length' 330

12.4.5 Ditch and Vallum 334

12.5 Identification of the work of the three legions 338

$\begin{array}{lll}12.6 & \text { Standards of workmanship } & 338\end{array}$

\section{CHAPTER 13 DISLOCATION OF WORK}

$\begin{array}{lll}13.1 & \text { Dislocation } & 341\end{array}$

$\begin{array}{lll}13.2 & \text { Progress at dislocation } & 341\end{array}$

13.2.1 Wallsend to MC4 345

13.2.2 MC4 to North Tyne 345

Milecastles $\quad 345$

$\begin{array}{ll}\text { Turrets } & 348\end{array}$

$\begin{array}{ll}\text { Curtain wall } & 349\end{array}$

Broad foundation $\quad 350$

13.2.3 North Tyne to the river Irthing 350

$\begin{array}{ll}\text { Milecastles } & 350\end{array}$

Turrets 352

Curtain wall 352

Broad foundation 353

13.3 Dislocation-discussion 354

13.4 The Narrow Wall decision 359

13.5 A second dislocation? 366 
CHAPTER 14 CONCLUSION AND SUMMARY 371

14.1 The existing view of Hadrian's Wall 371

14.2 The revised view 372

$\begin{array}{lll}14.3 & \text { Further research } & 378\end{array}$

\section{APPENDIX 1}

Curtain wall, milecastles, and turrets: wall and foundations widths

\section{APPENDIX 2}

Building the curtain wall 


\section{LIST OF PLATES}

following page

1 Lime from consolidation mortar leached out over

facing stones, Peel Gap tower (1996)

2 Splashing from mortar mixing at the foot of a modern brick wall

3 Mallet-headed ?Roman punch from Mumrills

151

4 Modern mallet-headed chisel

5 Poltross Burn stone

172

6 Poltross Burn stone: part-worked surface

172

7 Black Pasture stone: part-worked surface

showing chisel, claw, and punch marks

174

8 Black Pasture stone: surface worked with 1" chisel

9 Impressions in mortar of the putlogs used in scaffolding Ravenglass bath house

10 North wall of MC37, showing how irregularity of the stones make precision in fixing unnecessary

11 Rubbed ashlar wall, showing how the appearance is spoiled by errors of $2-3 \mathrm{~mm}$ in location and joint width 269 


\section{LIST OF FIGURES}

1.1 Gateway pier references

3.1 Contour section, Wallsend to Bowness 41

3.2 Geology of the Hadrian's Wall area 43

4.1 Foundations and footings $\quad 55$

$\begin{array}{lll}4.2 & \text { Stability of core } & 61\end{array}$

4.3 Comparative plans: Stone Wall and SW milecastles 72

$\begin{array}{lll}4.4 & \text { Milecastle gate plans } & 73\end{array}$

$\begin{array}{lll}\text { 4.5 MC52: theoretical garrison } & 77\end{array}$

4.6 Gateway through the fossatum Africae 84

$\begin{array}{lll}4.7 & \text { Knag Burn gateway } & 85\end{array}$

4.8 Comparative plans of towers in Africa and on Hadrian's Wall 85

4.9 The application of render/plaster to walling stones 94

$\begin{array}{lll}4.10 & \text { Turret and milecastle spacing variations } & 106\end{array}$

$\begin{array}{lll}5.1 & \text { Types of surface finish } & 116\end{array}$

$\begin{array}{ll}5.2 \text { Types of walling } & 120\end{array}$

$\begin{array}{lll}5.3 & \text { Twentieth century quarry tools } & 123\end{array}$

$\begin{array}{lll}5.4 & \text { Roman quarrying tools } & 124\end{array}$

$\begin{array}{ll}5.5 \text { Wedging } & 127\end{array}$

$\begin{array}{lll}5.6 & \text { Roman quarrying tools from Kriemhildenstuhl } & 129\end{array}$

5.7a Typical section through base of wedge slot 130

5.7b Effects of wedge as suggested by Bidwell and Watson $\quad 130$

$\begin{array}{lll}5.8 & \text { Wedge holes at Coombe Crag quarry } & 132\end{array}$

$\begin{array}{lll}5.9 & 134\end{array}$

$\begin{array}{lll}5.10 & 135\end{array}$

$\begin{array}{lll}5.11 & 136\end{array}$

$\begin{array}{lll}5.12 \text { Jumper } & 136\end{array}$ 
5.15 Waste in working a pier stone

$\begin{array}{lll}6.1 & \text { Modern masonry tools } & 144\end{array}$

$\begin{array}{ll}6.2 \text { Dressing hammer, picks, and adze } & 146\end{array}$

$\begin{array}{lll}6.3 & \text { Roman tools from Newstead } & 147\end{array}$

$\begin{array}{lll}6.4 \text { Axe/adze } & 148\end{array}$

$\begin{array}{lll}6.5 & \text { Roman stonemasons' tools } & 149\end{array}$

6.6 Cross-sections, wood and masonry chisels 150

6.7 Mallet- and hammer-headed chisels 151

$\begin{array}{lll}6.8 & \text { Egyptian mallet } & 152\end{array}$

6.9 Roman ?mallet-headed chisel 152

\begin{tabular}{ll}
6.10 & Varieties of claw tool \\
\hline
\end{tabular}

$\begin{array}{lll}6.11 \text { Gouge } & 153\end{array}$

6.12 Roman chisels from Kriemhildenstuhl 153

$\begin{array}{ll}6.13 & 153\end{array}$

$\begin{array}{ll}6.14 & \text { Punch and pitcher } \\ & 154\end{array}$

$\begin{array}{ll}6.15 & \text { The nicker, used for splitting stone } \\ \end{array}$

$\begin{array}{ll}6.16 & 157\end{array}$

$\begin{array}{ll}6.17 & \text { Thin slab built in to a wall face } \\ \end{array}$

$\begin{array}{ll}6.18 \text { Production and quantities sketch for a gateway } & 168\end{array}$

6.19 MC42, elevation of the south gate 168

6.20 Cross section of quarry showing beds and bedding planes $\quad 170$

$\begin{array}{ll}6.21 \text { Orientation of beds in an arch } & 171\end{array}$

$\begin{array}{lll}7.1 & \text { Sheerlegs } & 176\end{array}$

$\begin{array}{ll}7.2 & \text { Single-pole derrick } \\ 7 & 177\end{array}$

$\begin{array}{lll}7.3 & \text { Horizontal beam crane } & 179\end{array}$ 
$\begin{array}{lll}7.4 & \text { Mast derrick } & 180\end{array}$

$\begin{array}{lll}7.5 & \text { Use of a derrick in building a gateway } & 186\end{array}$

7.6 Building a gateway: moving stone from store to pier 188

$\begin{array}{lll}7.7 & \text { Nippers } & 189\end{array}$

$\begin{array}{lll}7.8 & \text { Dogs } & 189\end{array}$

$\begin{array}{lll}7.9 & \text { Dog hole } & 190\end{array}$

7.10 Chain or C-lewis 192

$\begin{array}{lll}7.11 & \text { Hero's lewis } & 193\end{array}$

$\begin{array}{lll}7.12 & \text { Three-legged lewis } & 193\end{array}$

7.13 Roman 3-legged lewis from Passau 193

$\begin{array}{ll}7.14 & \text { Two-legged lewis } \\ \end{array}$

$\begin{array}{llr}8.1 & \text { Flare kiln } & 199\end{array}$

$\begin{array}{lll}9.1 & \text { Parts of a scaffold } & 211\end{array}$

$\begin{array}{lll}9.2 & \text { Types of scaffold } & 212\end{array}$

9.3 Plan of standard and putlog holes in the south granary, Birdoswald 216

$\begin{array}{lll}\text { 9.4a Lifting jib } & 217\end{array}$

$\begin{array}{ll}\text { 9.4b Lifting tower } & 217\end{array}$

$\begin{array}{ll}9.5 & \text { Ravenglass bath house } \\ 9\end{array}$

$\begin{array}{lll}\text { 9.6a Putlog hole } & 222\end{array}$

9.6b Putlog hole made good 222

$\begin{array}{lll}9.7 & \text { Section through Wall and scaffolds } 226\end{array}$

9.8 Plan of likely scaffolding requirements to build an isolated turret $\quad 229$

9.9 Plan of likely scaffolding requirements 
11.1 Warburton's cross-section of the Wall near St. Oswald's 267

11.2 Different treatments of Narrow Wall on Broad Foundation 268

11.3 Building up one end of a unit length 271

11.4 Start of work in a gang length 272

11.5 Typical centre, suitable for a milecastle gateway 276

11.6 Loads on centring 277

11.7 Milecastle gateway: the work of the specialist gang 280

11.8 First stage in building a turret 281

11.9 T34a west wing wall 283

11.10 Milecastle and fort gateways 286

12.1 Location of centurial stones from the Vallum 300

12.2 Building up an intermediate section in a long gang length 313

12.3 Possible appearance at the end of a centurial length 315

12.4 Alternative positions of centurial stones at the end of a century/cohort/legionary length $\quad 316$

12.5 Least likely appearance at the end of a centurial length 316

12.6 Likely effect of Dislocation on units completing the curtain wall 317

12.7 Chart showing theoretical schedule of work for a legionary length 333

13.1a Progress at dislocation: MC0-N.Tyne 346

13.1b Progress at dislocation: N. Tyne-Irthing 347

13.2 Greatchesters fort north west angle tower 362 


\section{LIST OF TABLES}

2.1 Stanegate interval distances: first phase 31

$\begin{array}{lll}2.2 & \text { Stanegate interval distances: second phase } & 32\end{array}$

$2.3 \quad$ Fort spacing in the central sector 35

$3.1 \quad$ Heights above sea level 42

$\begin{array}{lll}\text { 4.1 Some pre-Hadrianic fortlet sizes and areas } & 67\end{array}$

$\begin{array}{lll}4.2 & \text { Comparison of TW and SW milecastles } & 71\end{array}$

4.3 Antonine Wall fortlets 76

$\begin{array}{lll}4.4 & \text { Milecastle barrack blocks } & 78\end{array}$

4.5 Dimensions of some pre-Hadrianic signal/watch towers and interval towers $\quad 82$

4.6 Some Wall fort tower dimensions 83

$\begin{array}{lll}5.1 & \text { Some stones in the Wall area } & 110\end{array}$

$\begin{array}{ll}5.2 & 132\end{array}$

$\begin{array}{lll}7.1 & \text { Pier stones, MC37, north gate } & 183\end{array}$

$\begin{array}{lll}7.2 & \text { Voussoirs, MC37 north gate } & 183\end{array}$

$\begin{array}{lll}7.3 & \text { Some Roman lewis hole dimensions } & 195\end{array}$

9.1 Scaffolding quantities for Hadrian's Wall 227

$\begin{array}{lll}10.1 & \text { Average weights of materials } & 233\end{array}$

10.2 Some pier stones from Chesters fort 235

10.3 Theodosian Code: capacity and types of vehicles 248

10.4 Calculated revised capacity and types of vehicles 255

12.1 Centurial stones certainly from the Vallum 299

12.2 Centurial stones suggested to have come from the Vallum 302

$\begin{array}{lll}12.3 & \text { Actual strength of a century } & 312\end{array}$ 


\section{GLOSSARY}

Arris

Banker

Banker mason

Bed (1)

Bed (2)

Bedding of stone

Carburising

Carver

Circular-circular-sunk

Dead man
The distinct line or edge formed by the meeting of two surfaces

A bench on which stone is worked, either a large block of stone or made up of heavy timber One who works stone, usually to a high standard and to closely defined forms, on a banker The height of stone in a quarry between breaks in sedimentary deposition or change in the character of the sediment

The upper or lower surface of a stone, or the bedding material on which the stone rests

1. Natural bedded. Stone laid in the same orientation in which is was originally laid down.

2. Face bedded. Stone laid so that the natural bedding planes are set vertically, parallel to the surface of the wall

3. Edge bedded. Where the stone is laid with the bedding planes set vertically at right angles to the surface of the wall

Heating iron on a bed of charcoal to produce a surface of steel

One who works stone to freehand designs, abstract, foliage, or figure

A moulding or feature which is convex in both directions; a sunk hemisphere is an example A temporary support for a building line which would otherwise sag owing to excessive length 
Dimension stone

Draft

Dressed stone

Dummy

Extrados

Fixing

Intrados

Joggle, joggled joint

Joint

Kivel

Make, to
Stone which is to be worked to a specific size. In the context of the Wall this is limited to gate piers, voussoirs, cornices, and similar items; it does not relate to the facing stones or to the string course Any worked strip on the surface of a stone; a marginal draft runs around the edges of the surface Worked to a specified shape, but 'roughly dressed' is quite different

A small hammer in the form of a truncated cone (base uppermost) with the shaft on the axis of the cone

The outer (upper) curve of an arch

Placing stones in position on a building

The inner (lower) curve of an arch (see also soffit)

1. Joints in an arch in which adjacent voussoirs are interlocked by means of visible rebates or steps

2. A groove cut on the joint of a stone to increase the hold of the mortar

1. The vertical side of a stone, against which another is placed

2. The mortar in the space between two adjacent stones

3. A natural crack or fault in a quarry, running vertically down through the beds. See also Shake

A form of scappling hammer, with a hammer and pick ends (the term is common in Portland quarries)

Where a quarried stone is of suitable size for a given requirement it is said to 'make', or where it is too small, it will not make. 
MC

Mitre

Moulded

Moulding

profile

Overburden

Pentapaston

Pinch bar

Pozzolanic

Raking joint

Rf

Roughly dressed

Sculptor

Shake

Sheave

Skelp

Soffit
Milecastle

A corner or angle of a moulding worked in solid stone. The mitre may be external, where the faces meet at more than $180^{\circ}$, or internal where the faces meet at less than $180^{\circ}$

Stone with a moulding worked on it

The profile formed by working a stone to a fixed

The non-stone material, soil, flaggy stone, etc., overlying the sought-after beds of stone

A tackle with five ropes

Small crowbar

Material such as volcanic sand or fired clay added to lime to produce hydraulic mortar

The temporary end of a length of wall, where the ends of each course are successively set back

Roman foot (pes Monetalis)

Usually used of stone given an approximate shape with simple tools such as punch or walling hammer An artistic carver

A natural crack in a stone, usually running vertically through the beds. Unlike a joint 3 it may well not be apparent until the stone is being worked

A wheel grooved to take a rope

Waste pieces of any size resulting from working stone

The under surface of an arch or lintel 
Spall

Spandrel

Spelch

Springer

String course

Sup., super.

Templet

$\mathrm{T}$

Toothed joint

Worked stone

Working/dressing
A detached piece of stone, the result either of deliberate action with a tool or due to frost or similar action

The triangular area of wall at either side of an arch, or between two adjacent arches

A small flake of stone detached by an accidental blow

The lowest voussoir in an arch, resting on the capital

A thin course of stone, usually moulded, which projects beyond the wall line and is generally deigned to shed water

Superficial area, surface area

Pattern made in rigid material showing the shape to which a stone is to be worked

Turret

The temporary end of a wall where the ends of alternate courses are set back to give a vertical line Also dressed, but not same as 'roughly dressed Shaping stone to a specified form. Strictly speaking, squared rubble is not worked stone as the final size is approximate 


\section{CHAPTER 1}

\section{Introduction}

A number of scholars, notably Stevens and Hooley and Breeze, ${ }^{1}$ have examined the building of Hadrian's Wall from the viewpoint of the order of construction and which legions were responsible for various sections. Others, such as Richmond and Child, and Bidwell, ${ }^{2}$ have examined the design of the Wall and its structural elements. This thesis, although impinging on their work, is concerned largely with the practical aspects of the physical construction of the Wall.

The purpose of this thesis is to examine all the processes necessary to build the Wall; it is concerned not simply with the work of putting one stone on another. The line had to be surveyed and the infrastructure and support services had to be set up; the principal relevant operations included quarrying, stone dressing, and lime burning, with the subsidiary operations of sand and water supply, scaffolding, and transport. Each is treated separately before consideration of the techniques of actually building the Wall. The digging of the Vallum and the ditch is discussed, and the addition of the forts and other changes to the programme are included. Organisational aspects arising from the study, such as the hours of work and the potential labour force are grouped together in chapter 12.

The study is confined to the curtain wall and turrets, and the defences of the milecastles and forts, on Hadrian's Stone Wall, and so far as possible all examples of Roman techniques are taken from the Wall and its immediate locality.

\footnotetext{
1 Stevens (1948 and 1966); Hooley and Breeze (1968).

2 Richmond and Child (1942); Bidwell et al. (1988).
} 
'The Wall' is regarded as the original scheme for a Broad Wall from Wallsend to the river Irthing, and the Turf Wall from the Irthing to Bowness, with a more or less continuous ditch to the north.

\subsection{The nature of the evidence}

There are several types of evidence which can be used to construct a picture of how the Wall was built: contemporary sources on Roman building methods; archaeological evidence and published excavation reports; considerations of the form and design, which will have an effect on the methods of building; models of the methods of building based on an interpretation of the physical remains, either by the excavators or others; later sources on building methods and related activities; and the extant remains of the Wall. These several types of evidence are discussed in the following sections.

The different approaches all have their drawbacks. Two of the principal difficulties are the need to understand fully the philosophy of the builders; and the fact that the building of the Wall was almost entirely a matter of practical, manual skills. Understanding the philosophy of a vanished civilization is extraordinarily difficult, as one is inevitably influenced by modern conditioning. Understanding manual skills is in its way just as difficult; despite the general belief that the theoretician is superior to the practitioner such skills cannot be fully comprehended by academic study, especially where those studies are written by other nonpractitioners. Some examples and problems arising from the various types of study, and their value as source material on which to construct another model, are discussed together with any shortcomings. 
This thesis is firmly based on the experience of the author. After early work on the shop floor of a major engineering company, an introduction to the masonry trade was gained with a small firm in Northampton. Work included minor quarrying, and both domestic and church work. Nine months was then spent working for the direct labour force of the Department of the Environment. Next, a formal apprenticeship as a stone mason at York Minster was followed by several years as a banker and fixer mason. Three years were then spent as a setter-out, that is preparing full-scale drawings and producing the templets for working stone, for everything from domestic window sills to almost every feature found in a Gothic cathedral.

Six years were then spent as Clerk of the Works of Lincoln cathedral, responsible for specifying and directing the work of stone masons, carpenters, joiners, plumbers (lead roofing and rainwater goods), and others. Since 1988 the author has practised as a stone consultant, work which has included survey and specification for repairs to major and minor historic buildings, as well as analysing excavated and standing archaeological stonework. In 1995 the results of twenty-five years' experience resulted in what has become the standard modern text book for the masonry trade, Practical Stone Masonry, jointly written with a trade colleague Mr. J.C.E David.

\subsubsection{Contemporary Roman sources}

The only near-contemporary text book of building practice to survive is that of Vitruvius' De architectura, dating to the reign of Augustus. This is a collection of notes on a wide variety of subjects as diverse as the proportions of temples, the making of water clocks, scorpiones, and ballistae, and the phases of the moon. The treatment is very uneven, as is to be expected in view of his advancing years. ${ }^{3}$ The

3 See Book II, Intro, 4, and V, xii.7. 
work is that of a man in retirement, whose powers were failing, writing for his patron as an act of pietas, giving thanks for his pension. He was very clearly not a practical man, and only occasionally sheds any useful light on building techniques. He will be quoted on occasions, but always with the reservation that he (or his source) was giving his own opinion of what is proper, an opinion which might or might not have been shared by his contemporaries. One text book can never be regarded as an infallible source of the best, or even current, practice.

It must also be remembered that what might have obtained in contemporary or near-contemporary Rome does not necessarily have any relevance to what happened in second century Roman Britain. Britannia was a small province on the edge of the empire, and along the Wall the army was clearly content, as will be brought out, with a low standard of workmanship. A glance at masonry work and letter-cutting in forts and fortresses in Germany shows a much higher standard of work than is usually found in Britain in general and on the Wall in particular. The Wall does not even bear comparison with Hadrianic work in the civil areas of the province; the fine inscription from Wroxeter ( $R I B$ 288) would have looked quite out of place on the Wall. It is not necessarily safe to draw parallels from one province to another.

\subsubsection{Archaeological evidence}

The traditional method of looking at the way in which the Wall was built has been for the archaeologist to extrapolate from the archaeological evidence. This often has the advantage of first-hand appreciation of excavated material, but the inherent limitations must be recognised.

Archaeological evidence of building works is limited in the information it can provide, unless interpreted from the practical point of view. It will yield useful data 
from those points where thorough excavation has taken place and where there has been detailed analysis of the building materials and methods. If the analysis is carried out by the excavator the utility will depend upon what the excavator regards as being significant, both during the excavation and in writing up. If the excavator has little interest in, or knowledge of, constructional methods and materials, then much may be missed and even more omitted from the report. This is not to impute 'blame' to the excavators, but rather to recognise the shortcomings of the method.

This is not a localised problem. The lack of detail available in reports on excavation in the Middle East is exemplified by this cri de coeur: ' . . et il est inutile d'en dresser le catalogue: çela va du "grand" au "petit", du large au small, avec des extrêmes, comme les "huge slabs of displaced bedrock ... "pierres locales" medium to large in size $\ldots .^{14}$

Much of the excavation of the Wall in the nineteenth and the first half of the twentieth centuries was aimed at finding the line of the Wall; uncovering structures in order to confirm their frequency; exploring variations in design, and obtaining dating evidence. It was not uncommon for the excavation of a building to result in a detailed exposition of pottery and small finds, while the building itself was treated in a few lines; and where technical references to materials are concerned, a little knowledge is often seen to be sufficient..$^{5}$ Terms can become confused, to the extent that rubble walling may be described as ashlar.

$4 \quad$ Aurenches (1981) 18.

5 A significant, and very early exception was the work of Gibson and Simpson (1911), where it was noted that the stones of the gateway at milecastle (hereafter MC) 48, Poltross Bum, were less good than elsewhere, describing them as '. . massive (though badly finished) masonry ...' This is one of the few early qualitative assessments of the work of the Roman builders which bears some relation to the extant remains. 
This can seriously affect the quality of the evidence for the structure of the Wall offered by excavation reports. An analogy is the passing reference to coarse pottery in very early descriptions of the unearthing of archaeological sites; it may be mentioned, it may be described as 'black' or 'red', but it may leave the modern pottery specialist with little idea of what was actually found. Similarly, glass has been described as 'of the usual colour'.

In a discussion on the design of the Wall, ${ }^{6}$ a reinterpretation of the type II/IV milecastle gateways relied to some extent on photographic evidence to confirm that they had been designed with flush piers at the rear. What could not be done was to give any reliable estimate of the quality of workmanship, something which is now becoming recognised as potentially important. Photographs cannot be a substitute for precise, informed measurement.

There is then some limitation on the utility of archaeological evidence, in that it is restricted in scope and has to be interpreted, and any interpretation is subject to error due both to the limitations of the original evidence and to the technical knowledge of, and any unconscious bias on the part of, the interpreter.

\subsubsection{Design and reconstruction}

In one sense questions of design and reconstruction carried out on paper have little relevance to the practicalities of building the Wall, but any consideration of the logistics of building must perforce take into account the size and complexity of the structure.

There have been many attempts in the last one hundred years to give detailed consideration to both the appearance of the Wall and to the technicalities of the

$6 \quad$ Hill and Dobson (1992), 35. 
process of building. Perhaps the more notable are: Parker Brewis (1932) on turret 18a; Richmond and Child (1942) on fort gateways; Bellhouse (1969) on Turf Wall and Stone Wall turrets; Simpson (1976) on the design of the gateway of MC37; and Bidwcll and Holbrook (1989) on Hadrian's Wall bridges. All these paper reconstructions have one thing in common: they examine closely much of the technical detail and in effect offer a blueprint from which one could build. This writer does not agree with all the proposals put forward, and some do not stand up to close examination, but in each case sufficient detail was offered to allow them to be used as a base on which to construct fresh hypotheses.

Full scale reconstructions can provide a useful source of inspiration. The Wall and turrets at Vindolanda and the compete gateway at South Shields are notable achievements which allow both amateur and professional alike to gain a feel for what the originals may have been like. The building experience at Vindolanda and the reasoning behind the design chosen for South Shields are also in print. ${ }^{7}$ Again, one may not agree with either reconstruction in detail, but the evidence is there as a basis for further discussion.

\subsubsection{Interpretation of building methods}

This type of evidence takes forms. First is the interpretive, secondary source drawn from text books and from discussions with, and observation of, craftsmen. Like Vitruvius, they tend to be very uneven in quality, depending on both the level of understanding of their own sources, and in their ability to draw inferences from that knowledge. To some extent they may be an '. . almost circular transfer of what is in

7 Birley (1977) (Vindolanda); Bidwell et al. (1988) (South Shields). 
some cases little more than a collation of imperfectly understood hearsay evidence. ${ }^{18}$ The common misuse of terms and incorrect explanation of misunderstood techniques have much in common with Gibbons' references to the scranlet and the rennet-post. ${ }^{9}$

Those sources based on a measure of practical knowledge of the techniques involved show a marked improvement, ${ }^{10}$ but unevennesses in quality can make them unreliable in use.

Probably the best-known description of how the Wall was built is given in chapter 2, section ix, of the Handbook to the Roman Wall (13th Edn.). In less than 2,000 words it provides a conveniently succinct account, authoritative in tone and readily digested. This edition was published in 1978, and so has inevitably been overtaken by more recent discoveries and new theories. More significantly, it repeats old errors of fact and nomenclature. To give two examples, Collingwood Bruce in the second edition ${ }^{11}$ referred to the facing stones as 'carefully squared freestone blocks'; this description has continued through to the current (1978) edition. The facing is in fact of roughly squared rubble, a vastly different finish in terms of time and labour. Also, he notes that quicklime, mixed with sand and gravel, and slaked only just before use, yields mortar which 'speedily hardens.' The setting of lime mortar depends entirely on the nature of the limestone or the addition of pozzolanic material, and has little to do with the moment of slaking (see chapter 8).

Stevens (1966) looked at the building of the Wall through a tour de force of centurial stone location. In the course of this he went to some lengths to explain the

$8 \quad$ Hill (1981), where a number of examples are discussed.

9 Gibbons (1932) passim. This satirical tale of rural life in the 1920s makes authoritative and wholly credible use of invented agricultural terms such as the two quoted.

10 e.g. Blagg (1976) although this is biased towards sculptural techniques.

$11 \quad$ Bruce (1884) 32. 
few examples of what he identified as 'horizontal building'12, by which he meant building in successive horizontal bands each of several courses, not realising that, for practical reasons, this method must have been how all of the Wall was built (see section 12.3). It did not unroll over the countryside as a $15^{\prime}$ entity.

Great benefit has been obtained by taking the advice of persons with first-hand experience of building work of a similar nature; Robert Rawlinson's input to Collingwood Bruce's Roman Wall is perhaps the best known of these but even this has its limitations. Rawlinson ${ }^{13}$ gives the daily output of a navvy as 20 cubic yards of earth per day; but he does not give the length of the working day, nor does he say whether, or how many, additional barrow-men were used for this task.

A wide-ranging survey of Roman building methods and materials is Jean-Pierre Adam's Roman Building. ${ }^{14}$ There is much useful information to be found in its pages, but it suffers greatly from its derivative nature and, just as important, the translation is very uneven in its use of terms. When describing four conjoined stone shafts found at Ostia, they are referred to as '... still joined together in groups of four, just as the quarryman had extracted them from the rock.' In fact, they resemble nothing so much as a part-worked cluster of shafts to be used as a group. They are certainly not 'as extracted from the rock', as they are worked on all sides. The uncertain treatment of tools is discussed in section 6.1.

Misuse of terms in all works can be a problem, leading to misunderstanding of the object described. To take one example, the face of a stone worked with marginal drafts and the centre of the face left in a more or less natural state is 'rock-faced with chisel-drafted margins'; Richmond and Child properly so described the gate piers at

\footnotetext{
12 Stevens (1966), 17, 28, and passim

13 Bruce (1851), 94.

14 Adam (1994).
} 
Housesteads in $1942,{ }^{15}$ in accordance with standard architectural terminology. There is a tendency now to describe this sort of work as 'rusticated', but work proper to this description is quite different and will take many times longer to work. There seems to be some confusion with 'rustic finish', a term used only of granite which is left with a natural face. Language changes, but this incorrect use of terms leaves what is traditionally known as 'rusticated' without a name, quite apart from the confusion entailed.

There is something of a modern tendency to describe all workers of stone as 'sculptors', on the grounds that the modern fine distinctions between trades did not exist in ancient times. The point has some validity in that the distinctions may have been blurred at times but the differences certainly did exist. Those who carved the images on Trajan's Column were 'sculptors' and had skills quite different from those who worked the gate piers of the Wall forts, men more properly described as 'masons' even though their level of skill was generally low. The proper use of language brings to the mind the levels of skill and artistic ability appropriate for the work under discussion. The very large altar top found at Burnfoot Farm, near Carlisle, appears to have been worked by two men who today would be called 'mason' and 'carver'. ${ }^{16}$

Text books written as educational material for craftsmen ${ }^{17}$ are of some value, in that they are firmly based on practical experience, although, recognising that manual skills can be learnt only by experience, they give no more than an outline of methods of working stone.

15 Richmond and Child (1942), 138.

16 Hill (2001f). Mr T. Wilmott kindly arranged for the assessment of this piece.

17 e.g. Purchase (1898), Warland (1929), Hill and David (1995). 
In order to gain or confirm ideas of the speed of working, builders' estimating tables are a possible source. The problem here is twofold. First, such tables are designed for estimating on the basis of skilled and experienced staff, whereas the Roman legionary was not, first and foremost, a building craftsman; he was a trained soldier who carried out building work as required. Many legionaries would have become highly experienced in building, but in normal times the more experienced and higher-skilled men would have concentrated their efforts on the more technically difficult parts of the project in hand; when building a stone wall from Tyne to Irthing, skilled men will have been in very short supply, as is evidenced by the results. The building of a single stone fort called for four gateways in dressed stone; a substantial task but one with which the training of a legion's establishment of craftsmen would presumably be designed to cope. The building of forty-nine stone milecastles (Wallsend to the Irthing), to which was added perhaps seven primary forts, called for a total of something in the order of 170 portals; this must have put an almost intolerable strain on the skill resources of the three legions. It is not necessarily impossible to use estimating tables, but it has to be done with great care.

Secondly, the Roman army did not build in a manner similar to nineteenth and twentieth century builders. The curtain wall of Hadrian's Wall is built with facing stones which are very large when compared with a more modern wall faced with squared rubble. Nineteenth century railway and dock engineering often uses stones of a similar size and nature to the Roman, but normally dressed to a higher standard and with very much better beds and joints. These factors make comparisons difficult.

Some of the work reviewed above has been based on archaeological evidence from the Wall itself, some on a combination of such evidence and the opinion of third parties, and some on what has perhaps seemed to the writers to be a reasonably 
likely method of working. The overall effect is not unlike a builder discussing excavation techniques; it may be done with great care and contain invaluable insights, but it is unlikely to be wholly satisfactory.

\subsubsection{The extant remains}

The Stone Wall originally had 49 milecastles (MC0-MC48) and 96 turrets, and on the Turf Wall there were 32 milecastles and 62 turrets. Eventually there were 17 forts, including Vindolanda and Carvoran. Today, there are comparatively few structures where masonry is visible: 14 stone wall turrets and 3 turf wall turrets $(7 \mathrm{~b}$, 26b, 29a, 33b, 34a, 35a, 36b, 39b, 41a, 44b, 45a, 48a, 48b, 49b, 51a, 51b, 52a) with two additional towers (Peel Gap and Pike Hill), seven milecastles (10, 33, 35, 37, 39, 42, 48), and seven forts (Wallsend, Chesters, Housesteads, Vindolanda, Greatchesters, Carvoran, Birdoswald), plus Vindolanda just off the line of the Wall; some of these structures are fragmentary remains. In addition there are several miles of curtain wall, ranging from the tiny fragment in a garage forecourt at the junction of Westgate Road and Denton Road in Newcastle upon Tyne, to the long stretches over Cuddy's Crag and Walltown Crags.

Almost all the remains are unsatisfactory to a greater or lesser extent in the evidence they provide. Some parts of the curtain wall were rebuilt, in part at least, by John Clayton in the nineteenth century, as were parts of the fort at Housesteads, and the turret at Brunton. Since his day, considerable lengths of the curtain have been exposed and consolidated by the Ministry of Works and its successors, the Department of the Environment and English Heritage. The greater part of this was carried out with only minimal archaeological supervision until the late $1970 \mathrm{~s},{ }^{18}$ and

18 Crow (1991b) 52. 
much of the detail is known only from the records kept by the late Charles Anderson in his role as site foreman. Consolidation involved dismantling of some of the facing stones, re-mortaring or grouting of the corework, and sometimes rebuilding the facing so as to present a vertical face regardless of the appearance when uncovered. No doubt many of the bulging faces were the result of decay and outward pressure from the core, but it is very likely that, at least in parts, the curtain wall was originally built less than accurately. Many minor variations of this sort have thus been lost. The practice of the National Trust, of replacing only sufficient fallen stone to give a level top, has much to recommend it from the viewpoint of preserving the original form of the curtain wall - apart from any intervention by Clayton.

The turret, milecastle, and fort walls, whether consolidated or rebuilt, are in similar case. The milecastle and fort gateways are in the main rather more original in form, although some have certainly been rebuilt as either part of the consolidation process or following excavation.

Much of the Wall now visible is thus not Hadrian's Wall but Clayton's wall, or DOE wall. However carefully a wall or structure is rebuilt, something is lost and it is to an extent archaeologically 'dead.' The writer worked as a stone mason with the DOE in the early 1970s, and now has some suspicion of consolidation. There was then a total absence of training in the philosophy of treating Ancient Monuments, and senior staff were seen to break stones to make them fit during reinstatement. It is difficult to say to what extent this was common, and Charles Anderson has a good reputation, but it leaves doubts. The original stones, if unbroken, provide a record of the original work, but position and alignment do not.

However, all extant parts of the Wall have been examined as parts of this study, and any doubts noted in the text as appropriate. 


\subsection{Present Method}

The method adopted in the following pages is based on every type of source material discussed above, observing the various caveats. Interpretation is based upon the writer's first-hand experience of stone masonry and building. Inferences have been similarly drawn, supplemented by informed interrogation of professional and craft colleagues.

Where first-hand knowledge of the other, non-construction, techniques and practices are not part of the author's experience recourse to secondary sources has been necessary. So far as practicable, only firm evidence and verifiable material has been used, regardless of period. Inferences drawn from the work of later periods are used with equal caution, and the reasoning behind them laid out.

In general, the evidence used has been drawn from the Wall itself and the immediately surrounding area. Only where necessary have parallels been drawn from elsewhere; the thesis is intended in part as a record of what actually happened in the north of England in the first part of the second century.

Perhaps the greatest difficulty likely to be experienced in essaying a sequence and programme for building the Wall lies in trying to get into the mind of the Roman builders. It must be remembered that those who built the Wall were not builders but soldiers who happened to be building. Their philosophy, as will be brought out, was apparently very different from that of twenty-first century society.

It has been necessary to make some assumptions, which are as far as possible reasonable and logical, although the dangers of applying logic to building, as to any human activity, have to be recognised. All assumptions are given as such. In view of the known variation in the size of structures, the structures for which no dimensions are available, and uncertain elements such as the original height, average, typical, or 
probable sizes have been selected for the curtain wall, milecastles, turrets, ditch and Vallum. Given the scale of the Wall and associated structures some contradictions to what is contained herein are bound to be recognised.

\subsection{Terminology}

The building terms used are defined in the sense in which they are normally understood in the building industry, and by the professionals and craftsmen therein. Masonry terms are taken from Hill and David (1995) and the Stone Federation (n.d.).

Where specific milecastles and turrets are referred to by number, they are are abbreviated to $\mathrm{MC}$ and $\mathrm{T}$.

\subsection{Measurements}

Dimensions are normally quoted in Imperial measure, with conversions given in millimetres for figures below ten metres, and in metres for greater figures. As one tonne is a little over $98 \%$ of one ton, this conversion is not normally given unless large numbers are involved; for 'ton' read also 'tonne'.

Conversions to Roman measure are based on $296 \mathrm{~mm}$ to a Roman foot, ${ }^{19}$ abbreviated to Rf.

\subsection{System of stone references}

Throughout this thesis references are made to individual stones in the piers of the milecastle and fort gateways. The following paragraphs and figure 1.1 explain the author's system.

19 Pes Monetalis, Walthew (1981). 
The piers at the four corners of a gate are given as SW, SE, NE, and NW. The several faces of each pier are identified by letter: the outer face of the pier which supported the arch - A; the face of the pier parallel to the passageway - B; the return of the pier to the passage wall - $C$; the face (if any) which continues the line of the passage wall - D. The east and west passage walls are given as PWe and PWw.
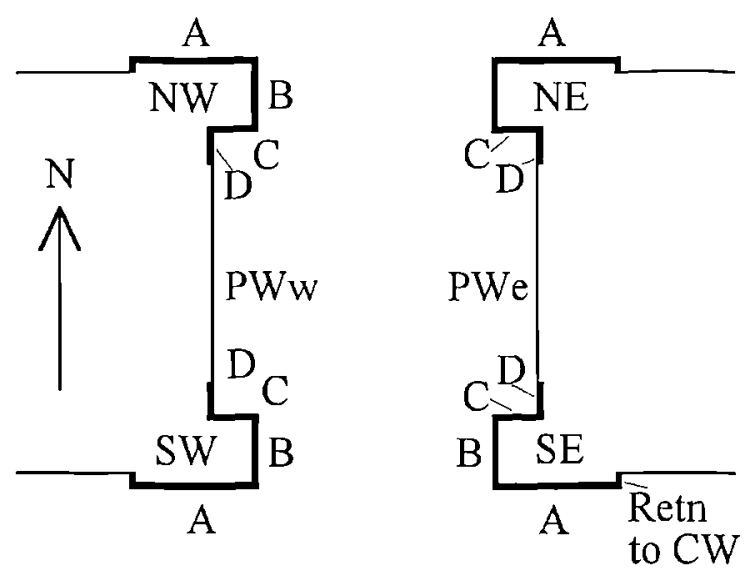

Fig 1.1 Gateway pier references

The stones of each pier are numbered consecutively and prefixed by the reference to the gateway, the initial letter of the pier, and the number of the course, thus SGNE2/1 is the first stone on the second course of the north east pier of the south gate. Unless otherwise specified, numbering of multiple stones in a course begins on face $\mathrm{A}$, starting at the quoin and completing face $\mathrm{A}$ before going on to face B. Foundation courses (that is, the course which includes or is at the level of the original pivot stone) are similarly numbered, with the suffix $\mathrm{F}$ following the identity of the pier, thus NWF2 is the second foundation stone of the north west pier. Any visible courses below the foundation course are shown as sub-foundation and numbered in the same way, suffix SF. Thus NWSF2/4 is the fourth stone of the second course of the sub-foundation of the north west pier. 


\section{CHAPTER 2}

\section{Hadrian's Wall: its development and place in Roman frontier policy}

Hadrian's Wall was probably the most elaborate and most magnificent of Roman frontiers, and certainly provides the finest surviving remains. The design was on a monumental scale with an unusually thick curtain wall and an endless repetition of grand gateways and substantial towers, with a unity of design from end to end. But these great imperial frontier works were merely one small part of the several thousand miles of boundary between the empire and those tribes not under the direct control of Rome.

Although this thesis is concerned with the physical aspects of building a specific linear frontier in relation to the surviving evidence, it is desirable to have a short overview of the Wall and its place among other frontiers of the empire.

\subsection{Roman frontier policy}

Rome always had need of frontiers, in the sense of a zone of interface with its neighbours, but at first these do not seem to have been formal or fixed boundaries. There was no sense in which the empire was considered by the Romans to have a limit; the world consisted of those parts occupied by the Romans and those parts not yet occupied. Livy, writing of 183 BC before Cisalpine Gaul was established as a province, described how a tribe settling there were sent back on the grounds that they 
had not been given permission to be there. ${ }^{20}$ Whittaker describes this a 'a provincia of power. ${ }^{21}$

Vergil writes of Augustus that he granted the Roman people 'imperium sine fine'. ${ }^{22}$ Strabo explains that Augustus reserved to his own governance provinces adjacent to 'those not yet subdued', ${ }^{23}$ a clear indication that the marches, even if not formally within the empire, were to behave in a manner approved by Rome. Suetonius points out that Augustus treated those parts subdued by the Romans but returned to their defeated dynasties not 'otherwise than as integral parts of the empire. ${ }^{24}$ Augustus himself makes the point that rather than make Armenia into a province he preferred to control it by appointing its kings. ${ }^{25}$ The implication is that the kings would have to follow Roman policy.

Mann sees Roman history as 'essentially the virtually unique story of a nation trying to keep up with ... the incredible success of its army'26 and says that the long successes of the armies of Rome were seen as part of the favour of the gods, and that the Romans felt no great need to explain or even comment on this: it was a part of the natural order. Vitruvius summed it up quite neatly, seeing the Roman people as occupying the truly perfect territory . . . in order that it might acquire the right to command the whole world. ${ }^{27}$

\footnotetext{
$20 \quad$ Livy $39,54,10$.

$21 \quad$ Whittaker (1994) 27.

22 Aeneid I, 279.

23 Book XVII, C, iii, 25.

24 Suetonius Augustus 48.

25 Res Gestae V, 27.

26 Mann (1974) 2.

27 Book VI, I.10.
} 
One reason for the growth of frontiers, from the later Augustan period onwards, was the need for emperors to prevent their generals from seeking military and political prestige except under strict imperial control. ${ }^{28}$

'Frontiers' tended to be zones rather than (although sometimes in addition to) linear features: broad bands of territory over which the Romans exercised control either directly or indirectly as occasion demanded. 'Roman control extended as far as her arm could reach; and the army was very mobile. ${ }^{129}$

It is not surprising that these frontiers were not closed. Whittaker, quoting Febvre, notes that 'the two concepts of a frontier as a fixed military "front" and a territorial boundary did not merge until the nineteenth century. ${ }^{130}$ In the ancient world frontiers might be administrative, territorial, or military, but these were rarely if ever the same. The general concept of a frontier was of a zone rather than a welldefined linear barrier which fulfilled all of these functions. Linear barriers, be they rivers or artificial lines, tended to mark the division between the directly administered and the indirectly controlled areas, rather than setting a finite limit to the authority of Rome.

To some extent the Romans seem to have regarded physical features as an inconvenience rather than as potential lines of defence. The anonymous author of $D e$ rebus bellicis regarded 'frenzied native tribes' as being protected by rivers, mountains, and marshes; from the Roman point of view these were obstacles to be overcome by means of boats or bridges. ${ }^{31}$

28 Mann (1974).

29 Wells (1972) 248.

30 Whittaker (1994) 7; Febvre (1922).

31 Hassall and Ireland (1979), 2, vi, 28 
Rivers may have been convenient points at which to make a temporary halt in the progress of conquest, but Rome expected to control those living on the far bank. Hodgson suggests that Rome 'gradually realised that there was to be no general advance beyond the rivers, but rather a constant, powerful influence in the affairs of the trans-riverine peoples.'32 Even after the Varus disaster in AD 9 and the withdrawal to the Rhine after the campaigns of Germanicus, when the idea of total control had been effectively abandoned, some supervision was maintained over the eastern bank. ${ }^{33}$ This was not yet a formal frontier, rather a temporary stopping point. It was left to Claudius to establish what seems to have been a controlled frontier line with forts close-set along the northern part of the Rhine. ${ }^{34}$

During the first century $\mathrm{AD}$ Roman troops were moved right up to the line of the middle Danube, and the German kings on the far bank were subject to increasing Roman control. Pitts says that by the mid second century 'Rome's right to choose the leaders of the tribes beyond the Danube was apparently firmly established'. ${ }^{35}$ E. Birley wonders whether some, at least, of the stone forts across the Danube might not be Hadrianic. ${ }^{36}$

Dio records that under Marcus Aurelius the Marcomanni were allowed to settle up to five miles from the north bank of the Danube as part of a relaxation of control. ${ }^{37}$ Under Commodus restrictions were increased, and they were allowed to assemble only once a month, in only one place, and in the presence of a centurion. ${ }^{38}$

\footnotetext{
32 Hodgson (1997) 61.

33 Maxfield (1988), 143.

34 Maxfield (1988) 145.

35 Pitts (1989) 49.

36 Birley (1956).

37 Dio 71.15.

$38 \quad$ Dio 72.2 .4
} 
Ti. Plautius Silvanus, governor of Moesia in the 60s AD, controlled lands across the Danube and accepted hostages from the rulers of the Bastarnae and Rhoxolani. ${ }^{39}$ Tacitus notes that the Frisians ' ... marched ... towards the banks of the Rhine and took possession of a large tract, vacant, indeed at the time, but in fact appropriated to the use of the Roman soldiers. ${ }^{140}$ As Whittaker repeatedly emphasises, rivers were scen as highways as much as boundaries, and peoples of common culture were to be found on both sides of rivers. ${ }^{41}$ Hodgson argues that the slight nature of rivers as obstacles suggests that they ... functioned primarily as visible lines of trespass. ${ }^{142}$

It was not just across rivers that Rome asserted their power. Whittaker points out that although Hadrian gave up Trajan's conquests in Armenia he exercised control through allied kings, after the Augustan method. ${ }^{43}$ Hadrian's biographer records that he 'showed many favours to many kings'; 44 these favours will not have been without some return for the empire.

Whittaker says that Rome saw the world as 'divided into the organised territory of Roman administration and beyond that the externae gentes who were subject but not usually worth annexing. ${ }^{145}$ Suetonius said that kings were treated as limbs and parts of the empire, that is as part of imperial control although not of the administered provinciae. ${ }^{46}$ Tacitus clearly states that 'the might and power of kings

\footnotetext{
$39 \quad I L S 986$.

40 Annals XIII, liv.

41 Whitlaker (1994) 78.

42 Hodgson (1997) 62.

43 Whittaker (1994) 57.

44 SHA Hadrian 17.10.

45 Whittaker (1994) 17.

46 Suetonius Augustus.
} 
depends on the authority of Rome. ${ }^{147}$ In expanding, Rome was taking in those tribes and states which it was convenient so to do, for reasons of closer control, economy, or security. The limit of the imperium was where Rome for the time being was content to allow it to rest. To view a linear feature as an absolute boundary, whether administrative or military, would have been to set limits to the power of Rome.

Hanson argues that the fort at Elginhaugh, its buildings demolished in the late $80 \mathrm{~s}$, continued to be used by the Romans after that date as a base for the collection of tribute from the local tribe, the Votadini, or as a collection point for animals as part of wide-ranging foraging. ${ }^{48}$ The nearest occupied fort at that time was at Newstead, some 25 miles to the south. Here, if Hanson is correct, there was no rigid boundary beyond which the Romans did not operate; and they seem to have been not merely patrolling but exercising some economic function. The outpost forts north of the Wall show the exercise of military control north of the Wall; any other function they had is unknown.

Antoninus Pius built a new artificial frontier in Britain, but elsewhere he operated by indirect control, giving a new king to the Quadi who were beyond the Danube 'frontier'. ${ }^{49}$ Peace was maintained on the European frontiers by diplomatic means for nearly half a century, and Rome's influence extended well beyond the confines of her frontiers. ${ }^{50}$ The Antonine Wall, in so far as it was built for reasons other than to enhance the reputation of the emperor, was probably not designed to control the Scottish Lowlands but to maintain influence over the tribes to the north of Forth-Clyde.

\footnotetext{
47 Germania 42.

48 Hanson (1997).

49 Pitts (1989) 49. RIC 3.620.

so Maxfield (1988) 187.
} 
The Parthians, to the east of modern Syria, the best organised and potentially most dangerous enemy, were in some respects Rome's equals but even here there was ambiguity about where the limit of empire lay. There was not, as one might have expected, an administrative boundary subject to agreement by treaty. ${ }^{51}$ There was no artificial barrier, supported by military installations. When Augustus achieved the return of the standards taken at Carrhae, his coin issue showed that Rome viewed this as an act of submission by Parthia. ${ }^{52}$

North of Syria the Euphrates might have been seen as a boundary in the first century BC, yet Pompey made it clear that this was not necessarily acceptable. ${ }^{53}$ To the south the river was a highway for east-west movement. South of that again the deserts were even more fluid, with neither side regarding any line as a boundary. In Arabia the via nova Traiana, which continued the road running south to Damascus through Bostra to the gulf of Aqaba seems, although studded with fortified posts, to have been a means of surveillance of a long-established trade route rather than a frontier. The tiny Trajanic fortlet of Qasr el-Hallabat, of similar size to a milecastle, ${ }^{54}$ was placed some $16 \mathrm{~km}$ in advance of the road, on the route towards Azraq $;{ }^{55}$ clearly the road was not a rigid frontier line.

To some extent the deserts in this area limit the practicable access between east and west to the 'bottleneck' between northern Syria and Mesopotamia, protected by the four legions based in Antioch. The rest of the borderland was at first left in the care of clicnt states, which during the first century were gradually absorbed into the

\footnotetext{
st Whittaker (1994) 53-4.

52 Whittaker (1994) 44.

s3 Plutarch Pomp 33.6.

54 Kennedy (2000) 90.

ss Kennedy (1982) 162,169.
} 
empire. The only practicable short route across the eastern deserts ran eastwards from Palmyra to Dura, which was held as an advance post until the fall of that city in AD 253.

The fact that there were no formal, defensive frontiers in this area, which faced Rome's most formidable enemy, suggests that the modern concept of a closed frontier did not exist in the Roman mind. The Romans seem to have preferred systems of control to closed lines of demarcation, and treated each of its marches in a way appropriate to the conditions of the locality. ${ }^{56}$

It is quite likely that the Romans viewed frontiers in discrete units, designed and built according to local circumstances, whereas there must be a modern temptation, encouraged by excellent maps not available in ancient times, to view, say, the RhineDanube frontier as a single entity and to wonder at the variations. All the evidence suggests that, far from establishing a single, overall frontier policy, the Roman army adapted to the situation in which they found itself. ${ }^{57}$ The variations apparent in the early frontier in Britain are discussed below (section 2.3.1).

The reasoning behind the location of frontier zones has been a matter of argument. Mann has seen frontiers growing up where the Roman war machine reverted to prudence in the face of difficult going, ${ }^{58}$ or as Whittaker puts it, when it 'ran out of steam'. But Whittaker believes that there were more practical reasons involved as well. He argues that economic and climatic factors were also of great significance, especially in those areas where the lack of rainfall made difficult occupation by a large army. This is especially true in North Africa and on the eastern frontiers; in both cases the limit of military occupation has a close correlation with

\footnotetext{
56 Whittaker (1994) 63.

57 Whittaker (1994); Breeze (1995).

$58 \operatorname{Maun}(1974)$.
} 
the line of $4 "(100 \mathrm{~mm})$ rainfall per annum. ${ }^{59}$ And it was not always necessary or sensible to annexe areas of poor economic advantage when control could be exercised by other means. It has been argued that successful permanent occupation was possible only where there was 'a well-organized proto-urban or urban structure';60 Roman administration was normally grafted on to existing 'local government' structures, and where these did not exist in a formal way the alternative would have been direct Roman administration.

There were other factors to be taken into account. Emperors were dependant on the support of the army, and military reputation was essential. Claudius, Domitian, and Antoninus Pius annexed southern Britain, Mauretania, Thrace, the agri decumates, and southern Scotland for reasons of imperial glory as much as for any economic justification. ${ }^{61}$ If these advances were later seen as impracticable they could be abandoned, as Hadrian pulled out of Trajan's conquests in Parthia. ${ }^{62}$ When there was a need for troops elsewhere in the empire, the limit of direct occupation in Britain was withdrawn under Domitian and Trajan. The Tyne-Solway isthmus then became the only practicable line on which to make a halt and, later, to establish a linear barrier. Before considering the nature of this particular frontier, the development of artificial frontiers will be briefly examined.

59 Whittaker (1994) 93-95.

60 Groenman-Van Waateringe (1980) 1041.

61 Whittaker (1994), especially chapter 3.

62 But when Corbulo was ordered by Claudius to return to the west bank of the Rhine in AD 47, he is said to have been so disgruntled as to express a preference for the Republic (Annals XI, xx). Emperors must have had a care to keep their generals reasonably content. 


\subsection{The growth of artificial frontiers}

The new frontier in Britain set a visible, if not in practice an actual, limit to the empire, and as such can only have been conceived by the emperor. There can in fact be no doubt that Hadrian, in line with his strengthening of the frontier in Germany, and abandoning Trajan's conquests in the east, set the limits of empire in Britain.

The existing frontier works in Germany, especially on the Taunus, Wetterau, and Odenwald sections, consisted of a track and timber towers linking a line of forts. Under Trajan, fortlets were added to the line but it was probably Hadrian who took the step of adding a timber palisade. ${ }^{63}$ Jones believes that this was begun under Trajan whom, he suggests, was also responsible for the ditch and timber palisade across Finglandrigg behind the Solway estuary. ${ }^{64}$ It is generally believed that it was under Hadrian that work was begun on the fossatum Africae. ${ }^{65}$

There are four areas where artificial land barriers were introduced by Hadrian: Britain, Upper Germany and Raetia (between the Rhine and Danube), in Dacia, and in north Africa. However, none of these frontiers was a wholly closed system. Hadrian's Wall had fortified gateways at every mile, while the palisade in Upper Germany had openings with fortlets alongside them (as at Degerfeld in the eastern

63 Dobson (1990) 52; Schönberger (1985) 378. A. Birley (1997), 116, implies, and Schönberger loc. cit. says, that Hadrian ordered the German palisade to be built, although direct evidence is lacking. HA Hadrian, XII says only that ' ... in many regions . . Hadrian shut them [the barbarians] off by means of high stakes ... in the manner of a palisade.' The towers have traditionally been dated to Domitian but Woolliscroft (2002), following Körtüm (1998), believes that the German towers date to the reign of Trajan. Hodgson (2002) points out that Körtum's work is no more than 'a suggestion, made on numismatic grounds.'

64 Jones (1982); Jones and Woolliscroft (2001) 67-71. It seems that more work in this area is essential before the extent and dating of this proto-frontier can be resolved.

65 Breeze and Dobson (2000) 64; Baradez (1949); Whittaker (1994) 48. 
Taunus $)^{66}$, and the earth-built limes Porolissensis and the dry-stone fossatum Africae were very clearly discontinuous. The Hadrianic fort of Gemellae lay several kilometres behind the line of the fossatum, and about $150 \mathrm{~km}$ in advance of the geographically quite separate barrier which almost enclosed Hodna. Here there is clearly a very wide zone over which the Roman forces wished to exercise control but without any closed linear barrier. ${ }^{67}$ It is said to have been designed to control, rather than to prevent, transhumance and the movement of the nomadic peoples in the area. ${ }^{68}$ Shaw points out that gaps in the frontier walls are up to $60-70 \mathrm{~km}$ wide and that tribes practising transhumance are subject to geographic and ecological restraints, and that their routes are defined by these factors. He sees that 'frontier' rather as defences for vulnerable settlements. ${ }^{69}$ In addition to the large gaps there were gateways through the barrier in the section known as the limes Gemellensis (see section 4.2.9). Some 4 miles $(7 \mathrm{~km})$ in front of the limes Porolissensis a stone wall $1.2 \mathrm{~m}$ thick with burgus-type fortlets has been discovered; this wall, $4.5 \mathrm{~km}$ long, which has an offset opening with no milecastle-type guard post adjacent, is suggested as Hadrianic, ${ }^{70}$ but it is not a continuous barrier along the whole line of the frontier. In the south east of Dacia the road known as the limes Transalutanus was protected by an unditched, timber-revetted earthwork which was slight but sufficient to define and deter; it may be of Hadrianic date. ${ }^{71}$ In every case these

\footnotetext{
66 Maxfield (1990) 12.

67 Baradez (1949).

68 Maxfield (1990) 17; Fentress (1979).

69 Shaw (1995), chapter 7. The defences surrounding Hodna are seen as preventing mountain tribes from descending to the cultivated settlements. Shaw also points out that the fossatum Africae is only just over $200 \mathrm{~km}$ in length, out of a total Saharan frontier of about $2,500 \mathrm{~km}$.

70 Matei (1995).

71 This paragraph is largely based on Maxfield (1990).
} 
'frontiers' were simply one part of an extended zone of Roman control rather than a rigid boundary. 'It seems clear that the choice of frontier line, and indeed the very definition of a precise boundary, was largely a matter of administrative convenience. ${ }^{172}$

In northern Britain is what appears to be a frontier line, known as the Gask Ridge or the Gask frontier, on the road from Camelon to Bertha. It consists of a series of closely-set towers (18 are known at the time of writing) with three known fortlets, running northwards and eastwards along the road and beginning just south of Ardoch. It is regarded as 'at the very least, a fortified and carefully monitored road, but it is usually seen as a fully fledged Roman frontier system'. ${ }^{73}$ On the basis of very limited dating evidence it has been assigned to the Flavian period, and has been suggested as a protection for Fife. Woolliscroft (2002) argues that it appears to have had a considerable life, some of the towers having at least two, and perhaps three, structural phases. It may have been built as part of Agricola's fortification of the Forth-Clyde isthmus ${ }^{74}$; Woolliscroft suggests that it could have been started as early as the 70 s under Cerialis, about whose operations there is little historical evidence. If this were so and if the line were finally abandoned on the withdrawal from the highlands in the immediate post-Agricolan period of the late 80 s it may have had a life of 15 years or more. This is at present speculation, but the system does seem to represent a very early frontier in Britain, and may be earlier than the towers on the German frontier. ${ }^{75}$

\footnotetext{
72 Hanson (1989) 59.

73 Woolliscroft (2002) 3.

74 Agricola xxiii.

75 See footnote 64.
} 


\subsection{The development of the Tyne-Solway frontier}

The location of Hadrian's frontier in Britain must be considered. There are two places in north Britain where cross-country communication is possible and 'where the seas are hindered from joining by only a narrow neck of land. ${ }^{176}$ The ForthClyde isthmus is the shortest, at about 40 Roman miles $(60 \mathrm{~km})$, but to choose that would have meant re-occupation of all the Lowlands of what is now Scotland. It was clearly more practicable to use the Tyne-Solway isthmus, about 90 miles $(140 \mathrm{~km})$ to the south, even though that was almost exactly twice the length. There was also a natural barrier of which advantage could be taken along the central part of the line. The Whin Sill has vertical cliffs up to $100^{\prime}(30 \mathrm{~m})$ high in places such as Sewingshields and Cuddy's Crags; the line is not uncrossable, there being numerous gaps through the crags, but the Sill does provide an obvious line to follow for the comparatively short distance, about twelve miles, from MC34 at the start of Sewingshields Crags to just east of MC46 near Carvoran.

The Wall was the culmination of some four decades of development along the Tyne-Solway isthmus. After the withdrawal of Legion II Adiutrix under Domitian and the giving up of the new fortress of Inchtuthil, Roman forces gradually withdrew into, and perhaps south of, the lowlands of Scotland. Trajan's Dacian wars in the early years of the second century called for more troops, and by around $\mathrm{AD} 105$ all forts were behind the Tyne-Solway line. ${ }^{77}$ Occupation in the fortress at York appears to show a marked reduction from around $110^{78}$ and it may have been then that the Ninth legion was withdrawn from the province. With only two legions in

76 Tacitus Agricola xxiii.

77 Breeze and Dobson (2000), 12. The authors wonder whether the retreat to the Tyne-Solway line may not have been largely the work of Domitian.

78 Dickinson and Hartley (1971). 
garrison, it would hardly have been practicable to do other than limit the area of the province which was under direct Roman military control. The limit seems to have bcen on the line of the Stanegate, the modern name for the Roman road running from Corbridge to Carlisle.

\subsubsection{The Stanegate}

The development of the Stanegate line has been discussed in detail by the author elsewhere, ${ }^{79}$ and only a summary will be given here. A fort at Carlisle was founded in $\mathrm{AD} 72 / 3^{80}$ and Corbridge Red House, of uncertain date but attributed to Agricola $^{81}$ may have a similar origin under Petillius Cerialis. Other forts were established between these sites: Vindolanda may have been founded around AD $85,{ }^{82}$ and Nether Denton seems to have been a Flavian foundation, with two phases, one large (up to almost 7 acres inside the ramparts), ${ }^{83}$ one small (perhaps 3 acres), ${ }^{84}$ although not precisely dated. ${ }^{85}$

Other sites are even less clearly understood. Carvoran is suggested as a Flavian fort, but again evidence is lacking; there are indications that there was an early, large fort here. ${ }^{86}$ It lies at the junction of the Maiden Way with the Stanegate, and may have a history not directly related to either the Stanegate or Hadrian's Wall.

\footnotetext{
79 Hill (2002).

80 Daniels (1989) 25.

81 Hanson et al. (1979).

82 Birley (1994) 19-35.

83 Author's calculation based on Jones and Woolliscroft (2001).

${ }_{84} H B^{13} 210-211$.

85 Simpson (1913) 385; Simpson and St. Joseph (1934); $H B^{13} 209-210$.

86 Bidwell (1999) fig. 43.
} 
Disregarding this fort for the present, the forts at Vindolanda and Nether Denton are set a short day's march apart from each other and from the terminal forts.

TABLE 2.1

STANEGATE INTERVAL DISTANCES: FIRST PHASE

Corbridge

13.5

Vindolanda

11

Nether Denton

13.5

Carlisle

It is known that two fortlets were added to the line, Haltwhistle Burn and Throp; both are believed to date to the reign of Trajan. ${ }^{87}$ An additional 3.7 acre fort at Old Church Brampton has produced pottery said to be identical to that found at Haltwhistle Burn and Throp. ${ }^{88}$ There is also a putative site at Castle Hill, Boothby for which there is not yet firm evidence. Simpson found a ditch, $17^{\prime}(5 \mathrm{~m})$ wide and five to six foot $(2 \mathrm{~m})$ deep with one piece of samian which he considered put it firmly into the period of 'intensive occupation' of the Stanegate. ${ }^{89}$ Jones and Woolliscroft have published an aerial photograph of the site, although they acknowledge that it does not appear to have an entrance facing the Stanegate..$^{90}$ Breeze and Dobson take no cognisance of the site, but perhaps it cannot be entirely dismissed. It lies $2 \frac{1}{2}$ miles

87 Gibson and Simpson (1909); Simpson (1913) 363-381, respectively. Abandonment of the two fortlets is believed to be around the time of the building of the Wall.

88 Simpson and Richmond (1936).

89 Simpson (1934) 154-5; E. Birley (1961) chapter V.

90 Jones and Woolliscroft (2001) 57-58. 
from Old Church Brampton and 31/2 miles from Nether Denton and is in sight of both. $^{91}$

The addition of the fort at Old Church Brampton, and taking into account Carvoran, would reduce the spacing between Carlisle and Vindolanda to half-day marches. In order to extend a system of half-day forts to Corbridge, a fort at Newbrough has been postulated by E. Birley. So far, however, the site has produced evidence only for a fourth century fortlet. With the addition of Haltwhistle, Throp, Old Church Brampton, and perhaps Castle Hill, Boothby, the spacing is as shown in table 2.2.

TABLE 2.2

STANEGATE INTERVAL DISTANCES: SECOND PHASE

Corbridge

13.5

Vindolanda

3.5

Haltwhistle Bum

3

Carvoran

2.5

Throp

2

Nether Denton

3.5

Castle Hill, Boothby

2.5

Old Church Brampton

7.5

Carlisle

91 ibid. 57-58. 
It will be seen that Corbridge is one day's march from Vindolanda, and Brampton and Carlisle are half a day apart; all other distances are well under two hours' march. These close-set posts seem to imply closer control of those wishing to move north and south across the isthmus, rather than to provide security for those moving east and west along the road.

Three towers are also known on, or within half a mile of, the line of the Stanegate, and have been seen as part of the 'Stanegate system'. These are at Birdoswald, Mains Rigg (Over Denton), ${ }^{92}$ and Barcombe. The purpose of these towers is not easy to determine.

The Birdoswald tower ${ }^{93}$ is uncertain in both purpose and date, but may have provided forward observation for Nether Denton which has a very limited view to the north. ${ }^{94}$ Mains Rigg tower is very close to the halfway point between Throp and Nether Denton; Woolliscroft sees it as connecting Throp to Nether Denton rather than for the purpose of observing the road. ${ }^{95}$ Two towers have been found on Barcombe Hill, Barcombe A and B, which had different fields of view; Woolliscroft sees Barcombe A as having greater utility in connection with the Stanegate. ${ }^{96}$

Two towers on the Wall are anomalous. Pike Hill, on the Wall but not in the sequence of Wall turrets, seems to have been built before the Wall, but E. Birley notes the lack of a ditch ${ }^{97}$ and it might have been built with the Wall in mind. There is no dating evidence, but the differences in constructional technique indicate that it

\footnotetext{
92 Richmond (1929) 314; Collingwood (1929) 141; Binns (1972).

93 Richmond (1931) 130 and fig. 1.

94 Jones and Woolliscroft (2001) 56.

95 ibid.

96 Woolliscroft et al. (1982) 61.

97 Birley (1961) 140-1; Simpson and McIntyre (1933b).
} 
was not erected as part of the Wall building programme. ${ }^{98}$ T45a, Walltown Crags East, is similar in that its construction is not the same as that of the Wall turrets, although it fits into the sequence of Wall structures. ${ }^{99}$ Like Pike Hill it has a ground floor doorway and no ditch. The morphology of these two towers suggests very strongly that they were built with Hadrian's Wall in mind. It should be noted that Pike Hill is set at an angle so that its south east face looks squarely towards Nether Denton, the north east to Robin Hood's Butt on Gillalees. It is also noteworthy that Pike Hill remained in commission when the Wall was built, and a turret at the standard spacing built only 200 yards to the west.

Three, or perhaps five, towers in a distance of about fourteen miles is a far cry from the $1-1.5 \mathrm{~km}$ spacing of the Gask towers. There is no evidence of them forming any kind of 'system'.

In order to complete the suggested series of forts and fortlets further sites have to be added. E. Birley suggested a fortlet at High Crosby between Carlisle and Brampton, which would divide the distance between those two forts into 4 and 31/2 miles. In the east he has a fort at Newbrough, and fortlets at Grindon Hill and Wall, dividing the distance from Corbridge and Vindolanda into intervals of $4 \frac{1}{2}, 3,2 \frac{1}{2}$, and $3 \frac{1}{2}$ miles. The evidence for High Crosby is provided by the find of early second century pottery in the ditches of the Stanegate, and this was taken to indicate the nearby presence of a Roman site although no trace has been found. ${ }^{100} \mathrm{~A}$ fort at

98 Hill (1997b), where these differences are discussed. Hill (2002) suggests in error that the tower may have been built after the Turf Wall; this was clearly not so, as the Turf Wall ditch zig-zags around the tower.

99 Hill (1997); it is 100 yards out of its measured position, not a significant divergence in the crags sector.

$100 \quad$ Simpson et al. (1936b) 184. 
Newbrough is assumed on similar spacing grounds, as are the fortlets at Grindon Hill and Wall, but there is no evidence for the existerice of any of these sites. Jones and Woolliscroft have recently reviewed all these sites and also conclude that evidence is lacking. ${ }^{101}$ The system of close control from Corbridge to Carlisle is thus incomplete.

In fact, the known additional fortlets and towers are restricted to just over a third of the distance between Corbridge and Carlisle, 131/2 miles out of 38. They occur in approximately the same area as the larger milecastles on Hadrian's Wall on either side of the river Irthing, from MC47 to MC54; their history and characteristics are discussed below (section 4.2.5).

Furthermore, in the second phase of Wall building, forts are closely spaced in the same area; the following table gives distances in Wall miles.

TABLE 2.3

FORT SPACING IN THE CENTRAL SECTOR

Housesteads
6
Greatchesters
3
Carvoran
3
Birdoswald

Vindolanda, although a Stanegate fort lying two miles south of the Wall, was rebuilt early in Hadrian's reign. ${ }^{102}$ Carvoran was excluded from the Wall zone by a northward diversion of the Vallum, perhaps because it was seen as related to the Maiden Way. It remained in commission or, more accurately, it is known to have

\footnotetext{
101 Jones and Woolliscroft (2001) 33-4.

102 Birley (1999).
} 
been rebuilt in stone in $136-8,{ }^{103}$ whether or not this was after a period of abandonment.

It may be that there was a particular problem around the Irthing valley, and that additional installations were built on the Stanegate to deal with it, and that the same problem was dealt with on Hadrian's Wall by means of the large milecastles and the close grouping of forts. Extra troops accommodated there can hardly have been significant in fighting terms, but they may well have engaged in patrolling to the north (see 4.2.7).

Breeze argues that the area immediately to the north of this sector of the Wall was largely unpopulated, and suggests that populated areas were relatively easy to control as unusual movement would be reported by friendly tribes or informers. Areas of low population gave easy access for intruders, and 'the strength of the army was increased along those sectors of the frontiers which faced the unpopulated hills.' ${ }^{104}$

\subsubsection{The Wall decision}

Following the fighting in Britain at the beginning of his reign, Hadrian visited the province, 'put right many things, and was the first to build a wall eighty miles long which would separate the Romans from the barbarians. ${ }^{105}$ It is generally considered that the emperor's visit took place in $\mathrm{AD} 122$, although there is no positive evidence for this date. The only fixed date for this period in Britain is the diploma of 17th July

\footnotetext{
$103 \quad$ RIB $1818,1820$.

104 Breeze (1985) 227. The author is grateful to Professor Breeze for discussion of this and other points.

105 SHA, Hadrian, 2.
} 
122, recording A. Platorius Nepos as a very recently appointed governor. ${ }^{106}$ This date has tended to attract other known events which are themselves undated; the transfer of Legion VI to Britain and the visit of the emperor are seen as occurring in 122 in the absence of other evidence.

In fact, Hadrian's movements in 121-2 are not precisely documented. Following his third consulship in the first four months of 119 he travelled to Campania, Gaul, Germany, Britain, and back to Gaul. He then wintered in Spain, but which winter is not known. ${ }^{107}$ It is not inconceivable that he visited Britain in 121 and set in train the planning of the new frontier, with building beginning in 122 under the new governor Nepos. ${ }^{108}$ The progress of building is discussed in chapter 13.

If the order of movement given in $S H A$ is correct, then Hadrian came to Britain from Germany and planned the Wall as a result of his observations of conditions in this province. ${ }^{109}$ Certainly his biographer implies as much, although Stevens points out that the source does not stand high as an authority. ${ }^{110}$ Stevens believed that the Wall was begun one or two years before the emperor's visit, and that it was the decision to build the Vallum which was taken by Hadrian in person, ${ }^{111}$ with the decision to move forts onto the line of the Wall as an immediate concomitant. This does not seem very likely: the political implications of the decision, the rigidity of the design, and the enormous investment in labour, all point to the personal involvement of the emperor. It is certainly most unlikely that a provincial governor

\footnotetext{
106 CIL xvi, 65. The diploma was issued under Nepos but recorded men discharged under his predecessor Q. Pompeius Falco.

107 SHA Hadrian, 8.

108 The author is grateful to the late Professor Mann for discussions of Hadrian's itinerary.

$109 \quad$ e.g. Breeze and Dobson (2000), 26.

110 Stevens (1966), 39.

111 Stevens (1966), 37-40.
} 
could take the decision to tie up the army in a huge building project for a period of years without the permission of the emperor.

It should be noted that Hadrian's Wall and the Antonine Wall were probably the nearest the Romans came to closed frontiers. The other artificial frontiers had gates in discontinuous sections, as in the case of fossatum Africae or, in the case of the frontiers of Upper Germany, Raetia, and Dacia, were pierced by gaps in the barrier rather than by gates. Hadrian's Wall and the Antonine Wall were the only frontiers which could be totally sealed from end to end by shutting the gates. Both frontiers were of course relatively very short, and can be viewed as discrete units. But despite the possibility of closing the frontier, at least three forts, Halton Chesters, Chesters, and Great Chesters, were supplied by aqueducts from the north, ${ }^{112}$ and the quarry at Queen's Crag is about one mile north of Housesteads, 113 all providing physical evidence that Roman control did not stop at the line of the barrier, as do the outpost forts. ${ }^{114}$

The Wall had outpost forts in the west some ten miles $(18 \mathrm{~km})$ in advance of the Wall, at Bewcastle, Netherby, and Birrens. After the return from the Antonine Wall, High Rochester remained in commission as an outpost 25 miles $(45 \mathrm{~km})$ north of the Wall in the east. These forts will have been used for patrols as well as static bases, further extending the limit of Roman control and influence.

Hadrian's Wall can be seen to fit into the general pattern of Roman frontiers as a line which marked a point beyond which outsiders came within the formal control of the empire. Peoples living beyond it were probably subject to varying degrees of

\footnotetext{
$112 \quad$ Richmond (1945).

113 E. Birley 'RB in 1960' 194.

114 There are also temporary camps to the north of the Wall, but these do not of themselves indicate permanent control.
} 
control depending on the particular political conditions of the moment and the nearness to an outpost fort or Roman patrol. It was unlikely ever to have been seen as a fixed military frontier to be defended against intruders and beyond which the Romans had no control or influence. Every frontier in the empire was built to a different design and perhaps designed for different purposes. What marks out Hadrian's Wall from other frontiers is the scale of the works, something which may have been influenced by its very short length. 


\section{CHAPTER 3}

\section{The nature of the countryside and its geology}

This section looks at the physical conditions facing the Roman builders, in terms of topography, geology, and climate, as a background to the planning of the Wall which is discussed in the following chapter

\subsection{Topographical description}

The Wall closed the isthmus between the estuaries of the rivers Tyne and Solway; it seems likely that it was planned from the beginning to run from Wallsend to Bowness-on-Solway. ${ }^{115}$ To the west of Bowness, the system of fortlets and towers extended down the coast but without a connecting wall.

The line of the Wall running west from Wallsend runs across what is now more or less level ground, although there were formerly a number of small valleys, running at right angles to the line, which have been filled in. ${ }^{116}$ The ground gradually rises to the summit of Byker Hill, around $200^{\prime}$, from where it falls towards the large, steep-sided valley of the Ouseburn; MC3 stood on the east bank. Approaching Newcastle was the valley of Pandon Burn.

To the west of Newcastle the ground rises to the site of the fort at Benwell, 415' above sea level ${ }^{117}$ over a distance of some two miles. Thereafter, the ground undulates, gradually rising to just under $800^{\prime}$ at the start of the crags of the Whin Sill (T33b, Coesike). In this stretch there are only two long, severe gradients, on either

\footnotetext{
115 Hill (2002a).

116 e.g. Stott's Pow, on the bank of which stood MC1.

$117 \quad H B^{13} 65$.
} 
side of the valley of the North Tyne at Chesters. Over the crags the Wall holds to the edge of the Whin Sill, rising to 1230' at Winshields. In this sector access to the Wall for constructional purposes is very limited from the northern side, where there are near-sheer cliffs; to the south the line is approached on the dip slope of the escarpment, giving access which varies from steep to near-inaccessible. The line is broken in places by steep-sided 'nicks', some of which can barely be climbed without using the hands (e.g. the east side of Peel Gap and the slope on which T44b, Mucklebank, stands).

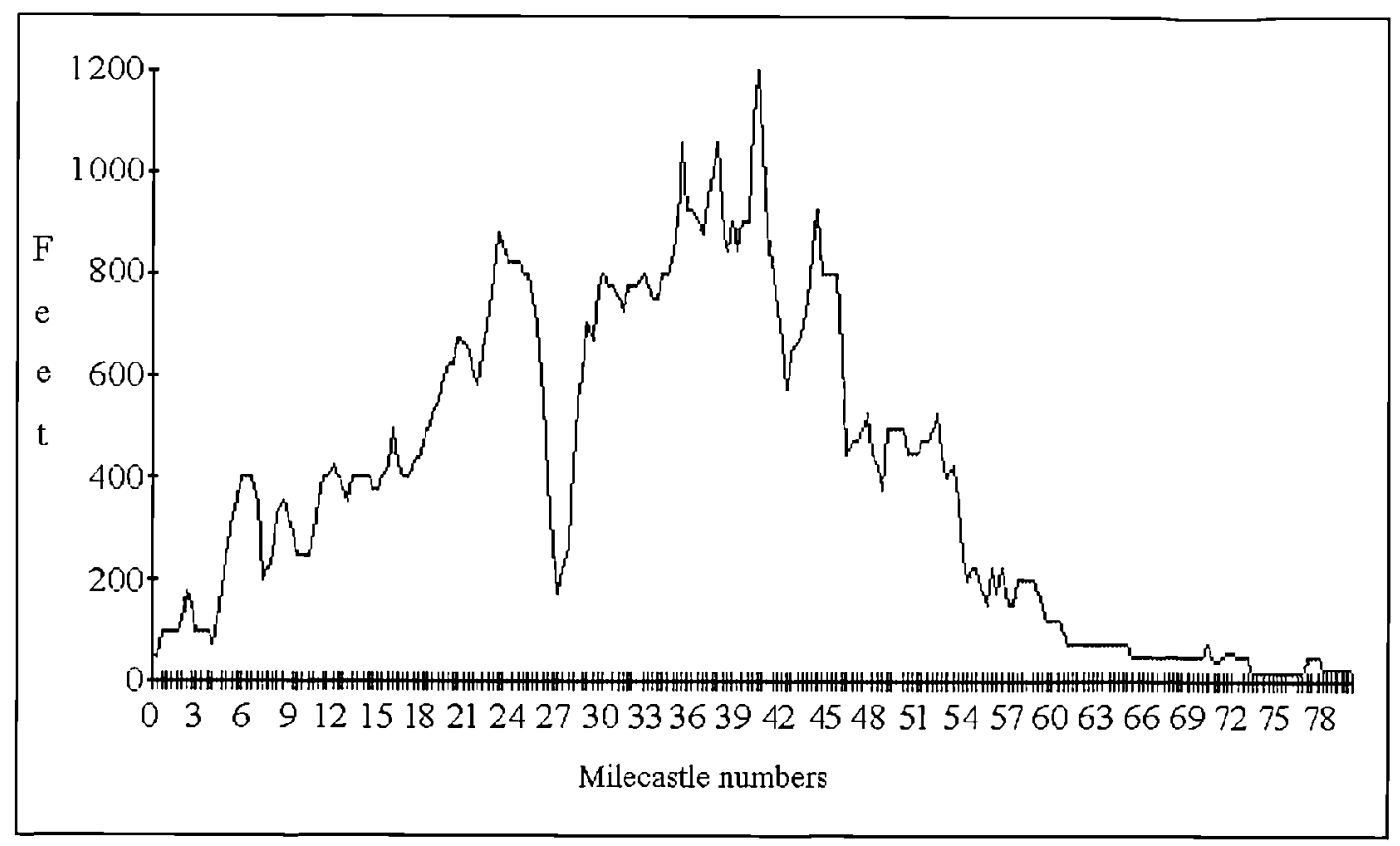

Fig. 3.1 Contour section Wallsend to Bowness

Immediately west of Carvoran the land dips down relatively gently into the valley of the river Irthing which it crosses by means of Willowford Bridge, after which it rises sharply by over $100^{\prime}$ to Harrow Scar and Birdoswald, which stand $500^{\prime}$ above sea level. Over the next ten miles the height falls to less than $75^{\prime}$, and 
thereafter continues to fall to the marshes west of Carlisle where the line of the Wall follows the edge of the estuary to Bowness.

Figure 3.1 and the following table of heights give an indication of the lie of the land from Wallsend to Bowness-on-Solway.

TABLE 3.1

HEIGHTS ABOVE SEA LEVEL

Based on the 2" O.S. map of Hadrian's Wall

\begin{tabular}{lcrrrr} 
MC & Feet above & \multicolumn{2}{c}{ MCFeet above } & \multicolumn{2}{c}{ MCFeet above } \\
& S/L & & S/L & 54 & 250 \\
0 & 50 & 27 & 175 & 55 & 225 \\
1 & 90 & 28 & 425 & 56 & 225 \\
2 & 125 & 29 & 700 & 57 & 150 \\
3 & 125 & 30 & 800 & 58 & 200 \\
4 & 75 & 31 & 750 & 59 & 175 \\
5 & 250 & 33 & 775 & 60 & 125 \\
6 & 400 & 34 & 800 & 61 & 75 \\
7 & 350 & 35 & 900 & 62 & 75 \\
8 & 250 & 36 & 925 & 63 & 75 \\
9 & 325 & 37 & 950 & 64 & 75 \\
10 & 250 & 38 & 875 & 65 & 75 \\
11 & 350 & 39 & 850 & 66 & 50 \\
12 & 425 & 40 & 1100 & 67 & 50 \\
13 & 350 & 41 & 875 & 68 & 50 \\
14 & 400 & 42 & 675 & 69 & 50 \\
15 & 375 & 43 & 675 & 70 & 50 \\
15 & 500 & 44 & 850 & 71 & 40 \\
17 & 400 & 45 & 800 & 72 & 60 \\
18 & 475 & 46 & 650 & 73 & 50 \\
19 & 550 & 47 & 475 & 74 & 20 \\
20 & 625 & 48 & 450 & 75 & 20 \\
21 & 650 & 49 & 500 & 76 & 20 \\
22 & 650 & 50 & 500 & 77 & 50 \\
23 & 875 & 51 & 450 & 78 & 25 \\
24 & 825 & 52 & 500 & 89 & 25 \\
25 & 800 & 53 & 400 & & 25 \\
26 & 550 & & &
\end{tabular}




\subsection{Geological description of the line}

The Wall divides into three very different geological sectors, east, central, and west, ${ }^{118}$ as shown in figure 3.2. In the east, stretching from the coast to the North Tyne at Chesters, the underlying sandstone and gritstone is covered by glacial drift to a depth of up to $80 \mathrm{~m}$. This gives a flat or rounded land surface over which building will have presented no great problems. There are sufficient outcrops on the ridges to provide supplies of building stone, but limestone is not always readily available. There is limestone in the coastal area to the south of the River Tyne, that is some 5 miles $(7-8 \mathrm{~km})$ due east of Wallsend; to the west, the first outcrop occurs at Harlow Hill where there are three seams of limestone between MC16 and MC18. Further west, there is a glacial erratic of Great Limestone at MC21, and thereafter seams occur with reasonable frequency.

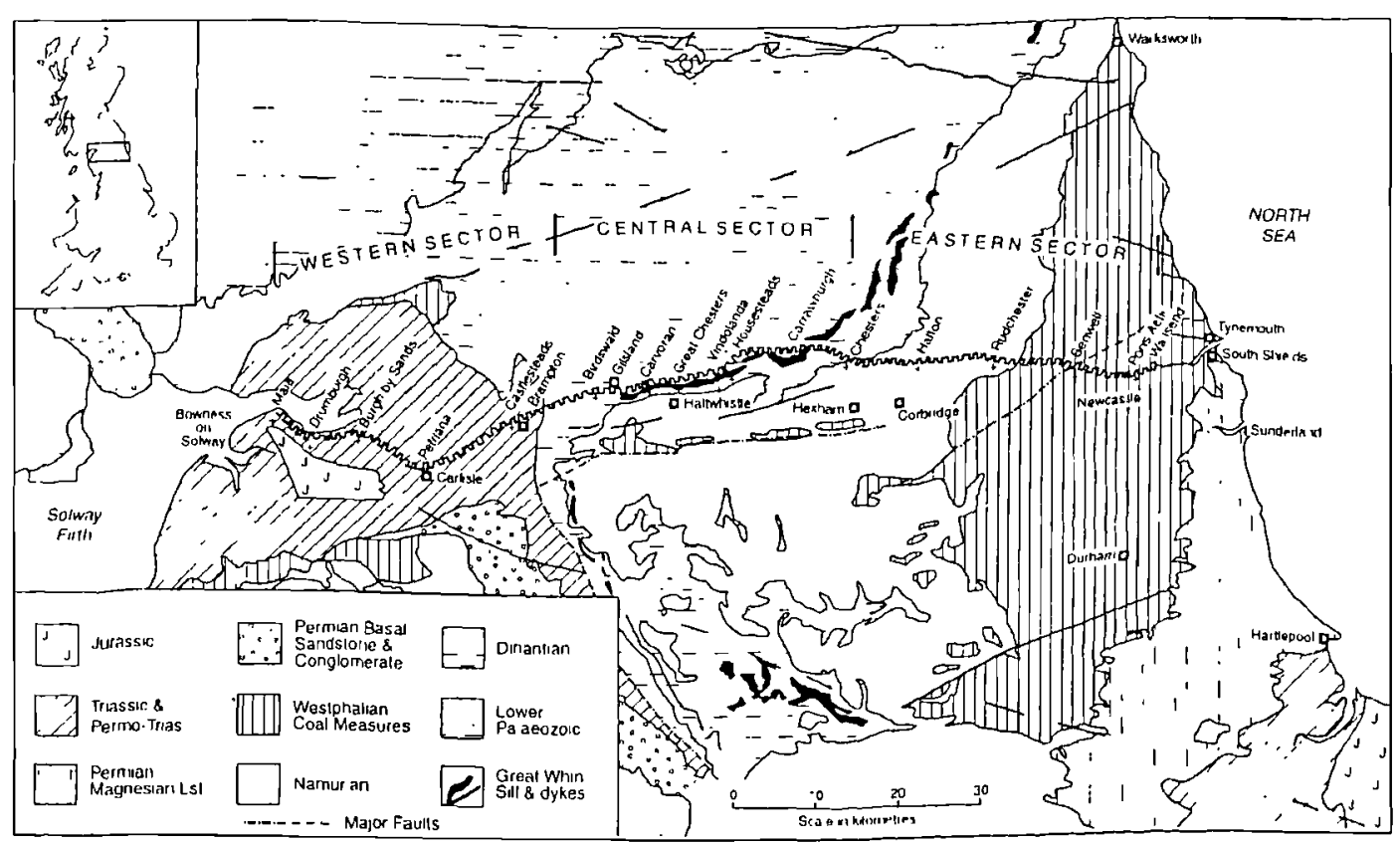

Fig. 3.2 Geology of the Hadrian's Wall area (after Johnson)

118 The following section is based on Johnson (1997) unless otherwise noted. Mr J. Senior kindly discussed some geological problems with the writer. 
The central sector, which geologically may be said to begin at the North Tyne, is dominated by the quartz-dolerite intrusion of the Whin Sill. Both to north and south of the line of the Wall are ample supplies of limestone and sandstone. The Sill is broken in several places by glacial spillways, most notably at Peel Gap which drained the glacial lake of Crag Lough. There is glacial drift in the valleys to the south, with bedrock exposures.

The western sector begins around Birdoswald. Close to MC54 the geology changes to Permo-Triassic, heavily overlain by deep glacial deposits. The countryside is softer and kinder than that further east and will have made for easier building. Building stone is less readily available close to the Wall, although the Gelt quarries lie $2 \frac{1}{2}$ miles $(4 \mathrm{~km})$ south of the Wall on a tributary of the river Irthing. These were heavily worked by the Romans, (the little dating evidence is of the early third century $)^{119}$, as was the exposure of the massive Sherwood sandstone near Weatherall on the river Eden. West of Carlisle there are no bedrock exposures along the boulder clay and alluvial soil of the Solway Firth and the nearest stone to be found is well to the south.

\subsection{Climate}

In the first millennium $\mathrm{BC}$ the temperature dropped by as much as $2^{\circ}$, with increased rainfall, but from around $150 \mathrm{BC}$ the climate became milder and drier. ${ }^{120}$ It has been suggested that by the second century AD it may have been 'a little warmer' than the present day, ${ }^{121}$ but the consensus tends towards the view that when the Wall was

\footnotetext{
$119 \quad$ RIB1009, 1016.

120 Lamb (1981), (1995).

121 Huntley and Stallibrass (1995) 43; Seaward (1976) 28-29.
} 
built the climate had come to resemble that of today. ${ }^{122}$ Later in the Roman period the climate became warmer; Lamb suggests that it was not until the mid-third century that the temperature may have increased by as much as $1^{\circ} \mathrm{C} .{ }^{123}$ It is not impossible that the temperature in the second century might have been very slightly higher than that of today, but this is difficult to quantify; the probability is that is very much the same as the present day.

\subsection{Flora}

The principal tool for the reconstruction of an ancient natural plant environment is pollen analysis allied to radiocarbon dating of the pollen deposits. It is still not a precise tool, but has developed to the point where an attempt may be made to give a general indication of the ancient landscape. ${ }^{124}$ In the case of individual sites, pollen analysis, especially from older excavations, has its own problems.

Dark and Dark point out that pollen from settlement sites can be expected to show an open landscape and that this does not therefore necessarily indicate the nature of the surrounding or pre-settlement conditions. ${ }^{125}$ It is necessary to look at pollen from pre-Roman levels below the structures or from further afield. The Wall runs through an area 'abundant in lakes and mosses ${ }^{126}$ which gives an opportunity to gain an idea of the landscape cover before and during Roman times.

Dark and Dark summarise the pollen evidence from mosses thus: 'The pollen evidence overall suggests that some areas of the Wall zone were already extensively

\footnotetext{
122 Lamb (1981), (1995); Dark and Dark (1997); Van der Veen (1992) 5.

123 Lamb (1981).

124 Dark and Dark (1997) 28-9 discuss recent developments.

125 Dark and Dark (1997) 29.

126 Dark and Dark (1997) 33.
} 
cleared long before Hadrian's Wall, but at several sites further clearance was connected with Roman military activity.' ${ }^{27}$ Dark and Dark believe that substantial tree clearances took place in the Wall zone in the late Iron Age, but that this intensified in the Roman period.

It is important to bear in mind that clearance of woodland is not permanent unless intended so to be. 'Most British [tree] species are difficult to kill . . . and grow again after felling. ${ }^{128}$ Clearance has to be deliberately maintained, for agriculture or other purposes, and without maintenance the land will revert to woodland.

In the Bronze and early Iron Ages there was a series of clearances, most of which were followed by forest regeneration. At the end of the Iron Age there were considerable clearances, resulting in an open landscape similar to today. ${ }^{129}$

A summary of findings along the line of the Wall will be useful. Excavations at MC4 in Newcastle revealed two major plant communities: woodland (chiefly alder, with some oak, elm, and a little birch, with sparse evidence for hazel and willow), and grassland of which some represented wet or water-logged soils. There was no evidence of cultivation. ${ }^{130}$

Examination of the soils from the fort at Benwell shows that it was built in part on a surface of turf, with the valleys to west and south carrying much hazel and alder, with some pine and lime; a wooded environment of open glades is suggested by the excavator. ${ }^{131}$

\footnotetext{
127 Dark and Dark (1997) 35.

128 Rackham (1986) 72.

129 Van der Veen (1992).

130 Huntley (1988).

131 Simpson and Richmond (1941), 3-4 and 39-40.
} 
Soil from beneath the Vallum mound at Wallhouses indicated 'predominantly open country with only a small amount of woodland (principally alder). ${ }^{132}$ Ard marks beneath the mound showed previous cultivation in the area, and pollen from the ditch silts gave an indication of cultivation resuming perhaps very soon after the construction of the Vallum.

Further west, at Black Carts, pollen evidence from north and south of the Vallum was somewhat contradictory but the main indications are of heathland and wet grassland, with few trees. ${ }^{133}$

Pollen from Fozy Moss, near Carrawburgh, indicates 'a major, and apparently rapid, reduction in the extent of woodland in the Roman period, resulting in an almost treeless landscape'. ${ }^{134}$ It is not possible to discriminate between clearance associated with the establishment of Roman forts on the Stanegate and that connected with the building of the Wall, but the apparent rapidity of the clearance might suggest that Wall building was the major incident. Although there were turf and timber forts on the Stanegate, there were only five of them (Corbridge, Vindolanda, Carvoran, Nether Denton, Old Church Brampton), and the Wall will have consumed very large quantities of timber for scaffolding, lime burning, and fire-wood for the builders (see chapters 8, 9, and 12), and at least some of the forts on the Wall are known to have had internal buildings of timber. ${ }^{135}$ Dumayne comes to a similar conclusion, with Fozy Moss showing ' . . massive, rapid forest clearance

\footnotetext{
132 Balaam (1983).

133 Huntley (1999) 53.

$134 \quad$ Dark and Dark (1997) 33.

135 E.g. Carrawburgh (Breeze (1972) 94).
} 
with an almost totally deforested landscape ... between approximately AD 130 and AD $370 \ldots$ the landscape was more open than today. ${ }^{136}$

At Fellend Moss, near Carvoran, the first substantial clearances 'apparently coincided with the start of the Roman occupation' again perhaps related to the Stanegate but continuing into the Wall building period. ${ }^{137}$

Pollen from Bolton Fell Moss (less than $6 \mathrm{~km}$ north of the Wall) indicates that from $500 \mathrm{BC}$ there were open woodlands of oak and birch with alder in the gullies; clearance did not begin before the Roman occupation. ${ }^{138}$ Evidence from Coom Rigg Moss (about $12 \mathrm{~km}$ to the north of the Wall) suggests that major forest clearance did not begin until the mid-fifth century. ${ }^{139}$

There is some evidence from excavations in the vicus at Vindolanda that native cereal cultivation was practised before the establishment of the fort (around AD 85), again suggesting a relatively open landscape in places at least. ${ }^{140}$ Excavations at Vindolanda have shown that wattle was made up of oak and birch, with hazel, and willow, ${ }^{141}$ which matches the pollen analysis from Bolton Fell Moss.

Excavations and analysis at Birdoswald revealed that the immediate site of the fort was relatively dense, wet deciduous woodland which was cleared for building. This environment seems to have been atypical of the area, owing to the unsuitability of the site for pastoral purposes (the site is boggy); a little to the west, Appletree had been subjected to clearance before Roman intervention and this seems to have been

\footnotetext{
136 Dumayne (1994) 220.

137 Dark and Dark (1997) 33.

138 Wilmott (1997) 39.

139 Seaward (1976) 10-11.

140 Seaward (1976) 22.

141 Seaward (1976) 7-8.
} 
the common picture in the central sector of the Wall, whether for woodland produce or for grazing. ${ }^{142}$

The analysis of pollen from MC54, Randylands, suggests that in the local landscape alder was common, with a little birch and some willow; there was scrub on the gravels which are crossed by the Wall line at that point. The rest of the Turf Wall was probably more open, with grass available for turf. ${ }^{143}$ The fact that the western 30 miles of the Wall could be built in turf indicates that the area was already largely given over to grassland rather than woodland.

Huntley summarises evidence from west of Birdoswald, and sees land to the east of the Pennines as generally open and that to the west as generally wooded. ${ }^{144}$ However, land on the line of the Wall must have been reasonably open to allow for the growth of turf.

The clearances are emphasised by the evidence of ploughing prior to the construction of the Wall. There are a number of sites where evidence of cultivation is provided by ard marks in the soil below and adjacent to the Wall; examples are Wallsend, ${ }^{145}$ Throckley, ${ }^{146}$ Wallhouses, ${ }^{147}$ and Carrawburgh. ${ }^{148}$ It is probable that at least a part of the course of the Wall ran through land which was in current use for arable farming.

Another source of information on the type of trees growing locally is provided by examination of preserved and excavated fragments of wood and other vegetation.

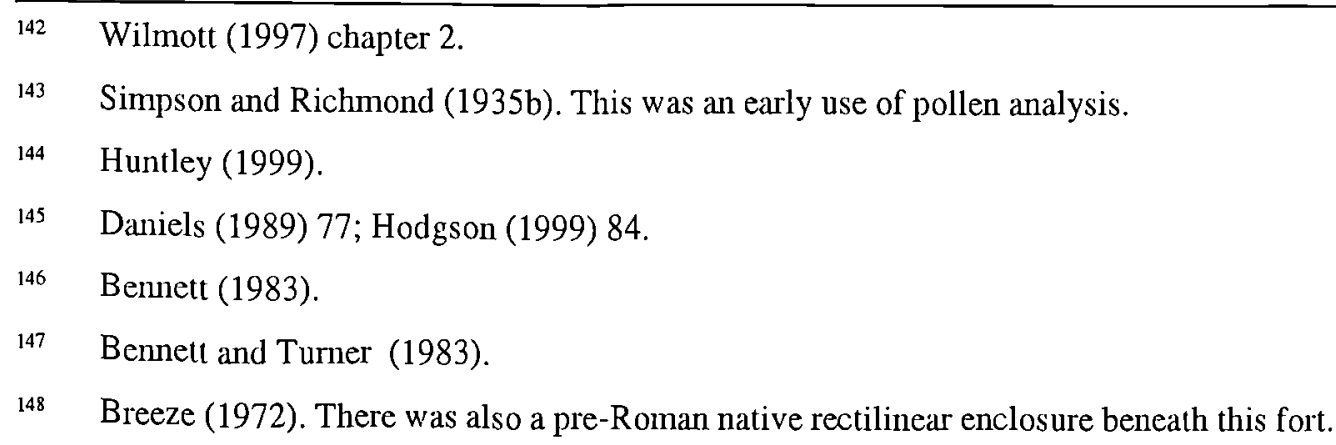


Large quantities of timber were needed for the building of a Roman fort in turf and timber, ${ }^{149}$ and this will have led to at least a measure of importation. That is not to say that the source will have been far away; distances are likely to have been short owing to the logistical problems in regard to the quantities required. ${ }^{\text {so }}$

Excavated and identifiable timber does not necessarily point to the type of the ground cover in the immediate vicinity of the site, but rather the nature of the general locality. Such evidence is perhaps best regarded as indicating the type of trees growing within $3-5$ miles $(6-9 \mathrm{~km})$ of the site, rather than those on the site before building work began. The disadvantage of this is that it gives little idea of what work was necessary to prepare the site for building.

In the excavations of the Flavian Red House baths near Corbridge, most of the wood from the stokeholes was oak and birch, with single examples of elm and hazel, which suggests that these species were growing in the locality. ${ }^{151}$ Unfortunately, no examples of timber from Hadrianic levels in the structures along the Wall line have been identified.

In summary it may be said that the line chosen for the Wall ran through countryside which was largely cleared, for arable use in the the east and for pastoral use in the west, with cultivation in some areas interspersed with light tree cover and with denser thickets in the valleys. ${ }^{152}$ The temperature was probably about the same as today, with a not dissimilar climate.

149 Hanson (1978).

$150 \quad$ McCarthy (1986) 343.

151 Daniels et al. (1959) 173-4. There was one fragment of hazel from outside the tepidarium praefurnium, a fragment of oak from the mortar make up of the flagged floor of the frigidarium. There were also three oak post stumps from the courtyard.

152 In addition to the authorities cited, see also Simpson and Richmond (1941) 40, Daniels (1959) 173-4, Seaward (1976) 8-11, Bennett (1983) 61-78, McCarthy (1986) 339-343. 


\section{CHAPTER 4}

\section{Concept, design, and survey}

This section looks at the general concept of the Wall, and at the design of the curtain wall, milecastles, and turrets. The question of design is ancillary to this thesis, and so has been treated in a relatively simplistic manner.

\subsection{Concept}

As discussed in chapter 2, at the time of Hadrian's visit the decision was made to build an artificial barrier across the isthmus. In its initial form this consisted of a stone wall 10 Roman feet (hereafter Rf) wide from the river Tyne to the river Irthing and a turf wall from the Irthing to the Solway, with a ditch fronting the whole length except where cliffs made this unnecessary, and with fortified gateways (milecastles) at intervals of one Roman mile. Between each pair of milecastles were two equispaced turrets, with one known extra tower added subsequently at Peel Gap, between T39a and T39b. The incorporation of defended gateways (see 4.2.5) and watch towers (see 4.2.8) in a running barrier in the form of a curtain wall was a totally new departure in Roman frontiers. This was clearly seen at the time to be a successful experiment as it was reproduced to some extent on the Fossatum Africae (see section 4.2.9) and on the Antonine Wall. Soon after building began a decision was taken to add forts to the line of the Wall (see chapter 13) and to provide a large, flat-bottomed ditch, now known as the Vallum, to the south.

Although the Wall was in commission for another three centuries, from the later second century onwards most of the turrets were abandoned; some of the milecastles 
were abandoned and the north gateways in others narrowed or eliminated, and the Vallum was filled in where its presence was inconvenient. ${ }^{153}$ Hadrian's Wall was adapted from its initial rigidity to the circumstances on the ground. This seems to emphasise that the original concept was that of the emperor, rather than of those working in the province.

The provision of milecastles and turrets was made regardless of the topography; they occurred with the same frequency in the undulating ground on the east, over the crags in the centre, and along the foreshore of the Solway Firth and the Cumberland Coast. Mann has pointed out that the very regularity of the structures made a strong rhetorical statement about the might of Rome; 'The only man who could have imposed such a rigidity is Hadrian himself.' ${ }^{\prime \prime 4}$ Furthermore, the scale of the work involved in building (in the first design) 81 milecastles and 160 turrets, with up to 26 milefortlets and 52 towers on the Cumberland Coast, ${ }^{155}$ whether or not actually needed, ought to point to the personal input of the emperor.

\subsection{The design of the Wall and its components}

This section looks at the physical aspects and general form and dimensions of the foundations, curtain wall, milecastles and turrets, and examines precursors and parallels.

The Wall was not completed as planned, for the width was reduced at what was probably an early point in the building programme (see chapter 13). The original Wall is known as the Broad Wall and the reduced Wall as the Narrow Wall. It is believed that from MC49 to MC54 the Turf Wall was replaced late in Hadrian's reign

\footnotetext{
153 Breeze and Dobson (2000) 135-6).

154 Mann (1990a), 53.

155 Breeze and Dobson (2000) 44.
} 
by a narrow stone wall. ${ }^{156}$ The traditional view is that the rest of the Turf Wall from MC54 to MC80 was replaced later in the century by a stone wall built to a gauge of 9Rf, known as the Intermediate Wall; ${ }^{157}$ doubt is cast on the description of this Wall below, section 4.2 .3 .

References to the dimensions and aspect of structures assume that 'North' is the side facing the outer or enemy side of the Wall or fort and the other cardinal points take their position from this theoretical aspect.

\subsubsection{Introduction}

Hadrian was well known for his interest in matters architectural - 'Architecture was, after all, one of his great passions ${ }^{158}$ - but there is no clear sign of his personal involvement in the detailed design of the Wall. There were at least three other hands at work: there are three designs of milecastle gateways; two different 'standard' milecastle ground plans; three ground plans of turrets; and variations in the form of the curtain wall footings. The inference is that the three legions were handed an outline scheme and left to get on with the work in their own way.

In a legion it was the praefectus castrorum who was responsible for works of building ${ }^{159}$ and for the tools used, and therefore presumably for the workshops. Tacitus relates how a praefectus castrorum was killed while commanding cohorts engaged in building forts; ${ }^{160}$ although not specifically stated, the implication is that he was responsible for the building, rather than it being a coincidence that he was in

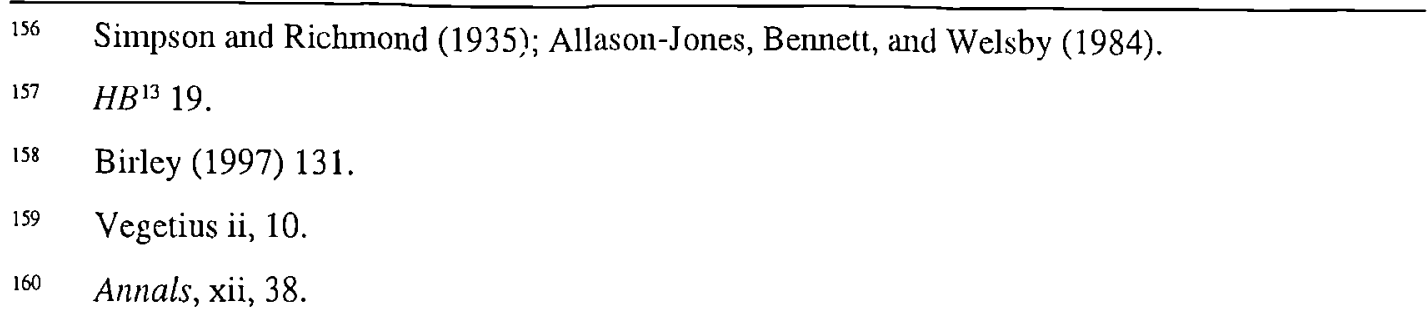


command of the detachment. It will have been his office which prepared plans and specifications, and who would have had oversight of major projects. The detailed design of the Wall would thus have been the responsibility of the praefectus castrorum of each legion, the legions apparently working quite independently in this respect within the overall plan.

An interesting point arises when considering the role of this officer. Looking at that part of his duty concerned with building works, he was, in effect, the head of a combined architectural and construction practice. His would be the guiding hand in the formulation of designs, but when he retired his successor might well have different design criteria which would be imposed on his drawing office. Any sudden design changes may be a reflection of such a change in authority, rather than a change of overall planning or of the sub-unit responsible for carrying out the work. One possible example of this is the changes made to the ground plans of the north and west gates of Housesteads fort; as these gateways are unlike any others it seems more likely that they are the result of a change in designer than a change in unit. The changes are not linked to the marked change to a lower standard of workmanship, which occurs higher up the piers. ${ }^{161}$

\subsubsection{The foundations and footings}

There seems to be some confusion in the use of the terms 'foundation' and 'footings'. In this thesis they are used with the meanings given by the $O E D$ and as is normal in the building industry.

$161 \quad$ For details see Hill (1995) 
Foundation 'solid ground or base, natural or artificial, on which building rests, lowest part of building, usually below ground level. ${ }^{162}$

In terms of the Broad Wall, this is taken to mean the course of flags or large stones at the lowest part of the Wall, together with any cobbles or rubble on which the flags rest; the equivalent in the Narrow and Intermediate Walls is the trench filled with rubble, cobbles, or other stone, topped with flags.

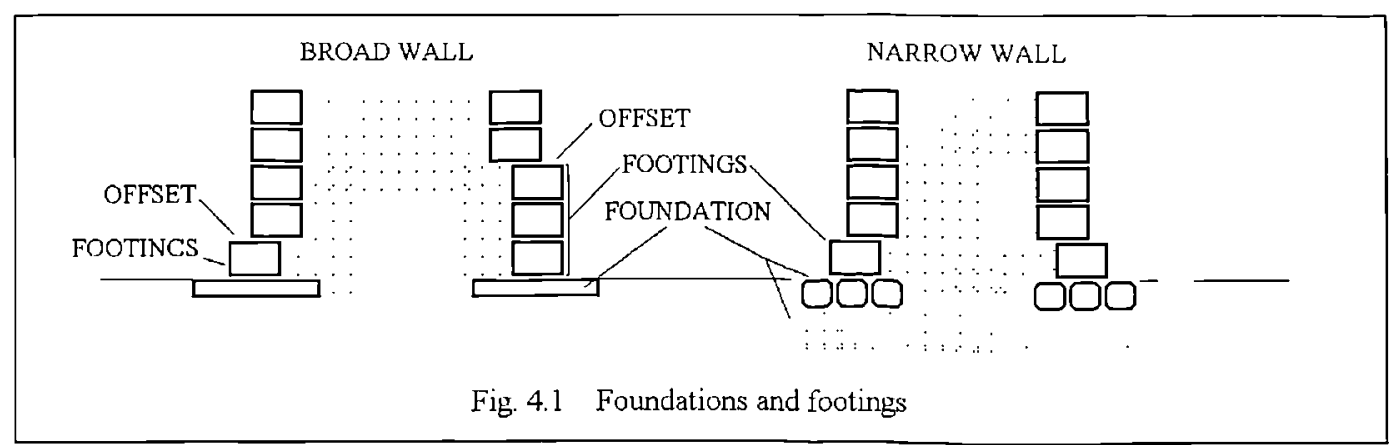

Footings 'projecting courses at foot of wall etc. ${ }^{163}$

In all varieties of Wall, this is taken to mean any course(s) of facing stones immediately above the foundation which are built to a wider gauge than the body of the curtain wall. In this sense, the replacement Wall from MC54 to Bowness has no footings. The flags above the foundation trench could be referred to as a footing course, but as the nature of the stone differs from that of the superimposed wall it seems best to be consistent in the terminology of all the types of wall and to treat these flags as the top of the foundation. Figure 4.1 makes clear how the terms are used here. The set-back of the curtain wall from the line of the footings, known as the offset, is also shown.

162 Oxford English Dictionary.

163 ibid. 
Reinforcement of this terminology is given by Bellhouse in a discussion on the Cumberland Coast; his illustration clearly exemplifies the difference between foundations and footings, even where they are both of the same width. ${ }^{164}$

Vitruvius, when discussing temples, ${ }^{165}$ recommends with typical lack of precision that the foundations should be carried down in to solid ground 'as far as the magnitude of the work shall seem to require'. Where substructures of houses are to be built for cellars, the lower walls should be thicker than the walls of the house proper. ${ }^{166}$ Although he is not entirely clear, he does seem to be making some distinction between foundations and footings.

\section{Broad Wall foundations}

The Broad Wall foundation, at all points where it has been investigated, consisted at most of a very shallow trench in which were laid rough slabs bedded in clay or earth with the centre filled with rubble or whin boulders, ${ }^{167}$ and sometimes covered with a layer of clay. In some places small, rough boulders are used instead of flags. A few examples from excavation reports will illustrate the nature of the foundations 'as found'.

(Denton Burn) '. . footing of rough flat stones about six inches thick, laid upon clay ... ${ }^{168}$

(Great Hill) '. . . but a slight trench seems to have been dug for the foundations.

The Wall stood practically upon the surface ... the turf was removed and the

\begin{tabular}{ll}
\hline 164 & Bellhouse (1969) App. 2. \\
165 & III, iv \\
166 & VI, viii \\
167 & $H B^{13} 44$. \\
168 & Brewis (1927) 111.
\end{tabular}


surface levelled up by a thin layer of clay laid upon the two outer margins. Flat footing stones four inches thick were laid upon this clay ...'169

(Heddon) 'The trench cut here to build the Wall appears to have been very shallow . . f flat stones, four inches thick, laid upon clay . . .'170

(Denton Hall, T7b) '. . . a shallow trench dug, in which a layer of clay and rubble was put to form a foundation ... .171

(St. Oswald's/Planetrees) The frontispiece to Warburton's Vallum Romanorum ${ }^{172}$ shows a section through the Narrow Wall standing on Broad Wall footings and is marked 'What is underground is laid in clay the rest is done in mortar.' The section shows only the footings and not the flag foundation which can be seen to exist at Planetrees, but indicates that mortar was not used for the lower part of the Wall (see fig. 11.1).

(25b) 'The foundation course of the turret and the Great Wall consisted of one course of flags laid on or just into the natural clay or rock, and were covered with solid yellow clay. ${ }^{173}$

(T26a, High Brunton) ' . . . Consisted for the most part of whin boulders ... Underlying the whin boulders was a smaller rather intermittent foundation of smaller stones set in sand . . .'174

Brewis (1927) 113-4.

170 Brewis (1927) 119-20.

171 Birley (1930) 146.

172 Quoted and illustrated in Simpson (1931) 312-3. Birley (1960) quotes this section as coming from Nathaniel Hill's map of 1749.

173 Woodfield (1965) 108.

174 Woodfield (1965) 129. 
(Highshield Crags, Mons Fabricius) 'An isolated length of Broad foundation ... of whin blocks without a trace of core or clay bonding. ${ }^{175}$

(Highshield Crags-Castle Nick) ' . . .the earliest element was the Broad Foundation: invariably constructed of the local whinstone boulders, with a core of soil and rubble.'176

(Greatchesters) '... a bedding of whin boulders ... not a trace of mortar. . .'177

(Approach to Willowford Bridge) ' ... the footings [recte foundations] generally consist of a single course c. $0.2 \mathrm{~m}$ in depth . . the depth of footings [recte foundations] increases westwards ... much of the Broad Wall foundation would have been below ground level ... [in order to increase the strength of the abutment] $]^{178}$

\section{Narrow Wall foundations}

From Wallsend to Newcastle the foundations consisted of a trench filled with clay and roughly quarried sandstone fragments, with water-worn boulders. Above this there were offsets forming a footing before the Wall proper began. ${ }^{179}$ There is no clear evidence for the nature of the Narrow Wall foundation between Newcastle and the Irthing, as here it is almost entirely built on the broad foundation.

From the Irthing to MC54 the foundations consisted of a trench of varying depth filled with clay and cobbles or other stone, with flags at or about ground level. The

\footnotetext{
175 Crow 'RB in 1984' 378.

176 Crow (1991b) 55.

177 Hall (1926) 199-200.

178 Bidwell and Holbrook (1989) 54.

179 Simpson and Spain (1930).
} 
Wall is inset from the edges of the foundation, but there are no offsets above this point. ${ }^{180}$

\section{Intermediate Wall foundations}

The foundations of the Wall from MC54 to the Solway are the same as those east of MC54, the only difference being their width which for about three miles west from MC53 rises to somewhere between $9^{\prime}$ and $9^{\prime} 8^{\prime \prime}(2740-2945 \mathrm{~mm}){ }^{181}$ This led Simpson to classify the Wall from MC54 to MC80 as the Intermediate Wall, built to a 9Rf gauge.

The Intermediate Wall is further discussed below, section 4.2.3.

\section{Footings}

On top of the foundation slabs the first few courses of the Broad Wall form an offset below the superstructure; these courses are the footings. They are classified as being of two types, Standard A with one course below the offset and Standard B with three courses below the offset. ${ }^{182}$ These variations appear to indicate the work of different legions; the position is summarised by Hooley and Breeze (1968). There is some lack of consistency: at MC20 and close to Willowford Bridge four courses were found with no offset. ${ }^{183}$

The Narrow Wall has similar footings; on the south side of the Wall at many points the footings of the Narrow Wall may be seen inside the Broad Wall

\footnotetext{
180 Simpson et al. (1934).

181 Simpson et al. (1934) 133.

182 Birley at al. (1932).

183 Simpson et al. (1936) and (Shaw (1926) respectively.
} 
footings. ${ }^{184}$ The stone replacement for the Turf Wall had no offset and thus no footings.

\subsubsection{The design of the curtain wall}

To what extent were standard plans available for building the Wall? The answer would seem to be that this was so only to a very limited extent.

In the $80 \mathrm{~s} \mathrm{AD}$ a stone facing was added, if not originally planned, to the new legionary fortress at Inchtuthil. In Britain there began under Trajan the practice of adding a stone outer face to turf-and-timber auxiliary forts. ${ }^{185}$ Some forts were built $a b$ initio in stone, the fortlet at Haltwhistle Burn and the forts at Gelligaer and Hardknott being three examples from this period.

At Haltwhistle the outer wall is $3^{\prime}(915 \mathrm{~mm})$ thick, built entirely with clay rather than lime as a mortar, with a rampart backing $8^{\prime}(2440 \mathrm{~mm})$ wide. ${ }^{186}$ At Gellygaer the wall is between three and four foot thick, bonded with lime mortar, backed by a $14^{\prime} 4270 \mathrm{~mm}$ ) rampart; the interior of the wall is filled with earth. ${ }^{187}$ Hadrianic Hardknott had 5'6" (1680mm) walls and a rampart which was perhaps $13^{\prime}(3960 \mathrm{~mm})$ wide. ${ }^{188}$ The defences at Inchtuthil consisted of a stone wall up to 4'11" (1500mm) thick, with a core sometimes of rubble and sometimes of solid mortared blocks. It was backed by a rampart which varied in width from $13-17^{\prime}(3960-5180 \mathrm{~m}) .{ }^{189}$

\footnotetext{
184 e.g. between MC48 and Willowford bridge.

185 Johnson (1983), 66. The introduction of stone walls began earlier elsewhere in the empire, see below 4.3 .

186 Gibson and Simpson (1909) 230-232.

187 Ward (1903) 35-37.

188 Collingwood (1928) 323 and fig. 2.

189 Pitts and St. Joseph (1985) 60-61.
} 
The walls of the forts built on the Wall were generally about $5^{\prime}(1500 \mathrm{~mm})$ thick and of two faces with a rubble core, again with an earthen rampart backing. The curtain wall of the new frontier was quite unlike any of these. Not only was it designed to be $10 \mathrm{Rf}$ thick but it had no earthen or clay rampart behind it.

It has been said that the width of the curtain wall was due, at least in part, to the method of construction. 'The building of the Broad Wall with clay and rubble ... entirely accounts for its curious proportions ... To make it thinner was to run risks with its stability. ${ }^{190}$ In fact the reverse is true, and any instability in a clay-bonded core would be greater in the broader wall.

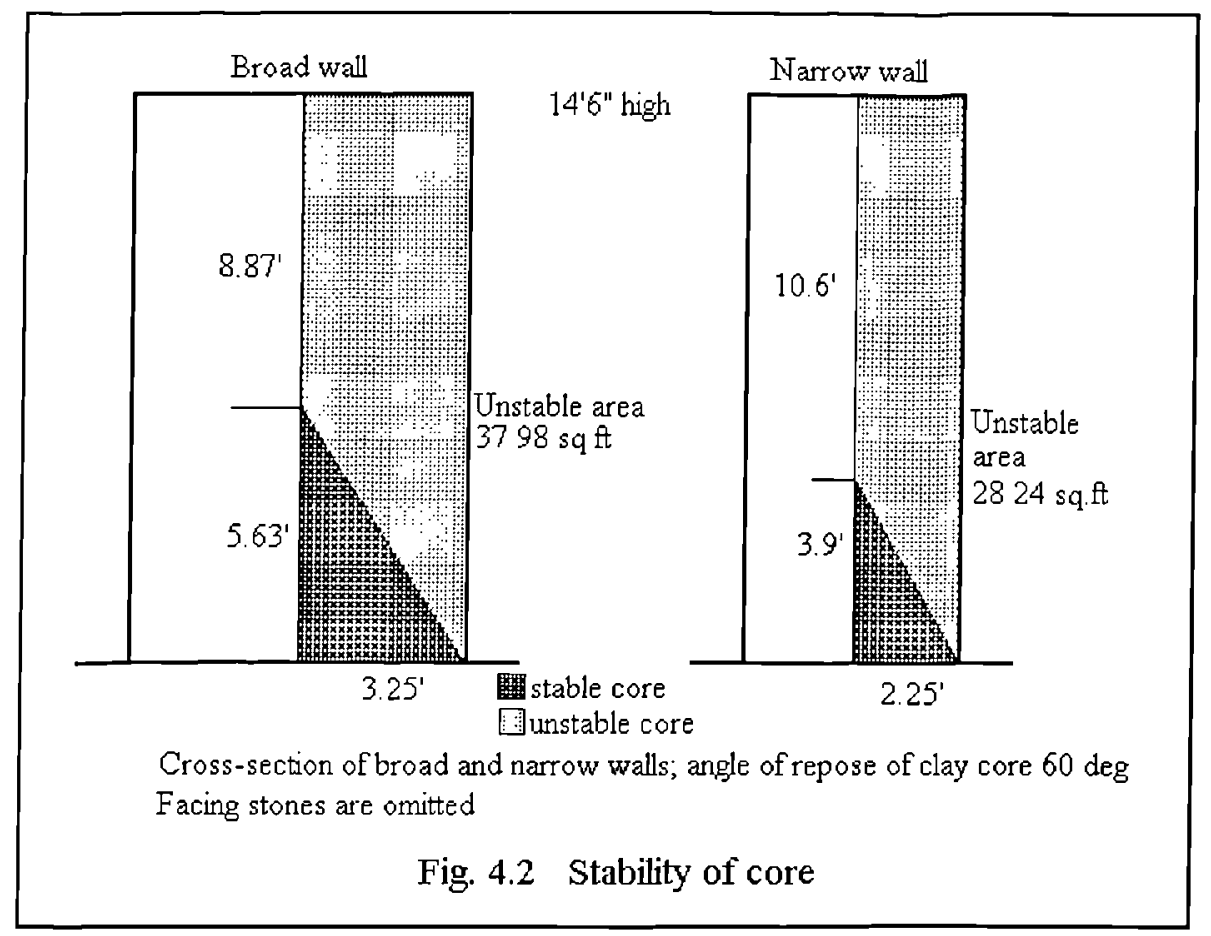

The only stable part of the core of a wall of this design is the triangle at the base (see fig. 4.2). The angle of repose of well-consolidated clay and rubble, protected as

$190 \quad$ Richmond (1950), 43. 
it was from the weather by the facing stones, might be as high as $60^{\circ} .{ }^{191}$ Taking the Broad Wall as 9'6" (2900mm) wide and the Narrow as 7'6" (2290mm) wide, and the facing stones being $18^{\prime \prime}(450 \mathrm{~mm})$ deep (Richmond's figure), then a section through the Broad Wall will show 37.98 sq.ft $\left(3.5 \mathrm{~m}^{2}\right)$, and the Narrow Wall 28.24 sq.ft $\left(2.6 \mathrm{~m}^{2}\right)$, of unstable core bearing on each face. ${ }^{192}$ Whatever the figure chosen for the angle of repose, the Narrow wall is more stable than the Broad. Figure 4.2 illustrates this with sections through the two walls.

The use of mortar to bond the core of the Broad Wall was once assumed to be the norm; it is now clear that very little mortar was used in the core. ${ }^{193}$ However, there are instances where it was bonded with mortar, especially at Great Hill where the Wall was uncovered and removed with gunpowder during road works. ${ }^{194}$ It has been argued that sun-baked clay (the work took place in summer) was mistaken by the excavator for concrete. ${ }^{195}$ But this is to argue that the Northumberland County Council road engineer was also mistaken, which seems most unlikely; he would hardly have gone to the expense of using explosives to remove clay of whatever hardness.

It seems probable that work began in places with the use of a mortared core, but that the specification was soon changed to the use of clay.

191 Molesworth (1910) 80, 86.

192 Broad wall: half-section of core $3.25^{\prime}$ wide; area of stable part 9.15 sq.ft $\left(\tan 60^{\circ} \times 3.25\right.$ gives height of stable part as 5.63. $5.63 \times 3.25 / 2=9.15)$; area of unstable part $9.15+(8.87 \times 3.25)=$ 37.98 sq.ft. Narrow wall: area of stable part 4.38 sq.ft $\left(\tan 60^{\circ}\right.$ x 2.25 gives height as 3.9); area of unstable part $(3.9 \times 2.25)+(2.25 \times 10.60) 4.38+23.86=28.24$ sq.ft.

193 Crow (1991a) and Bennett (1998) 27, contra Hill and Dobson (1992).

194 Brewis (1927) 115. Birley (1960) argues that the Wall had a mortared core in Wall-miles 7-12, and at other points also, although clay was occasionally used.

195 Benmett (1998). 
One reason for the provision of an earth rampart in new forts with stone walls may well have been to increase the effective width of the top of the fort wall. This point is discussed convincingly by Bidwell, Miket and Ford. ${ }^{196}$ Piling up an earth rampart was cheaper, in terms of skilled labour, and quicker than building a wider fort wall in stone. Lander points out that certain fort walls have engaged piers along the inner side of a (narrow) curtain wall, perhaps to support a timber patrol walk in place of an earth rampart. ${ }^{197}$ It may be no coincidence that the 10Rf width must have roughly matched the width of fort wall plus rampart top.

The Wall is the same thickness as part of the Hadrianic Fossatum Africae; there, the wall on the side of Teniet el Ouasta is given by Baradez as 3.00 metres $\left(10^{\prime}\right) .{ }^{198}$ The walls of Hadrianic Gemellae were $2.75 \mathrm{~m}\left(9^{\prime}\right)$ thick, almost identical to Hadrian's Wall. These similarities are echoed in the design of the towers, see section 4.2.8.

There is some evidence that the initial design of the Wall allowed for patrols along the top. The provision of bridges at Chesters and Willowford, not wide enough to carry a road and yet of monumental proportions and forming a continuation of the Wall, ${ }^{199}$ strongly suggests that a walk along the top of the wall was part of the original plan. ${ }^{200}$

The Broad Wall incorporated single courses of thin stone at varying vertical intervals. They are usually described as 'bonding courses'201 (sometimes, incorrectly, as 'string courses', see Glossary), and appear at varying vertical intervals.

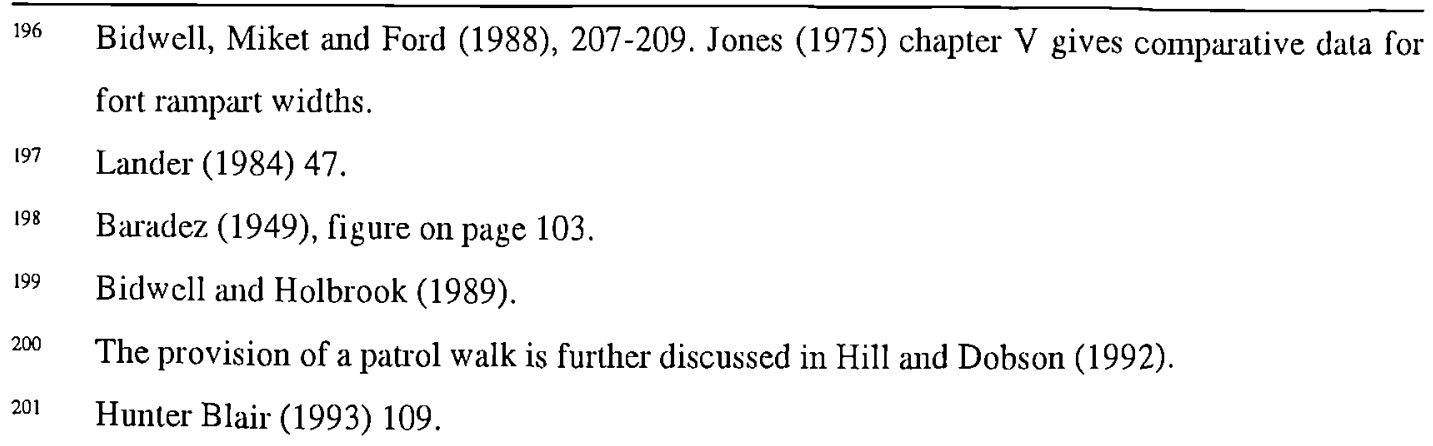


They are best represented at MC37, Housesteads, where two of them are seen to the west of the north gate; the lower one is between 4' and 6' (1200-2000mm) above ground level, and the upper one 4' above that. They do not occur in post-Hadrianic rebuilding, and not always in the original Wall; the west wing wall of MC42, Cawfields, and the north wall of MC48, Poltross Burn, both stand over 6' (2m) high but show no sign of a thin course. At T29a, Black Carts, the north wall shows one on the north face, at $39^{\prime \prime} / 1 \mathrm{~m}$ but not on the south face. Despite the name, their purpose is unclear. Although they tend to be longer on the face than the walling stones this is not always the case, and they are very little deeper into the wall than the stones they rest on. ${ }^{202}$ Bonding courses are further discussed in section 9.5 .

\subsubsection{Broad, Narrow, and Intermediate curtain Walls compared}

The widths of the foundations and the curtain wall are listed with references in Appendix 1, and these will be briefly summarised here using Roman feet. For an explanation of the location code, see the introduction to chapter 13.

The Broad Wall, where it occurs between Newcastle and the Irthing, is generally between 9 and 10Rf wide above the footings. It is on a foundation which varies in width from 10.3-12.2Rf.

The Narrow Wall, built in gaps where Broad Wall had not been completed, including from Wallsend to Newcastle, ${ }^{203}$ and as a replacement for the first five miles of the Turf Wall, varies between 5.8-8.9Rf, on a foundation of 6.7-9.6Rf. It is

\footnotetext{
202 Author's survey, especially MC49 to Birdoswald where the bonding course is in places the top of the Wall. 
believed on the basis of pottery comparisons that the first part of the Turf Wall to be rebuilt ran as far as approximately MC54. ${ }^{204}$

The Intermediate Wall, said to run from MC54-MC80, is between 7.7-8.1Rf wide on a 9.2-9.8Rf foundation, apart from Wall-miles 76-77 where the Wall runs along the very edge of the Solway marshes; here, for what were presumably local structural reasons, the foundation width increases to almost 10Rf. By comparison, the Wall from MC49-MC54 is 8Rf on a foundation of 9-9.3Rf.

There is in fact no effective difference between the Narrow and Intermediate Walls in the Turf Wall sector. The increased width of foundation claimed by Simpson occurs in a small length, from MC53 to approximately MC56. ${ }^{205}$ This is in an area where the subsoil is of such a 'treacherous nature' that it led to the berm being much wider, ${ }^{206}$ and it may simply be this which led to the building of a slightly wider foundation. This overlap with Simpson's Intermediate Wall immediately negates the latter which seems more likely to represent a local increase in width to meet local conditions. It is probable that when the Turf Wall from MC54 to MC80 was rebuilt, approximately the same width as used for the first part of the rebuilding was maintained, and the existence of a different specification for an 'Intermediate Wall' must be seriously doubted.

\subsubsection{Milecastles and milefortlets}

From the earliest days the Roman army adopted standard plans for its forts and camps, and maintained the basic form over several centuries. The camp described by

\footnotetext{
204 Simpson and Richmond (1935).

205 Simpson et al. (1934).

$206 \quad$ Simpson et al. (1934) 137.
} 
Polybius in the second century $\mathrm{BC}^{207}$ is recognisable in the camp of PseudoHyginus dated to either the first or the second century AD. ${ }^{208}$ Differences in detail reflect, in general, the changes in the organisation of the army over the intervening centuries. $^{209}$ Clearly, the Polybian plan, itself doubtless the product of experimentation, was found to be an efficient layout. A square or rectangular fort plan was still being used by the Byzantine army. ${ }^{210}$ Whether from motives of conservatism or efficiency, the army believed in standardisation.

It is very likely that each legion kept standard plans for forts, fortlets, signal towers, and other structures which it built; repetition would mean simply pulling out old plans and issuing copies to the working parties. This is supposition as no such records have survived, but similarity in plans suggests that work was based on past records rather than being designed anew on each occasion. A similar point is made by Johnson, in relation to forts and fortlets in Germany. ${ }^{211}$

However, fortlets of the size of milecastles were extremely rare, as can be seen from Table 4.1; even the fortlets on the Antonine Wall were somewhat larger, as discussed below, 4.2.6.

\footnotetext{
207 Polybius 6.42.2-5.

208 The date is unresolved. See Frere (1980) and Birley (1981).

209 Johnson (1983) 27.

210 Dennis (1985).

211 Johnson (1983), 44.
} 
TABLE 4.1

SOME PRE-HADRIANIC FORTLET SIZES AND AREAS

* Denotes dimensions scaled from published plan.

$\dagger$ Indicates that the dimension has been obtained by subtraction of given wall and rampart thicknesses from given external dimensions.

\begin{tabular}{|c|c|c|c|c|c|}
\hline & \multicolumn{2}{|c|}{ Feet } & \multicolumn{2}{|c|}{ Metres } & \multirow[b]{2}{*}{ Date } \\
\hline & $\begin{array}{l}\text { Internal } \\
\text { size }\end{array}$ & $\begin{array}{c}\text { Internal } \\
\text { area } \\
\text { sq.ft }\end{array}$ & $\begin{array}{l}\text { Internal } \\
\text { size }\end{array}$ & $\begin{array}{l}\text { Internal } \\
\text { area } \\
\text { sq.m }\end{array}$ & \\
\hline Martinhoe $^{212}$ & $79 \times 82$ & 6468 & $24 \times 25$ & 600 & Neronian \\
\hline Cappuck $^{213}$ & $267 \times 195 \dagger$ & 52065 & $81.4 \times 59.5$ & 4833 & Flavian \\
\hline Brownhart Law ${ }^{214}$ & $40 \times 55 \dagger$ & 2200 & $12.2 \times 16.8$ & 205 & Flavian?/Antonine? \\
\hline Chew Green II ${ }^{215}$ & $130 \times 100 \dagger$ & 13000 & $39.6 \times 30.5$ & 1207 & Flavian \\
\hline Degerfeld $^{216}$ & $114 \times 105$ & 11970 & $34.7 \times 32$ & 1110 & pre-Hadrianic? \\
\hline Kaims Castle 217 & $75 \times 70$ & 5250 & $22.9 \times 21.4$ & 490 & Flavian $^{218}$ \\
\hline Kemel I ${ }^{219}$ & $95 \times 92$ & 8740 & $29 \times 28$ & 812 & Domitianic \\
\hline Qasr el-Hallabat ${ }^{220}$ & $54 \times 54$ & 2916 & $16.5 \times 16.5$ & 272 & Trajanic \\
\hline Haltwhistle Burn ${ }^{221}$ & $146 \times$ c. $185 \dagger$ & 27010 & $44.5 \times 56.4$ & 2510 & Trajanic $^{222}$ \\
\hline
\end{tabular}

$212 \quad$ Fox and Ravenhill (1967).

213 Richmond (1950-51).

214 St. Joseph (1951).

215 Richmond and Keeney (1937) 146-7. The excavators estimate the size over the rampart 'which was 'not a small one' as 170' x 130'; a rampart thickness of $15^{\prime}$ has been assumed here.

216 Saalburg Jahrbuch xxiv 1967 14-32. This fortlet was originally built in turf and timber, and rebuilt in stone perhaps before the end of Hadrian's reign, or more likely 160-175 (Schönberger (1969) 165 , and (1985) 492.

217 Christison (1900-01), 20.

218 Rivet (1964) $196^{\prime}$... its probable relationship to the Ardoch signal post . . suggests a Flavian date.'

219 ORL A.I. Strecke 2,78: taf. 11,13.

220 Kennedy (1982) 51 and fig. 6, and (2000) 90. The wall thicknesses and internal dimensions have been scaled from the published plan and the given exterior dimensions.

221 Gibson and Simpson (1909) 223, 230, 232. Measured over the rampart, the fort is 167'6" by $202{ }^{\prime} / 213^{\prime}$. The walls are $3^{\prime}$ thick with an inner rampart $8^{\prime}$ wide.

222 The excavators suggested a pre-Hadrianic date (Gibson and Simpson (1909) 284); Breeze and Dobson (2000) 214, suggest Trajanic; Simpson (1976) 50-55, and (1974), gives a Trajanic date. 


\begin{tabular}{|c|c|c|c|c|c|}
\hline Maiden Castle 223 & $115 \times 85 \dagger$ & 9775 & $35 \times 25.9$ & 907 & 2 nd century \\
\hline Throp 224 & $162 \times 170 \dagger$ & 27,540 & $49.4 \times 51.8$ & 256 & Trajanic 225 \\
\hline MC $37^{226}$ & $50 \times 60$ & 3000 & $15.2 \times 18.3$ & 278 & Hadrianic \\
\hline $\mathrm{MC} 48^{227}$ & $70 \times 60$ & 4200 & $21.4 \times 18.3$ & 392 & Hadrianic \\
\hline
\end{tabular}

'Normal' small fortlets were generally constructed to hold a garrison of probably a century or so, ${ }^{228}$ whereas the majority of milecastles seem to have held eight or twelve men.229 Also, most fortlets have only a single gate rather than two gates with a roadway running between them. The milecastles thus fall into a separate class and the plans for them must have been drawn ab initio. Strictly speaking, milecastles are not in fact 'fortlets,' in the sense of being accommodation for units or sub-units. They seem rather to have been to provide protected accommodation for gate guards and/or lookouts, a completely new departure.

There is no obvious reason why milecastles should not have been $75^{\prime} \times 40^{\prime}$ or 65 $\mathrm{x} 45^{\prime}$, rather than the near-standard $50^{\prime} \mathrm{x} 60^{\prime} .^{230}$ It is almost as though a committee of praefecti castrorum had agreed a standard size and omitted to define the orientation of the long and short axes. The other point of similarity is the thickness of the side

223 Collingwood (1927), 173, where the dimensions are given to the centre of the rampart, and the rampart width as $15-20$ '.

224 Simpson (1913), 365, 367,

225 Simpson (1913), 381, suggests a probable pre-Hadrianic date; Simpson (1976) 50-55, and Simpson (1974), give a Trajanic date.

226 Hunter Blair (1934), 106. The precise figures are 49'6" x 57' $6^{\prime \prime}$.

227 Gibson and Simpson (1911), 395. Average 70' north-south, 60'9" east-west.

228 Breeze (1974), 150.

$229 \quad$ Breeze and Dobson (2000) 41; Hill and Dobson (1992) 37, 49. MCs47 and 48 probably held 32 men if the scale of accommodation was the same as in a normal auxiliary barrack. $H B^{13} 193$ gives 64 men, which seems excessive for the space available.

230 Hunneysett (1980). 
walls of the milecastles; the gauge of about 10Rf or a little less is almost twice the norm for fort walls. It is true that there was no inner rampart of earth, but a stone wall some 9' $(2.74 \mathrm{~m})$ wide around a very small fortlet is remarkable.

The relatively small internal area of milecastles was further reduced by their basic function of providing a gateway. The roadway, which presumably had to be kept reasonably clear, reduced the area by 500 or 600 square feet $\left(46-55 \mathrm{~m}^{2}\right)$ depending on the axis of the milecastle.

With a few exceptions, despite the differing axes and gate plans, the sizes of the milecastles on the stone wall are remarkably uniform. This suggests, not unreasonably, that one part of the overall scheme laid down the number of men who were to guard the gateways.

However, the last two milecastles on the Stone Wall, MCs 47 and 48 , are noticeably larger than the standard, at 4,200 sq.ft $\left(390 \mathrm{~m}^{2}\right) .{ }^{231}$ The adjacent milecastles on the Turf Wall, MCs49TW and 50TW, were dissimilar from the Stone Wall milecastles and from each other. MC49TW was probably of the standard size $^{232}$ and MC50TW falls midway between the 'large' and 'small' milecastles at 3630 sq.ft $\left(336 \mathrm{~m}^{2}\right) .{ }^{233}$ No dimensions are available for MCs51TW, 52TW, or

231 Simpson et al. (1936a) 270; Gibson and Simpson (1911).

232 Richmond (1956) 23. Calculated by the excavator as $54 ' \mathrm{~N}-\mathrm{S} \times 50^{\prime} \mathrm{E}-\mathrm{W}$. The east-west dimension is likely to be reasonably accurate, but the north-south dimension is calculated on the basis of the relationship of the single post holes to an eight-foot berm and on the assumption that the relationship of the post holes to the rampart was identical at both north and south. The berm in the sector 49-52a varies between 6' and 8', and in view of the relatively cramped site the berm here may well have been only 6', which would increase the north-south dimension to 56 ; it seems unsafe to take this milecastle as being smaller than the norm and there seems little reason to doubt that this milecastle was intended, and perhaps actually built, to be $60^{\prime}$ long.

233 Simpson, Richmond, and St. Joseph (1935), 220. 
53TW. The area of MC54TW seems to have been in the order of 4980 sq.ft. $\left(460 \mathrm{~m}^{2}\right) .^{234}$

In the first phase of building, then, the two milecastles to the east of the Irthing were larger than the norm, and of the six immediately to the west, one was of normal size, and one was slightly larger and one significantly larger than normal. This was not only continued but amplified when the Turf Wall was rebuilt in stone.

Following the rebuilding in stone, MC49SW was 2000 sq.ft $\left(185 \mathrm{~m}^{2}\right) \operatorname{larger}^{235}$ than its turf and timber phase. MC50SW was significantly larger than its already large turf and timber counterpart, at 4560 sq.ft $\left(423 \mathrm{~m}^{2}\right) .{ }^{236}$ The replacement stone milecastle 52SW, Bankshead, is the largest milecastle known, with an internal area of nearly 7000 sq.ft $\left(650 \mathrm{~m}^{2}\right) ;{ }^{237}$ little is known of its internal arrangements or of its turf predecessor. MC53SW is again large, at 5500 sq.ft $\left(510 \mathrm{~m}^{2}\right),{ }^{238}$ and MC54SW matches 49SW at just under 5000 sq.ft $\left(464 \mathrm{~m}^{2}\right) .{ }^{239}$ The only other known SW milecastle, 72SW, at 62 ' E-W, may have been a 'standard' milecastle in its stone phase, if it were short-axis. ${ }^{240}$ Some comparative plans are shown in fig. 4.3.

\footnotetext{
234 Simpson and Richmond (1935a).

$235 \quad$ Richmond (1956) 18.

236 Simpson (1913).

237 Simpson and Richmond (1935).

238 Simpson and McIntyre (1935a).

239 Simpson, Richmond, and McIntyre (1934).

$240 \quad$ Austen (1994) 45.
} 
TABLE 4.2

COMPARISON OF TW AND SW MILECASTLES

\begin{tabular}{lcccl} 
No. & \multicolumn{2}{c}{ Area } & \multicolumn{2}{c}{ Area } \\
& sq. ft. & Turf & Stone \\
& Turf & Stone & 278 & 273 \\
49 & 3000 & 4940 & 337 & 423 \\
50 & 3630 & 4560 & & \\
51 & & & & 642 \\
52 & & 6927 & & 511 \\
53 & & 5508 & & 462 \\
54 & $? 4980$ & 4980 & &
\end{tabular}

With the dimensions of only five milefortlets known, the evidence from the Cumberland Coast is inconclusive. Ignoring the atypical small fort at Cardurnock, there are only three for which have reasonably firm dimensions are known. MF20 was probably designed to 'standard' milecastle size, complete with two gateways, as was MF21, while MF22 was designed to be the size of MC48. ${ }^{241}$ The length of MF1 is not known, as the south rampart was not available for excavation; ${ }^{242}$ it may have been designed as very slightly larger than a 'standard' milecastle. Much more excavation is needed before any comparisons can be made with other parts of the Wall.

The milecastle walls are structurally and dimensionally very similar to the curtain wall, with the exception that the core was normally, though not invariably, bonded with mortar rather than clay. ${ }^{243}$

\footnotetext{
$241 \quad$ Bellhouse (1970) 26; Turnbull (1998); Bellhouse (1970) 11, respectively.

242 Potter (1977) 159.

243 Crow (1991). MC27 was clay bonded (Gillam (1953)).
} 


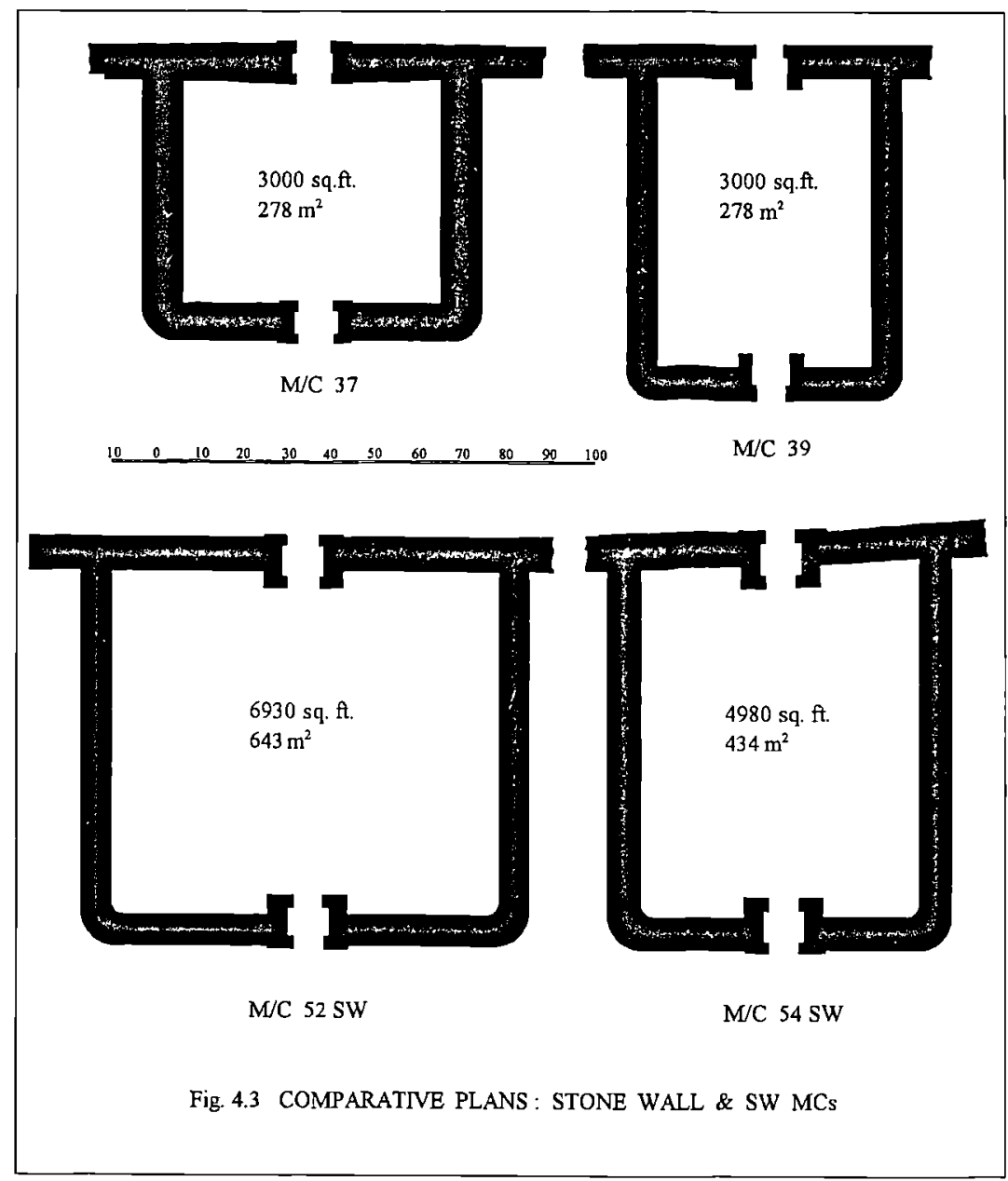

\section{Milecastle gateways}

The other design element to be considered was the form of the gateways. Here the legions were certainly operating independently as there are three distinct gate plans. Current thought is summarised by Breeze and Dobson, ${ }^{244}$ and the variations in milecastle gate plans are shown in fig. 4.4. The designation of the four types follows the Handbook.

$244 \quad$ Breeze and Dobson (2000) 68-70. 
The ground plans of the gateways have been discussed at some length by Hill and Dobson (1992). There it was argued that the identical plans shown by north and south gates of type III point very strongly to there having been a tower over both. Another point discussed there is that there is no obvious explanation for the wider rear arches in type II/IV; the same problem occurs in the gateways of Housesteads fort.

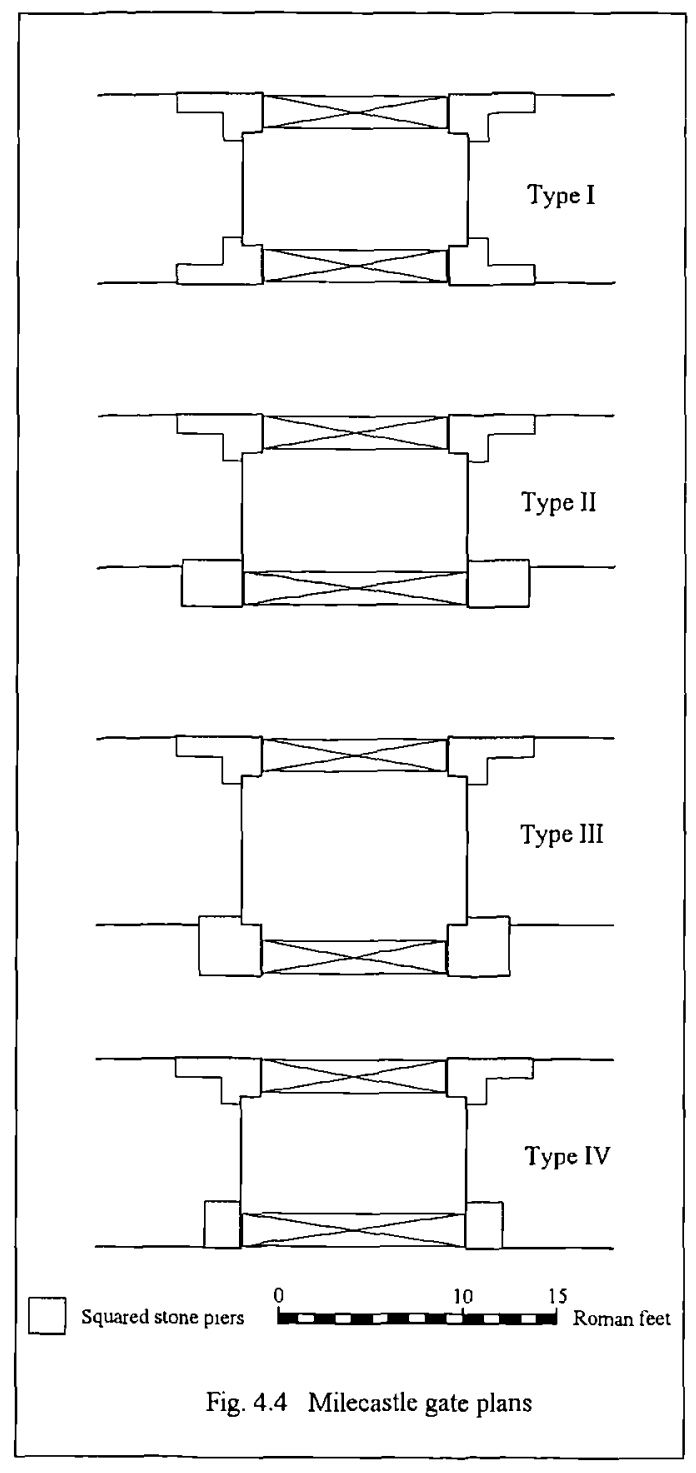


Type I

Type I always has the same length as the width of Broad Wall, plus a projection of 2$3^{\prime \prime}(50-70 \mathrm{~mm})$ beyond the faces of the milecastle walls as a form of emphasis. Where the curtain wall of the milecastle is less than $10 \mathrm{Rf}$ wide the gate projected slightly into the milecastle, as exemplified by the south gate of MC42. On the south side the projection is small, about $60 \mathrm{~mm}$ on the west side and almost nothing on the east side. However, the north west pier projects by about $6 \frac{1}{2}{ }^{\prime \prime}(170 \mathrm{~mm})$ and the north east by $15^{\prime \prime}(390 \mathrm{~mm})$. This is significantly greater than normal, and is due to the reduced width of the south wall of the milecastle which is only $8^{\prime} 4^{\prime \prime}(2540 \mathrm{~mm})$ rather than the average Broad Wall of 9'3" (2819mm). ${ }^{245}$

The major reason for the consistency of the length of type I gateways is that space has to be given for the doors to open, and the inner respond would prevent this if the length of the gate were reduced. The south gate of MC42 comes very close to this, as the foundation blocks for the inner piers have been cut away to give clearance to the doors; this is especially evident on the north west pier. ${ }^{246}$

\section{Type II/IV}

These gates have no projecting responds on the inner ends of the gate passage; they have instead flush piers which may or may not have carried an arch. ${ }^{247}$ These gateways are the same length as the thickness of the Broad Wall (type IV), and where there occur in Narrow Wall milecastles the inner ends project into the milecastle (type II). This is not due to the need to give clearance for the doors, as there is no projecting inner respond for the doors to foul, and the length is probably due to the need to maintain a reasonable depth to the towers over the gateways. The

\footnotetext{
$245 \quad$ Hill (2001b).

246 Hill (2001b).

247 Hill and Dobson (1992) 35-6.
} 
projection is more pronounced than that seen in type I in the same situation, but this may be due to the very limited number of Type I gateways found in association with narrow side walls - MCs37 and 42 are the only certain ones and both milecastles are transitional, having been begun in broad gauge and completed in narrow.

\section{Type III}

These gateways have both inner and outer responds, but this type always projects into the milecastle, regardless of whether the walls are broad or narrow gauge, by about $3^{\prime}-3^{\prime} 6^{\prime \prime}(1 \mathrm{~m})$. The only reason which can be put forward for this design is a desire to have a greater floor area to the tower over the gates.

MCs 19, 20, and 22 have very short projections (see Appendix 1) and could be a variant of Type 1, but without re-excavation they cannot be reclassified.

\subsubsection{Comparisons with the Antonine Wall fortlets}

It may be noted that the design of diminutive 'standard' milecastles did not survive into the Antonine frontier. The majority of the seven fortlets on the Antonine Wall of which the size is reasonably securely known are significantly larger, although still small by the standards for fortlets elsewhere. Only one, Watling Lodge, is around 3000 sq.ft $\left(278 \mathrm{~m}^{2}\right)$. Of the remainder, three of the four 'long axis' fortlets are over 4000 sq.ft $\left(370 \mathrm{~m}^{2}\right)$ (the size of the other is not entirely certain), while two of the three 'short axis' fortlets (Watling Lodge is the third) are a little under 3500 sq.ft $\left(325 \mathrm{~m}^{2}\right)$. 
TABLE 4.3

\begin{tabular}{|c|c|c|c|c|c|c|}
\hline & & NTONI & WALL & & & \\
\hline & & ETRES & & & FEET & \\
\hline & N-S & E-W & Area & $\mathrm{N}-\mathrm{S}$ & $E-W$ & Area \\
\hline & & & sq.m. & & & sq.ft \\
\hline Kinneil & c. 21 & c. 18 & 378 & 69 & 59 & 4069 \\
\hline Seabegs Wood & 21.8 & 18 & 392 & 72 & 59 & 4224 \\
\hline Croy Hill & 22 & 18.5 & 407 & 72 & 61 & 4381 \\
\hline Wilderness Pl. & c. 19.5 & 17.4 & 339 & 64 & 57 & 3652 \\
\hline Watling Lodge & c. 15.5 & c. 18.5 & 287 & 51 & 61 & 3087 \\
\hline Cleddans & c. 17.6 & 18 & 317 & 58 & 59 & 3410 \\
\hline Duntocher & 17.4 & 18 & 313 & 57 & 59 & 3371 \\
\hline
\end{tabular}

\subsubsection{The purpose of the milecastles}

The fact that MC37, Housesteads, only some $400 \mathrm{~m}$ west of the fort, was provided with a barrack block whereas the third century Knag Burn gateway, $100 \mathrm{~m}$ east of the fort, had no accommodation and must have been manned from the fort, suggests that the milecastles had a different, or additional, function to that of merely guarding a gateway. ${ }^{249}$ Mann suggests that one function of troops based in the milecastles was patrolling, but it is not easy to see how a detachment from a force of only eight or twelve men could do any serious work of this nature. The few larger Turf Wall milecastles known probably could have carried out patrols, especially if they contained a small element of cavalry for which there is space. In theory, MC52SW, the largest, had room for perhaps 32 infantry and 12 cavalry, although there is no evidence for the internal buildings. The putative accommodation shown in fig. 4.5 is based on the cavalry barracks at Wallsend and the infantry barracks at Housesteads.

\footnotetext{
$248 \quad$ From Keppie and Walker (1981) 158.

249 Mann (1990).
} 
The 'non-gateway' function of these milecastles may have increased in importance if their larger size when rebuilt in stone was related to larger accommodation.

There is room for much research needed into the later function of the milecastles, as opposed to their original purpose of a gateway.
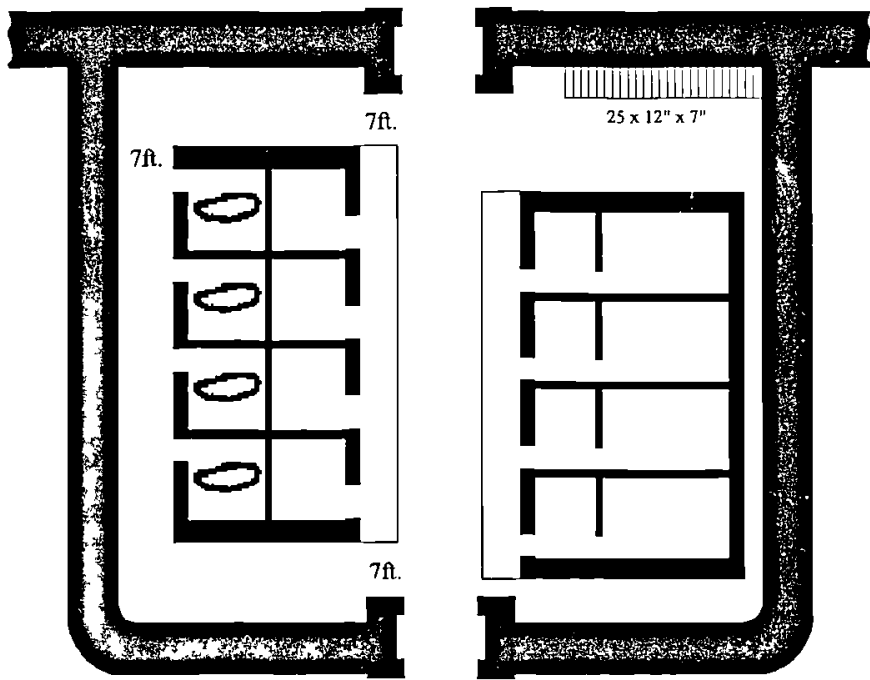

With 4 cavalry contubernia $(=12)$ and 4 infantry contubernia $(=32)$

Fig. 4.5 MC52SW: theoretical garrison 
TABLE 4.4

MILECASTLE BARRACK BLOCKS

Internal dimensions of original buildings $\left({ }^{*}=\right.$ scaled from pub. plan). References are as for Table 4.2 unless otherwise noted.

\begin{tabular}{llll} 
& \multicolumn{1}{c}{ West side } & East side & $\begin{array}{c}\text { Area of barrack } \\
\text { (sq.ft) }\end{array}$ \\
9 & Rems of slight structure & $21 \times 11^{* 250}$ & 231 \\
35 & none & $20^{\prime} \times 9^{\prime *}$ & 180 \\
37 & Rems of slight structure & $32 \times 13^{\prime *}$ & 416 \\
39 & & &
\end{tabular}

No trace remaining of internal buildings

No trace remaining of internal buildings

No trace remaining of internal buildings

Period 1 buildings uncertain

none

$250 \quad$ Birley (1930) 156 and plate XLII.

251 Simpson (1948), 87 and fig. 3. The dimensions given in the text are external. The internal figures might be $108^{\prime} \times 26^{\prime}$, and it is on these figures that the total area is calculated.

252 This includes the 'north' (actually west) block of two ?contubernia, but excludes the single block to the east. If this were included the total area would be $666 \mathrm{sq}$. ft.

253 On the east side, post holes were believed to indicate a second building $18 \times 14 \mathrm{~m}$ (1062 sq. ft.), 


\subsubsection{Turrets}

The design and appearance of turrets have been discussed by a number of writers, ${ }^{254}$ and the reasoning will not be repeated here. In general terms they were around $12^{\prime}$ by $13^{\prime}$ internally $(3660 \times 3960 \mathrm{~mm})$, perhaps $35^{\prime}(10.67 \mathrm{~m})$ to the eaves, with a ground floor entrance, and perhaps a balcony at second floor level. The roof may have been either flat or pitched. T48a and T48b are anomalous in their design (they have narrow north walls), possibly due to early experimentation;255 $\mathrm{T} 45 \mathrm{a}$ is somewhat similar, due no doubt to being built in advance of the Wall.

Apart from their incorporation into a running barrier, the turrets were not unlike other stone signal or watch towers. Their design may have derived from two sources: independent signal/watch towers, and fort interval towers.

Independent towers in a series seem to appear for the first time in Britain on the Gask ridge. ${ }^{256}$ They have parallels in the towers on the Upper German limes, where a road, and perhaps a cleared strip of ground, connected a series of forts and towers. ${ }^{257}$

The Gask towers are of timber and about two thirds of the size of turrets, with a typical floor area of only 122 sq.ft $\left(11.3 \mathrm{~m}^{2}\right) .{ }^{258}$ Although four out of the ten are

\footnotetext{
a total barrack area of $1728 \mathrm{sq}$. ft. This would be a remarkable provision in a 'standard' milecastle.

254 Brewis (1932), Bellhouse (1969), Charlesworth (1977), Dobson (1986), Hill and Dobson (1992), Hill (1997).

$255 \quad$ Hill (1997) 42.

256 Breeze (1982), 64; Jones and Woolliscroft (2001) 27.

257 Breeze and Dobson (2000), 64; Schönberger (1985) 378. These towers, thought to date to the reign of Domitian, have recently been suggested as Trajanic (see above, section 2.2).

258 Woolliscroft (2002). The figures given here exclude the abnormally large tower at
} 
rather larger than this, the generally small size of the Gask towers would seem to rule them out as suitable for other than short spells of duty as opposed to sleeping accommodation.

The turrets on the Wall, on the other hand, are of a size, ${ }^{259}$ and have yielded artefacts, ${ }^{260}$ appropriate to semi-permanent outposts with 'garrisons' being changed over at intervals of days or even weeks.

The mile-fortlet at Cardurnock had a single tower built into the rampart, and was nearer in size to the Gask towers and interval towers than to the stone turrets. The excavator quotes a size of 'about 14 feet square' $(4270 \mathrm{~mm}){ }^{261}$ but this seems to be to the outer side of the post holes; scaling from the drawing suggests a centre line size of about $10^{\prime}(3 \mathrm{~m})$ square. The timber tower over the 'north' gate of MF21 is $10^{\prime}$ (3m) square, again almost identical to the Gask towers and not designed for accommodation. Stone milecastle towers had a much smaller internal area, of 66 sq.ft $\left(6 \mathrm{~m}^{2}\right)$ for types I and II/TV or 88 sq.ft $\left(8 \mathrm{~m}^{2}\right)$ for type III gates, again for observation only and not for accommodation. ${ }^{262}$

A single-ditched tower of Roman date at Beattock Summit is very close in size to the Gask towers. ${ }^{263}$ No dating evidence was found, but the excavator suggests that it might be either Flavian or Antonine.

Greenloaning; if this is included, the average area is $126 \mathrm{sq.ft}\left(11.69 \mathrm{~m}^{2}\right)$. All dimensions are taken to the centre line of the posts in order to allow for those where the precise size of the posts is not known; if taken to the inner line of the posts, the sizes would be reduced still further. Hill and Dobson (1992), 38.

260 Allason-Jones (1988).

261 Simpson (1948) 89 and fig. 3.

262 Hill and Dobson (1992) 33. 
The Mains Rigg (Over Denton) tower (probably Trajanic) ${ }^{264}$ resembles the turrets in size and wall thickness, with the doorway at first floor level, appropriate for an isolated tower and a feature which is common in German examples. Robin Hood's Butt, again assumed to be Trajanic, 265 is a very similar structure. At Birdoswald, remains have been identified of 'A good building, twenty feet square, with three-foot walls . . .'266 No further evidence was found, but the similarity to Mains Rigg and Robin Hood's Butt strongly suggests a Roman signal tower. The tower at Pike Hill, on the Wall but not in the sequence of Wall turrets, is a similar size but with a ground floor doorway. Table 4.5 gives some comparative sizes. Some interval towers from turf-and-timber forts/fortresses have been included, although the width of rampart may have influenced the size of the towers.

Thus, before the Wall was built there were in the area at least three stone towers, Birdoswald, Mains Rigg, and Robin Hood's Butt, which were of a suitable size for occupation. When the details of the new Wall were considered, this design was an obvious one to use. The alterations needed for the turrets to form part of the new running barrier were the insertion of a ground floor doorway, probably ground floor windows, ${ }^{267}$ and provision for bonding with the curtain wall. This last was a completely new element. The upper floor(s) with windows and any balcony, and the roof form would need no alteration, although staircases were included in at least some turrets. ${ }^{268}$

\footnotetext{
$264 \quad C W^{2}$ xxix (1929) 314; Binns 'RB in 1971' 308; Binns (n.d.).

265 Haverfield (1901) 82-4, Richmond (1933), Birley (1961), 143.

266 Richmond (1931) 130.

267 Birley (1930), 150.

268 The wall thicknesses, staircases, size of accommodation, and other features of turrets are discussed at length in Hill (1997).
} 
TABLE 4.5

DIMENSIONS OF SOME PRE-HADRIANIC SIGNAL/WATCH TOWERS

AND INTERVAL TOWERS

Stone, internal measurement

Timber, on centre line of post holes

feet sq.ft Approx

Signal/watch towers

\begin{tabular}{|c|c|c|c|c|c|c|c|c|}
\hline Beattock Summit ${ }^{269}$ & $\mathrm{~T}$ & 3.2 & 3.2 & & 10.5 & 10.5 & 110 & \\
\hline Mains Rigg 270 & $S$ & 4.3 & 4.5 & 19.0 & 14.1 & 1.8 & 209 & ?Trajanic \\
\hline Robin Hood's Butt 271 & $S$ & 3.7 & 4.0 & 16.17 & 13.0 & 14.5 & 174 & ?Trajanic \\
\hline Birdoswald 272 & $S$ & 4.3 & 4.3 & 18.2 & 14 & 14 & 196 & ?Trajanic \\
\hline York tower SW(T) $4^{273}$ & $\mathrm{~T}$ & 6.1 & 3.0 & 18.6 & 20 & 10 & 200 & Flavian $^{274}$ \\
\hline York tower NE6 $6^{275}$ & $S$ & 2.8 & $3.4(a v)$ & 9.7 & 9.0 & 11.3(av) & 104 & Trajanic \\
\hline $\mathrm{Usk}^{276}$ & $\mathrm{~T}$ & 3.0 & 3.0 & 9.0 & 10 & 10 & 100 & Neronian \\
\hline Caerleon $^{277}$ & $S$ & 3.2 & 3.0 & 9.7 & 10.5 & 10 & 105 & Trajanic \\
\hline Burgh-by-Sands s 278 & $\mathrm{~T}$ & 3.1 & 2.7 & 8.4 & 10.2 & 8.9 & 91 & Early second \\
\hline Easton $^{279}$ & $\mathrm{~T}$ & 4.8 & 3.9 & 18.7 & 15.8 & 12.8 & 202 & Early second \\
\hline Gamelsby280 & $\mathrm{T}$ & c3.6 & $\mathrm{c} 3.6$ & 12.9 & 11.8 & 11.8 & 139 & Undated \\
\hline Farnhill 281 & $\mathrm{~T}$ & 3.6 & 3.2 & 11.5 & 11.8 & 10.5124 & & Undated \\
\hline
\end{tabular}

$269 \quad$ Maxwell (1976).

270 Binns (1972) 308.

271 Haverfield (1901) 82-4, Richmond (1933), Birley (1961), 143.

272 Richmond (1931) 130.

273 Wenham (1962) 557 and fig. 23.

274 Sumpter and Coll (1977), 83.

275 RCHM (1962), 31-33.

276 Manning (1981) 68. The dimensions are suggested by the excavator as being the intended size.

277 Nash-Williams (1931) 108-115.

$278 \quad$ G.D.B. Jones 'RB in 1978' 283.

279 G.D.B. Jones 'RB in 1979' 361. This tower is unusual in that it is supported on six posts, and has a possible barrack, $11 \mathrm{~m}$ by $4 \mathrm{~m}$, within the enclosure. It may be that the 'barrack' was a stable for a horse; this suggestion was made to the writer by Dr. D.J. Woolliscroft.

280 G.D.B. Jones 'RB in 1995' 405-6.

281 G.D.B. Jones 'RB in 1994' 342-3. 
TABLE 4.6

SOME WALL FORT TOWER DIMENSIONS

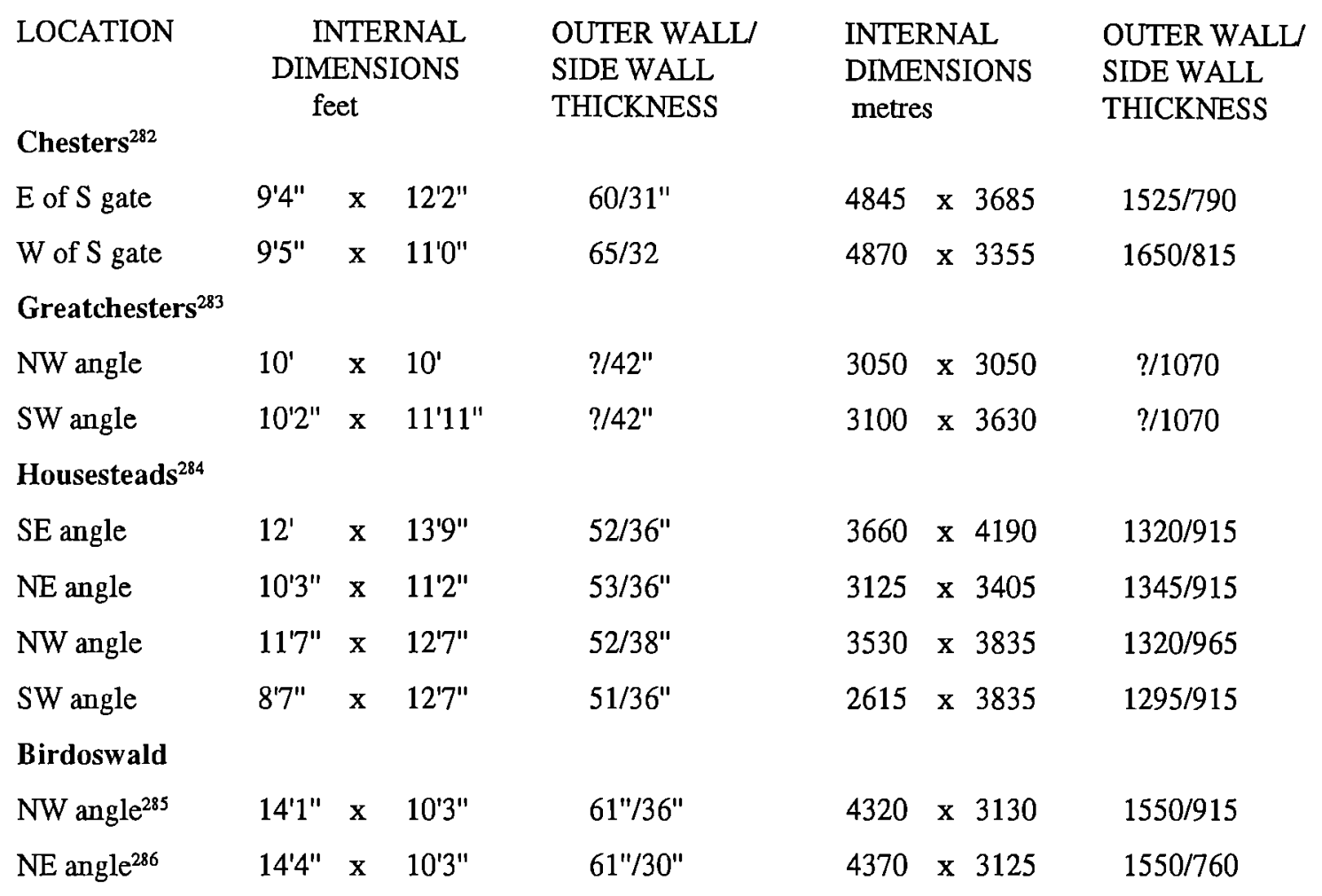

\subsubsection{Comparison with the African frontier}

Finally it is worth looking at the marked similarities shared between the Wall and Fossatum Africae, especially in the stretch known as the limes Gemellensis. The latter appears to have been built, or at least begun, within a few years of the start of work on Hadrian's Wall. ${ }^{287}$ Where the barrier of Hadrian's Wall is either turf and

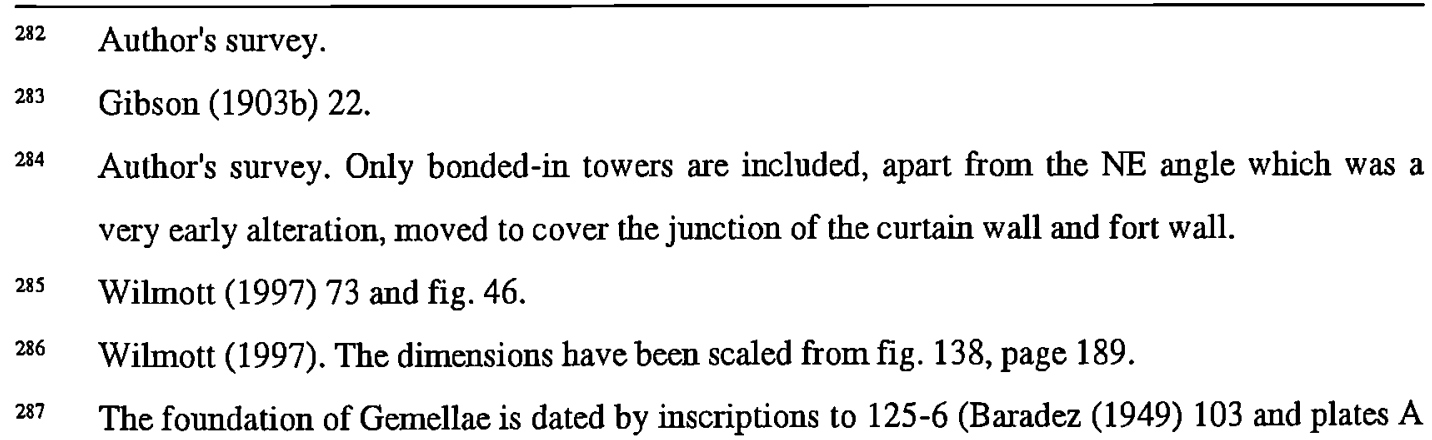


timber or mortared squared rubble, the Fossatum is sometimes of mortared stone and sometimes dry stone. Hadrian's Wall has openings every Roman mile with two turrets between each milecastle gateway. In the limes Gemellensis there appears to be a gateway at every mile but with only one turret in between. ${ }^{288}$ Baradez quotes a comment from Professor Eric Birley, that the Hadrianic principle of regular division by towers can be observed in the Fossatum Africae.

There are differences however. In Africa there is no fortlet at the gateways, but rather a tower on either side of a central, single portal gate with a door at each end of the gate passage (fig. 4.6). ${ }^{289}$ The design is almost identical to that of the Knag Burn gateway (fig. 4.7).

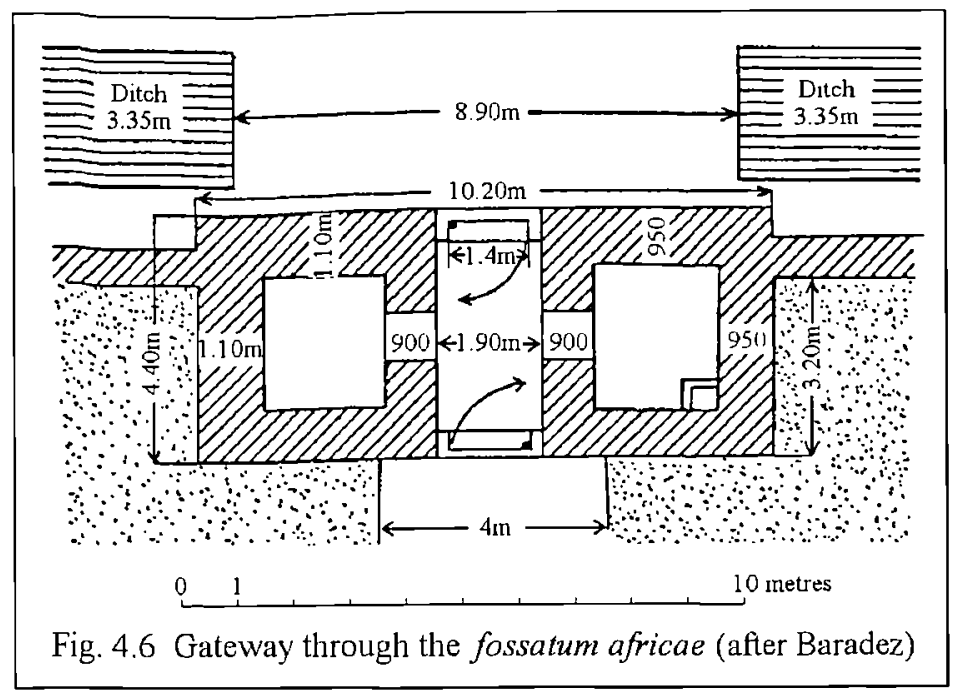

and B). Daniels (1988) accepts that the finds made by Baradez confirm the Hadrianic date of the start of this frontier, but by no means all elements can be dated. Hadrian was in Africa to deliver his adlocutio at Lambaesis on 1st July 128 (CIL VIII, 2532 and 18042).

288 Baradez (1967). Daniels (1988), 244, casts some doubt on the regularity of the gateways and the number of towers.

289 Baradez (1967) fig. 4. The gateway is not named, nor precisely located other than being to the south of Gemellae. 


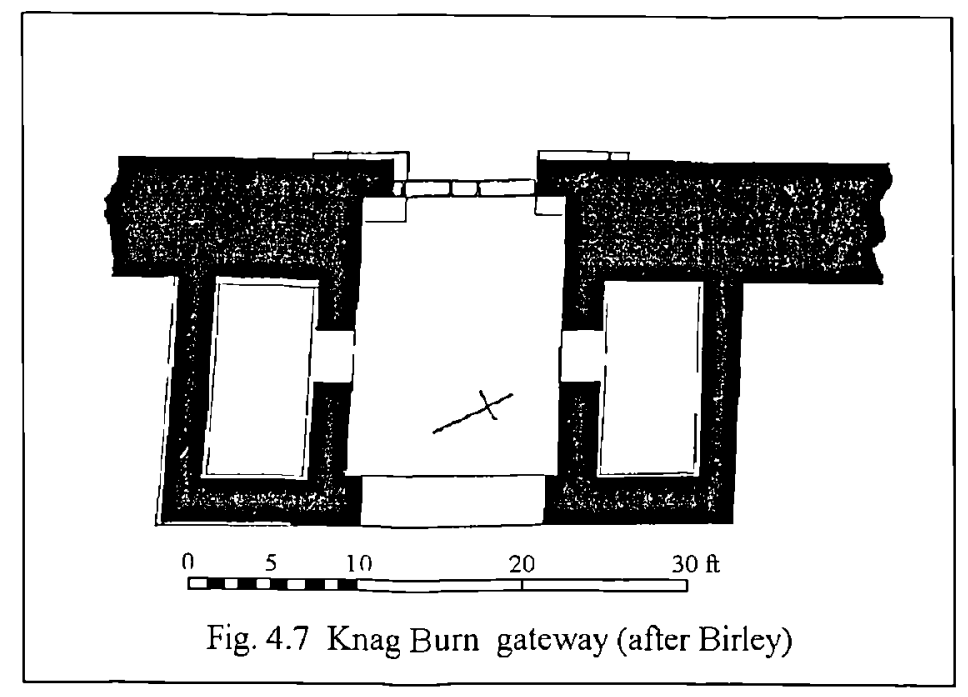

Figure 4.8 shows the similarity between the tower on the southern slope of Teniet el Ouasta, 70km north of Gemellae, ${ }^{290}$ and a typical turret of Hadrian's Wall. They are both recessed by the same amount into a wall of the same thickness to leave a north wall of $5^{\prime}$, and the side walls are almost identical to those of the turrets. However, as well as the reduction of towers to probably one per mile in Africa, the towers are smaller with an internal area of 100 sq.ft $\left(9.2 \mathrm{~m}^{2}\right)$ against typically 156 sq.ft $\left(14.5 \mathrm{~m}^{2}\right)$ on Hadrian's Wall.

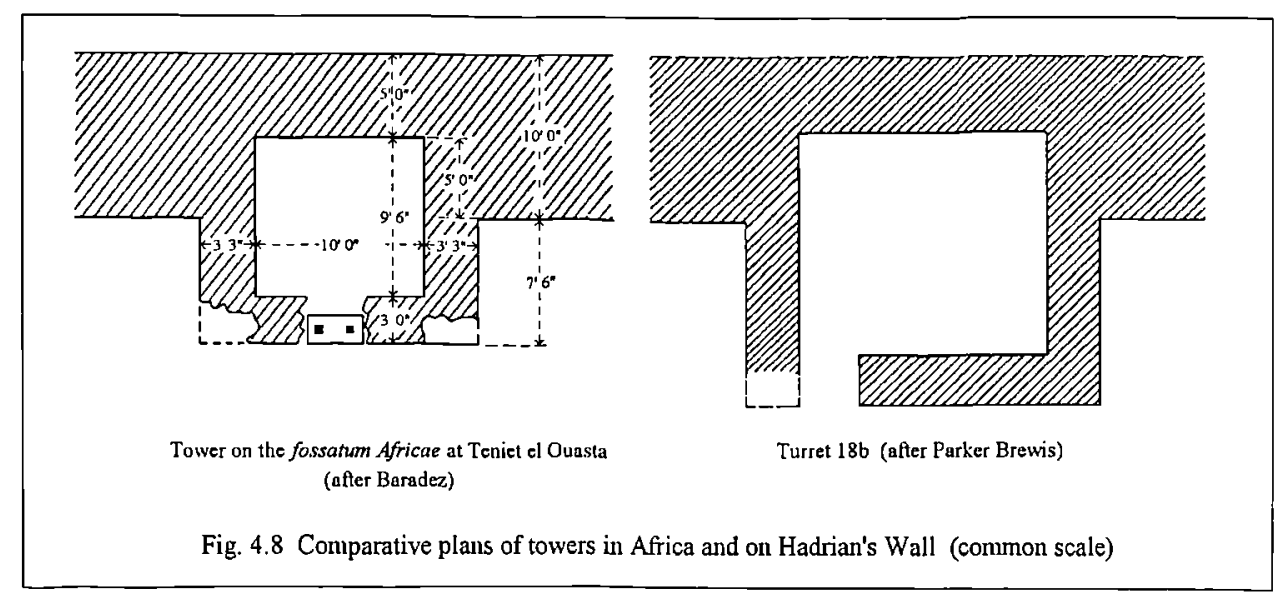




\subsubsection{Forts}

The purpose of this section is to look at the nature of the defences of the forts: curtain wall, towers, and gateways. The internal buildings are not included.

The detailed design of fort gateways has been well reviewed by Bidwell et al. (1988), by Richmond and Child (1942), and by others, and it is not the purpose here to duplicate such work. Only those features which are relevant to the building process will be noted; the interval towers and curtain wall will be similarly treated.

At an early point in the building programme (see chapter 13) the decision was taken to add forts to the line of the Wall. There were 15 new forts:

$\begin{array}{lll}\text { STONE WALL } & \text { TURF WALL } & \text { C. COAST } \\ \text { Wallsend } & \text { Birdoswald } & \text { Beckfoot } \\ \text { Benwell } & \text { Castlesteads } & \text { Maryport } \\ \text { Rudchester } & \text { Stanwix } & \text { Moresby } \\ \text { Halton Chesters } & \text { Burgh-by-Sands } & \\ \text { Chesters } & \text { Bowness } & \\ \text { Housesteads } & & \\ \text { Greatchesters } & & \end{array}$

On present evidence, Newcastle is post-Hadrianic, Carrawburgh dates to the 130s, Vindolanda and Carvoran were existing Stanegate forts, the latter not rebuilt in stone until later in the Hadrianic period, and Drumburgh is a later addition. ${ }^{291}$

The curtain walls of forts were significantly thinner than the curtain of the Wall, as discussed above (section 4.2.3), but were otherwise similar.

The towers have limited similarity to the turrets as discussed above (section 4.2.8). They are smaller in area and have thinner walls, but the difference in volume of materials required is less marked. Given a notional height of $35^{\prime}(10.7 \mathrm{~m})$ to the 
eaves for both tower and turrets, the volumes are typically 6755 and 8050 cubic feet (191 and $228 \mathrm{~m}^{3}$ ). The calculation ignores the wing walls.

The passage walls of the majority of fort gates were of squared rubble, calling for less careful working of the stone and less planning than in those few milecastle gateways where the passage walls are known to have been in large, squared stones. The guard rooms were also built in squared rubble, although Greatchesters is an exception here. The west gate at Greatchesters uses large squared stones for much of the south guardroom only; the excavator believed that the east guardroom of the south gate was also of large stones, but from the published photographs these appear to be confined to two foundation or footing courses only. ${ }^{292}$

The outer quoins resulting from the recessing of the gateways are mostly in squared rubble but in a few cases the quoins, including the stonework between the quoins and the gate piers, are in stone which is of much higher quality than squared rubble. The judgement is at times rather nice, but such stones tend to be longer than normal walling stones, with worked beds, and the faces tend to be worked to more or less a flat face. At Birdoswald and Chesters this feature appears only on the portae principales dextrae; at Housesteads it appears on all gateways; at Halton Chesters, there is a roughly squared foundation block remaining at the north east quoin of the porta principalis dextra but the superstructure is missing. A similar block appears on all gateways at Chesters although, as noted, there is only one gateway where there is higher quality walling above. At Greatchesters, the south and west gates have been

292 Gibson (1903b). The photograph is not clear and the point is open to dispute. It is not possible to make a useful survey of the gateways at Greatchesters until forthcoming re-excavation in advance of consolidation has been carried out. 
excavated and in neither case do the quoins appear to be other than squared rubble. ${ }^{293}$

The piers of the gateways are the same as in the milecastle gateways. The difference in span of front and rear arches in type II/IV milecastle gateways was noted above, (section 4.2.5); ${ }^{294}$ the same problem applies to the gateways of Housesteads fort which has flush inner piers. Presumably a larger centre was used for the rear arches.

The major difference between the milecastle and fort gateways lies in the superstructure. Whereas the former have small, simple towers, the latter have substantial upper storeys, with towers at either side and probably some superstructure above the portals as exemplified by the reconstruction at South Shields.

Arcuate window heads are found at both forts and milecastles, ${ }^{295}$ and the doors were very similar, turning in similar pivots even though the pivots in some milecastle gateways may have been somewhat smaller. ${ }^{296}$ Some aspects of the building of a fort gateway are discussed below, (section 11.6.2).

\subsection{Materials used in building the Wall}

The question of the materials used for artificial frontier lines must be considered. The traditional material used for Roman military defences in the republic and early

293 These judgements are based on the author's surveys (all but Greatchesters carried out for English Heritage) except for Halton Chesters, for which see Simpson and Richmond (1937b) esp. plate XXII.

294 See also Hill and Dobson (1992).

295 A summary of finds from fort gateways is given in Bidwell et al. (1988) 209-210. MC39 yielded two fragments of arcuate window heads (Crow (1988) 151).

296 Crow (1988) 148. 
empire was turf and timber; the gateways were in timber, with the ramparts in turf (or soil) sometimes revetted with timber. When stone defences were introduced, they usually took the form of the addition of an outer stone face to an existing rampart, although at some sites, such as Nijmegen and Neuss, stone gateways came before stone walls. Lander has shown that from the mid-first century onwards the legionary bases of Neuss, Vindonissa, Mainz, Strasbourg, Bonn, Vetera II, and possibly Nijmegen were built or rebuilt with stone defences. Some auxiliary forts, such as Remagen and Gunzberg were also rebuilt in stone from around 70 onwards. ${ }^{297}$

In Britain the change to stonework was rather slower, as the province was still developing and expanding until late in the first century. The earliest use seems to have been at Inchtuthil, where the new fortress was provided with a stone wall, albeit with timber gateways, almost from the first. The fortresses of York, Chester, and Caerleon were being rebuilt in stone at the end of the first century or just into the second, presumably when it was accepted that no further forward movement would be made. The auxiliary fort at Gellygaer and the fortlet at Haltwhistle Burn were built ab initio with stone walls, apparently under Trajan; at the same time, the fortlet at Throp was built in turf and timber.

The use of stone may have been thought to be advantageous in terms of maintenance, but it is not entirely clear why this should have been so. The reconstruction of a length of rampart at the Lunt has lasted over a period of some 20 years despite some visible compaction with gaps appearing below the boarded walkway. The Vindolanda reconstruction, despite early problems, also appears in good order. Rubble walls depend to a large extent on the strength of the mortar, and attention to regular repointing is essential if stability is to be ensured. It is true,

297 Lander (1984) 20-24. 
however, that given some regular maintenance a stone wall will survive better than a turf rampart; it also has a more imposing appearance.

Security may have been another consideration in that turf ramparts have of necessity a batter on the outer face, usually thought to be about $75^{\circ}, 298$ whereas stone walls have a vertical face. However, $75^{\circ}$ is too steep to be climbed easily, and very difficult for a man carrying a sword or spear. The author has experience of having to climb a rampart which was not dissimilar, but set at only $60^{\circ}$, while carrying a ranging rod; a child could have defended the top. ${ }^{299}$ The clay bank had been built 60 years earlier and was still in remarkably good condition.

Frontier works show considerable variation in materials. In Upper Germany there was a Hadrianic palisade of contiguous wooden posts, up to $1^{\prime}$ (305mm) diameter $^{300}$ and in Raetia a narrow stone wall was used. In Africa, the Fossatum varied between dry stone walls, and dressed and mortared stone. ${ }^{301}$ The limes Porolissensis was part earthwork and part narrow stone wall, while in Britain fiveeighths of the wall of Hadrian was in stone and the remainder in turf. There was clearly no over-riding policy on the design of linear barriers; they were built in the most appropriate materials for the locality. At the time of the building, it was still to some extent the norm in the west of the empire to build in turf and timber, and twenty years later when the Antonine Wall was built it was this material which was chosen for the greater part of the work.

\footnotetext{
$298 \quad$ e.g. Bellhouse (1969) 89.

299 This was a rampart around an ammunition store at the former Royal Ordnance Factory at Marchwiel, Wrexham. It was built in 1940 and surveyed by Tony Sumpter Archaeological Consultants with the assistance of the author in 1999, after it had been cleared of vegetation.

$300 \quad$ Maxfield (1988) 157.

301 Baradez (1949).
} 
As noted above (section 3.2), from the Tyne to Sewingshields and from the Carvoran westwards, turf, soil, or clay was readily available, whereas in the twelve miles between Sewingshields and Carvoran the soil cover is thin, and both sandstone and limestone are plentiful; the use of turf or clay to east and west and stone only in the central sector would have made good economic sense.

\subsection{Render and limewash}

In recent years it has been suggested that the curtain wall was either limewashed or rendered (and perhaps limewashed as well). 'Limewashing' is painting with a thin coat of slaked lime, with or without various additives such as casein; 'rendering' is to cover with a coating of mortar to give a more or less smooth surface.

There are a number of reasons for coating the surface of a wall. Limewashing can have a protective effect, reducing the erosion of mortar in the joints and keeping the weather from the surface of the stonework. This last is only really useful where the nature of the stone means that it is subject to rapid weathering, something which does not apply to the Wall east of the Irthing. To serve such a purpose the limewash has to be renewed at regular intervals, the time depending on the particular durability of the lime used. Limewash would also have a dramatic effect, emphasising the monumental nature of the work as a symbol of power.

Rendering also has a protective effect, but it more usually applied, in conjunction with scribed or painted joint lines, to give the false appearance of ashlar. It is debateable whether the natives would have been more impressed by false ashlar than by squared rubble, but it was certainly a common feature of Roman architecture..$^{302}$

$302 \quad$ e.g. Adam (1994) 140. 
This section reviews the evidence which has been put forward for both types of finish.

Excavations by Crow in Peel Gap in 1986-8 revealed a chamfered block (part of the string course) which had 'a distinct whitened outside'. ${ }^{303}$ His drawing shows that the portion which would have been exposed was about two thirds covered by lime. Crow took this as providing 'evidence for the use of whitewash'. ${ }^{304}$

On the surface, the white finish at Peel Gap does suggest that the Wall, or parts of it, may have been limewashed. However, rain falling on fresh mortar causes leaching out of the lime, producing a very white coating which sets hard on the surface of the stones below. Indeed, after consolidation work in 1996, on the east side of the tower in Peel Gap several stones were partly covered by a thick layer of lime which could easily be taken for limewash (see plate 1 overleaf). Crow himself says that other instances of a 'tufa-like accretion' on the Wall face in the Highshield to Peel Gap sector have been identified as lime leaching out from the mortar. ${ }^{305}$

In view of the effect of leaching, noted above, a few part-whitened stones cannot be evidence for the deliberate limewashing of the Wall. It might be expected that stones at the foot of the Wall, buried by detritus and fallen masonry, would preserve clear evidence of limewash, but such a find has not been made. Until a considerable number of stones limewashed over the entirety of the faces are found, the evidence cannot be regarded as satisfactory.

Excavations at Denton have revealed other evidence of how the Wall surface was treated. What the excavators describe as 'frequent small fragments of plaster ${ }^{306}$

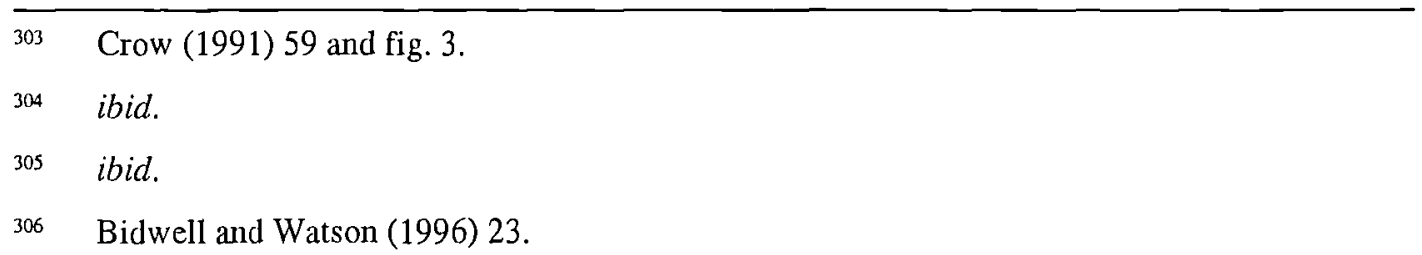




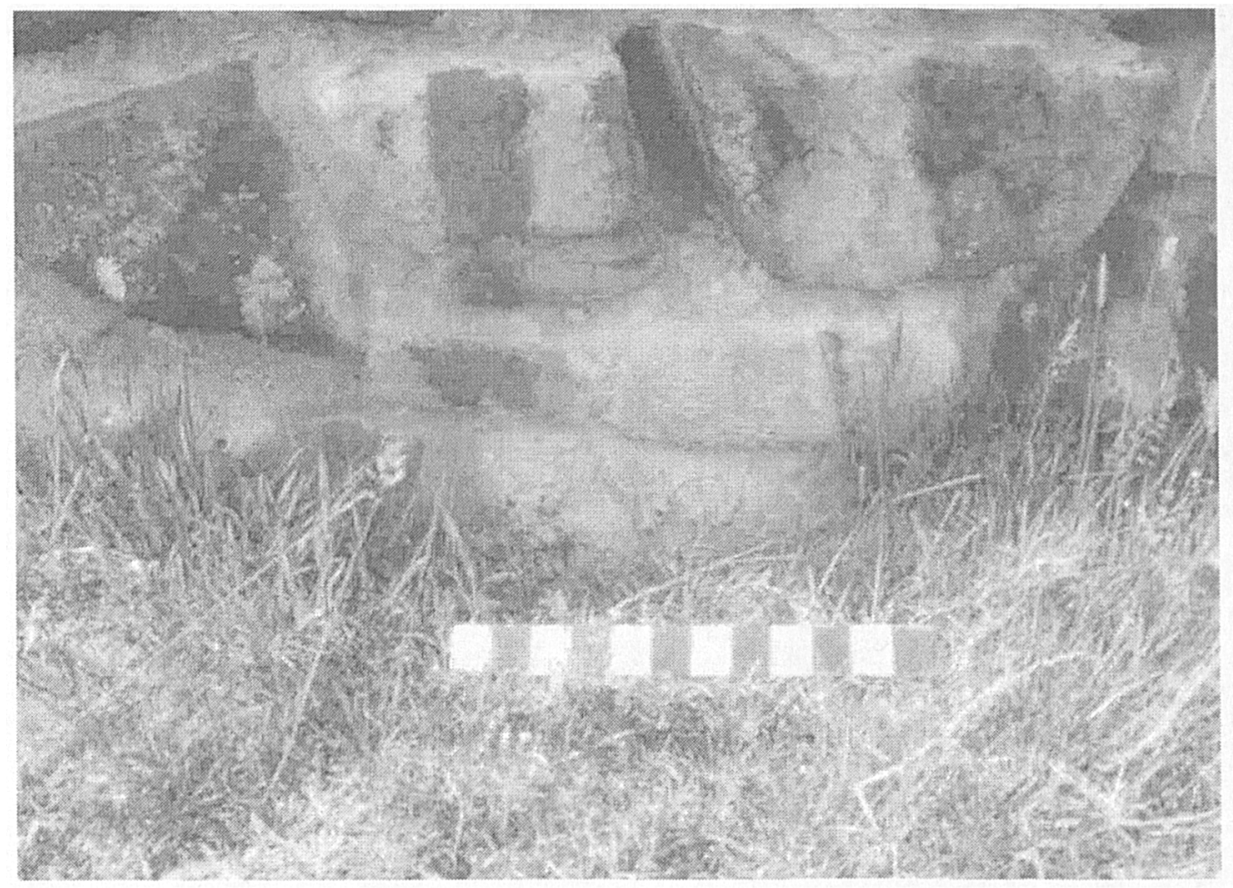

Plate 1 Lime from consolidation mortar leached out over facing stones, Peel Gap tower (1996)

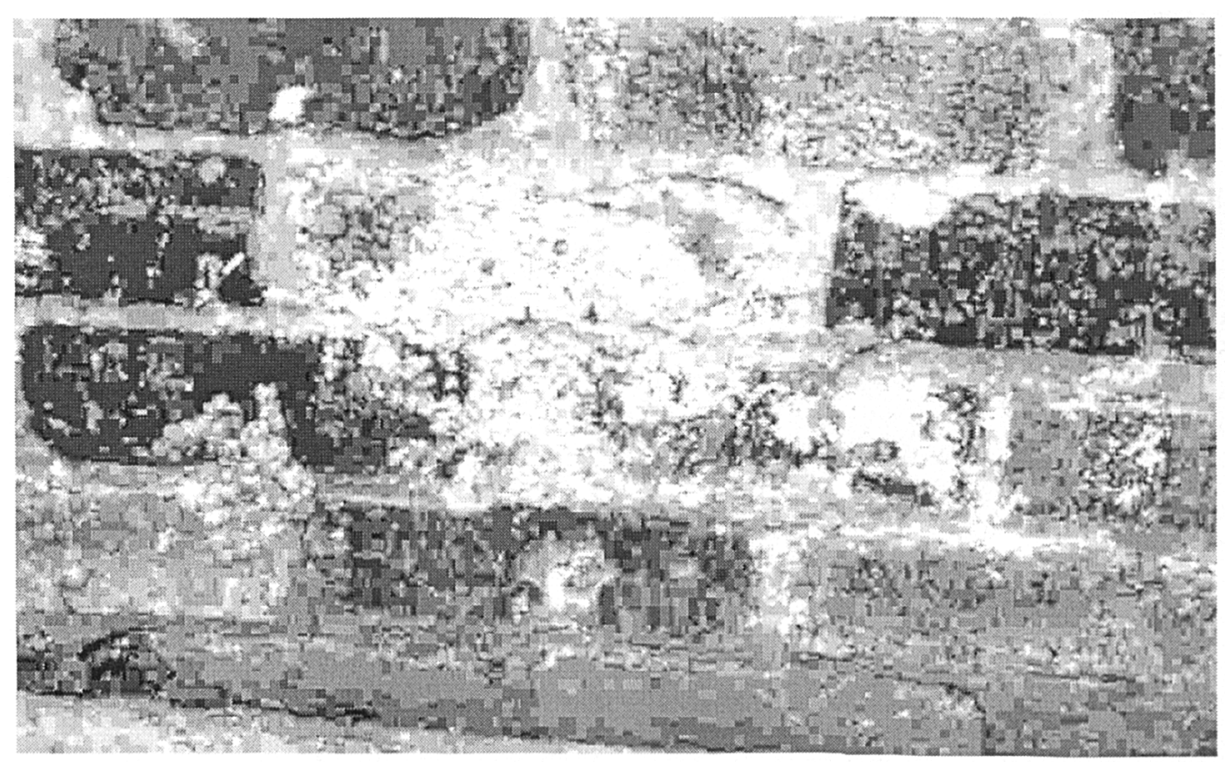

Plate 2 Mortar splashes at the foot of a modern brick wall 
were found where they were left after the fallen stones to which they had been attached had been robbed. Analysis of the material shows that it was a lightweight mortar made from hydraulic lime with a fine aggregate. ${ }^{307}$ The work appears to have been repointing rather than original, as a quite different mortar was found in the joints of the stones. In the surface of the mortar false joint lines had been struck, with 'a curved profile and are between $20 \mathrm{~mm}$ and $35 \mathrm{~mm}$ in width and $3 \mathrm{~mm}$ to $5 \mathrm{~mm}$ in depth. ${ }^{1308}$

The mortar seems to have been applied to the joints with a trowel in a manner which left mortar smeared liberally over the faces of the stones at either side of the joints. This was the common method of repointing rubble work until recent years, when fashion began to dictate that mortar should be kept off the faces. Excavations at Birdoswald revealed original pointing on building 197 (the south horrea) which is an exact parallel for the repointing found at Denton. ${ }^{309}$

It was, and in places still is, common to strike false joint lines with the edge of the trowel, leaving a line perhaps $2 \mathrm{~mm}$ wide and $2-3 \mathrm{~mm}$ deep. The widths of the false joints at Denton are quite different from this, and could well have been made with the handle of a trowel or a piece of wood selected for the purpose. The variations in width might suggest that the work was not treated as something especially significant, perhaps with more emphasis on pressing the mortar firmly into the joints than on creating a decorative effect.

\footnotetext{
$307 \quad$ Morgan (1996).

$308 \quad$ Bidwell and Watson (1996) 23.

309 Wilmott (1997) 119 and fig. 81. This pointing should be compared with his fig. 76, which shows the modern standard of repointing which bears no relation to the original.
} 
However, a decorative effect would certainly have been achieved and if, as the excavators suggest as a possibility, ${ }^{310}$ the whole was then limewashed the effect would have been striking. Evidence at this site for an overall render of the surface is lacking, although such treatment cannot be excluded (but see below for quantities of material). Heavy repointing is much more likely.

Bidwell and Watson also note the preservation of hard white mortar on the south face of the Wall at Heddon-on-the-Wall. ${ }^{311}$ There certainly are small areas of mortar on the stones (the largest dimension is $10-12 \mathrm{~mm}$ ), but they occur on the lower few courses where mortar splashes are to be expected. Not only does mortar fall from above during the building or repointing of any wall, but mixing of mortar at the foot of the wall can result in major areas of what could after many years be taken for the remains of render (see plate 2, following page 92).

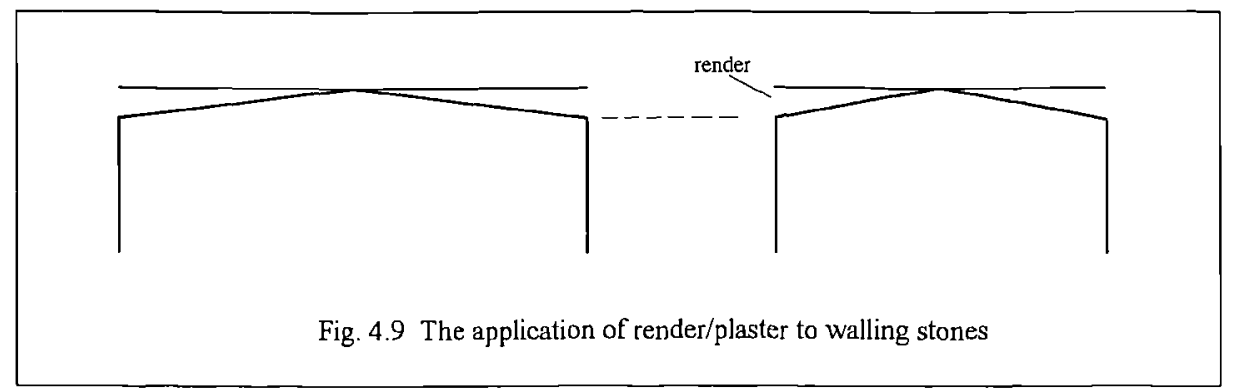

Using the following assumptions, the volume of mortar needed for rendering may be calculated:

Size of stones, average, (see section 12.4) $10.25 \times 7 "(260 \times 178 \mathrm{~mm})$.

Projection of the uneven faces is taken as a simple pyramid 1" high.

Number of stones per square yard 17 (20 per square metre).

Mortar finishes level with highest point of the stones (see fig. 4.9).

\footnotetext{
$310 \quad$ Bidwell and Watson (1996) 23.

311 Bidwell and Watson (1996) 26.
} 
The volume of mortar per square yard is thus 889.36 cubic inches, or about half a cubic foot. ${ }^{312}$ If, for simplicity, the Wall is taken as $15^{\prime}$ high, then to cover both sides of each running Wall-mile of 1618 yards, 308 cubic yards $\left(236 \mathrm{~m}^{3}\right)$ of mortar are needed. For the whole 80 miles, the figures are 24,673 cubic yards $\left(18,865 \mathrm{~m}^{3}\right)$. For the original 49 miles of stone curtain wall, before the rebuilding of the Turf Wall, the quantities are 15,112 cubic yards $\left(11,555 \mathrm{~m}^{3}\right)$. No allowance has been made for wastage, and the projection of the faces allowed for is small; quantities are likely to have been higher. The quantities given here are only one twelfth of the mortar needed for building the Wall (see section 12.4.1) but they are still considerable.

To render the external wall of a fort, such as Benwell, using the same basis of calculation, the figures are as follows. The fort measures $560^{\prime} \mathrm{x} 396^{\prime}(171 \mathrm{x}$ $121 \mathrm{~m})^{313}$ and, assuming the same height of $15^{\prime}$, to render the outer face of the wall flush with the projections would have taken 61 cubic yards $\left(47 \mathrm{~m}^{3}\right)$ of mortar.

As Crow points out 'The use of render, whitewashes and plasters is a common feature of Roman buildings ${ }^{1314}$ and some such finish is to be expected on the walls of internal buildings of forts and milecastles, and perhaps on their outer walls also. This could also extend to turrets, but whether the whole of the curtain wall were limewashed is as yet not proved. It would not be entirely surprising if it were so, and regular renewal would have provided work for the garrison, although rendering of the whole is probably unlikely in view of the quantities of mortar required.

\footnotetext{
312 One third of the base area multiplied by the height gives the the volume of the pyramid on the face of each stone, to be subtracted from the total thickness of the render.

313 Taylor (1997).

$314 \quad$ Crow (1991) 59.
} 


\subsection{The ditch}

On the north side of the curtain wall was a large ditch. At the best-preserved sections (because they were soon filled) at Haltonchesters, Chesters, and Birdoswald, the original dimensions appear to have been $27^{\prime}$ wide by $9^{\prime}$ deep ( 8230 by $2745 \mathrm{~mm}$ ), with a standard military V-shaped section, ${ }^{315}$ although there are wide variations in these figures elsewhere.

Excavations at Black Carts showed that the ditch, cut through whin bedrock, is only $11^{\prime} 6$ " wide by $2^{\prime} 8^{\prime \prime}$ deep $(3500 \mathrm{~m}$ by $800 \mathrm{~mm})$. The counterscarp, consisting of a bank and low mounds to the north, was composed of split whin boulders and stone chips and is thought by the excavator to represent possible quarry waste rather than resulting solely from upcast from the ditch. ${ }^{316}$

About one mile to the west, close to the site of MC30, the unfinished section at Limestone corner is about $14^{\prime}$ wide and $8^{\prime}$ deep $(4270 \times 2440 \mathrm{~mm}){ }^{317}$ Although very uneven, the width is reasonably consistent and was probably intended to be the finished size, although it has vertical instead of sloping sides. Immediately to the west of this section the ditch was never dug to full depth and appears now as a shallow depression.

There are a number of other points where the ditch was unfinished, such as Longbyre, ${ }^{318}$ Cockmount Hill, ${ }^{319}$ and Bays Leap, Heddon. ${ }^{320}$ At Cockmount Hill, like Limestone Corner, the ditch cuts through the Whin Sill but, given that the ditch

\footnotetext{
$315 \quad H B^{13} 20$.

316 Wilmott (1999) 121.

317 Author's survey.

318 Salway (1959).

319 Bidwell (1999) 139.

$320 \quad$ Jobey (1958).
} 
of the Vallum at Limestone Corner was completed, it does not seem likely that the legionaries were defeated by the hardness of the rock. At Longbyre and Bays Leap there was no reason at all why the ditch could not have been taken to full depth; it seems more probable that a policy change was responsible for all uncompleted sections of ditch.

The ditch is not continuous, as it is omitted where the crags, or the foreshore of the Solway, made it redundant. In broad terms it is present as follows: MCO to MC34, MC38-38a, Peel Gap to MC40, T42a-T43b, T45b-MC73, MC76-T77b, with some very short sections along the crags amounting to a few hundred yards. The total length is about 65 Roman miles, or 60 statute miles $(95 \mathrm{~km})$.

A series of holes has been found on the berm at Wallsend and Throckley. ${ }^{321}$ They are in three rows and are believed to have held some form of obstruction such as tree branches. No sign of similar features was found in the 1999 excavations of the berm at Black Carts and Appletree. ${ }^{322}$ Their precise purpose and extent is unknown; they are not lilia as found at Rough Castle on the Antonine Wall. ${ }^{323}$

\subsection{The Vallum}

The earthworks to the south of the Wall, incorrectly named by Bede as the Vallum, ${ }^{324}$ are unlike frontier works anywhere else in the Empire. They consist of a broad ditch with the upcast built up into mounds set back to either side; there is often a third mound on the southern lip of the ditch. To the east of Halton Chesters the south berm is consistently wider than the north, for unknown reasons.

\footnotetext{
321 Bidwell and Griffiths (1999), Hodgson 'RB in 2002' 293-4, respectively.

322 Wilmott (1999), Wilmott 'RB in 1999' 391-2, respectively.

323 Robertson (1990) 58.

324 Bede 1, 5.
} 
The ditch is not of the standard military type, but is flat bottomed, typically $20^{\prime}$ $(6100 \mathrm{~mm})$ wide at the top, $8^{\prime}(2440 \mathrm{~mm})$ wide at the base, and $10^{\prime}(3050 \mathrm{~mm})$ deep. The sides to this profile will have been $59^{\circ}$ to the horizontal. The north and south mounds are separated from the ditch by berms $30^{\prime}(9145 \mathrm{~mm})$ wide, and are typically $20^{\prime}(6100 \mathrm{~mm})$ wide at the base. ${ }^{325}$ The original height does not survive, but if all material from the ditch were used in building these mounds, and the sides were at $60^{\circ}$, they may have been $5^{\prime}(1525 \mathrm{~mm})$ high and $14^{\prime}(4270 \mathrm{~mm})$ wide across the top. ${ }^{326}$

The lesser south mound - 'marginal mound' - appears on the lip of the ditch at a number of places and has generally been regarded as the product of cleaning out the ditch. However, recent work has shown that this may be an original feature; excavations at Black Carts and Appletree indicate that the marginal mound was built on the same cleared ground surface as the main south mound. ${ }^{327}$ This could throw an entirely new light on the purpose of both the marginal mound and the Vallum, as the former appears to indicate a clear demarcation of the south berm. However, the marginal mound does not seem always to have been present and was sometimes on the north lip of the ditch. ${ }^{328}$ Also, as Woolliscroft notes, the mounds were sometimes omitted. ${ }^{329}$ At White Moss, the 'ditch' of the Vallum seems to have been created by building what was in effect an embankment across a bog, ${ }^{330}$ which eliminated the mounds. Furthermore, the berms were not always cleared, as may still

\footnotetext{
$325 \quad H B^{13}, 28-29$.

326 Author's calculation.

327 Wilmott 'RB in 1999' 391-2; Wilmott (1999).

$328 \quad H B^{13} 29$.

329 Woolliscroft (1999).

330 Simpson and Shaw (1922) 363-365.
} 
be seen at Limestone Corner where rocks lying scattered on both berms make them impassable to any kind of traffic.

The Vallum does not everywhere accord with the typical profile. At Black Carts it was $8^{\prime} 2^{\prime \prime}(2490 \mathrm{~mm})$ deep, $19^{\prime} 8^{\prime \prime}(5990 \mathrm{~mm})$ wide, with vertical sides, the lower third cut into the whinstone bedrock. ${ }^{331}$ At Denton, it was found to be $8^{\prime}(2440 \mathrm{~mm})$ deep, $18^{\prime} 8^{\prime \prime}(5690 \mathrm{~mm})$ wide at the top and $8^{\prime} 4^{\prime \prime}(2540 \mathrm{~mm})$ wide at the base. ${ }^{332}$ At neither of these places was the marginal mound identified. The Vallum at Limestone Corner varies in size, but is about 13-16' (3690-4880mm) wide, and about 7' $(2130 \mathrm{~mm})$ deep to the present bottom. ${ }^{333}$

A significant point about the Vallum is that the ditch is always present, in distinction to the Wall ditch which is intermittent or not fully dug. Clearly for the Vallum the ditch was the significant feature.

For the purpose of estimating the amount of work involved, the Vallum ditch may be regarded as being of typical section. It ran from the River Tyne adjacent to $\mathrm{MC4}^{334}$ to Bowness, without interruption, a length of 76 Roman miles or 70 statute miles $(112 \mathrm{~km}$.).

\subsection{Surveying}

\subsubsection{The general line of the curtain wall}

The initial task was to set the general line, and one may imagine the choice being made by a party of senior officers riding slowly across the countryside, covering perhaps ten miles a day, accompanied by a working party to erect small cairns or

\footnotetext{
331 Wilmott (1999).

332 Bidwell and Watson (1996) 35-40.

333 Author's survey.

$334 \quad N C H$ vol. $13,516-521$.
} 
posts at intervals; a matter of a week or so to cover the isthmus. Given that the new frontier was to be on the Tyne-Solway isthmus, the line was in a sense limited by the topography. The edge of the crags on the central sector was the obvious line to take, and it remained only for the two ends of this part to be joined to the estuaries of Tyne and Solway. It may well have been unnecessary for senior officers to do more than take a general look at the line on a map, something the Roman army was accustomed to working with. ${ }^{335}$

Marking out the precise line would have been carried out by legionary surveyors. An inscription of $\mathrm{AD} 228$ from Viminacium was dedicated by eleven mensores from legion VIII Claudia. ${ }^{336}$ Another third century inscription, from Lambaesis, shows nine mensores of legion III Augusta. ${ }^{337}$ This suggests that there ought to have been around 30 trained surveyors available in the three legions in Britain. Domaszewski shows that the mensor was a principalis. ${ }^{338}$ The only known reference to a mensor in Britain is on an altar from near Piercebridge, dedicated by a mensor evocatus (RIB 1024).

No very sophisticated surveying would have been necessary; unlike a road or an aqueduct the Wall did not have to have great regard for the contours beneath it but only those to the north, and perhaps to the south for signalling purposes. ${ }^{339}$ In practice the Wall made no great effort to take the line with the best outlook; west of Greatchesters there is a better line only about half a mile to the north, and there is

\footnotetext{
335 Sherk (1974) discusses the common availability of maps in the Roman army.

$336 C I L$, iii, sup. fasc i, $2,8112$.

$337 A E 1904,72$. The date, and the probably number of mensores in a legion is discussed in Sherk (1974).

338 Domaszewski-Dobson (1967) 49.

339 Woolliscroft (1989).
} 
rising ground within half a mile of MCs9, 10, 13-16, 20, and 26. It could be argued that the line around MC33 would have been better taken northwards to avoid the dead ground less than half a mile in advance, but the straighter line was chosen and perhaps only incidentally avoided the higher ground around Fozy Moss to the north. The line in the neighbourhood of Walton is also not good '... the Wall follows a very weak line, singularly overhung by rising ground immediately to the north. ${ }^{1340}$ Selecting the line with the best view would only have been of real significance if the line formed the absolute limit of Roman observation, which it did not. The practice of Rome in regarding land outside the formal provinces as under their influence has been discussed above, Chapter 2, and the existence of the outpost forts on the west suggests that the Romans maintained a serious interest in the land to the north. It is inconceivable that patrols working to the north were not an integral part of the functioning of the Wall; presumably this would have been carried out from the Stanegate forts before forts were added to the line of the Wall.

On the whole the surveyors preferred to run the line in a series of straight sections in the east and west, and in the central sector the line was fixed by the edge of the Whin Sill, whose turns were normally followed closely. In the eastern sector the Wall clearly makes changes of direction on local high points, notably adjacent to $\operatorname{MCs} 10,12,14,16,30$, and t20a. Changes of direction are made at other points, however; between $\mathrm{t} 25 \mathrm{~b}$ and $\mathrm{MC} 26$ a $30^{\circ}$ northwards turn is made part way down the hillside. ${ }^{341}$ From this point the Wall runs straight to Chesters fort, and then makes a turn of 2 or 3 degrees to the north to run straight to its most northerly point at

\footnotetext{
$340 \quad$ Haverfield (1903) 346.

34. The tum is made some way to the west of the edge of a stretch of flat ground on top of the hill. It looks as though the surveyors were working eastwards from the site of the bridge at Chesters, sighting up to the visible edge of the hillside.
} 
Limestone Corner, where it turns southwards again to aim for the start of the crags. A turn northwards of only $8^{\circ}$ at $25 \mathrm{~b} / 26$ would have allowed a straight line, over Tarney's Fell in the parish of Newbrough, to meet the start of the crags at around MC34. The larger diversion to the north may well have been to avoid broken ground with at least six small valleys to be crossed, some of them steep-sided. The chosen line crosses no valleys and follows a generally very easy route. It is not impossible that the Wall was taken to the site of an existing fort at Chesters, although the evidence is not strong. ${ }^{342}$

The Whin Sill is followed because it is there; the steepness of the slopes along the line and access from front and rear do not appear to have been given any consideration. There was certainly little regard given to the ease of access for transport of heavy materials and the ease of building.

Recent work on the surveying of the Wall ${ }^{343}$ has confirmed that Roman linear constructions were set out using the groma, in a series of straight alignments. East and west of the crags, the longest alignments are 3368 and 3379 yards (3080 and $3090 \mathrm{~m}$ ) respectively ${ }^{344}$ In a number of sectors between Housesteads and Walltown Crags, Hargreaves records 90 alignments totalling 2038 yards $(1864 \mathrm{~m})$, ranging in length from one yard to 109 yards ( $1 \mathrm{~m}$ to $100 \mathrm{~m}$ ), with an average of 22.6 yards $(20.7 \mathrm{~m})$. The average turn is $11.9^{\circ}$, with some as small as $1^{0}$; four turns each of $1^{0}$ are recorded on Cawfields Crags. ${ }^{345}$ For the short alignments Hargreaves suggests, logically enough, that cords were used in place of the groma..$^{346}$

\footnotetext{
$342 \quad$ Birley (1960) 173.

343 Hargreaves (1996).

344 Hargreaves (1996) 282-4.

345 Hargreaves (1996) 280.

346 Hargreaves (1996) 125.
} 
Curves were few; one which is visible today is on the west side of Sycamore Gap. Others are on Walltown Crags (2), Cawfields Crags (2), Peel Gap (1), and Highshield Crag (2). ${ }^{347}$ There is a very interesting turn to the west of MC42. About 20 yards short of the quarry face the Wall turns north through about 80 degrees; the south face makes a tight curve while the north face shows a sharp angle, in the same way as the southern corners of the Hadrianic milecastles. ${ }^{348}$

There were two separate operations to be carried out: surveying the precise line and measuring the positions for milecastles and turrets. The speed with which the precise line could have been marked out will have depended on the degree of urgency in the orders, but if necessary it could have been completed within four or five weeks. Access to the Wall line was initially from Dere Street and Carlisle, ${ }^{349}$ from which points the line might be surveyed to the Tyne and the Solway. At the same time, separate parties could have worked to the east and west ends of the Whin Sill. There were three additional fixed points from where survey had to be conducted, the crossing of the North Tyne at Chesters, of the Irthing at Willowford, and the Eden at Carlisle. The best position for the bridges from the point of view of the engineering must have been a consideration, something emphasised by the surveyors possibly working eastwards from Chesters, noted above. The crossings of the Ouseburn, and perhaps the Lort Burn, may also have been fixed points. In the central sector, the Wall simply stays as close as possible to the edge of the Whin Sill, which meant that any number of parties could have been at work there with little risk of the lines failing to join up.

\footnotetext{
347 Hargreaves (1996) 280.

348 Author's survey.

349 Breeze and Hill (2001).
} 
The approximate lengths of each section (in Wall-miles) are as follows:

$\begin{array}{lr}\text { Wallsend to Ouseburn } & 3 \text { miles } \\ \text { Ouseburn to Dere Street } & 18 \text { miles } \\ \text { Dere Street to North Tyne } & 5 \text { miles } \\ \text { North Tyne to the eastern end of Whin Sill (MC34) } & 7 \text { miles } \\ \text { Whin Sill } & 13 \text { miles } \\ \text { Western end of Whin Sill (say MC46) to Irthing } & 3 \text { miles } \\ \text { Irthing to the Eden } & 17 \text { miles } \\ \text { Eden to Bowness } & 14 \text { miles }\end{array}$

Given that the general line had been roughly marked out and the river crossing points selected, the final surveying could have been carried out from both ends of each section. The maximum length for one party to survey would thus be 9 Wallmiles, with twelve survey parties at work at once. At a rate of one hour to a quarter mile, and given a six hour day (to allow for returning to base), the longest section would be complete in 6 days, and the other sections within that time. An extra day at the junction of each of the sections to allow for any realignment would bring the total to a maximum of 13 days.

Measuring the location of the turrets and milecastles would ideally have been carried out from one end, and at a rate of 10 miles a day would take 8 days, a total of 23 days. Including the initial survey of the general line, the whole work could have been completed in a month. The fact that Wall-miles across the crags are often very far from a Roman mile (see 4.6 .2 below) may be an indication that the crags sector was left until last and then carried out from both ends, reducing the time by four or five days.

The surveying was presumably carried out by survey parties under a single control, whether all of one legion or a joint enterprise of staffs from all three legions 
under one senior officer, to ensure that the line was continuous. Bennett suggests that the change in direction at the foot of Denton Hill (just west of MC8) may be due to the meeting of two surveying parties, one working east-west, the other west-east. ${ }^{350}$ Although this is one mile west of the nearest junction between legionary blocks suggested by Hooley and Breeze, ${ }^{351}$ the surveying might very well have been carried out independently of the work allocation. It could also, the angle being very small, be the result of human error, or it could have been intentional and unrelated to any junction between surveying parties. Hargreaves's52 believes that 'Differences of more than $1^{0}$ are incompatible with Roman long distance surveying accuracy.' Dilke, on the other hand, while stressing the training of the agrimensores and the careful cross-checking undertaken, does note variations from the ideal which '... may simply be due to ... lack of care in measurement. ${ }^{353}$

\subsubsection{Positioning of milecastles and turrets}

The spacing of milecastles and turrets is not quite as rigid as often supposed, ${ }^{354}$ although the lengths of only twenty-three Wall-miles are known with some certainty. ${ }^{355} \mathrm{~A}$ Wall-mile is the interval between two adjacent milecastles, whether or not the distance is equal to one Roman mile.

\footnotetext{
$350 \quad$ Bennett (1990) 111.

351 Hooley and Breeze (1968), fig. 2.

352 Hargreaves (1996) 80.

353 Dilke (1971) chapter 4 and passim, and pages 85,134 . The tapered plan of the barrack in the north angle of Fendoch is difficult to explain in any other terms than simple error.

354 Woolliscroft (1989), 7 discusses the point.

355 Collingwood (1931). All the distances in this section are taken from Collingwood. Wall-miles where either a turret or milecastle position is uncertain or any distance is unknown, are
} 
Only one Wall-mile, 23-24, is exactly one Roman mile (1618 yards, 1480m); sixteen others are within plus or minus $5 \%$ of this figure (see fig. 4.10). The range is from c. 1410 yards to 1850 yards $(1289-1690 \mathrm{~m})$. The figures for the flatter land to east and west of the crags may well be closer to the nominal distance, although very few figures are available.

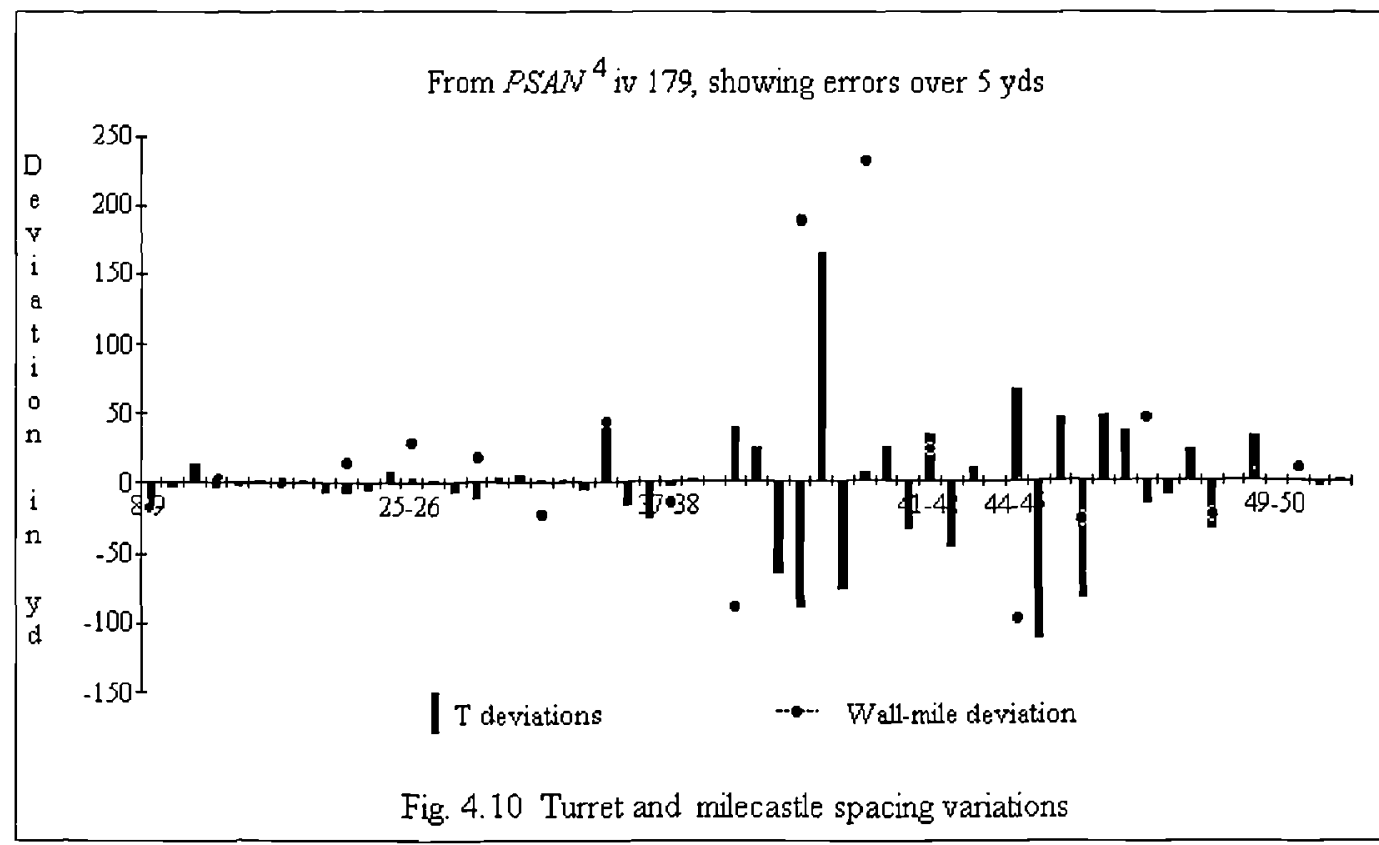

The standard of Roman land surveying could be very high ${ }^{356}$, and Woolliscroft notes that while the total range of Wall-mile deviation is $440 \mathrm{yd},{ }^{\prime}$. . the average milecastle spacing is one Roman mile and three inches . . . ${ }^{1357}$ But the total deviation figures depend on Collingwood's distances, and across the sites of Housesteads, Greatchesters, and Birdoswald forts there are clear arithmetical errors.

excluded.

$\begin{array}{ll}356 & \text { Dilke (1971). } \\ 357 & \text { Woolliscroft (1989) 7-8. }\end{array}$




\section{CHAPTER 5}

\section{Quarrying}

This section discusses the nature of the stone used for building, the proximity of the quarries, and the techniques used in quarrying. A description of the various of walling types is also included as an aid to understanding the different quarrying operations called for.

\subsection{Introduction to quarrying}

Comparatively little is known about the organisation of quarrying for ordinary building stone in Roman times. Much of what has been written concentrates on what is seen as 'the better end of the trade'; marble for tombs, granites for imperial buildings, and with an emphasis on the distribution of the products. This does not necessarily throw light on the how the army organised quarrying for their own, more humble, purposes. Rather more is known about the methods of quarrying although, because of the better survival of quarries, most of the research relates to the continental provinces. Few quarries in Britain are of certain Roman date, and fewer still provide evidence of the methods employed. ${ }^{358}$

There is some confusion as to what constitutes hard stone; marble, to take one example, is relatively soft when quarried, as compared to its hardness after exposure. Kozelj writes of marble, compared to limestone, as being 'un matériau beaucoup plus dur. ${ }^{359}$ Listing sandstone and limestone as soft stones ${ }^{360}$ is to ignore the fact that

\footnotetext{
$358 \quad$ Williams (1968).

359 Kozelj (1988) 6.

360 e.g. Dworakowska (1983) 149.
} 
some limestones can be extremely hard, to the extent that they can be very difficult to work a face on. Susini says that all sandstone is soft as compared to limestones; ${ }^{361}$ this may be true of Italy, but the sandstone from Peel Gap (see section 6.6) is so hard as to be almost unworkable. Many limestones, on the other hand are easily worked with wood chisels. ${ }^{362}$

Numbers of Roman quarrymen's tools have survived as identifiable artefacts, and representations on monuments give some hint of their existence. There can be problems in dating such tools with any precision, but some have been found in reliable contexts. Apart from the difficulty in dating unstratified tools, there will be a tendency for them to be appropriated for reuse if found by quarrymen. A chisel of possibly mediaeval date was found in the core of the east wall of the south transept of York Minster during repairs in the late 1970s is, to the best of the writer's knowledge, still in use. ${ }^{363}$ This emphasises the unchanging design of hand tools from antiquity to the present day.

The number of tools used only in quarrying is very small. The scabbling hammer, bursting hammer (see fig. 5.3), and other very heavy picks and hammers are the only tools which are not used in working stone. Wedges are typical of quarries, but may be used for subdividing blocks in the masons' yard, and picks and punches are used for dressing as well as in quarrying. Other tools found in quarries are more likely to represent working of stone to specific shapes within the quarry, and are discussed in chapter 6.

\footnotetext{
$361 \quad$ Susini (1973) 23-4.

362 See Hill and David (1995).

363 The author was one of the team of masons carrying out repair work, but not close enough to the find to appropriate the chisel for his own use.
} 
Ward-Perkins has noted that '. . . the tools and methods of quarrying [used] throughout antiquity ... remained until barely a century ago, ${ }^{1364}$ and Dworakowska points out that, in establishing a chronology [of tools], it would be wrong to rely on their shape alone. ${ }^{365}$ Adam makes much the same point, using modern observations to throw light on possible Roman tools and methods. ${ }^{366}$ The following pages take a similar approach, describing modern operations in the light of the experience of the author and his trade colleagues, and of published technical material, and makes reference to clear evidence from the Roman period where appropriate.

\subsection{Overview of the stone and quarries}

This is a convenient point to address the weight of stone used in building the Wall. The unit of measurement used is the cubic foot, as being more readily comprehensible than the weight per cubic metre, although conversions are given.

Little quarrying is now carried out in the Wall area but all the stones shown in the table below are reasonably close to the Wall, apart from Blaxter. Blaxter is very similar to stone from old quarries around Greenhead. ${ }^{367}$

364 Ward-Perkins (1971) 141. The point is supported by Waelkens et al. (1988), who, however, sees rather more variation than Ward-Perkins.

365 Dworakowska (1983) 86.

366 Adam (1994) 33.

367 Information kindly supplied by Border Stone Quarries Ltd, Greenhead. 
Table 5.1 SOME STONES IN THE WALL AREA 368

$\begin{array}{lll} & \begin{array}{ll}\text { lbs/ } \\ \text { cu.ft. }\end{array} & \begin{array}{l}\mathrm{kg} / \\ \mathrm{m}^{3}\end{array} \\ \text { Bearl, Bywell } & 137 & 2190 \\ \text { Black Pasture, Chollerford } & 145 & 2325 \\ \text { Blaxter } & 139 & 2190 \\ \text { Heddon } & 143 & 2293 \\ \text { Kenton, Newcastle } & 140 & 2245 \\ \text { Springwell, Gateshead } & 136 & 2174 \\ \text { Talkin Fell, Brampton } & 146 & 2350\end{array}$

This makes no pretence to be an exhaustive list, but gives an idea of the weight of the stone used on the Wall. Black Pasture is the stone used for Chesters Bridge ${ }^{369}$ and its weight will be used when considering the building of the Wall.

The stones generally used for building the Wall are sandstone and gritstone. Broadly speaking, gritstone consists of angular grains, often wind-blown, while sandstone has more rounded grains, often water-borne, thus becoming more abraded. Gritstone tends to have coarser grain sizes.

The nature of the stone varies along the line of the Wall. There does not appear to be any evidence that the selection of stone was based upon anything but its proximity to the Wall line, so long as some sort of face could be worked on it. For example, at MC48 the intractable contact-metamorphosed sandstone from the valley of the Poltross Burn ${ }^{370}$ has been used in preference to the much more suitable and more

\footnotetext{
368 Natural Stone Directory (Bearl, Black Pasture, Blaxter, Dunhouse, Springwell, Talkin Fell); Mitchell (1922) (Heddon, Kenton). No information is available on the weight of Red Sandstone close to the line of the Wall. Red Lazonby stone, quarried near Penrith, weighs 140lbs/cubic foot $\left(2242 \mathrm{~kg} / \mathrm{m}^{3}\right)$ (Natural Stone Directory).

369 Bruce (1867) 445. This point, and its weight, has been confirmed to the writer by Tyne Valley Stone Ltd, Haltwhistle, the current (2002) operators of the quarry.

370 Hill (2001c).
} 
easily-worked stone used at Birdoswald, which appears to have been quarried from, or is at least similar to, Coombe Crag; ${ }^{371}$ as a result the north gate is probably the worst-finished piece of work on the Wall. Dworakowska notes that the quarries associated with the Wall '... were placed as close [to the Wall] as only the terrain and the location of the deposits permitted. ${ }^{1372}$ It seems clear that the builders took stone from as close to the Wall as possible, regardless of its nature; this is logical as it reduces transport problems. Only the dolerite from the Whin sill was largely ignored for facing stones owing to its extreme hardness and difficulty of working.

In a sense, the line of the Wall was fixed by the position of the Tyne and Solway estuaries, and the Whin Sill, and is thus unlikely to have been influenced by the availability of materials. Perhaps fortuitously, durable stone is available from Wallsend to just west of T52a, Banks East, ' . . . where the entry of Permo-Triassic red sandstone, concealed by thick glacial deposits, is taken as the west end of the central sector of Hadrian's Wall. ${ }^{1373}$ It seems unlikely that the durability of the stone was a factor in the building scheme as the later rebuilding of the Turf Wall used the softer Triassic red sandstone available, with some difficulty, in this area. The short stretch of excavated red sandstone wall at Dovecote Bridge, formerly covered in the winter months to prevent frost damage, has had to be reburied in order to preserve it from disintegration. The durability is however relative, and there is no reason to suppose that the use of red sandstone gave the Romans much trouble during the working lifetime of the Wall. Furthermore, anecdotal evidence suggests that some stones withstand exposure much less well after excavation than when first used.

\footnotetext{
371 Johnson (1997) 65. The spelling of the name of this quarry varies; here, the spelling is that used in $R I B . \mathrm{MC} 48$ is about 4 miles from the quarry.

372 Dworakowska (1983) 18-19.

373 Johnson (1997) 67.
} 
Limestone, for the making of mortar, was available from Denton, just west of Newcastle, to the same break point. The initial use of turf west of the Irthing may have been partly due to the comparative scarcity of limestone, rather than the less durable nature of the New Red Sandstone and its greater distance from the Wall line.

In the central sector there are still ample traces of small quarries to be seen within half a mile of the Wall, both north and south, presumably many of them Roman although they are impossible to date without inscriptions which few of them carry. ${ }^{374}$ Immediately to the west of Haltwhistle Burn fortlet is a quarry which carried an inscription of legion VI $(R I B$ 1680) until it was removed by modern quarrying. As this legion is believed to have arrived in the province in $\mathrm{AD} 122$, the quarry was probably used, or reopened, to supply the Wall builders.

When a quarry on Barcombe Hill above Chesterholm was reopened in 1837 an arm-purse was discovered, holding coins current in the early years of Hadrian's reign; this quarry is discussed below (section 5.4).

In Roman and modern times wedges have been used in both individual holes and in long slots in the surface of the stone. ${ }^{375}$ Fallowfield Fell quarry, to the east of Chesters, has slots and wedge holes, ${ }^{376}$ either of which may represent work of the Roman period or of the nineteenth century. This quarry had an inscription, now removed to Chesters museum for safety, cut by Flavius Carantinus; ${ }^{377}$ the date of the inscription is unknown. A modern inscription was cut above the Roman one

374 Williams (1968) discusses all the known and possible quarries in the Wall area, and also emphasises some of the problems of identification.

375 Crawford, Röder, et al. (1955); Peacock and Maxfield (1997) 197; Dworakowska (1983) 144; Hill (2001g); Greenwell and Elsden (1913), chapter 6. Mr Kurt Kleemann, Remagen Museum, kindly supplied information on Roman quarrying tools.

376 Author's survey.

$377 \quad R I B \quad 1442$. 
using a chisel, which tends to confirm the presence of a stonemason rather than a casual passer-by. Wedge holes also appear in the quarries on the north slope of the valley to the south of Housesteads; this quarry was almost certainly used for at least a part of the building of the fort. ${ }^{378}$ Wedge holes are, of themselves, undateable, basic stone quarrying techniques having varied little from antiquity onwards. It would therefore be unsafe to classify either slots or wedge holes as Roman except on a quarry face buried since Roman times, or where there is good reason to accept them as such. The phallic symbol near to the wedge holes at Barcombe suggests that the holes are Roman, but does not prove it. On the other hand, the wedge holes in the block of basalt in the unfinished ditch at Limestone Corner are unlikely to be other than Roman, on the assumption that in any later quest for basalt the more accessible blocks on the north lip would have been taken first.

Resumption of quarrying at Barcombe, Fallowfield, and Haltwhistle, points up the difficulty of discriminating between Roman and relatively modern work.

Further Roman inscriptions are found at Coombe Crag, ${ }^{379}$ Lodge Crag, ${ }^{380}$ and the group of quarries in Cumberland. ${ }^{381}$ None are closely dateable, but their proximity to the Wall suggests that they were used, and presumably specifically opened, for its building. It is suggested in $R I B$ that a graffito on Coombe Crag stone, ${ }^{382}$ found at MC52, Bankshead, may have been a quarry inscription; if so the quarry was used either for the original building or for the repair of this milecastle. A

\footnotetext{
378 Williams (1968), who says that the stone is geologically identical to that used in the fort and the roofing slabs found in the praetorium came from the flaggy beds in the quarry.

379 RIB 1946-52.

$380 \quad R I B$ 1953-4.

$381 \quad R I B$ 998-1016.

382 RIB 1957.
} 
stone in the foundation of the Wall at Walton has been identified as being from Coombe $\mathrm{Crag}_{3}{ }^{383}$ indicating that this quarry was used as a source for the rebuilding of the Turf Wall in stone. The sandstone quarry at Queen's Crags bears an undated Roman inscription beneath an overhang; the inscription appears to have been cut by two different hands, ${ }^{384}$ but whether this represents two periods of working the quarry or merely two different groups taking shelter during one season is not known. Much of the Wall was probably built from small quarries opened all along the line, wherever reasonable stone could be found near enough to keep transport to a minimum.

Bidwell and Watson have argued that the ditch of the Wall was used, in one area at least, to provide all the materials used in building the Wall, on the basis that Wall and ditch had approximately the same cross-sectional area. Their thesis assumes that the solid bed of sandstone in the lower half of the ditch could have been extracted with no waste and they consider that ' ... the Broad Wall at Denton represents nothing more than the re-assembled contents of the Wall ditch. ${ }^{1385}$

Digging straight down into the sandstone would have called for quarrying by the guttering method (for which see below), a source of considerable waste especially when working in a confined space.

Overall it is unlikely that the wastage on quarrying facing stones from the ditch would have been much less than $50 \%$. It is virtually certain that the builders would have made use of material from the ditch to fill the core, but the use of the ditch to provide more than a very small percentage of the facing stones is most unlikely.

\footnotetext{
383 Haverfield (1902) ii, 391.

384 E. Birley 'RB in 1960' 194.

$385 \quad$ Bidwell and Watson (1996) 33.
} 
Before discussing the methods employed in quarrying it will be useful to establish definitions of types of wall and surface finishes, as an aid to understanding the nature of the requirements for the quarryman.

\subsection{Types of walling and surface finishes}

These definitions include some relatively modern finishes for the sake of completeness and to avoid confusion. The classification of the walling type can be a matter of the nicest judgment, and will be based in part on what the mason was trying to achieve; this calls for an understanding of the techniques and skills involved. Surface finishes are illustrated in figure 5.1 and types of walling in figure 5.2. The tools mentioned are defined in section 6.1 .

\subsubsection{Ashlar}

This term is sometimes used to describe any facing stone, but its use should be confined to stones which meet the following criteria. Ashlar ${ }^{386}$ has carefully worked beds and joints, finely jointed (generally no more than $3 / 16^{\prime \prime}(4.5 \mathrm{~mm})$ ), and set in horizontal courses; stones within each course should normally be of the same height although successive courses may be of different heights. In elevation the stone should ideally be perfectly rectangular and the face, unless rubbed or left off the chisel, must be bounded by neat, well-chiselled margins worked straight and square to the beds. Ashlar is described according to the surface finish, of which the following are the most common (see fig. 5.1). These finishes may be applied to stones other than ashlars. The illustrations of 'Claw tool' and 'Random punch' can be

386 Ash'ler, a trochee, rather than a spondee rhyming with -car. 
stages in working a stone rather than a deliberate, final surface finish, and are therefore shown without the chiselled margins appropriate to ashlar.

Ashlar must be quarried from solid beds of stone which will typically be at least $2^{\prime \prime}(50 \mathrm{~mm})$ higher than the finished height. Ashlar is in fact very rare on the Wall; ${ }^{387}$ it is discussed here in order to remove some common misapprehensions and incorrect descriptions.

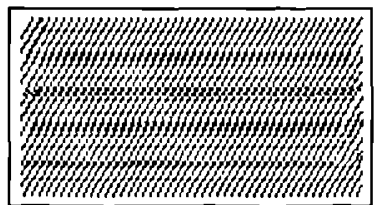

(a) Boastered

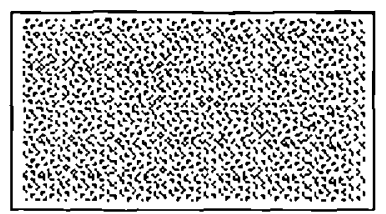

(d) Picked

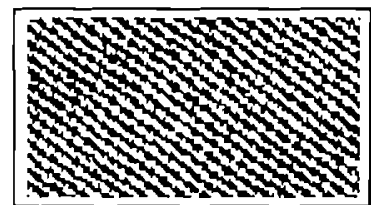

(b) Furrowed

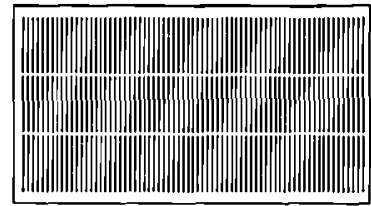

(e) Batted or Tooled

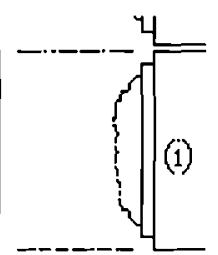

(g) Rusticated with (i) Rock face and (ii) Rubbed face
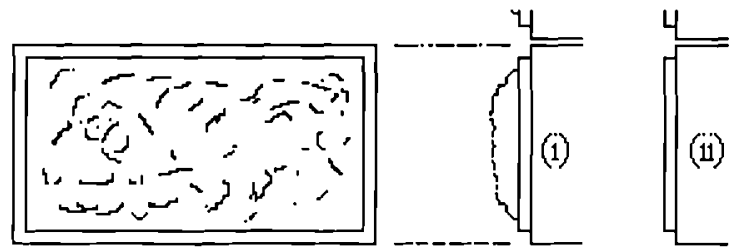

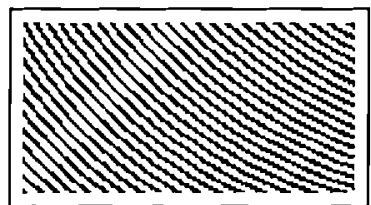

(c) Feathered

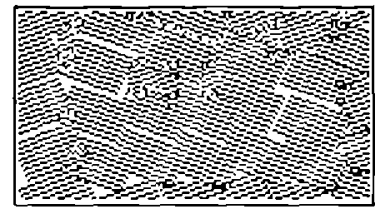

(f) Claw tool

Fig. 5.1 Types of surface finish

(i) Plain or rubbed ashlar is that where the surface has been rubbed with an abrasive material to remove all toolmarks, leaving a perfectly flat, smooth surface.

387 See Hill (1981), (1992). 
(ii) Boastered ashlar (5.1a) is left with the marks of the boaster (a broad chisel, see section 6.1.2) showing clearly, set at the usual angle resulting from working, typically about $60^{\circ}$ to the horizontal; the toolmarks should be neat, and all drafts set at about the same angle, without being excessively regular. The drafts will overlap. Also referred to as left off the chisel, or chiselled face. The term should not be confused with 'boasted for carving', an instruction to a mason to leave projections etc. roughly blocked out for later attention by a carver. It is also sometimes referred to as tooled, and while this is not actually incorrect as a shorthand, it can be confused with the alternative name for a batted surface.

(iii) Punched ashlar has the surface left off the punch inside the marginal drafts. The punch marks may be random or regular, but if regular are usually either in straight vertical, horizontal, or diagonal lines (furrowed (5.1b), if straight, or feathered (5.1c), if curved), or as small and very even indentations on a prepared flat surface (pecked or picked (5.1d)). Note: the term furrowed is sometimes applied to the modern finish consisting of a series of small vertical flutings; the terminology here is variable.

(iv) Rock faced ashlar Here the surface is left in its natural state, or with a little assistance from the pitching tool, within the chiselled margins. Rock-faced granite is often referred to as rustic, which is not the same as rusticated (for which see below).

(v) Tooled or Batted ashlar (5.1e) This is finished with regularly spaced chisel marks, resembling small flutes, set vertically on a rubbed or sawn surface, at specified intervals. It represents not a stage of work but an applied finish on a prepared flat surface, apparently evolved in the later mediaeval period and especially popular in the eighteenth and nineteenth centuries; it is common on railway and dock 
engineering works. The tool used resembles the boaster, but may be up to $100 \mathrm{~mm}$ wide. The term should ideally not be used as a substitute for, boastered work.

(vi) Rusticated ashlar (5.1g) is that where the joints are sunk below the marginal drafts in a distinct step to a second draft. The surface may be finished in any fashion. This term must never be used as a synonym for rock-faced work (rustic in granite), which is totally different in terms of both appearance and cost.

(vii) Claw finish (5.1f) This is a stage in working rather than a final finish, but in rougher work stones may well be left 'off the claw'. The same limits apply to random punched work (5.1h).

\subsubsection{Block-in-course}

This is an old-fashioned but convenient term to describe the large blocks of masonry seen nowadays in dock and railway engineering; it has much in common with Roman gate piers. The blocks are squared and brought to fair joints, and the faces usually either rock-faced or punched. Massive solidity rather than sophistication is the keynote of this class of work. Chiselled margins might be expected on the quoins but not elsewhere.

Block-in-course has the same quarrying requirements as ashlar: solid beds greater in height than the finished size.

Bidwell and Holbrook prefer the term opus quadratum for this class of work, a term used by Lugli and defined as 'construction with rectangular blocks laid in horizontal courses without mortar and sometimes joined together with clamps and dowels. ${ }^{1388}$ This seems a perfectly fair description, so long as there is a supplementary definition noting the quality of workmanship and intent. Opus

388 Bidwell and Holbrook (1989) 116; Lugli(1957), 48. 
quadratum may well be either high quality ashlar or may resemble large squared rubble; it is a method of construction rather than a type of stonework.

Rarely, a corner of one stone next to one of lower bed height may be cut away to form an internal right angle to receive a stone on the next course which makes up the difference in height. This is known as snecked (fig. 5.2(b)), but see also snecked rubble, below.

\subsubsection{Rubble}

This should not in any way be taken as a derogatory term. The majority of ancient buildings in this country are some style of rubble, and many have stood for centuries without any regular maintenance. Rubble is much more cost-effective than ashlar. However, all rubble walling relies to some extent on the strength of the mortar for its stability - ashlar does not; stability is achieved by the bonding of the stones and on the accuracy of the beds and joints.

Squared rubble wall construction is simple, relatively cheap, makes an adequate and reasonably durable job, and does not call for a high degree of skill either in preparation of the stones or in building. For a structurally simple building of whatever size there is no real need to put in any greater effort, and the Romans did not do so when building their forts.

Quarrying can be much simpler than for ashlar or block-in-course. Depending on the type of rubble, beds need be no more than $3-9^{\prime \prime}(75-225 \mathrm{~mm})$ in height, and a quarry with bed heights of no more than $6^{\prime \prime}(150 \mathrm{~mm})$ is ideal. As will be shown below (section 5.4 ) the techniques may be very simple indeed. 


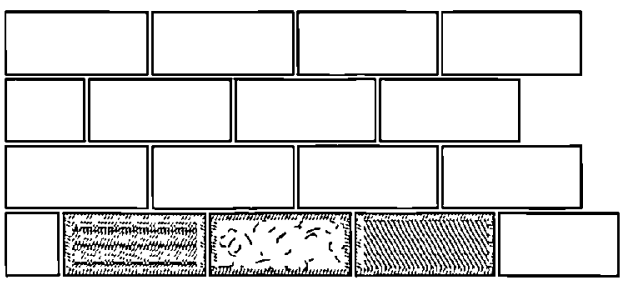

(a) Ashlar: note chiselled margins on all but nubbed finish

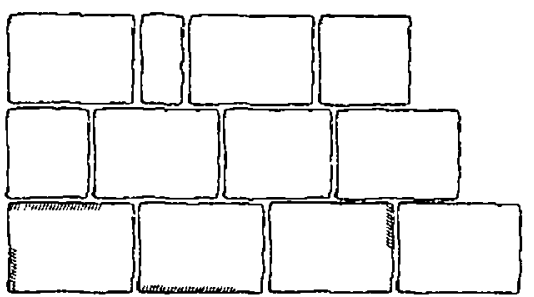

(c) Block-in-course: note absence of chiselled margins on all edges. Comparative size of blocks may be larger or smaller than shown here.

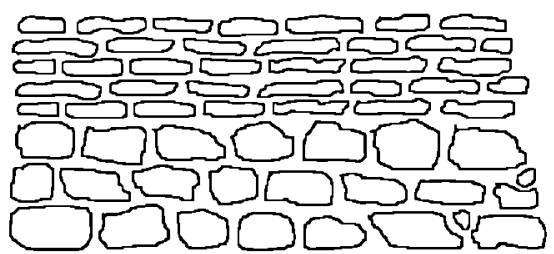

(e) Coursed rubble

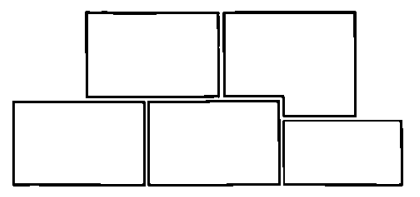

(b) Snecked ashlar

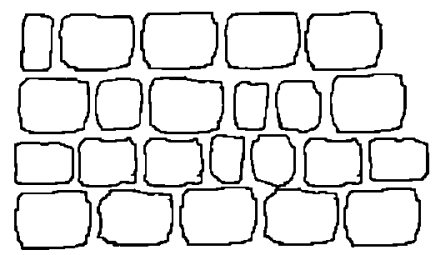

(d) Squared rubble

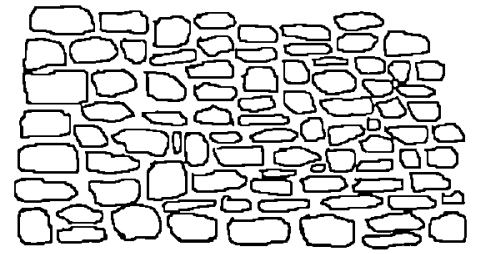

(f) Random rubble

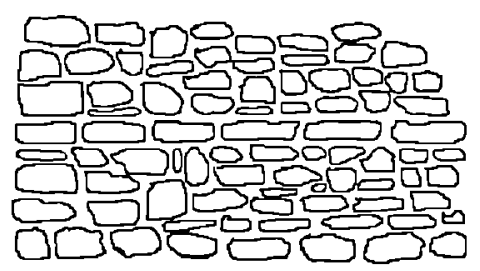

(f) Random rubble brought to courses

Fig. 5.2 Types of walling 
(i) Squared rubble The stones are more or less roughly squared up, the degree of dressing varying according to the quality of the work, to about the same height within each course. Course heights are generally between $5^{\prime \prime}$ and $9^{\prime \prime}(125-225 \mathrm{~mm})$, and joints may be $1 / 2^{\prime \prime}(12 \mathrm{~mm})$ or more. It is normal for joints to be worked to something of a taper, as this both increases the hold of the mortar and makes accuracy in working, and thus the cost, less important. Stones of this type are more likely to be left off the punch or the claw, at best, and are most often hammer finished or natural.

Where rubble walls have small stones inserted to equalise the different heights of stones within a course it is known as snecked rubble.

(ii) Coursed rubble Here, stones are used more or less straight from the thinner beds in the quarry, but are selected to give something like the same height within each course, although courses may taper over a distance. Joints tend to follow the profile of the stones, varying from almost nothing to around $1^{\prime \prime}(25 \mathrm{~mm})$. The stone is usually from thin or highly fissile beds between 3 and $6 "$ thick $(75-150 \mathrm{~mm})$. The illustration at figure 5.2(e) shows the effect that different beds of stone have on the appearance of the walling.

(iii) Random rubble This is walling in which the stones are taken straight from the quarry and are merely broken to about the right depth; they are laid as they come to hand, little or no attention being paid to coursing. Joint widths are as for coursed rubble.

Where the stones are built up so as to give a horizontal course at intervals, the work is known as Random rubble built to courses (fig. 5.2f).

On Hadrian's Wall there are three types of walling. The curtain wall is generally built of roughly squared rubble, typically $10^{\prime \prime}(250 \mathrm{~mm})$ wide, running $15^{\prime \prime}(375 \mathrm{~mm})$ 
into the wall, in 7" (175mm) courses; there are of course wide variations from these typical figures. Successive editions of the Handbook have followed Bruce $(1851,82)$ in describing the facings as 'of carefully squared freestone blocks' although Bruce himself confesses in a footnote that modern builders would describe it as 'a rough blocking course' (properly 'block-in-course'). The frequent references to 'ashlar faces' in the same work and in others gives a wholly misleading view of the Wall and of the skill and labour required for its construction.

In places the facing stones deteriorate to relatively thin coursed rubble, laid in rough courses; this is easily seen in parts of MC48, Poltross Burn, and on the stretch of curtain wall running down towards Willowford bridge immediately west of T48b.

The milecastle and fort walls, turrets and gate towers, and many of the internal buildings of milecastles and forts are built of squared rubble. Internal buildings may also be built in the less sophisticated coursed rubble.

The third type is stone which is suitable for dressing to specific profiles, such as the piers and voussoirs of the milecastle and fort gateways, and the various decorative pieces. This is usually referred to by the generic name of dimension stone; the term refers to the need for large blocks which can be worked to specific dimensions rather than to the style of building.

Each type of stone may call for different quarrying methods, and these are reviewed below.

\subsection{Methods of quarrying}

The simplest case is where the stone occurs in relatively thin beds, perhaps 100$150 \mathrm{~mm}$ thick. This sort of stone is often obtainable with the use of crowbars to lever out the thin beds, and heavy hammers to break the slabs into easily handled pieces. In 
modern times a 'bursting hammer' of up to $28 \mathrm{lbs}$ in weight (see fig. 5.3), with one flat face about 3 " square and one face shaped to a wedge with the axis parallel to the axis of the shaft, has been used. ${ }^{389}$

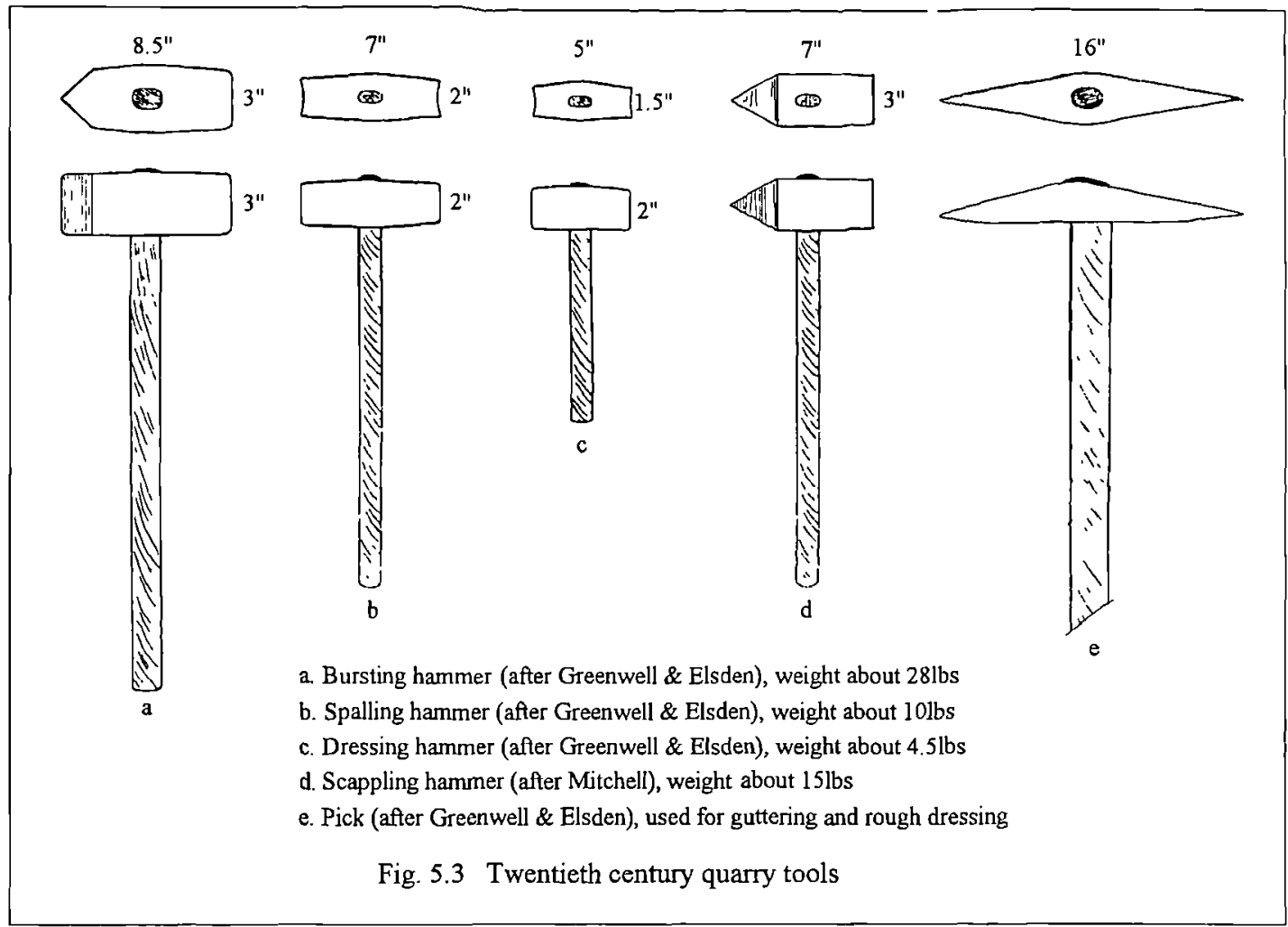

No certain examples of such a tool have survived from Roman times, but in the same pit which contained the altars of Marcus Cocceius Firmus (RIB 2174-2178) at Auchendavy were found two large iron hammers. Their function is not known, but they are described as having 'been much used, for their faces are greatly battered.' The illustration shows that one face of one of them is heavily burred over, indicating use on a dense material over a long period. ${ }^{390}$ They are almost exactly the same

389 Greenwell and Elsden (1913).

390 Roy (1793), Appendix 4 (by J. Anderson) 204 and plate. Noted as 'lost or disintegrated by the later 19th century' (Keppie and Walker (1985) 29. 
weight as the modern bursting hammer and are probably Roman examples of this tool.

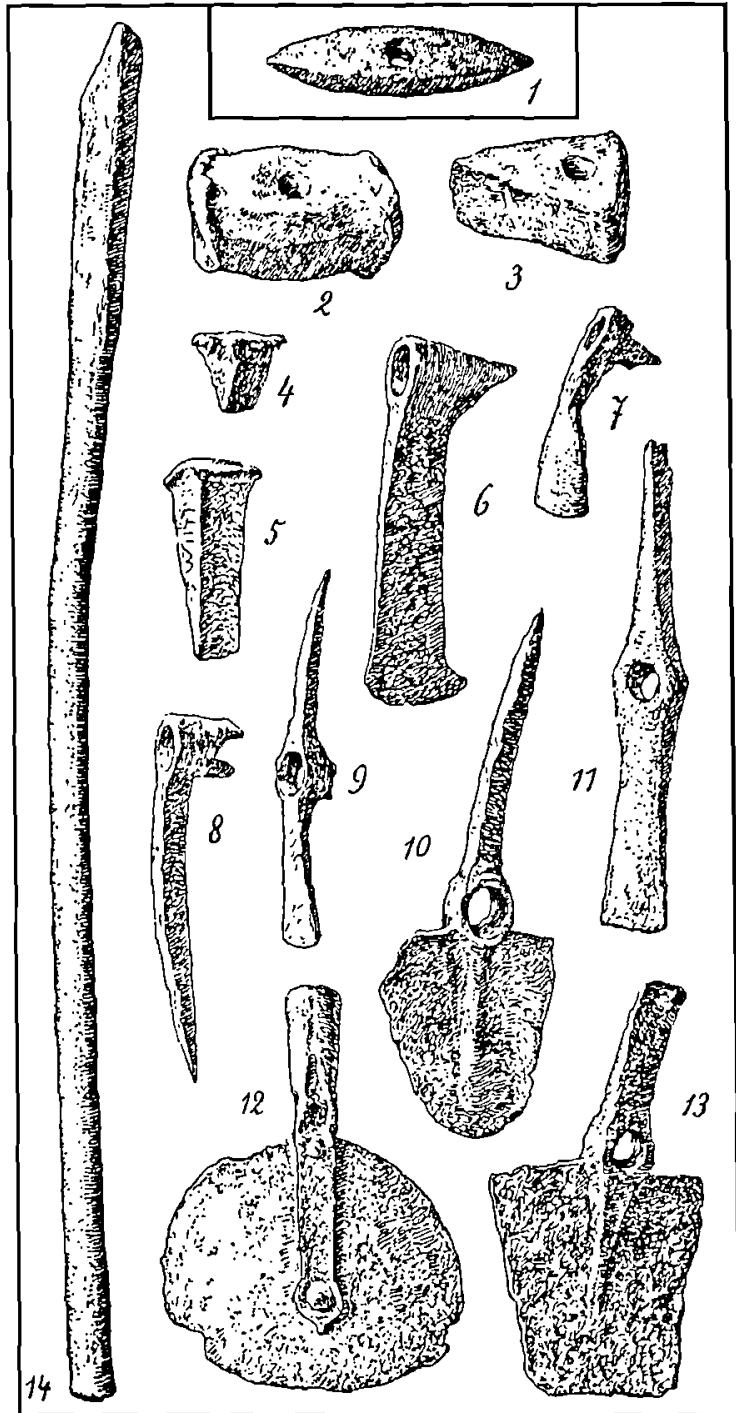

Fig. 5.4 Roman quarrying tools

From Felsberg (1) and Tussbriichen (2-14)

(from Behn (1926) Abb. 21)

The joints of the facing stones on the Wall sometimes exhibit signs of having been split by the wedge face of a bursting hammer, or perhaps by a large wedge struck with a very heavy hammer to produce a clean fracture. A hammer found at 
Puch $^{391}$ (Bavaria) of this general form weighs over 131/2 lbs $(6.2 \mathrm{~kg})$ and may have been used for a similar purpose. Two tools from Tussbrüchen (fig 5.4, items 2 and 3) may represent a bursting hammer and a splitting hammer.

There is some evidence that a large hammer was used in the conversion of whinstone into foundation or facing stones on the Wall. Investigations of large whin erratics lying to the north of the Wall at Melkridge showed that they ' . . had been used as anvil stones, each was surrounded by a depression and heaps of flakes ... large blocks must have been broken down by heavy sledge hammers . . . 392

Thicker beds may call for the use of the wedge to split them (for details see below). Where the strata are well divided by natural joints the use of lifting tackle to move the blocks from the working face is often not necessary, as they may be small enough to move by hand. Once broken into manageable pieces with the bursting hammer, minor dressing may be carried out to knock off any particularly awkward angles, but the stone can often be laid straight from the quarry. The appearance of the finished work depends very much on the regularity of the beds; the thinner beds will usually give a random or coursed rubble wall, but the thicker beds will, with some more or less rough dressing, produce the good squared rubble regarded as typical of the Wall. Details of the dressing are given below (section 6.3.1).

Quarrying by this simple method was being carried out in the early twentieth century on a commercial scale at the Keinton Mandeville quarries in Somerset, ${ }^{393}$ showing that it is not merely a passing expedient but a practical method. The author has quarried occasional blocks of around half a tonne from the Duston quarry (sandy Jurassic ironstone) near Northampton, with no tools other than crowbars and a

391 Dolenz (1955), quoted by Dworakowska (1983) 78.

392 Pickering (1956) 362.

393 Greenwell and Elsden (1913) 212. 
hammer. There, for a reason not clear to the author, once the bed was split it was advisable to wait a few minutes 'to let the air get to it'; the block was then easier to lever clear than if no pause were made.

Where the stone occurs in continuous deep beds the method of extraction becomes rather more technical; the problem facing the quarryman is to detach pieces of a size small enough to handle, using lifting tackle as necessary.

If the beds of stone have sufficient, naturally occurring fault lines, blocks of up to half a ton may be obtained by simply levering away from their surroundings, but in general quarrying depends on the principle that whilst stone will resist great compressive loads it has relatively low tensile strength. In order to take advantage of this it is necessary to introduce internal stresses; the Roman way of achieving this end was by the use of wedges. ${ }^{394}$

It may be possible to utilise existing open cracks, but it is usually necessary to use a hammer and punch to cut holes to take the wedges. The holes are usually cut to a rough taper matching that of the wedge, and sufficiently deep to allow the wedge to be driven to its full extent. It is most important that the end of the wedge should not hit the bottom of the hole. Should this happen the wedge is likely to fly out at unnerving speed, as the writer knows to his cost. 'Ragging' the wedges, the cutting of notches along at least one edge, is no sure prevention.

A series of holes is cut in a straight line on the top bed of the stone along the desired line of fracture. Depending on the particular nature of the stone the wedges may need to be continued, in the same plane, down one or more sides. The distance apart of the wedge holes will vary with the type of stone, the size of block and the

394 Ward-Perkins (1971). 
degree of precision aimed at; in Cornish granite between three and five inches, ${ }^{395}$ in sandstone, between 9" and 15" (225-380mm). ${ }^{396}$ The Roman lava quarries at Mayen shows wedge holes 'cut with a chisel at intervals of 3 or 4 inches'..$^{397}$ Wedges are normally much wider than they are thick, a form which encourages splitting along the predetermined line. Wedges are inserted in each hole and driven home with a heavy hammer in repeated sequence (see fig. 5.5). When the tension in the stone becomes too great, a crack will form in the plane of the wedges, and the stone will split away to give a surprisingly regular surface. In order to increase the accuracy of the break, a shallow groove is sometimes cut along the intended plane of fracture.

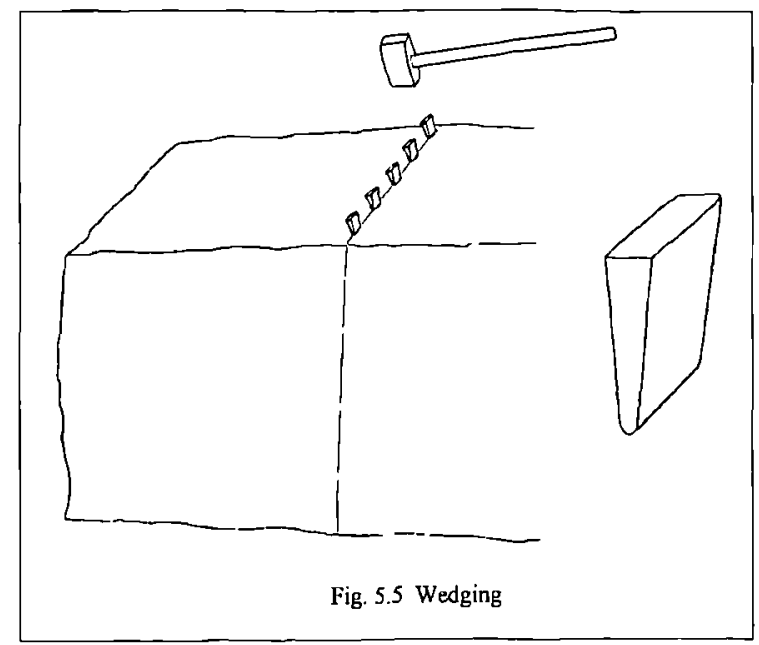

To ease the driving of the wedge, thin steel or iron plates ('slats') may be used on either side of the wedge. ${ }^{398}$ The use of slats in Roman times, usually of iron, but at Mayen (in the Moselle valley) of wood, is recorded at several places. ${ }^{399}$

\footnotetext{
$395 \quad$ Greenwell \& Elsden (1913) 217.

396 Greenwell and Elsden (1913); Hill and David (1995).

397 Crawford, Röder, et al. (1955).

$398 \quad$ Nall (1883): Bromehead (1956).

399 Dworakowska (1983) 78-83 quoting inter alia Höter, Michels, Röder (1950-51) 21, Spräter (1948) 42, Röder (1959) 24; Crawford, Röder, et al. (1955).
} 
Dworakowska refers to them as both 'feathers' and 'slithers', but they are clearly thin plates which are better called slats to distinguish them from feathers which in modern usage are of a different form (see below).

Early twentieth century quarrying sometimes made use of a continuous slot into which the wedges were inserted ${ }^{400}$, a practice well-known to Roman quarrymen. ${ }^{401}$ This method of quarrying has been identified by the writer on the Roman quarry face at Pigeon Clint, on the river Irthing about $50 \mathrm{~m}$ west of the quarry inscription RIB 1016.402 The slots at Fallowfield Fell (section 5.2) may well be Roman, although in the light of modern quarrying there this must be uncertain.

In the early twentieth century, wooden wedges were still in use on the continent; the dry wedges were driven tightly into individual holes and watered at intervals until the stone split. ${ }^{403}$ Peacock and Maxfield believe that it is necessary for the temperature to be below freezing for this to be successful, ${ }^{404}$ but the writer has been unable to find confirmation of this; they were referring to the quarrying of granite. The use of wooden wedges in Roman times is disputed by Dworakowska. ${ }^{405}$ Such wedges, believed to be Roman, were found in the fourth century marble quarry at Spitzelofen (near St. Georgen, Austria), although there had been previous disturbance in the quarry. ${ }^{406}$ The frequent finds of ferrous wedges (see figs. 5.4, 5.6) suggests that the Romans had no need of the more primitive technique.

\footnotetext{
$400 \quad$ Greenwell and Elsden (1913) 220.

401 Peacock and Maxfield (1997) 197; Dworakowska (1983) 144.

402 Hill (2001g).

403 Greenwell and Elsden (1913) 214. Their use is described as 'very primitive.'

404 Peacock and Maxfield (1997) 196.

405 Dworakowska (1988).

406 Schütte (1923) 13, quoted by Dworakowska (1983) 76.
} 


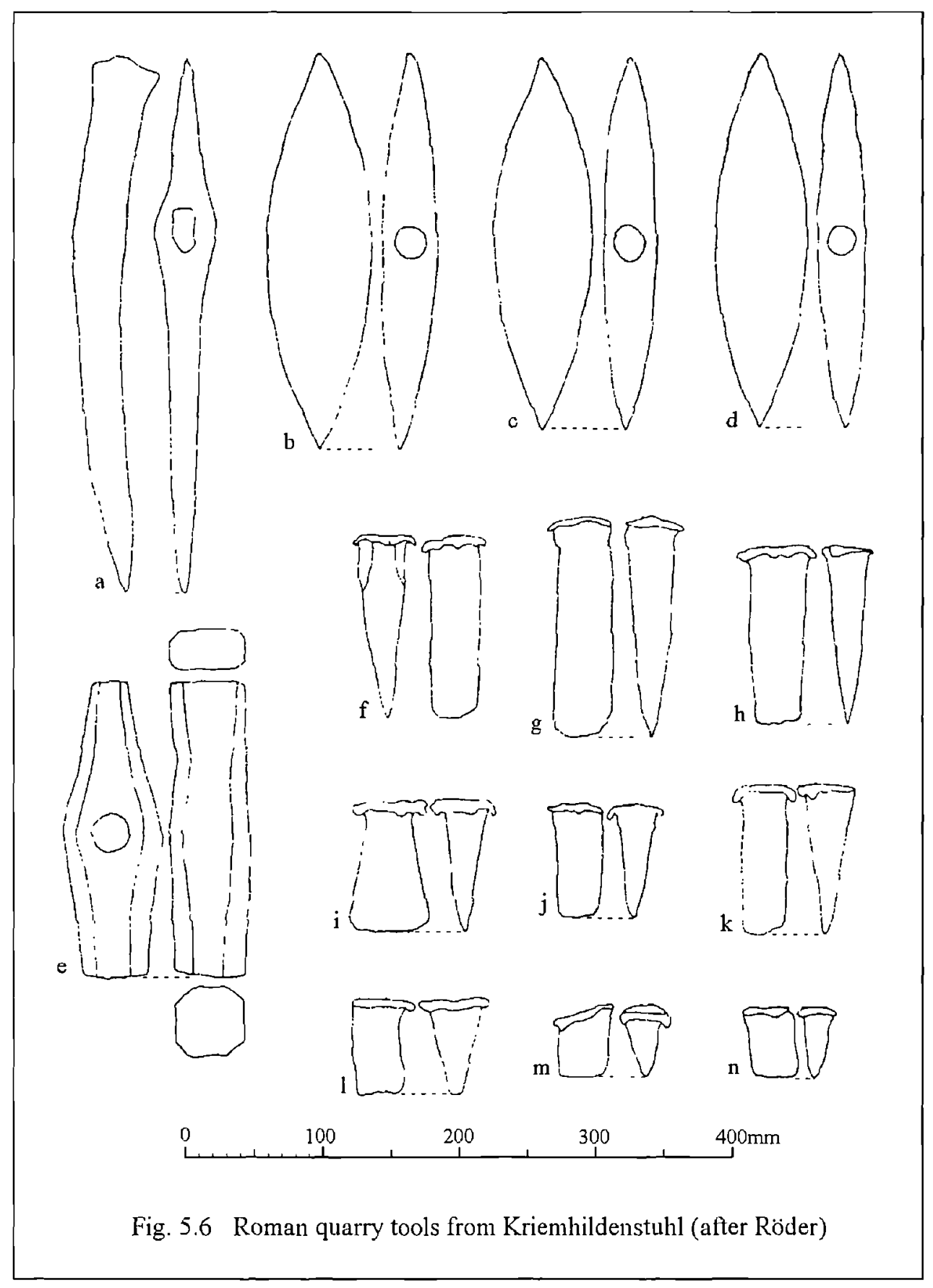


The line of fracture runs down through the wedge hole. Bidwell and Watson ${ }^{407}$ record shallow rectangular marks on the backs of three facing stones excavated at Denton, and take these to be the remains of wedge holes. The size, $70 \mathrm{~mm}$ by $20 \mathrm{~mm}$ on plan, is about right but stone will not fracture at right angles to the wedge hole (see figs. 5.7a, 5.7b).

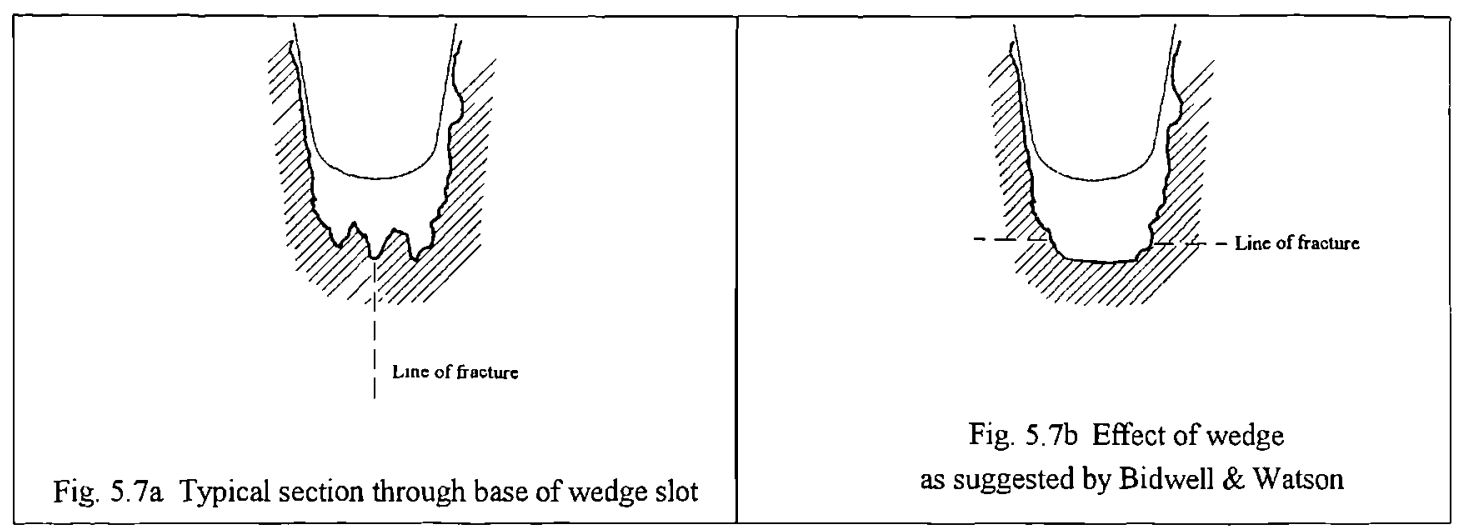

The evidence from Fallowfield Fell suggests that the wedges were 3.5-4" (85$100 \mathrm{~mm})$ wide, by $1.25-2^{\prime \prime}(30-50 \mathrm{~mm})$ thick at about one quarter of their length from the tip; the depth of holes suggests that the wedges might have been about $5^{\prime \prime}$ $(125 \mathrm{~mm})$ high. Inspection by the writer found one stone with half-impressions of two holes where it has been split off; these are $3 \frac{1}{2} 2^{\prime \prime}(85 \mathrm{~mm})$ long, and about the same deep. The original width now shows as $0.5-0.75^{\prime \prime}(10-15 \mathrm{~mm})$. A second, unsplit, stone has two holes at $16 \frac{1}{2} 2^{\prime \prime}(420 \mathrm{~mm})$ centres, $3 \frac{1}{2}-4^{\prime \prime}(90-100 \mathrm{~mm})$ long, just under $2^{\prime \prime}(50 \mathrm{~mm})$ wide, and about $4 \frac{1}{2} 2^{\prime \prime}(110 \mathrm{~mm})$ deep. A single hole in a third stone is $3 \frac{1}{4}{ }^{\prime \prime}$ ( $85 \mathrm{~mm})$ long, by $2 "(50 \mathrm{~mm})$ wide by $4 "(100 \mathrm{~mm})$ deep. One stone successfully split with two wedge holes, each $3 \frac{1}{2} 2^{\prime \prime}(90 \mathrm{~mm})$ deep, is 6' long and $3^{\prime}$ high (1830 x $915 \mathrm{~mm}) .^{408}$ It must be emphasised that these holes could be relatively modern.

$407 \quad$ Bidwell (1996) 19 and fig. 15.

408 Author's survey. 
At Limestone Corner there are four clearly identifiable wedge holes visible, undoubtedly Roman for the reasons given in the introduction to this chapter. They are $3 \times 0.75 \times 2.5 "(75 \times 20 \times 65 \mathrm{~mm}) ; 5 \times 0.75 \times 1 "(125 \times 20 \times 25 \mathrm{~mm}) ; 2.5 \times 0.75 \times$ $2^{\prime \prime}(65 \times 20 \times 30 \mathrm{~mm}) ; 2.75 \times 0.75 \times 2^{\prime \prime}(70 \times 20 \times 50 \mathrm{~mm}) .{ }^{409}$

The three wedge holes in Barcombe quarry form a vertical line, about $2^{\prime}$ $(600 \mathrm{~mm})$ from a natural split up to $4 "(100 \mathrm{~mm})$ wide which runs from top to bottom of the face. From the top, their centres are 12" and 15" (300 and 380mm) apart. The top one measures $1 \frac{1}{2}$ " wide $\times 4^{\prime \prime}$ high $\times 2$ " deep $(35 \times 100 \times 50 \mathrm{~mm})$; the middle one $1 \frac{1}{4} \times 71 / 4 \times 2 "(30 \times 85 \times 50 \mathrm{~mm}) ;$ and the lower one $1 \frac{1}{4} \times 3 \times 2 \frac{1}{4}$ " $(30 \times 75 \times$ $60 \mathrm{~mm}) .^{410}$ Presumably the intention was to split off a large section of rock up to the natural crack; they seem a little shallow for this, and one would expect more of them. It could be that the quarry was abandoned before this task was completed. The wedge holes are $10^{\prime}(3 \mathrm{~m})$ west of a phallic symbol, something which is presumably Roman. If it is, the wedge holes may also Roman as they are in the same plane on the same weathered surface. ${ }^{411}$ On a smaller face, a little to the right, is what appears to be a much weathered, shallow, and very rudimentary architectural carving of triglyph form; it appears that both these faces are Roman and have not been subject

\footnotetext{
409 Author's survey.

410 Author's survey.

411 Clayton (1859) records the finding of a Roman arm purse but does not give the location of the quarry other than 'upon the hill of Borcum'. He refers to 'a quarryman employed in working this quarry' which was perhaps, in the light of the weathered surfaces, some other quarry than the one with the wedge holes. Bruce (1871) records that the finder of the purse, 'and some other labourers' were engaged in winning stone from one of these old quarries, which sounds like a full-scale operation carried out at some other face than that with the wedge holes. Blagg (1990) accepts the wedge holes as Roman.
} 
to modern quarrying. However, it is not impossible that these wedge holes were part of an abandoned sampling in the nineteenth century.

In the quarry at Coombe Crag are six wedge holes which may or may not be Roman. They are arranged in two horizontal rows on a vertical face (see fig. 5.8); the rows are not parallel, and are $6.25^{\prime \prime}(160 \mathrm{~mm})$ apart at the left and $4.5^{\prime \prime}(115 \mathrm{~mm})$ at the right. ${ }^{412}$ They are in a middle of a face which makes their precise purpose uncertain. As shown in the table, they are generally rather smaller than those at Barcombe.

TABLE 5.2

\section{COOMBE CRAG WEDGE HOLES}

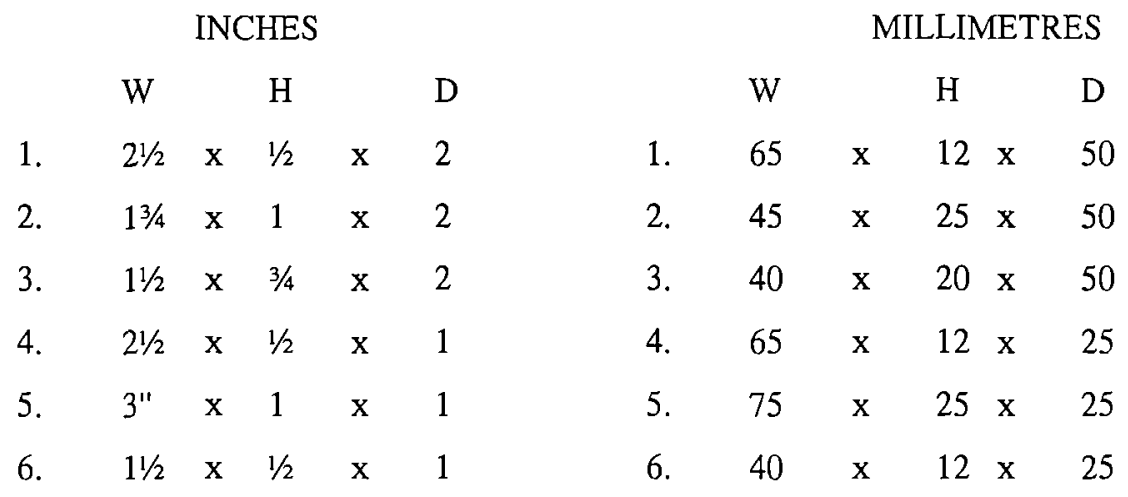

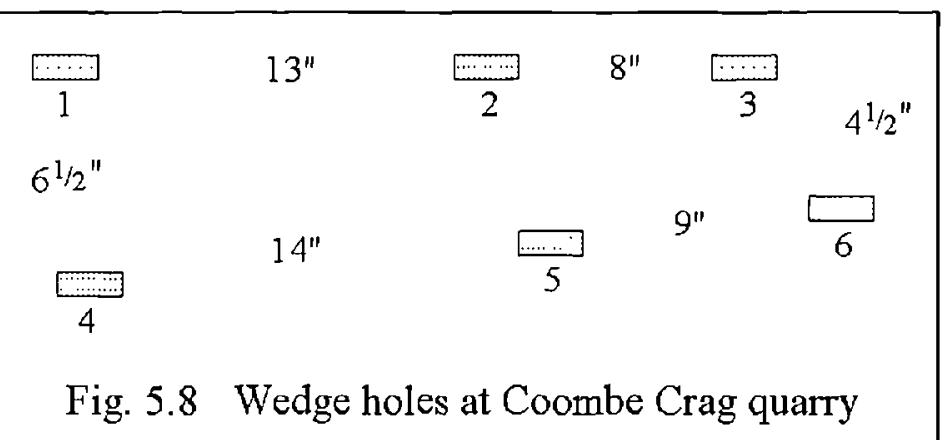

412 Author's survey. 
The larger of the wedges recovered from Kriemhildenstuhl, near Mainz, (see below and fig 5.6$)$ are only about $1 \frac{1 / 2 "}{11}(40 \mathrm{~mm})$ wide and $1 \frac{1}{4} "(30 \mathrm{~mm})$ thick; the height is about $5^{\prime \prime}(120 \mathrm{~mm}) .^{413}$

At Pigeon Clint (see above for location) one wedge hole was found in the main Roman quarry face; orientated horizontally, this is $120 \mathrm{~mm}$ wide, $60 \mathrm{~mm}$ deep $\mathrm{x}$ $20 \mathrm{~mm}$ high (10mm high at bottom). It is located some 30-40' $(9-12 \mathrm{~m})$ below the top of the quarry face, and this is perhaps a suitable point to raise questions about the purpose of some of the wedge holes. The one at Pigeon Clint cannot have been intended to split the stone, as this would have meant lifting several hundred tons of rock. As already noted, the wedge holes at Coombe Crag are in the middle of the face and again cannot have been for simple splitting. Williams illustrates a wedge hole in the quarry across the valley from Housesteads, which is near the base of the upper bed but above a very clear natural bedding plane. He also shows a photograph of the quarry face at Edgar's Field, Chester, where wedge holes run across a very deep bed and again cannot have been used to split the stone..$^{414}$

The precise purpose of these wedge holes is unknown, but it may well be that they are to give access to the top of the quarry faces. A face $20-30^{\prime}(6-9 \mathrm{~m})$ high cannot be exploited other than from the upper part of the face. At the very least a long ladder, or some sort of light staging, is essential; the 'wedge holes' may relate to securing the method of access. This is an aspect of quarrying which merits further investigation.

While training staff at South Shields (see section 6.3.1), wedge holes of the type described were cut in well under 10 minutes each, on a horizontal surface; much of

\footnotetext{
413 Dworakowska (1983).

414 Williams (1968) chapter 2 (Chesters) and 217 (Housesteads).
} 
the time was spent clearing the hole of debris, and a wedge hole cut in a vertical surface is rather quicker.

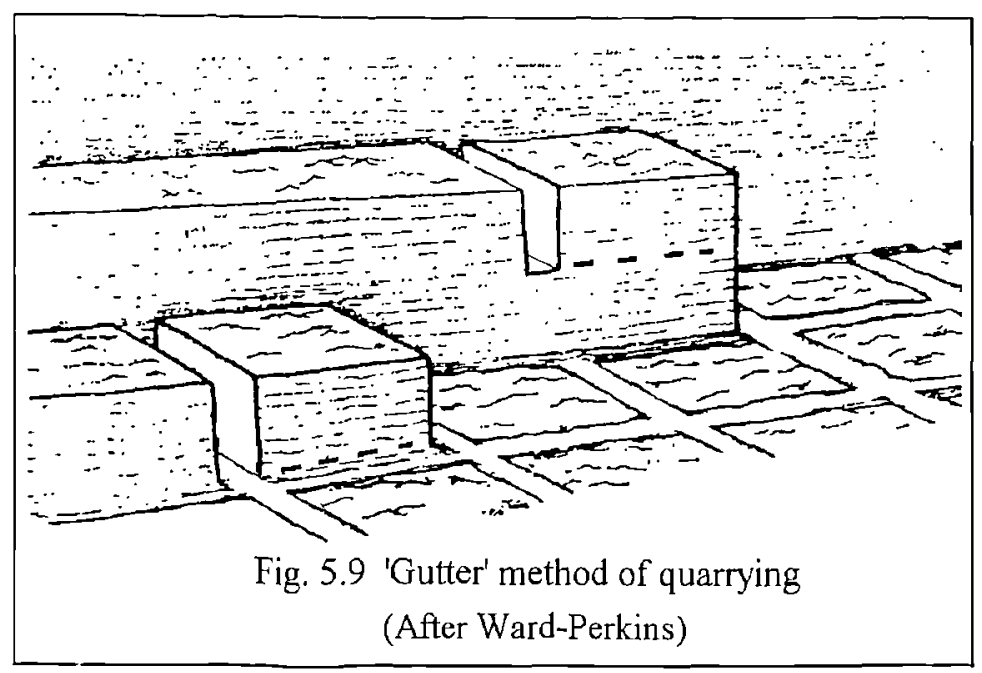

Another common method of extraction used in antiquity was by means of 'guttering' (fig. 5.9), the cutting of a channel to separate the sides and back of the block from the parent rock. ${ }^{415}$ This was a very labour-intensive and somewhat wasteful method of quarrying but Ward-Perkins notes that it was still being used in Italy for the quarrying of tufa and soft limestones in 1971.416 In Britain, the Grinshill, Shropshire, sandstone quarry was being worked in this way in 1913, '. . cutting main and cross channels, 9-12" (230-305mm) wide and 3-4' (915-1220mm) deep, by manual labour with special picks . . . ${ }^{147}$ It is not quite as wasteful as it first sounds as, once quarrying has begun, the channels are effectively 'shared' between adjacent stones and the separation of each block requires the equivalent of only two channels (half of each side and of back and front faces). A detailed attempt to define precisely what form of pick was used to cut the trenches has been made by

\footnotetext{
415 Ward-Perkins (1971) 140.

416 Ward-Perkins (1971) 140.

417 Greenwell and Elsden (1913) 222.
} 
Waelkens. ${ }^{418}$ A selection from a wide variety of picks available from a single manufacturer early in the twentieth century (fig. 5.10) shows the difficulty inherent in attempting to identify the precise function of a tool from its size.

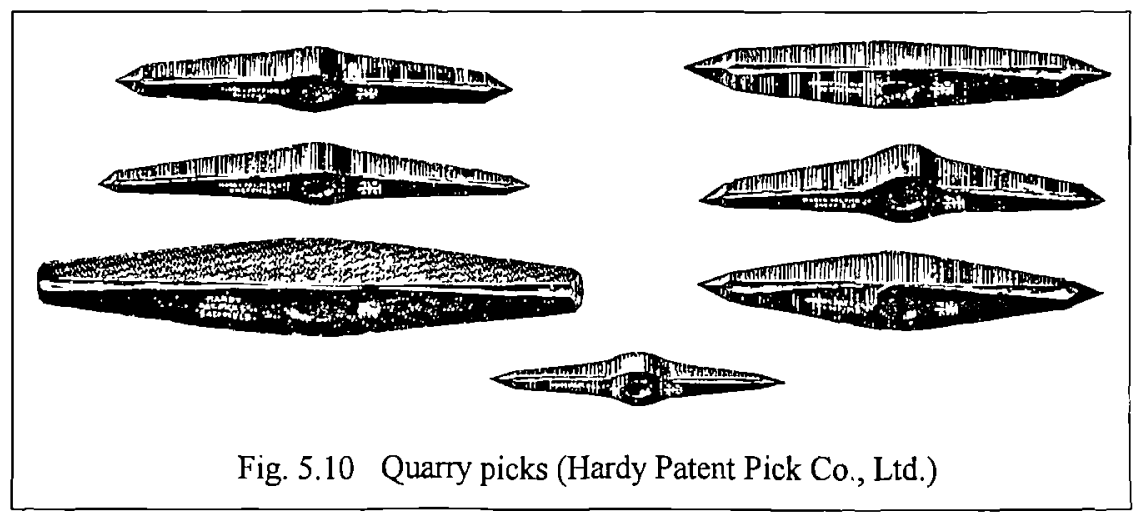

Whatever method is used to split the blocks from the face in the vertical plane, it remains to free the bottom bed of the block. Where the stone beds are shallow or divided by clay layers or other weak beds, is is often possible to use levers to free the block. Where the bed heights are inconveniently large the block must be split horizontally, and for this wedging is the normal method as shown in fig. 5.9.

The more modern method of splitting blocks, either from the quarry face or dividing into individual blocks, is by means of plug and feathers. These are referred to in an early account of the bridge at Chesters, ${ }^{419}$ where the term is quite incorrectly given as the common name for the lewis; the latter is in fact a device for lifting, not splitting, stone (see 7.4.2). There is no evidence for Roman use of plug and feathers.

Plug and feathers came into use when round holes were cut with a jumper (figs. $5.11,5.12$ ). This is a bar of iron with a fan-shaped steel cutting edge (often at both

\footnotetext{
418 Waelkens et al. (1988).

$419 \quad$ Budge (1903) 137.
} 
ends), which was used by continually dropping it onto the stone, turning a little at each blow. Although this was laborious, ' . . . it is possible to bore a 1" $(25 \mathrm{~mm})$ vertical hole to a depth of $16^{\prime \prime}(405 \mathrm{~mm})$ per hour in the case of granite, and about 30" ( $760 \mathrm{~mm}$ ) per hour in the case of crystalline limestone. ${ }^{1420}$ An alternative is to use a drill, a shorter, chisel-ended or star-ended bar, driven by a hammer; often one man held and turned the drill while a second used the hammer.

Once freed from the parent rock, the block has to be moved away from the quarry face; this will be considered in chapter 7 as part of a review of lifting tackle.
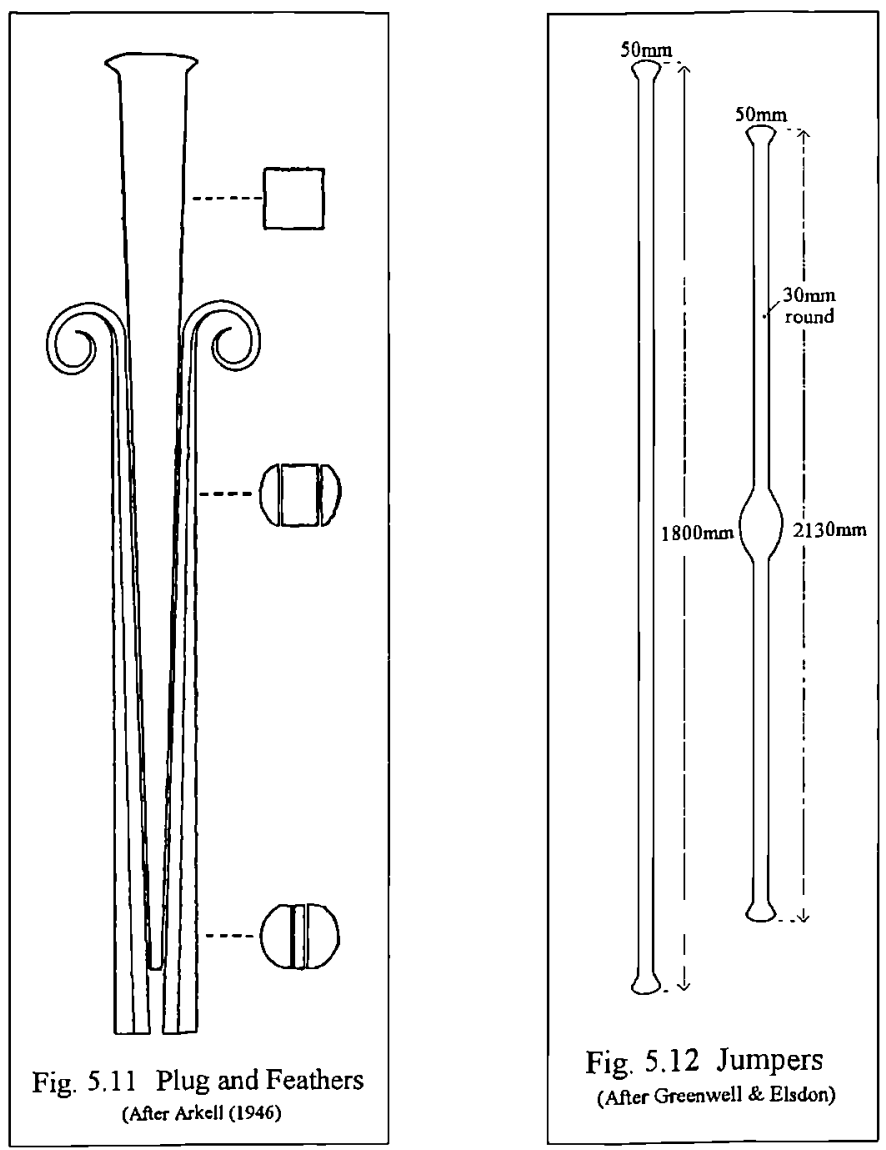

420 Greenwell and Elsden (1913) 219. The jumper is not, pace Peacock and Maxfield (1997) 197, quoting Gillette (1904), similar to a point or punch either in use or in sharpening. Gillette's suggestion that a jumper (which drills circular holes) is used to cut rectangular wedge holes is not readily comprehensible. 


\subsection{Quarry dressing}

For producing dimension stone, the next stage is to achieve a more rectangular prism in advance of detailed dressing. This operation is often referred to as scappling or scabbling, and is designed to remove the more awkward protrusions from the quarried block; this is done partly to make blocks easier to move and partly as an aid to judging what the block will 'make'. In modern times the form of tool used tends to be a heavy rectangular head drawn to a point at one end and known as a scappling hammer or kivel (fig. 5.3d).

Another tool used for roughly squaring quarried blocks is the spalling hammer, which has two concave faces, each face having two cutting edges (fig. 5.3b), and comes in various sizes. As its name suggests it is used for removing large spalls or lumps of stone. Both tools are normally used two-handed although the smaller spalling hammer, sometimes referred to as a 'dressing hammer' (fig. 5.3c), is small enough to use in one hand. There is also the large pick (fig. 5.3e) used for roughly squaring up blocks.

The quarried block will usually be too large for a specific piece of work, and have to be reduced into two or more smaller blocks. This may be done by splitting with wedges; these may be similar to those used for primary quarrying, or they may be smaller. The wedges found near $\mathrm{MC}^{2} 6^{421}$ are of a different form (see fig. 5.13) from quarry wedges, being of a squarer and smaller section in relation to their length, (about 1" (25mm) across at their widest points) and are more appropriate to splitting smaller stones. For small work, the use of ordinary punches can be successful, an operation usually referred to as coping (fig 5.14a); there is no need to use a heavy hammer for this work, a $41 \mathrm{~b}(1.8 \mathrm{~kg})$ hammer usually being sufficient.

$421 \quad$ Shaw (1958). 


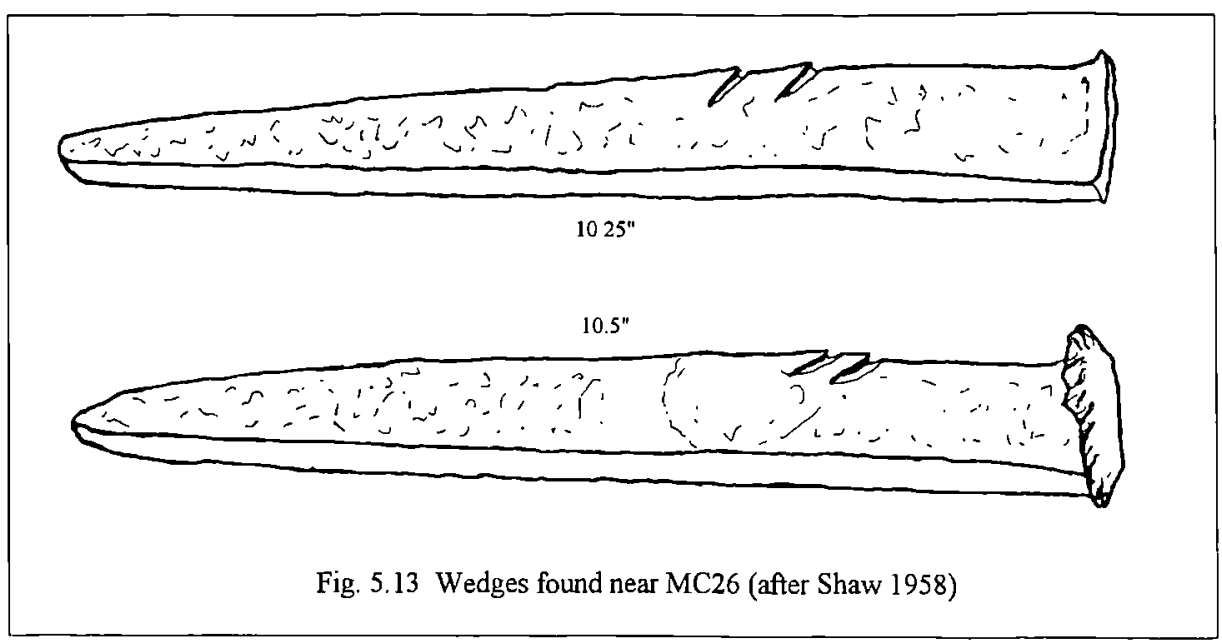

It may be noted that splitting small blocks and large slabs by striking with the hammer and nicker all round the intended plane of fracture, as defined and discussed in section 6.3.1, is also known as coping.

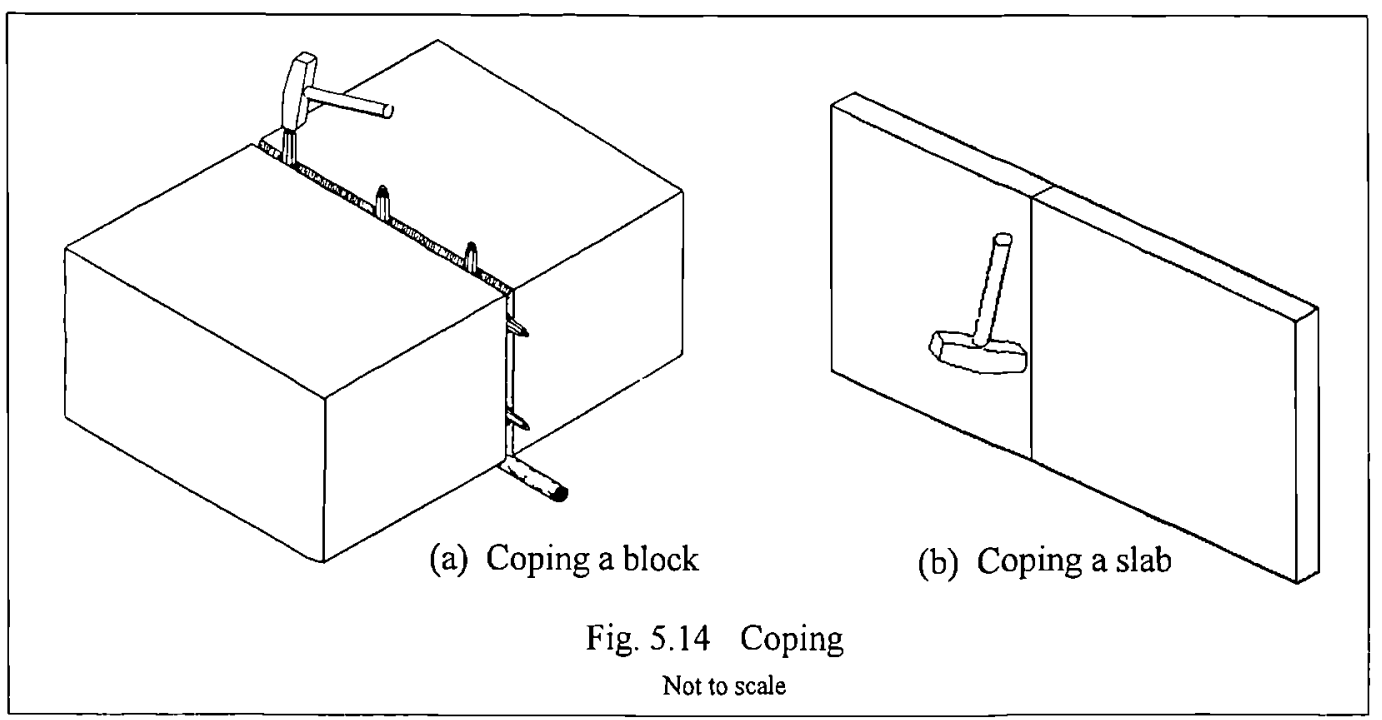

It is also possible to saw stone, using either a toothed blade or plain blade with sand as the cutting medium depending on the type of stone. Both types of saw were known in Roman times, ${ }^{422}$ but no evidence has been found on the Wall for their use.

422 Pliny, Book XXXVI, ix; xliv; xlviii. Reynolds and Ward Perkins (1952) note the finding of two stones at Lepcis Magna which show the use of multiple blades (No. 794a and b). 


\subsection{Quarry organisation}

For practical purposes, nothing whatsoever is known about the organisation of the building of the Wall although a great deal can be deduced. It can be assumed that quarry operations were carried out with the ultimate use of the blocks in mind, but we do not know whether, as one might logically expect, lists of cutting sizes were sent to the quarries. There is no reason why this could not have been done, and there is ccrtainly evidence from Rome of the detailed full size setting-out of significant architectural features which would make this possible, as discussed below, section 6.4 .

It is not unreasonable to expect that the quarry men would have had a list of sizes from which the finished blocks could be worked, and that they aimed to produce these in reasonably economical manner, leaving sufficient over the finished size to ensure that the block would 'make', ${ }^{423}$ and yet not so much as to entail excessive extra work for the mason.

The working of the stone to the required shape could be carried out either at the quarry or at the building site. In order to avoid transporting excessive weight, working at the quarry would be preferred wherever possible, but it must be borne in mind that stone is very easily damaged, particularly where adjoining faces are cleanly dressed to a right angle, or less. The squared rubble most often used in Roman military architecture could take no harm from the most careless transport, and that quality of work would most sensibly have been carried out at the quarry. Even the gate piers are not particularly susceptible to damage, owing to the generally rough nature of the dressing. One would expect that with these, and other stones with

${ }_{423}$ Trade shorthand for 'the rough block is of sufficient size to make the piece in question'. 
some pretensions to quality, all but the final finishing would have taken place at the quarry, leaving only minor work carried out at or close to the point of building.

The dangers of moving worked stone should be seen in perspective. In the Middle Ages there is ample evidence that templets were sent to the quarry and worked stone delivered from there to the building site. ${ }^{424}$ Transport of worked stone has traditionally involved a thick bed of sand or straw under the stones, with straw or other softening between the stones; transport by water, an option not available to the Wall builders, was of course much less likely to result in damage.

In practice there is little doubt that all the stone for the Wall was worked at the quarry. While there is no direct evidence for this, there is an absence of the large quantities of masons' chippings which would have resulted from work on site. Signs of stone-dressing adjacent to a building must be treated with caution; a very small amount of dressing produces an inordinately large quantity of chippings, which of course take up a greater volume than the solid stone; the increase is around $40 \% .{ }^{425}$ An hour's work of roughing out on a single stone can leave the banker mason standing on $3^{\prime \prime}(75 \mathrm{~mm})$ of spalls. A simple example will illustrate the point (see fig. $5.15)$.

Stone SGNE1/1 from MC42 is now approximately $23 \times 351 \frac{1}{2} \times 17.7 "$ " (585 x 900 $x 450 \mathrm{~mm}$ ), with faces C and D 9" and 15.75" (230 and 400mm) long respectively. If it were delivered from the quarry as a rough block $2 "(50 \mathrm{~mm})$ bigger all round than the final size (and this would imply careful scappling), reduction to the finished size, with a check out for the return to face $D$, would produce 45 square feet $\left(4 \mathrm{~m}^{2}\right)$ of chippings 2" $(50 \mathrm{~mm})$ thick. Each gateway contained some $36-40$ stones in the

$424 \quad$ Salzman (1952) 123

425 War Office (1935) 359 gives the increase for 1 " (25mm) gauge as $38 \%$, rising to $51.5 \%$ for $2 \frac{1}{2} 2^{\prime \prime}$ (65mm) gauge. 
piers $^{426}$ and, allowing that half of them would not have internal returns, the total of chippings would amount to somewhere around 1600 square feet at $2^{\prime \prime}$ thick. $\left(150 \mathrm{~m}^{2}\right.$ at $50 \mathrm{~mm}$ thick). There has been no find of chippings amounting to anything like this figure. It is worth noting that the saving in weight by working the example at the quarry rather than on site is around $900 \mathrm{lbs}(408 \mathrm{~kg})$.

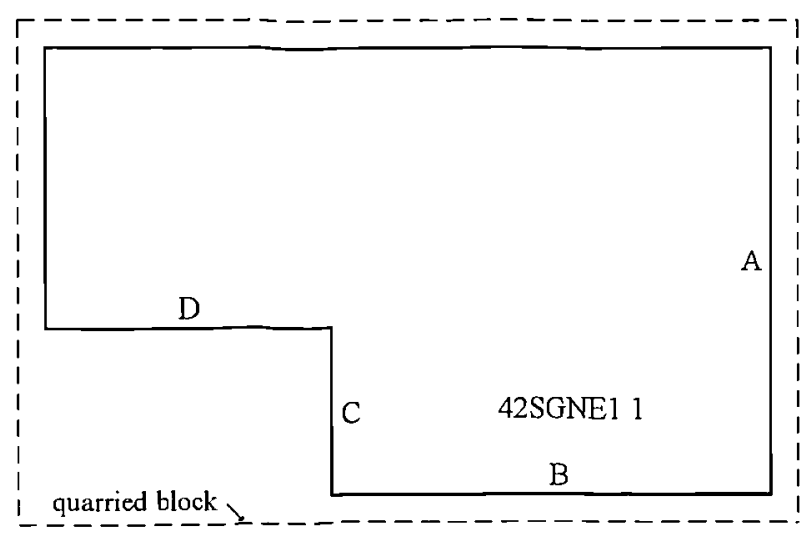

Fig. 5.15 Waste in working a pier stone

It is very likely that the quoins needed for the turrets and towers will have been worked on site, by modifying ordinary walling delivered from the quarry. In practice, the amount of work will have been small as it is very rare for the quoins to be other than very rough returns. Exceptions are very clear to see. Pike Hill is noted below, and one turret, 34a Grindon West, has very clean quoins to both turret and wing walls. ${ }^{427}$ Both these towers stand out from all others in the care taken with the workmanship, and in general the difference between quoin stones and ordinary walling stones is so slight that it would hardly be worth separating the different loads. It is unlikely that they were specially worked at the quarry; a gang doing such

\footnotetext{
426 MC37 has 40 stones, including the caps but not the foundation blocks (author's survey and Crow (1989)).

427 Hill (1997b) 29.
} 
work would have become so relatively proficient that their work would have stood out, which it certainly does not.

In the following pages it will be assumed that all work on the squared rubble walling, save a minimum amount to the quoins, was carried out at the quarry, ${ }^{428}$ and that virtually all work on the mouldings, columns, piers, and other architectural features was also carried out at the quarry, leaving only minor paring-in and correction of errors to be done on site.

428 Taylor (1999) 45 says, in relation to fort walls, that 'each stone was worked on site to ensure a close fit . . . as abundant masons' chippings show.' Taylor provide no supporting evidence and the present writer cannot agree with this statement. Squared rubble worked to tapered joints has no need of on-site working. 


\section{CHAPTER 6}

\section{Working stone: tools and methods}

This section examines the methods used to work the stone. The dressing of stone for walling, worked stone, and mouldings is discussed in some detail, along with the type of tools and their use. The need for, and methods of, sharpening of the tools used is briefly discussed. The discussion of methods will be based partly on surviving Roman tools and illustrations, partly on analysis of surviving toolmarks, and partly on modern practice having due regard to the differences which, although few, do exist between Roman and modern tools.

\subsection{Tools}

Before looking at the methods used to work stone it will be useful to have a brief summary of the tools. There has been little change in the hand tools over the past three or four millennia, something confirmed not only by surviving tools but by observation of the toolmarks on the stonework of the Wall. A selection of modern tools is shown in fig. 6.1; the similarities with the illustrations of Roman tools (see figs 6.2-6.13) will be clear.

Roman tools have been reviewed in the recent past by, among others, Adam, Blagg, and the writer, ${ }^{429}$ and modern tools by the author and a colleague; ${ }^{430}$ only a summary with examples will be given here. The form of a few tools is discussed in more detail where this may be signiricant in identifying excavated artefacts.

429 Adam (1994); Blagg (1976); Hill (1981).

${ }_{430}$ Hill and David (1995). 


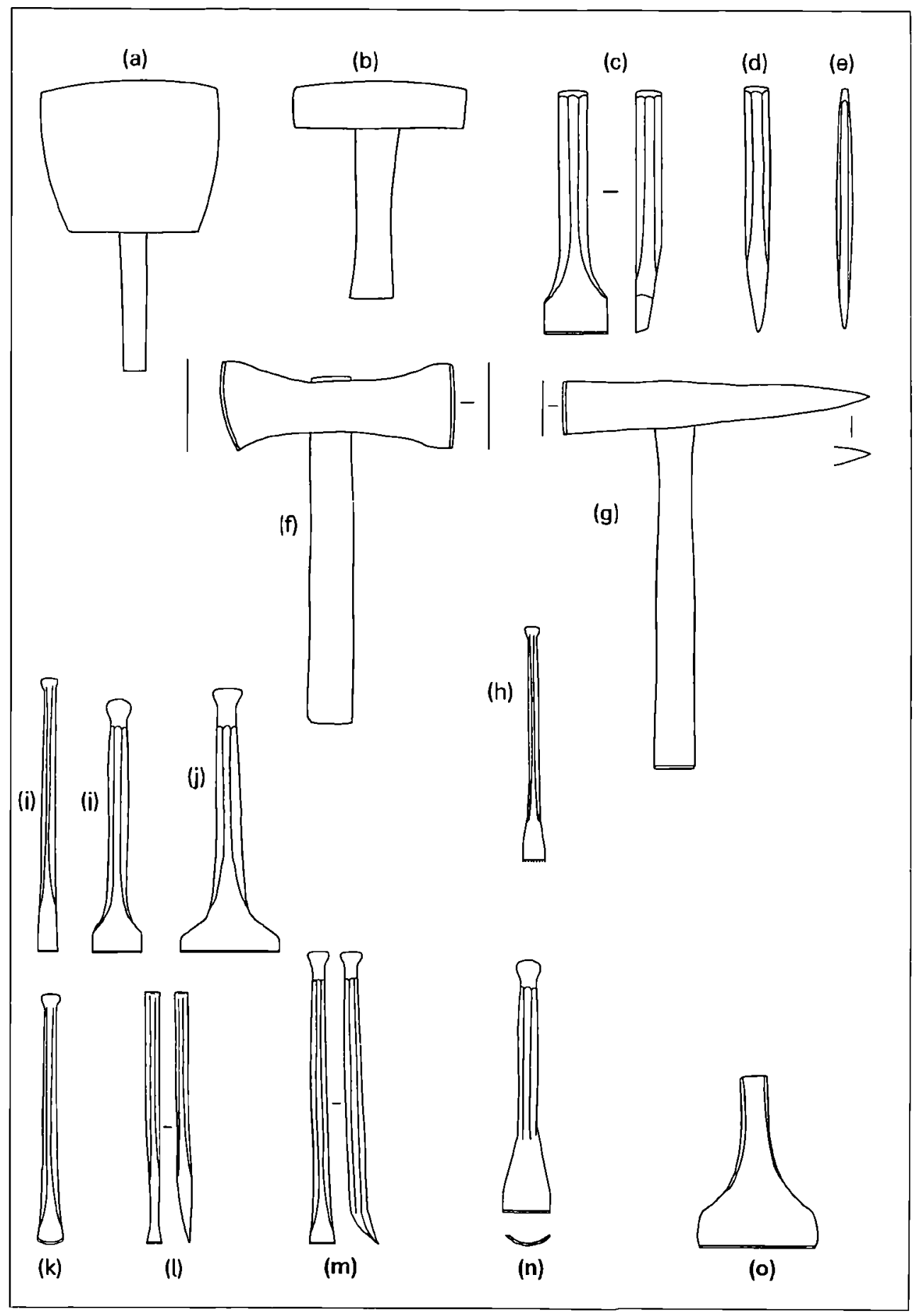

Fig. 6.1 Modern tools from the author's tool kit

Key to fig. 6.13:(a) Mallet; (b) Hammer; (c) Pitcher; (d) Punch; (e) Point; (I) Axe; (g) Walling hammer; (h) Claw; (i) Chisels; (j) Boaster; (k) Bullnose; (l) Quirk; (m) Bent chisel; (n) Gouge; (o) Nicker. 
Blagg divides cutting tools into those of direct percussion and those of indirect pcrcussion: axes and dressing hammers fall into the first category, while chisels and punches are in the second group.

Adam also discusses Roman tools and their uses, but his descriptions are not to be relied upon. ${ }^{431}$

\subsubsection{Tools of direct percussion}

These are tools which act directly on the stone; examples are picks, walling hammers, axes, and adzes. Fig. 6.2, no. 52 probably from Northumberland, shows what may be a type of walling hammer used for rough dressing of thin-bedded stone; this operation consists chiefly in removing awkward corners. No. 66 (Housesteads) is not dissimilar, and No. 65 (Housesteads) is a slightly larger version. Blake shows examples of similar tools from Vindolanda (Nos. 998, 999, 1618). ${ }^{432}$ The pick in fig. 6.2, no. 64 from Housesteads, could have been used either for roughing-out or for quarry dressing.

431 Adam (1994) 32-35 and figs. 48-52, and 56. The insistence on referring to tools of direct percussion as hammers or stone-hammers, makes it difficult to be certain just what he means, and he believes that the scappling hammer and the spalling hammer are one and the same. $\mathrm{He}$ also says that the scappling hammer, by definition a large, quarryman's tool, is used for the smaller work of shaping the stone, and that the dolabra and the stone axe, which he also calls a kivel, are the same thing. The mallet is referred to as a maul, a quite different and irrelevant tool, and mallet-headed chisels are defined as those with a cutting edge 'of greater thickness than its width' (see section 6.1.2).

432 Blake (1999). 


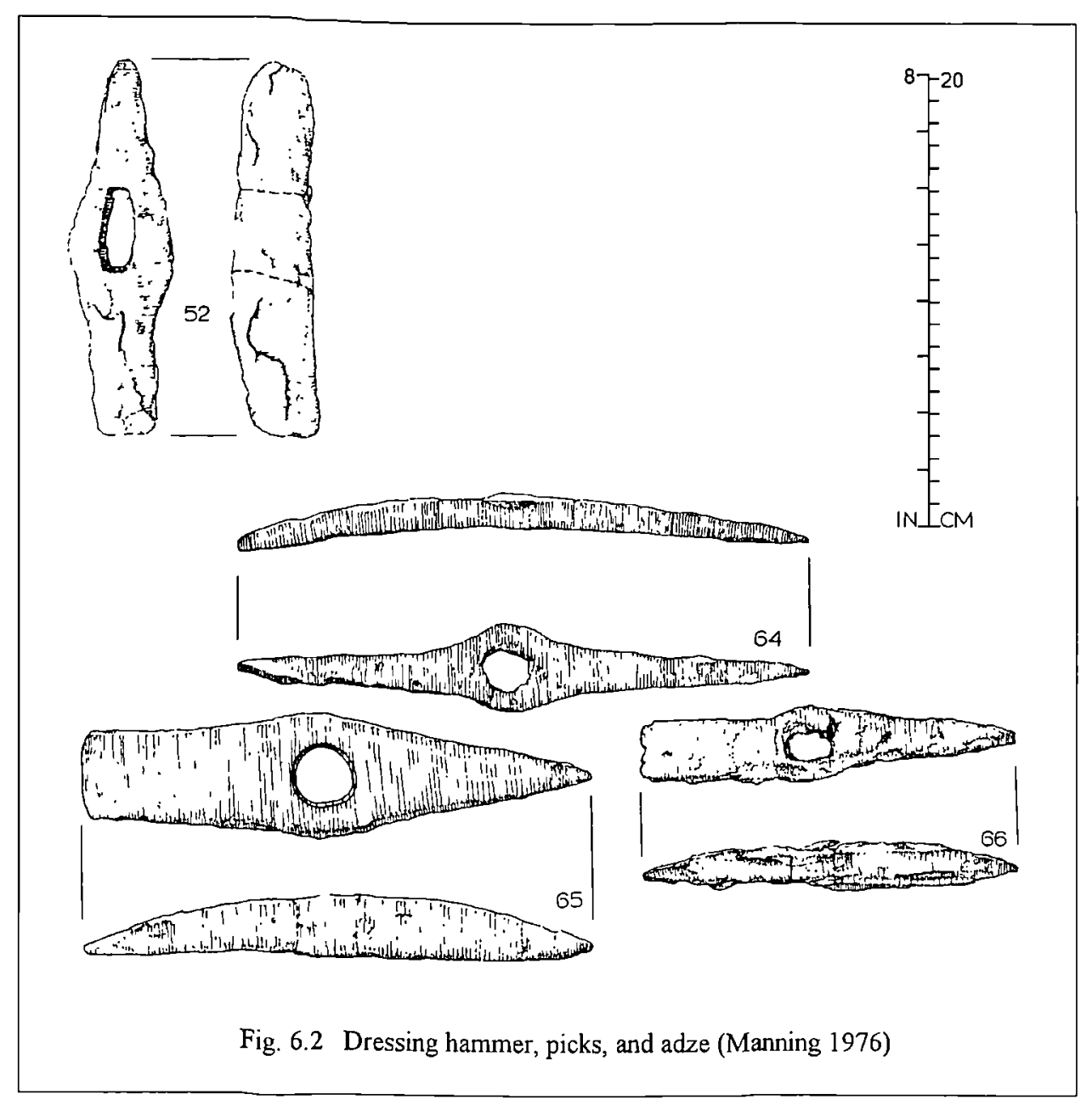

The pick from Newstead (fig. 6.3a) 11.5" (295mm) long is large enough for quarrying use but would be equally suitable for roughing-out large blocks in advance of more detailed working. The double-ended adze shown at figure 6.3(b) (it is described as a pick, ${ }^{433}$ but has blades rather than points) is almost certainly for detailed dressing. Figure 6.3c shows a tool very similar in function, if not in precise form, to a modern walling hammer, with a hammer at one end and a vertical blade at the other. A tool found at Housesteads, with axe and adze blades, is 6" (150mm) long and rather stocky in appearance, seems too small and heavy for a mattock and is very

${ }_{433}$ Curle (1911) plate LVIII. 
likely to be a mason's tool. ${ }^{434}$ As such it would be ideal for dressing walling stones; it is similar to the walling hammer in the author's tool kit (fig. 6.1g).

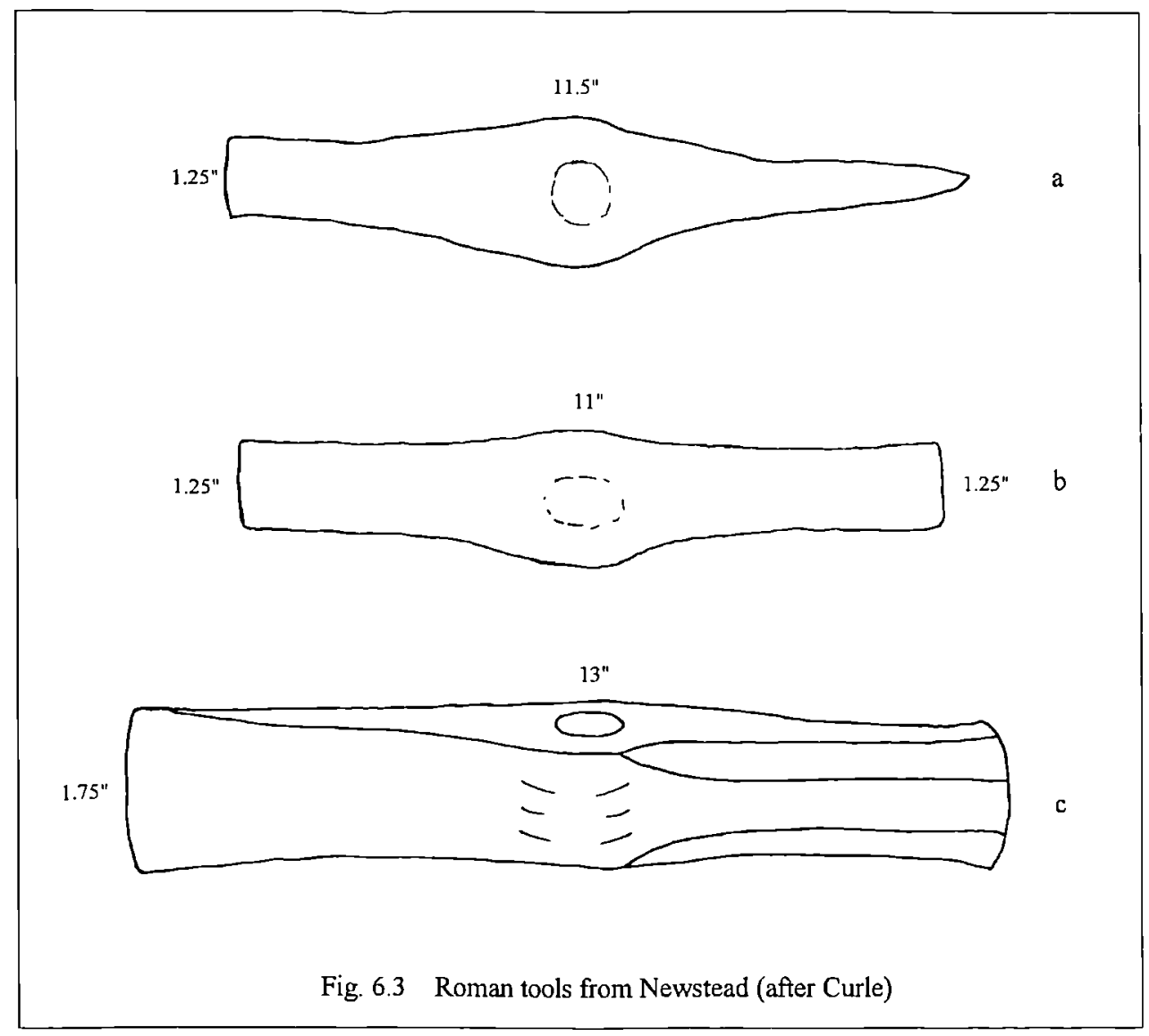

A modern tool used in France, the têtu, while similar in form to the scappling hammer, is distinctly smaller and somewhat resembles the tool shown in fig. 6.3a, from Newstead. It is accepted by Blagg as employed in dressing towards a finished form rather than roughing-out in the quarry. ${ }^{435}$

Axes for working stone do not need to be heavy or thick-bladed. Blake (1999) illustrates an axe/adze from Vindolanda (see fig. 6.4) which is only 4 " $(100 \mathrm{~mm})$ long

\footnotetext{
434 Manning (1976) 77 and fig. 18 (no. 78). It is listed there as a mattock but with the proviso that it may be a mason's tool.
}

435 Blagg (1976). 
and clearly appropriate for delicate work. ${ }^{436}$ As an example of how little tools have changed in the last 2,000 years, Blagg illustrates an axe which is almost identical to one in the author's tool kit (see figs. 6.5e and 6.1f).

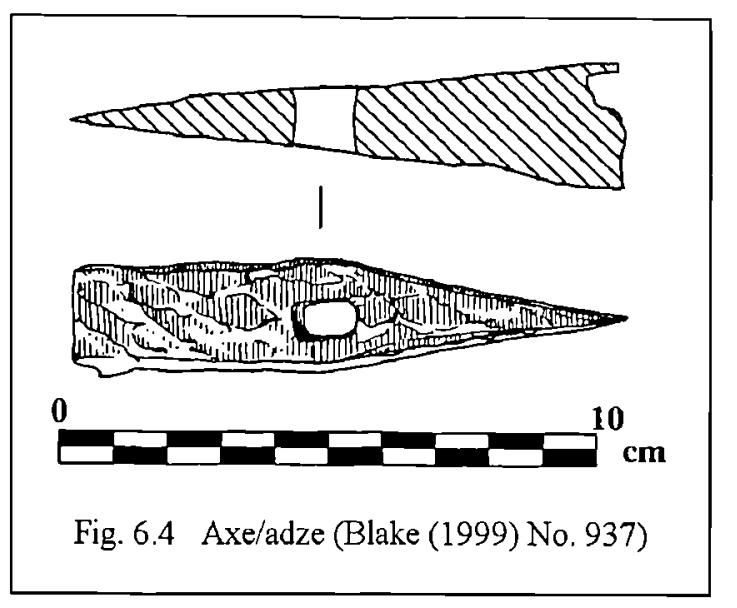

The axe and its variants are still in occasional use in Britain today, and are widely used in France. ${ }^{437}$ They are quite capable of producing a fine finish to ashlar; the author, while not accustomed to working with an axe, has used one experimentally and produced a finish indistinguishable from a boastered surface.

In the case of large blocks used in the milecastle and fort gate piers, there is obviously some overlap between rough squaring-up as part of quarrying work and rough dressing. But it is important to remember the difference between quarry dressing, which is roughly squaring up the blocks to see what they will make, and dressing or working stone which is an activity which can be carried out anywhere but is often carried out in a quarry for convenience. The point is that the pure stone mason and the pure quarryman use different tools and techniques and are aiming at quite different ends.

\footnotetext{
$436 \quad$ Blake (1999).

${ }^{437}$ The author is grateful to $\mathrm{M}^{\mathrm{r}}$. Albert Morel, tailleur de pierre, Marigny, Normandy, for discussion on and demonstrations with this tool.
} 


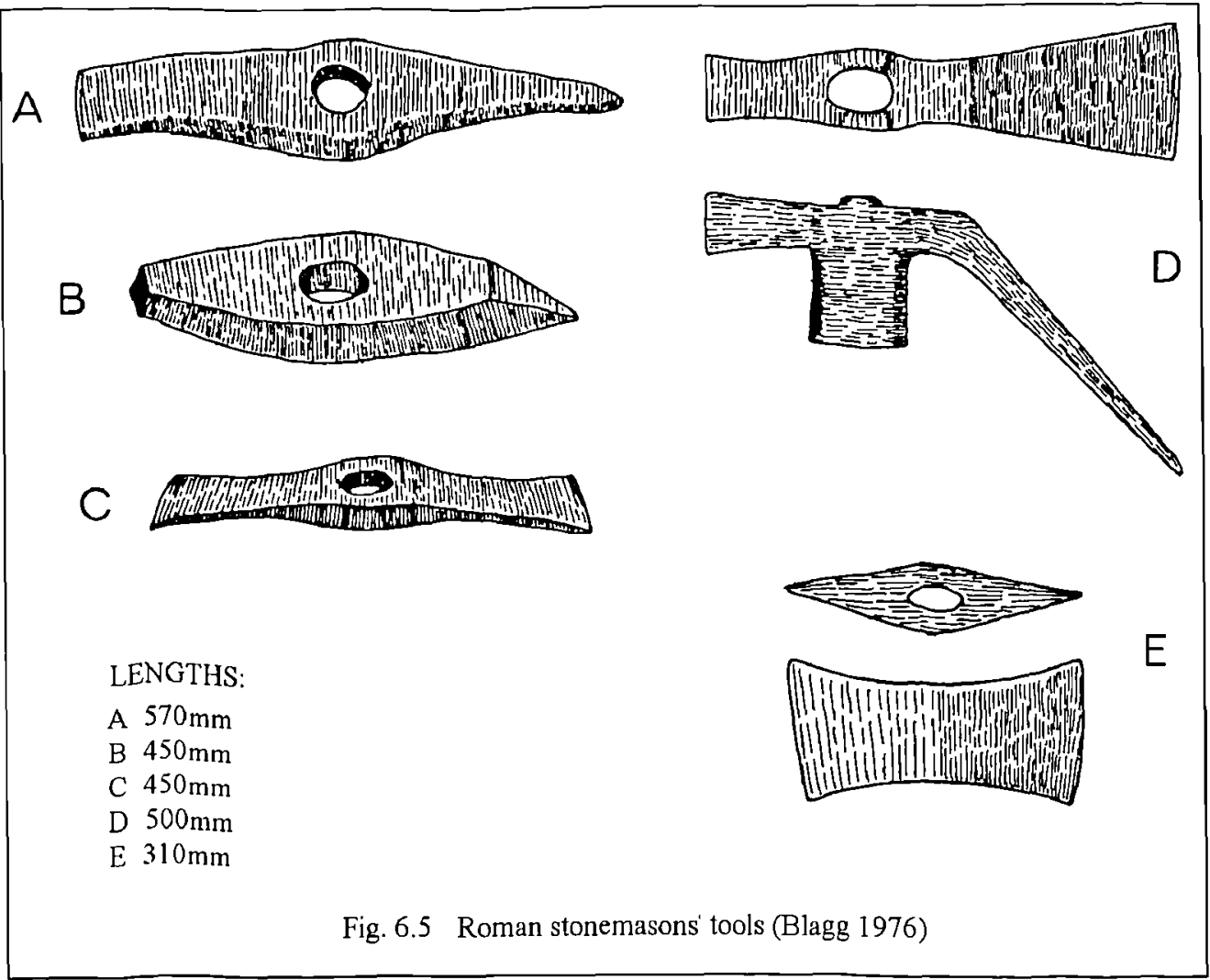

\subsubsection{Tools of indirect percussion}

These are tools which act on the stone when driven by a hammer or mallet.

The chisel is a bar of steel (or iron with a steel tip), typically about $3 / 4 "(18 \mathrm{~mm})$ in diameter and normally at least 6" $(150 \mathrm{~mm})$ long; the diameter may be as little as $3 / 8 "$ $(6 \mathrm{~mm})$ for fine work. The length rarely exceeds $9-10^{\prime \prime}(230-255 \mathrm{~mm})$ owing to the need to maintain control; the minimum length depends on there being sufficient on either side of the closed hand to give the hammer or mallet a fair target at one side and for the cutting edge to be visible at the other.

One end is drawn out in a tapered cross-section to form the blade, the width of which varies according to the work in hand. A very wide variety of work can be carried out with no more than a 1/2", $1^{\prime \prime}$ and $2^{\prime \prime}$ chisel $(12,25$, and $50 \mathrm{~mm})$; chisels of 
$2 "(50 \mathrm{~mm})$ and over are known as 'boasters'. ${ }^{438}$ When identifying artefacts, it should be remembered that while the body of the stone chisel may be significantly stouter than that of a wood chisel the blade is often more finely drawn out (see fig. 6.6). Most sedimentary stones are not particularly hard to work and do not necessarily call for the use of very stout chisels and heavy hammers; it is not uncommon for many limestones to be worked with wood chisels.

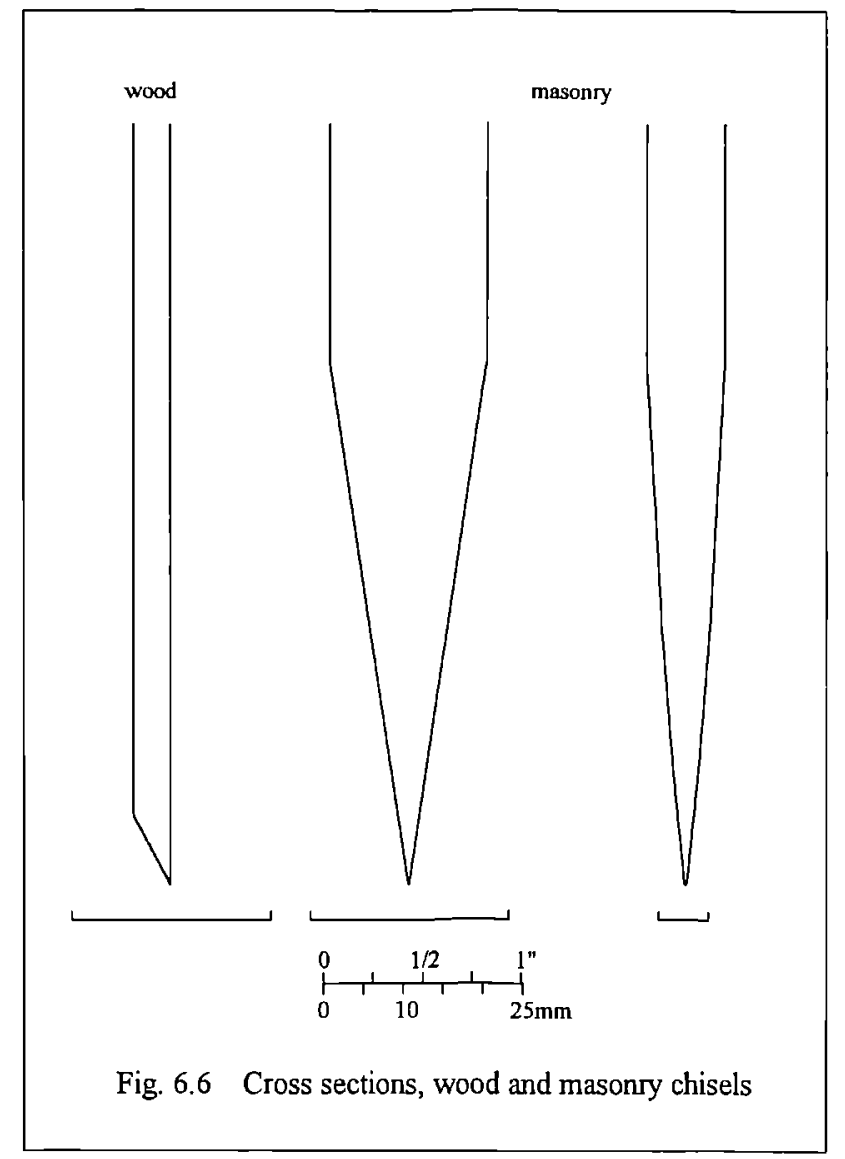

Chisels are today usually struck with an oval wooden mallet, although a hammer is more common when working marble and granite. Chisels used with a mallet are drawn out and upset at the upper end to form a broad, shallow dome, while those for

\footnotetext{
438 The word clearly derives from 'bolster', the bricklayers broad chisel, but the two tools are used quite differently.
} 
use with a hammer have a plain end (fig. 6.7, $a$ and b). Tools used with a hammer tend to spread at the head, as shown in fig. $6.7 \mathrm{c}, 6.11,6.12 \mathrm{a}$ and $\mathrm{c}$, and fig. 6.13 , but the effect is quite different from the deliberate mallet head.
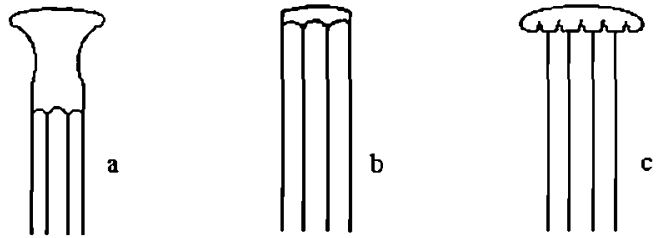

Fig. 6.7 Mallet- and harnmer-headed chisels

The use of a mallet in Roman times is uncertain, although highly likely; it was certainly used in Ancient Kingdom Egypt ${ }^{439}$ (fig. 6.8). What seems to be a very clear example of a mallet-headed chisel is shown in fig. 6.9, although it could equally well be a wood chisel (paring chisel) as catalogued. ${ }^{440}$ An even better example comes from Mumrills ${ }^{441}$ (plate 3 overleaf); the similarity to modern version (see plate 4 overleaf) is very marked and the four lines cut into the shaft are reminiscent of a more modern indication of ownership. However, the head is very similar to that shown in figure 6.9 and it does appear that not only did the Roman masons use a mallet, but that the mallet-headed chisel is a very ancient and enduring design.

Some variants on the ordinary chisel may be noted: the claw, the gouge, the bullnose, the pitching tool, and the nicker. The claw is in effect an ordinary chisel

\footnotetext{
$439 \quad$ Lloyd (1954) 481, esp. fig 314.

$440 \quad$ Manning (1984) 83 and fig. 37.3.

441 The writer is very grateful to Mr. Fraser Hunter, National Museum of Scotland, Edinburgh, who discussed the tool and kindly supplied the photograph. The chisel (museum ref. FRB 585) is not mentioned in the excavation report (Macdonald and Curle (1929)) and no other information has been found.
} 


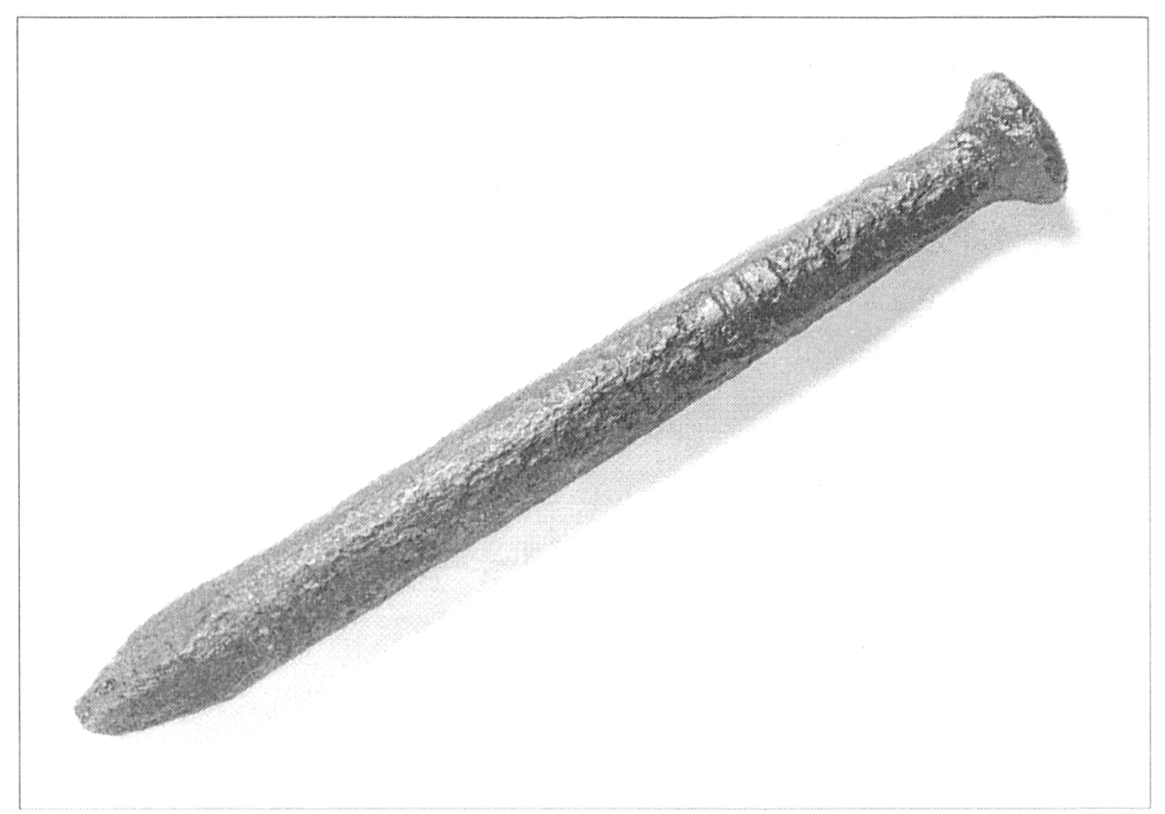

Plate 3 Mallet-headed ?Roman punch from Mumrills (photograph National Museums of Scotland)

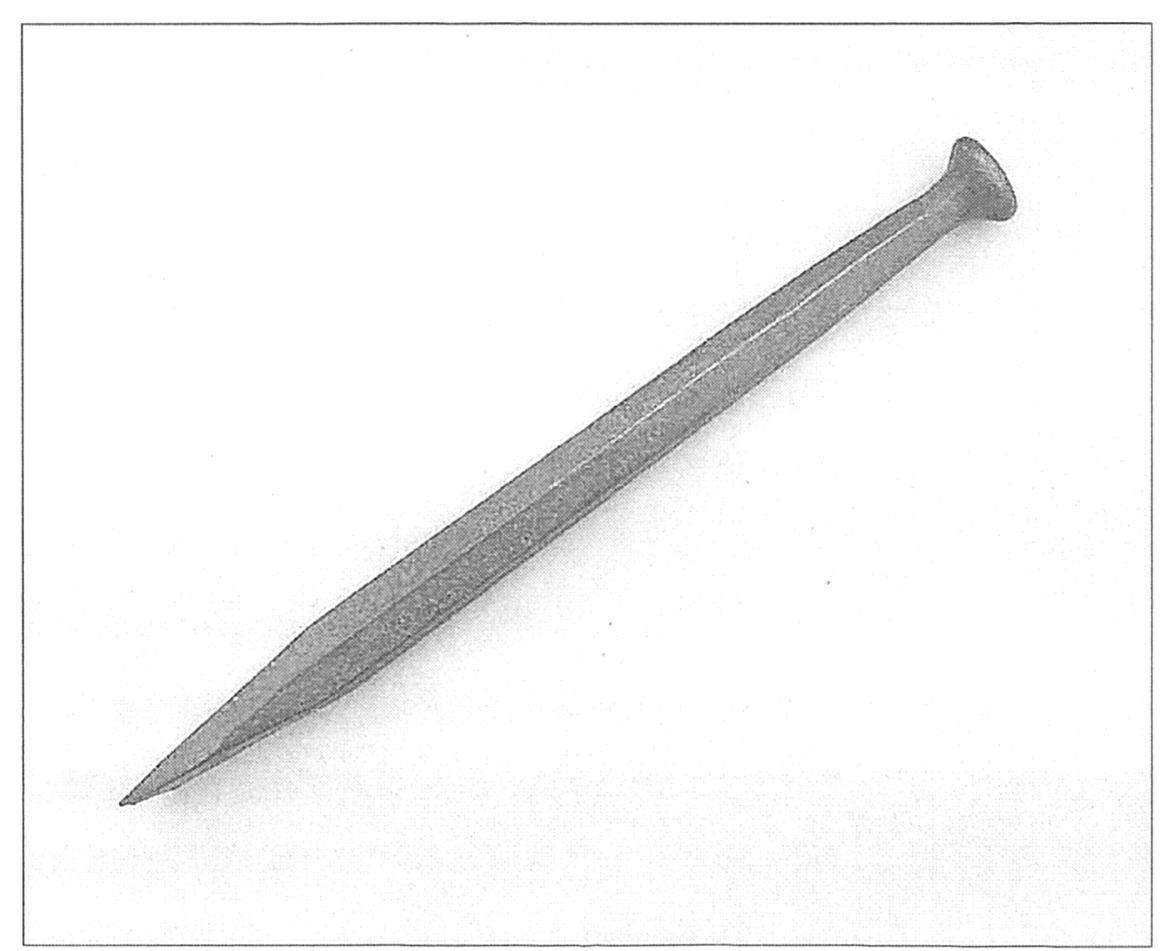

Plate 4 Modern mallet-headed chisel 
with nicks in the blade, and is used for roughing out the stone after the use of the punch, see below. The teeth vary widely in size and form, depending on the initial design and the degree of wear, and may be pointed or have short cutting edges (see fig. 6.10); they are best recorded as width of tooth and gap as well as overall width where this can be recovered. Thus, a claw recorded as $1+2 \mathrm{~mm}$ has teeth with cutting edges $1 \mathrm{~mm}$ wide and a $2 \mathrm{~mm}$ gap between the teeth.
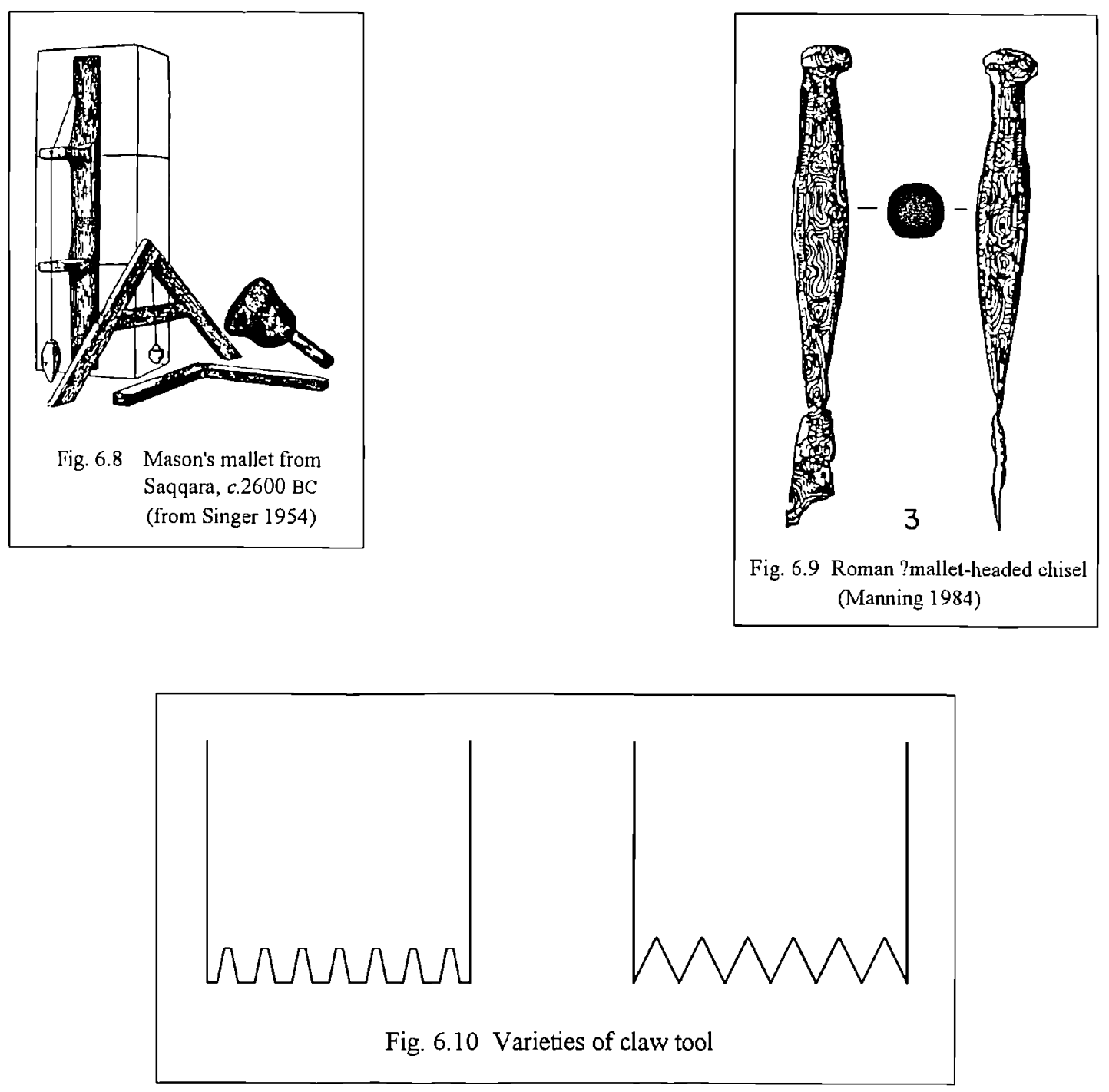


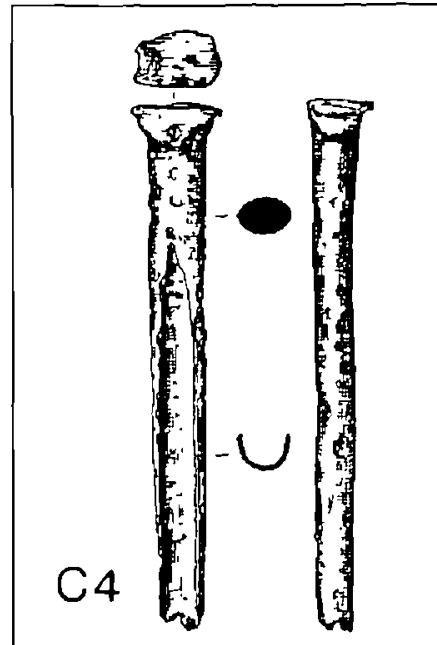

Fig. 6.11 Gouge (Manning 1976)

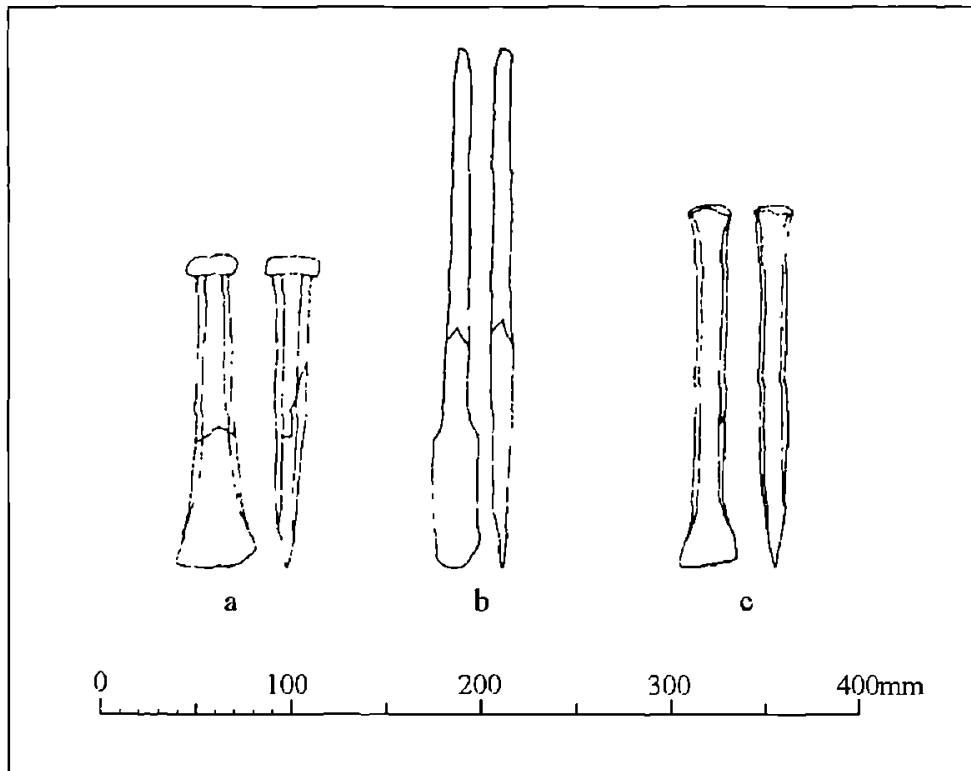

Fig. 6.12 Roman chisels from Kriemhildenstuhl (after Röder)

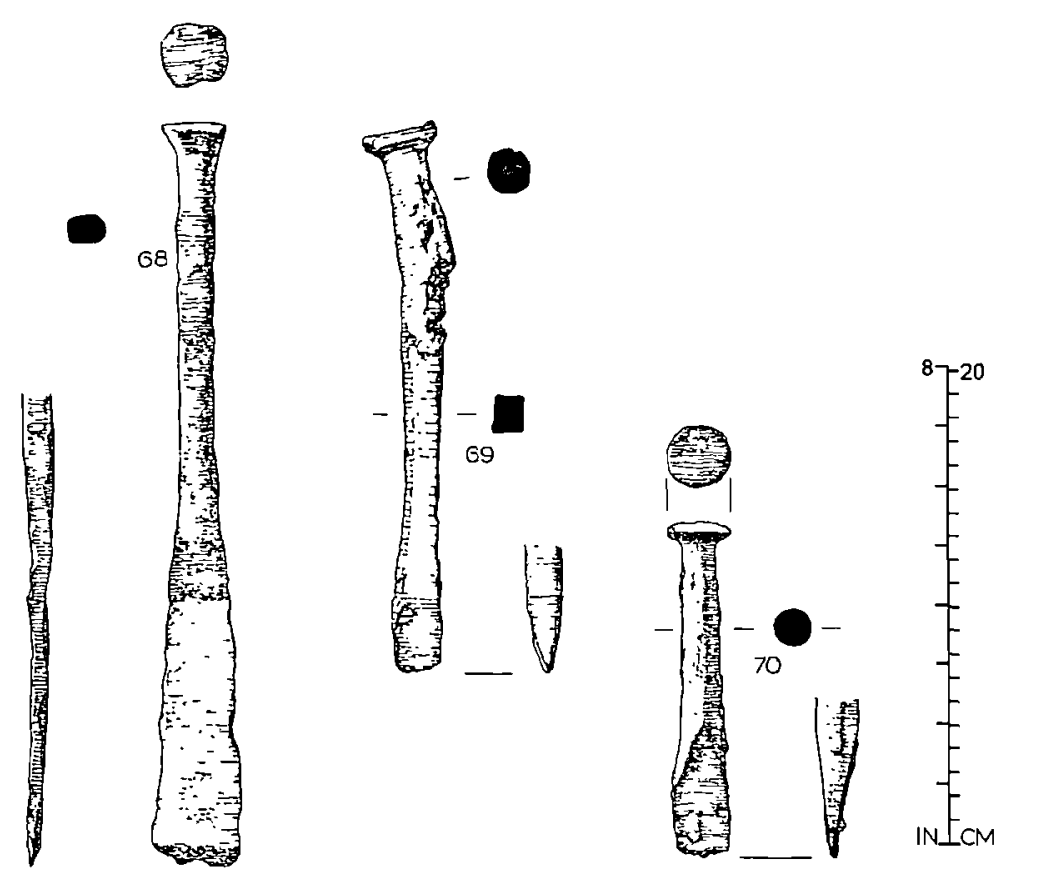

Fig. 6.13 Masonry chisels (Manning (1976) 
The gouge is curved in end view, exactly as a woodworking gouge, and was certainly known to the Romans (fig. 6.11) as well as to the modern mason (fig. 6.1n). The cutting edge of the bullnose is curved in elevation but flat in side elevation (fig. $6.1 \mathrm{k}$ ) and a possible Roman example is shown in fig. $6.12 \mathrm{~b}$. Both the gouge and the bullnose are used for working concave surfaces, with the bullnose preferred for circular-circular-sunk work.

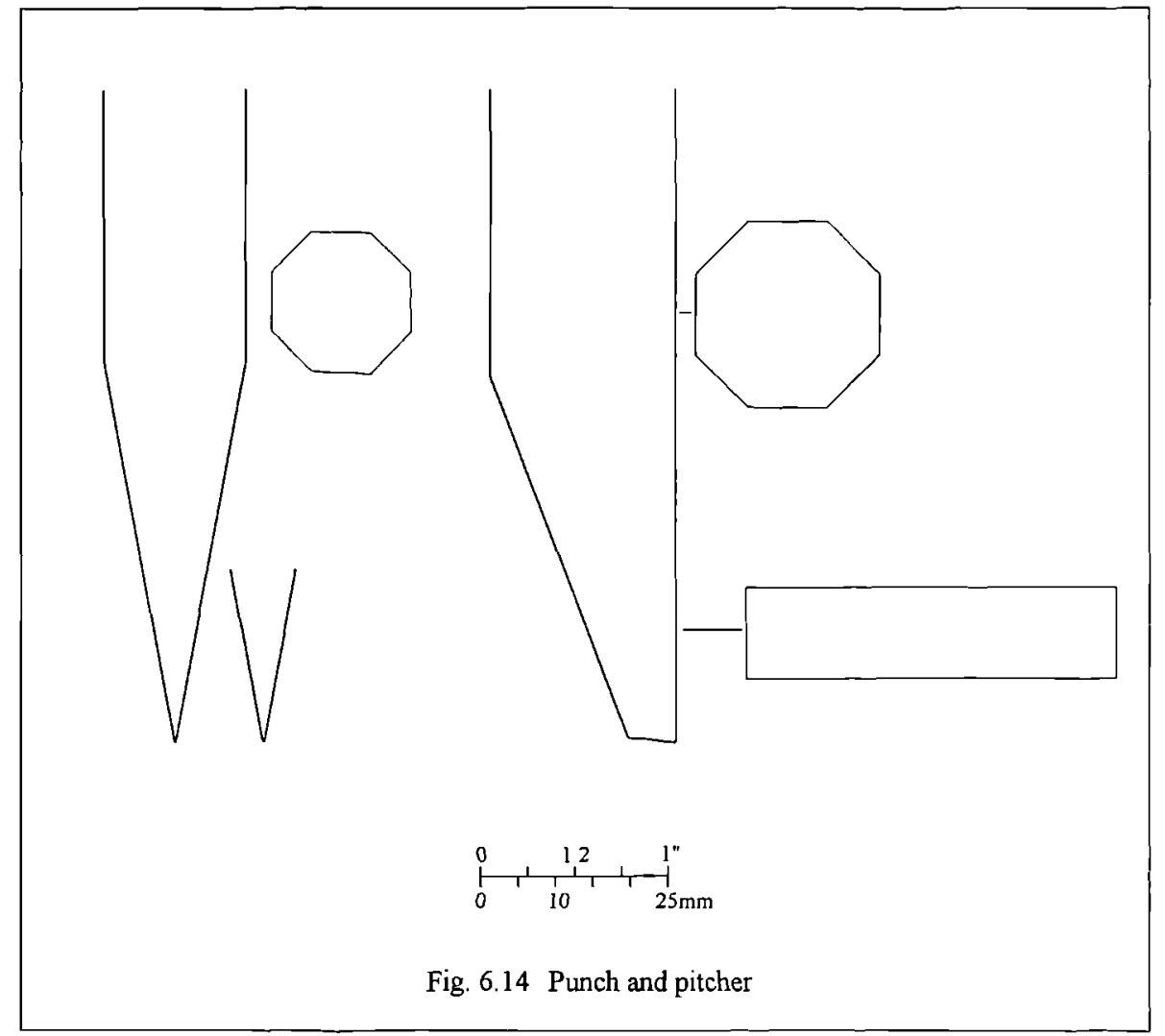

The punch is a chisel-like tool drawn out to either a point or a narrow cutting edge $(2-3 \mathrm{~mm})$ and struck with a hammer (see fig. 6.1d). It is made from similar stock to the chisel, with the thickness dependent on the heaviness of the work; $3 / 4$ " to $1 "$ is usually ample for most work. As with chisels, the punch may be much thinner for fine use by a carver, perhaps as little $3 / 8$ ". A point is a similar tool, but is either much lighter and finer (see fig. 6.1e), or struck with a mallet for use on softer stones. 
The extent to which the point of a punch is drawn out will tend to be greater for use on soft stone than for heavy work on hard stone; it may be much stubbier than shown in figure 6.14.

The pitcher, or pitching tool, shown in fig. 6.14, has not been found in ancient contexts but the use of this tool, or something similar, has provisionally been identified at Birdoswald. ${ }^{442}$ Its principal features are a thick shaft of at least $1 "$ ( $25 \mathrm{~mm})$ across, and a blade which is about $1 / 4^{\prime \prime}(5 \mathrm{~mm})$ thick at the cutting edge where there is a slight bevel. It is used for removing large pieces of stone with a singe blow of a mason's hammer, ideally applied at right angles to a reasonably flat face.

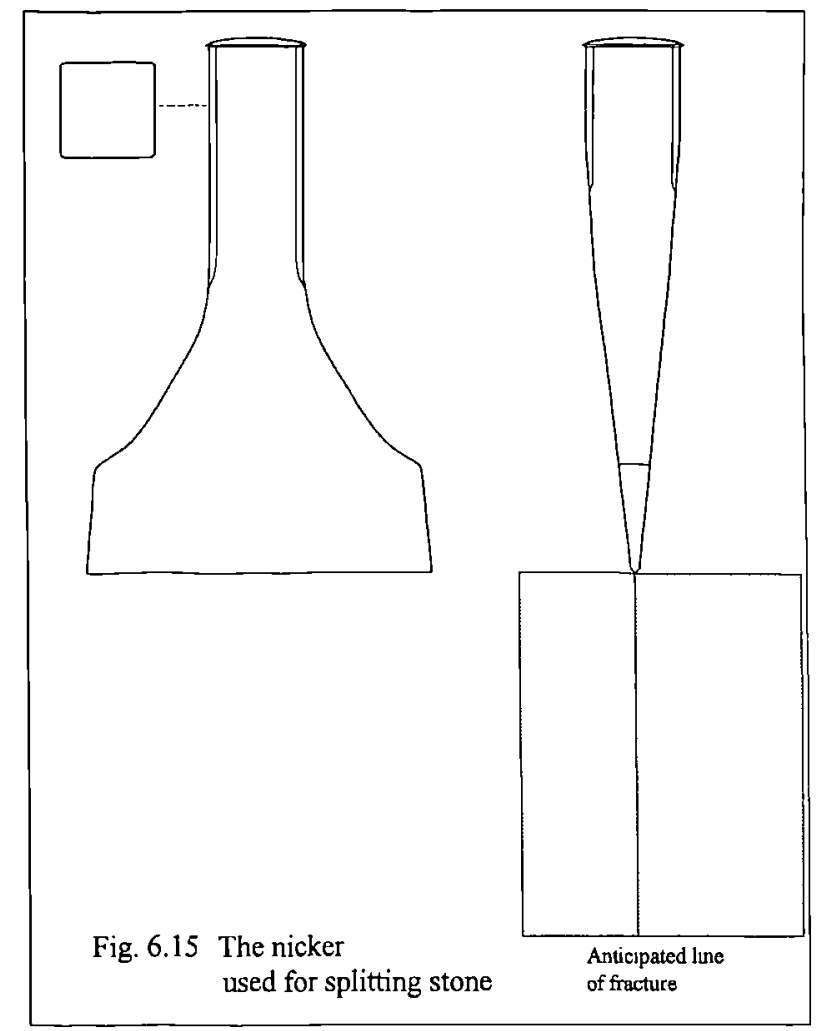

The nicker, fig. 6.15, somewhat resembles the bricklayers' bolster, but has a much short and thicker blade, the better to direct the hammer blow through the stone.

442 Hill (1992). 
Its use will enable stones to be split with remarkably clean faces; they may be slightly concave or convex, but in general will be roughly square to the beds and joints. This tool has not been identified in Roman contexts, but rusted remains would not look obviously different from a 3 " boaster.

The hammer used by the mason for driving tools of indirect percussion is ideally long-headed, usually around 6" (150mm), with a striking face not much more than 1 " square, and of a weight which varies from $2-61 \mathrm{~b}(0.9-2.7 \mathrm{~kg})$ according to the preference of the mason and the nature of the stone.

\subsection{Sharpening tools $\mathrm{s}^{443}$}

This section discusses the simple, practical methods used by stone masons to keep their edged tools in good condition; it outlines an activity which the Roman masons and quarrymen will have undertaken as a normal part of the work. The making of new tools, or other major work to tools, is outside the scope of this work, and was probably undertaken by skilled blacksmiths.

The tools used in Roman quarrying and working stone had steel cutting edges, provided by either welding a steel tip onto an iron shaft, or by carburising the whole chisel blank. ${ }^{444}$ Given the abrasive nature of sandstone they will have required frequent re-sharpening, which would have taken place close to the area of operation.

Sharpening of tools, especially chisels, is not difficult. A dull edge can be quickly refreshed by rubbing on a piece of well-wetted, preferably fine-grained, sandstone; a few strokes on each side of the blade, sweeping it in a figure-of-eight movement with the blade parallel to the direction of movement is sufficient to

\footnotetext{
443 The following section is based on Hill and David (1995)

$444 \quad$ Sim and Ridge (2002); Pliny XXXIV. xli.
} 
restore the edge. This will tend to give a less acute angle as the tip of the blade is worn back (see fig. 6.16).

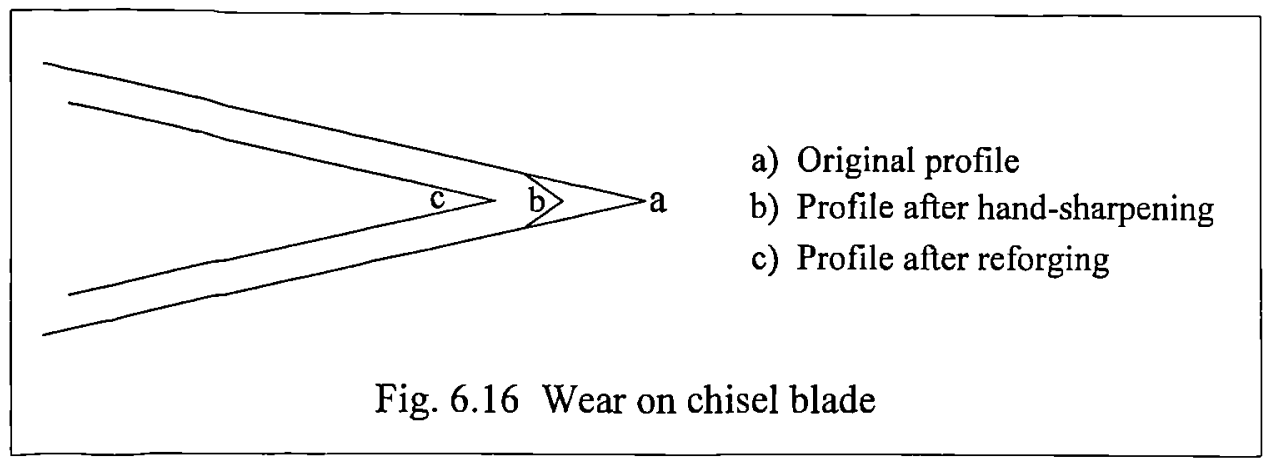

\subsubsection{Fire-sharpening and reforging of chisels}

A small fire, a bellows, an anvil, and a small quenching tank or bucket are all that is necessary for the fire-sharpening of tools. The method has been described elsewhere ${ }^{445}$ and will not be repeated here, but the experience of the author and his colleagues as working stone masons suggests that no great technical levels of skill are required. Obviously experience is vital, and some men would have to be detailed for this work; blacksmiths would be needed for the making of most new tools as replacements for those worn down too far for reuse. The significant point is that firesharpening of simple tools does not require a skilled blacksmith.

In the quarry at Mons Claudianus, between Safaga and Qena to the east of the Nile, the excavation of huts yielded quantities of charcoal used as a fuel for iron working. Also found was a tank which the excavators believed was probably used for tempering tools. ${ }^{446}$ This tank, perhaps more properly described as a basin, is about $300 \mathrm{~mm}$ long and $70 \mathrm{~mm}$ deep (12" x 3"); there are holes in the broad rim.

\footnotetext{
$445 \quad$ Hill and David (1995).

446 Peacock and Maxfield (1997), 236-7 and fig. 6.85.
} 
The holes in the tank from Mons Claudianus may have served for quenching the tips of chisels and punches, although they would hardly have held enough water to maintain the quenching effect; they appear to be no more than $25 \mathrm{~mm}$ in diameter. The excavators suggest that wear on the edge of the tank may indicate its use as an anvil; it is broad enough, at about $100 \mathrm{~mm}$, for this to be possible, assuming that the granodiorite was robust enough to take this use, but the proximity to cold water, which would inevitably splash out, would make this an uncertain practice.

Fant illustrates a 'tempering basin' from the quarry at Bacakale, Turkey. ${ }^{447}$

Peacock and Maxfield see the limited but intense activity in the area of the forges at Mons Claudianus ${ }^{448}$ as probably reflecting the simple process of fire-sharpening rather than making new tools. They also note the possible loss of carbon at the tip as the result of such work. Carbon can be re-introduced as a thin layer by heating on a bed of charcoal. ${ }^{449}$

\subsection{Working stone}

The detailed dressing, or working, of stone for the Wall is one of the more complex aspects of the building. There are two different types of skill involved, each requiring a different approach and learning time, exemplified by the different types of masonry visible on the Wall.

\footnotetext{
447 Fant (1989), 35 and fig 6.

448 Peacock and Maxfield (1997) 250.

449

ibid.
} 


\subsubsection{Squared rubble}

Production of squared rubble facing stones will have been something which most legionaries experienced as a normal part of their service. ${ }^{450}$ It is not a difficult skill to acquire, although different degrees of achievement are sometimes apparent. The surviving quoin of the pre-Wall signal tower at Pike Hill is of considerably better quality masonry than exhibited by the nearby $\mathrm{T} 52 \mathrm{a},{ }^{451}$ although whether this is because the former was built at a more leisurely pace than the latter, or whether it was built by a specialist group, is not easy to determine. The legions carried skilled stonemasons on their books, ${ }^{452}$ and these in more normal times would either have carried out the more accurate working themselves or would have been able to exercise greater supervision.

Examination of facing stones from the Wall shows that in most cases the beds and joints are either natural or result from splitting; any working is usually confined to a small amount of work with a punch to remove awkward projections. The dressing of a walling stone would all be done by eye, the judgement of the legionary being a sufficient standard to produce stones of approximately the right dimensions.

The faces are sometimes split but often roughly worked to give an unevenly rounded face. The tools used were principally the axe, the punch, and the (walling) hammer, and the stone was largely cut by their direct action. The use and effect of these tools has been fully described elsewhere ${ }^{453}$ and will not be repeated here, but a few general points may be made.

\footnotetext{
$450 \quad$ Direct references to training in building work are mostly concerned with camps (e.g. Vegetius, 1.21), and Hadrian's address at Lambaesis seems to refer to dry stone walling.

$451 \quad$ Hill (1997b) 29.

452 Digest 50, 6, 7, quoting Tarruntenus Paternus (late second century).

453 Hill (1981); see also Hill and David (1995).
} 
When reducing the surface with a punch used in the normal way, a series of roughly parallel furrows will be produced. Crossing these at right angles is a quick way of reducing peaks, but these will tend to disappear without leaving a second series of furrows; the diamond broaching ${ }^{454}$ seen on the Wall is a deliberate finish. The intermittent occurrence of these stones is most likely to result from the whim of a legionary or his centurion rather than for consistent decorative effect. It was not done to form a key for rendering, as has been suggested to the author in conversation; this would much more efficiently be achieved by a few random blows from a pick or punch aimed almost perpendicular to the surface.

The product of the work so far described is a stone which is usually approximately rectangular on elevation, with a flattish or roughly rounded face, and with beds and joints which are sufficient to allow the stone to fit with its neighbours given the use of a reasonable amount of mortar. The degree of exactitude required is not great. It is best if the beds are very roughly flat but with tapered stones it is quicker to take off too much rather than too little from the joints. Given a few tools of the right quality, a little practice, and some muscle development, squared rubble may be readily produced by almost anyone, with little training. 455

Robert Rawlinson, quoted by Bruce, ${ }^{456}$ dealt with railway masonry by using uneducated labourers under educated foremen. This course was followed because of 'difficulty in dealing with the regularly educated mason' and the passage implies that

\footnotetext{
454 This is the pattern of two sets of heavily incised grooves crossing diagonally on the face of the stone. A broach is a northern or Scottish term for a punch, and broaching is a similarly derived term for work done with punch or pick.

45s Blagg (1976) 153, who confirms from his own experience that '...one can make an adequate job of dressing rubble after only a few hours' training.'

456 Bruce (1851) 79.
} 
this was because of the low degree of skill required in work 'not unlike the Roman Wall in character.'

The author has trained unskilled labour in just this way. The rebuilding of a barrack block on the fort site of South Shields was carried out by excavation staff with no experience of working stone. After a large slab had been split into lengths by the author, using an electric drill and plug and feathers, and a demonstration of the methods given, the staff were immediately producing walling stones approximately $9 " \times 12 \times 12 "(230 \times 305 \times 305 \mathrm{~mm})$ in between four and six minutes each. The work was carried out using a $2 \frac{1}{2} \mathrm{lb}(1.13 \mathrm{~kg})$ hammer and a nicker to split the lengths into suitable sizes, and the individual stones tidied up using a pitching tool and a punch or axe. Very little of the latter work was required except on those stones which had not split cleanly. The slabs available for this work were of convenient size, and the operation on the single day the writer was present perhaps went more smoothly than the norm, but the experience does point up the relatively simple nature of the work.

\subsubsection{Gate piers and voussoirs}

The working of the gate pier stones is a quite different matter from squared rubble. The piers are there to support and transmit to the ground the mass of the arch and the superimposed walling of the towers. Ideally they will be stones with large, flat beds and thus the crushing strength of the stone is of greater importance than the strength of any mortar. ${ }^{457}$ For practical purposes, this is what is actually achieved in every known case; the lowest achievement is at MC48, where some of the beds are distinctly uneven. ${ }^{458}$

\footnotetext{
457 The crushing strength of the stone is far in excess of that required. Black Pasture has a strength of $10,512 \mathrm{lbf} / \mathrm{in}^{2}\left(72.5 \mathrm{MN} / \mathrm{m}^{2}\right.$.

458 See: Hill (1989), MC37; Hill (1992), Birdoswald fort; Hill (1995), Housesteads fort; Hill
} 
The voussoirs have similar characteristics, as can still be seen at MC37 and Birdoswald fort. Both voussoirs and pier stones called for dimension stone.

The quarried blocks would, or course, be larger than the finished size; the amount of excess stone would depend on the skill of the quarrymen and the nature of the quarry, but is unlikely to be less than $2-3 "(50-75 \mathrm{~mm})$ all round. The first operation would be to work one bed straight in all directions to an acceptable degree; this seems to have been around $1 / 8 "(3 \mathrm{~mm})$. The tools used were principally the punch or pick, first in furrows and then in smaller and smaller pecks; reasonably enough, the occurrence of 'holes' up to $5-10 \mathrm{~mm}$ deep was not seen as a problem. A blade, which might be an axe, an adze, or a broad chisel might be used to clean the edges and, occasionally, areas in the centre of the bed; at both Housesteads and Chesters the marks of blades of $1 \frac{112-2 "}{}(40-50 \mathrm{~mm})$ have been identified. ${ }^{459}$

From this bed, one of the faces would be worked, beginning with a marginal draft down each edge and squared off from the finished surface. Squaring from these drafts in turn would make the bottom bed parallel to the top at whatever bed height the stone would make - or to a predetermined height if needed. The drafts referred to were not always fully worked, and squaring from the face to the second bed would have been impossible. It is possible that the height was measured; this is not an accurate way to work, but it would be better than trying to square from half-worked drafts; it is noticeable that not all pier stones have their top and bottom beds exactly parallel.

Sometimes drafts were worked along the top and bottom of the faces, but sometimes the arris was marked by pitching off along a line to indicate the wall line.

(1997a) Chesters fort; Hill (2001a), MC42; Hill (2001c), MC48; Hill (2001e), MC10.

459 The identification of the tools used comes from the author's surveys. 
The faces were sometimes worked more or less flat, and sometimes left as rock faces. MC37 has mostly shallow rock faces dressed with a punch or pick in deliberate furrows, while stone NGNE1/1 of MC10 was worked with a good deal of care to give a reasonably straight face (author's surveys). The standards of work were remarkably varied, from good to very poor; this is discussed further in 12.6.

When completed, a lewis hole was often cut in the centre of the top bed. At Chesters, the extreme shallowness of some lewis holes suggests that at least some of the beds were worked down in situ, after fixing.

The techniques of working ashlar and mouldings have been discussed elsewhere by the writer. ${ }^{460}$ In the absence of Hadrianic ashlar and mouldings (apart from Benwell Vallum crossing) they are not included here.

\subsubsection{Inscriptions}

One aspect of working stone which was occasionally required was the cutting of the dedicatory inscription - less specialised in the case of the milecastles than the forts. The cutting of the letters is not strictly relevant to the building of the Wall, but some general points may usefully be made.

It is possible to attribute letter-cutting - or at least the ordinatio - to a particular man, as has been discussed elsewhere, ${ }^{461}$ although this is probably not possible in the case of the centurial stones owing to their generally crude nature. A study of Wall inscriptions, from the viewpoint of the techniques used rather than their content, would form a fruitful field of study in the future.

\footnotetext{
460 Hill (1981); Hill and David (1995).

461 Hill (1991).
} 
The cutting of the centurial stones on the curtain wall seems generally to have been left to whoever was nearest to the centurion when the stone was called for; the almost uniformly poor quality of these records suggests that the occasional ansate panel was the whim of a bored legionary or his enthusiastic centurion rather than a serious attempt to produce work of any quality. ${ }^{462}$ They were passing records rather than permanent statements for display. The tool commonly used for their cutting is the punch.

Large inscriptions are invariably on slabs which are thin in proportion to their visible area; they are typically $4-6 "(100-150 \mathrm{~mm})$ thick. The reason for this is to save weight. RIB 1738 from Greatchesters is $44 \times 32 \times 4.3^{\prime \prime}(1120 \times 810 \times 110 \mathrm{~mm})$ and weighs in the order of $508 \mathrm{lbs}(230 \mathrm{~kg}$ ), and could just about have been set in place by four men. The method would be to lift it face down, with a man on each corner, rest the lower edge on the wall and push it upright. If it had been 12" $(305 \mathrm{~mm})$ thick, which would have made it more stable when in position, the weight would have been about $1420 \mathrm{lbs}(643 \mathrm{~kg})$, requiring lifting tackle to set it in position.

Building-in the relatively thin dedication slabs has to be done with some care, to ensure that the wall is supported. Ideally, selected core stones would be built up behind the slab, both to give proper support to the wall above and the take the pressure of the rest of the core; while the walling stones are heavy enough to resist the core, inscriptions are relatively light in relation to their surface area. If the stones above the slab were fixed after it was in place, they would tend to hold the slab in position, but without some form of restraint there would be a tendency for the slab to fall if there were any movement of the wall. Ideally, a cramp would also be used to tie the slab back to the wall. A lewis hole in the upper edge of RIB 1137 (Corbridge

$462 \quad$ e.g. $R I B 1387,1408$. 
Museum) has an unusual, vertical groove cut into both the long sides; the purpose is unknown and it is not impossible that it was an adaptation of the lewis hole to take a cramp. Equally, a cramp may hook over the front of the slab, as shown in the sketch, fig. 6.17 .

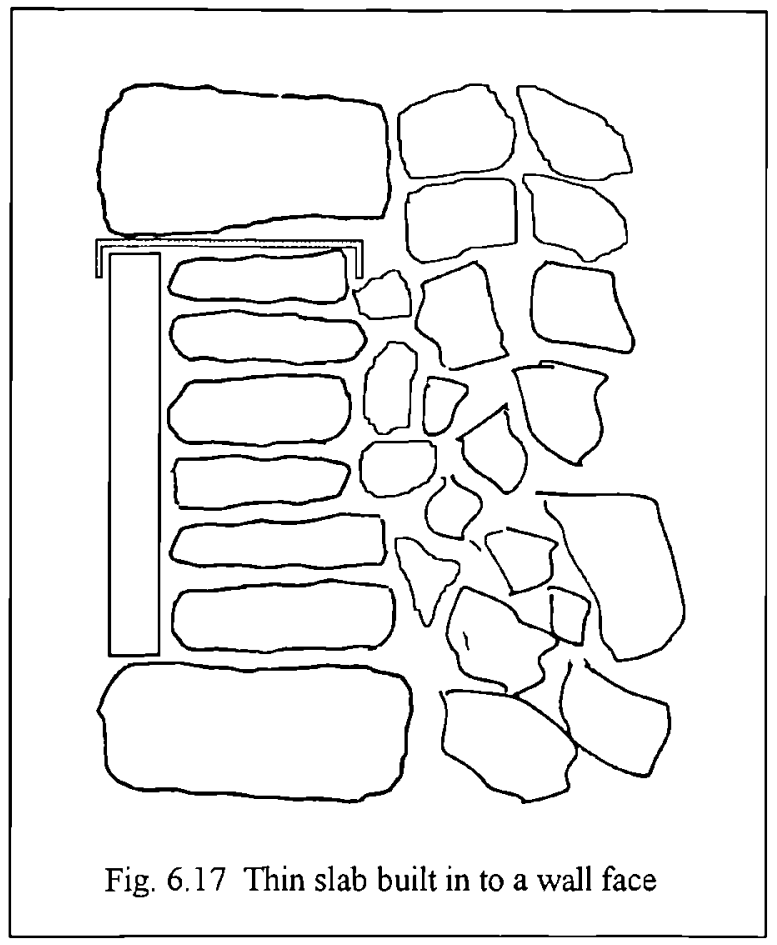

The thickness of inscription slabs in relation to stone and turf walls is further discussed below (section 12.2).

\subsection{Setting-out and templets}

In the sense used in this section, this is the process of making full-size drawings of masonry details; 'details' means anything other than plain walling. The cross section of mouldings is drawn out, as well as elevations of features which are too large to be contained in a single stone. A monolithic arched window head could have been scribed directly onto the stone, a milecastle arch could not. In the mediaeval period 
there is ample evidence for setting-out; it was usually done on a prepared plaster floor. ${ }^{463}$

\subsubsection{Setting-out}

There is limited but good evidence for setting-out drawings in the Roman period. Haselberger has shown that the portico of the Pantheon was set-out on the paving alongside the mausoleum of Augustus, ${ }^{464}$ and that four centuries earlier the Greek builders of the temple of Apollo used the floor and lower walls of the temple for setting-out the upper parts. ${ }^{465}$ However, Haselberger makes a major error when he assumes that worked stones were checked directly against the drawings. ${ }^{466}$ Not only is the picture of masons attempting to move their large stones onto the drawing an impractical one, but in the case of the temple of Apollo some of the drawings were on vertical surfaces making such a practice impossible. At this temple most features were set-out as half-elevations, as with mediaeval and modern practice.

The purpose of these often very complex drawings was to make the templets from which the mason worked and to establish stone sizes; there is in fact no other way in which they can be used. The drawing of the pediment of the Pantheon included the ashlar beneath the cornice, the only purpose of which must have been to give the sizes for the ashlar.

No such drawings have been found on the Wall, although elevations of the gate arches will have been essential to give the face moulds for the voussoirs. These are probably the only elements which needed any serious setting-out; the roughly

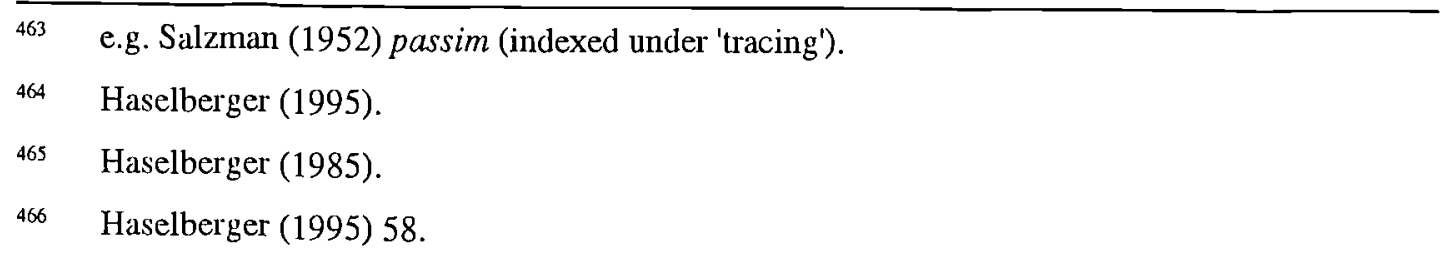


chamfered string course was a simple affair which will have been worked to given dimensions. Elements of the internal buildings of forts may have needed more in the way of setting-out.

The gate piers would not have needed templets as the stones have a simple plan. All that would be needed was small sketches on writing tablets, with dimensions, to give the plan and the elevation; the latter would be needed to avoid straight joints. It would not even be necessary to determine the length of the stones in elevation in advance. All the supervising officer had to do was to note the length of the stone used for the first course and make sure that the next course was longer or shorter. These sketches need not have been to scale, although the Greeks, and presumably the Romans, did understand the use of scale drawings. ${ }^{467}$ An example of what was needed is shown in fig. 6.18. The upper sketch gives the dimensions of the plan, and the lower two are completed as stones are worked.

Working in this way would accommodate changes in bed heights in the quarry without having to spend time and trouble to find beds which would make in accord with a predetermined list of dimensions. But however the work was organised it does not seem to have been universally successful. The straight joints on the north west pier of the south gate of MC42, fig. 6.19) and the ragged outer ends of the piers, can hardly have been planned.

467 Part of the setting-out for the temple of Apollo at Didyma was at one sixteenth scale (Haselberger (1995), 121). 

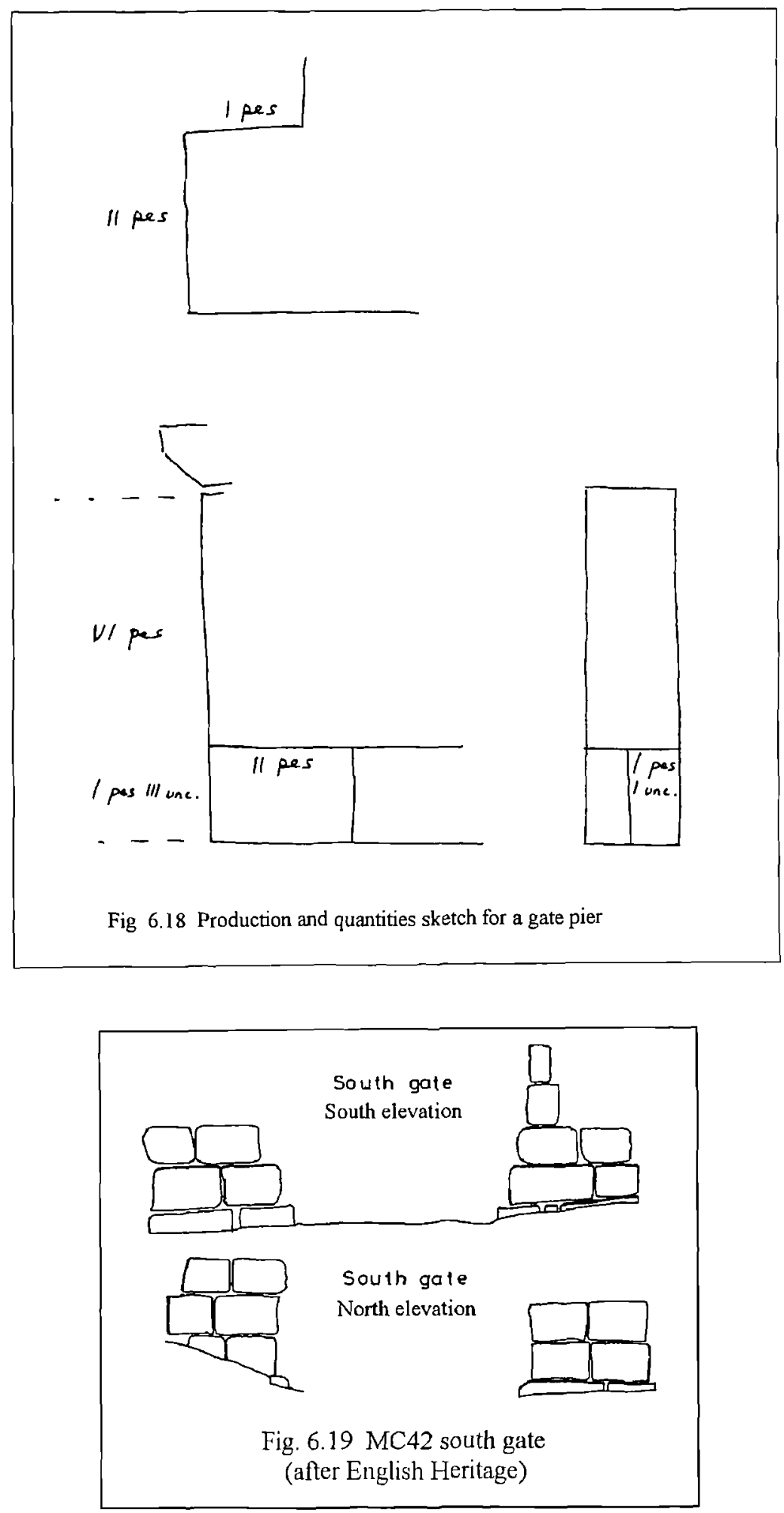


\subsubsection{Templets ${ }^{468}$}

The use of templets, to transfer the form of moulding sections and face and bed moulds from full-size setting-out drawings to the stone, is well-documented from mediaeval times onwards. ${ }^{469}$ The author has so far been unable to find any evidence for their use in Roman times; the fact that in the Wall area it is very rare for the two ends of a moulding to have the same profile indicates that their use was not the norm. A detailed study of Roman setting-out and the use of templets would be a useful separate area of research.

\subsection{Orientation of the stone}

In an ideal world the bedding plane of the stone should be horizontal, as it lay in the quarry (figure 6.20). The exception to this is voussoirs, where the bedding planes should lie on the radius of curvature at right angles to the line of thrust (figure 6.21). In practice is is not always possible to obtain a stone of sufficient bed height for something like an inscription or a column shaft, and the stone is often worked with the beds lying in a vertical plane parallel to the wall face (face bedded). The dedicatory inscription from Haltonchesters $(R I B 1427)$ is a case in point, where the face bedding of the stone is shown by the way in which the surface has lifted.

\footnotetext{
${ }_{468}$ Note, this is the correct form of the word often written as template; see $O E D$ etc.

469 Salzman (1952).
} 


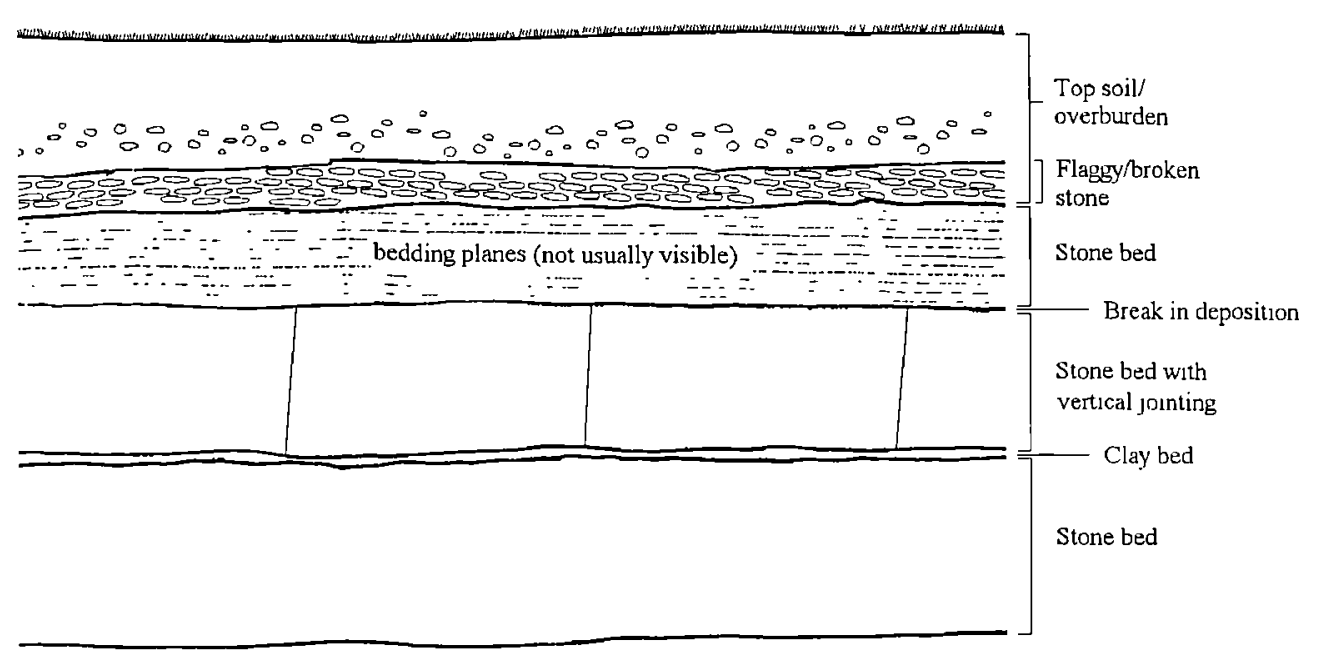

Fig. 6.20 Cross section of quarry showing beds and bedding planes

It must be emphasised that the trade standard is for measurements always to be given in the order length of face, depth in to the wall, and bed height; the bed height is not necessarily the height of the stone as built. In order to avoid confusion this standard should always be adhered to; an inscription on its natural bed would thus be given as, for example, $3^{\prime} \times 4^{\prime \prime} \times 2^{\prime}(915 \times 100 \times 610 \mathrm{~mm})$, whereas a similar but facebedded panel would be given as $3^{\prime} \times 2^{\prime} \times 4^{\prime \prime}(915 \times 610 \times 100 \mathrm{~mm})$. The former immediately tells the reader that the builders had access to a quarry with beds of at least $2^{\prime}(600 \mathrm{~mm})$, and that they had the skill and care to exploit it correctly. The latter indicates that the quarry yielded only low bed heights, or that the builders were content to use whatever was conveniently available. Where only two dimensions are available, they should be in the same order and clearly specified. 


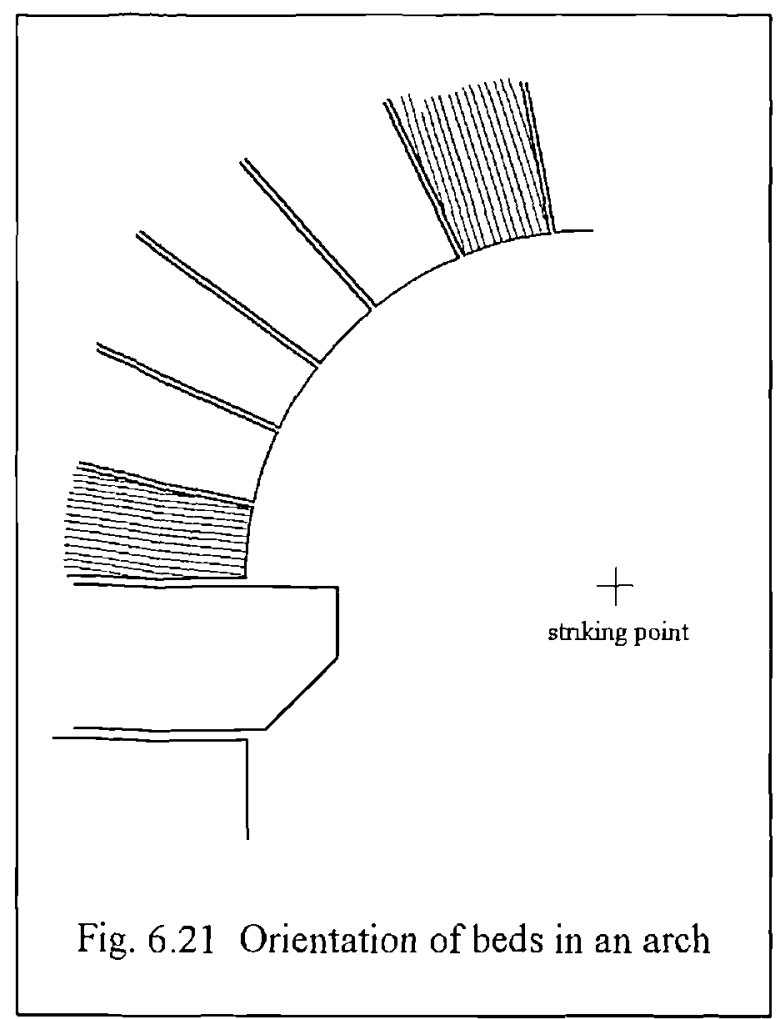

\subsection{Working stone from Roman quarries along the Wall}

Samples of stone from several quarries have been worked to assess their suitability and ease of working. In most cases the samples were relatively small pieces picked up from the ground; this is not always a fair test as the stone may become 'rotten' as a result of continuous wetting and drying. However, all the samples used seemed to be sound and may be taken as fair representation of the quarries. In one case, Black Pasture, freshly quarried stone was also used.

Working was carried out with modern masonry tools: 1" and 2" chisel, 1" and 2" claw, punch, and pitcher. Most of the work was with tungsten-tipped 1" chisel and claw, in order to avoid the need for fire-sharpening, but steel equivalents were also used. The use of tungsten tools makes no effective difference to the way the stone works. The tungsten claw had $2+2 \mathrm{~mm}$ teeth (see 6.1 .2 ), the $1 "$ and 2 " steel claws 
were pointed teeth at $2 \mathrm{~mm}$ centres. The chisels and the claw were used with a medium weight mallet, and the punch and pitcher with a 31b mason's hammer.

No aspects of the work were timed. The use of tungsten and modern steels made times to some extent irrelevant; the writer also suffers from wrist and elbow trouble which affects the time taken.

Each sample was worked with punch, claw, and chisel, and the way in which the stone worked was assessed by the writer using his experience as a trained stone mason; there is no way of making an objective judgment.

All the stones are sandstone. The nature of the stone emphasised the point that all tools should be sharp.

\section{Poltross Burn}

This was a piece picked up from the bank of the stream. It has all the appearance of a small facing stone $\left(9^{\prime \prime} \times 9^{\prime \prime} \times 5^{\prime \prime} / 225 \times 225 \times 125 \mathrm{~mm}\right)$ fallen from the Wall although it may be natural; there were no tool marks (see plates 5 and 6 , overleaf).

The stone, a contact-metamorphosed sandstone, was brittle and chisels tended to skid off unless held at a high approach angle; this revealed a strong tendency to pluck. The consistency was uneven, with hard and less hard patches. A flat face could be worked, but only at the expense of much time and trouble.

\section{Fallowfield Fell}

The trial piece was one picked up at random, with mosses and lichen on it. The approximate overall size was $11 \times 51 / 2 \times 8 "(280 \times 130 \times 200 \mathrm{~mm})$; the piece was very roughly square in its natural state. The buff-grey stone worked well, with a slightly 'tough' nature; it is not particularly soft stone but had a good 'feel'. No problems were 


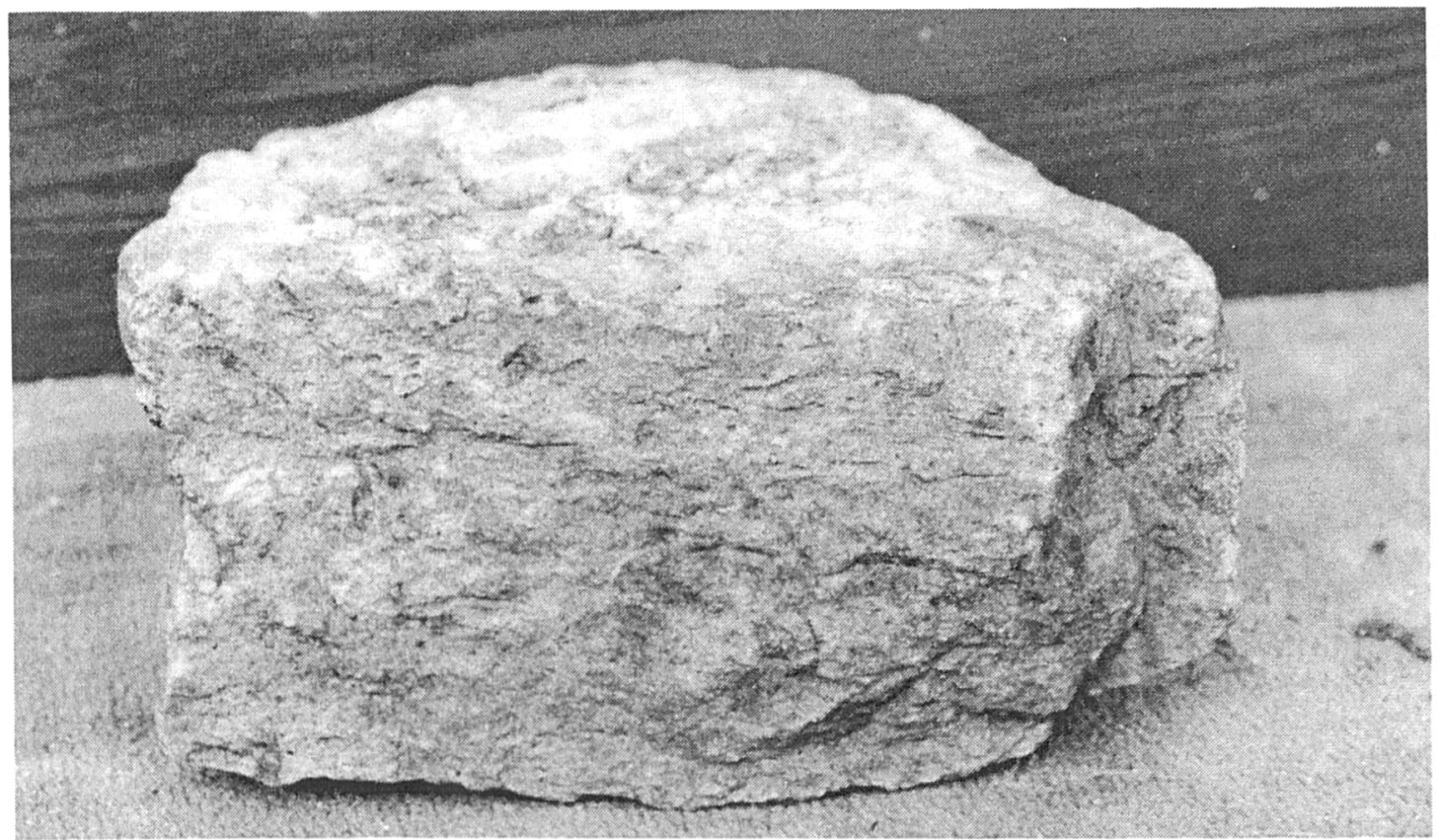

Plate 5 Poltross Burn stone

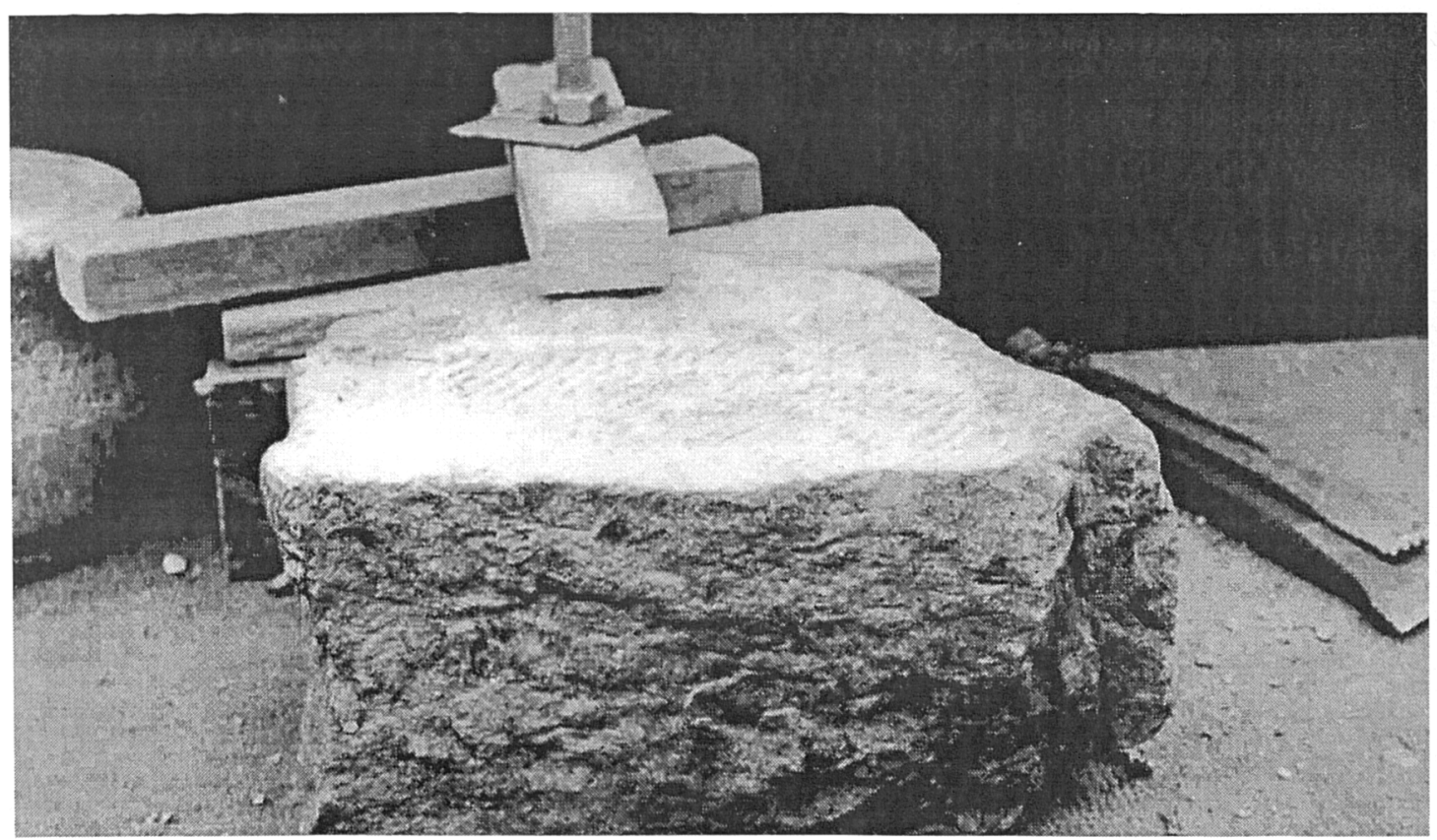

Plate 6 Poltross Burn stone: part worked surface 
encountered with chisel or claw, and with the punch $8-10 \mathrm{~mm}$ of stone was removed with ease. Although the sample was not of a suitable form, the stone could be pitched off quite well.

A V-groove was cut on the worked surface using a $1 / 4^{\prime \prime}$ chisel in the manner of letter-cutting; the stone took a good arris with little difficulty.

In summary, the stone is reasonably fine-grained and easy to work so long as the mallet or hammer were used with vigour. It would have be suitable for gate piers of good quality.

\section{Queens Crag}

This was another random piece, $9 \times 6 \times 4 "(230 \times 150 \times 100 \mathrm{~mm})$. It is a very fine grained yellow-grey stone, slightly harder than Fallowfield Fell. It worked very well with punch, claw and, chisel, and took an excellent finish with no trouble so long as sufficient effort was used. If obtainable in large enough blocks it would have made good pier stones.

\section{Harrow Scar}

Another small, random piece, $8 \times 7 \times 5$ " (200 x $175 \times 125)$ of yellowish-grey stone, slightly coarser than Fallowfield Fell and noticeably coarser than Queen's Crag. It had a tough feel, but worked very well with very little tendency to pluck.

\section{Black Pasture}

Two pieces were worked. One, $16 \times 7.3 \times 10.9 "(410 \times 185 \times 275 \mathrm{~mm})$, was collected at random from an abandoned area of the quarry at the end of the lane leading from the modern road (approximate grid ref. NY929699). The other piece was supplied 
sawn six sides, approximately $15 \times 9 \times 9^{\prime \prime}(380 \times 230 \times 230 \mathrm{~mm})$ from the modern quarry which is a little to the east of the presumed Roman quarry. Both pieces were identical in working; much more work was done on the sawn sample.

The sawn face was worked over with a punch followed by a claw. A surface was then worked with a 1 " chisel to give a face which was flat overall, with undulations of under $2 \mathrm{~mm}$ and all the tool marks clearly showing (see plates 7 and 8 , overleaf). A wedge hole and a lewis hole were also cut. The stone worked very well, needing heavy blows of hammer and mallet, and was 'tough' rather than very hard. It was about the same in working as Fallowfield Fell, which it resembles. It would have made excellent pier stones.

As a very rough guide, the wedge hole should have taken about 10 minutes, and the lewis hole about half an hour.

\section{A walling stone from Steel Rigg}

A common walling stone, surplus following excavation and consolidation near Steel Rigg (near T39b), was obtained. A brief trial showed it to be an intractable gritstone, coarse in texture and extremely hard; sparks were raised when chiselled. It would be possible to work a good face on this stone, but only at a considerable cost in labour and time. 


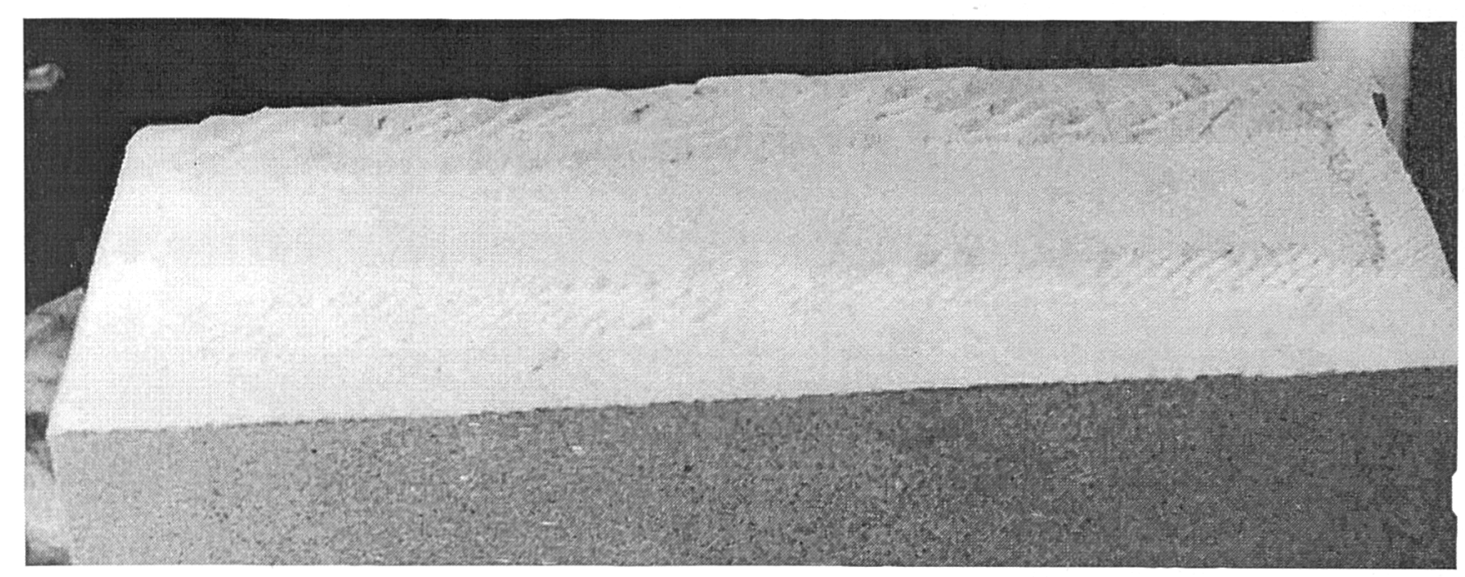

Plate 7 Black Pasture stone: part-worked surface showing chisel, claw, and punch marks

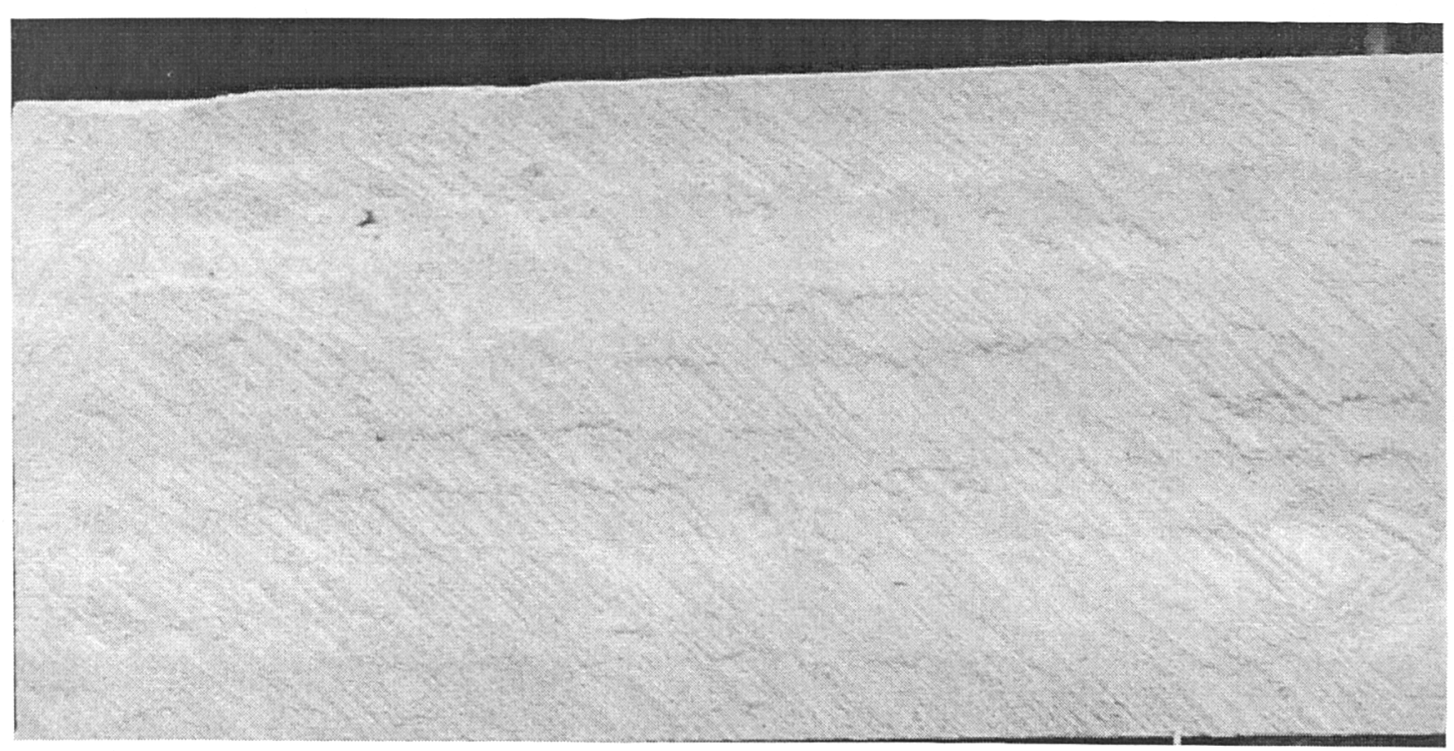

Plate 8 BlackPasture stone: surface worked with 1" chisel 


\section{CHAPTER 7}

\section{Hoisting}

The following section discusses the types of lifting tackle and means of attachment available to the Romans and considers what methods might have been used. All forms of lifting tackle will be covered in this section, whether appropriate for use in the quarry or on the building site.

\subsection{Types of lifting tackle}

Raising a heavy weight vertically above a fixed point was not particularly difficult even in ancient times. The Romans had ropes and the multiple pulley block, the windlass and the tread-wheel, and given the manpower the task was relatively simple. For loading a single item onto a cart an ad hoc tripod with pulley blocks at the head would serve, the cart being backed beneath the raised load. But this is only part of the problem; for most operations it was necessary not only to lift but to be able to swing the load either sideways or backwards and forwards.

Heavy lifting machines are exemplified by the sheer-legs shown in a bas-relief carving on the family tomb of the Haterii, dating from around AD 100; in essence it is the one described by Vitruvius. ${ }^{470}$ Fig. 7.1 shows the general form of a sheerlegs.

Landels says that the carver of the scene, while not an artist, had an eye for technical detail ${ }^{471}$ and his work, allied to Vitruvius, allows us to reconstruct the

\footnotetext{
470 Vitruvius $\mathrm{X}, 2,1-7$.

471 Landels (1978) chapter 4.
} 
machine. O'Connor ${ }^{472}$ calculates the length of the Haterii jib at about 52' $(16 \mathrm{~m})$, and its capacity as 6.1 tons (tonnes). Power could be delivered either by a windlass set across the lower part of the legs, or by a tread-wheel on an extension of the axle, as shown on the Haterii example. Landels suggests that one man working alone could raise as much as two tonnes with it, using the windlass, although it might take half an hour to raise the load $10^{\prime}(3 \mathrm{~m})$. For very heavy loads, the tread-wheel could be used.

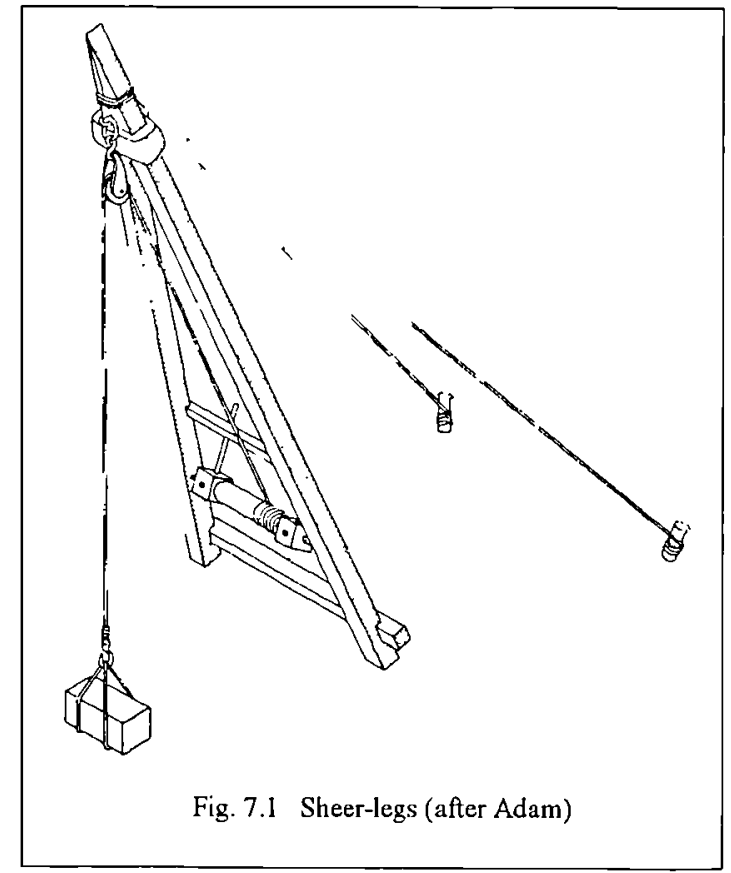

This crane is however limited to moving the load forwards and backwards and could not be swung sideways; at least, there are no literary or sculptural references to the legs being mounted on a turntable. Vitruvius says that its principal use was in building 'temples and public buildings'; it may have been used to raise loads to the top of the building, where simpler tackle could take over for movement to the actual site of operations. The sheer-legs, especially the very large sizes and when provided with a tread wheel, was in itself a not inconsiderable piece of engineering.

$472 \quad$ O'Connor (1993) 49. 
A single-pole derrick, which could easily be repositioned as required, is also described by Vitruvius, ${ }^{473}$ (see fig. 7.2). The pole has its heel set into the ground and held in place by stays on four sides. At the top of the pole a block with three rows of three sheaves (used as three separate triple-sheaved blocks with three independent lifting ropes) was made fast, and the three ropes rove through a similar but pendant block to which the lifting hook was attached. The three separate tails were led down from the upper block to the heel of the pole where they passed through a third, fixed, block of three sheaves, to a point where three gangs could conveniently exert a pull. The number of sheaves was of course variable. Using double or triple sheaved blocks weights could readily be hoisted, but swinging them sideways would be a different matter.

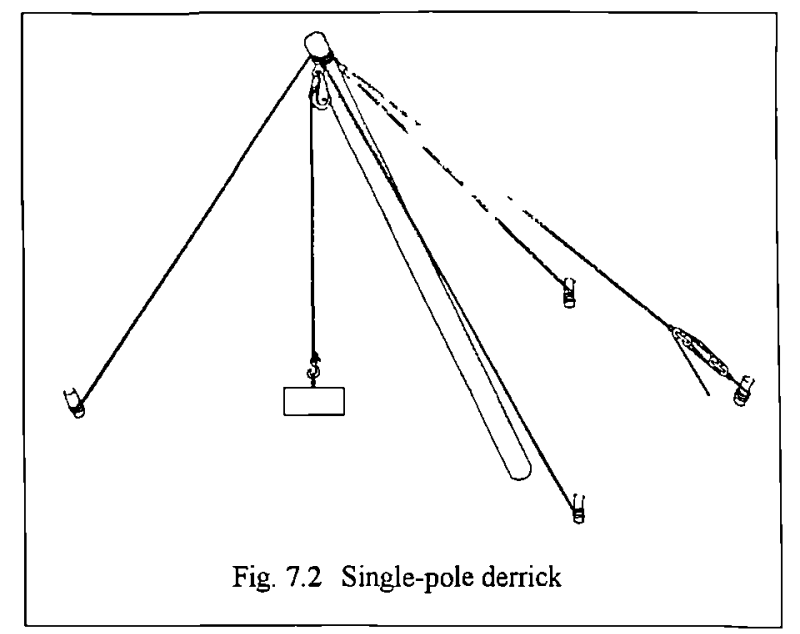

As Vitruvius says in the same passage, this machine is '... ingenious enough but only experts can work with it. . . by previously inclining it to the right or left as much as one wishes, the load can be set down at one side.' Experts would certainly be needed as, in order to swing the load sideways, the supporting guys have to be eased and used as manoeuvring lines, an operation of potential danger. Because the

$473 \quad \mathrm{X}, 2,8-10$. 
upper end of the back stay is not directly over the pivot point of the derrick but some distance ahead of it, any sideways movement robs the jib of much of its support; the distance from back-stay anchorage to the head of the jib is reduced and the head dips, very quickly reducing the mechanical advantage as well as lowering the load. Like the sheer-legs, the simple derrick is best suited for moving the load backwards and forwards. Despite its drawbacks, the single-pole derrick has the great merit of simplicity, cheapness, and easy repositioning. A spar $4.5^{\prime \prime}(115 \mathrm{~mm})$ diameter will bear 2.5 tons when used as a pole-derrick..$^{474}$

At the end of the section on the pole-derrick Vitruvius mentions in passing that the machines he has just been discussing '. . . are, in their principles, suited not only to the purposes mentioned above, but also to the loading and unloading of ships, some kinds being set upright and other placed horizontally with revolving carchesia.' This is a typically obscure sentence of Vitruvius. Landels suggests that a carchesion might be interpreted as either a swivel for the heel of the spar of a mast-derrick or as a swivel mounting, or universal joint, for a horizontal spar pivoted somewhere around the centre (see fig. 7.3). His preference is for a horizontal spar; Bidwell and Holbrook $^{475}$ tend to the same view.

A socket found in the east abutment of Chesters Bridge is thought by the excavators to be for the post of this type of crane, used for building the abutment. ${ }^{476}$ As much of the abutment would have been built before the stonework gave support to the post, one may speculate that it was used for unloading barges rather than for building, the abutment being used as a quay. ${ }^{477}$

\footnotetext{
$474 \quad$ Admiralty (1932) 247.

475 Bidwell and Holbrook (1989) 121-3

476 ibid.

477 This suggestion was offered to the author by Dr. M.J.T. Lewis (pers. comm.).
} 


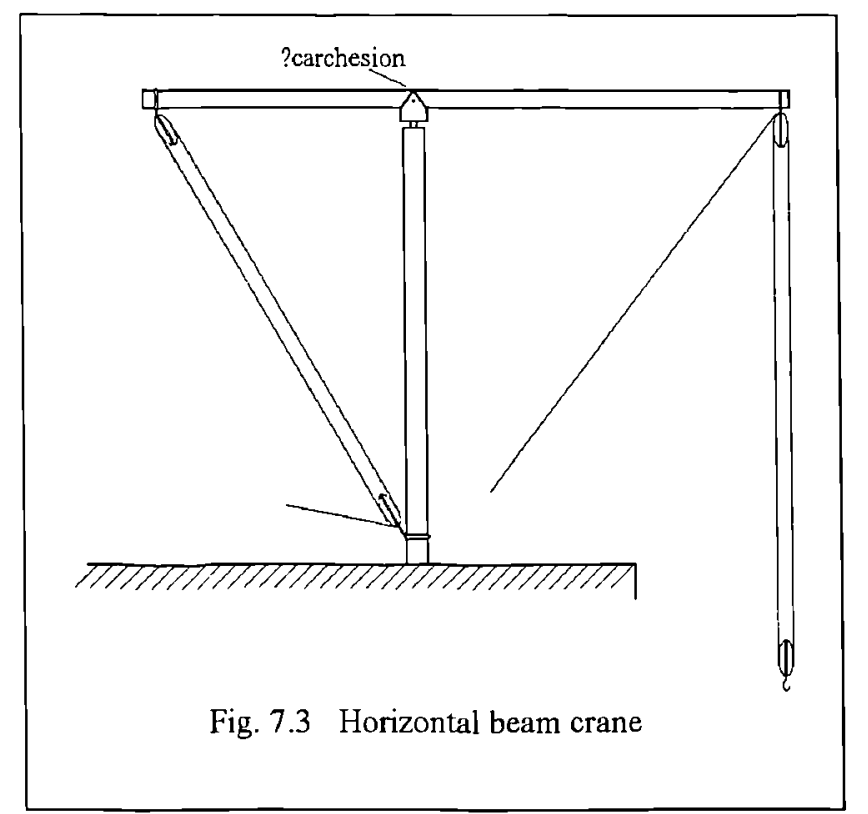

However, the 'upright' type mentioned by Vitruvius remains to be explained. Locations for derricks have been found adjacent to the gate towers at Oakwood and Fendoch, but the excavators believe these to have been fixed vertical posts, with pulleys attached at the top, used in raising the main timbers of the gateways. ${ }^{478} \mathrm{An}$ upright post with a moveable jib might be the real meaning of Vitruvius' phrase. Bidwell and Holbrook say that 'Derricks [i.e. masts with moveable jibs] . . . are such simple devices that it is difficult to believe that they were not well known and widely used in antiquity.'

This type of derrick consists of a jib whose heel is pivoted on the base of a fixed upright pole. Figure 7.4 shows the general arrangement and two possible methods of pivoting the jib about the mast are shown. The mast is supported by fixed guys; the height of the jib is controlled by a rope running from the head of the jib through blocks on the upright, and its inclination to right or left by separate guide ropes. The lifting tackle is independent of the support and control guys. This type of crane

$478 \quad$ Steer and Feachem (1954) 94-5 and plate XIX. 
would have been suitable for building the piers and arches of the milecastle and fort gateways. There is, however, no direct evidence for the use of such a derrick, hereafter referred to as a mast-derrick.

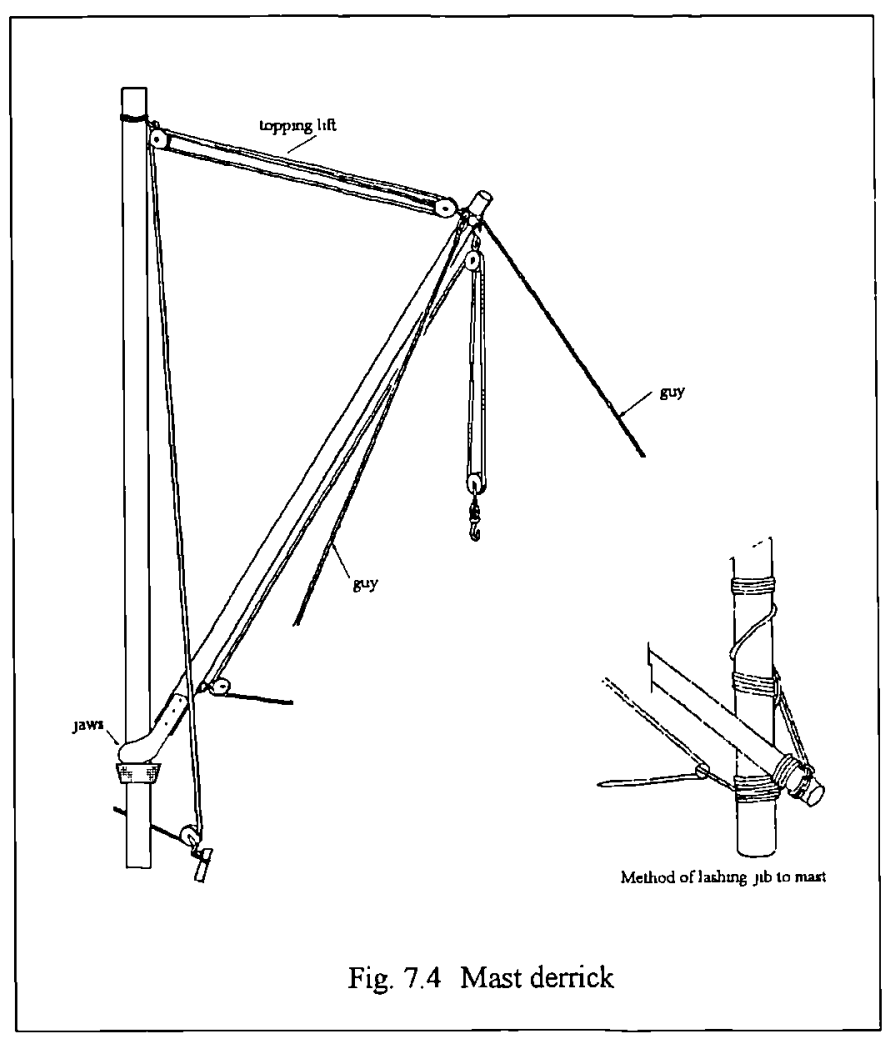

The use of lifting tackle in the quarry would probably be limited to loading the pier stones and voussoirs on to wagons for transport to the site. There may have been some need for lifting large blocks away from the quarry face before they were cut down to manageable size. This does not, however, necessarily depend on having a crane close at hand. Various types of crane have in recent times been used for dragging stones from the quarry face to a point where they could be lifted; ${ }^{479}$ there is no reason to suppose that this would not have been done in Roman quarries.

479 Greenwell and Elsden (1913) 328, and the personal experience of the author. 
Equally, a block and tackle secured to a holdfast some distance from the face could have been used for dragging the stone along the ground.

The use of rollers for moving stone in the quarry must be considered. The major problem with their use is that both the ground surface and the underside of the block must be reasonably smooth unless the rollers are to be of inconveniently large diameter.

\subsection{Ropes}

Apart from the timber and iron needed for the construction of the crane, a supply of reliable ropes was necessary; the fall of a large block of stone from inefficient tackle is startling in its speed and almost instantaneous contact with the ground - or the quarryman. It takes about one fifth of a second for a stone to fall six feet.

O'Connor discusses the likely strength of ropes in Egyptian and Roman times, and concluded that 'It is possible, therefore, that the capacities of ancient ropes may not have been greatly different from modern [natural fibre] ropes. ${ }^{1480}$ It is probable, then, that little difficulty would have been experienced in providing rope to lift the modest weights encountered in building the Wall. O'Connor gives the materials used as flax, grass and, in the east, papyrus and camel hair.

\subsection{The capacity and use of lifting tackle in building the Wall}

The stones used in the curtain wall, averaging around $64 \mathrm{lbs}(29 \mathrm{~kg})$ in weight (see section 12.4) could easily have been moved by hand by one or two men. The very large, roughly dressed stones used in the base of the Wall in some places, ${ }^{481}$

\footnotetext{
$480 \quad$ O'Comnor (1993) 48.

481 e.g. Great Hill, Heddon (Brewis 1927).
} 
weighing up to a quarter of a ton, could have been manhandled into place by rolling and levering without taking any harm. Loading onto a cart, if this were necessary, could be achieved by rolling up a plank.

Stones of up to about $2 \mathrm{cwt}(100 \mathrm{~kg})$ can be lifted by two men in a direct lift; stones of this size are less than two cubic feet (about 14"/355mm cube), and unless in slab form it is difficult to get more than two pairs of hands to them. A $4 " 1100 \mathrm{~mm}$ slab, $25 " / 655 \mathrm{~mm}$ square is about the same weight. The limits for man-carrying of stone are given in 10.3.1.

In the initial scheme the only need for lifting tackle was in the building of the forty-nine stone milecastle gateways. After the fort decision was taken, there were a further 28 double and 9 single portal gateways, a total of 159 portals with 318 $\operatorname{arches}^{482}$

The best preserved milecastle gateway is the north gate of MC37. During excavation the author was able to measure many of the stones which are now reburied. Table 7.1 lists those stones for which all three dimensions could be obtained, and only the inner piers are used as most of the outer ones could not be measured. The average weight is around $1120 \mathrm{lbs}(510 \mathrm{~kg})$, all much too heavy to be lifted without tackle. The same is true of the voussoirs, listed in Table 7.2; the problems of fixing voussoirs is discussed in 11.4.2. The stones of the south west pier of MC48 are somewhat smaller, with an average weight of $590 \mathrm{lbs}(270 \mathrm{~kg})$, but are still too heavy for convenient lifting. The heaviest stone weighs $790 \mathrm{lbs}(360 \mathrm{~kg})$. It

\footnotetext{
482 The figures assume that the Wall was to begin at Wallsend and that initially only forts to the east of the river Irthing were to be in stone; this excludes Carvoran and the later fort at Carrawburgh. All had four double portal gates and two single portal portae quintanae gates, except Wallsend (one single portal gate) and Housesteads and Greatchesters without portae quintanae. $\mathrm{MCs} 0$ and 43 were replaced by forts.
} 
would have been possible to use hand-lifting for the stones of the north gate of MC39, which are significantly smaller than those at other milecastles. The dimensions in the following tables are taken from the author's survey.

TABLE 7.1

PIER STONES, MC37 NORTH GATE

\begin{tabular}{|c|c|c|c|c|c|c|}
\hline \multirow{3}{*}{ SE pier } & \multirow{2}{*}{\multicolumn{3}{|c|}{$\begin{array}{l}\text { DIMENSIONS INCHES } \\
\text { Length } \mathrm{x} \text { depth } \mathrm{x} \text { height }\end{array}$}} & \multirow{2}{*}{$\begin{array}{l}\text { VOL. } \\
\text { CU.FT. }\end{array}$} & \multicolumn{2}{|c|}{ WEIGHT } \\
\hline & & & & & \multirow[t]{2}{*}{ LB } & \multirow{2}{*}{$\mathrm{KG}$} \\
\hline & & & & & & \\
\hline $5 / 1$ & 36.5 & 26 & 14 & 7.7 & 1115 & 506 \\
\hline $4 / 1$ & 26.5 & 23 & 12.75 & 4.5 & 652 & 296 \\
\hline $3 / 1$ & 37.5 & 23 & 19.75 & 9.86 & 1429 & 64 \\
\hline $2 / 1$ & 30 & 23 & 22 & 8.78 & 1274 & 578 \\
\hline \multicolumn{7}{|c|}{ SW pier } \\
\hline $5 / 1$ & 41 & 29.5 & 13.5 & 9.4 & 1370 & 622 \\
\hline $4 / 1$ & 22.5 & 22.75 & 11.5 & 3.4 & 494 & 224 \\
\hline $3 / 1$ & 37.25 & 22.75 & 21 & 10.3 & 1493 & 678 \\
\hline $2 / 1$ & 30 & 22.75 & 21 & 8.3 & 1203 & 546 \\
\hline $1 / 1$ & 32 & 32 & 12.5 & 7.4 & 1074 & 48 \\
\hline
\end{tabular}

TABLE 7.2

VOUSSOIRS MC 37 NORTH GATE

The volumes are calculated from the formula: length $\mathrm{x}$ depth $\mathrm{x}$ (BH at intrados+BH at extrados)/2 DIMENSIONS INCHES

Length BH BH Depth

VOL._WEIGHT@145lbs

\section{SE pier}

$\begin{array}{lcclllll}1 & 23 & 12 & 17.5 & 20 & 3.93 & 569 & 258 \\ 2 & 24 & 12.5 & 16.25 & 21.75 & 4.34 & 629 & 286 \\ 3 & 25 & 12.5 & 16 & 21.5 & 4.43 & 642 & 291 \\ \text { SW pier } & & & & & & & \\ 1 & 24 & 12 & 16.75 & 22.5 & 4.49 & 651 & 296 \\ 2 & 24.5 & 12.75 & 17 & 22 & 4.64 & 673 & 305 \\ 3 & 22 & 12.5 & 17.25 & 21 & 3.98 & 577 & 262\end{array}$


The long cornice stones found at the east gate of Birdoswald weigh up to 300lbs $(135 \mathrm{~kg})^{483}$ and, while they could have been lifted by hand, lifting tackle would have made the work much easier. While their date is not certain, it is likely that the original design also contained similar large stones.

One of the heaviest stones so far identified on the Wall is from the north gate at Chesters fort. The stone which formed jointly the foundation and first course of the north east pier of the north gate (NEF1/NE1) is $34 \times 45 \times 19^{\prime \prime}(860 \times 1130 \times$ $480 \mathrm{~mm}$ ). Allowing $50 \mathrm{~mm}$ all round for the quarried block, the weight will have been around 1.6 tons; lifting tackle will have been required to move this away from the quarry face.

Many stones used in the internal buildings of the forts have been removed for reuse and are not available for calculation of their weight. Of those likely to have becn of large size, the columns from the basilica of the principia are among the foremost candidates. The columns in the churches at Chollerton are said to be reused Roman stones (direct evidence is lacking), presumably originating from Chesters fort. The largest stones in the columns as they now stand are 59" circumference by $95 "$ high $(1499 \times 2413 \mathrm{~mm})$, weighing in the order of 1 ton. Assuming that the quarried block will have been roughly rectangular in section and allowing its dimensions to be at least $2^{\prime \prime}(50 \mathrm{~mm})$ greater all round (a minimum figure, given very careful quarrying), the quarried weight will have been a minimum of 1.7 tons. Three inches $(75 \mathrm{~mm})$ left on all round brings the weight to about 1.9 tons.

For actual building on the Wall there was no need for cranes of the capacity and complexity of the Haterii example, but there may well have been occasions where a

483 Wilmott (1997). 
simpler sheer-legs was used in building the forts. There is one stone which called for a crane of twice the capacity suggested by O'Connor.

On the counterscarp of the ditch at Limestone Corner is a large block of basalt which has split into three pieces since it was deposited there. The overall measurements of the original block are $10^{\prime} \times 3^{\prime} 5^{\prime \prime} \times 4^{\prime} 7^{\prime \prime}(3000 \times 1040 \times$ $1400 \mathrm{~mm}){ }^{484}$ At a weight of $185 \mathrm{lbs}$ per cubic foot ${ }^{485}$ it would have weighed 12.97 tons (13.2 tonnes). A sheer-legs would be the most appropriate form of crane, the capacity of which was clearly such that it was not thought worthwhile to split the stone before raising it from the ditch. There is no sign of the attachment of any form of tackle and it must have been lifted using rope slings.

A large amount of stone was taken from the ditch in much smaller pieces. It is a reasonable assumption that this was done before the sheer-legs was erected, using much smaller cranes, perhaps of the derrick type. It is a matter of speculation whether the sheer-legs would have been brought up from use elsewhere, or was built on site from scratch.

The building of the gateways is dealt with in section 11.4 .2 , but it will be convenient here to look at the type and use of lifting tackle. As suggested in section 7.1, a mast-derrick would be ideal; figure 7.5 shows this in diagrammatic form, with the pulley blocks omitted for clarity.

The extrados of the arches stood about $14^{\prime}(4270 \mathrm{~mm})$ above ground level. ${ }^{486}$ If the derrick were to work at a minimum angle of $60^{\circ}$, and allowing $2^{\prime}(600 \mathrm{~mm})$ clearance for the topmost voussoir and another $2^{\prime}$ for the attachments and pulley blocks, the working height of the jib would be a minimum of $18^{\prime}(5.5 \mathrm{~m})$ at the arch

\footnotetext{
484 Author's survey.

485 Holmes and H.F. Hanwood (1928), where the specific gravity is given as 2.95 .

486 Simpson (1976) plate xi; Hill and Dobson (1992) 46-47.
} 
nearest to the derrick. This gives a minimum length for the jib of $20^{\prime} 10^{\prime \prime}(6.3 \mathrm{~m})$ with the foot based $10^{\prime} 5^{\prime \prime}(3.2 \mathrm{~m})$ from the centre line of the arch.

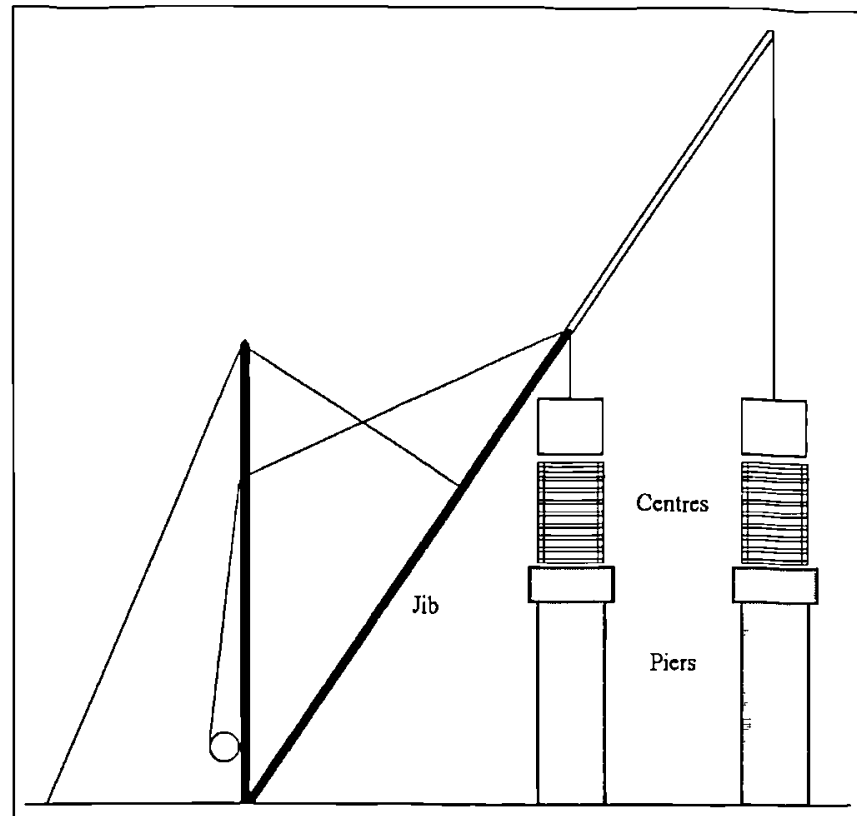

Fig. 7.5 Use of a derrick in building a gateway

If the derrick were to be based inside the milecastle for building all of a gateway (at some milecastles there is hardly room to base a derrick to the north) and for it to operate at the same minimum angle, the jib would have to be $37^{\prime} 9^{\prime \prime}(11 \mathrm{~m})$ long. The operating height of this jib would be almost $33^{\prime}$ from the ground. ${ }^{487}$ The foot of the larger derrick would of course be in the same place, but the angle of the jib when building the inner arch would be about $74^{\circ}$. All the above figures apply equally to a single-pole derrick and a mast-derrick.

The derrick could have been a smaller one and moved from inside to outside the milecastle, but the evidence from MC37 indicates that the southern piers of the north

${ }_{487}$ These figures make no allowance for the attachment to the mast and assume that the pulley blocks were right at the upper end of the jib. It is assumed that the centre lines of the inner and outer arches were 8'6" (2.6m) apart. Mrs V.M. Croll kindly checked the calculations. 
gate were incomplete when the northern ones were started, which suggests that building of both sides was proceeding in parallel; 488 it would have been a generous provision of equipment if two derricks were provided for each gateway.

The speed of using a derrick for raising the stones for the gate piers will be briefly examined, taking a notional stone weighing $1000 \mathrm{lbs}(454 \mathrm{~kg})$. A six part purchase, with two three-sheaved blocks will give a velocity ratio of 6 . Both Landels and $\mathrm{O}^{\prime}$ Connor suggest that the loss of energy in the pulleys might be in the order of $30 \%$ ( $5 \%$ per pulley); ${ }^{489}$ mechanical advantage may be calculated at 4.2 , calling for an effort of about $310 \mathrm{lbs}(140 \mathrm{~kg}){ }^{490}$ A man can exert a horizontal pull of about $100 \mathrm{lbs},{ }^{491}$ so at least three men would would be required to raise the load.

The average height to which the pier stones and voussoirs must be raised is about $8^{\prime}(2440 \mathrm{~mm})$; with a velocity ratio of 6 , the hauling part must travel $48^{\prime}$. Using the mast-derrick shown in figure 7.4, but rigged with a six-part tackle, three or four men could stand in line to haul. To pull the rope $18^{\prime \prime}$ and take a fresh grip might take seven or eight seconds, or a little under five minutes to raise the stone $8^{\prime}$.

In view of the comparative difficulty in manoeuvring a single-pole derrick, it will be useful to examine the extent of movement needed (see fig. 7.6).

488 Hill (1989).

489 Landels (1978) 89; O'Connor (1993) 49.

490 Mechanical advantage/Velocity ratio = efficiency, in this case $70 \%$. The load is therefore actually $1300 \mathrm{lbs}(690 \mathrm{~kg})$; this divided by the mechanical advantage gives the effort required.

491 O'Connor (1993) 48. The figure assumes a coefficient of friction between the man and the ground as 0.5 . 


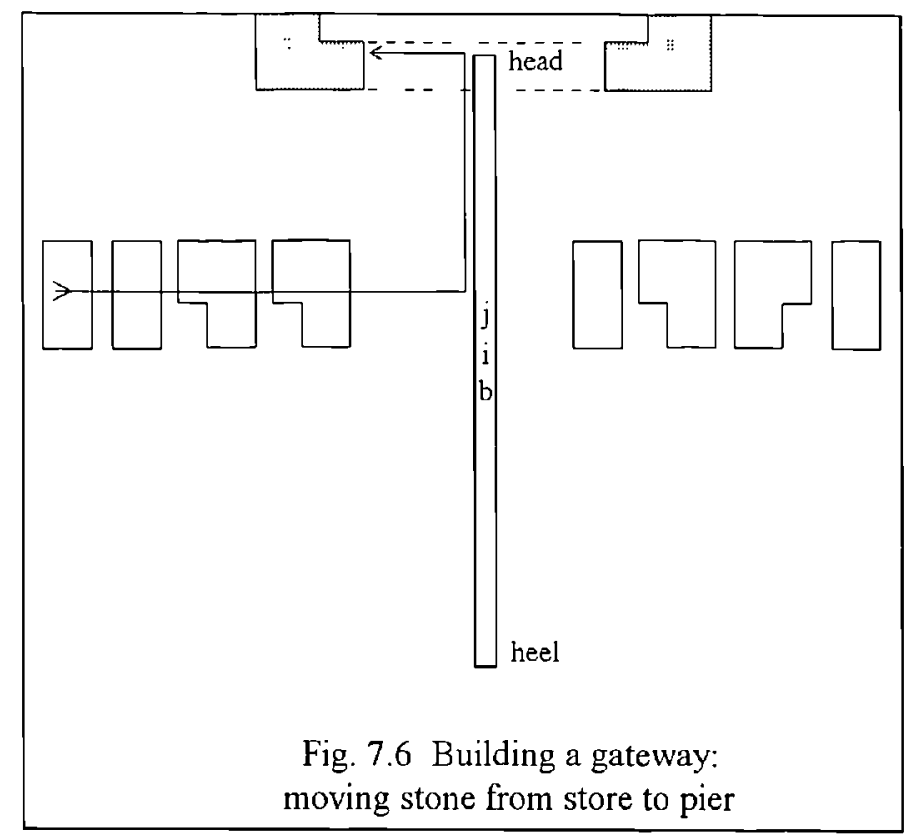

When stone was delivered from the quarry it would be unloaded as close to the gate as convenient - about a yard would be the minimum if it were not to be in the way of the builders, with the centre of gravity of the stone at about $4^{\prime}(1200 \mathrm{~mm})$ from the gate. But unless the stones were delivered in exactly the right order (in fact, in reverse order to that required for building, and this implies an unrealistic degree of organisation) the stones could not be placed on top of each other but side by side. Half a dozen stones, if laid in a line would extend over some 12' (4m); they could not be laid within, say, $6^{\prime}(2 \mathrm{~m})$ of the foot of the jib or the jib would have to be raised too near to the vertical. The small single-pole derrick would have to be raised until the peak was about $6^{\prime}(2 \mathrm{~m})$ from the gateway, and at the same time swung round as far as possible. The sideways movement can be no more than about $20^{\circ}$, owing to the need for forestays. It is possible to raise and lower a stone which is not vertically below the tackle, but this is limited and with large stones calls for one or two men pulling hard on a tail rope. Once the selected stone had been lifted, the process would have 
to be reversed - slackening the back guys (which are not only positioning but also supporting the jib), slackening one fore guy and tightening another, with perhaps half a ton of stone on the hook. A moment's inattention could result in disaster.

\subsection{Attachment to the crane}

A block of stone may be attached to the lifting tackle either by tying the main lifting rope around the block in a single rope hoist, by using a rope sling attached to the lifting hook, or one of the forms of mechanical attachment.

\subsubsection{Nippers and dogs}

A convenient tool for lifting small blocks is the nippers, ${ }^{492}$ a scissor-shaped device, with the tips of the 'blades' turned inwards to form hooks (fig. 7.7).
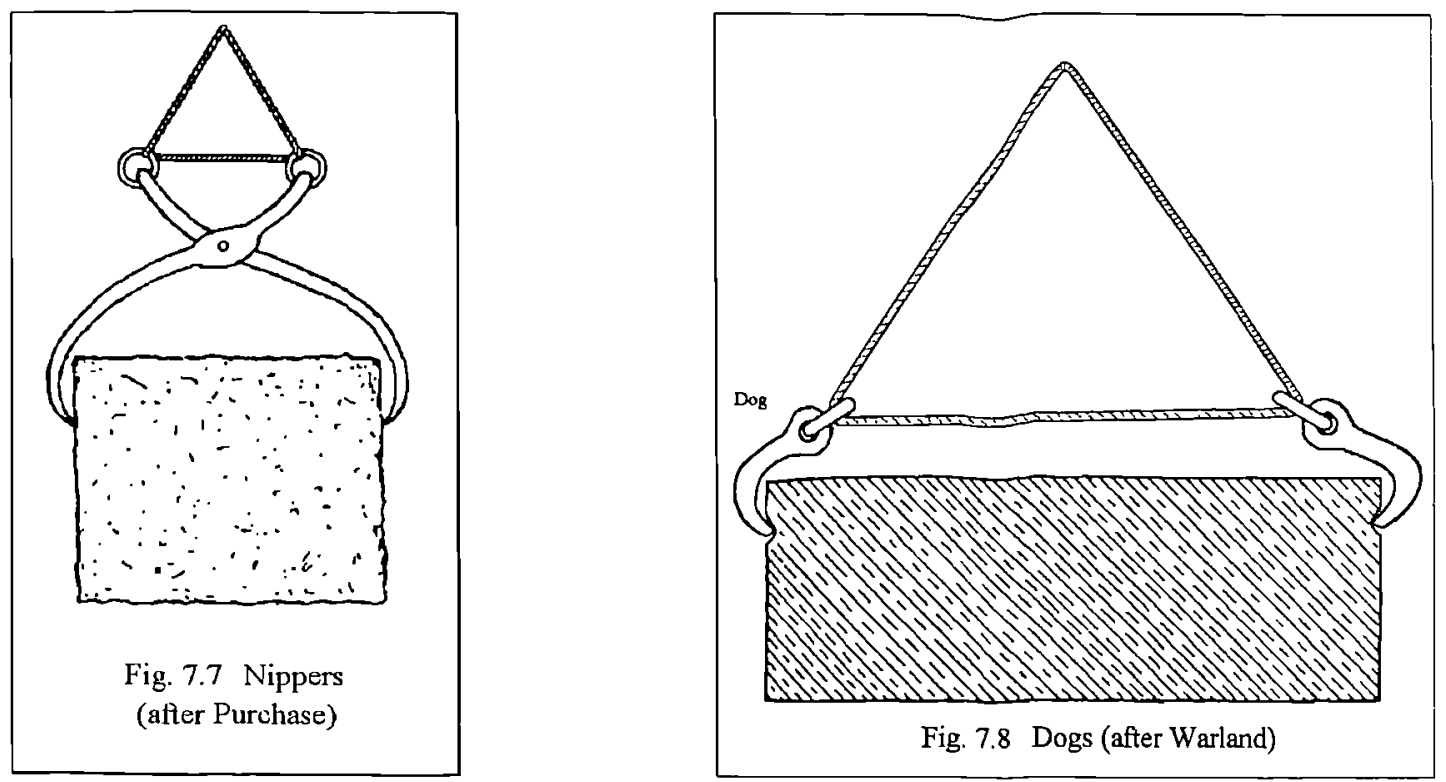

492 Known in France as une chévre, and formerly in England as a crab, a term now often used for a hand-operated, geared winch. 
A rough, cone-shaped, shallow hole ('dog hole') is cut in each end of the stone (see fig. 7.9), on the vertical plane, using a hammer and punch, an operation which takes a matter of seconds. O'Connor (1993) says that rectangular holes are cut, implying neatness and care, but this is unnecessary; all that is needed is sufficient depth. A rope or chain is rove through the rings at the 'handle' end of the nippers, and slung from the lifting hook. The hooks are placed in the holes, and when the strain is taken, the scissor action causes the hooks to bite into the stone and the stone to lift.

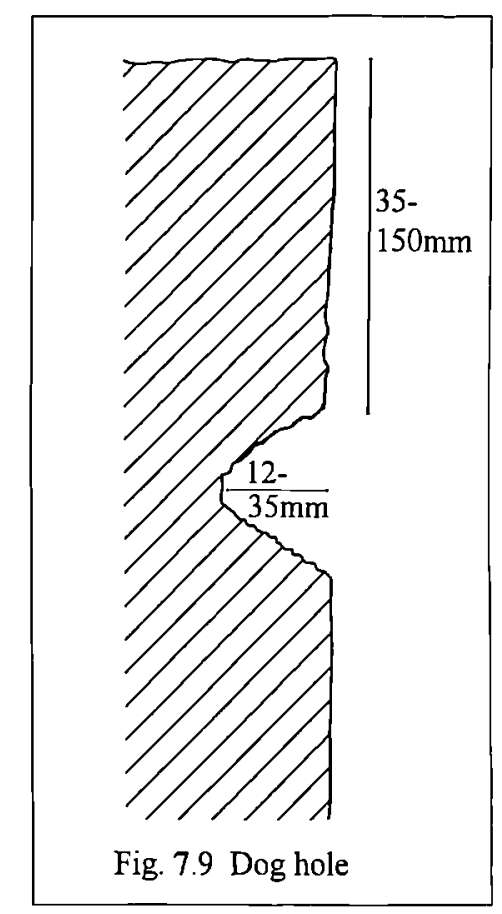

Working on a similar principle, but much more convenient to handle, are what are now generally known as 'chain dogs', 'rope dogs', or simply 'dogs'. ${ }^{493}$ Here, there are again two hooks, fitting into similar holes to those used for the nippers, but the hooks are separate and each terminates in a ring (see fig. 7.8).

\footnotetext{
493 Masons' dogs are not the same as carpenters' dogs; the latter are used not for lifting but for spiking timbers together.
} 
The size of the hole and its position depend entirely on the size of the stone; for a foot cube it might be $1 / 2 "(12 \mathrm{~mm})$ deep and $1 \frac{1}{2} 2^{\prime \prime}(35 \mathrm{~mm})$ below the top surface, while for a five tonne block the figures might be $1 \frac{1 / 2}{1}$ and $6 "$ (35 and 150mm). These figures will vary according to the type of stone; as a very general rule, the harder the stone the smaller the hole and the nearer it can be to the top bed.

These holes are common on buildings and Roman bridges elsewhere in the empire, ${ }^{494}$ but are virtually absent in Britain. Only two examples of stones with dog holes are known to the author from Britain, both from Vindolanda; ${ }^{495}$ it may well be that there are more still awaiting recognition. This tends to suggest that, during the building of the Wall at least, the lewis was regarded as the 'proper' means of attachment for military work.

\subsubsection{Lewises}

Nippers and dogs, especially the latter, are very suitable for quarry work as well as on buildings. Where large stones have to be butted tight up to their neighbours, and therefore cannot be gripped on the joints, nor on the faces lest they be spoiled, some other device has to be used. Rope slings around the stone are simple but inconvenient as they are not easily removed when the stone is in place, and the usual method was the lewis. There are several types which are of some antiquity, the chain lewis, (sometimes called the self-adjusting, two prong, or $\mathbf{C}$ lewis after its shape), and the three-legged lewis and its variants.

\footnotetext{
494 Adam (1994) and O'Connor (1993), passim illustrate a number of examples.

495 Hill (2000). Both examples are undated voussoirs lying outside the north gate of the fort.
} 


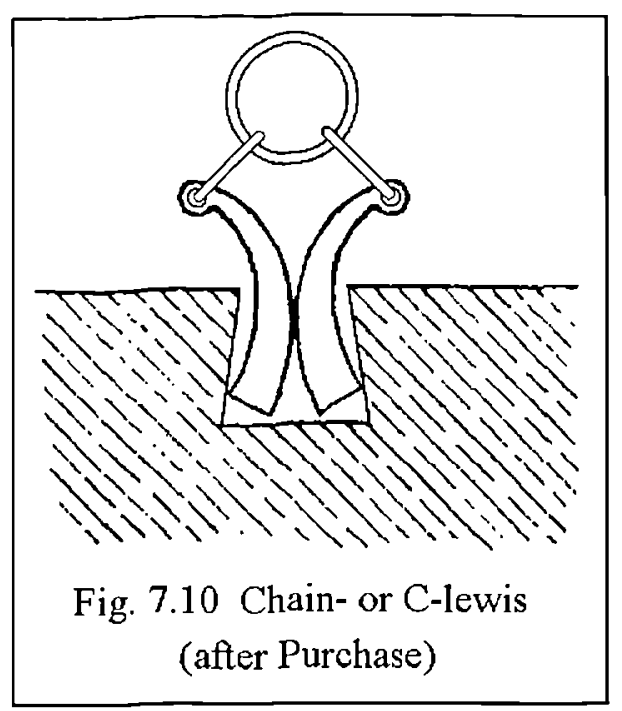

The chain lewis consists of two curved pieces of iron, each one terminating in a ring (see fig. 7.10). The two rings are connected by a third ring, forming a short chain which gives the name. The two legs are put back to back into a slot undercut at its short ends and when the strain is taken the lower ends of the legs are held against the undercut. This type of lewis depends on the tensile strength of the legs. If there is any tendency for them to straighten, the load will fall; in this respect the chain lewis is unsatisfactory. Ward-Perkins refers in passing to this lewis being used by the Severan builders of Lepcis Magna. ${ }^{496} \mathrm{He}$ gives no evidence to support the use of this type, but the lewis holes at Lepcis Magna are much longer and over twice as wide as those found in the north of England (table 7.3, below). Brewis suggests that this type of lewis may have been used by the Romans as it would better accommodate wide variations in the length of lewis holes. ${ }^{497}$

The lewis hole is rectangular in plan with the two long sides cut vertically; the short ends are undercut so that the length of the hole is greater at the bottom than the

\footnotetext{
496 Ward-Perkins (1993) 97.

497 Brewis (1925) 104-5.
} 
top. This is an important feature, and the only sure way in which a lewis hole can with certainty be distinguished from a hole cut for some other purpose. The angle of the ends when used with a modern 3 -legged lewis is something like $10^{\circ}$ to the vertical.
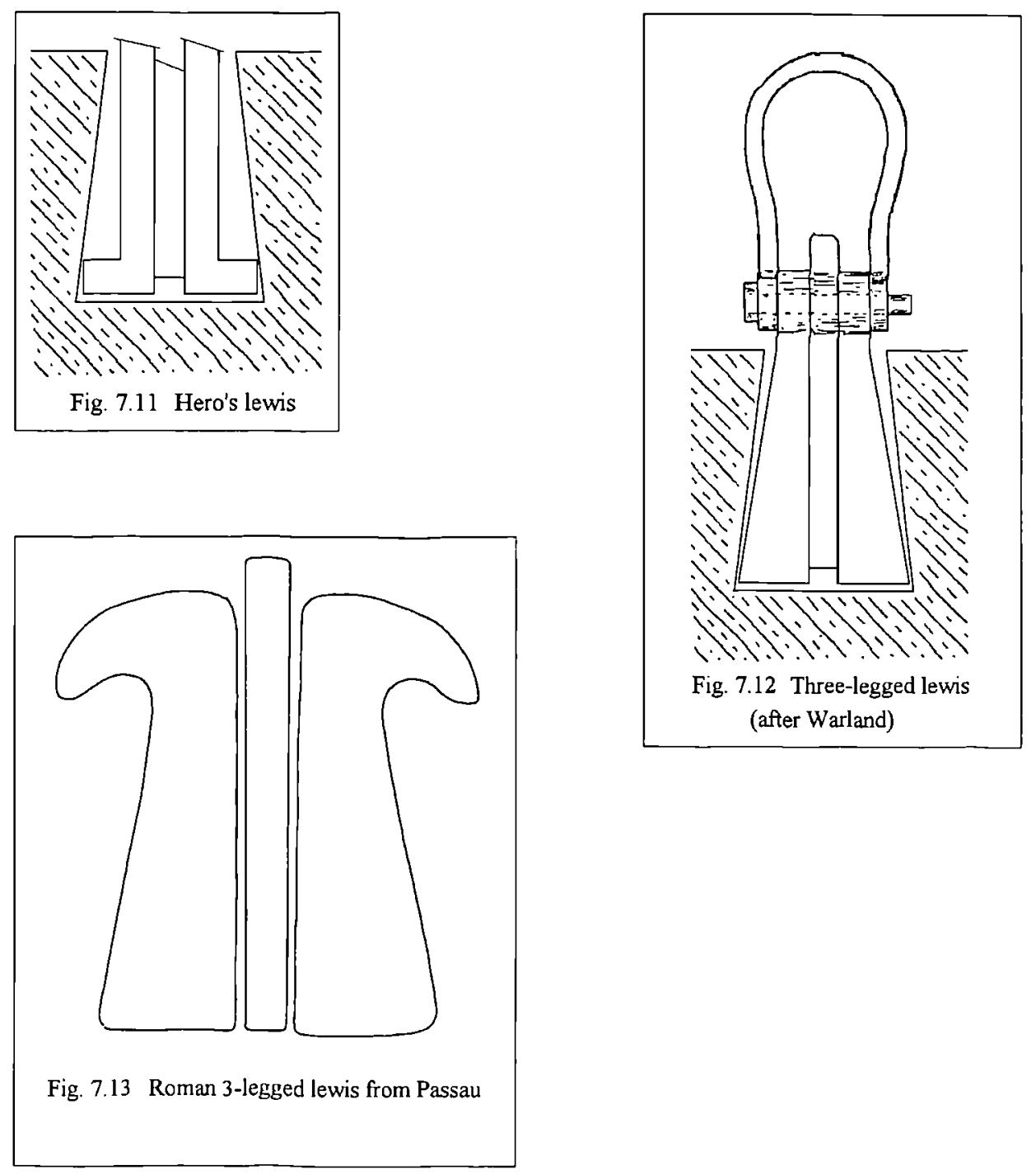

The type of 3-legged lewis described in Hero's Mechanica, ${ }^{498}$ in the form of an inverted gamma or letter $\mathbf{L}$ (see fig. 7.11), is similar to the chain or $\mathbf{C}$ lewis in that its lifting ability relies entirely on the strength of the metal used in its manufacture. Any 
weakness will result in the legs of the lewis tending to straighten out or to fracture, and it is to that extent unreliable. Hero was well aware of this, as of the danger to workmen if the lewis failed.

The three-legged lewis is still occasionally to be found in use today; the two outer legs are solid tapered bars (see fig. 7.12), and thus less dependent on the strength of the metal, but the date of the introduction of this type is not known. The Islamic illustration reproduced in Drachman ${ }^{499}$ shows no bend on the outer legs. This may be carelessness or it may be that solid outer legs were in use then and perhaps earlier. The legs, although not the hole, are in fact shown as parallel-sided in that illustration.

A Roman variant in Passau museum fulfils all the requirements of the 3-legged lewis. The outer legs are solid as in the modern one, and the only difference is in the much simpler means of attachment to the hoist; instead of a shackle and pin, the upper ends of the outer legs are curved downward, forming a hook to take a sling (see fig. 7.13).

The solid-bar type is extremely reliable, providing the angle of splay of the hole is smaller than the angle of the lewis (see fig. 7.12) which ensures that the grip is at the bottom of the hole rather than the top. Failure to attend to this point will result in bursting of the stone and the release of the lewis.

There is some similarity in the sizes of lewis holes from Roman times to the present day. In a sense this is to be expected, as they have a continuity of design for a specific purpose. A range of Roman lewis hole dimensions is given in table 7.3, below.

$499 \quad$ Drachman (1963) 105. 


\section{TABLE 7.3 SOME ROMAN LEWIS HOLE DIMENSIONS}

\begin{tabular}{|c|c|}
\hline \multicolumn{2}{|l|}{ Birdoswald $^{500}$} \\
\hline $53 / 8^{11} \times 3 / 4 \times 2^{11}$ & $(135 \times 19 \times 50 \mathrm{~mm})$ \\
\hline $5 \times 3 / 4 x^{3 / 4 "}$ & $(125 \times 19 \times 19 \mathrm{~mm})$ \\
\hline $43 / 4 \times 3 / 4 \times 1^{11}$ & $(120 \times 19 \times 25 \mathrm{~mm})$ \\
\hline $43 / 4 \times 3 / 4 \times 1 / 8^{11}$ & $(120 \times 19 \times 3 \mathrm{~mm})$ \\
\hline $5 \times 7 / 8 x^{1 / 211}$ & $(125 \times 22 \times 12 \mathrm{~mm})$ \\
\hline $5 \times 3 / 4 \times 1 \frac{1}{12}$ & $(125 \times 19 \times 38 \mathrm{~mm})$ \\
\hline $51 / 4 \times 3 / 4 \times 1 "$ & $(125 \times 19 \times 25 \mathrm{~mm})$ \\
\hline $43 / 4 \times 3 / 4 \times 11 / 4 "$ & $(120 \times 19 \times 32 \mathrm{~mm})$ \\
\hline $5 \times 3 / 4 \times 1 "$ & $(125 \times 19 \times 25 \mathrm{~mm})$ \\
\hline $4 \frac{1}{2} \times 1 \times 2 \frac{1}{4} "$ & $(115 \times 25 \times 57 \mathrm{~mm})$ \\
\hline
\end{tabular}

$M C 37$ voussoirs $^{501}$

SE pier

$144 \times 33 \times 100 \mathrm{~mm}$

SW pier

$144 \times 30 \times 95 \mathrm{~mm}$

NW pier

$135 \times 33 \times$ uncertain depth

Lepcis Magna $a^{502}$

$120-140$ x 60-70 x 140-180mm

(Average dimensions)

\author{
Vindolanda ${ }^{503}$ \\ $5 \times 0.9 \times 2.75^{\prime \prime}(128 \times 23 \times 70 \mathrm{~mm})$ \\ $4.9 \times 0.8 \times 2.2^{\prime \prime}(125 \times 20 \times 55 / 80 \mathrm{~mm})$
}

Benwell Vallum Crossing 504
WPF $75 \times 20 \times 80 \mathrm{~mm}$
WP1/2 $120 \times 18 \times 90 \mathrm{~mm}$
WP1/3 $140 \times 16 \times 45 \mathrm{~mm}$ (this hole is unfinished
at one end, or has been lengthened at a later date)

Chesters $^{505}$

$3 \times 3 / 4 \times 1 \frac{1}{11} \quad(75 \times 20 \times 30 \mathrm{~mm})$

$23 / 8 \times 5 / 8 \times 31 / 8 " \quad(60 \times 15 \times 80 \mathrm{~mm})$

$21 / 2 \times 5 / 8 \times 1^{\prime \prime} \quad(62 \times 16 \times 25 \mathrm{~mm}) \mathrm{u} / \mathrm{c}$ one end

$3 \times 3 / 4 \times 1^{\prime \prime} \quad(75 \times 18 \times 25 \mathrm{~mm})$

$53 / 8 \times 5 \times 1 / 2 " \quad(135 \times 15 \times 12 \mathrm{~mm})$

$23 / 4 \times 3 / 8 \times 1 / 4 " \quad(70 \times 10 \times 6 \mathrm{~mm})$

$25 / 8 \times 3 / 4 \times 25 / 8 " \quad(65 \times 20 \times 65 \mathrm{~mm}) \mathrm{u} / \mathrm{c}$ one end

$25 / 8 \times 3 / 4 \times 33 / 8^{11} \quad(65 \times 20 \times 85 \mathrm{~mm}) \mathrm{u} / \mathrm{c}$ one end

$4 \times 7 / 8 \times 4^{\prime \prime} \quad(100 \times 22 \times 100 \mathrm{~mm})$

? $\times 1 \times$ ?" $\quad(? \times 25 \times$ ?

$4 \times 3 / 4 \times 23 / 4 " \quad(100 \times 20 \times 70 \mathrm{~mm})$

$43 / 4 \times 5 / 8 \times 23 / 8^{\prime \prime} \quad(120 \times 15 \times 60 \mathrm{~mm})$

$25 / 8 \times 5 / 8 \times 13 / 8 " \quad(65 \times 15 \times 35 \mathrm{~mm})$

$51 / 2 \times 3 / 4 \times 31 / 8^{\prime \prime} \quad(140 \times 20 \times 80 \mathrm{~mm})$

The width of surviving Roman lewis holes is mostly between 15 and 20mm; Adam ${ }^{506}$ quotes $100 \times 20 \times 100 \mathrm{~mm}$ deep as typical of lewis holes found around the

\footnotetext{
500 Hill (1992). These are reused stones from Willowford Bridge, used for repairs to the curtain wall of the fort adjacent to the porta quintana dextra.

so1 Author's survey.

502 Ward-Perkins (1993) 97.

503 Author's survey. These are in a stone slab of unknown provenance, leaning (April 2002) against the garden wall to the east of the museum. The first quoted is in the unworked face and thus shows the full depth of the hole. The second is in the worked surface forming the upper edge of the slab. The stone weighs around $450 \mathrm{lbs}(205 \mathrm{~kg})$.

504 Author's survey (Hill 2001a).

505 Hill (1995).

$506 \quad$ Adam (1994) 49.
} 
Mediterranean. The lengths vary widely at Chesters, with the largest being over twice the length of the smallest. At Birdoswald, there is a consistency centred around $120-125 \mathrm{~mm}$ long. Most, if not all, of the holes at both sites have clearly been reduced by working off the top bed of the stone after fixing, but this does not seriously affect the length, which will increase only slightly with the depth.

A relatively modern lewis in the tool kit of the writer, which can be sunk to a maximum depth of $140 \mathrm{~mm}$, is $15 \mathrm{~mm}$ wide and a hole cut for it tends to be about $20 \mathrm{~mm}$ wide and at least $80 \mathrm{~mm}$ long at the top, to allow for comfortable fitting. This appears to be very suitable for use in many of the Roman lewis holes, and has been used, with a little packing, in a mediaeval lewis hole.

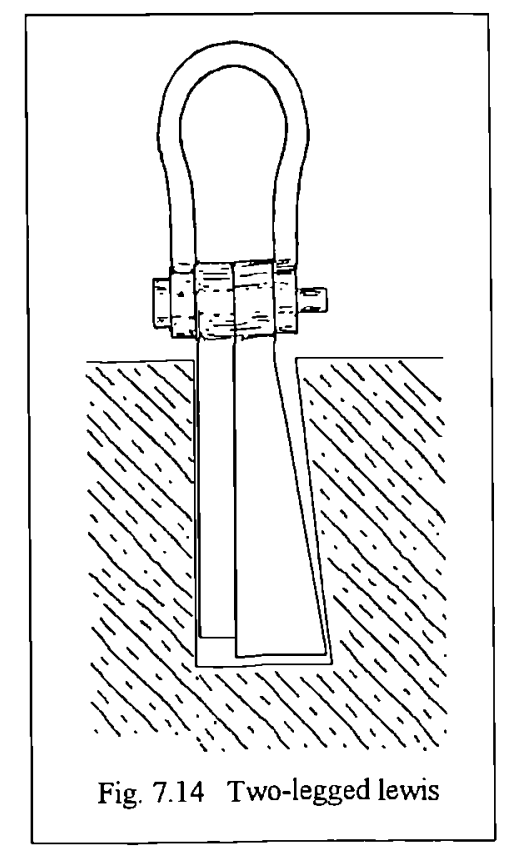

The two-legged lewis has one tapered piece and one parallel piece; it has been used for lifting light stones but is not a certain method of lifting except perhaps in such stones as granite where there is less chance of the stone bursting. The two-legs shown in figure 7.14 has the two parts of the lewis connected by the shackle pin; 
sometimes only the tapered leg is attached to a ring, with the packing piece provided by any suitable material to hand.

The existence, in three stones at Chesters (see table 7.3), of lewis holes with apparently only one end undercut shows (assuming a reasonable degree of care in the cutting) that a 2-legged lewis may have been used rather than the more usual 3legged. The three stones in question each weigh between 900-1410lbs (409-640kg), heavier than the present writer would care to lift with a 2-legged lewis. It is not impossible for the 3-legged lewis to find a grip with only a very shallow undercut, and, as always, it must be remembered that what is seen may be the result of an error which perhaps did not result in disaster. 


\section{CHAPTER 8}

\section{Lime, sand, and mortar}

Lime mortar was used in the building of the Wall for bedding the facing stones in some parts and for bonding some of the rubble of the core. It was not the only material used; for details see section 4.2. The production of lime for mortar is treated here in outline only. ${ }^{507}$

\subsection{Lime}

Lime, as used in mortar, is obtained by heating limestone (calcium carbonate) in a kiln over several days to a temperature of between $900^{\circ}$ and $200^{\circ} \mathrm{C}$ which, with a loss of $50 \%$ in weight, results in the formation of calcium oxide, or quicklime; the burning of a limestone containing a high proportion of magnesium carbonate will of course also give magnesium oxide. The addition of water to quicklime converts the oxides to hydroxides; an excess of water yields, when allowed to stand, a putty-like material known as slaked lime.

Low firing temperatures are likely to lead to lumps of unburnt lime. Poor slaking leaves unslaked lumps which may later react with moisture in the building and can cause structural problems.

Cato ${ }^{508}$ describes the use of a flare kiln (see fig. 8.1), in which a single charge of limestone is calcined by a fire beneath the charge, the lime extracted and the kiln

507 The following notes on the nature and production of limes are based chiefly on Cowper (1998), Davey (1961) 97-100, Grundy (1930) 119-125, and Vicat (1837).

s08 XXX viii 1-4. 
recharged, over a period of four or five days. ${ }^{509}$ This yields a whiter lime than that produced in a draw kiln, where alternate layers of limestone and fuel are loaded and the burning is continuous, with the lime drawn out from the base as it falls through a grid.

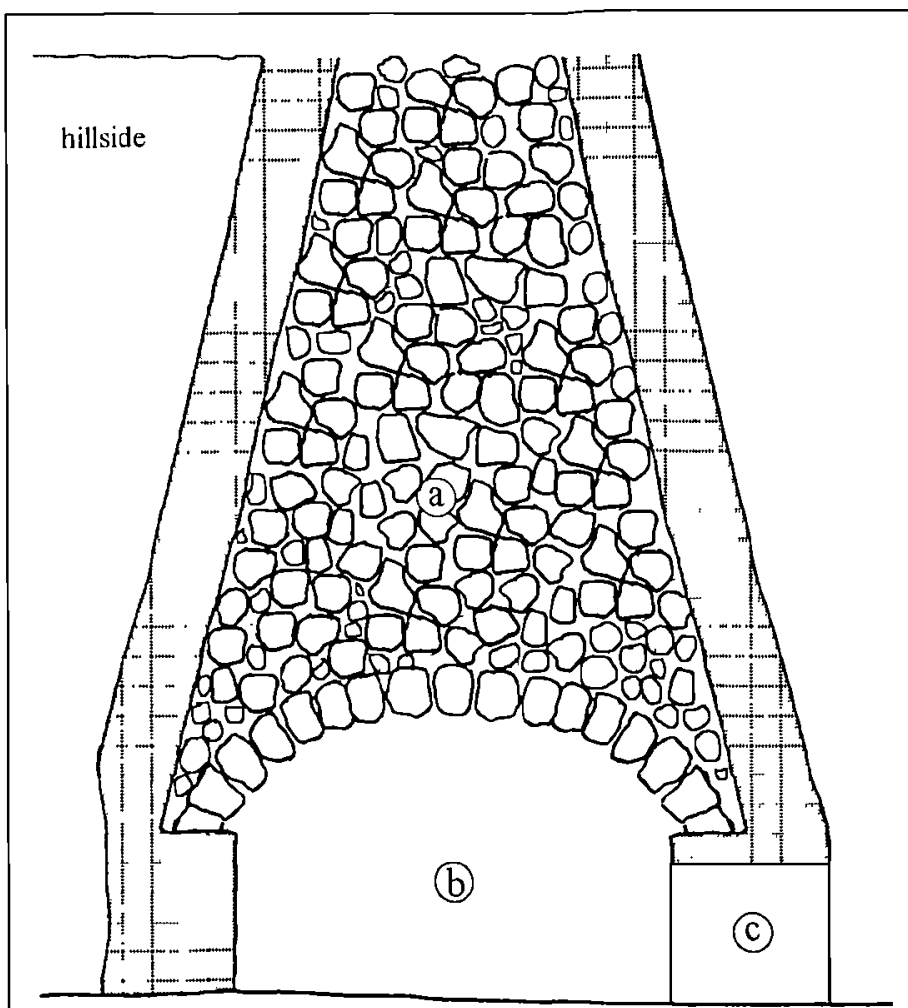
a) limestone
b) fire
c) eye

Fig. 8.1 Flare kiln

There is one certain Roman lime kiln known in the Wall area, that close to the Knag Burn. ${ }^{510}$ The more extensive excavations of Roman limekilns and experimental work at Iversheim ${ }^{511}$ and Weekley ${ }^{512}$ have provided useful

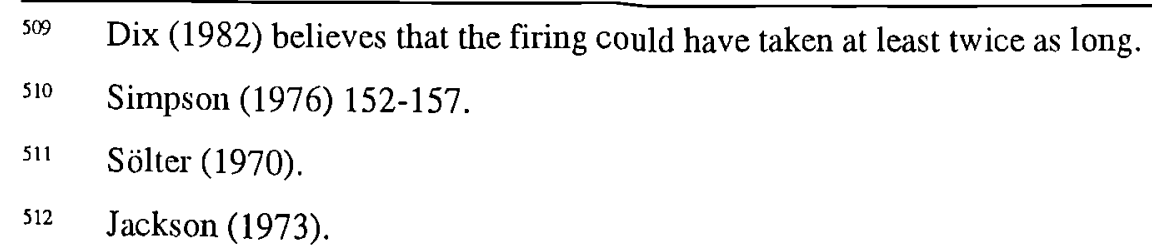


information on the use and capacity of Roman lime kilns. Lime kilns are normally sited in, or close to, the limestone quarries to avoid transport of the raw stone.

Simpler kilns are also known from Roman Britain. These are clamp or sow kilns, in which alternate layers of stone and fuel were formed into a shallow pile and covered with turf. The product of these kilns is uncertain in quality, but they remained in use until recent times. ${ }^{513}$ Small ad hoc, coal-fired draw kilns are used today for demonstration burning of lime, and these will produce a usable quicklime in under twenty-four hours. ${ }^{514}$

There is one, perhaps two, references to lime burning in the Wall area, pre-dating the Wall by some twenty years. One of the Vindolanda writing tablets refers to men being sent ' . . to the kilns'; these could be either lime or pottery/tile kilns. ${ }^{515} \mathrm{~A}$ second tablet is quite definite: 'to burn stone'. sit $^{5}$

Different types of limestone will give lime with different characteristics. Those consisting of around $95 \%$ calcium/magnesium carbonate are known as fat limes; when there are inert impurities present and the carbonate content falls to around $70 \%$ they are known as lean or poor limes. There is little difference in setting qualities between the two, both developing little strength, although there is some evidence that magnesian limes develop greater strength than chalk limes. Fat limes slake very rapidly with much heat and steam, lean limes slake more slowly. Both fat and lean limes set by the absorption of carbon dioxide from the atmosphere, to produce a

\footnotetext{
513 Dix (2000).

514 Information from Mr Gerard Lynch M.A., who has made extensive studies, both theoretical and practical, of the subject and has regularly burnt lime overnight using coal. The length of burn depends entirely on the heat produced by the fire.

515 Bowman and Thomas (1994) document 18.

516 Bowman and Thomas (1994) document 156.
} 
crystalline carbonate of lime. Setting may not begin for several months, and then only at the surface. Slaked fat and lean limes can be kept for months so long as protected from the atmosphere, and indeed benefit from such maturing. If air is allowed to get to the lime before slaking it will combine with $\mathrm{CO}_{2}$ to form air-slaked lime, rendering it useless for building purposes.

For ordinary building purposes it is not necessary to allow the slaked lime to mature to produce lime putty. ${ }^{517}$ Instead, the method known as dry-slaking is used. Here, the lumps of quicklime are put in a ring of sand, sufficient water added to reduce the lumps to powder, and then mixed with the sand. Ideally, this 'coarse stuff' is screened to remove lumps of unburnt lime and over-size aggregate. When mixed up again with more water ${ }^{518}$ it is ready for use after only a few hours. The dryslaking method is ideal for the production of large quantities of mortar, and much quicker and easier than using lime putty, which is more appropriate for plastering and stucco work. Vitruvius does not mention dry-slaking but, given the very uneven quality of his information, cannot be taken as evidence that the Romans did not dryslake.

The setting of a mortar joint will take place first at the surface, which tends to seal off the interior of the joint from atmospheric carbon dioxide; coarse sand in the mortar will help to make it more porous to the air and thus aid setting at depth. In very thick walls setting may well never take place in the interior, but this is not necessarily detrimental.

The stability of rubble walls relies to some extent on the strength of the mortar, but solid ashlar and block-in-course walls rely more on the massiveness of the

517 Frost and Boughton (1954): Lynch (1998a) and Lynch (1998b), together with discussion with the latter writer.

S18 Lynch (1998b) discusses the addition of water at some length. 
construction and the careful bonding of the stones. In this type of work, a degree of plasticity of the mortar helps to absorb some of the thermal and seasonal movement which will always take place. The present writer, when working on York Minster, was required to cut out several stones from the fifteenth century north-east choir pinnacle. In the interior, at a depth of no more than one foot, the mortar was still plastic, with the consistency of hard Plasticine; when a long punch was driven in, the grip on the tool and the stones was remarkable.

Limestones which contain argillaceous material, usually in the form of hydrated aluminium silicate, yield hydraulic limes; these are referred to as feebly hydraulic (up to $12 \%$ clay), moderately hydraulic (12-20\% clay), or eminently hydraulic (20$40 \%$ clay). These proportions are approximate. Slaking is slower and less violent than fat and lean limes, taking from a few minutes upwards.

Setting of hydraulic limes is by the combination of water with the silicates and aluminates of lime, formed at the time of burning, to form hydrated calcium silicate and hydrated calcium aluminate crystals. There will also be free lime present, which will harden by the absorption of $\mathrm{CO}_{2}$. The eminently hydraulic limes, being little dependent on exposure to the atmosphere, will set under water. Analysis of mortar from the curtain wall at Sycamore Gap showed it to be an extremely durable and still effective hydraulic mortar, probably due to the use of the local highly siliceous Four Fathom limestone. ${ }^{519}$

Until modern production methods gave lime of exceptional purity, it was normal for limes to be impure and thus likely to be more or less moderately hydraulic. ${ }^{520}$ Only such stones as chalk and alabaster are likely to give non-hydraulic limes.

\footnotetext{
519 Rayment and Pettifer (1987).

520 The writer is indebted to Mr G. Lynch for discussions on this point.
} 
Where limestones occurs in association with clays, any clay put into the kiln with the stone will add to the hydraulic nature of the lime.

Vitruvius gives no indication of how the Romans may have identified stone for the making of hydraulic limes, noting only that 'Lime made of close-grained stone of the harder sort will be good in structural parts; lime of porous stone, in stucco..$^{521}$ He relies on the use of pozzolana (see 8.2) to give a hydraulic mortar. This is discussed by Plommer, with no conclusion, in relation to the ingredients for the best Roman concrete; ${ }^{522}$ Plommer holds that Faventinus had a better empirical knowledge of lime than had Vitruvius, but the improvement is not significant. ${ }^{523}$

Although hydraulic limes slake more slowly than non-hydraulic lime, slaking must not be prolonged or the lime will begin to set; this can begin in as little as one hour, but is normally up to a few days. For this reason the lumps of burnt lime should be broken small to ensure that slaking is completed before use.

In the second edition of the Handbook to the Roman Wall, and repeated in all editions up to and including the 13th, the description of lime mortar suggests that the ground lime was mixed dry with sand and gravel and slaked immediately before use: 'Mortar thus prepared speedily hardens. ${ }^{1524}$ This is dry-slaking as described above, but the speed of setting does not depend on this; the principal factor influencing the speed of setting is the chemical composition of the lime. In any case it is most unlikely that the Roman builders of the Wall dried and ground their lime before use.

\footnotetext{
521 Vitruvius, II, v, 1

$522 \quad$ Plommer (1973) Appendix 1.

523 Vicat (1837), chapter xvi and table 15, discusses the qualities of various Roman mortars.

$524 \quad$ Bruce (1884) 34.
} 
The burning of lime requires the quarrying of limestone of a suitable kind, the collection and transport to the kiln of large quantities of wood for use as fuel, ${ }^{525}$ and the transport of the finished product to the building site.

\subsection{Pozzolanic additives}

Any lime can be converted to a hydraulic lime by the addition of a material which has constituents which will combine with free lime to form an insoluble cementitious compound. Such a material is known as pozzolana, after Pouzzuoli from where the Romans obtained supplies of natural materials of volcanic origin. Similar natural materials are quite widely available.

There are also less effective but still useful pozzolanic materials deriving from the decay of igneous rocks such as basalt. This would have been available to the Wall builders, although no mortar from the Wall has shown evidence for their deliberate use.

Artificial pozzolanas are made from, among other things, pounded brick and tile; such materials were commonly used by Roman builders (opus signinum) where strength and waterproofing were important. Vitruvius ${ }^{526}$ mentions pozzolana from the area of Baiae and around Mt. Vesuvius, recommending its use for marine and general underwater work, although he gives no hint of the proportions to be used. In discussing the merits of river and pit sand he advises the former be used with the

525 Wood was the fuel used in the experimental firing of a rebuilt kiln at Iversheim (Sölter (1973)). Although it is known that coal was mined, for example at Housesteads, during the Roman period, its availability during the construction phase is unknown. Charcoal is a possible alternative fuel.

526 Book II, vi. 
addition of a third part of pounded brick to make it 'of a better composition to use', $^{527}$ but he fails to mention that this will produce a hydraulic mortar.

\subsection{Sand}

Lime is normally mixed with sand both to increase its bulk and to reduce cracking as the lime sets; sand also aids the setting of non-hydraulic limes, as noted above. The proportion of sand to lime should be such that the lime fills the voids between the sand grains. Proportions of 3:1 sand:lime are usual for fat limes, but the lean limes and hydraulic limes tend to need less sand owing to the presence of inert material in the lime.

Vitruvius recommends the use of three parts of pit-sand to one of lime (usually expressed as 3:1), or two parts to one when using river sand. ${ }^{528}$ Pliny seems to give 5:1 and 4:1 respectively, although he may mean $4: 1$ and $3: 1 .^{529}$ Pit sand is often regarded as better than river sand owing to its sharpness, which gives a more open texture and a coarser feel. However, almost all sand has been water-borne at some point, and pit sand can be rounded and 'soft'.

Sand, unless carefully washed, almost always contains clayey matter and silt, which can affect both the workability and subsequent analysis of the mortar. The cleanliness and relative uniformity of sand produced today relies on washing and grading.

Gravel, contra all editions of the Handbook, is not normally used deliberately in the preparation of mortar for bedding, although sand which naturally contained very coarse grit and even pebbles may well have been used. Analysis of mortar from the

527 Book II, v, 1.

528 Book II, v.

529 Pliny XXXVI, liv. 
Wall at Willowford showed, in one case, that the aggregate included stones several centimetres in diameter; ${ }^{530}$ the sample came from the inner face and may have included material from the core. It is certainly not easy to build with mortar containing aggregate of this size, as the stones will not bed down on to the mortar but rock from side to side on the aggregate unless the joints are at least twice the thickness of the aggregate size. Sand from mortar found at Denton tended to peak in the range $0.15-2 \mathrm{~mm},{ }^{531}$ indicating a coarse grit sand. This is about the maximum convenient size of aggregate.

Sand will have been available down the slope from any outcrop of sandstone; Fallowfield Fell, for example, shows large pockets of sand at the surface in the small valley bclow the quarry face. Its collection would have added to the transport problems.

\subsection{Water}

Water was required in large quantities, for slaking the lime, mixing the mortar, wetting down the larger stones in dry weather, cleaning tools, washing lime from the hands at intervals, and so forth. ${ }^{532}$ Although there are abundant rivers and streams in the general area of the Wall, the builders could easily have found themselves up to half a mile away from the nearest water source, and on the crags this was over difficult terrain; the cleanliness of the water, in terms of detritus and vegetable matter, is unlikely to have been a matter of concern. ${ }^{533}$ Transporting the water was

\footnotetext{
530 Bidwell and Holbrook (1989) 97.

531 Bidwell and Watson (1996) 54-5.

532 Each cubic foot of mortar takes about 3 gallons to slake and mix (Molesworth (1910) 103.

533 Modern specifications usually call for mains water, or water to a specified cleanliness; the author has worked on small sites where bricklayers were using mortar mixed with semi-
} 
presumably by means of skins or barrels carried on on to mules or carts, although evidence for the nature of such transport is lacking.

\subsection{Mortar mixes}

As noted above, Vitruvius recommends a sand:lime mix of either $2: 1$ or $3: 1$. Analysis of mortar from Willowford Farm has suggested (the analysis was uncertain owing to the age of the sample), that the proportions by volume were roughly $1: 1$ sand:lime. ${ }^{534}$ Excavations of the Wall at Denton yielded bedding mortar in the proportions of about two parts of sand to one of lime. ${ }^{535}$ There is however a major problem in the analysis of mortar proportions, as they are taken by weight whereas mortar is mixed by volume. ${ }^{536}$

There is no known example of the Wall builders using a pozzolanic additive to produce hydraulic lime. However, some limestones on the line of the Wall give a natural hydraulic lime ${ }^{537}$ although again there is no evidence that the builders deliberately sought this out. The hardness of the mortar at Great Hill suggests that hydraulic lime was used there, but the source is not known. ${ }^{538}$

The excavation of the villa at Park Street, Herts., showed the late first centurymid second century builders using a mix of 3:1 coarse (i.e. pit) sand:lime. Later in the second century a finer (i.e. river) sand was used in the proportions of $2: 1$. In the

stagnant water from a pond, with dead leaves and other organic matter in it.

534 Whitworth (1997).

535 Bidwell and Watson (1996), 53-54.

536 This point is highlighted by Taylor (2000) 17. Presumably the weight could be converted to a volume equivalent, although the author is not aware that this has ever been done.

537 e.g. The Four Fathom limestone (Rayment and Pettifer (1987)) and the Great limestone at Crindledykes (pers. comment, Dr. G.A. L. Johnson).

$538 \quad$ Parker Brewis (1927), 115. 
later period there was a deliberate admixture of crushed tile, presumably with the intention of converting the local moderately hydraulic lime into a stronger and quicker-setting mix. ${ }^{539}$

It must be remembered that the mixing of mortar is neither a skilled job nor an exact science; measuring by volume, normally reckoned by the shovelful, can be very hit and miss. It depends on the conscientious application of the specification by the labourer and his ability to make his shovelfuls of consistent size. Furthermore, if the mix comes out too wet further material will be added to it, and the addition might be either lime or sand according either to the judgement of the mixer or the location of the sand and lime heaps. If the mix does not seem to work well, the fixer may ask for more lime to be added to the next batch. Sand, especially on a large work such as the Wall, might be delivered to one site from a number of small sources; this may well cause marked colour changes.

It will be clear that variations in mortar mixes cannot always be indicative of relative dating. Similarity of mortar can also be misleading. The hard white mortar generally regarded as typical of the Severan rebuild, also occurred in an Antonine context at Willowford Bridge..$^{540}$ There is no way in which the style of the mortar can be used to date work, and it is not usually possible, except on other evidence, to discriminate between original mortar and that of reconstruction.

\subsection{Transport to the site}

If the dry-slaking method were adopted, then it would probably be simplest to slake at the kiln and transport the coarse stuff to site. This would reduce the quantity of

\footnotetext{
539 Davey (1971).

540 Bidwell and Holbrook (1989) 81.
} 
water to be taken to the site, and would mean that all sand would first go to the kiln site rather than to many individual sites.

If the coarse stuff were made at the site, then the quicklime could be carried in barrels on pack animals. The barrels would have to be tight and proof against ingress of moisture; any inadvertent slaking while in transit could have a serious effect on the animals. Similarly, if the lime were wet-slaked, it could also be carried in barrels, or skins. 


\section{CHAPTER 9}

\section{Scaffolding}

This section looks at the need for scaffolding in building the Wall and structures, reviews the evidence for its use on the Wall and elsewhere in Britain and the empire, and examines the nature of the scaffolding and the volume of materials required.

\subsection{Definitions}

First, it will be useful to define some of the terms used in scaffolding; the parts are identified in figs. 9.1 and 9.2.

Bay The length of scaffold between adjacent standards

Braces Long poles running diagonally across the face of the scaffold, their purpose being to restrict lengthwise racking of the scaffold Cross brace An angled strut connecting the inner and outer standards to restrict lateral racking

Guard rails Poles lashed to the standards at a height of some $3^{\prime}(1 \mathrm{~m})$ above the working platform to prevent workmen falling

Ledgers Horizontal poles connecting the standards and running parallel to the wall face. They carry the putlogs and are normally set at equal vertical intervals or lifts. There may be an extra ledger to tie the feet of the standards together

Lift The interval, usually standard within one scaffold, between ledgers, or a run of putlogs whether or not decked out as a working platform 
Putlogs (pronounced pŭdlŭk, not put-log) are short poles at right angles to the wall face, resting on ledgers at the outer ends and with the inner ends either resting on a second ledger or temporarily built into the wall.

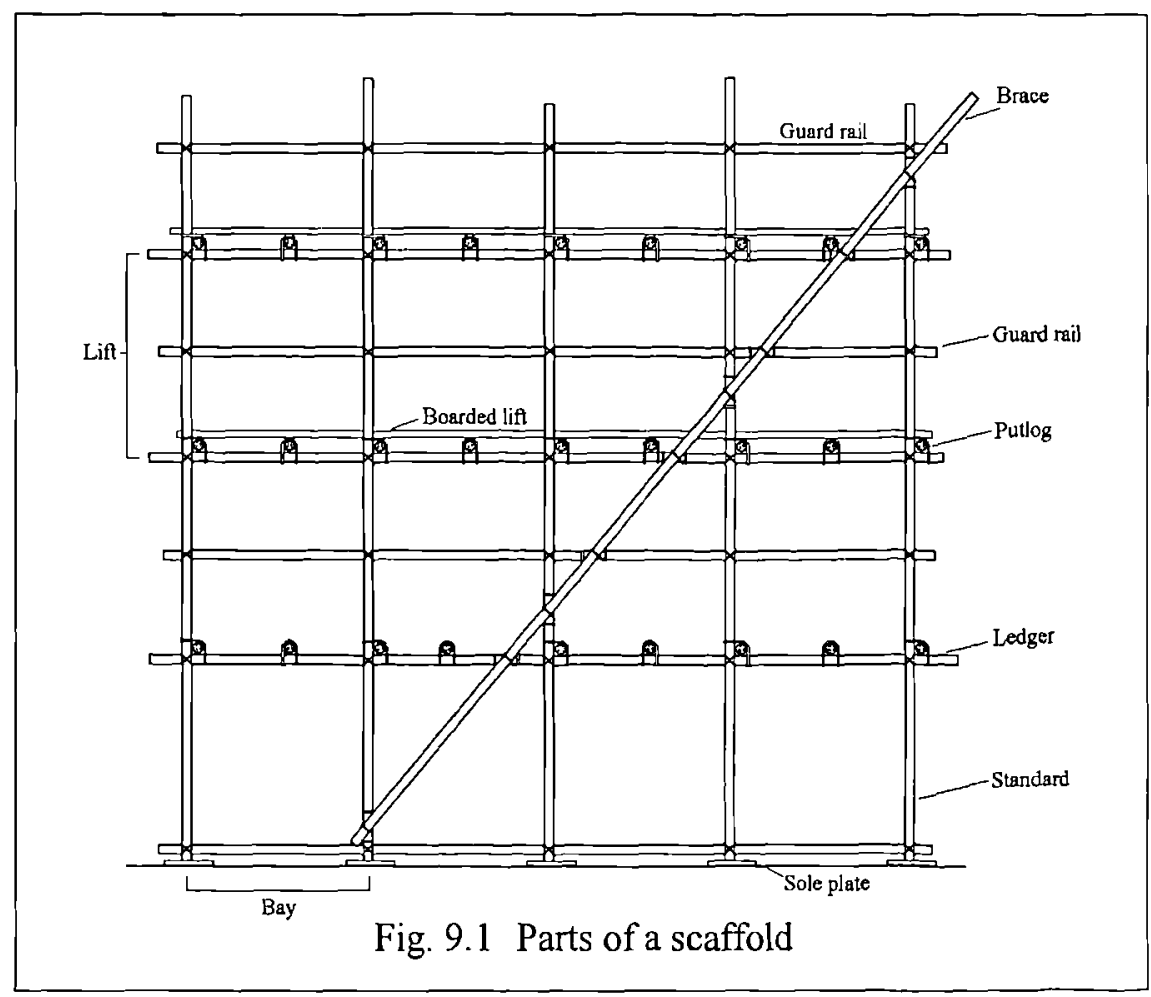

Rakers are poles running at an angle, usually around $60^{\circ}$, from the scaffold to the ground to resist overturning. They may be used on both putlog and masons' scaffolds (see below).

Scaffold types There are three relevant types of scaffold: the putlog scaffold, where there is a row of standards $4-5^{\prime}$ from the wall face with one end of the putlogs resting on the ledgers and the other supported by the wall under construction; the independent or masons' scaffold, where there are inner and outer rows of standards each carrying ledgers to which the ends of the putlogs are lashed; the trestle, where boards 
are laid between two trestles, or across two blocks of stone, used for temporary, low access. The several types of scaffold may be combined in a single wall face if circumstances so dictate.

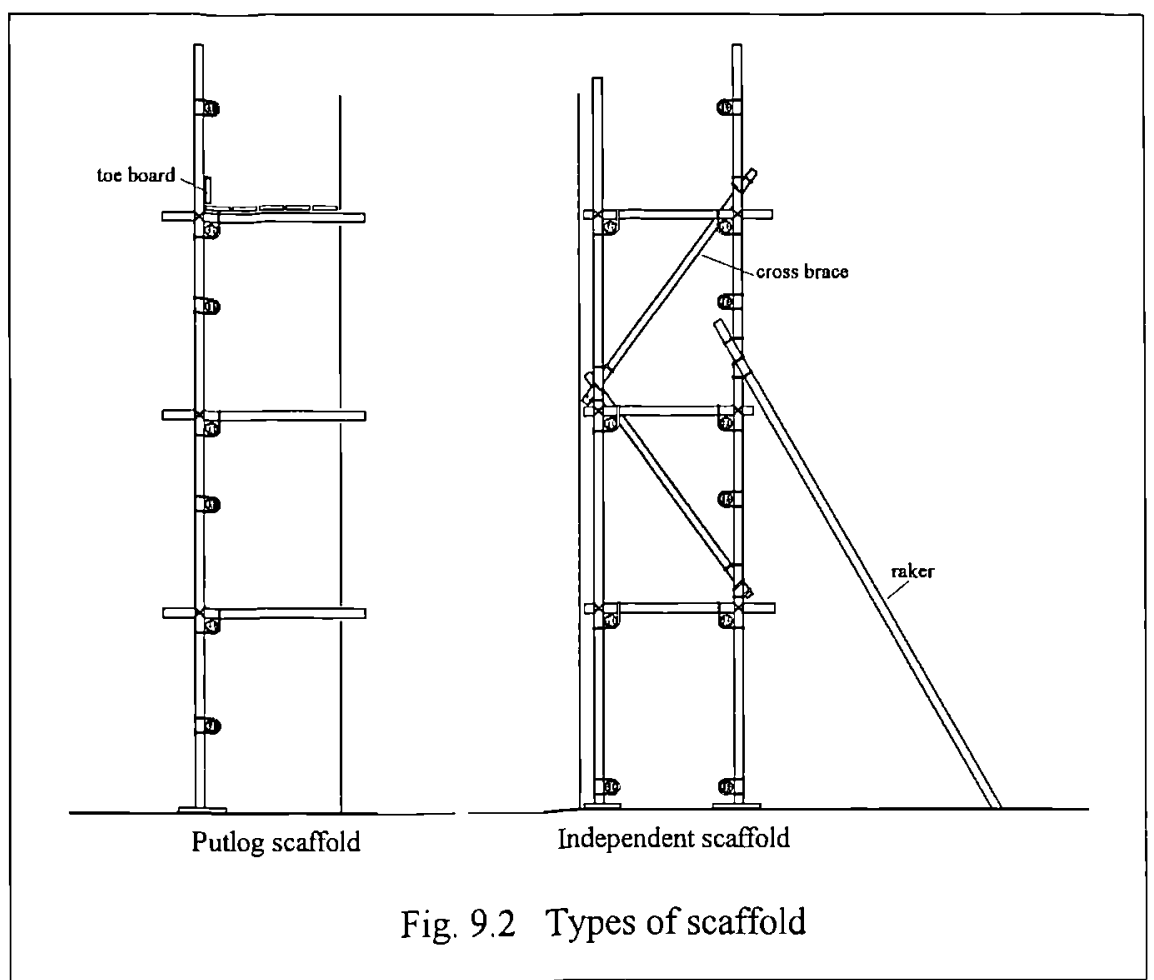

Standards are upright poles, which may be set directly on to a hard ground surface, or may rest on planks or stone pads, known as sole plates, or sunk into the ground by up to $2^{\prime}(600 \mathrm{~mm}) .^{541}$ Toe boards are low barriers, around 9" $(225 \mathrm{~mm})$ high, at the outer edges of the working platform to limit the likelihood of materials falling. 


\subsection{The need for scaffolding}

In 1947 the Handbook introduced the statement that 'No scaffolding would be needed on so wide a work. ${ }^{542}$ The effect of so working must be examined.

In the absence of scaffolding there are two ways to get men and materials to a height greater than $5^{\prime}(1500 \mathrm{~mm})$. The first is by ladders resting against the newly laid stone. It is a possible operation, but the difficulties of carrying heavy materials up a ladder and handing then to someone standing on the core, who has to lean over the wall to receive them, has to be experienced to be believed; it works, as the present writer can testify from experience, as an ad hoc system for moving half a dozen stones and a bucket of mortar, but would be hopelessly slow and inconvenient on a major building project involving millions of stones.

The alternative is to have men follow the difficult route of climbing up the core at the end of the stretch under construction, or ascending by means of scaffolding towers erected at intervals along the wall. But walking over the core, whether it were dry-laid, or clay or mortar bonded, would be immensely difficult. Dry rubble would make for a difficult footing when carrying heavy loads and the stones would move, causing undue pressure on the facing stones. It must be remembered that the roughly squared rubble facings would not, of themselves, be stable; there is considerable reliance on the strength of the mortar. Dependant on the nature of the mortar it might be anything from two or three days to the same number of months before a reasonably good set was achieved.

Clay bonded core would be slightly more stable in perhaps a day or so, but walking on the uneven surface would be just as difficult as on dry laid core. Mortar bonded core, where this existed, would have its own problems. Apart from stability

$542 \quad H B^{10} 37$. 
and the uneven surface, lime mortar can burn the skin to the point where the mediaeval stone layers were provided with gloves for protection ${ }^{543}$, and the effect on sandalled feet could be serious.

Furthermore, without scaffolding those laying the facing stones would have had to stand on the core. As the core would need to have been built up to within one or two courses of the top, the fixers would have been bent nearly double, while constantly handling heavy stones, for the duration of the project.

A less significant disadvantage of using the core as a working platform is that, given the rather rounded faces of the stones, working overhand would have made it difficult to check that the bed joints were fully pointed, although this could have been either ignored or done later by someone else using a ladder.

The statement in the Handbook may have derived from Alberti, who says that 'A very thick wall has no need of scaffolding because it it broad enough for the mason to stand on the wall itself. ${ }^{544} \mathrm{He}$ seems to be discussing walls of substantial cut stone held together by cramps, a very different proposition from the rubble of Hadrian's Wall. He gives no indication of how the materials were to be provided.

Certainly there is no alternative to the use of scaffolding for building the turrets where the side and south walls are only 3-4' thick. This is very close to the thickness of the horrea walls at Birdoswald, where unequivocal evidence for scaffolding has been found (see 9.3). The fact that there is as yet no clear evidence available from the turrets for the use of scaffolding ${ }^{545}$ cannot be taken as evidence that it was not used, and the same must be true for the building of the curtain wall.

\footnotetext{
543 York Fabric Rolls 92, quoted in Salzman (1952), 80.

$544 \quad$ Alberti (1775) 53. Taylor (1999) 148 accepts Alberti's statement.

545 The hole in the north face of the interior of T29a may represent a putlog hole, but there is not the same certainty as at Birdoswald. It would take a pole up to $115 \mathrm{~mm}$ diameter and is $250 \mathrm{~mm}$
} 
As will be seen from the possible speed of laying given in section 12.4 , the lack of scaffolding would call for an endless stream of men making a difficult ascent and walking along the core to the layers, carrying stone, mortar or clay and, on occasions, water. Men would certainly have to stand on the core in order to tip rubble into the middle and to tip and spread clay or mortar, but the picture of the core as a highway for the provision of all materials and as a platform from which to fix the facing stones is a ludicrous one; the current absence of signs of scaffolding must not be allowed to override practicalities.

\subsection{Scaffolding in Roman Britain}

There is ample evidence for the Roman use of scaffolding, both in Britain and the empire. A few sites are reviewed here to illustrate the point.

At Birdoswald, there is probable evidence for the use of scaffolding in building the porta principalis sinistra and certain evidence for its use in building the horrea $^{546}$

The standards used on the horrea were in post holes of $8^{\prime \prime}(200 \mathrm{~mm})$ diameter, but no indication was found as to the diameter of the posts. The four putlog holes (one pair in each of two bays), which went right through the wall, were between $5 \frac{1}{2} 2^{\prime \prime}$ and $61 / 2 "$ (140 and $165 \mathrm{~mm}$ ) square, but there is no indication of the size of the putlogs.

The standards are spaced at horizontal intervals of $51^{\prime \prime}(1300 \mathrm{~mm})$, and the putlogs at 61" and 67" (1550-1700mm) (see fig. 9.3). The offsets allow for the putlogs to lie on the outside of each pair of standards ${ }^{547}$ to give maximum support

deep to the corework at the back; the base of the hole is $1470 \mathrm{~mm}$ (57") from present ground level (author's survey). It may just represent a missing facing stone.

546 Wilmott (1997) 85-6 (porta principalis sinistra) and 114-5 (horrea).

547 Pace Wilmott (1997) fig. 75, where it is suggested that the putlogs butted against the standards. 
to the ends of the decking adjacent to the buttresses. The existence of the buttresses may have dictated the spacing of the standards, making it unsafe to use these figures on their own to establish normal Roman practice. It is clear, however, from the absence of intermediate putlog holes, that a spacing of around 63" (1600mm) between the putlogs was considered safe. The first lift seems to have been at a height of $66^{\prime \prime}(2 \mathrm{~m})$, which would have allowed movement around the base of the scaffold. Succeeding lifts may have been lower or could have been at the same height, with the fixers working from low trestles to reach the higher courses at the top of the lift. Lower lift heights were used at Wroxeter and Ravenglass, as discussed below.

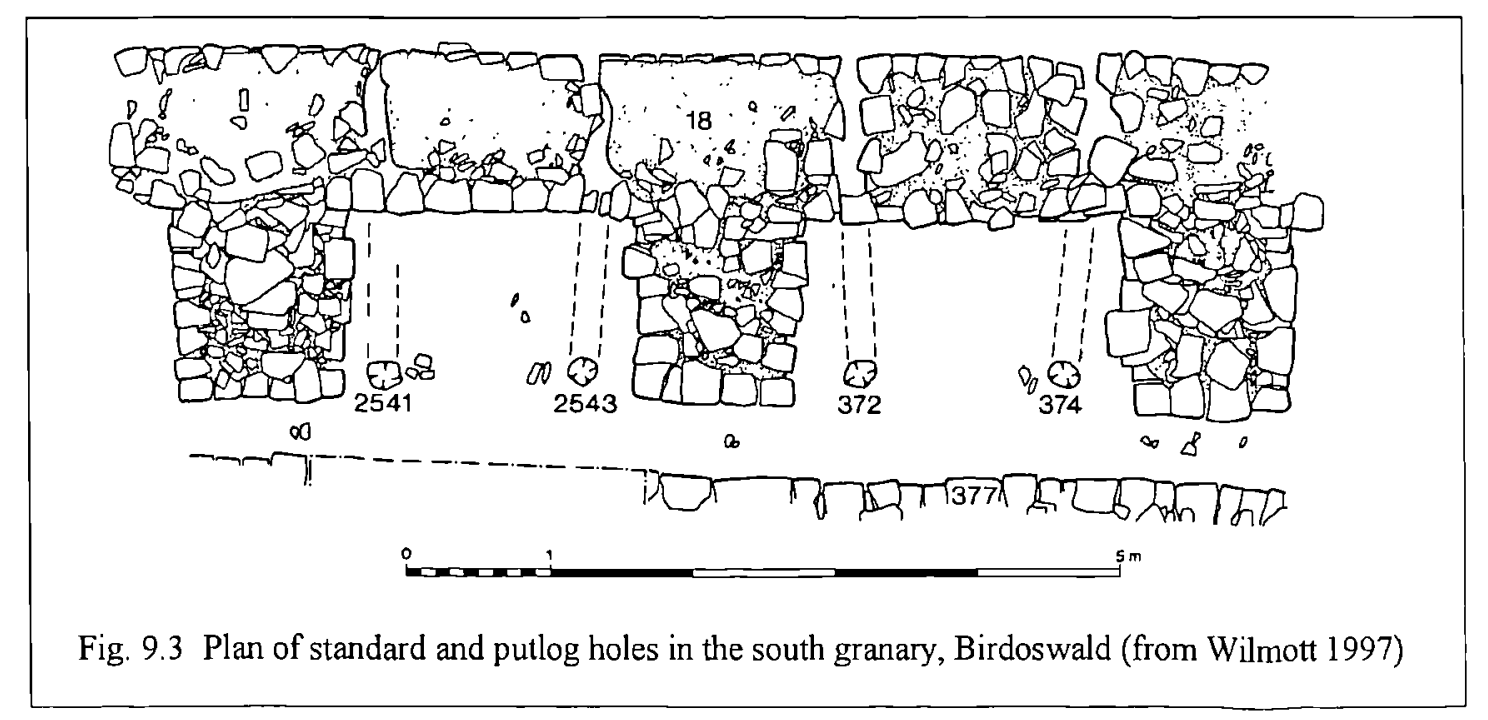

Two post-holes on the inner side of the porta principalis sinistra at Birdoswald were suggested by the excavator as possible seatings for standards. ${ }^{548}$ However, they are $11^{\prime}(3400 \mathrm{~mm})$ from the face of the tower, much wider than a normal scaffold; even with large stones to be handled, a 6 ( $(2 \mathrm{~m})$ wide scaffold is usually more than sufficient. The standards are $14^{\prime} 6^{\prime \prime}(4500 \mathrm{~mm})$ apart, about three times as

They are made fast to the ledger, alongside the standard.

Wilmott (1997) 85-6. 
wide as the normal spacing. The fact that they are joined by a slot also tends to indicate that they had some purpose other than simple scaffolding.

There is a possibility that these post holes represent provision for hoisting large stones. Weights of up to, say, 1cwt (50kg.) are easily lifted using a simple jib projecting from the face of the scaffold; there is an overturning moment, but that is usually resisted by a well-built scaffold. For heavier weights, a tower may be built onto the face of the scaffold, and the pull taken down within it.

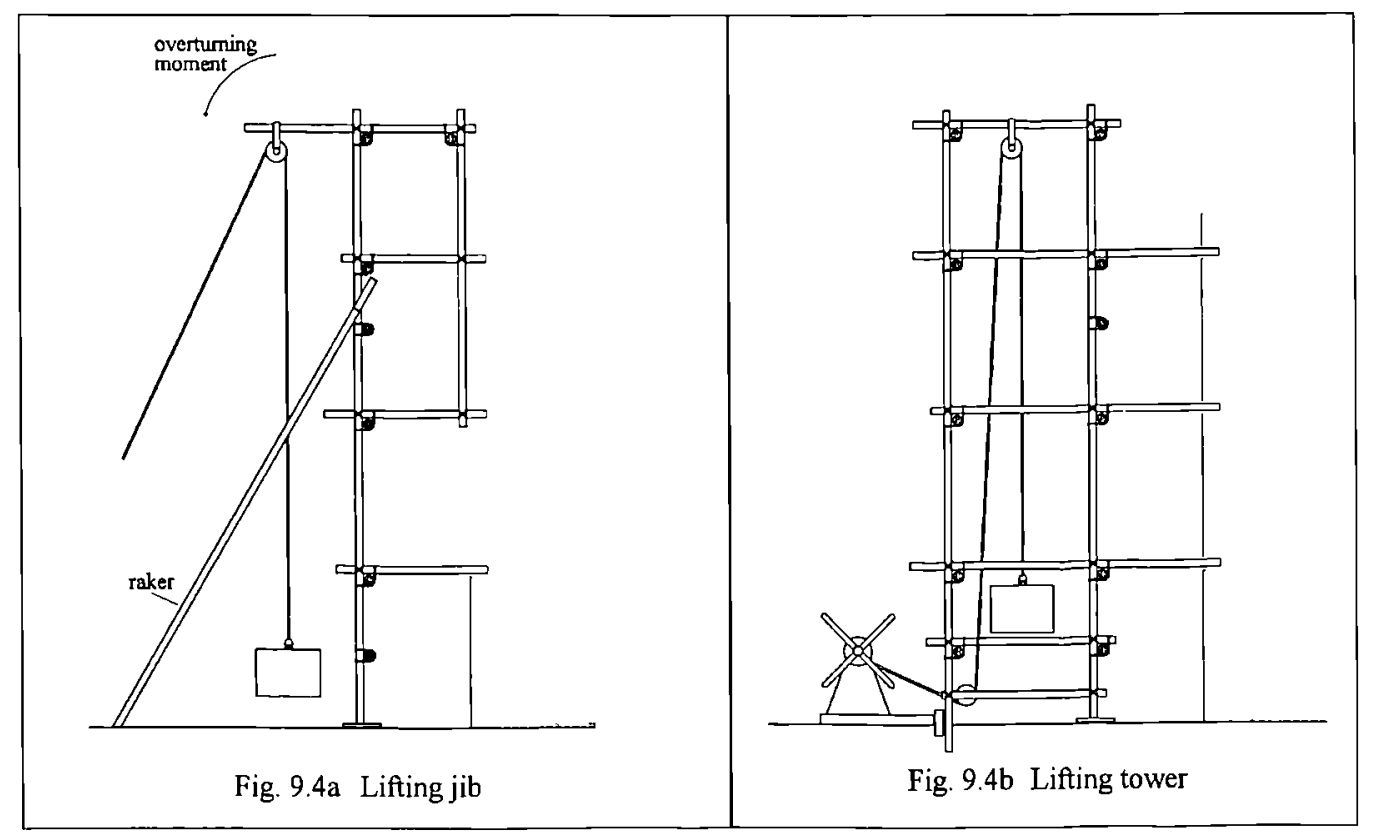

Figure 9.4a shows a lifting jib with simple gin wheel; figure $9.4 \mathrm{~b}$ shows a tower which is consistent with the two posts joined by a slot at Birdoswald. The purpose of the slot would be to take a beam to restrain the horizontal movement of the windlass. The identification is not certain; the slot is aligned towards the outer edge of the southern post hole but is on the centre line of the northern one. However, the holes are $21^{\prime \prime}(540 \mathrm{~mm})$ diameter; if they held posts $6 "(150 \mathrm{~mm})$ diameter, reasonable for the feet of major standards, there is ample room for the beam in the slot to pass on the eastern or outer side of the posts. The fact that they are cut into the primary road 
surface is not surprising, as a load-bearing surface would have been necessary for the movement of heavy stones. There was no trace of the scaffold itself, which may have rested on stone or timber pads on this surface.

Excavation of the north wing of the forum at Leicester produced three small post holes which were interpreted as the sockets for standards. The spacing is not regular; the intervals are $4^{\prime} 3^{\prime \prime}$ and $5^{\prime} 9^{\prime \prime}(1300$ and $1750 \mathrm{~mm}),{ }^{549}$ with no clear reason for the variation.

The Jewry Wall at Leicester shows several rows of Jarge putlog holes at horizontal intervals of $5^{\prime}(1500 \mathrm{~mm})$; the vertical interval is a little less. ${ }^{550}$

The standing wall of the frigidarium at Wroxeter ('The Old Work') shows putlog holes running through the thickness of the wall. The putlog holes 'occurred generally in $4 \mathrm{ft}$ to $5 \mathrm{ft}(1200-1500 \mathrm{~mm})$ vertical lifts', ssi but there does not seem to be sufficient remaining to show the horizontal spacing of the standards.

The bath house at Ravenglass is a better site to use, as being on a more 'domestic' scale than the baths of Caracalla (see 9.4) or those at Wroxeter and the Jewry Wall; the height to the wall plate may have been $11^{\prime} 6^{\prime \prime}(3.5 \mathrm{~m}) .{ }^{552}$ A detailed survey was made by the writer with the following results. The spacing of the putlogs is at horizontal intervals of $48-60^{\prime \prime}(1200-1500 \mathrm{~mm})$. The spacing is to some extent affected by buttresses, doors, and windows, but wall 5 (see fig. 9.5, where the wall numbers are those given by the writer) may indicate what the 'normal' spacing would be. There is a hole well to either side of the doorway, but not at the extreme ends of the wall, with an interval of $118^{\prime \prime}(3000 \mathrm{~mm})$; this is by any measure too long a run

\footnotetext{
549 Hebditch and Mellor (1973) 13 and fig. 7.

sso Kenyon (1948).

551 Webster and Woodfield (1966): Barker et al. (1997).

552 Brann (1985).
} 
between putlogs. An intermediate standard against the wall somewhat south of the centre line of the door opening to carry the inner end of a putlog would reduce the interval to about $5^{\prime}(1500 \mathrm{~mm})$. This does suggest that this might be the normal spacing, as seen at the Jewry Wall. Putlog spacing may have been influenced by the hurdles probably used for decking out the lifts (see below, 9.6.1).

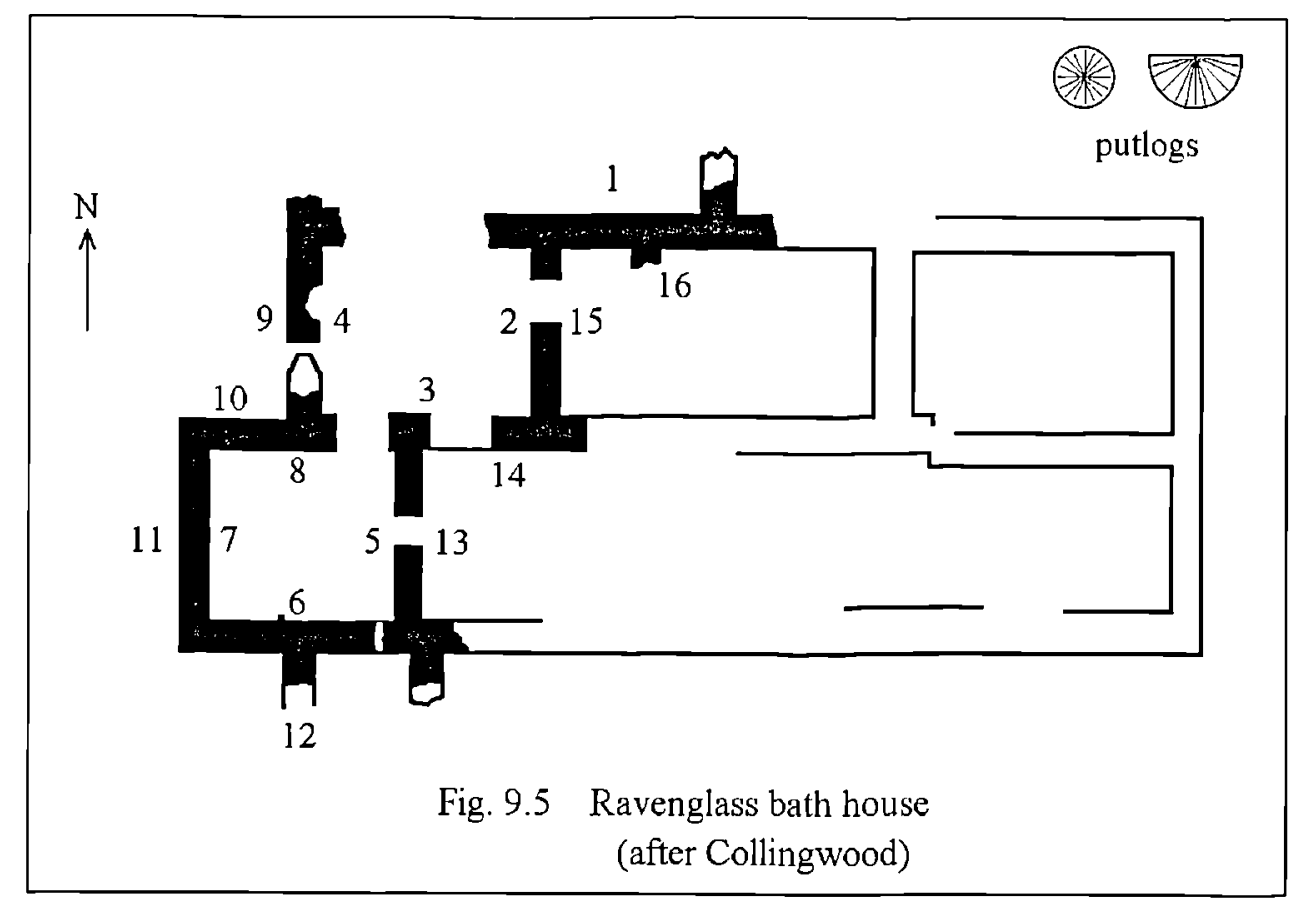

Impressions in the mortar inside the putlog holes give clear evidence of the size and form of putlogs used (see plate 9 overleaf). The majority were round poles 4 " $(100 \mathrm{~mm})$ diameter, with occasional use of split poles to give half-round putlogs up to 6" (150mm) wide by up to $41 / 2 "(110 \mathrm{~mm})$ (see fig. 9.5$).{ }^{553}$ The putlog holes go through the walls, but both mortar impressions and the position of core stones indicate that the putlogs were not always continuous poles but rather went something less than half way through the wall, giving a bearing of $12-18^{\prime \prime}(300-450 \mathrm{~mm})$.

553 This is at variance with Brann (1985) who records that the putlogs were roughly rectangular; the evidence for the circular form is very clear to the writer. 


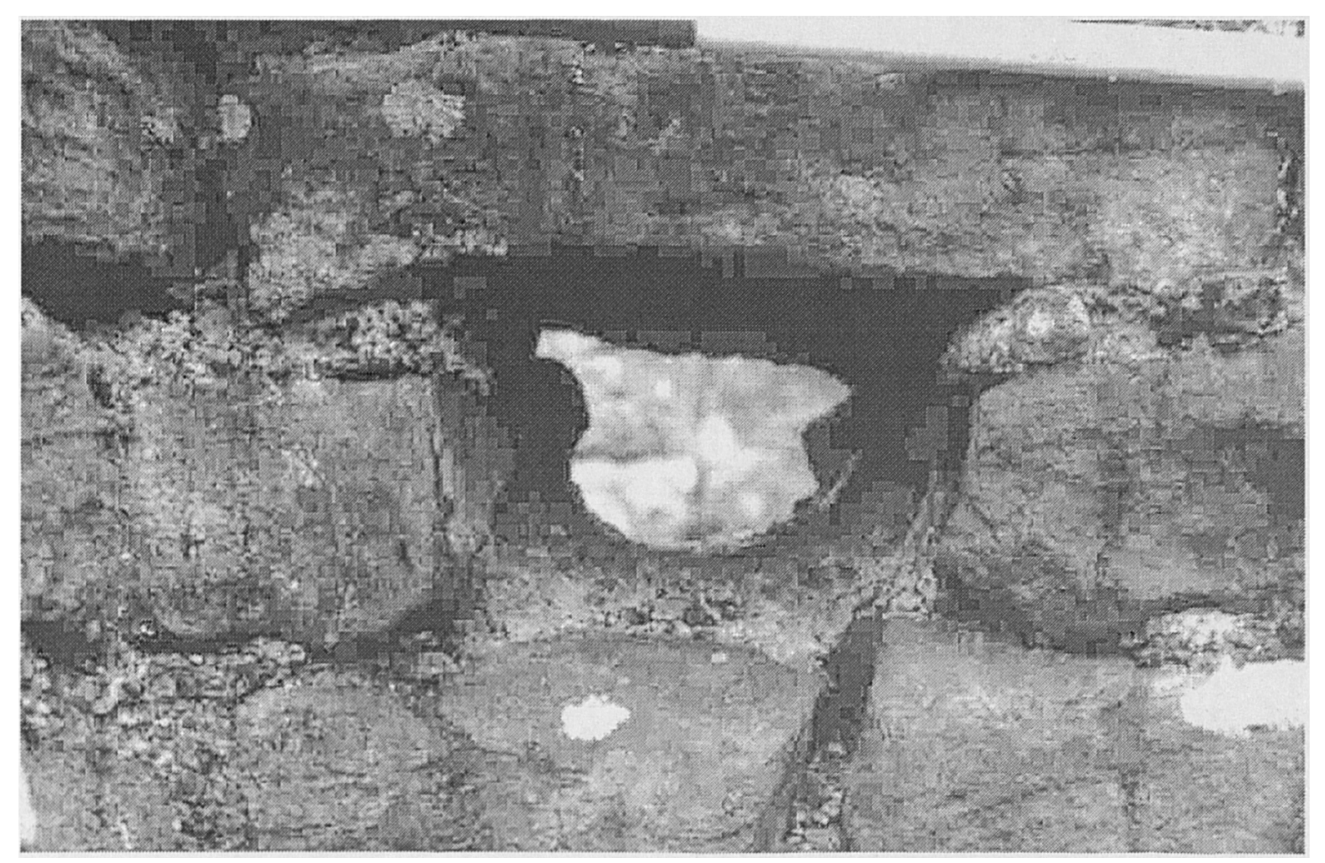

a. Putlog hole, wall 10

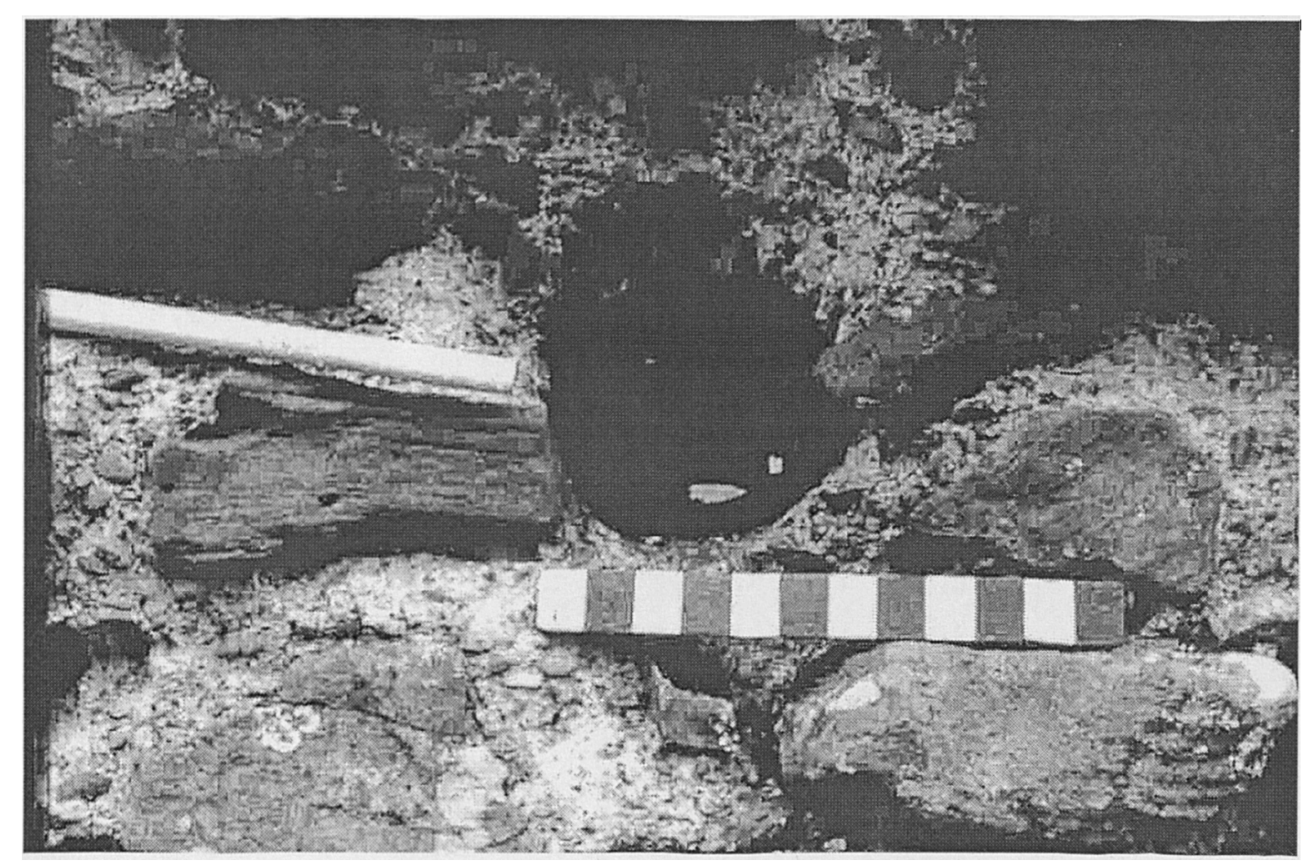

b. Putlog hole, wall 9 (scale 12”)

Plate 9 Impressions in mortar of the putlogs used in scaffolding, Ravenglass bath house 
The vertical spacing ranges from 45-54" (1140-1370mm), averaging 50" $(1270 \mathrm{~mm})$. Clearly, the builders were putting in a new lift of scaffolding as soon as the height became inconvenient; the stones used in the wall weigh in the order of 50$601 \mathrm{bs}(23-27 \mathrm{~kg})$.

\subsection{Scaffolding elsewhere in the Roman empire}

Ling gives the height of lifts on the 'Temple of Janus' at Autun as 39-60" (1-1.5m), but the figures here seem to be influenced by 'horizontal breaks' or 'building lines. ${ }^{554}$ These appear to be divisions visible in the building due to pauses in construction.

Some of the best evidence comes from the baths of Caracalla in Rome, ${ }^{555}$ where the walls are of brick with a concrete core. There were apparent variations in the design of the scaffolds, but it is clear that in the lower parts, at least, the putlogs were 4" $(100 \mathrm{~mm})$ diameter poles which went $20-24 "(500-600 \mathrm{~mm})$ into the wall. The horizontal spacing of the putlogs is irregular, but 'intervals roughly equivalent to 3 or 4 feet $(900-1200 \mathrm{~mm}) \ldots$ are common.' The lowest part of the walls, that is up to between $8^{\prime} 6^{\prime \prime}$ and 13' (2640-3960mm), appear to have been built with an independent scaffold. The higher figure is close to the presumed height of the Wall, around 14' 5 " $(4400 \mathrm{~mm})$, but it would be unsafe to draw parallels as to the nature of the scaffold used on Hadrian's Wall; building a very large, high bath house is very different from building a simple, comparatively low wall. There is no certain indication of the spacing of the standards; it would be surprising if they were coincident with every

\footnotetext{
$554 \quad$ Ling (1985) 23.

sss DeLaine (1997), esp. chapter 6. The quotations in this paragraph are all from this work.
} 
putlog. DeLaine's fig. 65 indicates that the vertical separation of the lifts was about the same at the spacing of the putlogs, that is some $3-4^{\prime}(900-1200 \mathrm{~mm})$.

The best contemporary illustration of scaffolding is from the tomb of Trebius Justus. ${ }^{556}$ This shows a single lift of independent scaffold; it is of no relevance for judging dimensions, but interestingly shows a guard rail at one end and a brace used across the other to prevent the scaffold racking outwards from the building. Toe boards are not shown.

Adam states that a Roman scaffold was always a light construction and could not be used for heavy blocks. ${ }^{557}$ He gives no evidence to support this, and it is difficult to see how any major building could be built without a scaffold capable of supporting single loads of at least half a ton. DeLaine shows that putlog holes in the upper parts of the baths of Caracalla are up to $200 \mathrm{~mm}$ square, suggesting a very substantial load-bearing capacity.

\subsection{The evidence for scaffolding along the Wall}

The evidence for scaffolding on the curtain wall is non-existent. The late Charles Anderson, formerly maintenance charge-hand on the Wall, recorded in conversation what he saw as evidence for scaffolding at Thorney Doors.

'About the centre of the picture, 99, you can see two small stones, flat stones, built into a hole which may be for a scaffolding point, and then further along the cliff, towards the rock, there appears to be two more in about the same level. ${ }^{558}$

\footnotetext{
556 Reproduced in e.g. DeLaine (1997), fig 63, and Connolly and Dodge (1998) 139.

557 Adam (1994) 82.

558 Taken from page 41 of a typescript of conversational notes made by Charles Anderson on his work along the Wall, held (2000) by English Heritage, Carlisle. The photograph number is that
} 
Having looked at the site and the photographic evidence, there is no obvious sign that they are putlog holes. When using putlogs built into a wall it is of course essential to be able to remove them. This is achieved by ensuring that the course above does not rest on the putlog; this is done by bridging the hole with a stone across the top (see fig. 9.6). It is not necessary to use thin flat stones either above or below the putlog. Given the variation in the sizes of facing stone, putlog holes, once made good, are not necessarily easy to identify. However, it is clear from Anderson's notes that in consolidation work parts of the Wall were dismantled and it would be surprising if any sure signs of putlogs were not seen.

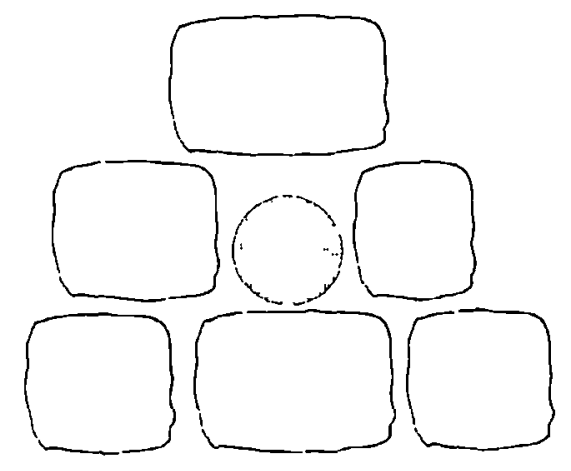

Fig. 9.6a Putlog hole

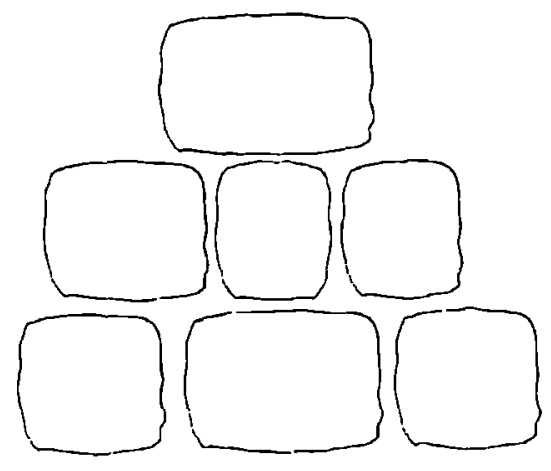

Fig. 9.6b Putlog hole made good

It is not necessary to use a putlog scaffold at all; the Wall could have been built using an independent scaffold, with an inner line of standards. Although this uses more timber, it has some advantages. An independent scaffold would allow more than one lift to be built at a time, but with a putlog scaffold each lift has to be built when the wall has reached the appropriate height; work would have to halt until the next lift of scaffold was erected, but if three lifts (see section 9.6.1) of independent

used by Charles Anderson; the caption on No. 99 refers to the south elevation of Thorney Doors, but is in reality the north face. 
scaffold were then erected at once there need be no more halts. This does of course use twice as many standards and might tie up large areas of scaffold which were not in immediate use, which could have been a disadvantage in such a major project when large quantities of wood were needed for many purposes.

Although the settings for the feet of the standards were identified at Birdoswald, these have not been found along the line of the Wall in excavations despite a consciousness of their possible existence. ${ }^{559}$ It is not in fact essential for the feet of the standards to be buried as they may be stood on a sole plate which might be a thick board or a stone slab, and thus little or no sign would be left. The rocky nature of the ground along the central sector, where the most extensive excavations of the curtain wall have taken place, also limits the likelihood of traces of the uprights being found. The fact that the Birdoswald horrea date to the early third century ${ }^{560}$ may indicate that sinking the standards into the ground was not Hadrianic practice.

The bonding courses (see section 4.2.3) may represent intervals in the work, and any relation to scaffolding lifts must be considered. If the former, they would be expected to be at equal intervals, but at MC37 the lower (sloping) course is between $4^{\prime}$ and 6 ' from the ground and the upper one about 4' above that. Between MC49, Harrow's Scar, and Birdoswald the single surviving course is 65-70" above ground level. Their use in relation to scaffolding is quite impossible as the coursing of the Wall normally follows the slope of the ground and scaffolding must be built horizontally. The bonding course on the west wall of Greatchesters, for example, slopes at about $20^{\circ}$ to the horizontal.

\footnotetext{
$559 \quad$ e.g. Bennett (1983) 32.

560 Wilmott (1997) 100.
} 


\subsection{The use of scaffolding on Hadrian's Wall}

Following the arguments above (section 9.2) it is taken for granted that scaffolding was used on Hadrian's Wall wherever sensible building practice dictated. ${ }^{561}$

\subsubsection{The probable nature of the scaffolding}

Until the mid-twentieth century most scaffolds were still of wood, in the form of poles lashed together with rope. If sufficient young trees were not available, mature trees could be split to size. The trees typical of the area were oak, alder, birch, and hazel, with some elm and pine (see section 3.4), all of which could have been useful in constructing scaffolds.

The figures for the size of scaffold poles which can be extrapolated from the Birdoswald and Ravenglass evidence accord reasonably well with early twentieth century practice for masons' timber scaffolds. Standards at this time were typically $10-30^{\prime}(3-9 \mathrm{~m})$ long, $5^{\prime \prime}(125 \mathrm{~mm})$ diameter at the base (unless cut down from larger timber, scaffold poles are tapered), 4-5' (1200-1500mm) apart, and resting on sole plates; putlogs were 3" (75mm) square, spaced 'more closely' than the 3-4' (900$1200 \mathrm{~mm}$ ) apart recommended for bricklayers' scaffolds. ${ }^{562}$ The Roman putlogs were slightly more substantial and their spacing slightly greater, as shown by the $4-5^{\prime}$ (1200-1600mm) average spacing on the Birdoswald horrea and the Ravenglass bath

\footnotetext{
561 As an incidental point, it should not be forgotten that stone walls need repairing from time to time. If maintenance were being carried out on a regular basis it is certain that within thirty to fifty years (the precise time depending on the quality of the original work) the Wall and every fort would always have a scaffold erected somewhere on the circuit for the rest of its life, either for repointing, replacement of rotten stone or the removal of destructive vegetation. Some work could have been carried out from a ladder, but a good deal of it would require scaffolding. 
house. Alder, poplar, fir, and ash were used for scaffold poles in mediaeval building, lashed with ropes of withies or bast, with alder predominating for the uprights. ${ }^{563}$

It is not known what Roman builders used to board out the working lifts; the painting in the tomb of Justus ${ }^{564}$ does not show this. Mediaeval practice was to use hurdles, as confirmed by contemporary building accounts, ${ }^{565}$ and it would be reasonable to assume the same for Roman builders.

The quantity of scaffolding required is difficult to estimate with any accuracy, as it is not possible to determine what the Roman army considered to be safe working practice, but it is worth making an attempt, based on reasonable assumptions, on mediaeval and early twentieth century practice, ${ }^{566}$ and what is known of Roman scaffolding. In view of the absence of putlog holes on the Wall the design is for an independent scaffold.

The standards are taken as $20^{\prime}(5.5 \mathrm{~m})$ high on the north side, $15^{\prime}(4.6 \mathrm{~m})$ on the south, standing $4^{\prime}(1.22 \mathrm{~m})$ from the face of the wall, connected by ledgers at $4^{\prime}$ $(1200 \mathrm{~m})$ lifts, with 5 putlogs secured to the ledgers at both ends. This gives three lifts on the south side and four lifts on the north side (see fig. 9.7). The height of the standards allows for a guard rail on the top lifts, and there is an extra ledger connecting the feet of the outer standards.

The spacing of the standards is at $5^{\prime}(1500 \mathrm{~mm})$ centres, ${ }^{567}$ with a putlog at every standard. Even when not being used to support the decking, the full complement of

\footnotetext{
S63 Salzman (1952) 318.

564 See note 556.

565 Salzman (1952) 320.

s66 Mr. P. Carlill, Foreman Scaffolder, York Minster, has kindly discussed the details of scaffolding with the author.

567 Newbold (1907) 28.
} 
putlogs and ledgers would be required to stiffen the scaffold. One diagonal brace might be expected for every two bays of the scaffold. The standards and putlogs might have been $5^{\prime \prime}(125 \mathrm{~mm})$ diameter at their thickest points, averaging 4 " $(100 \mathrm{~mm})$, the ledgers similar, and the braces and guard rail perhaps 3 " diameter.

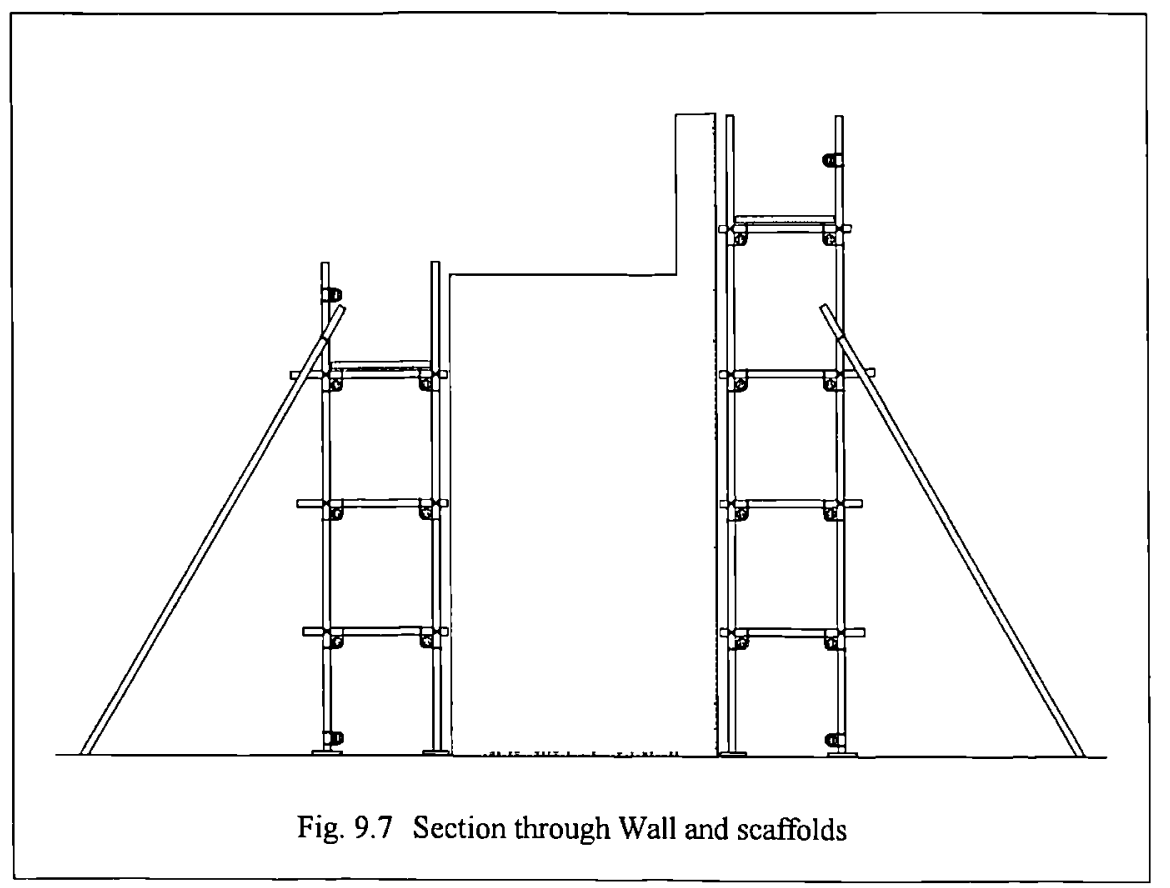

The full length of the ledgers, braces, and guard rail would have been made up by overlapping and lashing. An extra $2^{\prime}$ has been allowed for this at each joint, with the assumption that poles were obtainable in no more than $20^{\prime}$ lengths.

The working platform would probably have been hurdles, with one lift fully decked out. The length of the hurdles would match the spacing of the putlogs, with either an extra putlog to support the end of touching hurdles, or the hurdles might be overlapped at the junctions. In the assessment of material, overlapping is assumed, with one $6^{\prime}(1800 \mathrm{~mm})$ hurdle to each $5^{\prime}(1500 \mathrm{~mm})$ bay.

Such a scaffold cannot be tied-in to the Wall, and must be prevented from overturning. This would best be achieved by $4^{\prime \prime} \times 20^{\prime}(100 \mathrm{~mm} \times 6 \mathrm{~m})$ rakers running 
from the top of the third lift to the ground at $8-10^{\prime}(2.5-3 \mathrm{~m})$ from the foot of the scaffold; one raker to every three bays might be expected.

Building in squared rubble is a relatively rough process calling for speed rather than precision in the placing of the stones, and it would therefore be sensible to erect as long a run of scaffolding as possible to avoid frequent halts while the scaffolding was moved. What this length might have been is a matter of guesswork, and the very uncertain question of cohort and centurial lengths is discussed in section 12.3. The following table uses a module of one hundred feet, divided into twenty bays, which can be multiplied up as preferred. Scaffolding would be needed on both sides of the Wall at once, as discussed in section 9.6.

\section{TABLE 9.1 SCAFFOLDING QUANTITIES FOR HADRIAN'S WALL}

\begin{tabular}{|c|c|c|c|c|c|c|c|c|}
\hline Type & No. & $\mathrm{x}$ & length & $x c$ & dia & Overlap & $3^{\prime \prime}$ & $4^{\prime \prime}$ \\
\hline Standards $(\mathrm{N})$ & 42 & $\mathrm{x}$ & $20^{\prime}$ & $\mathrm{x}$ & $4^{\prime \prime}$ & & & $840^{\prime}$ \\
\hline Standards (S) & 42 & $\mathrm{x}$ & $15^{\prime}$ & $\mathrm{x}$ & $4^{\prime \prime}$ & & & $630^{\prime}$ \\
\hline Ledgers $(N)$ & 9 & $\mathrm{x}$ & $100^{\prime}$ & $\mathrm{x}$ & 4" & $72^{\prime}$ & & $972^{\prime}$ \\
\hline Ledgers (S) & 7 & $\mathrm{x}$ & $100^{\prime}$ & $\mathrm{x}$ & $4^{\prime \prime}$ & 56 & & $756^{\prime}$ \\
\hline Putlogs (N) & 84 & $\mathrm{x}$ & $5^{\prime}$ & $\mathrm{x}$ & $4^{\prime \prime}$ & & & $420^{\prime}$ \\
\hline Putlogs (S) & 63 & $\mathrm{x}$ & $5^{\prime}$ & $\mathrm{x}$ & $4^{\prime \prime}$ & & & $315^{\prime}$ \\
\hline Braces $(N)$ & 10 & $x$ & $20^{\prime}$ & $\mathrm{x}$ & $3^{\prime \prime}$ & & $200^{\prime}$ & \\
\hline Braces (S) & 10 & $\mathrm{x}$ & $20^{\prime}$ & $\mathrm{x}$ & 3" & & $200^{\prime}$ & \\
\hline Guard rail (N) & 1 & $\mathrm{x}$ & $100^{\prime}$ & $\mathrm{x}$ & $3^{\prime \prime}$ & $8^{\prime}$ & $208^{\prime}$ & \\
\hline Guard rail (S) & 1 & $\mathrm{x}$ & $100^{\prime}$ & $\mathbf{x}$ & $3^{\prime \prime}$ & $8^{\prime}$ & $208^{\prime}$ & \\
\hline Rakers (N) & 10 & $\mathrm{x}$ & $20^{\prime}$ & $\mathrm{x}$ & $4^{\prime \prime}$ & & & $200^{\prime}$ \\
\hline Rakers (S) & 10 & $\mathrm{x}$ & $20^{\prime}$ & $\mathrm{x}$ & 4" & & & $200^{\prime}$ \\
\hline \multirow[t]{2}{*}{ Totals } & & & & & & & $816^{\prime}$ & $4333^{\prime}$ \\
\hline & & & & & & & $249 m)$ & $(1320 \mathrm{~m})$ \\
\hline
\end{tabular}

The hurdles will have been made from brushwood resulting in part, assuming a reasonable degree of organisation, from the clearances and from the branches of 
trees cut for fuel. The British army gives times for soldiers to make them: ${ }^{568}$ a panel 6' by 4' (900 x 1200mm) would take three men some three and a half hours and use about $851 \mathrm{lbs}(39 \mathrm{~kg}$ ) of brushwood. Each module of curtain wall scaffolding calls for 40 hurdles, to deck out one lift on each side, taking six men 70 hours to produce.

One module of scaffolding so described allows for three lifts each of four feet on the south side, which brings the top lift just below the wall top giving reasonable access for flagging over the wall top, and four lifts on the north side to allow for building the parapet. The scaffold poles weigh about 8.5 tons, with another $1 \frac{1}{2}$ tons for the hurdles. ${ }^{569}$ Each one hundred foot scaffold run (both sides of the Wall) would also have called for some $4460^{\prime}(1360 \mathrm{~m})$ of rope or withies ${ }^{570}$ for lashing the spars.

Such a scaffold, with lifts not high enough for a man to stand upright on, could only be erected one lift at a time; if $6^{\prime}$ lifts were used there would have been some saving in timber and all could have been erected in one operation, but this does not accord with what is known of Roman practice.

The turrets and milecastle gate towers probably reached $35^{\prime}(10.7 \mathrm{~m})$ to the eaves, ${ }^{571}$ and needed more scaffolding in proportion to the curtain wall, in order to negotiate the corners and to allow an access hole in the interior scaffold. Using putlog scaffolds, a reasonable estimate of the scaffolding needed to take a turret to full height, in advance of building the adjacent curtain wall, is $4460^{\prime}(1340 \mathrm{~m})$ of

\footnotetext{
568 Manual of Field Engineering (HMSO 1911), plate 5.

569 Just over 400 cubic feet of timber, with the average weight of the unseasoned softwood timber reckoned at $45 \mathrm{lbs}$ per cubic foot (see section 10.2).

570 Salzman (1952) 319-320. The length of rope needed is based on 10' per joint.

571 In Hill and Dobson (1992) it is argued that the height of turrets and towers was at $29^{\prime}$ (9m). This was very much a minimum figure and the greater height assumed here ensures that the scale of the work is not underestimated.
} 
poles, and $200^{\prime}(60 \mathrm{~m})$ of $4^{\prime}(1200 \mathrm{~mm})$ wide hurdles, the whole weighing just under 7 tons (see fig. 9.8).

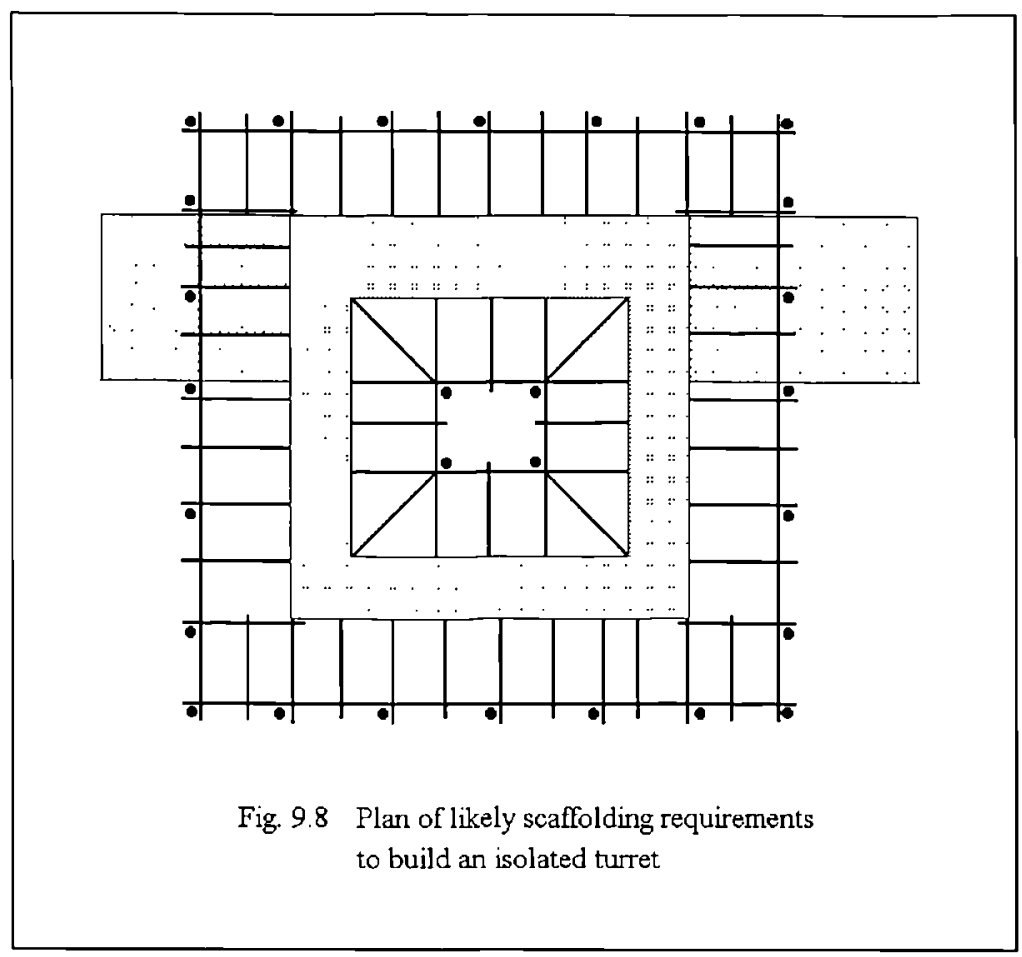

Again using a putlog scaffold, each tower on a type I or type II milecastle gateway would take 2,220' $(675 \mathrm{~m})$ of poles and $100^{\prime}(30 \mathrm{~m})$ of hurdles for the exterior. The interior scaffold is difficult owing to the need to provide internal access for materials; using the scheme illustrated in fig. $9.9,664^{\prime}(200 \mathrm{~m})$ of poles, 14' $(4.2 \mathrm{~m})$ of $3^{\prime}(915 \mathrm{~mm})$ hurdles and $8^{\prime}(2400 \mathrm{~mm})$ of $2^{\prime}(600 \mathrm{~mm})$ hurdles would be required.

There would have been many gangs working at the same time along the length of the Wall, making heavy demands on the timber resources of a countryside which had to a considerable extent been cleared for agriculture (see chapter 3 ). If each of the three legions had at any one time, say, five gangs taking curtain wall to full height, four gangs building milecastle towers, and two gangs completing turrets, the total 
requirement for scaffolding would have been about $150,000^{\prime}(45,720 \mathrm{~m})$ of straight poles to supply each legion. The provision of these large quantities of scaffolding may have been the major bottle-neck in the building programme.

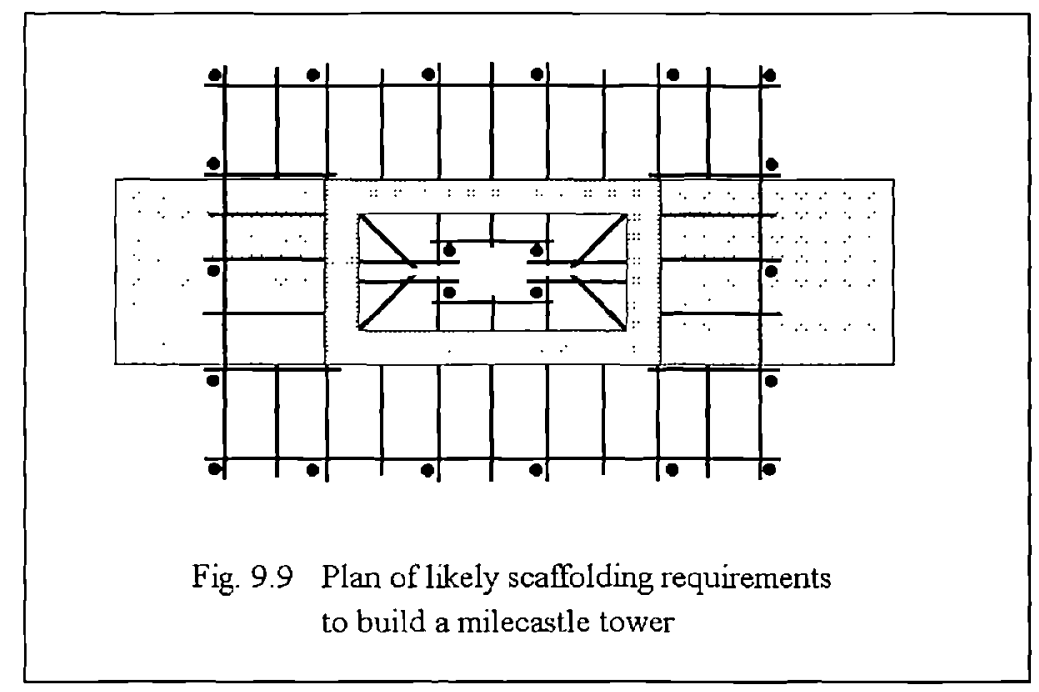




\section{CHAPTER 10}

\section{Transport}

The construction of the Wall will have called for resources to be devoted to the movement of materials to the building site. This section looks at the materials to be moved and their weights, and the various methods of transport available.

\subsection{Introduction and road construction}

The biggest problem facing the Roman builders was transporting the stone from quarry to building site. Stone has, at times and for special purposes, always been moved long distances, but only at the cost of a large expenditure in time and labour.

For the fourteenth century, when transport technology was not so very different from that of the second century, figures are available on which to base an appreciation of the problem. Salzman ${ }^{572}$ quotes the cost of transport at $2 \mathrm{~d}$. per ton/mile compared to the cost of the quarried stone at about $2 \mathrm{~d}$. per cubic foot (about 30d. per ton). Over a distance of about fifteen miles transport costs thus equalled the original cost of the stone, and the round trip by ox cart would have taken the best part of two days. A properly made road in the Roman period is quite likely to have been rather better than the average mediaeval road, but the difficulties would have been almost as great.

The typical Roman road had a sound bottoming of large stones, a separate layer or layers of smaller stones to form a smooth, cambered running surface, and a ditch

572 Salzman (1952), 119. 
at each side to drain away surface water. ${ }^{573}$ A section cut across Dere Street shows very clearly the method of construction. ${ }^{574}$ It consisted of three layers rising 2'3" $(680 \mathrm{~mm})$ at the centre from the natural whinstone surface: $3^{\prime \prime}(75 \mathrm{~mm})$ of soil and small pebbles; 9" $(230 \mathrm{~mm})$ of undressed broken stone, which tapers to the edge of the road; $15^{\prime \prime}(380 \mathrm{~mm})$ of rubble, again tapering to the edge. This upper layer is described as being 'largely angular except at the surface, where they are mostly rounded and more regular in size.' The roundness was presumably the result of wear. The ditches are $18^{\prime \prime}(450 \mathrm{~mm})$ below the original surface.

The notion of a 'smooth' running surface is comparative. Small stones used for the top dressing of nineteenth century toll roads were likely to be broken stone or gravel, and the former could be the size of a walnut or even a hen's egg. ${ }^{575}$ The intention was that this small stone would be ground down by the iron-shod wheels, the resulting dust helping to bind the surface.

Late twentieth century roads have a top dressing bound with tar or bitumen, and heavily rolled. This gives a very different surface from the untarred road used by iron-tyred wheels. A 'smooth' Roman road is very far from smooth when one is pulling a cart shod with iron tyres, which cannot deform to absorb inequalities but have to climb over them. The writer has moved building materials on a cobbled road, using a large-wheeled, iron-tyred builders' cart; it was not a rewarding experience. However, it should be noted that this is not the same surface as described above for Roman roads; a cobbled surface is made up of fist-sized, water worn stones set singly to give a very hard-wearing but uneven surface. The same cart used on a road similar to Roman roads, but with a newly (mechanically) rolled surface of 1 " to dust

\footnotetext{
573 For a discussion of the varieties of Roman road construction, see Chevallier (1989).

574 Ball (1927).

$575 \quad$ Bird (1973) 53.
} 
limestone dressing, was a much easier proposition, but the cart was still liable to be deflected by small stones. After a period of use, such roads become rutted, if only lightly, and stones larger than the top dressing tend to work to the surface making progress less easy.

\subsection{Materials to be transported}

Table 10.1 AVERAGE WEIGHTS OF MATERIALS ${ }^{576}$

$\begin{array}{lll}\text { MATERIAL } & \text { SPECIFIC } & \text { LBS PER } \\ \text { GRAVITY } & \text { CUBIC FOOT } \\ \text { Sandstone facing } & 2.32 & 145 \\ \text { Basalt (whin) } & 2.86^{577} & 178 \\ \text { Clay } & 2.0 & 125 \\ \text { Sand (coarse pit) } & 1.61 & 100 \\ \text { Quicklime } & 0.96 & 60 \\ \text { Mortar } & 1.6 & 100^{578} \\ \text { Core stone } & 1.76 & 110^{579} \\ \text { Water } & 1.0 & 101 \mathrm{bs} / \text { gallon }(6.25 \text { gall/cubic foot) } \\ \text { Oak, green } & 1.0 & 62^{580}\end{array}$

Lime, sand, water, and clay would break down into loads of any size. The facing stones weigh, on average, around $64 \mathrm{lbs}(29 \mathrm{~kg})$ each; in some parts the lower courses

\footnotetext{
576 The following figures are taken from Molesworth (1910) 26-29, unless otherwise noted.

577 Holmes and Hanwood (1928), where the specific gravity is given as 2.95. Molesworth (1910) gives a range from 2.70 to 2.95 , with an average of 2.86 ; it is the latter figure which is used here.

578 Sand, clay, and lime are average figures.

579 War Office (1935) 309,360 . The figures vary from 96 to $110 \mathrm{lbs} /$ cubic foot, for stone broken to 8-12" gauge. Rea (1902) says that excavated rock increases in volume by $50 \%$ (size not specified). He gives chalk as increasing by about $20 \%$ depending on size. $110 \mathrm{lbs}$ seems to be a reasonable compromise for whin stone core; sandstone will be nearer to 96lbs (s.g. 1.54).

580 Newbold (1926) 39. This is an approximation - it can be heavier.
} 
of the Wall incorporate much larger stones. For a more detailed discussion of the weight of facing stones see below (section 12.4). The largest scaffolding poles, for the standards, would have weighed around $601 \mathrm{bs}(27 \mathrm{~kg})$ for a $15^{\prime}$ length.

The milecastles and turrets needed beams, for upper floors and barrack roofs; the heaviest of these is likely to have been the turret floor joists, estimated at around $180 \mathrm{lbs}(81 \mathrm{~kg}) .^{581}$ The milecastle gateways were built of large squared stones with weights of $285-1630 \mathrm{lb}(129-739 \mathrm{~kg}) .{ }^{582}$ The merlon caps found on several sites had a transport weight of about $109 \mathrm{lbs} / 49 \mathrm{~kg} .{ }^{583}$

When the forts were added to the Wall, the problem became much greater. The fort gateways used on occasions very large stones, as has already been discussed (section 7.3). Chesters fort has such large stones in its gate piers that a sample is worth listing in table 10.2; for a key to the stone references, see section 1.6. The given weights assume that the stone was fully worked in the quarry. As the remains of lewis holes are often too shallow to be serviceable 584 it is certain that the top beds of some stones at Chesters were worked down on site and thus the transport weight will have been heavier than the extant stones.

581 Based on dimensions in Hill (1997b), and assuming the use of unseasoned softwood at an average of $45 \mathrm{lbs} / \mathrm{cubic}$ foot. Green oak could have weighed half as much again.

582 Based on the author's surveys of MCs37, 39, 42, and 48. There are 25 fully measurable stones in the piers of MC42; the average weight is $1085 \mathrm{lb}(496 \mathrm{~kg}$ ). The average at MC37 north gate is $11201 \mathrm{bs}(510 \mathrm{~kg}$ ); see section 7.3 .

583 This is the writer's calculation of the weight of the half-cap found in T7b, see Birley (1930) 150.

584 Hill (1997a). 


$\begin{array}{cll}\text { TABLE 10.2 SOME PIER STONES FROM CHESTERS FORT } \\ \text { Stone } & 1 \mathrm{bs} & \mathrm{kg} \\ \text { EGNE1/1 } & 2505 & 1140 \\ \text { EGSE1/1 } & 2270 & 1030 \\ \text { WGNW1/1 } & 2970 & 1350 \\ \text { WGSW1/1 } & 2920 & 1325 \\ \text { EGES1/1 } & 2415 & 1095\end{array}$

Several stones from the south and west gates at Housesteads are well in excess of half a ton as now seen. ${ }^{585}$

The largest stones of the base course of the later second century abutment of Chesters Bridge typically weigh in the order of 0.58 tons (tonnes). ${ }^{586}$ The column lying on the east abutment weighs about 1.67 tons (1.7 tonnes); the weight of columns in the principia has already been discussed (section 7.3).

The tie beams spanning the principia basilica will almost certainly have been the largest timbers used in a fort. At Chesters, the span of the nave averages 27'6" $(8390 \mathrm{~mm}){ }^{587}$ giving an allowance for bearing of one foot at each side, a beam of $29^{\prime} 6^{\prime \prime}(9 \mathrm{~m})$ will have been needed. Based on mediaeval practice ${ }^{588}$ a beam $12^{\prime \prime}$ $(300 \mathrm{~mm})$ square might have been used, with a weight of $1830 \mathrm{lbs} / 830 \mathrm{~kg}$. Four such beams would have been needed, one to each pier.

It is perhaps unnecessary to go into further detail. It is clear that a proportion of the building works will have called for the transport of a considerable number of

\footnotetext{
$585 \quad$ Hill (1995).

${ }_{586}$ Measurement of stones on and in the bridge was carried out by the author. Calculation is at a weight of 1451bs/cubic foot. Bidwell and Holbrook (1989) 48, calculate the average weight of the stones used in the bridge to be an almost identical 0.59 tonnes.

587 Author's survey.

${ }_{588}$ As observed by the author in mediaeval cathedrals.
} 
stones well in excess of half a ton, with some well over one ton and a few approaching two tons; the problems of transport would have been exacerbated in terms of individual load size, as well as simply of quantity, when forts were added to the line of the Wall. In most cases it would have been easy to reduce the dimensions of the larger stones such as those used in Chesters fort; the fact that they were not so reduced indicates that their transport was not a serious problem.

\subsection{Methods of transport}

\subsubsection{Man carrying}

Where the material sources were very close to the Wall, animals would not be necessary, and manpower would be substituted. This would be by means of buckets, baskets, or skins, on hurdles, or directly by the legionary, depending on the material.

For short carries, stones and turf could have been carried on the shoulders or backs of the soldiers, as shown on Trajan's column. ${ }^{589}$ Weights of perhaps $112 \mathrm{lbs}$ $(50 \mathrm{~kg})$ could have been moved in this way over short distances. ${ }^{590}$ Fitchen $^{591}$ quotes several sources which show that porters accustomed to the work could carry two or three times this load, but the legionary was a general purpose worker and not a porter. Shirley allows for man-carry loads of $50 \mathrm{~kg}$, recognising that many loads would in practice be smaller where materials were not conveniently divisible into $50 \mathrm{~kg}$ loads. ${ }^{592}$ It might be better to allow for a man-load to be about $751 \mathrm{~b}(34 \mathrm{~kg})$. This limit would serve to move large core stones, most of the facing stones, and

\footnotetext{
$589 \quad$ e.g. scene $\mathrm{lx}$.

590 The present writer, in days gone by, was accustomed to unloading 1cwt bags of cement, and carrying over a distance of perhaps 20'. Heavier loads called for a wheelbarrow.

591 Fitchen (1986) 172.

592 Shirley (2000) 145.
} 
other materials where the quarry was close to the line of the Wall. It must be remembered, however, that stone is an unyielding material and much harder to carry than soft loads such as turf or sacks.

The distances for man-carrying are not easy to determine. The British army, working with native labour, saw wheeled (horse) transport as economical for distances of above 200 yards and, by implication, the use of man-carrying for shorter distances. $^{593}$

That ideal device for moving materials over short distances, the wheelbarrow, does not appear to have been available to the Romans. The subject is discussed at some length by two writers, Sherlock and Lewis. ${ }^{594}$ The following notes are based on the latter's article. Its origins seem to lie in first century AD China and the first record in the west is around $\mathrm{AD} 1200$. Roman literature gives no word for a singlewheeled cart and the only illustration of a two-wheeled hand barrow appears to be a forgery. But in Greece, in two inventories of a temple treasury and building equipment stores in Eleusis, there appears monokyklos, a single-wheeled cart, which can hardly be other than a wheelbarrow. ${ }^{595}$ It is not known how widely it might have been used or whether it was taken up by the Romans; perhaps not, as the language of the wheelbarrow owes virtually nothing to Latin. But very few inventories of builders' yards survive, and other literature could not be expected to be interested in such a humble device. However, in the absence of firm evidence the use of the wheelbarrow must be discounted.

\footnotetext{
593 War Office (1935) 358.

594 Sherlock (1978); Lewis (1994).

595 Lewis (1994) 471. The inventories date to 408-407 and 407-406 BC.
} 


\subsubsection{Pack transport}

It is likely that where the distance from the source to the site was above that suitable for man-transport, carriage of items which would break down into suitable loads would have been by pack animal of which each legion had several hundred. ${ }^{596}$ Building stone was certainly so transported as late as the end of the eighteenth century. 'I have seen building stone carried on horseback along the finest road in the kingdom, close by the side of which they were raised and conveyed to a neighbouring town through which the road passed. ${ }^{1597}$

Varro remarks that all vehicles on the road were pulled by mules; 598 this may be overstating the case but it is clear that the mule was very widely used in the Roman world. The Theodosian Code (see 10.3.5) refers to the use of mules for pulling the vehicles of the cursus publicus, and Trajan's Column shows army mules used for both traction and as pack animals. ${ }^{599}$ Josephus describes the Roman soldiers placing their baggage upon mules as they prepared to march. ${ }^{600}$ The use of the mule is not surprising, as he is more sure-footed, can work on a poorer diet, carry heavier loads,

596 Six hundred at the minimum of one per contubernium. Dr. Brian Dobson has pointed out to the writer that there is no justification for this generally accepted figure, the space in the PseudoHyginus marching camp being simply allocated iumentis. There can hardly have been a lower scale, and in practice each legion is likely to have had well over a thousand. It may be relevant that in the 1846 war between Mexico and the USA, General Taylor's army limited pack mules to one for every eight men (Essin (2000)).

597 Marshall (1796) I, 294.

598 de Rustica II, 8, 5.

599 Adams (1993) argues that the majority of draught mules were female, and that pack mules were more usually (castrated) males. He points out that although mules can very rarely reproduce, the castrated male is more manageable than the entire.

600 Josephus III, v, 4. 
is less prone to sore back, and is generally hardier, than the horse. ${ }^{601}$ It is also said that 'the make and shape of a number of mules' backs are not liable to great variation. ${ }^{602}$ This clearly makes the fitting of a universal pattern of pack saddle much easier.

Despite this, there is very little direct evidence for the use of the mule in Britain, or indeed in other provinces. Mules are not easy to identify from skeletal remains, and there has been very little study of mule dentition which seems to give the best means of differentiating between horse/pony and mule. A jaw bone from Billingsgate is believed, on the balance of probabilities, to have been that of a mule, and the writers suggest that 'many more mules await identification among excavated bone material in the province of Britain and elsewhere. ${ }^{1603}$ An ass of $13 \mathrm{hh}$ was identified at Newstead, ${ }^{604}$ and at Tripontium (Caves Inn, near Rugby) the remains of one donkey were found in a well, ${ }^{605}$ and possible remains of one at Frocester Villa in Gloucestershire, ${ }^{606}$ but no other finds of mules or their sires are known in Britain.

In the Thames Valley a funerary vase records the profession of the deceased in a Greek-Latin compound form of mulomedicus; ${ }^{607}$ the presence of a mule physician suggests that mules were used in the province in sufficient numbers to support the work of a specialist rather than a horse doctor. A possible saucepan handle terminal in bronze from Great Llanmelin Farm, Gwent has been identified as being the head

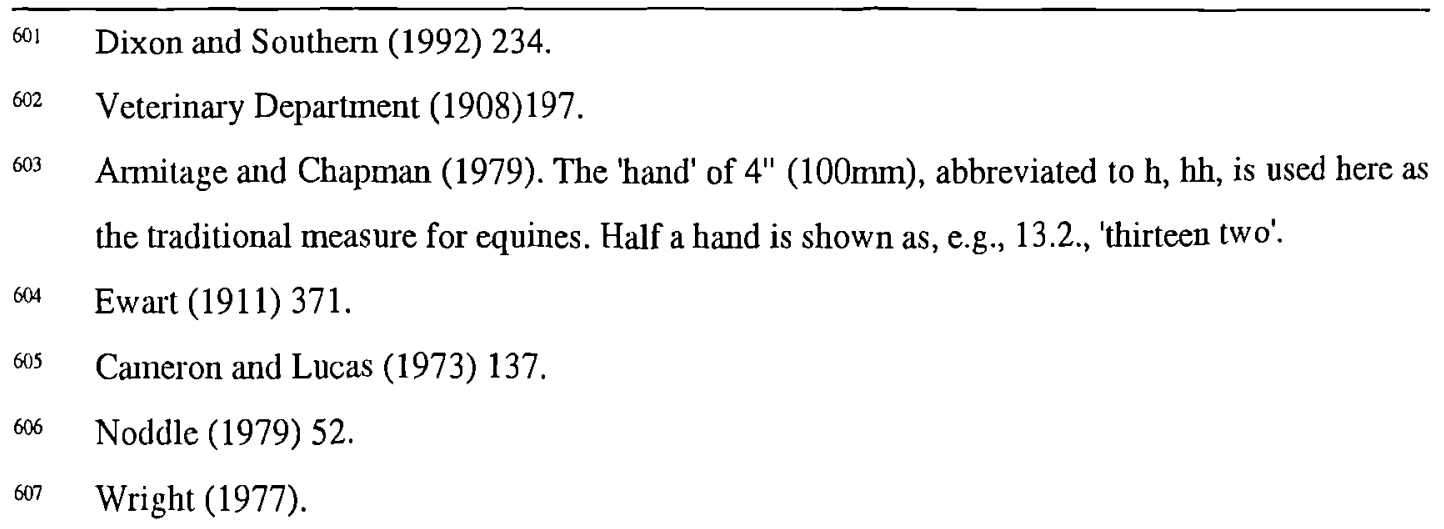


of a mule; ${ }^{608}$ this may suggest that the mule was known in the vicinity, although the possibility of it being imported ware cannot be ignored. A Pictish carved stone from Inchbrayock in Angus, probably of the eighth century, shows a huntsman mounted on a mule. ${ }^{609}$ This ought to mean that mules were not unfamiliar in north Britain at that time; perhaps the tradition of the mule, in fact or memory, had come down from the Romanised parts of the north. None of these instances provides serious direct evidence for the presence of the mule in Roman Britain, but they do perhaps suggest that it was not unknown.

Hyland notes that mules and asses, like horses and ponies, do not do well in miserable, wet, and cold conditions, but that ponies do rather better and that 'Europe has many breeds of weight-carrying pony that would have supplied the legions in place of mules. ${ }^{1610}$ It is difficult to assess to what extent the Roman army was affected by adverse conditions, and Mendoza believes that mules stand extremes of temperature better than horses. ${ }^{611}$ The fact that an ass was found at Newstead ${ }^{612}$ suggests that these animals were in use in northern Britain, and if there were an ass there are quite likely to have been mules as well. The modern donkey survives well enough in Britain and it seems improbable that the Romans, far less kind to their animals than the modern British, would not have taken advantage of the useful qualities of the mule even if it meant a high turnover in animals.

\footnotetext{
608 Webster (1991).

609 Dent (1972) 69-70. The identification cannot be beyond doubt, but the marked difference between this equine and those on other Pictish stones which are distinctly horses makes it probable.

610 Hyland (1990) 72.

611 Mendoza (1983) 147.

612 Curle (1911) 371.
} 
'Donkey' it should be noted is simply an English term for the domesticated ass; the British donkey is normally a small animal as a result of breeding in a less than favourable climate. ${ }^{613}$ It may not be a large animal, but it survives and until the 1940s was widely used as a light draught animal. ${ }^{614}$

There seems no good reason to doubt that the mule was used by the Romans as extensively in Britain as in the rest of the empire, even though it may well have been bred in other provinces and exported to Britain.

It is also to be expected, as Hyland suggests, that the Romans used the local ponies found in Britain. Among the skeletal remains from Newstead were a number of ponies of between $11 \mathrm{hh}$ and $12.2 \mathrm{hh}$ which Curle considers were probably used for baggage. ${ }^{615}$ Some of these were the Shetland type, equus robustus, thick-set with coarse limbs, and some of the Exmoor type descended from equus agilis with finer limbs. These latter are believed to be direct descendants of the native wild ponies ${ }^{616}$ which would have been available to the Romans. They grow to a height of about 12.2hh. Excavations at Corbridge from 1906-11 produced bones from at least ten equines. The analysis indicated that there must have existed in Roman Britain at least three types of horse: one around $14.2 \mathrm{hh}$, and perhaps up to $15 \mathrm{hh}$, which even today makes a respectable mount for a man; a type approaching the New Forest pony, of around 12.2hh; and one of the Exmoor type, around 11.2hh. ${ }^{617}$ Hyland discusses the variety of breeds in the ancient world and concludes that types of horse suitable for

\footnotetext{
613 Dent (1972) 145.

614 Dent (1972) chapter 7.

615 Curle (1911) 364-371.

616 Groves (1974) 84.

617 Meek and Gray (1911).
} 
all purposes were available in the Roman empire. The remains of both slender and broad-boned types of pony have been found at Vindolanda. ${ }^{618}$

Dixon and Southern $(1992,167)$ point out that as Caesar was able to mount men on baggage mules in order to present them as cavalry, there cannot have been a significant difference in the size of baggage and riding animals.

The Przewalski horse, which appears to be of similar build to the Exmoor, stands 13.2-14.2hh and weighs $250-300 \mathrm{~kg} .{ }^{619}$

There seems to be little doubt that the Romans did have available mules, ponies, or horses capable of carrying the substantial loads called for in transporting materials to the Wall.

\subsubsection{Loading of pack animals}

Armitage and Chapman refer to the apparent abuse of mules in the Roman period, at least when employed in the service of the cursus publicus, and the considerable numbers of replacement animals which must have been available. ${ }^{620}$ Modern concerns for animal welfare should not be allowed to intrude to an excessive extent on considerations of the likely loads placed on pack animals during the building of the Wall. Against this, one must perhaps set the affection which soldiers, at least in modern times, have for animals under their direct care. ${ }^{621}$ However, there is ample evidence that in the nineteenth century military pack animals were often treated as

\footnotetext{
$618 \quad$ Seaward (1993) 111.

619 Groves (1974) 55.

620 Armitage and Chapman (1979).

621 Lt.-Col. C.H. Jackman, Royal Logistic Corps (pers. comm.).
} 
disposable assets, and at times very little consideration was given to their condition. ${ }^{622}$

There seems to be no direct evidence for the load of a Roman army mule or packhorse (but see below, the discussion on tents in section 10.3.4), but as the size of the mule and pony seems to have changed little, more modern evidence ought to be relevant.

The pre-First World War British army mule of between 12.1 and 13.2hh was expected to carry $160 \mathrm{lb}(73 \mathrm{~kg}$ ) load plus a $65 \mathrm{lb}(30 \mathrm{~kg})$ pack saddle, a total of $225 \mathrm{lb}$ $(103 \mathrm{~kg})$ over distances of twenty or more miles in a day. ${ }^{623}$ This was at a time when the welfare of the British army horse and mule was studied and attended to probably more closely than at any time previously, ${ }^{624}$ and considerable care was taken to see that saddles were sufficiently rigid and well fitted so as to distribute the load in the way best suited to the animal's conformation ${ }^{625}$; this is likely to have meant both a heavier pack saddle and a lighter load than the Romans would have used. Even the War Office Veterinary Department cast doubt on the need for the heavy pack saddle in use in 1908,626 and it is quite possible to use a simple sawbuck pack saddle weighing as little as $7 \mathrm{lbs}(3 \mathrm{~kg}){ }^{627}$ This consists of two $\mathrm{X}$-frames joined by short planks with well-padded panels beneath.

\footnotetext{
$622 \quad$ e.g. Essin (2000), especially chapter 4.

623 Field Service Pocket Book (HMSO 1914), 134, 135, and Animal Management (HMSO 1908) $271,274$.

624 J.M. Brereton The Horse in War (Newton Abbot 1976) 127.

625 Veterinary Department (1908) 196-201, where a rigid pack saddle was reckoned to weigh one quarter of the total load.

626 Veterinary Dept. (1908) 197.

627 Constable (1983). Constable identifies a pack saddle on Trajan's Column (Cichorius No. 39) as being of this type.
} 
The more modern Mk IV British Army pack saddle weighs $40 \mathrm{lbs}(18 \mathrm{~kg})$ and a 14.2hh Highland pony is expected to carry this and a $160 \mathrm{lb}(73 \mathrm{~kg})$ payload for $15-20$ miles a day. ${ }^{628}$ This type of animal is similar to those available to the Roman army. On exercise, the rate of march is $20 \mathrm{~km}$ (12.5 miles) in 4 hours over rough country, or just over $3 \mathrm{mph}$ including halts; these are recommended as 10 minutes in the hour with a 30 minutes rest off-loaded every three hours. Some of the Defence Animal Centre training material allows a load of $310 \mathrm{lbs}(140 \mathrm{~kg})$ for a mule. ${ }^{629}$

The use of pack animals during the Second World War was on the basis of a $200 \mathrm{lb}(90 \mathrm{~kg}$ ) load for the average or typical animal; this was the norm for both ponies and mules when working day in and day out, often for long periods. Some animals could carry up to $300 \mathrm{lbs}(135 \mathrm{~kg})$ without problem, but carrying capacity depends more on conformation than height. Overloading of animals can give rise to saddle sores, which is the major problem to be avoided. ${ }^{630}$

The figures used by the modern British Army are $25 \mathrm{lbs}(11 \mathrm{~kg})$ less than was called for in 1908, and significantly lower than those used by civilians. This may be prompted by an absolute necessity of avoiding breakdowns in combat conditions, as well as welfare concerns. ${ }^{631}$ Under the Army loads, the animals are able to jump

628 DAC (1997). Miss S. Waldock and Mr F. Brudenell also kindly provided information on pack animals.

639 This paragraph is based on information from Sergeant Major Kohler, Defence Animal Centre, Melton Mowbray, in charge (2000) of Army pack transport training.

${ }_{630}$ This paragraph is based on a discussion with Major R. Jones (retd.) who was in charge of training 2,500 ponies for pack transport for a projected invasion of Norway in 1942.

631 It may be noted that the only mule now (2001) in the British Army, Alfred, stands 16.2hh and is not required to carry more than is Donald, a Highland pony of 14.2hh (Sergeant Major Kohler, Defence Animal Centre, pers. comm.). This very much suggests standardisation at the lowest practicable level. 
obstacles in very rough terrain, something which would not apply in the building of the Wall.

Shirley believes that the mule could carry $150 \mathrm{~kg}$ (330lbs), and the donkey $75 \mathrm{~kg}$ (165lbs). ${ }^{632}$ Mendoza gives the capacity of the nineteenth century Spanish ass as $90 \mathrm{~kg}$ (1981b) over $30 \mathrm{~km}$ a day, and of the mule as $120 \mathrm{~kg}$ (265lb) over the same distance. ${ }^{633}$ Dent says that the standard pack-horse load has been $224 \mathrm{lbs}$ (100kg) for the last 25 centuries or so, and that mules can carry more. ${ }^{634}$ Lugard says that mules of 13 hh carry $180-200 \mathrm{lbs}$ over rough country. ${ }^{635}$

In the eighteenth century pack horses were used to carry iron ore in Weardale; such a load was not unlike stone in having a small bulk but high density. Each animal carried two bags each of one hundredweight $(224 \mathrm{lbs} / 102 \mathrm{~kg}$ in total) in addition to the pack saddle, and moved in strings of between fifteen and twenty five with a single handler. The horses used were Galloways, $12-13 \mathrm{hh}$ and apparently similar to the Dales pony. ${ }^{636}$ One must expect that they were well up to their loads, as no civilian contractor would risk rendering his animals unfit due to overwork.

In the nineteenth century in the Yorkshire Dales 'the packhorse carried two pigs of lead, each weighing approximately $148 \mathrm{lb}[67 \mathrm{~kg}]^{\prime} .{ }^{637}$ The pay load of $256 \mathrm{lb}$ $(134 \mathrm{~kg})$ plus pack saddle may seem high, but there is other evidence that these ponies were good weight carriers.

\footnotetext{
632 Shirley (2000) 145, note 63.

633 Mendoza (1983) 150.

634 Dent (1972) 72.

635 Lugard (1893) 467.

636 Monkhouse (1942); Lee (1946).

637 Jennings (1959) 207.
} 
Dales ponies were bought by the British army to carry mountain guns weighing $3501 \mathrm{~b}(160 \mathrm{~kg})$, and were 'found to be all that was required. ${ }^{1638}$ Jankovich (1971). 165) quotes the Austro-Hungarian cavalry manual as referring to 'the standard English packhorse load of 2cwt' (224lb, 100kg).

The American army in the nineteenth century tended (there were exceptions) to prefer a mule of 13-14.2 hands, on the grounds that it could carry almost as much as the much larger Missouri mule, needed less food, and was hardier. It was also more nimble in rough country. ${ }^{639}$ Such a mule was expected to carry a payload of 200 250lbs $(91-114 \mathrm{~kg})$ on long marches. With a load of 200lbs $(91 \mathrm{~kg})$ the mule could move at eight miles an hour for 25 miles a day for seven continuous days. ${ }^{640}$ In the Second World War, Italian ponies and mules in the Apennines were loaded with up to $400 \mathrm{lbs}(180 \mathrm{~kg}$ ), and sometimes more, for short hauls and this in difficult country that was accessible only to the pack animal. The Italian animals were 'smaller and lankier' than the American mule. ${ }^{641}$

All the above indicates that the mule or pack pony could carry a payload of at least $250 \mathrm{lbs}(113 \mathrm{~kg})$ on long marches. Difficult country reduces the load, but the topography of the Wall area in the central sector is in this sense undulating rather than rough. In building the Wall, the distances materials had to be moved were very short, and half the round trip would be unladen. In view of this, and the apparent abuse suffered by animals in the Roman world, it will here be accepted that the mules or ponies would carry a payload of at least $250 \mathrm{lbs}(113 \mathrm{~kg})$, and probably more.

\footnotetext{
$638 \quad$ Hulme (1980) 32.

639 Essin (2000) 101.

640 Essin (2000) 105-6.

641 Essin (2000) 164-168.
} 


\subsubsection{Wheeled transport}

Where conditions permitted, or where loads such as the stones for the milecastle gate piers and voussoirs were either too heavy for pack mules or would not break down into balanced loads, draught animals would have been used. The carts may have been drawn either by mules or oxen, although until the advent of the modern heavy horse the ox has generally been preferred for very heavy loads or in poor conditions. ${ }^{642}$ Ox-drawn waggons are slower than those drawn by horse or mule, the former moving at about two miles per hour, the latter at three or four miles per hour. ${ }^{643}$

\subsubsection{Types and capacities of wheeled transport}

There is no factual information available on the capacities of wheeled transport or the size and nature of teams used by the Roman army in the second century. Leighton points out that much of what is 'known' is derived from later interpolations into classical texts, especially by Johann Christian Ginzrot who was himself a master coach-builder. ${ }^{644}$

The most detailed evidence for transport in the Roman world comes from the Theodosian Code. A decree of AD 357 issued by Constantius Augustus and Julian Caesar set limits of 1000 librae $^{645}$ for a raeda and 200 librae on a birota. A maximum weight on an angaria of 1500 librae was given in $\mathrm{AD} 368$ in a decree of Valentinian, Valens, and Gratian. ${ }^{646}$ In $\mathrm{AD} 385$, Valentinian, Theodosius, and

\footnotetext{
642 Crofts (1967) 6. Gail Brownrigg kindly sent information on draught animals.

643 Kendal (1996) 143.

$644 \quad$ Leighton (1972) 71.

645 VIII, 5,8 .

${ }_{646}$ VIII, $5,30$.
} 
Arcadius further set a limit of 600 librae on a carrus. ${ }^{647}$ The nature of these vehicles, the motive power, and modern equivalents of their capacities are given in the table below.

TABLE 10.3 THEODOSIAN CODE: CAPACITY AND TYPE OF VEHICLES

$\begin{array}{lrrrl} & \text { librae } & \mathrm{kg} & \mathrm{lb} . & \text { type } \\ \text { Angaria } & 1500 & 491 & 1080 & \text { 4-wheeled waggon } \\ \text { Raeda } & 1000 & 328 & 722 & \text { 4-wheeled waggon } \\ \text { Carrus } & 600 & 197 & 361 & \text { 2-wheeled cart } \\ \text { Birota } & 200 & 66 & 145 & \text { 2-wheeled cart }\end{array}$

The birota was probably intended chiefly for passengers, and will be ignored for the purposes of this discussion. The types of vehicle are taken from the list given in Kendal (1996), and the table is subject to the caveats in the following paragraphs.

Mitchell argues that the Prices Edict of Diocletian implies that the carrus could have either two or four wheels, and that one type could carry a load of 1200 Roman pounds. ${ }^{648}$ This alone makes the use of the Theodosian Code for computing the number and type of carts or waggons ${ }^{649}$ needed for building the Wall an uncertain undertaking.

The weight limits set by the Code are very low for substantial vehicles. It may be the restrictions were aimed, in part, at reducing wastage of animals in unfamiliar hands when working on long-distance transport (the hire-car effect). The decree of

647 VIII, 5, 47.

648 Mitchell (1976) 122. One of the writing tablets from Vindolanda refers to the use of a carrulum for carrying stone (document 316, Bowman and Thomas (1994). Carrulum is given there as a neuter diminutive of the masculine noun carrus. Unfortunately this does not help with type or capacity as carts as well as waggons were used for the carriage of stone well into the early twentieth century.

649 By definition, a cart has two wheels and a waggon four. 
Constantine Augustus notes that 'very many persons by means of knotty and very stout clubs force the public post animals .. to use up whatever strength they have ...' Kendal, in the course of a discussion of transport and Hadrian's Wall, suggests that the restrictions seem to be aimed at minimising damage to the road surface, and that the true limits of draught would have been higher.650 The restrictions do not necessarily have any relevance to the usage of waggons by the army.

As Spruytte points out, the Code does not specify any limit on the gait of the animals, and that the drawing force increases in proportion to rising speed. ${ }^{651}$ All these reservations tend to limit the utility of the Code in relation to a localised military building programme two centuries earlier. Mitchell also takes the view, strongly shared by the writer, that the Code cannot be used as an accurate guide to capacity at any period. ${ }^{652}$

Burford rejects the notion that heavy transport could not be used in ancient times, and gives many examples of building stones weighing well in excess of the limits of the Code. She also shows that heavy transport was sufficiently common to give rise to its own small vocabulary and that, while not necessarily routine, movement of heavy loads was not uncommon..$^{653}$

In addition to the vehicles mentioned above, the sarracum, a solid-wheeled vehicle, was used for the transport of tree trunks, beams, and building materials. ${ }^{654}$ There is no indication of its capacity nor of the size of team required.

650 Kendal (1996). He suggests that the draught capacities given in the Code should be increased by an arbitrary $75 \%$. His final figures are still insufficient for transporting the loads needed for Wall building.

651 Spruytte (1983), 122, 123.

${ }_{652}$ Mitchell (1976) 122.

653 Burford (1960).

654 See entry in Pauly-Wissowa for the many references. 
Use may be made of representations of wheeled transport shown in sculpture. Carts of various types are shown on Trajan's Column and on sculptures but can provide no more than a generalised view. There are four-wheeled waggons with poles and two-wheeled carts with shafts. The Column shows two-wheeled carts pulled by pairs of mules (e.g. scenes $x \mathrm{l} / 104-5$ and $\mathrm{xlix} / 123-4)$ and by oxen (xlix/124 and $1 x i-i i / 148-9)$.

A panel from Museé St.-Didier, Langres, shows a loaded waggon pulled by two equines, and another relief from the same museum shows a waggon pulled by four equines. ${ }^{655}$ The scale of the carvings can never be seen as accurate, and trying to assess the size, and thus the possible weight, of a load shown in sculpture would seem to be a fruitless exercise. However, there may be one exception to this.

Scene cvii/285 on the Column shows a two-mule cart piled high with what are believed to be tents; ${ }^{656}$ it is not possible to see the number of tents, but an estimate of the weight carried may be made. Fragments of a tent from Vindolanda were interpreted by van Driel-Murray in a design which was later reproduced in goatskin by the Ermine Street Guard. ${ }^{657}$ This tent, waterproofed with tallow, weighs $96 \mathrm{lbs}$ dry and $113 \mathrm{lbs}$ when wet (44 and $51 \mathrm{~kg}$ ). Taking the capacity of a mule as argued above, the weight of two tents would be a reasonable, and even light, load for one pack mule. Indeed, the same scene appears to show a pack mule Ioaded with tents; two tents would be a minimum in order to make for a balanced load. To make the use of a two-mule cart worthwhile, it must be assumed that it is carrying at least five wet tents and probably more, a weight of $565 \mathrm{lbs}(257 \mathrm{~kg})$ at the least. This postulated

\footnotetext{
655 Illustrated in Spruytte (1983).

$656 \quad$ Lepper and Frere (1988) 261.

657 van Driel-Murray (1990): Mayes (1994).
} 
figure would seem to be the best evidence available for the capacity of any Roman army vehicle.

What is clear from the section 10.2 is that there was a need for the reasonably regular transport of stones weighing in the order of half a ton, and that the transport of stones weighing up to two tons did not present a major problem to the army. It was shown above that a number of stones at Chesters fort weighed well over a ton, and as it would be very wasteful to carry single stones from quarry to building site, it might be expected that at least one of these very large stones and at least one smaller one could be carried without problems. This tends to suggest that a fairly common type of army waggon could take a payload of around 2 tons; this would allow for carrying one large and one small pier stone, or up to 70 typical walling stones.

Despite their surprisingly low limits, the figures given in the Code have often been accepted, in part on the basis that ancient harness systems were very inefficient. Spruytte has shown that this was not necessarily so, although the major part of his work is concerned with light vehicles rather than the carriage of freight. But he does show that two horses in breast collars of the ancient type could pull a load of $2150 \mathrm{lb}$ $(975 \mathrm{~kg})$ gross, $970 \mathrm{lb}(440 \mathrm{~kg})$ nett, at the trot on sand which is one of the most unfavourable surfaces for traction. He also shows that 'a harness of this type, although less appropriate than the modern breast collar harness with traces, is in no way a hindrance to traction'.658

It may be noted that using breast collars the gun teams of the Royal Horse Artillery were accustomed to 'Driving a six-horse team with a ton and a half of gun behind it at a gallop across country which a fox-hunter might look twice at . . .659

\footnotetext{
658 Spruytte, (1983), 98-9.

659 Bidwell (1973) 6.
} 
Even allowing that the horses will have been bigger than the Roman and that the modern breast harness is more efficient than the ancient breast strap, this does not suggest that the shoulder collar (the modern 'horse collar') is in any way essential for movement of freight. One reason for the continued use of the breast collar in the British army is that it is easier to adjust a new breast collar than a horse collar; both types require careful fitting, but the British army manual has to devote ten pages to the horse collar and just over two pages to the breast collar. ${ }^{660}$

Spruytte does however suggest that loads in ancient times were limited by the friction between the wooden axle and the wooden nave of the wheel, due to the increase in friction if the axle were made of sufficient diameter to support the load. He argues that the increase in diameter necessary to support heavy loads increases the friction, but this is not strictly true. If the hub bears on the lower third of the axle, and the bearing length is $4^{\prime \prime}(100 \mathrm{~mm})$ the following results are obtained. A $2 "$ $(50 \mathrm{~mm})$ diameter axle has a bearing area of 16.75 square inches $\left(10800 \mathrm{~mm}^{2}\right)$ and a $4^{\prime \prime}(100 \mathrm{~mm})$ axle has a bearing area of 33.5 square inches $\left(21600 \mathrm{~mm}^{2}\right)$. If the diameter of the axle is increased, then for a given load the pressure on the bearing surface is reduced.

Metal axles and nave linings would have further reduced the friction, but Spruytte believes that these did not appear until well after the Middle Ages. However, one of the wheels found at Newstead had a strong iron ring at one end of the hub to reduce wear. The length of the ring is not given, but the illustration in the report (which shows a ring at both ends of the hub) suggests that it is about $1 \frac{11}{2}$ "

660 Veterinary Department (1908) 201-211 and 211-213. 
(40mm) long. ${ }^{661}$ Hub-linings have also been found at Verulamium, and Manning indicates that iron linings were normal in Romano-British wheel hubs. ${ }^{662}$

The modern type of shoulder collar for horses came in around the tenth century, ${ }^{663}$ which makes the use of the figures available from building accounts of the Middle Ages less than satisfactory. But the yoke used for oxen has changed little and the technology of the mediaeval ox-cart (so far as is known) was similar to that of the Roman period.

Salzman quotes figures for the carriage of lead from Caldstanes in Nitherdale to Boroughbridge, a distance of 20 leagues (about 60 miles) 'by high and stony hills and by miry roads'. Although the location of Caldstanes is not known, the farthest end of Nitherdale is such that the distance given must be for the round trip. Two waggons, each drawn by 10 oxen, transported 24 fother (about 24 tons) of lead in 24 days. ${ }^{664}$

If the average distance covered in a day was 15 miles, it would have taken four days to complete the round trip, and thus six such journeys could be made in the given time. Each waggon would therefore have carried 2 tons, four times the Theodosian limit. This is a large increase, but the facts are clearly stated and to reduce the increase even to three times the Theodosian level, that is one and a half tonnes, the oxen would have had to travel 20 miles a day and make eight journeys. While not impossible, this must be considered to be at the limit for working draught oxen, ${ }^{665}$ especially over such country. Fifteen miles a day with a load of two tons is the more likely.

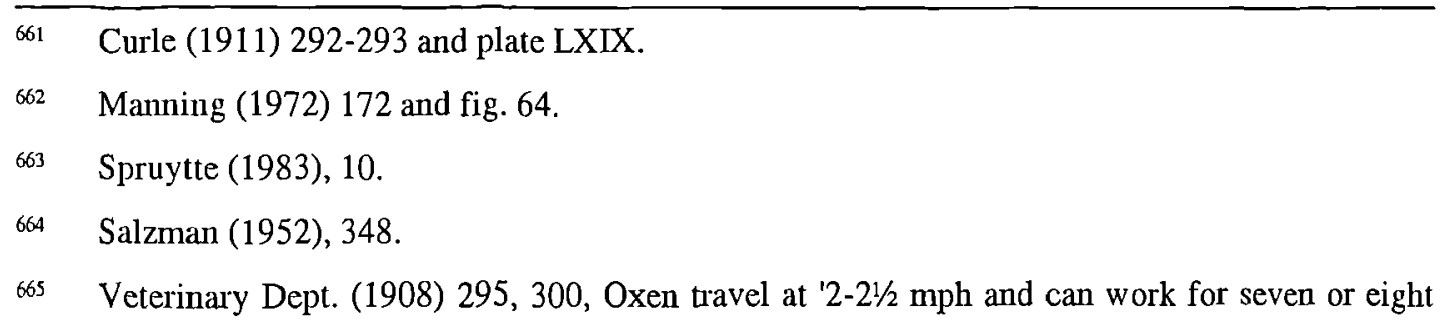


The limits in the Code are bureaucratic rules imposed for unknown reasons. The mediaeval capacity is an accountant's record of precisely what did happen, and apparently with animals and vehicles belonging to a private contractor. It may be assumed that the contractor would have been at least as careful of his animals as the Roman army would have been. If ten oxen could pull a nett weight of two tons in 1363 , it would be remarkable if they could not have managed something similar in the early second century; furthermore the distances on the Wall will have been short.

Cattle bones from Vindolanda are of the Celtic shorthorn breed, and some of the long bones are massive. This massivity may be due to inheritance from ancient stock such as the aurochs, or it may be the result of the Romans introducing large draught oxen. ${ }^{666}$ Audoin-Rouzeau lists the withers height for cattle and shows an increase in the Roman period as compared to the Iron Age, with a small decrease especially around the eleventh to thirteenth centuries; by the fifteenth century the size was increasing again with the average being a little smaller than the Roman but with some animals reaching a greater size. ${ }^{667}$ Audoin-Rouzeau says that the Romans imported large stock to improve the local breeds. It is clear that oxen available to the Roman army could have been larger than those in the fourteenth century, and were most unlikely to be smaller. ${ }^{668}$

It may be assumed that in building the Wall, with journeys of no more than two or three miles, the Romans were able to move two ton loads as a matter of course. If

hours a day' and 'will travel fifteen to twenty or even twenty four miles a day under favourable conditions'. But 'high and stony hills' are not favourable and in that sort of country an ox-wagon would be lucky to average $2 \mathrm{mph}$.

666 Seaward (1993) 110.

${ }_{667}$ Audoin-Rouzeau (1991), especially the tables on pp 19-26.

$668 \mathrm{Mr}$ Unberto Albarella of Durham University kindly discussed the size of Roman oxen with the author. 
the figure for the angaria can be increased to two tons, then the same proportional increase (4.15) ought to be permissible for the other vehicles. ${ }^{669}$

\section{TABLE 10.4 CALCULATED REVISED CAPACITY AND TYPE OF VEHICLES}

$\begin{array}{lrrrl} & \mathrm{kg} & \mathrm{lb} . & \text { TONS } & \text { type } \\ \text { Angaria } & 2033 & 4480 & 2.00 & \text { 4-wheeled waggon - oxen } \\ \text { Raeda } & 1360 & 2995 & 1.34 & \text { 4-wheeled waggon - oxen/mules } \\ \text { Carrus } & 680 & 1497 & 0.67 & \text { 2-wheeled cart - mules }\end{array}$

The figures suggested in the table allow for the heaviest waggons to carry the more exceptional two ton loads, and for the raeda to carry two or three of the more typical pier stones or about 45 walling stones. This seems to be more in keeping with the practical requirements of the army than the theoretical figures given in the Theodosian Code.

\subsection{Access roads}

Wheeled transport needs some kind of road unless the weather is arid and the natural surface is reasonably smooth and hard. Again, iron tyres are more of a problem than pneumatic, the width and deformation of the latter considerably reducing the ground pressure. 'Road' does not in this context necessarily mean a properly engineered permanent way, but hollows, holes, and soft areas have to be made up with rough metalling. The ability of the Horse Artillery to jump its guns and limbers over tree trunks and ditches is not a parallel which can be followed when considering the movement of freight. One should expect to find that the Military Way had a flimsy and intermittent predecessor, at the least on the approaches to all milecastles and

\footnotetext{
669 The increase may seem large but, for example, carts pulled by a single horse (a cob was usual) were designed to carry up to 1.5 tons in the late nineteenth century (Bristol Wagon (n.d.)).
} 
forts. However, it should be noted that excavations at MC39 failed to find any trace of a track between the later Military Way and the milecastle, ${ }^{670}$ although wheeled transport must have been used (and the situation of the milecastle allows no other route) for transport of the stones of the gate piers. It may be of course that when that milecastle was under construction the weather was hot and dry which might obviate the need for any metalling.

The Gourdie quarry used for the building of the fortress at Inchtuthil was served by an engineered road, ${ }^{671}$ but that ran between a single quarry and a single site. Even though it was built in anticipation of the passage of around 20,000 tonnes of stone, ${ }^{672}$ this road does not appear to have been especially substantial but it did have a metalled surface won from quarry pits alongside the flanking ditches. In building the Wall the use of numerous ad hoc small quarries close to the line of the Wall and the large number of individual building sites would have made the installation of properly made roads leading directly to all parts prohibitive in terms of time and labour.

A lightly metalled surface showing wheel ruts, and overlying a dump of clay, has been found at Denton Burn. ${ }^{673}$ Two further layers of metalling and clay were found above this, the latest surface containing a coin of the early third century. The metalling is very close to the Wall, and in some places peters out no more than one metre from the south face while in others spreads as much as eight metres south.

The excavator does not believe this very light metalling to represent a service track predating the Military Way. It seems to the present writer to be in the right

\footnotetext{
670 Information from Mr J.G. Crow; see Crow (forthcoming).

671 Pitts and St. Joseph (1985) 47, 256 and fig. 77.

672 Author's calculation.

673 Bidwell (1996) 20, 33-35.
} 
place and in use at the right times for building the Wall and then repairing it under Severus, with perhaps an intermediate repair programme either in the 160 s or at some date not connected with an historical event. This would not be a formal service track but an ad hoc and discontinuous provision of light metalling for a specific purpose. Some sandstone chippings were found in the surface but no serious quantities of building debris, although there was a small amount of mortar in the later levels. In fact, the lack of debris need not be surprising. The Wall in this area was originally built with a minimum amount of mortar, and the core was set in clay; ${ }^{674}$ dressing of the facing stones would have been carried out entirely at the quarry.

About 10m south of the Wall at Tarraby Lane near Stanwix a heavily rutted trackway was found in $1976 .{ }^{675}$ This was unmetalled and consisted of a 'worn double scoop profile and a churning of the underlying subsoil.' Its position is not incompatible with its use during the building of the turf wall, but it went out of use when the turf wall was demolished. No sign was found of a later track associated with the replacing stone wall.

The suggestion that these two tracks might have been used by the builders and repairers of the Wall can be no more than supposition, but it is difficult to imagine any other use for unmetalled or lightly-metalled tracks so close to the Wall.

E. Birley has suggested ${ }^{676}$ that the line of Vallum might have followed a preexisting traffic route, or service track. This seems unlikely, at least in the central sector, where it runs up to half a mile to the south of the Wall at several points such as MCs35, 40, and 44. At White Moss, the 'ditch' of the Vallum seems to have been

\footnotetext{
674 Bidwell (1996) 19.

675 Smith (1978) 23-4.

676 Birley (1961), 122-3.
} 
created by building what was in effect an embankment across a bog, ${ }^{677}$ a line not suitable for a service track. Although in many places the Vallum is so close to the Wall that there is barely room for the north mound, it is hardly conceivable that the line was of any value in building operations.

Birley also discusses the 'lesser Military Way, ${ }^{678}$ first referred to by Gordon. ${ }^{679}$ Horsley mentions '... a smaller military way near to the wall, for the convenience of small parties passing from turret to turret.' and '. . . some vestiges of the smaller military way . . ., ${ }^{1680}$ particularly in the Carrawburgh area. Excavations have failed to reveal this feature, although the surface found at Denton Burn and the track at Tarraby Lane could conceivably be parts of it. There have in fact been very few excavations which extend much to the south of the Wall, apart from those designed to test the Vallum or the Military Way.

If the lesser military way existed as the remnants of a track used in building the Wall it would be close to the Wall where the ground was reasonably level, but running to the south or the north in places where the topography gave an easier route. The question can only be settled by excavations specifically designed to test it, and of course, as noted above, if it existed it may very well not be continuous and thus proof might be hard to find. In many places it would not be possible to find room for a track between the Military Way and the Wall.

In the present state of knowledge, then, there is no firm archaeological evidence for the use of wheeled traffic during the construction of the Wall. But the gate pier

\footnotetext{
677 Simpson and Shaw (1922) 363-365.

678 Birley (1961), 114-116.

679 Gordon (1726), 74 and plate 49.

$680 \quad$ Horsley (1732) 118 and 146.
} 
stones were too heavy for transport on pack animals, ${ }^{681}$ and it is clear that carts of some sort must have been used in the building of the milecastles.

\subsection{The Military Way}

The Military Way appears to have been built on the return from the Antonine Wall, which was designed from the start to have a service road. ${ }^{682}$ Although thus not a feature of the original design of Hadrian's Wall, a brief discussion will be useful to judge whether it may have been founded on an earlier service track used in building the Wall.

The road runs mostly less than 100 yards behind the Wall and only in a few places, such as King's Hill (NGR 797601) and from MC41-2, does it run as far as 200 yards to the south. This gives a reasonably good route for materials along the line, and it could be that the general line of the Military Way was to some extent dictated by a pre-existing track used in building the Wall. However, access to this route is limited by the cliffs to the north and the steep ascents from the south, and it has unnecessarily severe gradients which must limit the utility of the line for wheeled construction traffic.

In at least one place it makes an extraordinary effort to stay close to the Wall. As the Military Way climbs up the rocky slope to the east from Peel Gap it turns sharply to the north in a cutting through a rock outcrop, as though to reach a more level gradient in the shortest time or to stay as close as possible to the Wall line (see fig.

681 The smallest stones seem to be those at MC39. The four stones visible on the north west pier weigh between $137 \mathrm{lbs}$ and $203 \mathrm{lbs}(62-92 \mathrm{~kg})$. Two of the smallest could just have been carried on a pack animal - giving a load of $274 \mathrm{lbs}(124 \mathrm{~kg})$ - but not the larger ones.

682 Breeze and Dobson (2000) 131-2. 
10.1). ${ }^{683}$ Diverting a little way to the south around the outcrop would have given a longer but much more gentle gradient at the cost of a slightly greater distance from the line. ${ }^{684}$

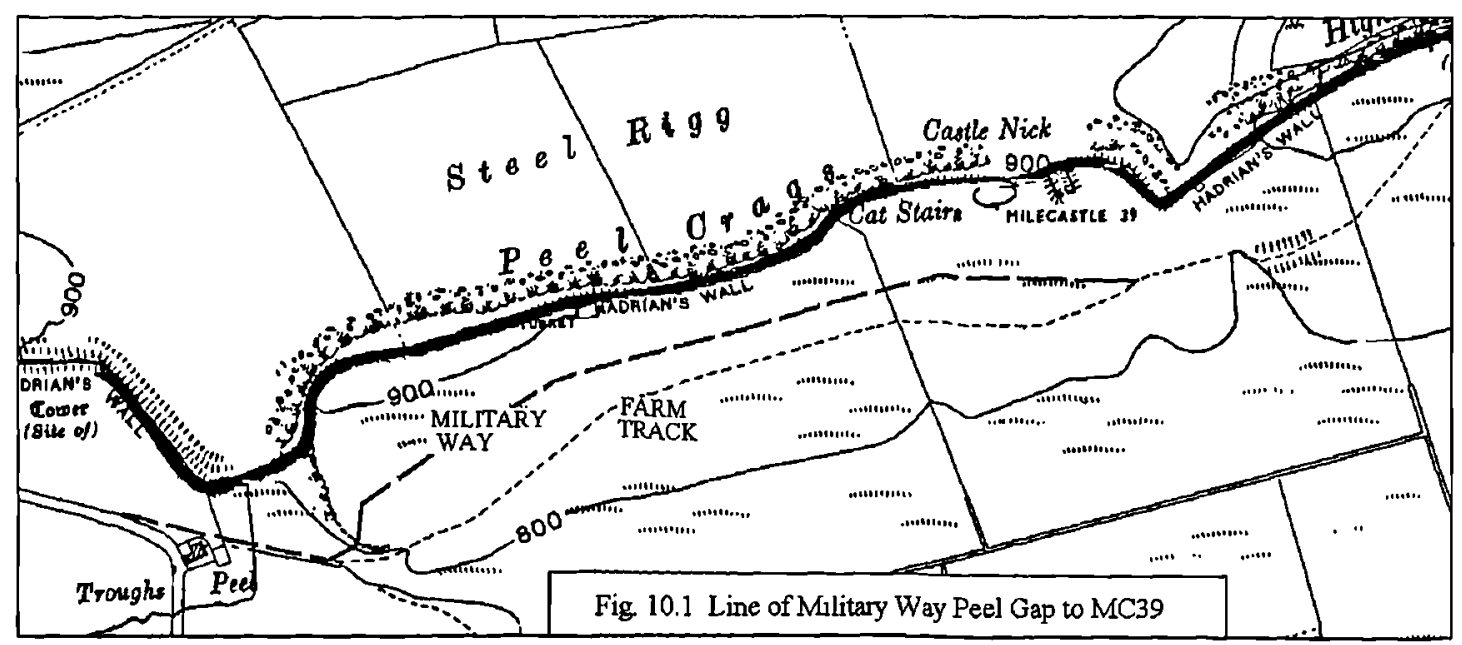

The labour of making the cutting seems excessive for a temporary track for servicing a building project, although the line may have been revised when the permanent road was built.

Ideally the maximum gradient for wheeled animal transport will be 1 in 10 over very short distances; the ruling gradient should be 1 in $20 .{ }^{655}$ It is probable that this could have been adhered to even over the crags, with the possible exception of the final run up from the line of the Military Way. In a few stretches, even the later Military Way, presumably surveyed and built at leisure, exceeds the modern recommended maxima, and here manpower or spare teams would have been needed

683 This is not as shown by MacLauchlan who gives the line as following the present farm track. It is very clear on the ground that it followed the line given here.

684 The modern farm track is briefly on the line of the Military Way on the east side of Peel Gap, but as it heads east it takes a very much easier line to the south, and rejoins the Military Way just to the west of MC39.

685 War Office (1935) 32. These figures, and those for pack animals given below, relate to temporary roads and tracks rather than to permanent roads which should be less steep. 
to assist draught animals. While these gradient figures relate to British Army practice in 1935 they are based on what is reasonably practicable. It may be accepted that the Roman army learned the limitations of gradient in the same empirical way as more modern armies. The steeper gradients on the Military Way are in fact very short.

In the 1920s, when horse buses were still not uncommon in country areas, it was normal to take steep hills in a zig-zag to lessen the effective gradient. ${ }^{686}$ On a road $20^{\prime}$ wide on an incline of 1 in 5 , a zig-zag at $45^{\circ}$ to the axis will reduce the effective gradient to 1 in 7 ; a zig-zag at $30^{\circ}$ to the axis will only reduce the gradient to 1 in 5.77.687 At Peel Crag, the present line appears to be about $10^{\prime}(3 \mathrm{~m})$ wide, but surface indications are that the road bed of the Military Way has been washed away to a depth of about $18^{\prime \prime}(9450 \mathrm{~mm})$; if this is correct than the roadway could have been some $11^{\prime}(3.4 \mathrm{~m})$ wide as it descends the cutting, still not wide enough to allow for any useful zig-zag. ${ }^{688}$

A little to the east of MC39, the Military Way climbs steeply with a sharp northward turn on the east side of Sycamore Gap; again, a relatively small diversion to the south would have reduced the gradient considerably and the same applies at other points. One wonders in fact whether the road was built with wheeled traffic in mind.

Bruce seems to have had similar doubts '... the steepness of the road in some places is such, that most of our modern carmen . . . would be greatly puzzled if

\footnotetext{
686 Mrs E.M. Hill, pers. comm. from personal experience.

687 The reduction is calculated by dividing the gradient (expressed as a ratio, e.g. 1 in 5) by the cosine of the angle of the zig-zag to the axis. Mrs V.M. Croll kindly supplied this information and made the calculation.

688 Author's survey, 1999. The cutting acts as a water course.
} 
required to traverse it with a waggon laden with military stores.' ${ }^{689} \mathrm{He}$ also notes that the carriers who used the Military Way before the building of the Military Road in the mid-eighteenth century used pack horses and not wheeled carriages. ${ }^{690}$ Wilmott notes the lack of wear on the southern portal of the porta principalis sinistra at Birdoswald and casts doubt on the volume of wheeled traffic on the Military Way ${ }^{691}$ There are no wheel ruts in the thresholds of the west gate at Housesteads, showing that wheeled traffic did not leave the fort to go west along the Military Way, unless for some reason it always used another gate; the only wheel ruts at this fort are at the east gate, and presumably derive from deliveries coming on the branch road running up from the Stanegate to the south east. ${ }^{692}$

The British army regarded the limiting gradient for pack mules as 1 in 5 with a ruling gradient of 1 in 10. For pack horses and oxen the figures are 1 in 6/1 in 10 and 1 in $8 / 1$ in 10 respectively. ${ }^{693}$ Again these maxima should be permitted only over very short distances. Loaded pack animals work better on ascending gradients than descending, ${ }^{694}$ and thus could cope with short, very steep ascents in order to reach the more inaccessible parts of the Wall over the crags.

\footnotetext{
689 Bruce (1851) 75.

$690 \quad$ Bruce (1867) 75.

691 Wilmott (1997) 192, based on Hill (1992)

692 MacLauchlan (1858) 39-40. The south gate was unsuitable for wheeled transport owing to the steepness of the gradient inside the fort.

693 War Office (1935) 32. Loaded mules can go up any slope which a man can climb without using his hands (S/M Kohler, Defence Animal Centre, Melton Mowbray (pers. comm.), but it would not be sensible to build a road which caused problems to the transport animals.

694 The reverse is true for draught animals, War Office (1935) 31.
} 
'Long steady ascents are most fatiguing for horses and mules, while the contrary is the case with oxen. ${ }^{1695}$ The sudden, very steep ascent on the east side of Peel Gap leading to a very gentle gradient might seem to be designed with pack mules rather than draught oxen in mind.

In conclusion, the Military Way does not appear to be relevant to a construction track used during the building of the Wall, and was not constructed for use by wheeled traffic.

695 War Office (1935) 30. 


\section{CHAPTER 11}

\section{Building operations}

This section looks at the work of laying the foundations, building up the curtain wall, turrets and milecastles, and the more specialised work of building the milecastle and fort gateways. Evidence for the apparent or logical sequence of various operations are discussed. The digging of the ditch and Vallum is also considered.

\subsection{Preparation of the ground}

As was shown in section 3.4 , the line chosen for the wall ran through countryside which was largely cleared or cultivated, but in part more or less lightly wooded, with denser thickets in the valleys which had to be cleared both for a working area and to give a clear line of sight either side of the wall. Undergrowth may have been cleared by burning. ${ }^{696}$ It has been thought in the past that ploughing was used as a method of clearance, ${ }^{697}$ but this has now been challenged. ${ }^{698}$ Gangs would have been at work along most of the length of the Wall at the same time (see chapter 13), and there would have been an 80-mile long corridor of building sites.

Tree felling was well within the experience of the legionary, as is shown on Trajan's Column (e.g. scene lxxiii) along with ground clearance and other building

\footnotetext{
696 J.G. Crow 'RB in 1987' 434-6 implies that the undergrow th which had developed in the interval between the laying of the Broad foundation and the building of the Narrow Wall was disposed of by burning. The same process may have been used in the initial clearance.

697 e.g. Harbottle et al. (1988) 155.

698 Bidwell and Watson (1996) 17-18; Bidwell (1999) 10.
} 
operations. The sort of work shown in this scene is precisely what would have been required for preparing the ground in advance of building operations on the Wall.

\subsection{Foundations and footings}

\subsubsection{Laying the foundation}

The simple work of foundation-laying could have been carried out by any available soldier under suitable supervision. A shallow trench was dug, in some cases involving no more than removal of the turf, ${ }^{699}$ and into this flags or large stones were bedded in clay or earth. The clay has often been referred to as 'puddled'; 700 the use of this term has properly been condemned in relation to the Broad Wall at Denton. So far as the Wall in that area is concerned, the core was composed of a mixture of stones and clay, the latter 'compacted perhaps by treading but not puddled. ${ }^{1701}$

\subsubsection{Laying the footings}

On top of the Broad Wall foundation was laid one to three courses of facing stones to a wider gauge than the finished wall; the stone was usually the same squared rubble as used higher up. These footings could be regarded as part of the foundation, although they would more conveniently have been laid by the curtain wall builders who were dealing with large quantities of facing stones. Laying the foundations was very different work, and used quite different stones, from that of building the curtain

\footnotetext{
699 Brewis (1927) 113-4.

700 e.g. Bruce (1863) 36, and successive editions of the Handbook

701 Bidwell and Watson (1996) 19. Puddling is 'to knead and temper a mixture of wet clay and sand to form a plastic mass impervious to water' and is used for waterproofing canals, ponds, etc.
} 
wall and footings. It would thus be entirely logical for the footing courses to have been built by the curtain wall builders.

The question of which gang laid the courses below the offset is important in relation to the allocation of curtain and structures to particular legions. Two legions, $\mathrm{A}$ and $\mathrm{B}$, built with a single course (Standard A), legion $\mathrm{C}$ with three, or sometimes four, courses (Standard B) below the offset. ${ }^{702}$ If the offset courses were laid by the legion which laid the foundation, they do not indicate which legion built the superstructure; they might be one and the same legion, but they might well not be.

There are a number of points where the Narrow Wall was built on the Broad foundation, and in many cases this foundation carries one to three courses of broad footings. Examples are: Planetrees; immediately east of T26b, Brunton; and from a little way west of MC48 to T48b, Willowford West. At the first two points this could represent the work of the curtain wall builders, who were putting up Broad Wall close by. Between MC48 and T48b there is a tiny piece of Broad Wall proper, consisting of three or four stones of the first course above the standard B offset, ${ }^{703}$ and yet the Broad footing courses can be seen over most of the distance from MC48 to $\mathrm{T} 48 \mathrm{~b}$. It could be that the footings were built by gangs from the curtain wall builders, preparing for the curtain wall to be carried up from the footing, but it is not impossible that these courses were laid by the foundation builders.

702 Breeze and Dobson (2000) 71. The reference to legions A, B, and C, obviates the need to refer to legions by number, which seems unwise in the present state of knowledge; see Hill (1991), where the allocation of short axis milecastle design to Legion II is questioned. Legion II appears to have built long axis milecastles on the Antonine Wall (Hanson and Maxwell (1983) 129).

703 Author's survey. 


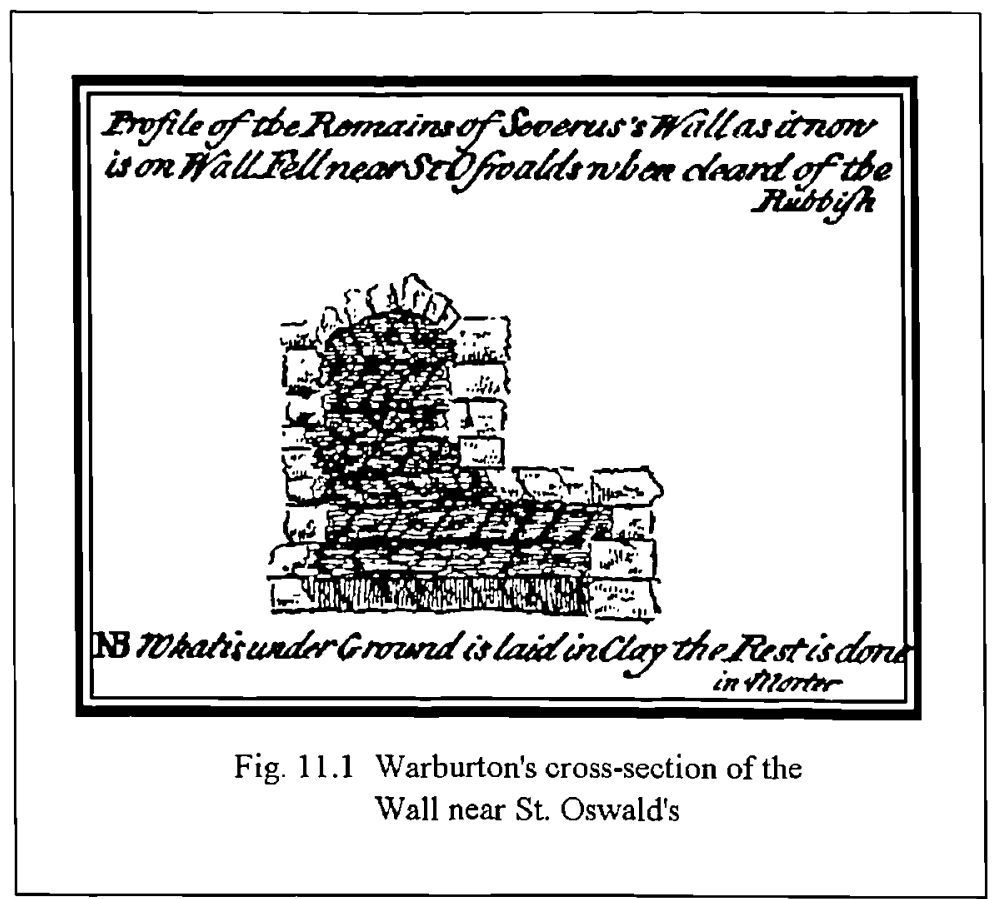

The foundations and footings seem, where evidence has been collected during excavation, to have been built chiefly with clay as a bonding medium. In his crosssection of the Wall near St. Oswald's (Wall-mile 25) Warburton (1753) describes in the frontispiece 'what is underground is in clay' (see fig. 11.1). He seems to be referring to the Broad footings, and Simpson appears to argue the same as he wondered if the Narrow Wall represents 'total reconstruction above ground'. ${ }^{704}$ The evidence for the use of clay in the footings, as against mortar to bond the facing stones, does tend to suggest the work of the foundation gangs.

On the other hand, at T34a (see section 11.5) there were no footings in place when the building of the turret began, which ought to indicate that the footings were normally laid by the builders of the curtain wall.

The evidence tends to suggest that the footing courses were the work of the curtain wall gangs, but it seems to the writer that this view is not entirely beyond

\footnotetext{
704 Simpson (1931) 313.
} 
question. Stronger evidence will be needed before the question can be finally settled, and this can only be provided by excavation, and very careful recording, of the curtain wall in as many parts as possible where there has been no previous excavation.

In the garden of the former Romanway Guesthouse (the sometime Vicarage. between MC48 and T48a), the core of the narrow curtain wall is homogeneous with the core of the Broad Wall courses below the offset. ${ }^{705}$ It may of course simply be that the layers of the Broad Wall footing courses had not completed their work when the design of the Wall was changed. This homogeneity of the core throws no light on whether it was foundation or curtain gang which laid the courses below the offset.

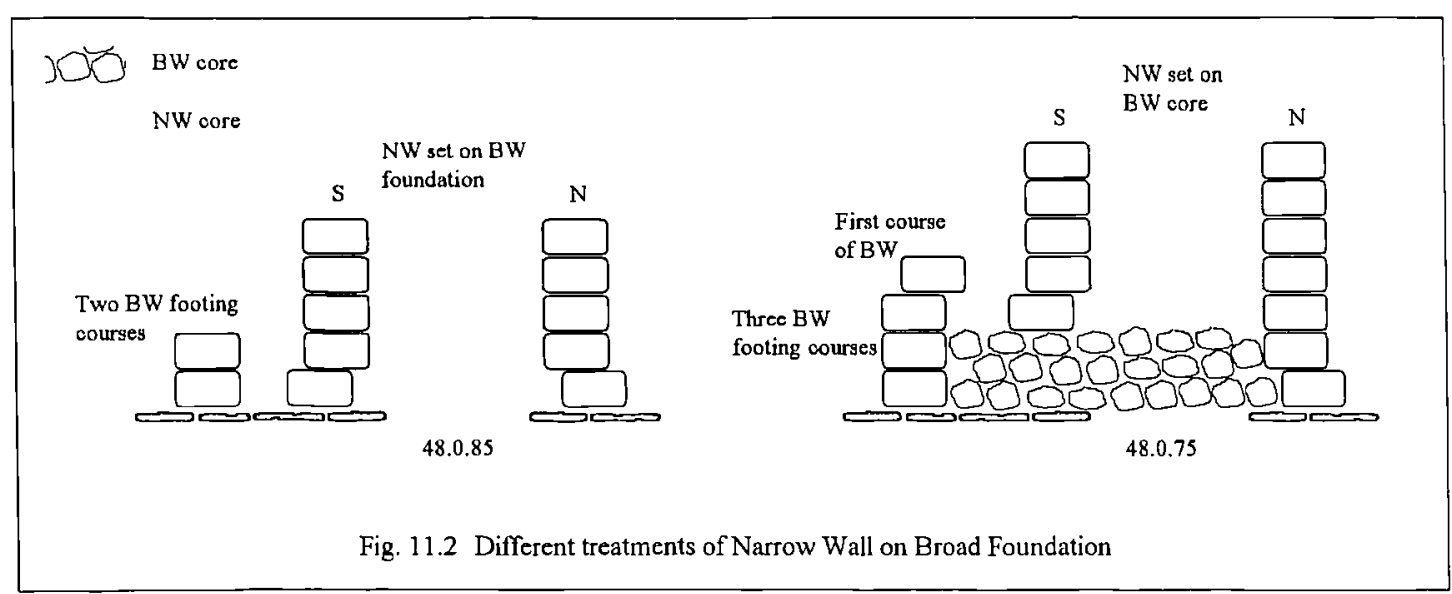

It is clear from the extant remains of the Wall between the Vicarage Garden and T48b that the core of the footings was laid by those building the footings. The Narrow Wall here is built sometimes directly onto the broad foundation, behind one or two courses of broad footing, and sometimes onto the broad core at the level of the top of the second broad footing course. The broad footing builders were clearly

705 Simpson (1976) 66. 
filling in the core as they built. Equally, it is clear that at least two courses of footing could be built without any core between the faces (see fig. 11.2). ${ }^{706}$

\subsection{The curtain wall}

Once the foundations had been built, the laying of the facing stones was a simple business which could be taught to any legionary within the hour; of course speed and efficiency would come only with experience, but reasonable dexterity could be expected within a few days. An outline of the operations will make this point clear.

A mortar bed, the thickness of which called for more judgement than any other operation, although this need not have been particularly accurate, had to be laid on the preceding course with a trowel and the stone placed in position. The very roughness of the dressing of the stones called for only approximation in the laying, as the lack of a sharp arris marking the transition from face to joint made exactitude both impossible and unnecessary (see plates 10 and 11, overleaf). The roughly squared rubble can be positioned to the nearest five or ten millimetres without looking out of place, using a thump of a hammer to bed it down onto the mortar (or clay) and to correct any major misalignment. The tapered joints of many of the facing stones, though they may well have helped in 'bonding to the core', ${ }^{707}$ also had the advantage of always providing plenty of clearance between the stones however rough the dressing had been. Once the stone was in position it remained only to fill the joint between it and the previous stone, an operation made easier by the tapering joints which would allow mortar to fall easily to the bottom of the joint in successive trowelfuls until the joint was filled solid. This assumes that mortar was used in these

\footnotetext{
706 Author's survey.

$707 \quad H B^{13} 41$.
} 


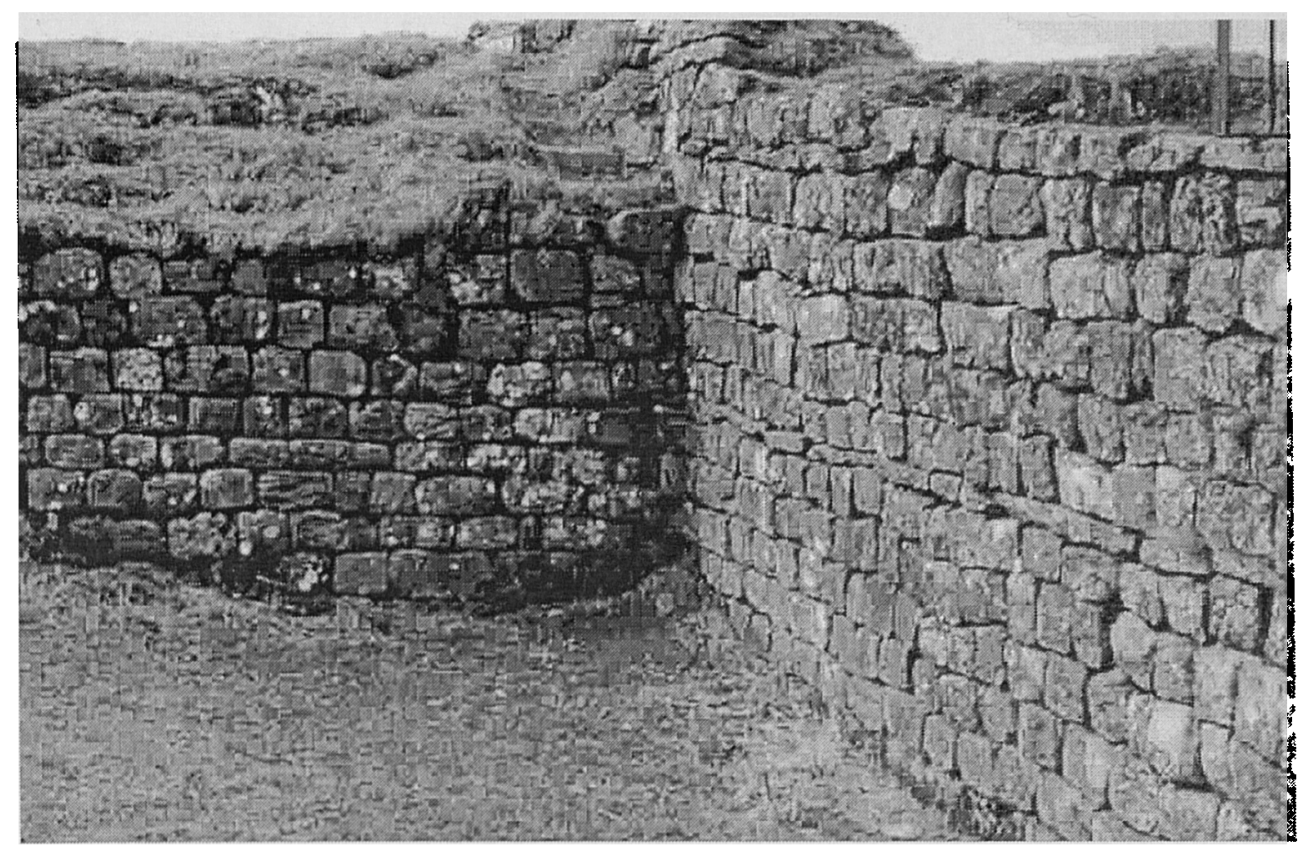

Plate 10 North wall of MC37, showing how irregularity of the stones makes precision of fixing unnecessary

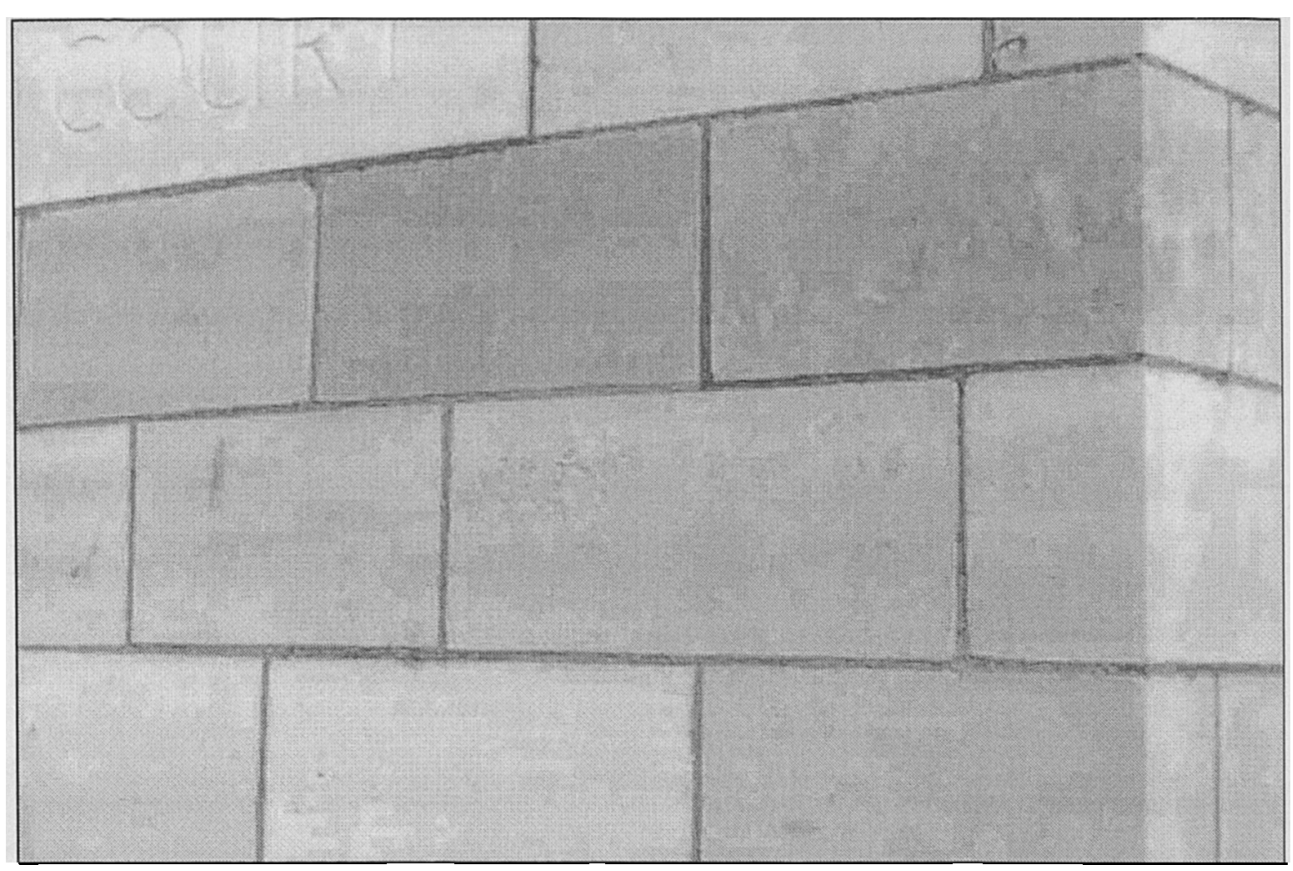

Plate 11 Rubbed ashlar wall, showing how the appearance is spoiled by errors of $2-3 \mathrm{~mm}$ in location and joint width 
quantities, a point discussed further below. If the weight of the tail of a stone caused it to tip backwards, it would be an easy matter to wedge a small piece of stone under the back to maintain stability until the mortar had set. The facing stones would probably have been fixed to a line (a stretched string), making it unnecessary for the fixers to check for alignment and plumb.

It should be noted that clay alone was certainly used for bonding the facing stones in Wall-mile $1,{ }^{708}$ although this is Narrow Wall. At Denton, some of the white mortar used for pointing (or repointing) the Wall had grey mortar adhering to the back; as the white mortar went to a depth of $20-30 \mathrm{~mm}$, the grey mortar is more likely to represent mortar used for bonding rather than merely pointing. ${ }^{709}$

As soon as two or three courses of facing stones had been laid it would be necessary to back them up with corework before proceeding higher, as the roughly squared rubble would hardly have been stable without it. The facing stones must have been built up equally at each side, requiring pairs of gangs working together.

The core consists of rubble, sandstone along most of the wall, whinstone over the crags. ${ }^{710}$ As discussed above (section 4.2.3), the majority of the Broad Wall core was bonded with clay rather than mortar.

The builders of the reconstruction at Vindolanda found that the core had to be built first and to set hard before the facing stones could be fixed. ${ }^{711}$ This is a strange reversal of normal practice, and the core immediately behind the facings could not have been tipped until they were laid.

\footnotetext{
708 Bidwell and Griffiths (1999).

709 Bidwell and Watson (1996) 23. The excavators note that little mortar was found, but this does not seem to exclude that the original wall used the grey mortar for bedding the facing stones.

$710 \quad H B^{13} 44$.

711 Birley (1977) 162. The core was mortared.
} 
The Wall could have been built up at each end of the gang-length to the height of the first scaffold lift, as shown by the dotted lines in fig. 11.3; this would give eight courses given the average size of stones (see section 12.4). The height of $58^{\prime \prime}$ $(1472 \mathrm{~mm})(7.25 " / 184 \mathrm{~mm} \times 8)$ is about right for the first lift of scaffolding. However, it would have been difficult to build up the core work right to the top, and it is more likely that the ends were build up in two stages of four courses each with a height of $29 "(735 \mathrm{~mm})$. The ends of the core would have to be built up rather carefully if it were not to collapse. ${ }^{712}$ It is also advisable not to build too high at one go in order to allow the mortar to take an initial set. Once the two ends were complete, the intervening gap could be filled very quickly course by course (figs. 11.3, 11.4).

As a first stage, building would have proceeded to a height of something like 4-5' $(1200-1500 \mathrm{~mm})$, the precise height depending on the size of stones, the slope of the ground and the enthusiasm of the centurion; the facing stones could not be lifted and laid at more than shoulder height even by two men. Above this point scaffolding would be needed, as discussed in chapter 9.

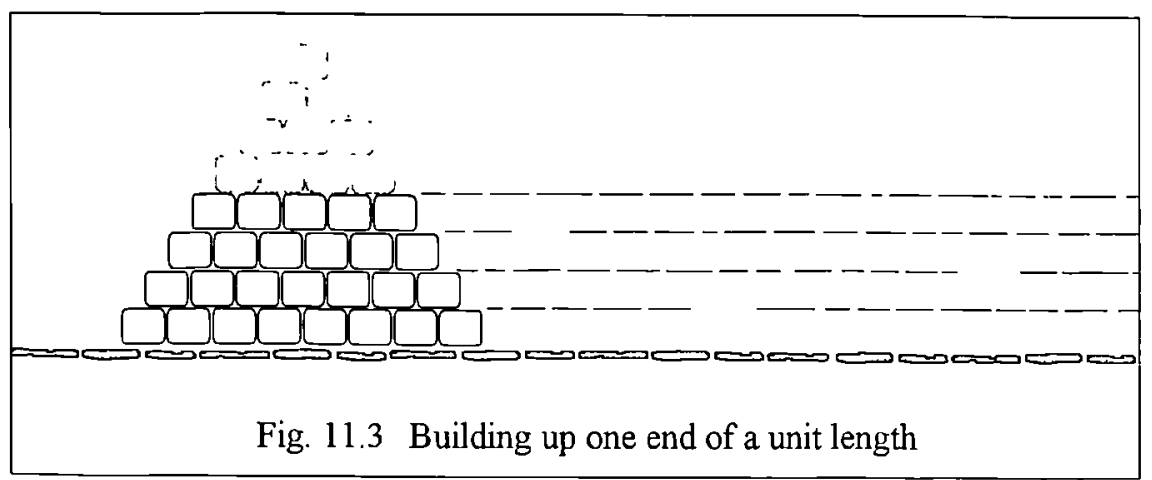

712 The stepped end of the core, reinforced by large stones running through the Wall seen at Willowford Bridge, (Bidwell and Holbrook (1989) 56) presumably represents this method of working, as the authors suggest. 


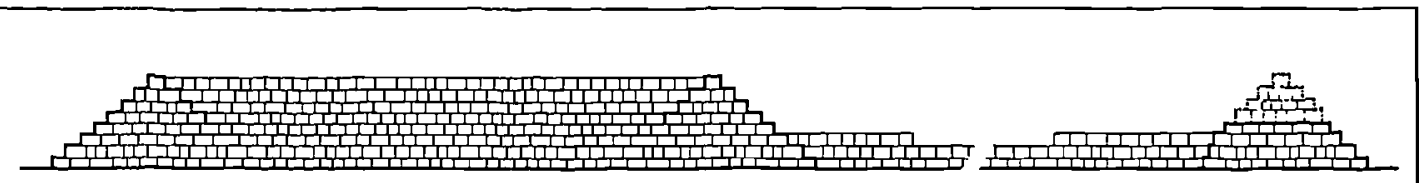

Fig. 11.4 Start of work in a gang length

\subsection{The milecastles}

The milecastle walls were built in the same manner as the curtain wall and, at least in the original plan, to approximately the same gauge; the techniques of building these were broadly the same as the curtain wall. It is with corners, gateways, and towers that a different range of skills was called for and presented, for unskilled or semiskilled builders, problems which are both different and more complex.

\subsubsection{Milecastle walls}

When erecting the walls of a building it is normal to build up the corners first with a raking joint, to as great a height as possible, establishing both alignment and plumb. It is likely that the corners would be built by specialist gangs who had at least a modicum of experience although this need not have been great.

Once the corners are accurately built it is a simple matter to complete the wall in between by a less skilled gang, in the same way as lengths of curtain wall. This may explain some inaccuracies found in the junction of wall and corner, represented perhaps by a slightly projecting raking joint, such as found at the south-east angle of MC37, ${ }^{713}$ explicable otherwise only as rebuilding or a pause in the building programme. No matter how long a pause in building there might have been, there is no reason why the infill and the corners should not be properly aligned. Such

713 Hunter Blair (1934) 110-111. 
misalignment does not of itself imply two phases of work (but merely lack of care), any more than accuracy of alignment necessarily indicates a single phase. Misalignment of such junctions have been recorded in forts, and properly accepted as the result of carelessness. ${ }^{714}$

The external southern angles of the milecastles are invariably rounded rather than square, and the known internal angles are all square to the east of MC47. There is no structural reason for making the southern external corners rounded. However, a rounded corner is easier to build when using unskilled labour and calls for less in the way of organisation and stone dressing. When building a square external angle each side of the corner has to be plumbed; movement of one side of the stone may displace the other and the corner can quickly lean to one side. The difficulties are not necessarily great, but have to be corrected and the building can be time-consuming and slow. Furthermore, a supply of stones dressed on two faces to form the quoins has to be ordered and delivered to site at the right time; alternatively, a gang of men has to be put to dressing on site.

Building a curved wall is a somewhat easier proposition. Once the curve has been set out by the foundation builders, the wall builders have only to follow the line and check that it is plumb on the one face. There is no need for quoin stones, and the whole corner can be built with ordinary walling stones. The fact that the stones were generally worked to a taper would have made building a curve much easier than building with parallel-sided stones.

Internal square corners are easier to build than external ones. Each wall has to be built on the correct line and plumbed, and alternate courses have to be lapped in order to achieve a tie, but adjustment of one wall will not affect the other to any

$714 \quad$ Richmond and Child (1942) 137-8. 
extent. Again, no specially dressed stones are needed, although it is easier if the faces do not project excessively. There is no obvious reason for MCs47 and 48 and all the known replacement stone milecastles in the turf wall sector being rounded on their internal southern angles. They might have proved slightly easier to build than square angles, but it may equally be due to an unknown change in design philosophy.

The northern angles are simply right-angled junctions with the curtain wall of Hadrian's Wall. This, incidentally, indicates that the designers were not thinking in terms of joining a series of fortlets by a curtain wall, but were adding the milecastles to the Wall. This is in distinction to the forts, which have rounded northern angles even where they do not project; $7^{15}$ this is presumably because they were built to existing standard plans.

\subsubsection{Milecastle gateways}

It is worth looking at the building of the gateways in some detail, taking MC37 as a model. The piers of the north gate have five courses above the foundation, including the impost cap, with two stones to each course; the weight of the stones is listed in tables 7.1 and 7.2, as was the need for, and type of, lifting tackle.

The hoisting and fixing of large stones is a relatively slow business - perhaps three or four stones per hour rather than one every two minutes as with the facing stones. ${ }^{716}$ Because of the closeness of the joints, around $5 \mathrm{~mm}$, the mortar bed had to

\footnotetext{
715 The side walls of Carrawburgh are believed to form a square junction with the Wall, but the Wall lies under the modern road. E. Birley tunnelled under the road to within $2^{\prime}$ of the Wall and found no trace of a curved northern angle (Birley (1935) and (1961) 176). Breeze (1972) fig. 1 shows a square junction. As an additional fort it is not strictly relevant to the discussion.

716 The rate of fixing depends very much on the nature of the work. The author, working in a gang of three, fixed four stones per day over a period of three or four days on a repair to a Gothic cathedral; there were serious problems.
} 
be carefully judged, mortar spread on the vertical joint of the previous stone and the stone lifted, positioned and lowered. Spreading mortar to the right thickness is something which an experienced man can readily do, and just as readily an unseen lump or the too-rapid drying of the mortar means that the stone does not sit firmly on its bed, and it has to be lifted off and a fresh bed applied. In dry weather the stone has to be wetted to reduce the suction in the stones; if the suction is too great the mortar can become crumbly and sandy before the stone is bedded down, and it will not squeeze out a little as it ideally should. There is no information available about the extent to which the vertical joints in gateways were filled.

It was said in chapter 9 that one could not build over $1200-1500 \mathrm{~mm}$ without a scaffold, but an exception can be made in the case of large square stones like these. Here the weight is taken by the derrick and all the mason has to do is to guide it into place; there is no reason why this cannot be done with the aid of a ladder or trestles and a plank, and one may expect the building of the piers to proceed to the height of the impost caps without scaffolding. Indeed, scaffolding would have been a positive hindrance.

Once the stone was released from the lifting tackle final adjustments would almost certainly be needed, calling for a different technique from that used in laying facing stones. It is often easiest to stand on the top bed while swinging a heavy (preferably wooden) hammer against face or bed to adjust either the horizontal position or any vertical inclination. In many places, where a course is inset from the one below, small slots were cut in the lower stone, apparently to take the toe a pinch bar as an aid to moving the position of the upper stone. ${ }^{717}$

717 e.g. Benwell Vallum Crossing, stone WPF1 (Hill (2000a); MC42, stone SGNWF2 (Hill (2000b)); MC10, stone NGNW1/2 (Hill (2001e). 
For erecting arches, the voussoirs are built up on a timber formwork, known as a centre, which must be supported at the level of the springing line (see fig. 11.5). This is one function of the projecting impost caps; the overhang is easily massive enough to carry the whole weight of the centre and the arch. ${ }^{718}$ In fact, most of the weight of the arch is carried by that part of the cap which rests on the piers, rather than by the centre resting on the overhang of the cap (fig. 11.6). ${ }^{719}$ For this reason the centre does not have to be a particularly massive structure and it is often a surprisingly lightweight affair; the struts and ribs for an arch of up to $2^{\prime} 3^{\prime \prime}(680 \mathrm{~mm})$ deep and $20^{\prime}$ $(6100 \mathrm{~mm})$ span may be made from no wood thicker than $2^{11}(50 \mathrm{~mm}) .^{720}$

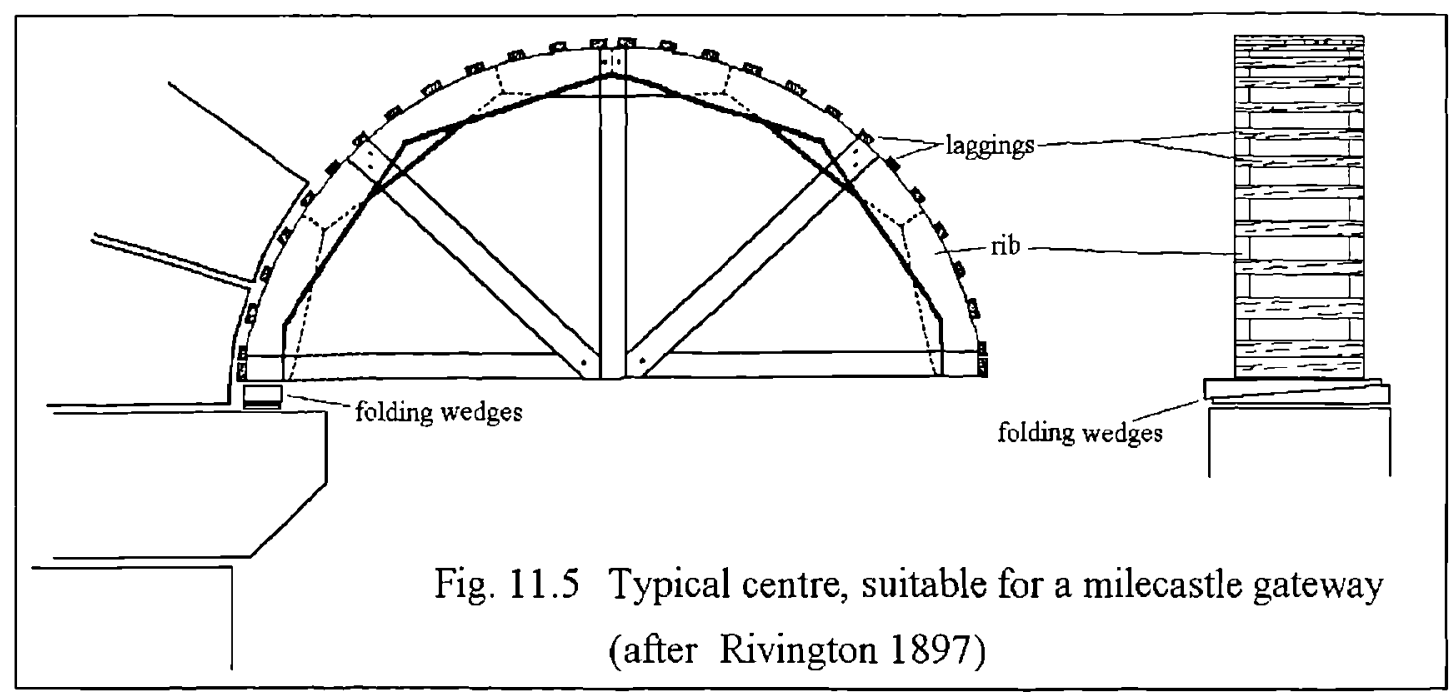

$718 \quad$ Contra Bennett (1988) 121.

719 Smith (1946) chapter 5, esp. fig. 36.

720 Rivington (1897) Part I, 120. 


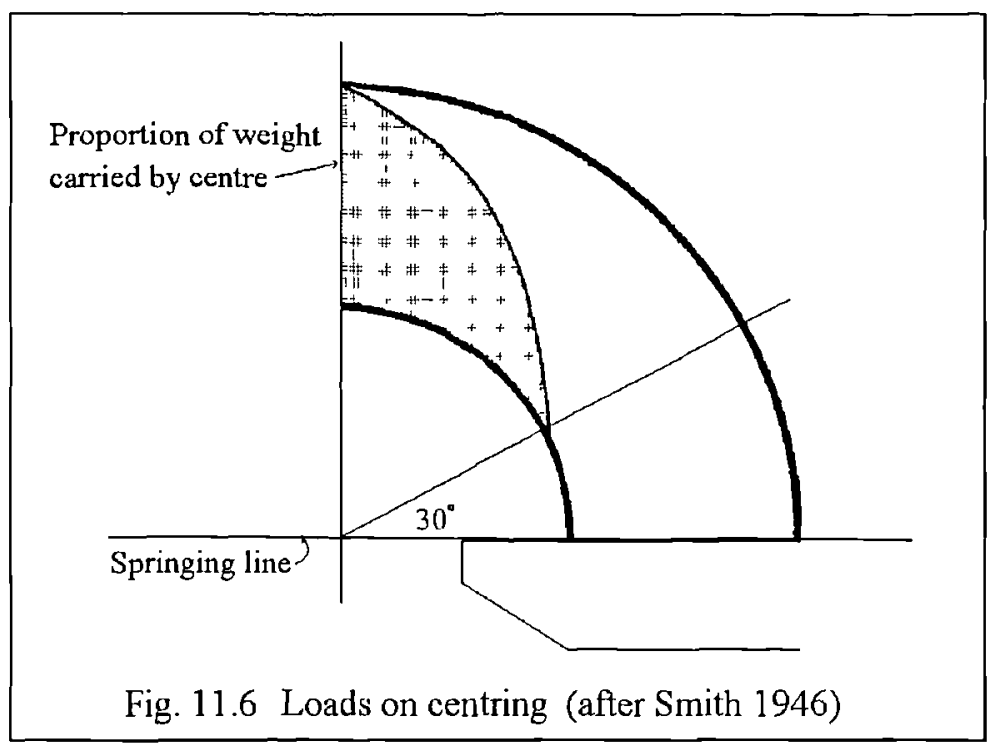

The centre rests not directly on its supports, but on folding wedges. When the arch is complete the wedges are eased out to allow the centre to drop. There is no need to wait until the mortar is set; indeed it is advantageous to allow the weight of the voussoirs to settle as soon as possible to consolidate the mortar joints. ${ }^{721}$ Once the centre is clear of the soffit of the arch the wedges are removed altogether, giving room to slide the centre sideways without disturbing the arch. The wedges are better eased slowly rather than being knocked out suddenly, to prevent a sudden shock to the abutments, but once the centre is clear of the arch, it serves no further purpose. It takes a matter of minutes rather than hours or months. ${ }^{722}$

721 Rivington (1897) 118, and Alberti (1775) 60, among many others, recommend easing the centre in slow, small stages, but there is no good reason to do this.

722 During the rebuilding of a Norman vault of thin-bedded coursed rubble, supervised by the writer, the masons struck the centre immediately the work was finished on a Friday. On the following Monday, well before the lime mortar was fully set, the masons were not only standing on the vault but resting a very heavy steel joist on it. Neither the masons nor the writer had any qualms about this, and seven years later the vault shows no signs of distress. 
It is axiomatic that an arch is stable only when it is loaded, and an arch standing in isolation can in theory buckle under its own weight. O'Connor notes that if the depth of the arch ring is too small, the arch will buckle if the centre is removed before it is loaded (that is, the superincumbent masonry built up). ${ }^{723}$ There is not the slightest danger of this in milecastle or fort gate arches. Heyman says that with a depth of arch ring of just over $10 \%$ of the radius, the arch will be stable under its own weight; ${ }^{724}$ at MC37 the ratio is $40 \% .{ }^{725}$ These arches will stand alone without the slightest danger of collapse, provided the piers do not move.

The only reason for leaving the centre in place would be to counteract any eccentric loads experienced before the abutments (in this case the walling at the haunches) are completed. However, as milecastle arch rings each weigh about 2.8 tons, it is unlikely that the action of fixing the walling stones would have had the slightest effect on the arch.

The voussoirs in Roman military construction have tolerably well-worked beds, and mortar has a comparatively small part to play in the stability of such an arch. Its function is to keep the stones apart and to transmit the pressure evenly rather than to stick them together; ${ }^{726}$ any inequalities in working are best dealt with by letting the mortar squeeze out from below the high spots while still soft.

Bidwell and Holbrook ${ }^{727}$ suggest that the 'fairly small' voussoirs at MC37 could be raised by hand without the use of a crane. This is extremely unlikely, as the

\footnotetext{
723 O'Connor (1993) 174

724 Heyman (1997) chapter 2. O'Connor (1993) 168, suggests that the Roman builders reduced to as little as $5 \%$ for spans over $50^{\prime}(15 \mathrm{~m})$; for such arches the centring would be eased very slightly and then left in place until the surrounding masonry had been built up.

725 The radius is $60 "$ and the voussoirs are an average of 24 " deep (author's survey).

726 Smith (1946) 17; it is also a traditional saying in the masonry trade.

727 Bidwell and Holbrook (1989), 121
} 
average weight of the surviving voussoirs there is around $625 \mathrm{lb}(285 \mathrm{~kg})$. Certainly the present author, who has built a number of arches in solid stone, would be reluctant to attempt the exercise with stones of this weight. Roughly speaking, especially when stones have to be positioned with some care, an absolute minimum of four men would be needed for stones of $200 \mathrm{~kg}$; in order to lift a voussoir they would all be needed on one side of the centre for the initial lift. One edge of the stone could be placed onto the centre, but the voussoir would then have to be pushed rather than lifted onto the centre, an action very likely to result in instability of the centre and of stones already in place. The fact that all the voussoirs at MC37 have lewis holes indicates that lifting tackle was used.

It is possible to build up the lowest voussoirs on either side, which would be stable without the use of a centre, ${ }^{728}$ and these could perhaps be lifted into place by hand, using a bar through the ring of the lewis, or slid sideways from a scaffold built at the right height, but it would be an extremely difficult operation.

The differing spans of front and rear arches in gateway types II/IV was noted in section 4.2.5. It may have been possible to use the same centre for both arches by packing out the smaller centre from the front arch, when building the wider rear one.

Unlike the piers, scaffolding would be desirable for the building of the arches. One could make do without, but trying to adjust the position of a voussoir, even when the weight is taken by a derrick, while standing on a ladder leaning against the centre would be interesting rather than rewarding. No more than a light access scaffold would be necessary.

728 Smith (1946) 113-4 and fig. 36, where the stable angle is given as $30^{\circ}$. At MC37 this represents two voussoirs at each side; friction might keep a third one in place. 
It will be appreciated that the work of building a gateway is a different specialisation from other work on the Wall, and would have been the responsibility of separate, specialist gangs. It would be desirable for the gate-building gang to complete the turning of the arch immediately following completion of the piers, rather than having to return at a later date (see fig. 11.7).

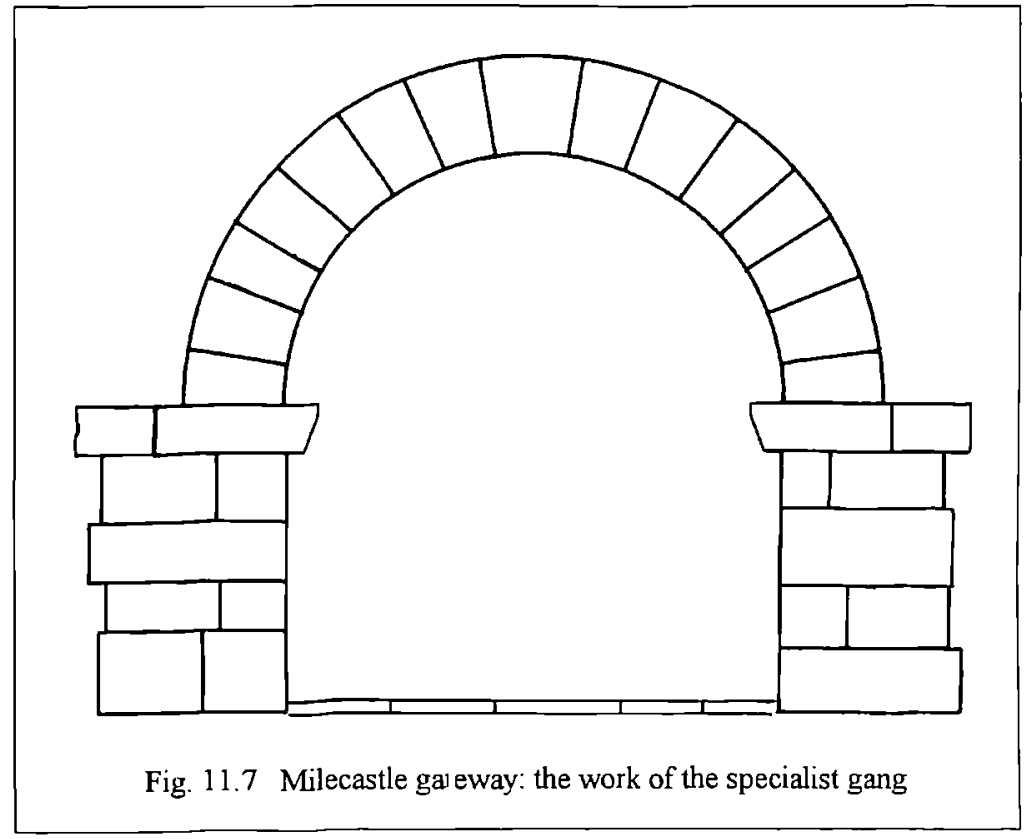

Where evidence is available, the north gates and north walls of the milecastles seem to have been built up in advance of the side walls and perhaps the south walls. ${ }^{729}$ The north walls may have been built at the same time as the gateways, the wall builders following the raising of the piers course by course. It would, however, not be convenient to have a wall-building gang working at the same time as the pier builders and there is no reason why wall-building could not have been delayed until the piers were fully built. Although the outer (i.e. east and west) faces of the piers

729 e.g. MCs $9,13,17,18,19,20,22,27,41,42$. For a convenient summary see Hunnysett (1980). 
often have upper courses projecting over lower ones, the stones are massive enough to be perfectly stable without support.

The towers of the milecastle gateways present the same problems as the turrets, which are considered below.

\subsection{Turrets}

The building of a turret was not a simple operation. Square corners and openings for doors, and windows are significantly more difficult to build than simply putting one stone on top of another to build a long length of wall.

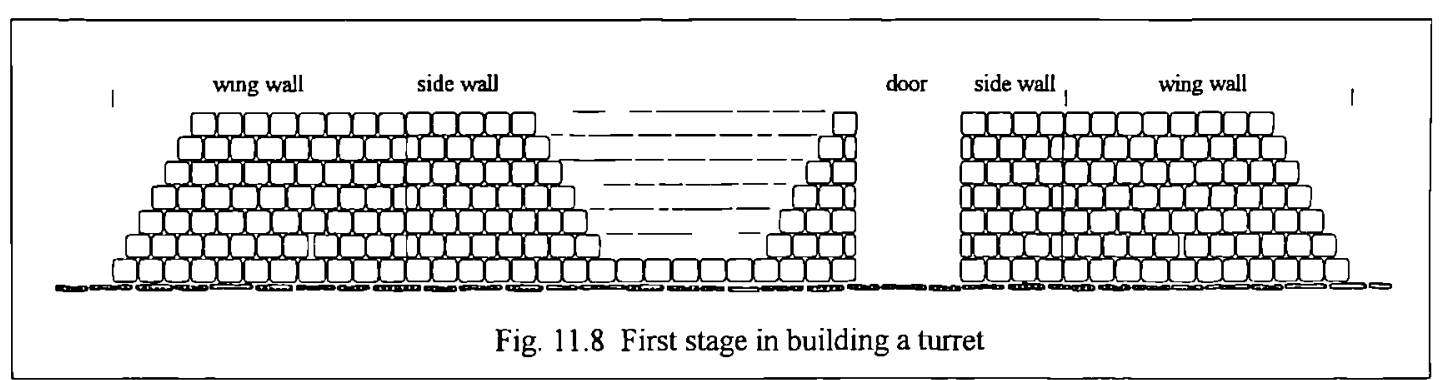

As usual the corners would be built first, taking up good part of the external wall of a turret and even more of the internal walls (fig. 11.8). As suggested for the curtain wall, this lowest stage may have been built in two phases. The square corners will have taken a degree of skill and care if the turret walls were to be more or less vertical. There would thus have been comparatively little straightforward walling to be done on a turret; almost all the work calls for a higher degree of skill than that required for the curtain wall or the milecastle walls. On the ground floor the provision of a doorway will have added to the skill needed, with a square end to two of the side walls to form the door jambs. At the higher levels the corners continue of course, and windows, the number of which is unknown, will have called for building jambs and perhaps arched heads. If, as has been suggested, the walls were reduced in 
thickness above Wall-top height, ${ }^{730}$ the offset will have to have been provided for. The gangs responsible for the work on a turret will have needed a significantly greater degree of skill and experience than those building the curtain wall. Turrets are relatively complex structures.

The purpose of the wing walls is to allow the curtain wall to bond with the turret by means of a raking joint. In the absence of wing walls, provision for bonding would have to have been a vertical 'toothed' joint, something which is not possible in a double skinned wall with a core. The length of the wing walls suggests that building to full height was initially planned, or at least provided for, but it is almost certain that practical logistics of scaffolding would have dictated otherwise. The quantity of scaffolding needed to build a turret or tower (section 9.6.1) makes it highly unlikely that any such structure was built to a height of more than 4-5' (1200$1500 \mathrm{~mm}$ ) or so in advance of the completion of the curtain wall. The probable plan was for the several milecastle gateway and turret gangs to precede the curtain builders to begin the building of each structure both in order to mark the site and because of the level of skill needed. In view of the surviving stonework at T34a, it is worth looking at the way in which the work was actually carried out.

The logical first stage in building a turret would be to set up the lower part of the corners and the end of the wing wall, and then to fill in between. The footing course of the wing wall would also be laid. At T34a, a Standard A turret, only part of the footing course of the wing wall was laid (dark shading in fig. 11.9, which is a diagrammatic representation of the existing bonding), and on that was built part of the first course of the wall proper, and probably the second. This sequence is the most likely as the squaring-off of the wing wall, following the reduction in gauge,

$730 \quad$ Hill (1997b) 
takes in the footing course and two more. Each succeeding course added to the turret wall would have necessitated adding one more stone to the preceding course of the wing wall. It is not easy to think of a more inefficient way of building. It may be that the gang building the turret were doing no more than laying the first three or four courses before handing over to a less skilled gang to complete the building, and that the second gang did not arrive on site until after the reduction in gauge.

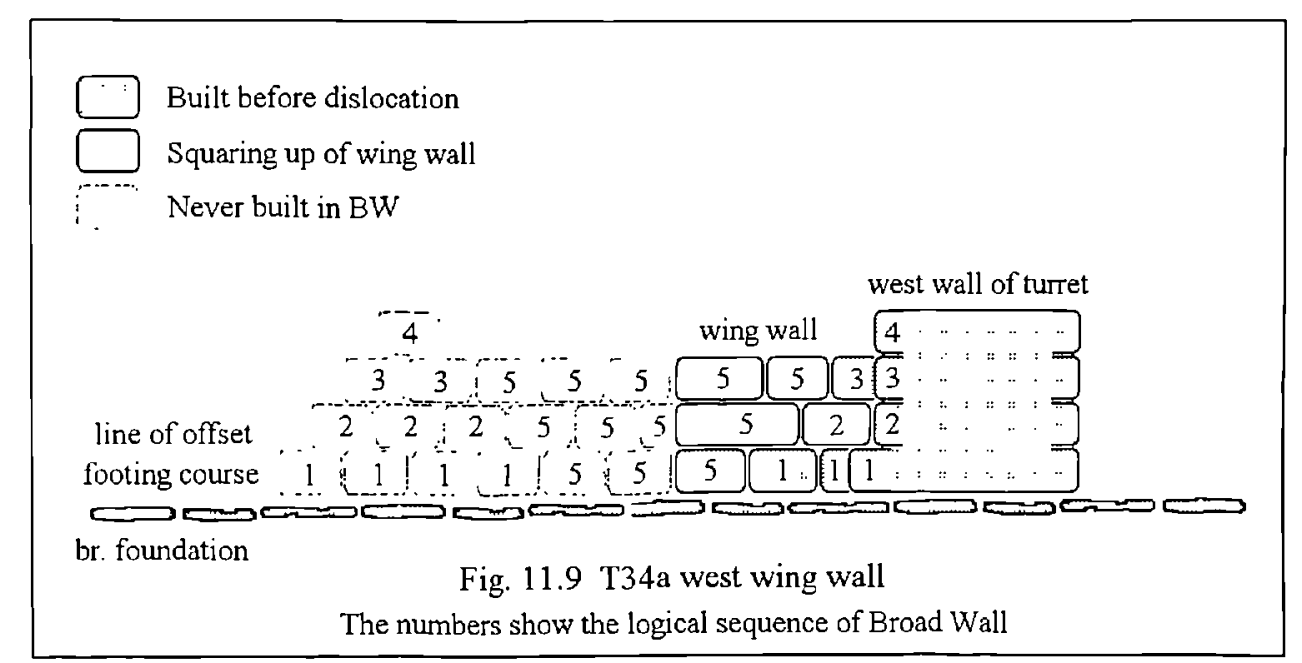

At T41a the work is again not what might be expected. The north wall of the turret is $57^{\prime \prime}(1450 \mathrm{~mm})$ wide ${ }^{731}$ which ought to indicate that it was designed to be part of the Broad Wall. However, no part of the the wing walls appears to have been built and the broad foundation projecting south of the Narrow Wall shows no sign of a footing course. This might indicate that, as at T34a, work concentrated on the turret rather than the wing walls. The north wall now stands only 41" (1040mm) high, and if it never went higher at this gauge the wing walls would have been small indeed. However, this turret was one of those demolished in the Roman period and there is no indication of how much masonry the rebuilders removed.

\footnotetext{
731 Author's survey.
} 
Apart from materials, which would have to be taken to the site anyway, the turret builders would have only themselves to move from site to site. ${ }^{732}$ Any signs of occupation in turrets which were demolished (as part of the fort decision) before the curtain wall reached them cannot be taken as indicating that they were ever completed. On building sites today the existence of two walls meeting at right angles provides shelter for breaks, unofficial or otherwise, and from wind and rain, and it must be assumed that human nature, military or not, has remained unchanged.

The building of the milecastle towers will have called for a similar level of skill to that needed for a turret. Given the significantly smaller plan of the tower, the building of the corners will have taken up all the side walls and most of the front and back walls. As with the turrets, windows, perhaps doors leading on to the curtain wall, and possibly a doorway leading to a balcony, were also needed.

\subsection{Forts}

The purpose of this section is to look at the nature of the work entailed in building the defences of the forts: curtain wall, towers, and gateways. The internal buildings are not included.

The curtain walls of forts were significantly thinner than the curtain of the Wall, as discussed above (section 4.2.3). The building of the curtain walls was identical to that of the Wall.

732 The points in this and the preceding paragraph are discussed at greater length in Hill and Dobson (1992) 39. 


\subsubsection{Interval towers}

The techniques of building the towers were no different from the turrets. Both were built of squared rubble, both had doors, windows, floors, and roofs. They were similarly complex structures and, like the turrets, begun in advance of the curtain wall, complete with wing walls. This was not ${ }^{733}$ because the Romans saw them necessarily as distinct structural units but because that is the most convenient way to build, just as the turrets and milecastles were begun before the curtain wall.

\subsubsection{The gateways}

In many respects the gateways of the forts present similar problems to those of the milecastles. They have in common the large, squared stones of the piers and the worked voussoirs, and the twin arched portals of the fort gateways are not unlike two milecastle gateways.

Dressing the stones for the piers and arches of the fort gateways was a similar process to that required for the milecastles, although with some added complications. On the milecastle gateways the length of the stones of the outer sides of both piers could be of variable length (marked as 'unmeasured' on fig. 11.10). Putting two such gateways together to form the twin portals of the fort gateways meant that what was in effect a conjoined central pier had to be of definite dimensions to form the spina. The difference in working would not be great, but the size of the spina had to be determined and the stones worked to that size.

733 contra Richmond and Child (1942) 137-8. 

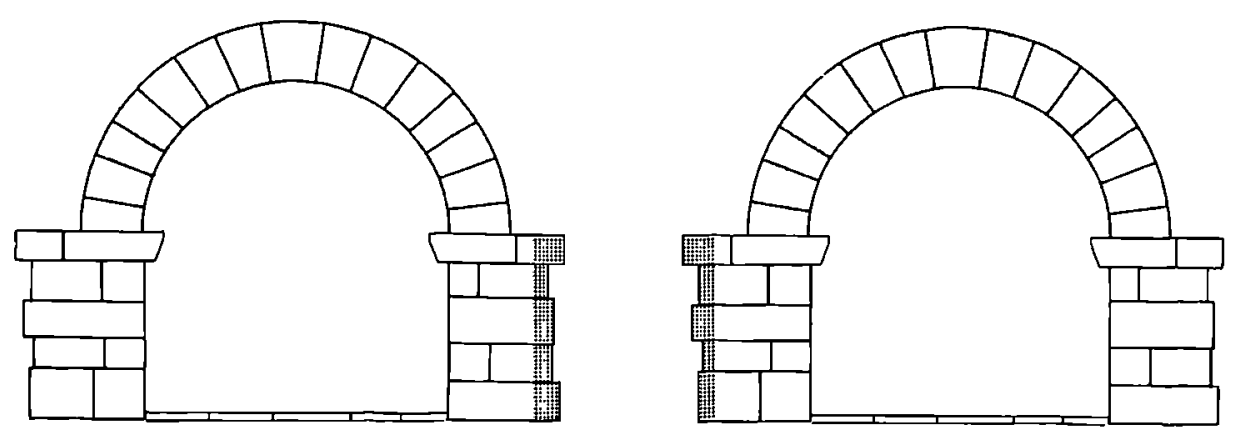

Milecastle gateways

Unmeasured edge

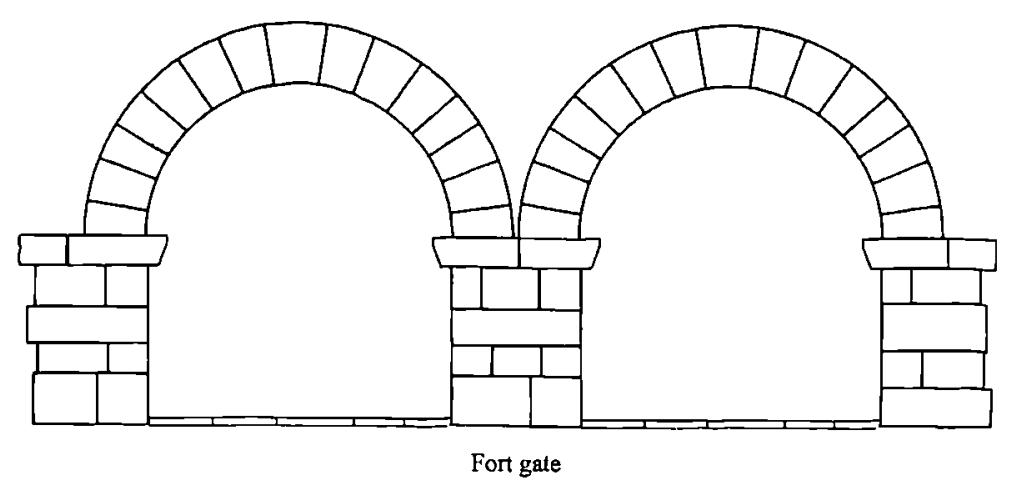

Fig. 11.10 Milecastle and fort gateways

The arches of the gateways called for exactly the same techniques in building as those of the milecastle, and the remarks made under that heading apply equally here. Here notice may be taken of the small sinkings on the top bed of the capital of the south west pier of the east gate of Chesters fort. At the north end of the bed, approximately on the centre line of the stone, is a rectangular sinking $75 \times 125 \mathrm{x}$ $25 \mathrm{~mm}$; the sides slope inwards. It was neatly cut in with a punch with a fairly flat bottom, although there seems to have been no deliberate attempt to make it flat. The north edge is only $50 \mathrm{~mm}$ from the vertical fillet of the moulding. To the west of this is a second sinking, about $65 \times 125 \times 15 \mathrm{~mm}$; this is not as neatly cut and is irregular 
and looks unfinished. The south edge is aligned exactly with the first sinking, and perhaps the north edge was similarly aligned but it has suffered damage. The south edge of these features is about $5 \mathrm{~mm}$ to the north of the line of face B of the cap. ${ }^{734}$ There is no obvious purpose for these sinkings; they cannot have been in any way connected with the centring for the arch. It is just possible that they played some part in a repair of the arch, but one would expect them in that case to be seatings for timber struts and it is very difficult to see them being suitable for this purpose.

The difference in span of front and rear arches in type IU/IV milecastle gateways was noted above (section 11.4.2); the same problem applies to the gateways of Housesteads fort.

The major difference between the milecastle and fort gateways lies in the superstructure. Whereas the former have small, simple towers, the latter have substantial upper storeys, with towers at either side of the portals and probably some superstructure above the portals as exemplified by the reconstruction at South Shields. The overall width including the towers was twice that of two milecastle gateways.

Despite the size and sophistication there was no call for any techniques of construction different from those required for the milecastle gateways. Arcuate window heads are found at both, ${ }^{735}$ and the doors were very similar, turning in similar pivots even though the pivots in some milecastle gateways may have been somewhat smaller. ${ }^{736}$

\footnotetext{
734 The above comments are from Hill (1997a).

735 A summary of finds from fort gateways is given in Bidwell et al. (1988) 209-210. MC39 yielded two fragments of arcuate window heads (Crow (1988) 151).

736 Crow (1988) 148.
} 


\subsection{Specialisation}

'Turret gangs' have been referred to as a separate force, and one would expect specialised gangs to be building turrets as the work was more skilled, and called for more experience, than building the curtain. The same is true of the milecastles, especially the gateways which would very probably have been built by yet another gang as the work of building in massive solid stone is very different from building with squared rubble, and the final dressing of the gate piers called for a degree of skill which was not necessary for curtain building. Fort gateways and towers will have been work calling for similar skills. Skilled legionaries must have been at a premium in such a huge enterprise, and to make best use of the available men one may suspect that there were separate gangs engaged in building foundations, turrets and towers, gateways, and curtain wall; it is doubtful if they were ever interchangeable other than by the 'promotion' of individuals as the result of experience.

The building of scaffolding may also have been the work of specialist gangs, although it is possible, if not desirable, that this could have been carried out by the building gangs under guidance.

\subsection{The ditch and Vallum}

The features of the ditch to the north of the Wall and the Vallum to the south have been discussed in sections 4.4, 4.5 respectively. This section will look at the nature of the work involved in their digging and the size of the task.

Digging the ditch was one part of the work with which every Roman legionary would have been familiar, such activities being a part of their training, ${ }^{737}$ and was a

737 Vegetius I.4 and I.21; Davies (1989) Chap V. 
straightforward matter of excavation with dolabra and spade, shovelling the earth into baskets to be hauled out and dumped as a glacis, and raked level, although in places along the Wall it was left in heaps. ${ }^{738} \mathrm{~A}$ ditch of these proportions, with the sides at an angle to the horizontal of about $33^{\circ}$, has something in common with a small road cutting, and as such British army methods may be usefully applied, thus: 'to dig small trenches at each side along the cut lines at ground level at each side, and to take off the soil in between in layers of about $1 \mathrm{ft}$ in depth, commencing each layer $1 \mathrm{ft}$ nearer the centre line at each side. By this means stepped sides will be formed, which can be dressed to the required slope. ${ }^{739}$ Whether the Roman builders used precisely this method cannot be established, but it, or something on similar lines, would certainly be more satisfactory than trying to form the finished profile of the ditch as work proceeded.

The presence of the ditch would have interfered seriously with the movement of materials from any quarries to the north of the wall, and ideally it would have been planned as the last part of the programme to be carried out. The unfinished state of the ditch at Limestone Corner may indicate that it did indeed fall late in the sequence after any initial enthusiasm had evaporated. The ground does slope significantly to the north at this point, but probably not enough to make the ditch redundant given the care taken to provide the ditch at almost every gap in the crags.

In fact the only gap along the crags where, so far as it known, the ditch was not dug, is at Housesteads. It may be no coincidence that the only quarry definitely known to be north of the Wall along the crags was at Queen's Crag to the north east of Housesteads, as well as at points between Queen's Crag and the Wall. ${ }^{740}$

\footnotetext{
$738 \quad$ e.g. Wall Fell and Appletree $H B^{13} 20$.

739 War Office (1935) 95.

740 E. Birley 'RB in 1960 ' 194 . The quarry is undated.
} 
Premature digging of the Vallum, too, would also have been a considerable nuisance to the builders; the limiting of access from the south to roughly seven mile intervals would have added insult to injury for men already called on to add forts to a project of which they had probably already seen enough. Frequent causeways would ideally have been left to ease this problem or perhaps, if the organisation were not very tightly controlled, temporary causeways would have had to be introduced on both ditch and Vallum. Indeed R.G. Collingwood suggested ${ }^{741}$ that the 'crossings' were put in for precisely this purpose; although the much later date of the crossings has now been established, it is interesting to see this early and practical consideration of the logistics of building the Wall.

$741 \quad$ Collingwood (1931a) 93. 


\section{CHAPTER 12}

\section{Organisational aspects of the work}

\subsection{The Building Season and Working Week}

Two climatic factors affect building work, rain and frost. Heavy rain can be a more serious event than frost; the latter can usually be predicted, in broad terms, whereas the onset of rain is uncertain. Moderate or heavy rain against the face of new work is liable to wash out unset mortar. Remaining mortar will be weakened as excess water causes lime to leach out.

Heavy rain would prevent work continuing, but there are surprisingly few days on which the weather is too bad for outdoor work for men accustomed to it. It is normal for light drizzle to be ignored; the point at which work stops is determined by the force of the supervision.

Working stone is affected by rain in two ways. First, hammers used on tools of indirect percussion (chisels, punches) will tend to slip from the head of the tool causing injury to the hand. Secondly, when chiselling stone, rain forms the resulting dust into a paste which makes it near impossible to see what is being done; this is more relevant to working pier stones than walling stones. The problem can be avoided by the provision of simple overhead shelters.

The factor which has an immediately damaging effect and occurs at reasonably well-fixed seasons of the year is frost, which affects mortar by freezing any uncombined water and disrupting the partially-formed crystalline structure. ${ }^{72}$ The harder the frost, the greater the depth to which unset mortar will be affected, but all

742 Grundy (1930) 138. 
frost action is deleterious. It is said that lime-rich non-hydraulic mortars (less than two parts of sand to one of lime) are more susceptible to frost attack in the winter following its use than the less-strong mortars. ${ }^{743}$ In general, once mortar has taken an initial set, the effect of frost is much reduced. The effect of moderate frosts can be mitigated by covering new work with straw, bracken, or other suitable materials until the frost has lifted or until the mortar has set. ${ }^{744}$

The climate in the second century appears to have been broadly similar to that of today, with the temperature also very close to the present (see section 3.3). Today, building work can normally be carried out from the beginning of March to the end of October without serious risk of frost damage, and in the second century the position is likely to have been no more restricted. This gives a notional season of about 35 weeks, or 245 days, for building with lime mortar.

It cannot be supposed that the troops worked continuously throughout this period, and some allowance must be made for rest days, festivals, and other public holidays. The seven day week was known in Rome by the time of Augustus, but the weekend as we know it was not recognised, and the seventh day was not a day of rest until the conversion of the empire to Christianity. ${ }^{745}$ The third century Feriale Duranum shows 46 festivals $;^{76}$ some of these were not applied during the building of the Wall as they include second century deified emperors, but perhaps earlier ones may have been dropped. Taking a slightly arbitrary figure of 45 days of rest leaves a

\footnotetext{
$743 \quad$ Vicat (1837) chapter 13.

744 Today, work is effectively protected against mild frost by no more than one or two layers of hessian.

745 Balsdon (1969) 260.

$746 \quad$ Fink (1971) No. 117.
} 
season of 200 days, coinciding with the estimate given by Robert Rawlinson of 200 working days in a year permitted by the weather in the Wall area. ${ }^{747}$

The working day might reasonably be taken as eight effective hours, or 48 hours in a six-day week; this excludes time for rest and refreshment, and for marching to and from the temporary camps. A total of ten hours away from camp is not excessive, and during the season suggested there is sufficient daylight for this to be possible.

Provided the weather was not too bad for the legionaries to continue to live in tents, it is possible that some work may have continued during at least part of the October-March period. Digging of the ditch and Vallum was certainly possible in dry periods which were free of hard frosts. Transport of prepared walling stones could easily have been carried out in the absence of rain (which would have turned the tracks into quagmires). Quarrying in the winter is not normally carried out, as there is an increased chance of newly quarried blocks being damaged by frost before they have dried out, but some work could probably have been done. Blocks which had already been quarried could have been worked into walling stones or pier stones; simple, open-sided shelters would have allowed this work to be continued over most of the year.

Against this scenario must be balanced the unhappiness of legionaries living in tents over part of the winter while auxiliaries (unless they were involved in the building) were living in well-built barracks with families and friends close by ${ }^{748}$

\footnotetext{
$747 \quad$ Bruce (1851) 94.

748 Tacitus implies that after the rebellion of Boudica the legions were kept in tents outside the nomal campaigning season; the fact that he mentions this suggests that it was an unusual occurrence (Annals XIV, 28).
} 
Much speculation is inherent in this discussion of the working season. For how many days in the season were the men actually available for work? Was the effective working day of six, eight or ten hours (which suggests an overall day of something approaching eight, ten, and twelve hours respectively)? Did the legions return to winter quarters, and if so, how long did they spend there?

All that can be done is to take note of all the above points, and suggest around 200 days as a realistic estimate for building work and rather more for other works.

\subsection{The labour force}

In order to make an assessment of the possible labour force present during the building of the Wall, it is necessary to look for evidence of what units, or types of unit, were involved and the part or parts for which each was responsible. This will be done by examining the inscriptions left by the builders and extrapolating from these to establish to what extent legionaries and auxiliaries were involved in the various elements of the work. A judgement will be made as to the possible total manpower engaged on the project: it is unlikely that this can ever be more than a rough approximation.

\subsubsection{The evidence of inscriptions}

The inscriptions are of two types. First, there are the formal dedications naming the emperor, the governor, and the unit responsible. In general, the size and formality is relative to the size of the building but this is not wholly consistent.

Secondly there are the centurial stones, records left by work gangs on the curtain wall and Vallum and in forts, which simply record the the gang, normally a century, sometimes with the cohort and/or legion in addition. The addition of the cohort 
number will establish the century as being legionary, whereas centurial stones left by auxiliary units can only be so determined if the unit name is given. These inscriptions are almost uniformly crudely cut, as befitted what were probably no more than temporary records, with the occasional higher-class piece.

\subsubsection{Inscriptions from the Wall and forts}

The builders of forts were recorded in inscriptions set up over the gateways. ${ }^{749}$ Only three Hadrianic dedicatory inscriptions survive from fort gateways. That from Haltonchesters (RIB 1427), although surviving only in part, is clearly of excellent quality; it commemorates the work of legion VI. The complete inscription from the east gate of Greatchesters ( $R I B$ 1736) has execrable lettering and layout; ${ }^{750}$ the unit responsible is not named. In both cases there are raised mouldings around a sunken die; that from Haltonchesters has peltae at either end, which may explain why is it about one third larger. Both slabs were designed to be of imposing and dignified appearance, as though to reflect the status of the unit as well as that of the emperor and the project as a whole. $R I B 801$, found near the east gate of Moresby on the Cumberland Coast, commemorates the work of legion $\mathrm{XX}$ on a slab which carries stylised foliage decoration rather than mouldings; like the Greatchesters inscription it is dated to post $\mathrm{AD} 128$ and is of similar surface area.

\footnotetext{
749 Richmond and Child (1942) discuss the placing of these inscriptions in relation to the overall design of the gateways. The inscription from Hardknott (JRS lv (1965) 222, no 7) has been cut away at the two lower comers, as if to fit into the spandrel between the two arches.

750 Lindsay Allason-Jones kindly gave access to inscriptions in the Museum of Antiquities, Newcastle upon Tyne, for detailed examination and measurement.
} 
Milecastle gateways carried smaller and less formal inscriptions, which probably sat above the string course. ${ }^{751}$ Six such inscriptions survive: $R I B 1634,1637$, and 1638 name legion II Augusta and the governor Platorius Nepos; this governor is also named on the fragmentary $R I B 1666$ which is very similar in style to the previous three and was almost certainly the work of legion II; RIB 1852 names legion $\mathrm{XX}$ (but not the governor), and $R I B 1935$ is a wooden fragment, on which the name of the unit does not survive, although Nepos does appear to be named. The fact that legion VI is not known to have built milecastles does not mean that they did not do so; there is a severe paucity of milecastle inscriptions and there are three designs of gateways. The five stone inscriptions were simple slabs, with no mouldings or sunken die and with little attention paid to squaring the edges of the slab; the lettering is significantly less well designed than on RIB 1427. This is perhaps a little surprising. Milecastles, although small, had imposing gateways and accommodation for troops and might have been thought to be important in their own right.

The detailed summary of centurial stones provided by Stevens (1966) confirms that all three legions, II Augusta, VI Victrix, and XX Valeria Victrix had an involvement in building the curtain wall and turrets.

It was not only the legions which had some involvement in building the forts; the only Hadrianic dedication from an internal building of a fort, $R I B 1340$, found in the portico of the granary at Benwell, ${ }^{752}$ was put up by the Classis Britannica. This has a moulded surround with well-designed lettering and will have been an imposing stone. It is about one third larger in area than RIB 1638 from MC38. It is the only Hadrianic non-legionary record relating to the original building. The similarity in

\footnotetext{
$751 \quad$ Hill (1991) 36.

752 It presumably comes from the granary, as it was found more or less on the centre line of the building 'lying face downwards and shattered by a fall.' (Simpson and Richmond (1941) 19).
} 
design of granaries at Rudchester and Haltonchesters has been held to suggest that the fleet may also have built those as well. ${ }^{753}$ The fleet is also recorded on two centurial stones from the western part of the Wall; although lacking provenance, both appear most likely to have come from the rebuilding of the first four miles of the Turf Wall in stone, ${ }^{754}$ believed to have taken place later in Hadrian's reign. ${ }^{755}$ Both stones, undated, record building an unspecified length in feet, which might suggest that they were building curtain wall. ${ }^{756}$ The fact that the fleet may have been building curtain wall as part of a relatively small building programme means that their involvement in similar work during the major campaign cannot be ruled out.

Auxiliary army units have left no dated record of the initial building of the Wall, although there are a few auxiliary centurial stones which relate to the latter part of Hadrian's reign. RIB 1550 records building work at Carrawburgh by cohors I Aquitanorum on an inscription which seems most likely to date from 130-133. ${ }^{757}$ $R I B 1818$ and 1820 record work in $136-8$ on the fort of Carvoran, a fort excluded from the Wall area by the northward deviation of the Vallum. There is an undated

753 Breeze and Dobson (2000) 66-7. Taylor (2000) 38 supports the similarity in design.

754 RIB 1944 was found in Triermain Castle 11/2 miles north west of Birdoswald, and RIB 1945 in the Birdoswald area.

755 The latest review of the pottery from MC54 found that 'The ceramic evidence in no way invalidates the claim that MC54 was rebuilt in stone under Hadrian.' (Allason-Jones, Bennett and Welsby (1984)). The pottery finds were few. It has been argued that MC50SW shows the same number of occupation periods as other milecastles and that it must therefore have been in use under Hadrian (Newbold (1913)). The excavators of MC50TW reached a similar conclusion as to date (Simpson, Richmond, and St. Joseph (1935)). An undated building stone from Chesters fort, which appears to have come from the porta quintana dextra, also records building an unspecified length in feet (JRS lii (1962) 193, No. 14). See notes to this inscription in $R I B$; the fort was built over the filled-in Vallum. 
auxiliary building inscription from the line of the Wall just to the west of T26b, Brunton, and a similar one, which gives no indication of the unit, from Chesters fort. ${ }^{758}$ A stone from just east of the secondary tower at Willowford Bridge names a centurion with possible Dacian origins: $;^{759}$ as Chesters was garrisoned by ala Augusta ob virtutem appellata under Hadrian and by ala II Asturum in the late second/early third century, ${ }^{760}$ and cohors $I$ Dacorum was stationed at Birdoswald, ${ }^{761}$ it is possible that all three stones refer to repair by units in garrison rather than to original building. However, the building of the forts need not be related to the unit which eventually occupied them. E. Birley, in the belief that the Brunton stone was from Chesters fort, was quite happy to accept that an ala was involved in the original building of the fort. ${ }^{762}$

A fragmentary dedicatory inscription from building $x v$ at Housesteads has been heavily restored to show a Hadrianic dedication by an unnamed (auxiliary) cohort. $^{763}$

Auxiliary units are known to have been directly involved in building work before and during Hadrian's reign; documents from Vindolanda and a Hadrianic dedication from Hardknott provide firm evidence of this. ${ }^{764}$ It is not impossible that auxiliaries

$758 \quad R I B 1445$ and 'RB in 1961' 193, no. 14. respectively; the first stone refers to a turma for which there is evidence only in alae and cohortes equitatae. Georgina Plowright kindly allowed access for detailed measurements of this stone. See also Hill (forthcoming). 'RB in 1962' 161, no. 8c. The centurion may be the same as on RIB 1365 in which the cohort is given as I Dacorum.

$760 \quad$ Austen and Breeze (1979); RIB 1463, 1465.

$761 \quad$ RIB 1886-1894 and others.

$762 \quad$ Birley (1937) 241.

763 I.A. Richmond 'RB in 1961' 193-4, no. 15.

764 Bowman and Thomas (1983) 77-79 (Inv 195, 198) and Bowman and Thomas (1994) No.156 (Vindolanda); 'RB in 1964' 222, no.7 (Hardknott). 
were directly involved in the original building of the Wall; this is discussed further in 13.5 .

\subsubsection{The Vallum}

Auxiliaries certainly dug at least a part of the Vallum. There are sixteen inscriptions listed in $R I B, J R S$, and Britannia which are known or suggested to relate to the building of the Vallum. Of these, eight stones listed in Table 12.1, RIB 1361, 1362, $1363,1364,1365,1367,1376$, and $J R S 1$ (1960) 10, were all found on or close to one or other of the Vallum mounds. The remaining eight stones are judged to have come from the Vallum largely on the basis of the thickness of the slabs. These stones are listed in Table 12.2, along with other stones which, on the same basis, could also be from the Vallum. There is some danger in this approach, as will be seen. Only those stones which are known to come from the Vallum are shown within the mounds on the Vallum diagram, fig. 12.1.

TABLE 12.1

\begin{tabular}{|c|c|c|c|c|c|}
\hline \multirow[b]{3}{*}{$R I B$} & \multicolumn{5}{|c|}{ CENTURIAL STONES CERTAINLY FROM THE VALLUM } \\
\hline & & UNIT & THICl & KNESS & LOCATION \\
\hline & 1361 & & $1.5^{\prime \prime}$ & $38 \mathrm{~mm}$ & Vallum, $S$ of $7 b$ \\
\hline$R I B$ & 1364 & & $2 "$ & $52 \mathrm{~mm}$ & Vallum, $W$ of $7 b$ \\
\hline$R I B$ & 1363 & & $2.5^{\prime \prime}$ & $64 \mathrm{~mm}$ & Vallum, $S$ of $7 b$ \\
\hline$J R S$ & $50(1960), 10$ & & $2.5^{\prime \prime}$ & $64 \mathrm{~mm}$ & Vallum, 42 \\
\hline$R I B$ & 1362 & & $2.75^{\prime \prime}$ & $70 \mathrm{~mm}$ & Vallum, Denton Burn \\
\hline$R I B$ & 1365 & $\begin{array}{l}\text { Coh I } \\
\text { Dacorum }\end{array}$ & $3^{\prime \prime}$ & $76 \mathrm{~mm}$ & Vallum, $7 \mathrm{~b}-8$ \\
\hline$R I B$ & 1367 & & $5 "$ & $127 \mathrm{~mm}$ & Vallum, $W$ of $7 b$ \\
\hline$R I B$ & 1376 & & $6 "$ & $152 \mathrm{~mm}$ & Vallum, E of Walbottle \\
\hline
\end{tabular}




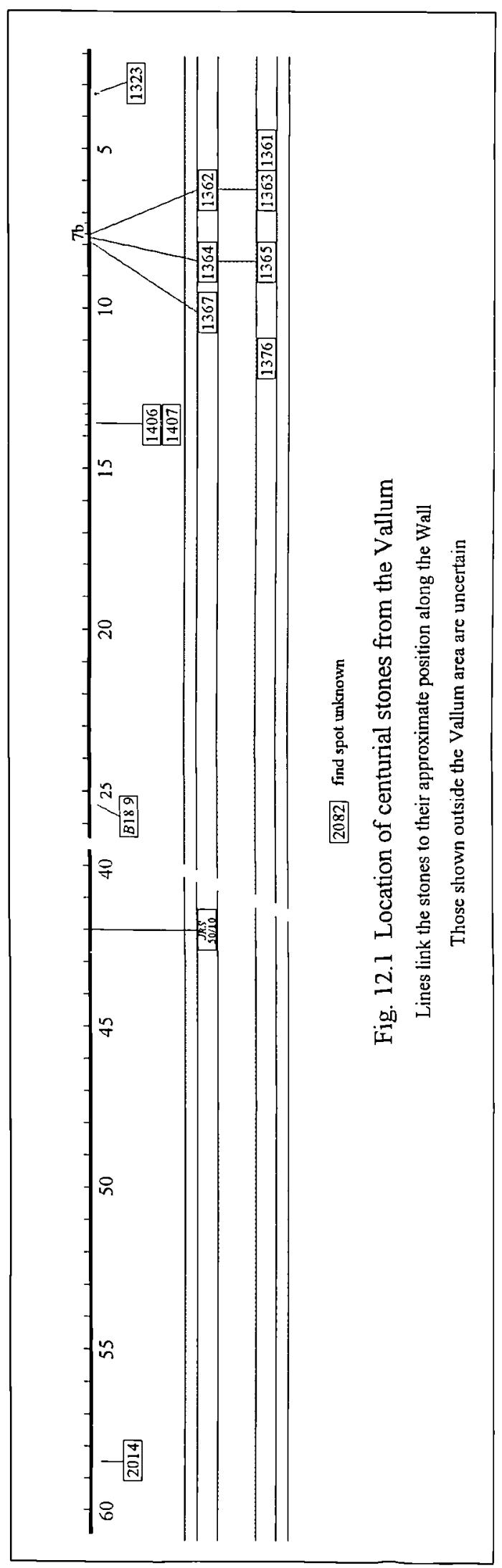


As may be seen in Table 12.1, some of the inscriptions which certainly relate to the Vallum are as little as $1 \frac{1}{2}$ " thick; they seem to have been laid in the slope of the mounds, set into the turf cheeks. What was probably a centurial stone from Carlisle is believed to have come from the turf rampart of one of the forts on the site. ${ }^{765}$ It was on the basis that a very thin stone equals turfwork that it has been suggested that a stone from Newcastle ( $R I B$ 1323), two reused stones from Rudchester (RIB 1406, 1407), a stone from near MC59 (RIB 2014), and one of unknown provenance (RIB 2082), ${ }^{766}$ all come from the Vallum. In order to assess the utility of these suggestions, the reader is reminded of the reason for the thickness of stone inscriptions (section 6.3.3). Large dedication slabs typically fall into the range of 4$6 "$ thick (author's survey), much thinner than the average walling stone.

By contrast, there is little restriction, upper or lower, on the thickness of slabs set in to turfwork; they may be as thin as can be lettered safely or they may be as thick as are convenient to carry. If thin-bedded stone is available then that is likely to be used; a highly fissile stone will split down to a thin slab with little effort and is likely to present a naturally flattish face easy to cut an inscription on without further work. Less fissile and more thickly bedded stone would usually call for the face to be dressed more or less flat before lettering; working off the back simply to produce a thin slab is a pointless exercise for small inscriptions of only passing utility. For small stones such as Vallum inscriptions, the weight of a thick stone would not be a problem. For example, the reason that Vallum stone RIB 1376 is 6" $(150 \mathrm{~mm})$ thick is no doubt because that is what was readily available; the weight is around 301bs

\footnotetext{
765 'RB in 1990 ' 296, no. 4.

766 See notes under these entries in RIB. In fact, it is the thinner dimension of RIB 1406, 1407 which has been inscribed, making it certain that they originated in one of the bonding courses of the Wall.
} 
(14kg). Digging out a few inches of turfwork to let it in to the mound would have been much simpler than working the stone to a thin slab.

TABLE 12.2

CENTURIAL STONES SUGGESTED TO HAVE COME FROM THE VALLUM, AND OTHER THIN STONES

Question marks before Vallum indicate designation by others.

UNIT

Brit 22 (1991) 296, no. 4

RIB 2082

RIB 1323

RIB 1461

RIB $\quad 1462$

RIB $\quad 1281$

RIB 1322

RIB $\quad 1818$

RIB 2012

RIB $\quad 1345$

RIB 1346

RIB $\quad 1402$

RIB $\quad 1705$

JRS 49 (1959) 136, no. 4b

RIB 2014

Coh I Lingonum

RIB 1406

RIB $\quad 1407$
THICKNESS

$1.3^{\prime \prime} \quad 33 \mathrm{~mm}$

$1.5 \quad 38 \mathrm{~mm}$

$2.5 \quad 64 \mathrm{~mm}$

$2.5 \quad 64 \mathrm{~mm}$

$3.590 \mathrm{~mm}$

$4 \quad 102 \mathrm{~mm}$

$4 \quad 102 \mathrm{~mm}$

$4 \quad 102 \mathrm{~mm}$

$4 \quad 102 \mathrm{~mm}$

$4.5 \quad 115 \mathrm{~mm}$

$4.5 \quad 115 \mathrm{~mm}$

$4.5 \quad 115 \mathrm{~mm}$

$4.5 \quad 115 \mathrm{~mm}$

$5 \quad 127 \mathrm{~mm}$

$5.5 \quad 140 \mathrm{~mm}$

$6 \quad 152 \mathrm{~mm}$

$6 \quad 152 \mathrm{~mm}$

\section{LOCATION}

Carlisle (turf fort)

(?)Vallum, location unknown

(?)Vallum, Newcastle

Chesters (139)

Chesters (3rd cent)

High Rochester

Newcastle (Antonine)

Carvoran (?stone fort)

MC58

Benwell (?poss Vallum)

Benwell (?poss Vallum)

Rudchester (?poss Vallum)

Chesterholm

$35-35 \mathrm{a}$

(?)Vallum, half mile $\mathrm{E}$ of 59

(?)Vallum Reused in Rudchester mithraeum

(?)Vallum Reused in Rudchester mithraeum

In practice, it is unlikely that small slabs of under, say, $3 "(75 \mathrm{~mm})$ thick would be used as part of a wall, so such slabs can reasonably be assigned to turfwork although without absolute certainty. Stone of over, say, 7-8" (180-200mm), especially with a tapered back, are much more likely to have come from a wall. Between these 
extremes, assignment of stones to Wall or Vallum on the basis of their thickness is unsafe in the absence of supporting evidence.

Even very thin inscribed slabs do not necessarily come from the Vallum. They are equally likely, given the right circumstances, to be from turf and timber forts (as with the stone from Carlisle mentioned above) or milecastles. One of these stones, RIB 2012, only 4" (100mm) thick, was found in the ruins of MC58 and may have come originally from the rampart of the turf wall milecastle; but as argued above, a stone of this thickness could very well be from a stone building. A stone from Newcastle, $R I B 1323$, is only 2 " $(50 \mathrm{~mm})$ thick and could be a candidate for a Vallum stone - but there is no evidence that the Vallum came so far east. Three stones of Arrius, two from Benwell and one from Rudchester, are all 41/2" (115mm) thick and may also be Vallum stones but this cannot be proved; he clearly seems to have been working along the line of either Wall or Vallum. A stone from near Brampton and one from Carvoran, naming the Lingones and the Batavians respectively, have been claimed as Vallum stones. The Brampton stone comes from an area where the Turf Wall was built, but unless the auxiliaries were building the Turf Wall it ought to be from the Vallum. The stone fort at Carvoran had a turf predecessor, and so the identification of that stone must fall unless further evidence is forthcoming.

The stones mentioned give either the names of auxiliary units, with or without the century, or the name of a centurion. Three of the stones from Benwell are, however, claimed or at least suggested as legionary. ${ }^{767}$ One, Valerius Flavus RIB 1362 has been so claimed on the basis that the same name appears on RIB 337 from Caerleon, the base of legion II. The second, Peregrinus RIB 1376, also appears on $R I B 401$ from an uncertain location in south Wales, the date of which is not known.

767 For references, see entries in $R I B$. 
The names are not particularly unusual: Mócsy shows that Valerius occurs 42 times in Britain, and Peregrinus 6 times; Flavus appears once in Britain, but is well represented elsewhere in the empire. ${ }^{768}$ Peregrinus may have been an auxiliary in Wales, as the auxilia did take over much of the building work from the second century onwards. E. Birley has suggested that the third one, Atisius (RIB 1367), is a legionary centurion on the grounds that possession of nomen and cognomen indicates citizenship. But citizens did enlist in the auxilia, and legionaries were promoted there as centurions. ${ }^{769}$

The only firm evidence shows that auxiliaries were digging the Vallum; evidence for legionary involvement is tenuous at best.

\subsubsection{The ditch}

There is no evidence as to which units dug the ditch to the north of the Wall; it may have been auxiliaries, legions, or the fleet.

\subsubsection{Other auxiliary and native involvement}

The auxiliaries may have taken part in ancillary aspects of the work, such as transport and fuel gathering, which would leave no epigraphic trace and for which there is no basis on which to make reasonable estimates. Similarly, the number of auxiliary units engaged on building the Vallum cannot be judged as only one unit is mentioned on the eight stones found in close association with the Vallum.

The engagement of the native population on some parts of the work cannot be ruled out. There are inscriptions referring to work by civitates from some distance

\footnotetext{
768 Mócsy (1983).

769 Holder (1982) 71.
} 
away but it is believed that these relate to later repairs. ${ }^{70}$ It is possible that local native labour may have been present as paid labourers, or suppliers of materials, or as forced levies, ${ }^{771}$ but in the absence of any evidence it is not possible to make any estimate of possible numbers.

It will be assumed for the purpose of estimating the rate of building (section 12.4) that all transport was by auxiliary and native labour.

\subsubsection{The size of the legionary labour force}

Each legion consisted of ten cohorts: II-X had 480 men but cohort I had been increased to 800 men in the late first century. There is some uncertainty about the size of cohort I in the first half of the second century and for the purpose of this exercise it will be taken as 480 men. ${ }^{72}$

Stevens (1966) took cohort I as still of double size, giving eleven 'cohort equivalents'. Looking at legion XX, he found that cohorts II and IX are rarely represented, VII appeared once only and IV had no record. This Stevens regarded as seven 'cohort equivalents' of legion XX building curtain wall, with the other four cohorts engaged in building foundations. Recorded occurrence of cohorts II, VII, and IX he put down to intrusions from the other two legions on the grounds that these cohorts of legion XX were building foundations. The circularity of the argument needs no further comment. E. Birley points out that Vegetius records these cohorts as

$770 \quad R I B 1672,1673,1843,1844,1962,2022,2053$. C.E. Stevens (1940) 148 suggests that these records relate to repairs in $\mathrm{AD} 369$, but evidence is lacking.

771 Tacitus has Calgacus complain that 'Our limbs and bodies are worn out in clearing woods and draining marshes ...' (Agricola XXXI) implying the use of forced labour.

772 Frere (1980). The double first cohort seems to have been established by Vespasian; the date of its later reduction is uncertain, but second century fortresses show accommodation for a normal-size first cohort. 
being those detailed to train recruits, ${ }^{773}$ but it may not be necessary to take this into account.

If those cohorts present were known to have done equal amounts of work on the Wall, and if each cohort's work were randomly distributed along the length of the Wall, and if finds of centurial stones were equally distributed along the Wall, it would have been statistically significant to have found fewer than three inscriptions from any one cohort among the seventy five inscriptions listed by Stevens. However, it is not known that each cohort present did the same amount of work, and was thus equally represented in the original record. Also, only a small percentage of the Wall survives, and under-represented cohorts could have worked on the unknown sections.

As referred to below (section 12.3), under Stevens' rules each cohort should be signing at each end of every $120^{\prime}$ length of the stone Wall. As the Wall was almost certainly built in three or four 'horizontal layers' (see section 12.3) each cohort, and the individual century at the end of the length, ought to be signing three times at each end of the cohort length and three times at the end of each centurial length within the cohort length. On the original Wall from Wallsend to the Irthing there should be almost 16,000 stones showing the cohort and over 95,000 showing the century. ${ }^{774}$ In fact Stevens lists no more than 75 cohort/legion inscriptions of legion XX, and of these only 7 actually record both cohort and legion without relying on inference from other arguments. Even if the arguments for identifying the legion or cohort in those cases where they are not named are correct, the argument still falls, on statistical grounds.

\footnotetext{
773 Birley (1961) 257; Vegetius II, 6.

774 On the given cohort length, there are 9 cohort lengths and 54 century lengths in a 'curtain', each signing on each of the three stages, and on both sides of the Wall.
} 
In these circumstances, it is not possible to come to any conclusion at all from the available data, and Stevens' conclusions as to the identity of cohorts present must fall..$^{775}$

It would seem that there is room for a great deal of speculation about the extent to which each legion was involved in Wall building. In the absence of evidence, reasonable supposition must be used instead. It will be assumed that each legion was present for the same length of time and in the same numbers throughout the building programme. Stevens' argument that legion IX was still in Britain is discounted; ${ }^{776}$ legions II Augusta, VI Victrix, and XX Valeria Victrix are seen as the legionary garrison of the province during Wall building.

Some men must have been left as a garrison in the legionary bases of York, Chester, and Caerleon, if only to prevent theft and to carry out routine maintenance; one cohort per legion might be a reasonable assumption. It is unlikely that training and similar military affairs would have been forgotten, and it might be allowed that at all times the equivalent of one further cohort per legion was engaged in such activities. This leaves eight cohorts per legion, or 144 centuries, available for building the Wall. ${ }^{777}$ The cohorts would presumably be rotated between training, building, and garrison duties.

It might be assumed that the legions were up to establishment strength and that eighty men per century were nominally available, but it is not normal in modern armies for military units to be at their paper strengths. It is difficult to know what allowance to make for any shortages as no such detailed evidence survives. The

\footnotetext{
775 Mrs V.M. Croll kindly discussed with the writer the statistical methods used by Stevens.

776 See Birley (1971) for a discussion of the fate of legion IX.

777 This follows Frere (1980) in the belief that the ?Vespasianic milliary first cohort of the legions had effectively been returned to quingenary strength by Trajan.
} 
rosters from cohors $X X$ Palmyrenorum have survived in part, ${ }^{778}$ but these are for an auxiliary cohort serving in the east in the first half of the third century. The estimated strength appears to drop from 1,210 to 1,040, but as an equitate unit with dromedarii the nominal strength is unknown.

The pridianum of cohors I Hispanorum Veterana quingenaria shows a total of 546 men, made up of 119 cavalry and (by subtraction) 417 infantry. There were later additions which brought the total to $596 .{ }^{779}$ In $\mathrm{AD} 156$ cohors I Augusta Praetoria Lusitanorum equitata had on its books 505 men, made up of 363 infantry, 145 cavalry, 18 camel-riders, 6 centurions and 3 decurions. ${ }^{780}$ In theory both units should have had a total strength of $608,{ }^{781}$ although the camel element of cohors I Lusitanorum may have been additional to the cavalry establishment.

The detailed roster for much of one century of legion III Cyrenaica (see below) under Domitian is not sufficiently complete to give the total strength, and records for the other 59 centuries are missing. The record of cohors I Tungrorum from Vindolanda ${ }^{782}$ shows an unusual strength for either a quingenary or milliary cohort, and does not help here. It seems best to use a modern analogy to give an indication of what might be likely.

The modern British army is about $8 \%$ short in infantry soldiers, and of those nominally present about $1 \%$ are absent without leave; ${ }^{783}$ applying this to the Roman century gives an actual strength of 73 men which will be used as the basis for the

\footnotetext{
$778 \quad$ Fink (1971) Nos. 1 and 2; Davies (1989) 40.

779 Fink (1971) No. 63, dated to AD 106.

780 Fink (1971) No. 64. The numbers given there do not add up; the total of the individual numbers comes to 508 plus 9 officers and 18 camel-riders.

781 Breeze and Dobson (2000) 161.480 infantry, 128 cavalry.

782 Bowman and Thomas (1994) No. 154.

783 Based on information supplied by Lt. Col. C.H. Jackman, Royal Logistic Corps.
} 
following calculations. These and other subtractions are summarised in table 12.3 below.

The most detailed record of duties within a century comes from legion III Cyrenaica dated to October $\mathrm{AD} 87$ or thereabouts. ${ }^{784}$ This shows that a total of 36 men (of which five had been added to the list later than the rest) were nominally available for general duties. Five other men are listed as immunes, and one each as tribune's orderly and tribune's housekeeper; ${ }^{785}$ the tribunes presumably needed their staff whether the legion was in its fortress or engaged on building the Wall, and for present purposes these men may be regarded as immunes. ${ }^{786}$ As the record covers less than half the nominal strength of a century, the figure is unsafe to use for calculation. Breeze argues that at a conservative estimate 'the administrative staff and technicians' of the legion amounted to over 600 men. ${ }^{787}$ He also points out that they would be spread throughout the legion. A figure of ten men per century unavailable for building work seems to be a reasonably safe figure to use.

In Fink no 9, three men were on leave, each on separate days, but out of the 170 'cells' on the roster 74 , or $43 \%$, are blank or have horizontal lines through them. Fink argues (note to line 3 , a) that a line indicates no duty rather than a repetition of the previous duty, but it is at least as likely that no duty is indicated by a blank cell. The entries for L. Valerius Felix (line 24) subsequent to the first day appear to have been marked by a vertical line, which could indicate a repetition showing that he could

\footnotetext{
$784 \quad$ Fink (1971) no. 9 and no. 58.

785 Davies (1989) chapter 2, 40. (Originally published in Aufstieg und Niedergang der römischen Welt II.I, 299-338.)

786 P. Mich 465 confirms that an immunis (if Apollinarius was really that rather than a principalis as he claimed (see Watson (1969) 77), did not have to take part in quarrying.

787 Breeze (1969).
} 
have been on leave for the whole ten days. If at any one time only one man of the 36 was on leave, then in a full century two men might have been on leave on a given day.

Some men will have been on the sick list. No records of legions' sickness rates are available, ${ }^{788}$ but there is one from an auxiliary unit in Britain: the strength report of cohors I Tungrorum at Vindolanda in the early years of the second century. ${ }^{789}$ The roll carries 752 men of whom 296 were actually at Vindolanda and of these 31, or $10.5 \%$, were on the sick list. This includes men listed as 'wounded', these might have been concentrated at the base rather than in outstations, which would distort the figures; on the other hand, sick men at outstations would be recorded there and not at their base where their status might well not be known. Also, during building work there would be a higher than normal rate of unfitness (torn muscles, mashed fingers, strained backs, broken bones due to falling stones) which must be taken into account, and so perhaps this rate can be taken as appropriate to a unit so employed. If it can be assumed that this rate applied to the whole unit, and that the sickness rate in a legion would be roughly the same, then the century of 73 would lose about 8 men.

It is known that legionaries served on the staff of the provincial governor, ${ }^{790}$ and some were sent out on various duties such as: to the granaries, to the mint, paper-making, river guard, and with the frumentarii. ${ }^{791}$ The normal work of the province would have to be maintained, and some allowance for absence on these

${ }_{788}$ Fink (1971) records only three papyri where sickness is mentioned but these all relate to auxiliary units and in any case the numerals have not survived: no. 63 ii 44 ; no. 66 b ii $6:$ no. 89 4 i 7.

789 Bowman (1994) Tab. Vindol. I 154.

790 Davies (1989) 46.

791 Fink (1971) no 10. 
duties must be made. The majority of such duties might be awarded to the cohort left at base, but some would come from those cohorts engaged in building. It would have been sensible to use some of the immunes for this work, but perhaps one man per century could be allowed for this element; this is listed as 'official duties'.

In all armies of all ages there has been a strong tendency for soldiers to engage themselves on duties not directly related to the tedious task in hand, finding specious reasons which would satisfy all but the most searching enquiry. ${ }^{792}$ It is difficult to estimate the numbers who might have found thenselves such employment; a minimum figure might be one man in a century, listed as 'non-official' duties.

While building the Wall the troops were based in temporary camps, which could not be left unattended during the day. Apart from the tents there would be food stores and reserves of tools, as well as personal possessions, and some guards would be needed to counter casual theft from both opportunist civilians and light-fingered soldiers.

A rough indication of the size of a tented labour camp for, say, two cohorts can be obtained. P-Hyginus ${ }^{793}$ gives one method of allocating space for a cohort as 150 $\mathrm{x}$ 150Rf. The via sagularis running around the camp he gives as 30Rf with an increase to 40Rf for five legions; presumably less can be allowed for a much smaller camp, and perhaps $20 \mathrm{Rf}$ will suffice. A central range to house the commander, camp HQ, workshop (for tool making and repairs), and stores might be the width of the camp by the width allowed for a century, 30Rf; with space for an extra road the total might be 50Rf. The internal size of the camp would thus be $490 \times 390 \mathrm{Rf}$, or $475 \mathrm{x}$ $377^{\prime}(145 \times 115 \mathrm{~m})$, with an internal perimeter of $1760^{\prime}(536 \mathrm{~m})$. The walking

\footnotetext{
$792 \quad$ Lt. Col. C.H. Jackman, Royal Logistic Corps.

793 de munitionibus castrorum 2.
} 
wounded could easily keep lookout, with more formal guards on the stores and the commander's tent. With, say, four men for the latter duties, changing over at intervals, twelve men might be a generous estimate. There would be some camp fatigues, such as filling old latrines and digging new ones, consolidating soft patches in the 'roads' to keep mud to a minimum, and generally keeping the camp tidy. Half a dozen men ought to be ample, and could alternate this work with that of guard duty. One fit man from each of the twelve centuries should do for all camp duties.

The collection of firewood could be an extra duty, but it is just as likely that the soldiers from the working parties would be left to fend for themselves after work. The British soldier in the early twentieth century was certainly expected to do this at the end of a day's march. ${ }^{794}$

TABLE 12.3

ACTUAL STRENGTH OF A CENTURY

$\begin{array}{lrr}\text { Establishment } & & 80 \\ \text { Understrength \& AWL } & & 7 \\ \text { Actual strength } & & 73 \\ \text { Less } & & \\ \text { Immunes } & 10 & \\ \text { On leave } & 2 & \\ \text { Sick/injured } & 8 & \\ \text { Official duties } & 1 & \\ \text { 'Non-official' duties } & 1 & \\ \text { Camp duties } & 1 & \\ & & \underline{23} \\ \text { Actual strength } & & 50\end{array}$

This gives a hypothetical figure for available manpower of 2400 men in 48 centuries in each of three legions, a total of 7200 .

794 Quartermaster General (1914) 171n. 


\subsection{Horizontal building and centurial lengths}

In chapter 9 it was noted that the availability of scaffolding had a bearing on the way in which the Wall was built. Stevens refers to the occurrence, in places, of what appears to be 'horizontal building', regarding it as something of a puzzle to be solved. ${ }^{795}$ In fact, 'horizontal building', by which he means division into horizontal as well as vertical blocks of work, is precisely what would be expected.

At the start of work, it is probable that each unit, whether century or cohort, would build up sections of wall at the ends and perhaps also at intervals along their allocated length, as seen in fig. 12.2, and then fill in up to the level of the first scaffold lift; see section 11.3 for further details of the method of building.

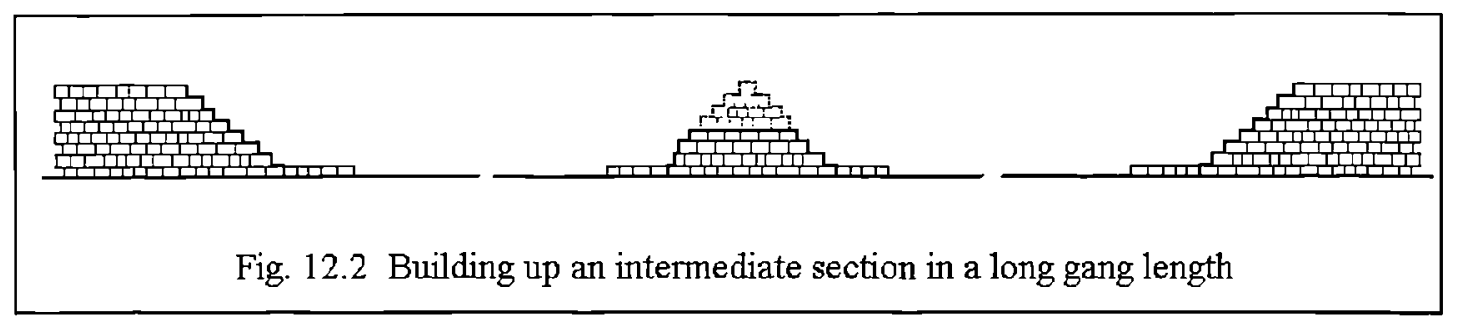

As was argued in chapter 9, the Wall would initially have been built to a height of $1200-1500 \mathrm{~mm}$ or so, and the upper part built only after the provision of scaffolding. Unless scaffolding was immediately available, the gang which built the lower part would be obliged to move on to another section, leapfrogging within the legionary length; this would naturally divide the work into horizontal blocks. It may be that the plan was to build all the lowest part first, and then continue upwards later. When returning with scaffolding, the order of work might be quite different, with century One building on the work of century Six, and so on. Add to this the effect of dislocation, and the building of the upper parts of the Wall could be by different centuries, cohorts, or even legions.

795 Stevens (1966) $17,28,60,74$ 
Evidence from Wall-mile $49-50$ is said to suggest a change of gang at the junction of the ninth and tenth courses. ${ }^{796}$ The top bed of the ninth course, measured by the author from present ground level, is between $65-70$ " (1651-1778mm); in most cases the ninth course is the bonding course. Stevens's evidence led him to assume two 'layers' with the division at something like half way up the Wall. This may represents a change in gang at the height of the first lift of the scaffold..$^{797}$

Scaffolding would have been erected with three or four lifts (working platforms) for completion of the Wall (see chapter 9). The scaffold, even if an independent one, would probably have been erected one lift at a time to conserve materials; decking out all three lifts would be wasteful. If the scaffold were not independent, but with the inner ends of the putlogs resting on the wall, building it up lift by lift would have been unavoidable. Any breaks in construction are therefore to be expected at scaffolding intervals as the building gang waited for, or erected themselves, the next lift of scaffolding.

The large quantity of scaffolding needed (see section 9.6.1) might well mean that some centuries would leapfrog at ground level while some carried on building to full height. Thus, sections of wall begun at the lowest level by one century could be completed either by the same century or by another century which had the use of scaffolding. The speed of building the lowest section would be greater than building from a scaffold, and the building of the lower part would far outpace the completion of the upper parts. The length allocated to a century or to a cohort (see below) is likely to have a bearing on the length of scaffolding erected at any one time.

\footnotetext{
$796 \quad$ Stevens (1966) 60

797 This part of the Wall represents later rebuilding of the Turf Wall, but the height of scaffolding lifts must have been about the same as in the original building of the Broad Wall. It is somewhat higher than might be expected.
} 
The likelihood is that at any one time a legionary length would have some parts built to full height, some built up to an intermediate height, some built to 5 ', some just started, some with only the foundation put in, and some still virgin ground. These sections would not necessarily all be contiguous but would be scattered over the legionary or cohort length. Any disruption, be it war, rebellion, end of season, or temporary shortage of materials might well lead to completion by another unit, whether that unit was century, cohort, or legion. What most certainly did not happen was that the Wall unrolled over the countryside as a complete $15^{\prime}$ entity.

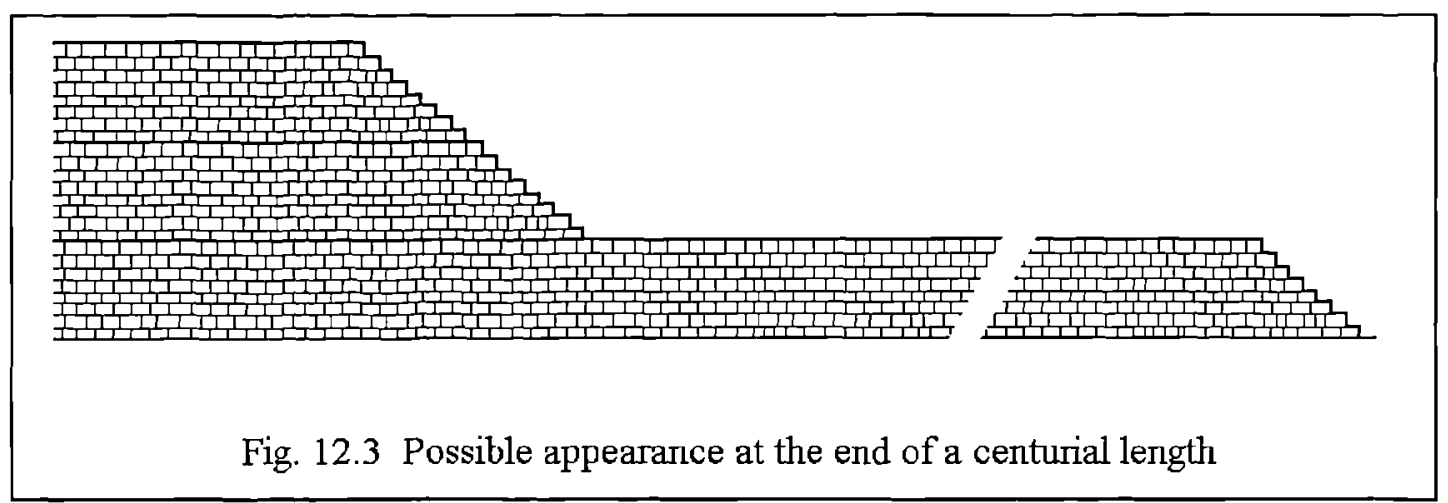

This last point may explain Stevens' difficulties with apparent slight variations in century lengths between MC49 and Birdoswald fort, leading to a search for the reasons. At the start and finish of a 'length' the Wall did not have a vertical end; each course would be stepped back up to the height to which that section had been built, whether this was $5^{\prime}, 10^{\prime}$, or $15^{\prime}$ (fig. 12.3). If at full height, the raking joint would cover a horizontal distance of $6-8^{\prime}$ along the wall; the century completing the adjoining section might put their stone anywhere within the area of wall above the raking joint, or indeed to one side of it (fig. 12.4). Centurial stones are evidence for the builders of a wall in their immediate vicinity and for nothing else. 


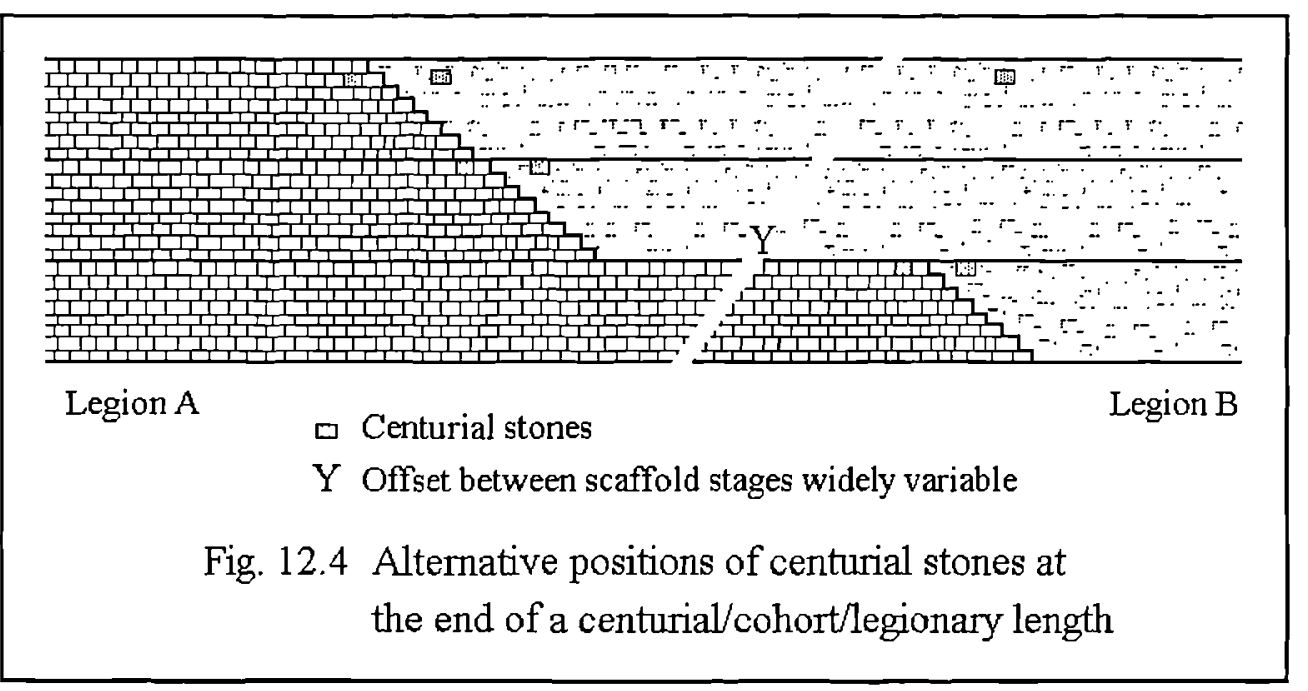

The theoretical and very tidy junction shown in fig. 12.5 is the least likely form of junction; indeed, it is beyond the realms of possibility. It would require elements of both legions to be building at the same point, and for them both to have sufficient scaffolding to build to the full height in a single operation. Neither is it at all likely that the end of a length was left as a toothed joint as shown on the right of the figure. Quite apart from the impracticality of the operation, the core would have to be built up as a butt end within the two skins, a difficult operation needing shuttering.

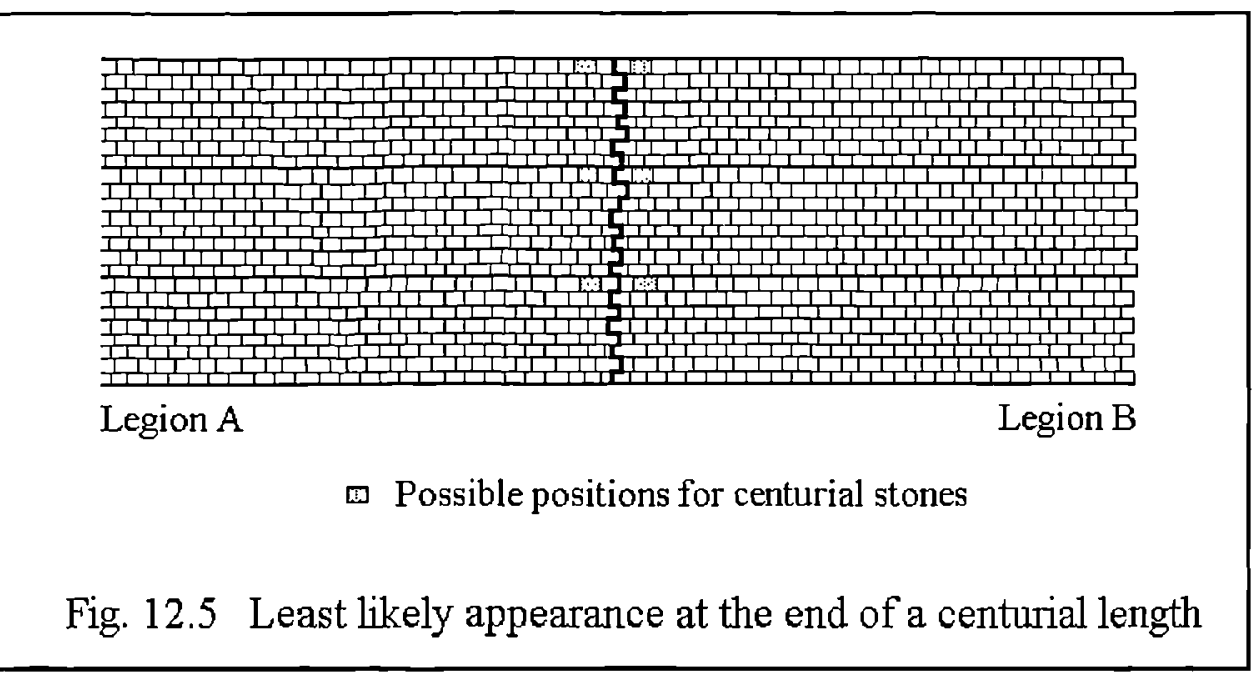


Nor is it particularly likely that at the end of a season or at the moment of dislocation a unit, be it legion, cohort, or century, would have built up their current piece of work to full height. There may very well have been only one or two lifts completed, as shown for legion $\mathrm{A}$ in fig. 12.6. This situation certainly obtained at Brunton, where Broad Wall was built to the west side of the uncompleted turret; no more than one lift of curtain could have been built. ${ }^{798}$ On the east side of the turret, only the foundation had been laid; the Broad Wall builders seem to have been coming downhill towards the turret and had reached Planetrees when the gauge of the Wall was narrowed. Again, it is most unlikely that more than the lowest 5 ' of Broad Wall had been built. The work may have been completed by a different legion, cohort, or century leading to a variety of 'signatures'; any attempt to build up a pattern of working using these stones would depend very much on which stones had been discovered. If legions $\mathrm{A}$ and $\mathrm{B}$ had each built up two lifts before dislocation, then a third legion could have built the third lift, introducing even more complications. To repeat, centurial stones are evidence for the work immediately around those stones and for nothing else.

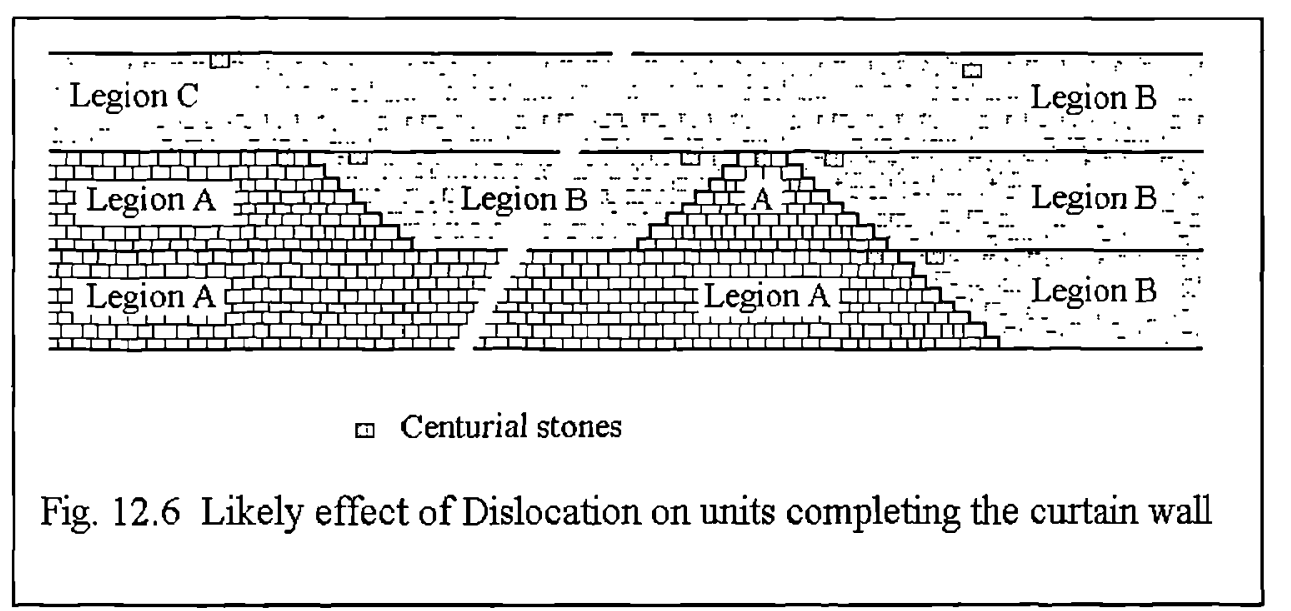

$798 \quad$ Hill and Dobson (1992) 39-40. 
It must never be forgotten that, while a considerable degree of organisation must have existed, work will not always have gone to plan. In particular there will have been shortages of materials due to such factors as transport difficulties (sick or lame animals), shortage of lime (collapse of a kiln, difficulty in obtaining fuel, a poor 'burn'), shortage of stone (difficult beds in a quarry, need to open a new quarry), and so on. Today, with multi-million pound factories, high speed transport, and instant communications, hold-ups in building work owing to late deliveries are still not uncommon. Disruptions in building the Wall may not have seriously held up the overall programme, as men could be moved to other work, but they would give rise to dislocation of the work in progress. Some signs of 'dislocation' may, in part at least, be due to these factors rather than actual, widespread major dislocation due to a single cause.

It is not clear to the writer whether, at the junction of work between the elements of two legions or between two cohorts of the same legion, a stone recording that unit or sub-unit was always erected. Equally, it is uncertain whether a centurial stone was put at the end or in the centre of the length for which it was responsible. Also, it cannot be proved that a century only mentioned its cohort if working at the end of a cohort length. Hooley and Breeze wisely abandoned anything smaller than legionary lengths in view of the elaboration of hypotheses necessary to cope with the scarcity of the evidence. ${ }^{799}$

A stone recording the presence of a legion surely indicates no more than the presence of some members of that unit. A cohort stone might equally indicate that only a part of the cohort was present. Whether a centurial stone indicates that the whole, or at least the greater part, of the century was present must be uncertain. It

799 Hooley and Breeze (1968). 
may well be that a century might at times be divided between two sections of wall not immediately adjacent; whether in that case both sections would 'sign' their work is a matter of speculation.

It is argued in section 12.2.6 that the effective strength of a century might be no more than 50 men, and in section 12.4 that the size of a gang engaged on actually building the Wall might be 28 men. If these figures are even approximately right, it suggests that centuries were not broken down into two or more building gangs, but that most of them were engaged in one gang and the remaining men were perhaps assisting with transport, either in a general way or specifically for their century.

Stevens suggests that in Wall-mile 49-50 each century was responsible for a length of $20^{\prime}$ and a cohort for $120^{\prime} .^{800}$ This is very short, as a century could have completed its allotment in a very few days (see section 12.4). However, this part of the Wall was probably rebuilt after the rest of the Wall was completed, and perhaps timber was available to allow for very long lengths to have been scaffolded at once. This would allow a number of gangs to work alongside each other, and perhaps the whole, or a large proportion, of this mile was built simultaneously.

E. Birley has suggested that, assuming two legions were at work in the central sector, the length allocated to a century might have been 22 yards $(20 \mathrm{~m}){ }^{801}$ But in the central sector it is clear that work was being completed after the decision to narrow the wall, and thus that this was not necessarily organised in the same way as in the original scheme.

It seems that in the present state of knowledge the question of centurial lengths must remain an open question.

\footnotetext{
$800 \quad$ Stevens (1966) 63.

801 Birley (1939) 219-236.
} 


\subsection{Rate of building}

This is another very speculative area of study, as there are so many unknown factors involved. The rate at which stones could be laid in the Wall depends very much on the level of organisation, the methods of transport, the precise nature of the quarry from which stone was being extracted for a particular length of Wall, and the difficulty or otherwise in working the stone; to none of these can a wholly satisfactory answer be obtained.

In view of this, there will be no attempt to produce an overall timetable for the works. What will be offered is a theoretically possible rate, with appropriate labour force, at which building could have taken place under predetermined conditions. It will serve as an indication of what could have been done, but it would be very dangerous to multiply this up for the Wall as a whole.

A number of others have made attempts to calculate the rate of building Roman walls. They do not seem to be particularly satisfactory, as they tend to be based on estimating tables. This can be a useful method of approach, but is limited by the nature of the Roman construction which is not the same as that normally given by such references. To take one example, Shirley gives rates for building the perimeter wall at Inchtuthil, quoting two figures, dating from $1902,{ }^{802}$ for random rubble and for stone in squared courses. The former is not relevant to the Wall, which is largely in squared rubble. The latter is more useful, but is given as a rate per cubic yard with no indication of the size of the blocks in question; this makes it impossible to convert to the rate per square yard/metre for building up facing stones.

In Hadrian's Wall it is reasonably easy to arrive at a 'typical' size for the facing stones, and thus clearly separate the labours of building wall facing and core. It is

802 Shirley (2000) 100. 
this approach which is taken here, based on the experience of the author in consultation with appropriate trade colleagues. ${ }^{803}$

The size of the facing stones varies considerably, with occasional instances of very large stones being used. Equally, small stones are used in places, such as between T48b and Willowford Bridge, where the style comes close to random rubble. On the whole, however, the statement in the Handbook that the stones are 'tolerably uniform' can be upheld. As a result of taking measurements at a number of points along the Wall, the writer sees the typical size as $10.25 \times 15 \times 7 "(260 \times 380 \times$ $180 \mathrm{~mm}$ ), and this has been used in the calculations of the rate of building. An allowance of $1 / 4^{\prime \prime}(6 \mathrm{~mm})$ for bed joints and $1 / 2 "(12 \mathrm{~mm})$ for vertical joints has been made; this may be too low, but there are a number of indications that the mortar was used sparingly. ${ }^{804}$ This gives an overall size of stones including joints as $10.75 \times 15$ $\times 7.25^{\prime \prime}(273 \times 380 \times 185 \mathrm{~mm})$. This in turn gives an average figure of approximately 17 stones per square yard of facing, or 20 per square metre.

As discussed in chapter 5.2, the weight of sandstone, very much the predominant type of stone used, is taken as $145 \mathrm{lbs}$ per cubic foot $(2325 \mathrm{~kg}$ per cubic metre). Allowing a taper of 3 " on each of the two vertical joints, the typical stone will weigh about 64lbs (29kg).

\subsubsection{Speed of fixing}

Detailed times for each operation are given in Appendix 2. Here they are briefly described with justification for the times allotted. It is assumed that the work is that

\footnotetext{
803 Especially Dr. M. O'Connor, formerly foreman mason, Lincoln Cathedral.

804 e.g. Bennett (1998); Bidwell and Griffiths (1999), where it is reported that in Wall-mile 1 mortar was omitted altogether in favour of clay bonding of the facing stones.
} 
of building the body of the broad curtain wall, and in reasonably easy country with good access.

One man, fit and used to the work, can lift a 64lb stone on his own, but the effort would soon lead to a serious slowing of the pace. It is not an unreasonable burden for two men working continuously, and it is here assumed that there were two men lifting stones from a heap, placing them on the wall, and adjusting their position. As part of their work they would also spread mortar for the bed and fill the joints after fixing; it is assumed that the joints would be roughly pointed as work proceeded. This would not take them more than two minutes per stone, but to ensure that times are not too tight, spreading the bed and filling the joints might be the work of a third man. The rate of under two minutes per stone may seem very quick, but it ought to be well within the capacity of three fit men with some experience; the laying of roughly-squared rubble does not call for any great degree of precision. ${ }^{805} \mathrm{~A}$ team of three fixers would be able to interchange to give a variation between lifting and spreading mortar as work proceeded. It is assumed that the stones would be dumped, or moved by others after dumping, within 3 yards of the working area.

The amount of mortar required is based on the bed joints being $1 / 4^{\prime \prime}$ thick in the centre of the stone, increasing to $1^{\prime \prime}$ at each side to allow for some curvature of the beds. The vertical joints are allowed at $1 / 2$ " in the centre rising to 1 " at top and bottom. Allowing, as given above, $3^{\prime \prime}$ taper on each side of each stone, then the mortar for each square yard will amount to about 4.6 cubic feet $\left(0.16 \mathrm{~m}^{2}\right.$ per square metre). Some mortar would inevitably fall into the core as well as on to the ground, and wastage could be considerable as there would be nothing to stop mortar falling

\footnotetext{
805 Discussions with trade colleagues confirm that the rate for fixing suggested here is reasonable, given that the work was well-organised and under keen supervision. It is approximately the same as for large concrete block-work, but with a more generous labour allowance.
} 
out of the back of the joints. An allowance of $20 \%$ has been made, giving 6 cubic feet per square yard of walling $\left(0.2 \mathrm{~m}^{3}\right.$ per square metre). Rea gives the rate for hand mixing of lime mortar as 1 cubic yard in 7 hours, or 3.86 cubic feet $\left(0.14 \mathrm{~m}^{3}\right)$ per hour; ${ }^{806}$ two men would thus be needed for each gang to maintain this rate of fixing, which would leave about half a man-hour spare.

It is necessary to build on each side of the Wall at once in order for the core and facing stones to be mutually supporting. Taking the Wall thickness as 9'3" $(2819 \mathrm{~mm})^{807}$ and the facing stones as typically $15^{\prime \prime}(381 \mathrm{~mm})$ deep, and dividing the core between each face, for each square yard of walling there is 30 cubic feet of core $\left(0.86 \mathrm{~m}^{3}\right.$ per $\left.\mathrm{m}^{2}\right)$. At $110 \mathrm{lbs}$ per cubic foot $/ 1764 \mathrm{~kg}$ per $\mathrm{m}^{3}$ (see section 10.2 Materials), this weighs $3341 \mathrm{lbs}(1517 \mathrm{~kg})$ per square metre of wall face. It is assumed that this is moved in baskets with $50 \mathrm{lbs}(23 \mathrm{~kg})$ in each, or by carrying one or two large stones equalling this weight. As shown in the table, to keep pace with the fixers 2.3 men would be needed; 3 men have been allowed plus one to spread the core. A slightly longer distance from core dump to site than from facing stone dump to site has been chosen as the smaller volume of facing stones meant that unloading from transport could be closer to the fixers.

Almost double the time has been allowed for collecting and tipping clay for the core as for the stone. Picking up 50lbs $(23 \mathrm{~kg})$ of stone is very easy; clay of the right consistency for treading into the core is very sticky, has to be dug from the heap with a spade to fill the bucket, and will stick when tipped out. An extra man has been allowed for help in filling the buckets and to keep the clay well-wetted, and one for assistance with tipping and compacting the core stone into the layers of clay.

\footnotetext{
$806 \quad$ Rea (1902) 70.

$807 \quad$ Hill and Dobson (1992) 28.
} 
The labour force for each gang is 3 fixers, 2 mortar mixers, 3 men for filling the core, and 4 men for providing clay for bonding the core. To this may be added 1 man for general labouring, and ten per cent extra to allow for short rest periods while working. This brings the total to 14 men on each side of the Wall, giving a gang strength of 28 men. It should be noted that, in addition to an allowance for breaks, the precise number of men has been rounded up by almost two men.

The rates given above are for work at ground level. Once scaffolding came into use more men would be needed, but this is an even more imprecise area which will not be discussed.

It must be clearly understood that the above is no more than an example of how efficient, well-motivated gangs under good supervision might work in good weather on simple walling. It would be quite improper simply to multiply this up to arrive at a global figure for building the Wall. However, it may be justifiable to see what might happen if this rate of working were maintained for a period, and this will be done after looking at the rate of quarrying and working the stone.

\subsubsection{Speed of quarrying and dressing}

This is the most difficult part to estimate as the nature of the quarries varies so much. $^{808}$ At Fallowfield Fell the stone occurs in beds of up to $3^{\prime}(1 \mathrm{~m})$ thick, whereas some of the small outcrop quarries on the south side of the Military Road in the central sector yield thin beds. ${ }^{809}$ Once the overburden had been removed there are thus two scenarios: extraction of large blocks to be split down, and extraction of

808 Rea (1902) 88, gives the rate of quarrying sedimentary rock as 5 to 8 tons per man day, but does not specify the nature of the beds nor the purpose to which the stone is to be put. It is unsafe to use these figures in relation to quarrying facing stones.

809 Author's observations. The modern Black Pasture quarry yields beds of up to $2.5 \mathrm{~m}$. 
thin beds to be broken with the bursting hammer or by simple wedging on the upper surface only. In the following examples it will be assumed that in both cases the top bed of the stone has been fully exposed, that the face is exposed down to the bottom of the bed being worked on, that there is a free end to the stone, and that in plan a slab $3^{\prime}$ long by $2^{\prime} 6 "$ wide $(1 \times 750 \mathrm{~mm})$ is to be extracted.

Looking first at deep beds, it would be necessary to split the stone at the back, across one end, and along the beds at about $8 "(175 \mathrm{~mm})$ below the top. This figure is more than suggested as the average bed height of facing stones, allowing for some waste and variable lines of fracture. The back might call for three wedges at 12 " $(305 \mathrm{~mm})$ centres, front to back two wedges at $10^{\prime \prime}(255 \mathrm{~mm})$ centres, and the bed four wedges set at 9" $(230 \mathrm{~mm})$ centres, a total of nine. If each wedge hole takes ten minutes to cut (see section 6.6), and two men are employed on the work, then it will take no more than 45 minutes to cut the holes. ${ }^{810}$ Inserting and driving the wedges might take as much as five minutes for the bed and five minutes each for the back and side, bringing the total time to about 60 minutes.

The slab thus produced would weigh about $7201 \mathrm{bs}(325 \mathrm{~kg})$. It could be dragged clear for further splitting, but it would be easier to do that in place. One further split along the length down the centre, using three wedges, would take another fifteen minutes, a total of 75 minutes. The two long slabs thus produced would then be dragged aside for cutting into facing stones.

If the stone occurred in shallow beds, of a height appropriate for facing stones, quarrying would be much quicker. Shallow bedded stone is much more likely to have natural shakes or joints, which facilitates its extraction. It is often possible to

810 This accords reasonably well with the figures given by Greenwell and Elsden (1913) 219, for cutting deep holes with a jumper. 
lift a slab with a crowbar, as described in section 5.4. Alternatively, cracks can be induced with the bursting hammer, or by use of a heavy wedge held in a wire holder, moved along a predetermined line while being hit with a sledgehammer. It should be possible to loosen such a slab as described above in say, fifteen minutes. More careful splitting with wedges along the centre line to produce two long slabs would take another twenty minutes, a total of about thirty-five minutes. As with the extraction of stone from solid beds, it is assumed that two men are used.

In both cases, these two slabs would easily be split into, say, seven stones; this gives stones averaging $10^{\prime \prime}(255 \mathrm{~mm})$ long, which allows for variation in size and for poor splitting and waste. Using a nicker as described in section 6.3.1, a bursting hammer, or wedges and a heavy hammer (section 5.4), this would take no more than five minutes each which includes time for further rough trimming.

Taking an average between quarrying from deep and shallow beds gives two men working for one hour to quarry sufficient for seven facing stones. One man will cut and roughly dress seven stones in 35 minutes.

Labourers would be needed to give general assistance, to move the slabs to the dressers, clear away broken stone, and fetch and carry tools for resharpening. The total number of men for quarrying and dressing the facing stones, in support of a gang of 28 , comes to 46 .

Times for quarrying and breaking stone for the core is relatively easy to estimate. Rea's figure of 5-8 tons per quarryman per day, quoted above, is relevant here as an approximate figure, with the higher figure being used here as the shape of the quarried stone would be irrelevant. A figure of 2 tons an hour for breaking moderately hard rock is provided by military engineers, ${ }^{811}$ to give a rate of 16 tons

$811 \quad$ War Office (1935) 309. 
in an eight hour day. As shown in Appendix 2, another 10 men will be needed for this work, bringing the total for quarrymen and dressers to 56 men.

\subsubsection{Speed for foundations, milecastles, and turrets}

The turrets and milecastles are even less easy to quantify than the curtain wall; they are not included in Appendix 2.

The turret wing walls are normally $10-12^{\prime}(3000-3600 \mathrm{~mm})$ long; as they are raked down to ground level the volume and surface area are halved. Taking the length of the north wall of the turret proper as $20^{\prime}(6100 \mathrm{~mm})$, the total for north wall and wing walls might be taken as 10 yards $(9.15 \mathrm{~m})$. The first four courses would be equal to 8 square yards of curtain wall on each side (see section 11.3). If one gang of 14 men built the north wall, and the rate were halved to allow for the internal returns and the junction with the side walls, this part of the work would take perhaps 16 hours. The length of the side walls amounts to about 13 yards on the inside and 12 yards on the outside long, or 20 square yards in total, and typically about 3' (1m) thick; the quantity of core is minimal, and would reduce the number of men providing stone for the core to perhaps one. If 3 fixers, 2 mortar mixers, 1 man for

the core, with 1 labourer (total 7 men) were employed, and if the rate of building were halved to allow for corners and jambs, the side walls would be built in about 20 hours. For both the north and the side walls this assumes that the fixers would lay a couple of courses on each side of the wall in turn.

All the walls would be built at once, so 21 men would complete the first four courses in 20 hours, with a little time to spare. For simplicity it might be allowed that the lower part of a turret would be built by 20 men in 20 hours, or about two and a 
half days; five days would see the turret built to a height of $58^{\prime \prime}(1470 \mathrm{~mm})$ (see section 11.3). This feels about right, and could be too much.

The reduced volume and speed would call for fewer quarrymen and dressers than the curtain wall. Quarrying and dressing walling stones is taken at half the rate for the curtain wall, reducing the number of men to 23 . Less core stone is needed; half the rate for the curtain wall core would need 5 men, but less very little core stone is needed and perhaps 3 men would suffice. This brings the total for quarrying and dressing to 26 men, and the total gang size to build a turret to 46 men.

Building the milecastle gateways might be at the rate of three stones an hour (see section 11.4.2), using two men to fix, three men on the derrick, a mortar mixer, and a labourer. Allowing for some problems, a rate of 20 stones a day would see the piers of one gate completed in no more than 2 days. Some time must be allowed for erecting the centre and trestles twice on each gate; one day would be generous. At the same rate of building as for the piers, the twin arches of a gate would take one and a half days. This brings the total to $4 \frac{1}{2}$ days; relaxing the rate a little, one gang might build the north and south gates of a milecastle in 10 days.

The time needed to quarry the stone for the milecastle gateways is another difficult area, as it depends very much on the nature of the quarry. Rea gives a figure of 5-8 tons per man-day, ${ }^{812}$ but without specifying any parameters. It was shown in section 7.3 that the average weight of the pier stones of MC37 is about half a ton. If one man could quarry enough for only only eight stones a day, then the 78 stones of each gateway would take about 10 man-days. Five quarrymen would thus take 4 days to produce the stone for both gateways. The same number, a total of 10 men,

$812 \quad \operatorname{Rea}(1902) 88$. 
might be needed to scapple the stones to the right size for the masons to begin working.

The number of men needed to work the piers and voussoirs of the milecastle gates is very difficult to estimate. Among the unknown factors are the efficacy of Roman steel and Roman tools on a typical stone. If a very rough estimate is made, then perhaps an average of two man-days per stone would not be unreasonable. Taking the north gate of MC37 as an example, then the 40 pier stones (see section 11.4.2) would take 80 man-days. There were probably 15 voussoirs to each of the two arches; allowing the same time per stone adds 60 man-days, a total of 140 mandays for each gateway, or 280 man-days for both gates. To this figure must be added the working of the less-exacting foundation blocks beneath the piers, say one manday for each of two stones beneath each pier. This adds 16 man-days, total 296, for each milecastle; 30 men would take about 10 days to work the stone.

The labour force for all operations to build two milecastle gateways is: builders 8 , quarrymen 10 , dressers 30 , a total of 48 men.

Looking now at the foundations, it was shown in section 4.2.2 that they were usually laid in a very shallow trench; this would mean no more than digging out turf or cutting into the top soil to perhaps $6 "$ deep. Rea gives a rate of 2 yards super. per man-hour for very shallow excavation; ${ }^{813}$ as the foundation is less than 4 yards super. per linear yard two men should be able to work at the rate of one linear yard an hour.

Spreading clay and laying flagstones along the edges might involve, at each side, one man spreading clay and two men laying the large slabs which average no more than three per yard. This could be done at the rate of at least one yard every quarter

$813 \quad$ Rea (1902) 47 
hour. Four men filling the centre of the foundation with clay and small stone could work at the same rate. To keep pace with this, eight men would be needed to excavate, a total of 18 men; adding the usual $10 \%$ suggests a foundation gang size of 20 men laying 4 yards an hour.

If the proportion of stone and clay in the foundation is taken as $2: 1$, then a foundation 6" deep needs just under 3 tons per linear yard, or 12 tons an hour. Using Rea's figures as above, approximately 12 quarrymen and 6 stone breakers would be needed to keep up with the rate of laying. This brings the total foundation gang including quarrying to 38 men.

\subsubsection{Rate for building a 'legionary length'}

This section looks at how quickly a legionary length, as defined by Hooley and Breeze, could be completed, given the same conditions as outlined at the start of section 12.4.1. Transport is assumed to be by auxiliary and native labour.

The speed given there for building curtain wall uses a gang of 28 men backed up by 56 men quarrying and dressing the stone. These numbers could build one square yard in about half an hour; at an initial height of $29^{\prime \prime}(735 \mathrm{~mm})$ (see section 11.3), they would build at the rate of 20 linear yards in an 8 hour day. ${ }^{814}$ This would be a practicable length to build in one go, using a stretched line between the built-up ends. A line of this length would need two or three temporary intermediate supports (dead men) to obviate sagging and to stop the wind blowing it sideways.

The intervals between turrets and milecastles is 540 yards, Stevens' 'curtain'. The first four courses of a curtain would be completed in 27 gang-days.

814 Coincidentally, this is very close to E. Birley's centurial length of 22 yards (Birley (1939) 219236). 
Hooley and Breeze suggest five miles, fifteen curtains, as a 'legionary block'; this would take 405 gang-days. If a legion allocated 1260 men, 15 complete gangs of fixers and quarrymen, to building curtain wall, there would be three gangs to each mile, one to each curtain. The first four courses of a block would thus be completed in 27 days. Allowing, as suggested in section 12.1, for working on 6 days out of 7 , this is equal to four and a half weeks. The lowest eight courses, or 58" (1470mm) would be built in 54 days, or nine weeks. This, it must be remembered, is about the maximum height of surviving Broad Wall - and very little survives to that height.

A little more time has to be allowed to build up the wall at the ends of a gang length. To build an end four courses high takes ten stones on each side, with the core carefully built up as already described (section 11.3). A total of perhaps three extra days for each curtain might be allowed. This brings the total to five weeks for the first four courses, or ten weeks for the first eight courses.

It is clear from the evidence adduced from MC48-T48b (see section 11.2.2) that long lengths of footings - in that case three courses - were laid before the curtain wall was begun and sometimes without the core built up between the first two footing courses. This, however, should not affect the total time for the lower part of the curtain wall.

The rate for laying the foundations was given above as 4 yards an hour. If this is rounded down to 30 yards in an eight hour day and ten gangs were employed by each legion, then the legionary length of 8100 yards would be completed in 27 days, or less than five weeks, by 380 men.

In one legionary length there are 10 turrets. If one day is allowed for a gang to move from site to site, and two turret gangs were employed, totalling 92 men, then 25 days, or just over 4 weeks, would suffice to build all of a legion's turrets to a 
height of $58^{\prime \prime}(1470 \mathrm{~mm})$. There is a certain amount of work not allowed for, such as monolithic threshold slabs for those turrets which had them, and a total of 5 weeks may be allowed.

If two milecastle gate building gangs were employed, then at the rate given above they would complete the piers and arches for all five milecastles in 30 days or five weeks. This would involve 96 men.

The total thus allocated for turrets and curtains is: curtain wall 1260 , foundations 380 , turrets 92 , milecastles 96 , total 1828 men. This leaves 612 men in each legion free for other work, such as any ground clearance needed.

To summarise, within five weeks of beginning work a force of just over 1800 men could build the curtain wall to a height of $29^{\prime \prime}(735 \mathrm{~mm})$, the turrets to a height of $58^{\prime \prime}(1470 \mathrm{~mm})$, and erect all the milecastle gateways in a legionary length. If building work began eight weeks after the initial decision, and quarrying began one week ahead of building work, then a total of thirteen weeks would have elapsed. This is shown in figure 12.7, where decision is shown as made on 1st July. If Hadrian spent six months in Britain, there would be ample time for him to have made the initial decision and to have revised the plans before he left.

It must be stressed yet again that the above is an intellectual exercise which gives an indication of how quickly part of the Wall could have been built given a reasonably high level of organisation. It cannot be applied to the building of the whole Wall. 


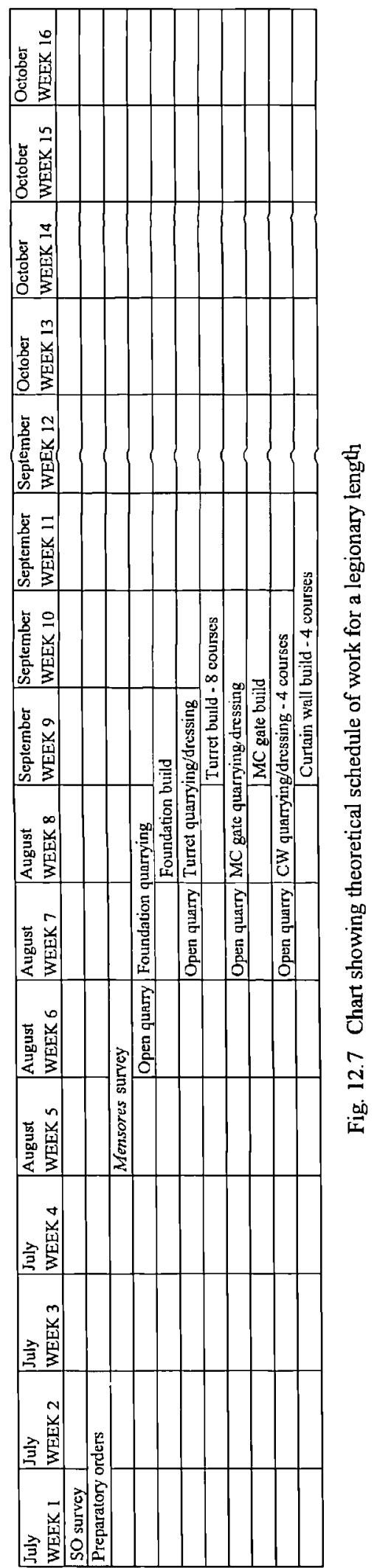




\subsubsection{Ditch and Vallum}

In view of the unique nature of the Vallum, it is worth taking a brief look at what labour input might have been necessary for the addition of this work to the Wall.

There are wide variations in the rates of excavation given in different sources. According to Rawlinson ${ }^{815}$ the nineteenth century navvy could '... remove the enormous quantity of twenty cubic yards of earth per day.' The length of the working day is not specified, but if of ten effective hours, then the rate is just over one minute per cubic foot. Rawlinson's men were professional diggers of canals and railway cuttings, using iron shovels and wheelbarrows, and cannot fairly be compared with the legionary.

Modern estimating tables for building work are not appropriate as most of this sort of work is now done by machine, and professional navvies are rarely found; older tables assume the use of the navvy, which the Roman soldier was not. The closest available parallel to the legionary is probably the early twentieth century British soldier, a man who was basically fit and had had some practice in this sort of work. The Roman dolabra and spade, ${ }^{816}$ whether iron-shod or all iron, are not unlike the pick and shovel specified for the British field exercises. In the following discussion, British army figures will be used..$^{817}$

For road cuttings up to $10^{\prime}$ deep the average output per man using a pick and shovel is reckoned at 0.67 cubic yards $\left(0.5 \mathrm{~m}^{3}\right)$ per hour in light clay (sand 1.36 cu.yd., hardpan 0.39 cu.yd). In the Great War, digging trenches, not under fire,

815 Bruce (1851) 94. All the following quotations from Rawlinson are from this source, 94-95.

816 Illustrated in Collingwood and Richmond (1969) plate XX. The dolabra as an entrenching tool appears on Trajan's column, Scene lii.

817 The following figures are taken from War Office (1935) appendix XIV; War Office (1936) appendix II and III. 
British labour companies could be reckoned on to dig to a depth of $6^{\prime}$ at the rate of 90 cu.ft. in 4 hours in stiff clay with flint or gravel requiring considerable pick work. Allowing 50\% extra time given in the tables for digging up to $9^{\prime}$ deep, this translates to a rate of 0.55 cubic yards $\left(0.43 \mathrm{~m}^{3}\right)$ an hour, or about 4.5 cubic yards in an 8 hour day.

This is just over one quarter of Rawlinson's rate for the navvy, but in his final calculations Rawlinson in fact allowed for use only of the '... ancient Briton ... driven to his ungrateful task ...' for whom he allows a rate of 8 yards a day. This is still faster than suggested here for the Roman army. ${ }^{818}$ However, the legionary was no more a slave than he was a navvy; he was a trained soldier who occasionally dug ditches. He was not, as Rawlinson's navvies were, ' . . stimulated by pay proportional to his work ...', nor is it likely that the other major spur to productivity, job satisfaction, would have entered his thinking to any great extent as he took his part in digging two large ditches from sea to sea: 59 miles for the Wall ditch and 70 miles for the Vallum (see sections $4.4,4.5$ ).

If the British army figures are averaged, a rate of about 0.6 cubic yards an hour for digging the ditch and Vallum can be arrived at. The cross section of the 'typical' Vallum is 5.55 square yards, and the length 70 miles (section 4.5), giving a notional volume of material to be excavated of $1,916,444$ cubic yards $\left(1,465,313 \mathrm{~m}^{3}\right)$. At the

818 Experimental work cannot reconcile the variations between these and the following figures, unless carried out with men accustomed to this sort of basic army pioneering work and using the same tools as available to the Roman army. R. Birley (1977) deliberately eschewed timing the reconstructions at Vindolanda, recognising that the personnel were of widely differing experience and physique. On the other hand, trials can be extremely useful in demonstrating the effectiveness or otherwise of techniques which have been theoretically devised. 
rate given above, this would have taken $1,577,550$ man-hours, or 399,259 man-days (8 hour day).

Rather surprisingly, disposing the spoil to either side into mounds would have taken somewhat longer than the excavation, if one assumes that the mounds were always revetted in turf. Moving soil on a stretcher is at the rate of two man-minutes per cubic foot. If movement were in baskets, the same rate would apply as one man could not move loads of one cubic foot of soil all day. Shovelling the excavated earth into baskets is at twice this rate, averaged over 8 hours. Digging turf and building a revetment is at the rate of 32 square feet per hour. ${ }^{819}$ Loading, moving and dumping, and revetting comes to 550,407 man days. The total thus arrived at for excavating the ditch and building the mounds is 949,667 man-days.

On the same terms, and on the calculation (section 4.4) that it was 59 miles long, the Wall ditch amounted to $1,401,840$ cubic yards $\left(1,071,846 \mathrm{~m}^{3}\right)$ and would have taken 292,050 man-days to excavate. Spreading the upcast carefully into a smooth glacis is at the rate given above for filling baskets, that is one man-minute per cubic foot. This amounts to 78,854 man-days, with a total for excavation and the glacis of 370,904 man-days.

Inscriptions from the Vallum (see section 12.2.3) are too few in number to estimate how many men might have been engaged on its excavation at any one time. As an example, and no more, six cohortes quingenariae peditatae might yield a work force of $2000 .^{820}$ These men could dig the Vallum and raise the mounds in 475 days, or two and a half seasons. The same number working on the ditch would complete it in 185 days, or about one season.

$819 \quad$ All figures in this paragraph are taken from Field Service Pocket Book (1914) 98. Excavated material, taking an average between loam and clay, weighs about $90 \mathrm{lbs}$ per cubic foot.

820 This is about 55 men per century, slightly higher than that allowed for the legions. 
These figures make no allowance for digging through rock, which would have taken longer than the time saved when digging through easy soil, nor is any allowance made for the weight of excavated rock rather than soil, nor for incomplete digging of the ditch or incomplete smoothing of the glacis. However, the calculations give an indication of the relative scale of the works.

Rawlinson ${ }^{821}$ arrived at figures of 698,134 man-days for the ditch and 465,422 man-days for the Vallum; it could reasonably be assumed that this was for days of ten hours. These figures are not in any way comparable with the figures suggested here, as Rawlinson was working to incorrect figures for the cross-section of both ditch and Vallum, and his totals for the volumes of soil to be removed do not relate to the cross-section he was using. Rawlinson takes the Wall as 68 miles long, and Bruce (whom Rawlinson presumably followed) accepted that Hutton's figure of 34' wide by 9 ' deep for the ditch was tolerably correct. ${ }^{822}$ These dimensions ought to give a volume of $4,069,120$ cubic yards, whereas Rawlinson arrives at a total of $5,585,072$. For the Vallum, Rawlinson took it as one third less in cross section than the ditch and believed that it fell short of his 68-mile Wall at both ends, but allowed for the full length in order to offset the problems of digging through rock.

One major problem in any calculations is that in modern times all-steel shovel blades are available, whereas it was normal in Roman times for shovels to be of wood tipped with an iron edge. These would be less efficient owing to the increased thickness of the edge and greater friction of the blade. It must be emphasised that the figures do not purport to show how long the Vallum or ditch actually took to dig:

\footnotetext{
821 Bruce (1851) 94-5.

$822 \quad$ Bruce (1851) 51.
} 
they provide no more than an indication of the scale of the works relative to each other and to the overall work of building the Wall complex.

\subsection{Identification of the work of the three legions}

The allocation of Standard A and B footings to legions has been mentioned above (section 4.2.2). While this allocation is probably safe, it is by no means clear that changes from one to the other were made precisely at a milecastle or turret as one would expect. Also, no long length of Broad Wall has been excavated to check the consistency of the current Standard.

The most satisfactory way to distinguish the work of each legion would seem to be the plan of the milecastle gateways, (see section 4.2.5). Although it has been argued in conversation that the milecastle designs were the product of individual gangs, the design of the three types of gateway and their occurrence in relation to the axes is sufficiently consistent to accept the traditional allocation to legions $A, B$, and $\mathrm{C}$, even though it is not entirely certain which legion is which. ${ }^{823}$

There is room for further research on this question, which must be outside the scope of this thesis.

\subsection{Standards of workmanship}

The following observations are based on careful observation and measurement by the writer, following the methods given in Hill (1981).

The curtain wall is of roughly squared coursed rubble, and as such the individual stones are of adequate quality. It could be argued that with more attention paid to squaring the stones the appearance would have been better, but the writer is unable to

${ }^{823}$ Breeze and Dobson (2000). 
see any change in the standard from the start of the Broad Wall to the completion of the Narrow Wall. The Romans built what they were intending to build, and what was built is recognisably satisfactory.

The worked stone, that is principally the gate piers, is a different matter. There are wide variations in the surface finish: the flat, chiselled face on the north-east pier of MC10; the flat, carefully pecked faces of Benwell Vallum Crossing; the stones which are little more than large squared rubble at MC48; the shallow, punched rock faces at MC37; the poorly worked stones of both gates of MC42; and the more or less flat faces of the east gate at Birdoswald. ${ }^{824}$ Those stones which have a rock face are defined by chiselled margins, but these are very often ill-worked and rounded, and in many cases not even completed. The rock faces even within one pier can vary widely in their projection and finish.

Those faces clearly intended to be worked to a straight-edge rarely achieve the intention. Even the western stone of the north pier of MC10, definitely one of the better ones, is straight over only two thirds of the face. The general impression given by most gateways is that near enough was good enough.

Standing out from the others is Benwell Vallum Crossing. Here was a gateway built with real effort, and by skilled men. It has been said that 'The modern stonemason works to specifications so exact that they were hardly met with in the best masonry in the ancient world, let alone in the rough work typical of military architecture. ${ }^{1825}$ In fact, the legionary stonemason could and did produce high quality work comparable with that of today; two examples are Benwell, and the blank inscription tablet lying, at the time of writing, in the porta quintana dextra at

\footnotetext{
824 Hill (2001e), (2001a), (2001c), (1989), (2001b), (1992), respectively.

$825 \quad$ Bidwell et al. 1988, 221-3.
} 
Chesters. ${ }^{826}$ These are both of very good, though not fault-free, workmanship and show what the army was capable of, given the skill, the motivation, and the time. The important point is that these examples were clearly worked by trained stonemasons; the Wall was built by legionaries with no more training than the minimum needed.

The standard of training needed to produce the piers of the fort and milecastle gateways is considerably higher than that required for the curtain wall, but in such a major project every man who showed the slightest aptitude seems to have been called upon to work above the level of his training. The gate piers are structurally adequate, in that they have reasonably well-worked beds, but that is about all.

Practical trials with samples of stones from quarries along the line of the Wall show that, in some cases at least (see section 6.6), it would have been perfectly possible to produce high quality work with little effort if some investment in training had been made. If the army, or the emperor, had accepted a delay of perhaps six months before starting construction, and a longer delay in completing the work, it would have been a relatively simply matter to train large numbers of legionaries to a far higher standard than was evidently available. In the event, this was regarded as unimportant, hence the ill-worked, half-finished stones which are typical of milecastle and fort gateways on the Wall. ${ }^{827}$ Perhaps even more relevant than the level of training is the obvious lack of care about the appearance of the finished work. The standards of workmanship are discussed further in section 13.5.

\footnotetext{
826 Hill (1997a).

827 Hill 1992), (1995), (1997a), (2001b), (2001c), (2001e).
} 


\section{CHAPTER 13}

\section{Dislocation of work}

This section defines and discusses the dislocation of work which occurred in the building programme; the progress made at that time; the decision to narrow the gauge of the Wall; when this occurred in the programme; and at what point the Vallum was added to the rear of the Wall.

\subsection{Dislocation}

The notion of dislocation as an event was apparently first raised by Stevens, adopted by Hooley and Breeze, and accepted as a commonplace by Breeze and Dobson, and others. ${ }^{828}$ In brief, building of the curtain wall and structures was disrupted or halted for an indeterminate time, and work began on the addition of forts to the line of the Wall itself. This event is usually referred to as 'Dislocation'. The effect of the disruption, and what allowed Stevens to identify it, was the movement of work gangs from their current tasks, some of which were completed by others.

At about the same time as dislocation, a decision was made to reduce the gauge of the curtain wall from 10Rf to about $8 \mathrm{Rf}$ or even less. The narrowing of the curtain wall is one of the factors which enables the point of dislocation to be identified.

\subsection{Progress at Dislocation}

To determine progress at the point of dislocation, every relevant reference to the Wall as excavated, as well as personal observation of all extant fragments, has been

828 Stevens (1948), (1966); Hooley and Breeze (1968); Breeze and Dobson (2000). 
listed in a spreadsheet Appendix 1 and the results presented in graphical form in figs 13.1a, 13.1b. The results are in a sense unsatisfactory as many older excavation reports do not clearly distinguish between the body of the Wall and the footing courses, or between footings and foundations. Much work in the 1930s was confined to locating structures, and the location of sections across the curtain wall are often recorded as 'between the turrets' or 'close to the turret'. Where there is reference to 'at several points between the turrets', the location is shown at three equi-spaced points between the turrets; see, for example, turrets 19a-19b. References to 'Broad Wall' or 'Narrow Wall' are made where the excavator has so described the Wall but has not given dimensions. Where Broad Wall is recorded, broad foundation is shown in the graphic even if not mentioned by the excavator; broad foundation is shown on the spreadsheet only where so recorded by the excavator. The spreadsheet records only that evidence resulting from excavations or from personal observation of the writer, whereas the graphic is to some extent interpretive.

A word of explanation of the spreadsheet is necessary. The location of structures is shown in a similar way to the Collingwood numbering system, but extended to give a three-part number.

The first pair of digits is the milecastle number, the second digit defines the structure thus nn. $0=\mathrm{MC}$, nn. $1 / \mathrm{nn} .2=$ turret $\mathrm{a} / \mathrm{b}$, and the last pair defines the precise location of the section:

nn.n.01e=east wing wall (i.e. CW within $2 \mathrm{~m}$ of structure if no visible WW) nn.n.01 w=west wing wall (i.e. CW within $2 \mathrm{~m}$ of structure if no visible $\mathrm{WW}$ ) nn.n.99 is the curtain wall abutting the east wing wall, taking the number from the previous structure. 
nn.n.09 is the curtain wall abutting the west wing wall of a structure, taking the number from that structure.

nn.n. $10, .20, .20, .40, .50, .60, .70, .80, .90,=$ approximate percentage of distance to the next structure.

The following examples will make clear the system. 27.0.00 is at MC27 with no more precise location 27.0.01e is the (notional) east wing wall of MC27 27.0.01w is the (notional) west wing wall of MC27 $27.0 .00 \mathrm{n} / \mathrm{e} / \mathrm{w} / \mathrm{s} / \mathrm{si}$ is the north/east/west/south/side wall of MC27 26.2.00 is at T26b, with no more precise location.

26.2.01e is the east wing wall of the turret

26.2.01w is the west wing wall of the turret

26.1.99 is the curtain wall abutting the east wing wall of T26b

26.2.09 is the curtain wall abutting the west wing wall of $\mathrm{T} 26 \mathrm{~b}$

19.2.50 is midway between $\mathrm{T} 19 \mathrm{~b}$ and MC20; this is also used for 'between the turrets' where the location is not further specified.

19.2.20 is west of T19b, about $20 \%$ of the distance to MC20

In cases where the final digits refer to a well-known point on the Wall, the Notes column makes this clear.

The identification of structures begun in Broad Wall but completed in Narrow Wall is not always straightforward, but two rules have been followed. First, where the curtain wall or any wall of a milecastle is less than $8.9 \mathrm{Rf}\left(8^{\prime} 6^{\prime \prime} / 2590 \mathrm{~mm}\right)$ wide, the structure is shown as completed in Narrow Wall. Broad foundation is regarded as a minimum of 9.9Rf. Secondly, where Broad Wall is recorded at a structure but the only record of curtain wall to one side or both sides is of Narrow Wall, the structure 
is again shown as completed in Narrow Wall. This follows the argument put forward in section 11.5 , that no structure would have been taken above the first 4-5' (1200$1500 \mathrm{~mm}$ ) in height until scaffolding was available as part of the progress of the curtain wall.

The lower limit on the width of the broad foundation and of the curtain wall and the milecastle walls is to some extent arbitrary, but a limit has to be made somewhere and the selected figure has some justification. The Wall was designed to be 10Rf wide and, while some deviation is inevitable in squared rubble construction, a reduction of a full Roman foot is a significant amount. A small margin of 0.1Rf over this figure has been allowed. The limit of 9.9Rf for the broad foundation is well below what ought to be the foundation for a wall of 10Rf, but it takes into account the abandoned broad foundation east of MC39 which is 9.95Rf. It is of course possible that some gangs managed to build the Wall well below specifications.

Entering the structures and curtain on the diagram has not been influenced by what one expects to find. For example, at a number of structures between Newcastle and North Tyne, even where excavation has been thorough, the north face of the Wall was hidden under the modern road; although Broad Wall is very likely to have existed, this has not been assumed. Turret $18 \mathrm{~b}$ is a case in point. Wall narrower than the average Broad Wall has not been seen as later rebuilding, unless this is supported by evidence, but has been entered as Narrow. The symbol for a turret includes the wing walls, which provide the major evidence for determining whether a turret was begun as part of the Broad Wall scheme; if a point of reduction is found, regardless of whether the north face of the Wall is seen, the turret is likely to have been completed to the narrow gauge. Where the north face of the turret was found, a north wall of under 4' $(1220 \mathrm{~mm})$ is likely to indicate wholly Narrow Wall construction. 
This is not entirely a safe conclusion given that Broad Wall turrets $48 \mathrm{a}$ and b have very narrow north walls, but these do seem to be exceptions.

It will be convenient to review the evidence for building Broad Wall as a part of the general view from east to west, in conjunction with the graphic representations. References are given in Appendix 1 and to avoid constant repetition are not repeated in the text. Wall widths are only included in the text where they make an argument easier to follow, or for significant comparisons. In the context of the following, references to 'Narrow Wall' are to the Hadrianic wall; the existence of later (confirmed) rebuilding is ignored. In a number of cases the excavators have been content to record their findings as 'Broad Wall' or 'Narrow Wall', and such findings have been noted as 'bw', 'nw', 'bf', 'nf'. The width of the foundation is not shown in the graphic in those cases where Narrow Wall has been recorded without information on the foundation.

The following summaries mention only those sites where the situation merits explanation.

\subsubsection{Wallsend-MC4}

This part of the Wall has been discussed at length elsewhere (Hill (2001d)) and will not be repeated here. In summary, all the curtain wall appears to have been Narrow.

\subsubsection{MC4 to North Tyne}

\section{The milecastles}

MC4 is taken as a Narrow Wall milecastle on the basis of the discussion in Hill (2002a). 
Chapter 13 Dislocation of work

346

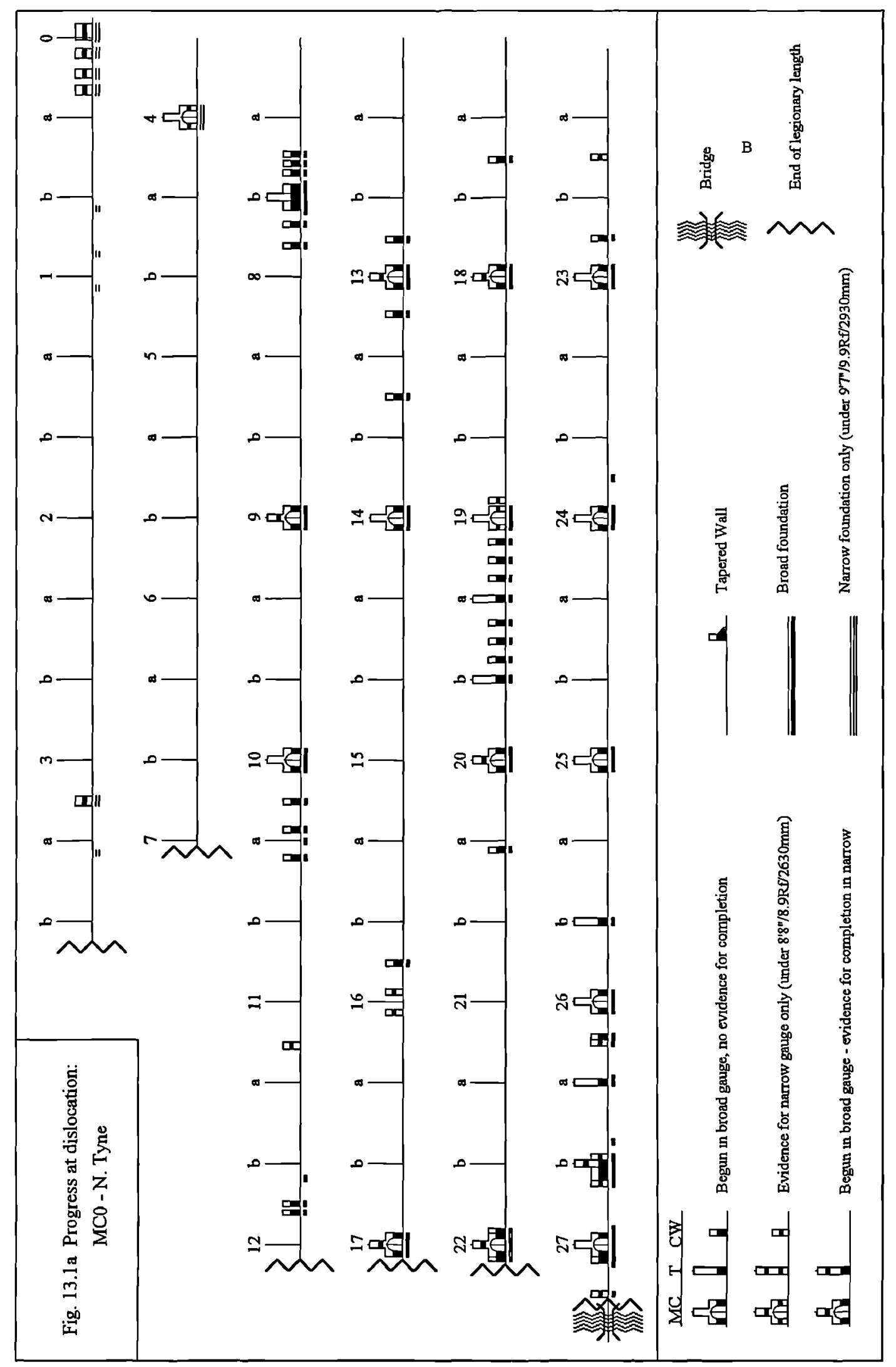




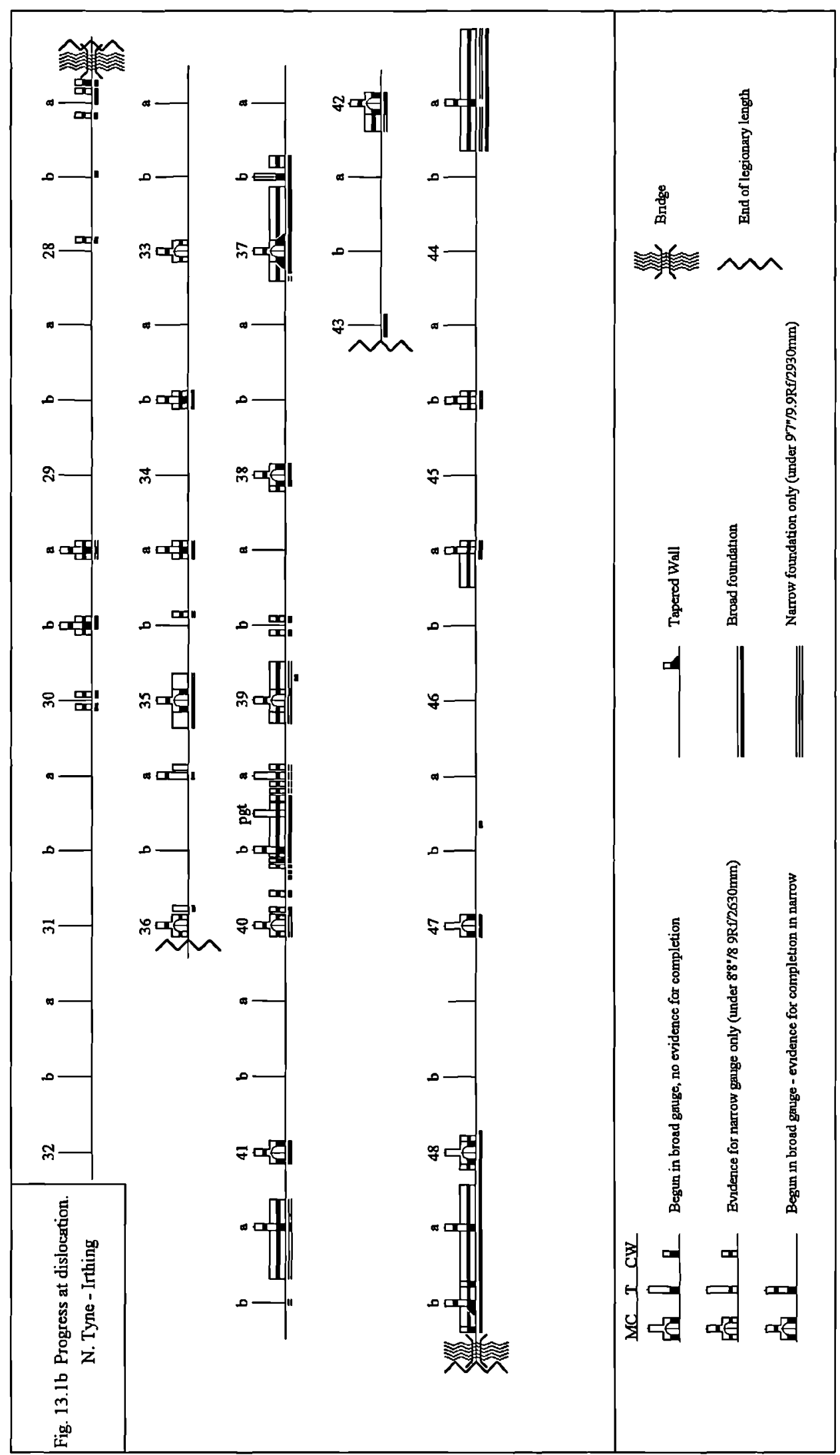


The north wall of MC18 was broad gauge (9.53Rf) with narrow (7.98Rf) side walls; it has a type I north gate but is long axis. MC19 has a narrow south wall; the north wall is not known. MC20 has a broad north wall (9.27Rf) but the side walls have been calculated by Hunneysett ${ }^{829}$ from the internal dimensions as being narrow (7.21Rf); they are so marked on the diagram, but it is at least possible that the milecastle was all in Broad Wall. MC22 has a broad north wall, with Broad Wall immediately to the west, but narrow side walls (8.24Rf) which, by implication from the text, had no broad foundation.

From and including MC4 to MC27 there are 24 milecastles. Evidence is available for 15 of them: MCs4, 9, 10, 13, 14, 17, 18, 19, 20, 22, 23, 24, 25, 26, and 27. Of these, eight have at least some narrow side walls: MCs 4, 9, 13, 17, 18, 19, 20, 22. The other seven milecastles, MCs $10,14,23,24,25,26,27$, are known to have had broad side walls with no occurrence of narrow; measured widths are given for MCs 10 and 27 , but the other five are simply recorded as 'broad'. ${ }^{830}$ As very few milecastles have been fully excavated it is possible that the list of milecastles completed after dislocation could be extended.

\section{Turrets}

At T26a the east wing wall $\left(10^{\prime} / 3 \mathrm{~m}\right.$ from the turret) was estimated by Woodfield at 8.92Rf, which is barely broad gauge. Broad foundation projected some 14 " (355mm) to the south but only $2-3^{\prime \prime}(50-75 \mathrm{~mm})$ to the north (a total width of just over $\left.10^{\prime} / 3.3 \mathrm{Rf} / 3050 \mathrm{~mm}\right)$; this may indicate that its broad foundation was not fully laid when the decision was made to narrow the Wall. Turret $26 \mathrm{~b}$ has broad wing walls,

\footnotetext{
829 Hunneysett (1980).

830 MCs 23-26 were excavated by Simpson, whose notes are not available to the writer.
} 
met by Narrow Wall on the east side and by Broad Wall on the west side; completion of T26b must relate to the later phase of work, after scaffolding had arrived on site (see section 11.5).

In this length of Wall there were 46 turrets; information is available on six, Ts $7 \mathrm{~b}$, 19a, 19b, 25b, 26a, and 26b. Three of these, turrets 7b, 19a, and 19b, have Broad Wall known close to or abutting their wing walls and at intervals between them. This ought to suggest that all three were finished before dislocation, but the picture is not straightforward. There is Broad Wall close to MCs19 and 20, meeting the east wing wall in the case of the latter, yet they were both completed with narrow gauge side walls.

\section{Curtain wall}

The Wall found in front of the Mining Institute in Newcastle was seen by F.G. Simpson, who believed it to be Broad. However, only one side was seen and in view of the uncertainty it is not marked on the diagram.

Some 50 yards to the west of T26b, Narrow Wall was reported with the comment that the Wall apparently tapered. There is no sign of this now and it must be assumed that there is a point of reduction just to the west of the present consolidated length. The surviving length of Wall approaching the river North Tyne is Narrow on the broad foundation.

Looking at the seventy intervals between structures from MC4 to North Tyne, useful information on the curtain wall is recorded in twenty-three of them. Of these, only eight provide evidence at more than one point in the interval. In most monuments this would not be a problem; it would be eminently reasonable to assume a constant width. On Hadrian's Wall, where the gauge is known to have changed, this 
assumption cannot be made. Looking at the intervals rather than the number of individual references, twenty show Broad Wall and eight show Narrow Wall; the numbers do not tally as three intervals show both broad and narrow.

This should not be seen as a statistical analysis: there are too many intervals where there has been no excavation. Only in the curtain wall from MC19 to T19b can there be any degree of certainty that Broad Wall exists throughout, and even there, as the milecastles at each side were finished to narrow gauge, there can be no certainty that the curtain wall was completed to full height as designed. It is merely that the likelihood that it did so is rather stronger than in the other intervals. It would be more accurate to say that from MC19 to T19b all the curtain wall may have been begun in broad gauge.

\section{Broad foundation}

Almost every record from just east of T7b to North Tyne shows broad foundation beneath the curtain wall; the only small question mark comes from T26a where the excavator wondered whether the foundation to the west may have been laid after the reduction in gauge. The likelihood is that broad foundation was laid throughout this length, although not under all milecastles.

\subsubsection{North Tyne to the river Irthing}

\section{Milecastles}

The reported 'joggled' (recte 'raking') joint in the north wall of MC33, which has narrow walls, may indicate that the piers had been built and a small start made on the north face of a broad north wall when dislocation occurred. MC35 may have been begun in broad gauge; the small section of apparent Broad Wall at the south-west 
corner may be an indication of this, but the amount of rebuilding carried out there makes certainty impossible.

MC37 has a tapered north wall, and the side walls are on the defined borderline between Broad and Narrow.

MC40 has broad foundation beneath the east wing wall, with one course inset by $7 "(175 \mathrm{~mm})$ and a second course inset above that, but all four walls are narrow. It has been recorded on the graphic as a short piece of Broad Wall, but it may be no more than a footing course with two offsets. It is not included in the list of milecastles begun in Broad Wall, although technically perhaps it ought to be.

Little is known of MC43. The fragmentary remains of the side walls are measured from the excavator's drawing as $8^{\prime} 6^{\prime \prime}(2590 \mathrm{~mm})$ wide, but there does not appear to be evidence to support this width as only one edge of each of the side walls was found. Hunneysett believes that they were only $8^{\prime}(8.24 \mathrm{Rf} / 2440 \mathrm{~mm})$. Although only the southern edge of the foundation beneath the north wall was seen, it may be reasonably be assumed as broad in view of the broad foundation found immediately to the west of Greatchesters. ${ }^{831}$

Of the 21 milecastles in this sector useful information is available on 11. Of these, seven (plus MC40?) were begun in Broad Wall; five of these, MCs 35, 37, 38 , 41, 42, were completed in Narrow Wall. Two of them, MCs47 and 48, may have been completed to broad specification but there is no Broad Wall known in their vicinity. Four milecastles, $33,36,39,40$, were built wholly in Narrow Wall.

831 It should be noted that the excavator assumed that its gateway was of Type I, although no evidence was found to support this (JRS $\mathrm{xxx}$ (1940) 162-3 and fig. 12). All that can be said is that it ought to be of Type I in view of the width of the milecastle (but see MC18, long axis with type I north gate). 


\section{Turrets}

Turret $33 \mathrm{~b}$ has broad but low wing walls, and T34a has broad but very short wing walls indicating that work had only just been started at the change of gauge.

No measurements were published in the report of the excavation of T36b, ${ }^{832}$ but as it was begun before the fort decision it ought to have been started in Broad Wall, and is so recorded.

Turret 41a has a broad north wall but the wing walls were never built (see below Broad foundation); it looks as though work had just begun on the turret. Turret 43a is built on the broad foundation and was almost certainly begun before dislocation (see below, Broad Foundation). Turret 45a, a pre-Wall tower or very early turret, has no broad foundation, although the foundation close to either side is as much as 14" $(355 \mathrm{~mm})$ wider than the Narrow Wall adjacent to the turret.

There were 44 turrets in this length of the Wall, of which relevant information is available for 14. Half of these were begun in Broad Wall, the remainder in narrow Wall.

It is most unlikely that any of the turrets examined in this sector were completed before the change in gauge of the Wall.

\section{Curtain Wall}

There are two small lengths of Broad Wall; one abuts Willowford Bridge. The other occurs just to the east of T48b, where there are traces remaining of Broad Wall superstructure; these amount to a few stones on top of broad footings. Clearly, a gang was beginning work on building Broad Wall on to the extensive broad footings in this area. In the rest of this sector, there is only one piece of curtain wall, other

832 Simpson and Richmond (1946). 
than a wing wall, which is not narrow gauge. This is on the west side of T48b, where the curtain wall tapers down from the turret to a point $39^{\prime}(13 \mathrm{~m})$ to the west by which time the width was 'the normal $7^{\prime} 7^{\prime \prime}(7.8 \mathrm{Rf} / 2310 \mathrm{~mm})$ '.

\section{Broad foundation}

Turret T29b has broad foundation on the east side, but this was not completed. ${ }^{833}$

Immediately to the west of Housesteads fort the excavator believed that the broad foundation had been started but not completed before the gauge of the Wall was reduced. From Highshield Crags westwards there are short stretches of broad foundation, some of which were ignored by the builders of the Narrow Wall who laid new narrow foundation. The north east corner of MC39 also has a small length of broad foundation beneath the curtain wall.

About 100 yards east of T41a there is a short stretch of what appears to be broad foundation (with no footing course) which quickly tapers back to the narrow foundation. No sign of Broad Wall was reported at T41a but it is said to have broad foundation beneath; below where the wing walls would have been is only a single line of stones as an edge to the broad foundation, with no corework, and was clearly unfinished.

From the west side of Greatchesters fort, unused broad foundation runs on a line separate from the later narrow foundation to the site of T43a which sits on the broad foundation; the two gauges then separate again to beyond Cockmount Hill. The fact that the Narrow Wall converged with broad foundation suggests that the turret had been partly built at the point of dislocation, and was thus begun in Broad Wall. The

833 Newbold (1913), fig 4, where broad foundation is represented by two marginal stones at the southern edge with nothing inside them. 
broad foundation is strictly foundation only and includes no footing course. A small length of the narrow foundation either side of T45a is on a slightly different alignment from the Narrow Wall superstructure.

West of T48b the gauge tapers as described above (and the excavator's drawing shows clearly that the foundation as well as the Wall is tapered), although at about the same point broad foundation has been found more recently..$^{834}$

Broad foundation was clearly very much unfinished in this sector.

\subsection{Dislocation - discussion}

This overview of foundation and Wall thicknesses suggests that there are a number of new assumptions which can be made, and a number of old assumptions which now seem to be doubtful.

It seems clear that Broad Wall was by no means finished to the east of North Tyne before work began to the west. Not only were there stretches of broad curtain wall not built, but eight out of the fifteen known milecastles were completed in narrow gauge. One of the six known turrets was certainly not completed, and completion of the remainder cannot be assured. Probably all the broad foundation beneath the curtain wall was laid.

The curtain wall at Planetrees is significant in that it shows the only confirmed point of reduction other than at a turret, and it holds lessons for other observations. It would be remarkable if this were the only point at which the gauge was changed between structures, and records of 'Broad Wall' cannot be held to be constant throughout an interval between structures unless examination has been made at a large number of points. If century lengths were really as short as $20^{\prime}(6 \mathrm{~m})$ and cohort

834 Shaw (1926); Whitworth (1997). 
lengths $120^{\prime}(36 \mathrm{~m})$ (see section 12.3), then, especially in areas where Broad and Narrow Wall are known to exist, examination at intervals of no more than, say, $150^{\prime}$ $(50 \mathrm{~m})$ is necessary to establish a full record of the width as actually built.

Evidence from excavations shows that, while the north walls, and perhaps the south gates, of the milecastles might be started, the side walls might be left until later. ${ }^{835}$ The fact that a part of a structure was built in Broad Wall does not necessarily mean that it was completed before the change of gauge occurred. It is clear from the excavations of MC22 that broad foundation was not always laid under the side (and perhaps south) walls of milecastles with broad north walls until work began on their completion. To that limited extent broad foundation was not laid throughout the eastern sector. The picture of construction work which emerges is very much as one would expect, and is as discussed above (section 11.3). There were clearly gangs of men at work simultaneously throughout Hooley and Breeze's four legionary lengths from just east of MC7 to the North Tyne, and they had not finished when dislocation occurred. The hard evidence for completion of a structure to broad gauge is no greater at, say, MC27, than at MC10.

There were clearly many gangs at work between North Tyne and the Irthing, putting in broad foundation and beginning to build in Broad Wall before the sector east of North Tyne was complete. Progress was apparently not so far advanced; seven of the known milecastles were begun in Broad Wall but, at most, only two may have been so completed. Four were not begun until the change in gauge. Half of the fourteen known turrets were begun in broad gauge, although probably none of them was completed before the gauge was reduced. Much of the broad foundation was incomplete, although too few intervals (38 out of 65 ) provide information on

835 Hunneysett (1980) discusses this point in some detail. 
which to base an estimate of the percentages. Only fragments of broad curtain wall are known to have been started.

East of North Tyne 53\% of known milecastles and $16 \%$ of the known turrets were completed to the narrow gauge, compared with $82 \%$ and $50 \%$ respectively west of North Tyne. It must be emphasised once again that the samples are small and almost certainly do not present an accurate picture.

Although work is said to have been divided into legionary blocks which were equal to one season's work, ${ }^{836}$ the evidence indicates very clearly that no one block was completed before the next one was started. Breeze and Dobson show legion B at work in sectors 7-12 and 22-27a, legion $A$ in 12-17 and 36b-43, and legion $\mathrm{C}$ in 1722 and 43-49. As none of these sectors was completed in broad gauge and yet there is Broad Wall represented in every single legionary length (in structures if not in curtain wall), all three legions must have been divided along the whole length of their several sectors almost from the beginning. It is probable that there were gangs working on curtain wall, turrets, and milecastles simultaneously; the proportion of men allocated to each probably varied from legion to legion. ${ }^{837}$

What is less clear is the length of time which may have elapsed between the start east of North Tyne and the start to the west. It has been argued (section 12.4.4) that a gang of 28 , if supplied with the materials by others, could build 20 yards $(18 \mathrm{~m})$ of Wall to a height of $29^{\prime \prime}(735 \mathrm{~mm})$ in one day. The model given there allows for all the curtain wall in a legionary length to be built up to four courses high in five weeks. However, as has been shown, not all the Broad Wall was even begun in the eastern sector. There are 30 distinct records of broad curtain wall, that is excluding turrets,

\footnotetext{
836 Hooley and Breeze (1968); Breeze and Dobson (2000) 75-6.

837 Hunneysett (1980) 102.
} 
milecastles, and their wing walls, between T7b and North Tyne. If each of 15 gangs built two recorded instances of Broad Wall, the amount of known broad curtain wall, as opposed to foundation and footings, in this sector could have been completed in a week or so. There is no evidence for more than about four weeks' work from Newcastle to the North Tyne including milecastles and turrets. Hunneysett points out that the legion working immediately east of MC22 (close to Dere Street) was concentrating on completion of curtain wall, and that to the west was concentrating on milecastles. ${ }^{838}$ As these legions were thus doing only a part of the work allocated to them, the time needed to complete the amount of Broad Wall known to have been built is reduced.

The suggested rate of work is of course theoretical, and the difference in overall working time east and west of North Tyne is not easy to quantify. Given that the topography of the crags makes for more difficult transport and working conditions there need not have been any great interval between starting work in the east and starting in the west.

The records suggest that a start had been made on the MC4-North Tyne sector, perhaps to impress the emperor (Corbridge would have been an ideal place for him to stay), with work continuing for no more than about two months. Gangs were then moved to the central sector as convenient, and a start made there. This movement would have involved delay and reorganisation, and it might have been no more than another month or so before plans were revised and the decision made to put forts on to the line of the Wall and to dig the Vallum. As suggested in section 12.4.4 this could all have been done during Hadrian's visit to the province.

${ }_{838} \quad$ Hunneysett (1980) 102. 
It could be that the two sectors were begun at the same time, but with a much greater number of men allocated to the eastern sector. This model has the advantage of explaining the considerable progress with MCs47 and 48, and the start of Ts48a and $\mathrm{b}$ as possibly early-design turrets with broad wing walls and a narrow north wall. ${ }^{839}$

In fact, in the present state of knowledge, the best that can be said is that the evidence so far points to greater progress to the east than to the west of North Tyne, but that east of North Tyne a considerable amount of work was uncompleted before the change of gauge.

However, only limited weight can be put on the perceived completion ratio as between Narrow Wall and Broad Wall. Fewer than one third of the structures excavated have yielded relevant information, and the sampling has not been done on any formal basis; understandably, much excavation has had to depend on availability of sites and labour. Even the information to hand is by no means complete, as a number of excavations were limited to answering certain specific questions such as the type of gateway, the width of turret walls, or the position of the doorway. Unless it is possible to excavate a turret to beyond the normal length of the wing walls, and the wing walls and turret are found to be standing at least several courses high, any possible evidence for Narrow Wall would be missing. More turrets in the east may have been finished in Narrow Wall than have so far been identified from the very small sample. Equally, it is possible that more turrets and milecastles in the central sector were begun in Broad Wall.

839 The design of these turrets is discussed in Hill (1997b). 


\subsection{The Narrow Wall decision}

That the effect of this decision impinged on the structures and the curtain wall is clear: the width of the Wall is reduced from $10 \mathrm{Rf}$ to as little as $6 \mathrm{Rf}$. Milecastle walls were reduced in thickness, and those turrets not yet started had narrow wing walls. What is less clear is the relationship of this decision to the fort decision. The Narrow Wall may have preceded the fort decision or they may have been coincident; the Narrow Wall decision cannot have come significantly later than the fort decision as no fort, so far as is known, is abutted by the Broad Wall other than its foundations.

Wallsend is on the Narrow Wall, at Benwell the Wall lies beneath the road and is not available for excavation, and at Rudchester the Broad Foundation and ditch ran across the site, but only the north edge of the Wall was found in a tunnel beneath the road to the west of the fort. Here, a degree of sophistication was found in the form of a moulded plinth; ${ }^{840}$ this elaboration might suggest the start of the Broad Wall.

At Haltonchesters, too, the ditch ran across the site but only the south edge of the Wall was found adjoining the west gate: ${ }^{841}$ the gauge is not known. The foundation is entirely covered by the modern road.

The first evidence comes from Chesters fort, where Narrow Wall on broad foundation appears to be bonded into the fort curtain wall at both east and west gates. However, when Clayton first excavated the east gate he was clear 'That the two structures are obviously distinct and separate works, and though they touch each other there is no intermixture of masonry. ${ }^{1842}$

\footnotetext{
840 Parker Brewis (1925) 103 and plate XIV. The tunnel was 'ten feet west of the west face of the fort.'

841 Simpson and Richmond (1937b).

${ }^{842}$ Clayton (1876a). Consolidation work may have distorted the appearance of the junctions.
} 
The ditch and broad foundation run across the site, where the foundations of T27a were also discovered in 1945.843 The relationship between the fort ditch and the Wall is interesting. The broad foundation runs over the north end of the ditch, but the north side of the Wall appears to have been clear of the ditch; it is not known whether the ditch reached as far as the southern edge of the Narrow Wall. ${ }^{844}$ Either way, it looks as if the ditch diggers were at work before the foundation builders, and that the latter laid broad foundation over the filled-in end of the ditch in a post-fort decision context.

There was a different situation at the next primary fort, Housesteads, where the junction of the west fort ditch and the Wall was re-examined in in the late $1960 \mathrm{~s} .{ }^{845}$ The text suggests that clay packing under the foundations of the Narrow Wall may have been to support the Wall between two outcrops of whinstone. The ditch itself cut the partly laid broad foundation and stopped just short of the narrow foundation; this is contrary to the previous belief that the ditch ran under the Narrow Wall. ${ }^{846}$ Here, the ditch diggers appear to have been aware that the gauge of the Wall had been changed, although it is not known whether the Narrow Wall was already at least partly built when the ditch was dug. Charlesworth questions why the two works approach each other so closely. The reason may simply be that the builders were grappling with a very new design concept: a ditch around a fort which was part of a running barrier. The solution to a theoretical attacker getting around the end of the ditch was to take the ditch right up to the Wall. However, on the east side of the fort

\footnotetext{
843 Simpson and Richmond (1946) 134 and fig. 10.

844 Simpson (1923). Similar conditions were found at the east ditch, but this was not fully excavated.

845 Charlesworth (1971).

846 Birley, Charlton, \& Hedley (1933) 84.
} 
the ditch stops well short of the Wall and broad foundation, and there is no clear relationship between the two; perhaps the ditch here was not dug until a little later, by which time it was realised that it was unwise, and perhaps unnecessary, to take the ditch right up to the Wall.

It is clear that the fort was built in advance of the Wall, as the two meet with a straight joint at the north east angle. The Narrow Wall meets the fort well to the north of the true corner, and the angle tower begun in its normal position had to be taken down and rebuilt to cover the junction. Simpson believes that the Wall and fort are contemporary at the north west angle, although there is no sign of bonding above foundation level. ${ }^{847}$

The position at Greatchesters is more complex than at the other forts, and it is worth summarising some salient points. It was planned as a fort of the primary series, for the Vallum has an original undug crossing, ${ }^{848}$ although it appears, from the inscription $R I B$ 1736, that the fort was built after $\mathrm{AD} 128$. In general terms, the Vallum seems to be approximately co-incident with the fort decision. ${ }^{849}$

The south-west angle tower was excavated in 1894 , and found to be of the normal type. ${ }^{850}$ The north west corner was quite different, and projects oddly beyond the line of the fort wall (see figure 13.2). The tower and the Narrow Wall appear to have been of one build, and no trace was found of alterations. It was, however, suggested that the angle tower and Wall were built before the west wall of

\footnotetext{
847 Simpson (1976) 128 and fig. 45.

848 Heywood (1965) 87.

849 There is a somewhat irregular diversion around Benwell (Birley et al. (1934) 184); at Rudchester the indications are that on the west side the Vallum was being dug before the fort was planned (Bowden and Blood (1991)).

850 Gibson (1903).
} 
the fort, which was found to have been robbed to foundation level. As discussed in section 11.6.1, it would be normal to build a tower before the curtain wall, and there is nothing in this tower to suggest that anything unusual was happening. ${ }^{851}$ The best interpretation is the commonly accepted one, that the Narrow Wall and the north west angle of the fort were built at the same time. The Narrow Wall cannot have been in existence unless it was pulled down along the north side of the fort, and rebuilt to the narrower dimensions of a fort wall, an unlikely scenario. At Drumburgh, contemporary with the rebuilding of the Turf Wall in stone, ${ }^{852}$ the fort meets the stone wall (in one build) at right angles. ${ }^{853}$ The northern angles of Carrawburgh fort are beneath the modern road, but the west wall was excavated by tunnelling 'to within two feet of the calculated position of the south face of the Wall' with no trace of a curve being found..$^{85}$

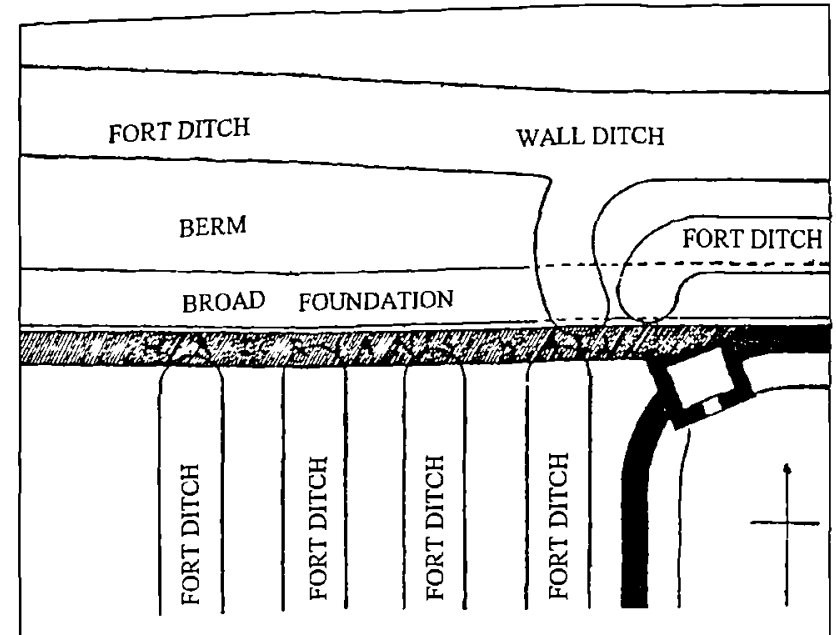

Fig. 13.2 Greatchesters fort, north west angle: as built (after Hull (1926))

851 But it is not normal for a straight joint to appear, as found at the west gate of this fort (Gibson (1903) $28-30$, especially the illustration on page 30 ).

852 Daniels (1989).

853 Haverfield (1900).

854 Birley (1935). 
The fort ditches on the west side of Greatchesters were cut to stop just short of the broad foundation, the builders presumably believing that it was the Broad Wall which was to be built. It is unlikely that the broad curtain actually existed as no trace of any superstructure survives and not a trace of mortar was found. ${ }^{855}$ Evidence from elsewhere shows that Narrow Wall builders did not demolish any existing Broad Wall or footings even to reuse the stone. The two spur ditches which cut the broad foundation are said by the excavator to be later additions, although the drawing (reproduced as fig. 13.2) shows that the western one cut into the Narrow Wall.

It is difficult to reconcile these aspects of the fort and Wall. A tentative scenario might be put forward as follows:

1. MC43 was laid out and perhaps the north wall built. A start was made on laying the foundation (but not the footings) of the curtain wall to the west. The fort decision was then made and this fort was planned as part of the primary series; accordingly a causeway was left undug for the Vallum crossing.

2. The fort was begun very early in the fort programme, before the decision had been made to narrow the Wall. Part of the west and south gates were built, ${ }^{856}$ and perhaps more, and the ditches were dug in anticipation that the planned line of the Wall would be used (see fig. 13.2). As much of MC43 as had been built was demolished.

3. There was a long break in building, for whatever reason, as occurred at Birdoswald; the two events need not be contemporary. By the time work was resumed, the Narrow Wall decision had been taken, the broad foundation was

\footnotetext{
855 Hull (1926).

856 Gibson (1903).
} 
overgrown, and the spur ditches were cut in anticipation of the new line for the

Narrow Wall; the western one was cut too far to the south and was overlaid by the narrow foundation.

The evidence from the ditch at Chesters indicates that the Narrow Wall decision came after the fort decision, although by how long is not discernible. At Housesteads, it seems that by the time the fort ditches were dug the decision had been made to reduce the thickness of the Wall. At Greatchesters, the fort ditches respect the planned line of the Wall, which was presumably still expected to be broad. It is not possible to say at what point in the construction of a fort ditches were dug; logically they ought to have come after the completion of the fort walls to allow easy access for men and materials, but at Greatchesters they do seem to have come very early. It has been suggested that fort rampart backing material was derived from the ditches, and thus they may have been dug as the first element of a fort. If gaps were left to allow easy access to the curtain wall, they would not have presented a serious obstacle. This hypothesis has not been tested archaeologically, but it certainly seems to be the case that the ditches came first at Greatchesters as they respect the broad foundation.

It may be significant that at Housesteads, and probably at Chesters, the Wall is not bonded with the fort wall. This could indicate that it was realised that it would be some time before the curtain wall would arrive. On the other hand, the builders of the fort may simply have made life easy for themselves by not providing wing walls. As a late-built fort Greatchesters may have been looked at differently from Housesteads, or there may have been a more cooperative gang at work. One would 
expect there to have been wing walls to the forts, just as at milecastles and turrets; they certainly appear at Balmuildy on the Antonine Wall. ${ }^{857}$

There is some evidence from milecastles. At MC37 there is a very small amount of Broad Wall to each side of the north gate; the tapered Narrow Wall leads off from these small triangles with an offset of up to $2^{\prime \prime}(50 \mathrm{~mm})$. There would be no need at all to build any of the north wall until the piers had been built up to the capitals, and indeed it would have been in the way. It has long been known that work on MC37 was affected by dislocation, and it has been argued that the north gate piers were incomplete at this time. ${ }^{858}$ It appears that the piers and arches were completed after resumption of work following dislocation, following which a start was made on the north wall to the broad gauge. This suggests, and no more, that the Narrow Wall decision was not implemented until after the fort decision, although the interval need not have been long. There is no reason why, once work on the forts had been put in hand, work on the milecastles, turrets, and curtain wall could not have been resumed almost at once, albeit with a much reduced work force.

Similarly, the reported 'joggled' (recte 'raking') joint to the west side of the north gate of MC33 ${ }^{859}$ (it is not now visible) may also have been the start of Broad Wall after the piers had been built, but at what point in the programme these were begun is not known.

The interval between work on the Wall being temporarily abandoned in favour of the forts, or for other reasons, could have been a very short one, or it could have been long. Crow points, out in his review of work on the curtain wall, ${ }^{860}$ that at Peel Gap

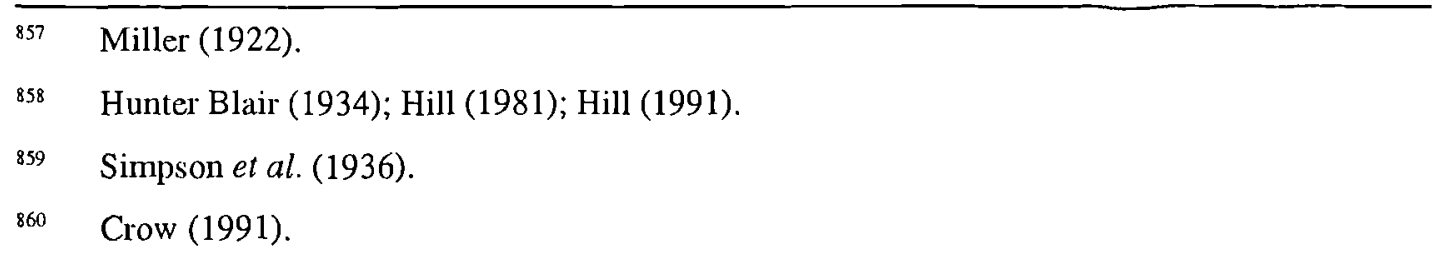


there must have been a considerable interval between the laying of the foundation and the building of the Narrow Wall. This is not to say, however, that this situation obtained at all points. It has long been held that at least one legion was left at work in the central sector completing the work of others, ${ }^{861}$ as there are inscriptions naming Nepos from MCs37, 38, and 42, and work may have proceeded at once in some places and more slowly in others. However, the interval could still have been up to, say, two years, given the possible speed of building suggested in section 12.4.4, and still fall within the governorship of Nepos. Even if the suggested speed were halved, the amount of Broad Wall known could still have been completed in under a year, leaving perhaps two years for the granaries at Benwell, the west gate of Haltonchesters and the gateways of at least three milecastles to be completed in time for Nepos to be named on the inscriptions. ${ }^{862}$

\subsection{A second dislocation?}

There appears to have been a second 'dislocation' in work on the Wall. It has been argued that work on some forts and milecastles shows a distinct loss of quality at a fairly early stage in their construction. ${ }^{863}$

There was clearly a second dislocation at Birdoswald, demonstrated archaeologically as well as by masonry survey, but the received chronology there

$861 \quad$ e.g. Breeze and Dobson (2000).

862 Bewcastle fort may also have been completed under Nepos, see Tomlin and Hassall (1998) 443, and Bidwell (1999) 17-18. The following governor, L. Trebius Germanus, was in post by August 127 but the date of his appointment is not known. If Nepos had the usual three year term he will have left in 125 , but evidence is lacking.

863 Hill (1981), (1991). 
does not allow for parallels with other forts on the Wall. ${ }^{864}$ It was after the second break in construction there that the quality dropped markedly. ${ }^{865}$

There is good evidence from other forts. At Chesters, the north gate seems to have been started with a great deal of skill shown on NGNE1/1; at the east gate, the the south west pier is worked to a reasonable standard and the shows ample skill and care. Again at Chesters, EGSE1/1 is clearly unfinished, with only the bottom quarter of the internal return completed. The foundations of the north gate at Housesteads are of high quality beneath the north east and north spina piers; the foundations beneath the north west pier are markedly less well-worked and are to a different design. At the west gate, there are marking-out lines on the foundation block of the south west pier which are not followed by the pier above (the difference is over $300 \mathrm{~mm}$ ); the pier itself was not good. The north west pier is good at the base, but the top two courses show marked deterioration as though time was of the essence. The west pier of the spina at this gate shows a remarkable lack of care, and the topmost stone, which contains the locking bar hole is frankly dreadful. ${ }^{866}$ At Birdoswald, the south west pier of the west gate was begun well (there are only two stones remaining), and it sits on a well-worked foundation block. The west spina pier of this gate is very poor and founded on a stone which is little better than a natural boulder. At the porta quintana dextra the north east pier was begun (there is now only one stone remaining) reasonably well, but the upper part of the south east pier is extremely poorly finished. ${ }^{867}$

\footnotetext{
864 Wilmott (1997). It is reasonably clear that the first fort was turf and timber, followed by a stone fort with two breaks in the construction of the stone fort, all within Hadrian's reign.

865 Hill (1992).

866 Chesters, Hill (1997a); Housesteads, Hill (1995).

867 Hill (1992); Wilmott (1997).
} 
The same effect is to be seen on the north gateway of MC37. The lower courses of the piers are what might be described as honest Roman military engineering, but the upper part is noticeably worse; the cap of the south east pier is particularly badly finished. The piers of MC42 are of bold appearance, but when examined closely are far from well-worked, showing a fairly consistent lack of care and skill. The north gate is no better than the south. At MC 10, NSNE1/1 shows remarkably high quality on the face, while NGNW1/1 and 1/2 are much less good. These stones appear to have been put in their present positions subsequent to the uncovering of the site in 1864, and presumably originated higher up one or other of the northern piers. Again, this suggests a marked lowering of quality. The poor work in the piers of Broad Wall MC48, Poltross Burn, can be entirely explained by the very difficult nature of the stone used there. ${ }^{868}$

These changes were not solely due to lack of skill, as EGSE1/1 at Chesters was not finished; the man working it was clearly part way through, and making an acceptable job, when it was taken from him to be transported to site and built into the pier. It is probably true that some skill was lacking, as Chesters WGNW1/1 has all the appearance of a stone being worked by someone who was not capable of a better job, but it is adequate; it has the feel of being under the supervision of an officer who knew what he wanted.

The impression is very strongly that of a job where the nature of the supervision changed markedly. At first, is seems that the men carrying out the work, some of whom were skilled and some much less so, were supervised with an insistence on work of at least adequate quality. The lower parts of MC37, for example are by no

868 MC37, Hill (1981 and 1989); MC42, Hill (2001b); MC10, Hill (2001e); MC48, Hill (2001c).

The writer is very grateful to Mr D. Sherlock who arranged for the assessments at MCs 42 and 48 , and at Chesters fort. 
means of the highest quality, yet the appearance is impressive. Later, it seems to have become a matter of completing the work as fast as possible without the slightest regard for the appearance. Here the south east pier of the porta quintana dextra at Birdoswald is a case in point. It seems that, quite suddenly, no one cared.

The reason for this marked drop in quality during the building work is not easy to understand. Stevens suggested that there may have been fighting during the building ${ }^{869}$ others have argued against the idea of any fighting in Britain during Hadrian's reign after $119 .{ }^{870}$ Casey, on the other hand, argues that there was fighting in the middle 120 s. $^{871}$

It is not within the compass of this thesis to examine whether or not there was fighting, but such an event would explain much. If the legions were taken off the building work to spend one or more seasons in fighting, they could well have been reluctant to return to work on a wall 80 miles long.

There is another explanation which may very tentatively be put forward. The legions will inevitably have been dismayed by the prospect of building a Wall 80 miles long, but started their work in a responsible manner. When the forts were added, work began well enough at first, but the legions may have rebelled against the additional work. It could be that auxiliaries were drafted in to assist with all aspects of the building, not as units in their own right but as additional labour for each legion. Their comparative lack of experience soon showed up in the poor quality of the masonry, although the legions continued to put up the inscriptions. Auxiliaries

\footnotetext{
869 Stevens (1966).

870 Jarrett (1976); the argument focuses on the possibility of fighting in the early 130s.

871 Casey (1987).
} 
were certainly building forts at some point during the reign of Hadrian, as shown by inscriptions from Carrawburgh, Carvoran, and Hardknott. ${ }^{872}$

It must be said that the involvement of auxiliaries is a very uncertain hypothesis, put forward simply as an alternative explanation which more or less fits the few known facts. There is no hard evidence to support it, and the quality of workmanship is not necessarily related to the type of unit responsible. ${ }^{873}$

872 RIB 1550, 1820, (JRS lv (1965) 222, no 7), respectively.

873 Gillam and Mann (1970), 21-22, make much the same point 


\section{CHAPTER 14}

\section{Conclusions}

This thesis has examined the methods, techniques, and operations necessary for the building of Hadrian's Wall. The examination has taken a different approach from

previous work in that it is based on the application of personal, practical experience rather than a theoretical viewpoint. This has resulted in a picture of the Wall which is rather different from the received view, and some aspects of the building process have taken on greater significance than was previously accepted to be the case. In addition, a number of points of technical interest have emerged, and areas of research have been identified for future work.

\subsection{The existing view of Hadrian's Wall}

The conventional view of the Wall is that it was begun, or at least planned, during the visit of the emperor in 122. After some one or two seasons work, during which the Wall was virtually completed as planned between Newcastle and the river North Tyne, major changes were made: forts were built as an integral part of the Wall and the Vallum dug as a line of demarcation to the south, and at about the same time the thickness of the Wall was reduced. These changes caused a dislocation of the building gangs, which may have led one legion to continue work started by another. The work is generally seen as being of high quality, to the extent that the facing stones have often been referred to as ashlar. 


\subsection{The revised view}

- One point which has emerged very clearly is that comparatively little is known about the Wall in detail; the limited extent of that knowledge is shown graphically in figures $13 \mathrm{a}$ and 13.1b. Excavations of a limited number of sites have perforce been used to provide a view of the Wall as a whole; from Wallsend to the Irthing there were 49 milecastles of which information is available on only 27 . In some cases the amount of information is very small (see chapter 13); for example, all that is known of MCs22-26 is that the side walls were 'Broad'.

Similarly, there are very large gaps in knowledge of the curtain wall; it has been argued (see section 13.3) that sampling of the curtain wall at long intervals is insufficient in view of the known change of gauge.

All this emphasises that discussion of most aspects of the Wall is to some extent making bricks without straw. In the preceding pages likely scenarios are offered based on an understanding of building processes, backed by careful and informed measurement and assessment; it is an interim view pending more excavation and detailed technical surveys of previously unexcavated parts of the Wall. It is hoped that this thesis will act as a guide to what is important in recording excavated masonry in the future.

- The appearance of the Wall, massive and imposing, will have dominated the landscape in a way not seen in any other frontier, yet it is a work of often inferior quality when examined in detail. The workmanship along the Wall varies markedly (see section 12.6). At least one of the stones from the north gate of MC10 shows a considerable input of skill and care, as does the gateway of the Vallum crossing at Benwell. A stone from the north gate of Chesters fort is clearly the careful work of a skilled man, yet one from the east gate of the same fort was fixed before it was 
finished. Much of the extant work, such as the gateways of MC42, is of distinctly poor quality and shows a large disregard for the appearance of the finish; the Wall will have been impressive from a distance, much less so from close up. If the emperor had delayed the start of work for six months a great many men could have been trained to a significantly higher standard. Hadrian, or perhaps the army, was not concerned with a work of high quality, but rather a work of unprecedented and impressive scale. Other Hadrianic work in Britain is of far higher quality; for example, there is nothing on the Wall which can compare with the inscription from Wroxeter, $R I B$ 288. Unfortunately there are no formal qualitative assessments of masonry elements from elsewhere in Britain which would allow fuller comparison. Judged by any standards, however, the Wall is for the most part a utilitarian work of military engineering carried out by the army to low but acceptable standards.

The comparatively high quality of some parts shows that the legions were capable of much better work than is generally seen on the Wall (see section 12.6). The fact that there was large scale rebuilding under Severus indicates that the curtain wall was badly built, probably as a result of pressure to complete as quickly as possible. ${ }^{874}$

It seems to have been built for imperial effect rather than for the utility of its design, something emphasised by the later abandonment of turrets and the blocking of many milecastle gateways. The Antonine Wall, on the other hand was a more practical design, although its turf construction will have looked less imposing. Both Walls are unique among Roman frontiers in that they could be sealed from end to end by simply closing the gates.

874 Crow (1991b), in suggesting that it was always intended to rebuild the Wall at some future date, hints at low quality work. 
- The curtain wall (see section 4.2.3) is of unusual thickness, although the wall of the slightly later fossatum Africae is of similar size. The fact that the gauge was reduced at an early stage, and that the replacement for the Turf Wall was also reduced, presumably indicates that the original size was found to be unnecessary. What has emerged is that the so-called Intermediate Wall probably did not exist; any thickening of the Wall around MC54 was likely to be related to local soil conditions.

It has been claimed that a clay-cored Broad Wall was more stable than a similar Narrow Wall; in fact, the reverse is true (see section 4.2.3).

It has ben argued from an examination of the evidence (see section 4.4) that the curtain wall was not rendered, although some attempt was made in at least one place to give a decorative finish to the joints. It is not impossible that the curtain wall was limewashed, although the evidence is at present insufficient to confirm this.

- Milecastles are unique in size and form; one or two fortlets are similar in size (see section 4.2.5) but no other fortlets approaching this size have two gateways and a roadway running through. In addition, the manning level, 8-12 men in 'standard' milecastles, is much lower than for any other fortlet, apart perhaps from signal stations. Fortlets of similar morphology were included in the design of the Antonine Wall, but were somewhat larger. The form was not repeated elsewhere in the empire; even the Fossatum Africae has gateways of the Knag Burn type rather than milecastles.

- The detailed description of the building of milecastle walls (see section 11.4.1) has led to an understanding of why the external corners are rounded; it is simpler to build round corners than square ones, and thus more appropriate for men with limited skills (see section 11.4.1). 
$\checkmark$ New light has been shed on the design and function of the Stanegate (see section 2.3.1). it is seen here as a lateral road strengthened by only two fortlets in the central sector; this strengthening was later reflected by the large milecastles, MCs 47-54.

- Doubt has been cast on the purpose of some apparent wedge holes in some Roman quarries (see section 5.4). The function of such holes part way up large quarry faces had no function in relation to splitting stone, and they were probably used in connection with supporting scaffolding or ladders.

- There is a long-held and widely accepted view that the stone was normally 'very carefully selected'; ${ }^{\prime 25}$ the evidence put forward in chapter 6 suggests that stone was taken from a large number of small quarries all along the line of the Wall and was chosen chiefly for its location rather than its quality. The greatest distance from quarry to Wall is probably just over one mile, from Black Pasture to Chesters fort. The manifestly inferior stone used for the gateways of MC48 came from the valley of the Poltross Burn, some 50 yards away.

- The use of these many small quarries will have had a serious impact on the local environment. The constant passage of pack animals and carts criss-crossing the whole area must have made the use of existing arable fields next to impossible; grazing will also have been affected. It is quite likely that civilian inhabitants of the area will have been prevented from carrying on any farming activities within a corridor up to a mile wide and extending both sides of the Wall. This, added to the use of cultivated fields for the line of the Wall itself (see section 3.4), must have given rise to considerable disaffection and may have given impetus to any fighting occurring during the building programme (see section 13.5 ).

875 Most editions of the Handbook. 
- The review of hoisting has revealed, apparently for the first time in Britain, that nippers or dogs were used by the army, at least to a limited extent (see section 7.4.1). It remains true that the usual method of attaching stone to a crane during the building of the Wall was the lewis.

- It is argued in chapter 9 that scaffolding was not only essential but the enormous quantities needed would have put a considerable strain on local resources and may have been a limiting factor on the rate of building the upper parts of the Wall. This adds weight to the limit on the amount of work completed before dislocation.

- The examination of the transport requirements in relation to what had to be transported (see chapter 10) has shown that previous studies have not been based on the practical requirements of the army. It has been argued here that the Roman army had available waggons which could readily cope with payloads of two tons. Carts and smaller waggons could probably have carried greater loads than hitherto thought likely. The review of pack transport argues that, given the short journeys from quarry to site, pack animals could carry four typical walling stones.

- Chapter 11 discusses the way in which the Wall was built, and emphasises that the building of the curtain wall was very simple and could be carried out by any legionary with only minimal training. The gateways and turrets on the other hand called for different techniques and for higher levels of skill and experience.

- An estimate has been made of the possible labour force, and this suggests that a century had perhaps only 50 men available for construction work (see section 12.2). The total legionary labour force may have been in the order of 7,200 (see 12.2.6). It is argued that the available evidence suggests that the auxiliaries alone were responsible for digging the Vallum. 
- The possible rate of building put forwards (see section 12.4), allied to the simple nature of the surveying needed (see section 4.6), suggests that at least the initial work on the Wall may well have been much quicker than has previously been put forward. This makes existing timetables for the work uncertain, although not enough is known about the Wall to attempt a programme for the whole of the work.

The widespread, although not uniform, occurrence of Broad Wall in all legionary lengths between Newcastle and the river Irthing indicates that small gangs were at work simultaneously at very many points. Alongside this, the argument in chapter 13 that there is no evidence for completion of any part of the Wall to the original Broad gauge makes it possible for both the initial decision and the changes in plan to have occurred during Hadrian's time in the province (see section 12.4.4).

- There is good evidence, presented in section 13.5, that there was a second dislocation of work as shown evidenced by the sudden and marked drop in quality in the fort gateways. This may have been no more than a sudden, unexplained, change in philosophy; alternatively it may have been the result of fighting in the province or, a very tentative suggestion, it may have been due to the introduction of auxiliary labour under legionary direction.

- There are no other artificial frontiers which can be compared directly with Hadrian's Wall. The only one which comes near to it in form is the Fossatum Africae, but there is no detailed review of the structural elements of this work against which comparisons can be made. The same is true for other Roman forts and fortresses across the empire. 


\subsection{Further research}

This thesis has covered a very wide spectrum of the operations necessary to build the Wall. A number of areas where greater depth of research is called for have been identified.

- Roman setting-out (full-size drawing) is not fully understood, and although Haselberger has published useful evidence on the subject there is no information available about materials or the way in which Roman masons used templets (see section 6.4). Indeed, there is no evidence from Britain that templets were used at all, and thorough and informed examination of all moulded dimension stone is long overdue.

- More investigation is needed on the nature of Roman scaffolding; chapter 9 has established a provisional design for scaffolding used by the army in north Britain but there is still no hard information on the diameter of standards and ledgers, and nothing at all known about the material used for decking.

- Both the author and others have written extensively about the Roman tools used for working stone; no one has used reproductions of tools made to Roman steel specification to work stone according to Roman methods. This could be expected to provide a great deal of useful information, providing the person carrying out the research were already a skilled mason.

- There is a great need for complete excavation of undisturbed curtain wall, especially Broad Wall and preferably in long lengths, with careful recording of every detail of the construction. Chemical analysis of bonding material from both facing stones and core is essential.

- It would be extremely useful to know for certain which quarries were used for building the Wall. To this end samples should be taken from every part of the Broad 
curtain wall, the milecastles and turrets, and from Hadrianic work in the forts, and compared by petrological analysis with likely sources of stone along the line of the Wall. One benefit of this would be to establish a reasonably firm base from which a realistic calculation of transport requirements could be made.

- This thesis has presented a view of one frontier in the Roman empire from the aspect of the physical aspects of its construction, and provides a record against which other frontiers and military works may be judged. Technical assessments of the stonework on other frontiers, especially the fossatum Africae, as well as Hadrianic forts and fortresses in other provinces, would provide a standard of comparison with Hadrian's Wall. This is at present lacking. 


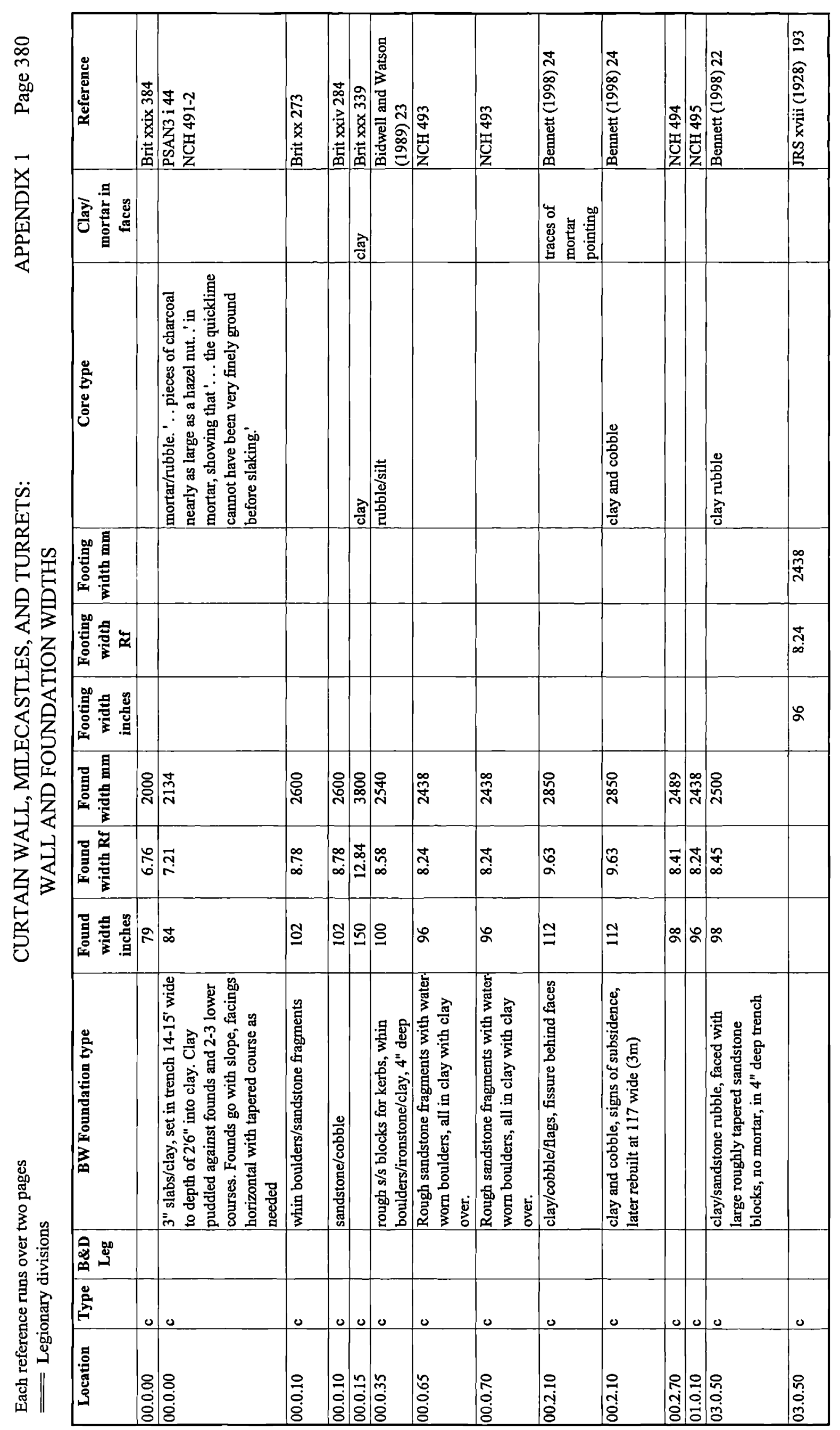




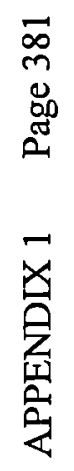

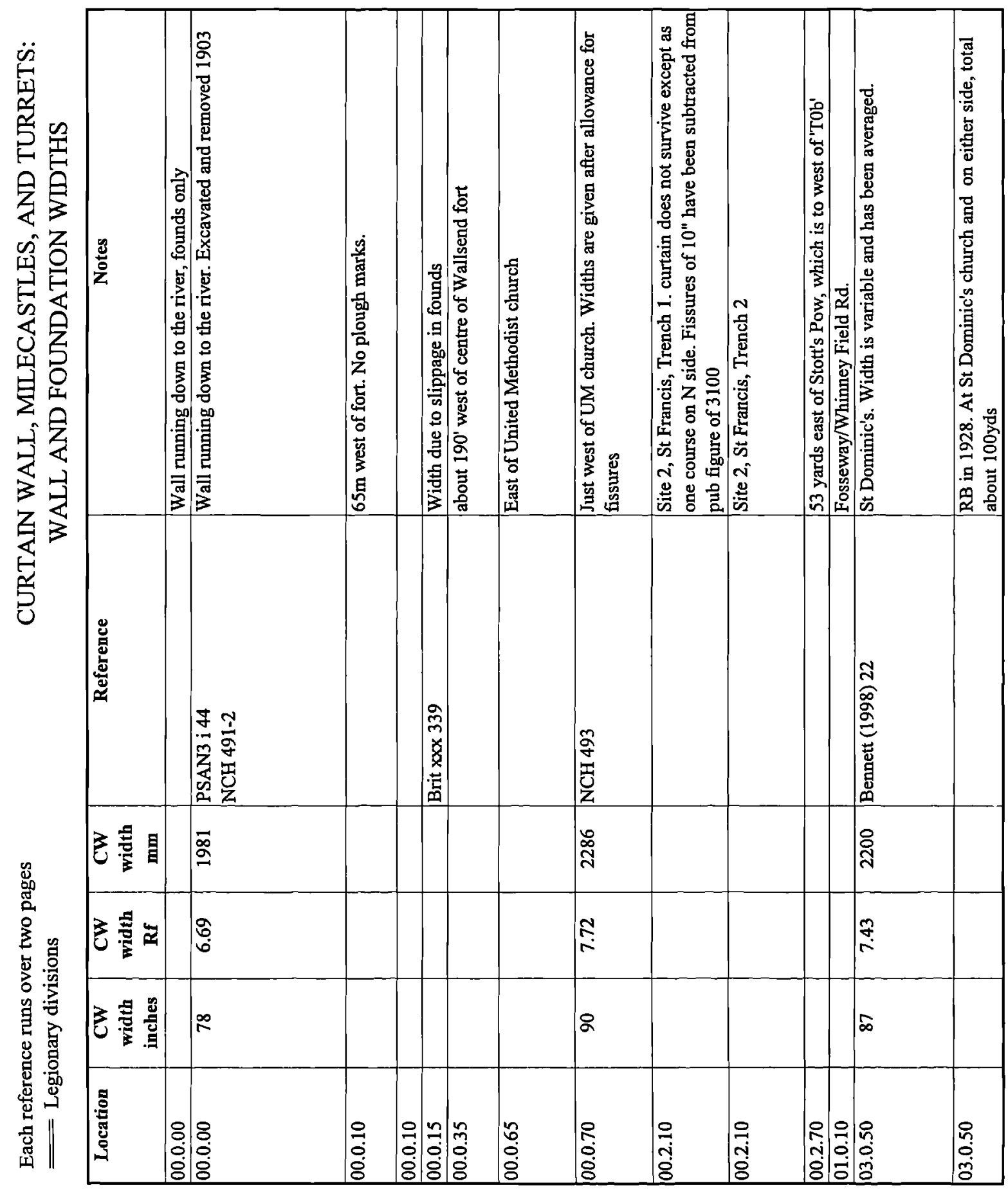




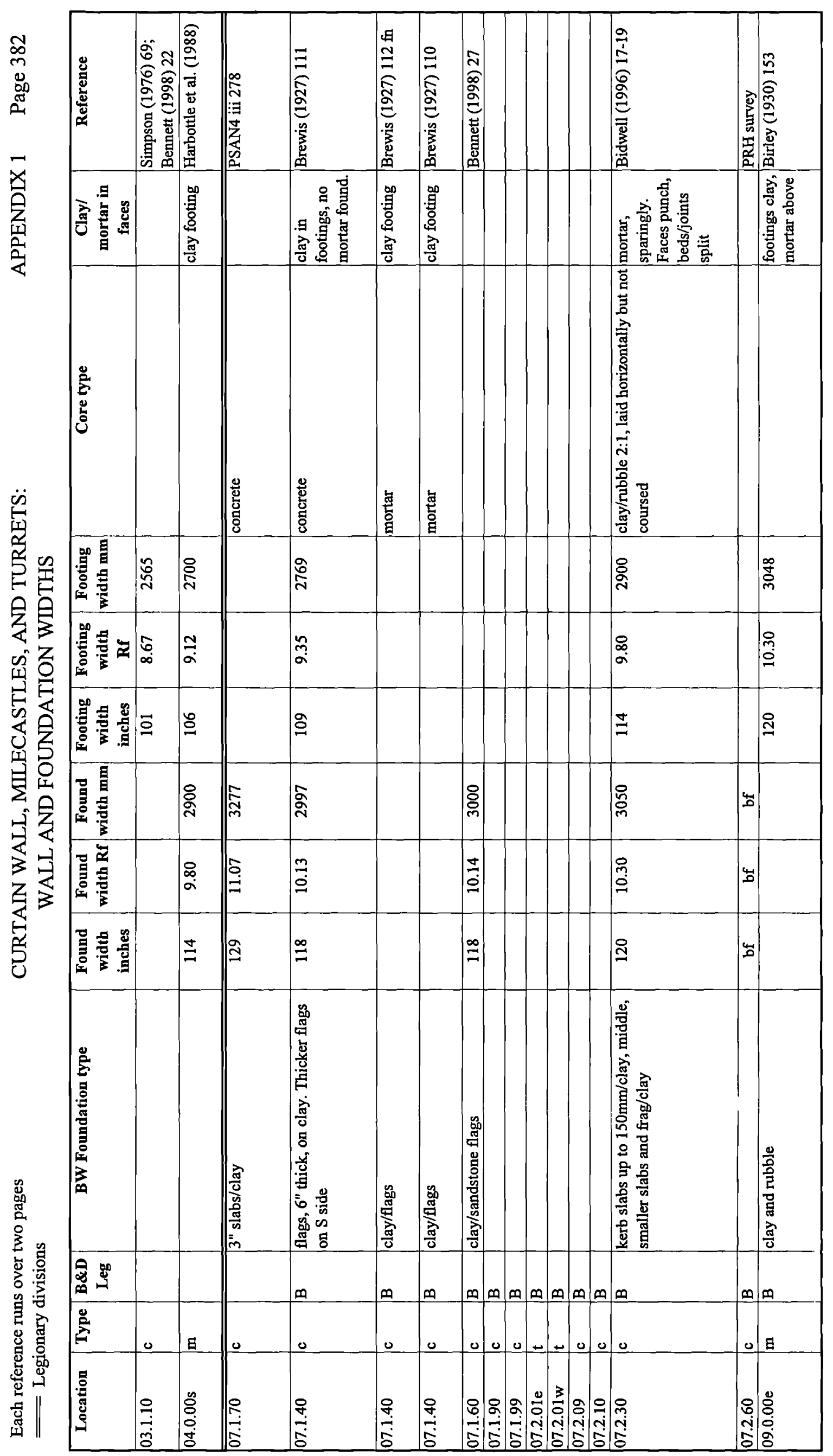




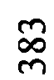

递

离

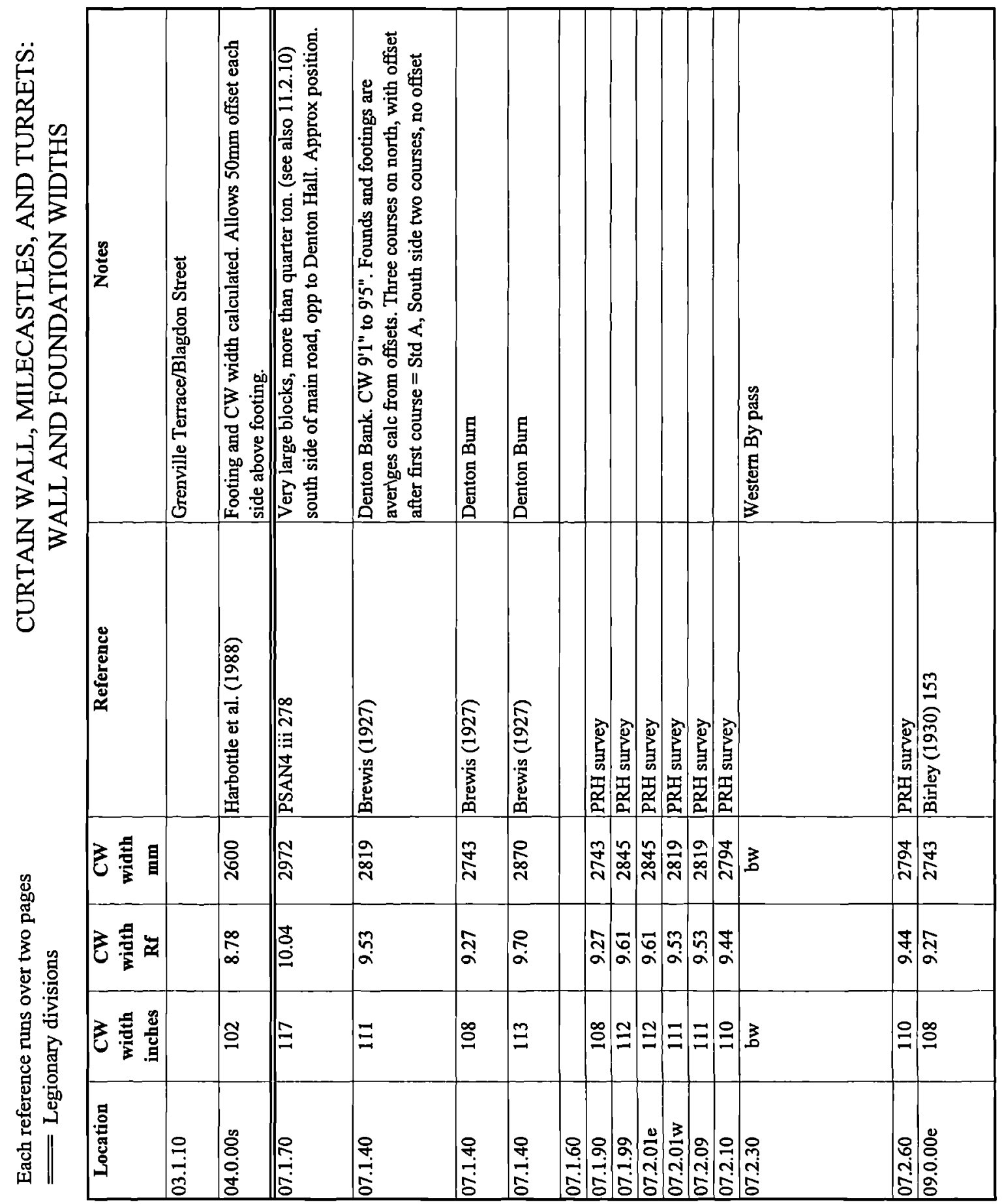




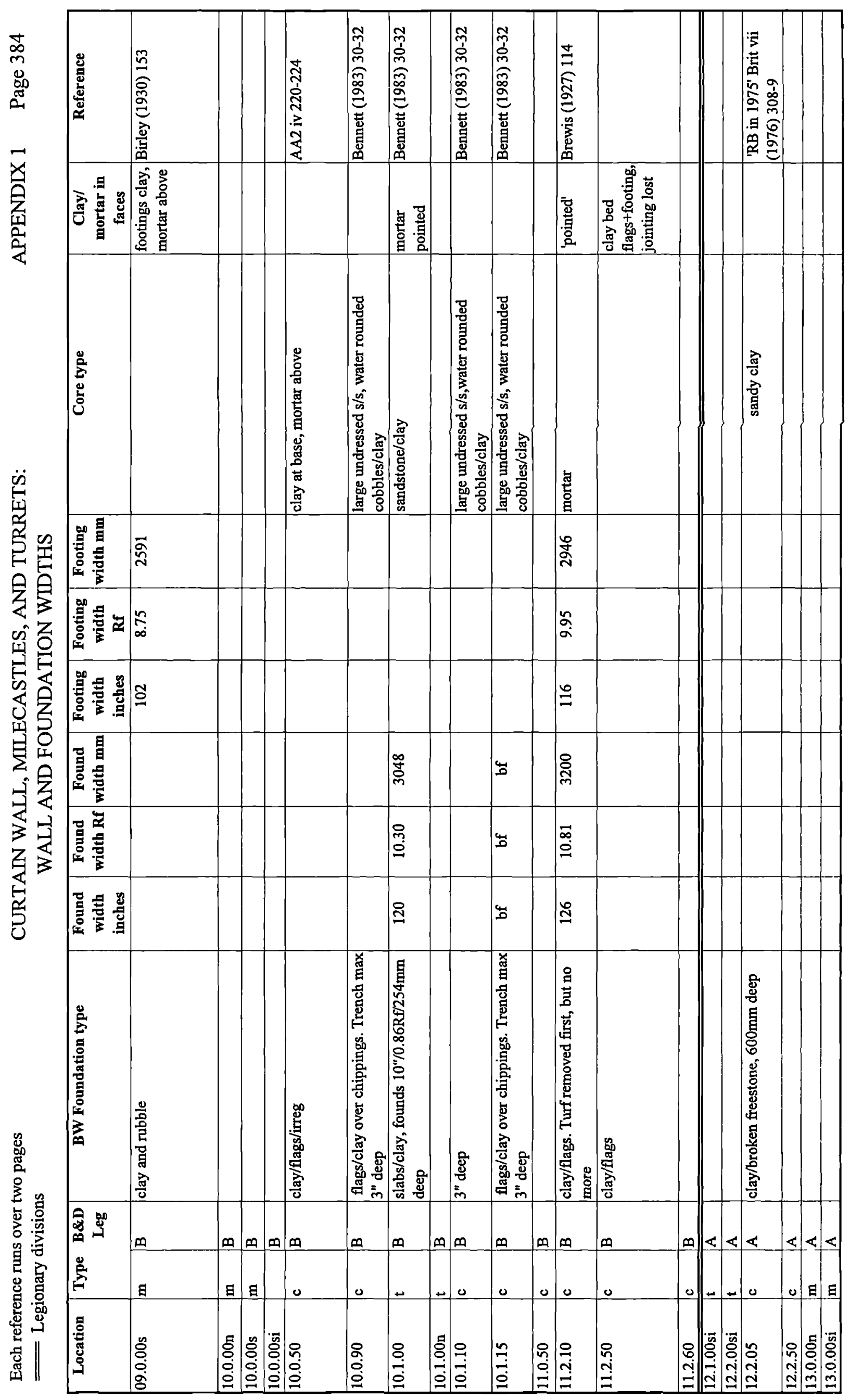




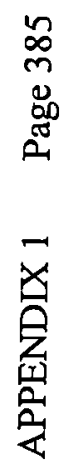

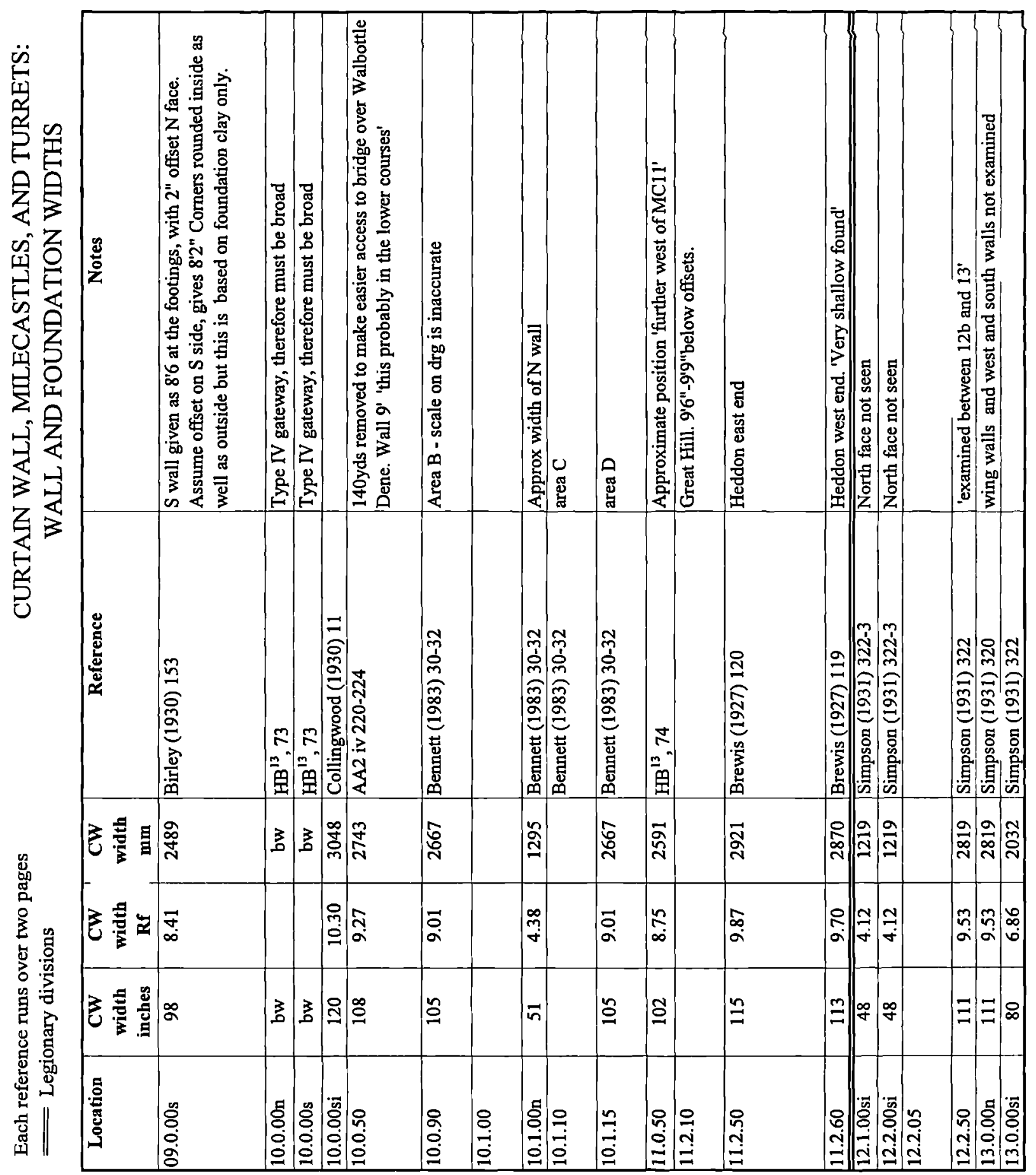




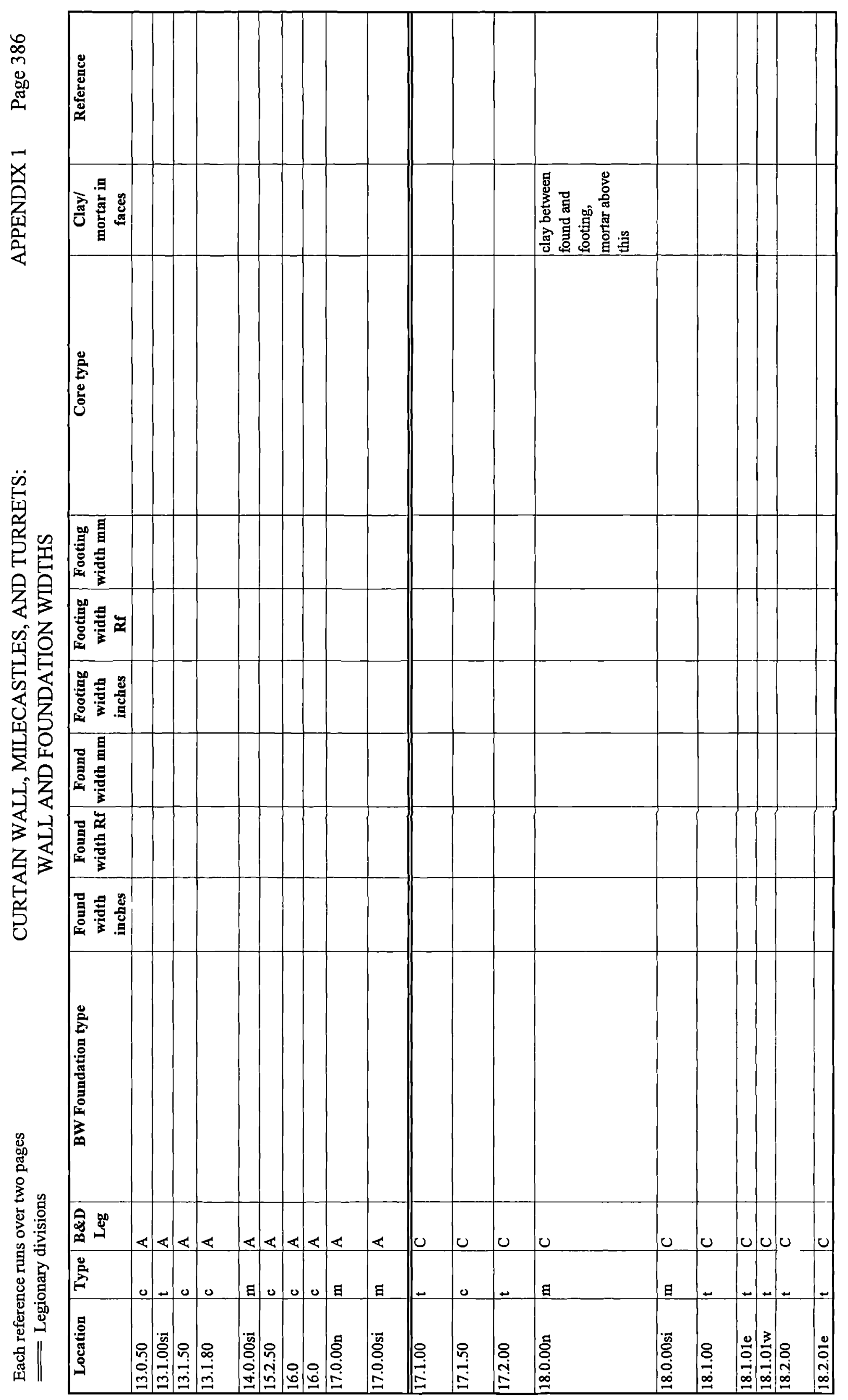




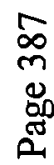

肴

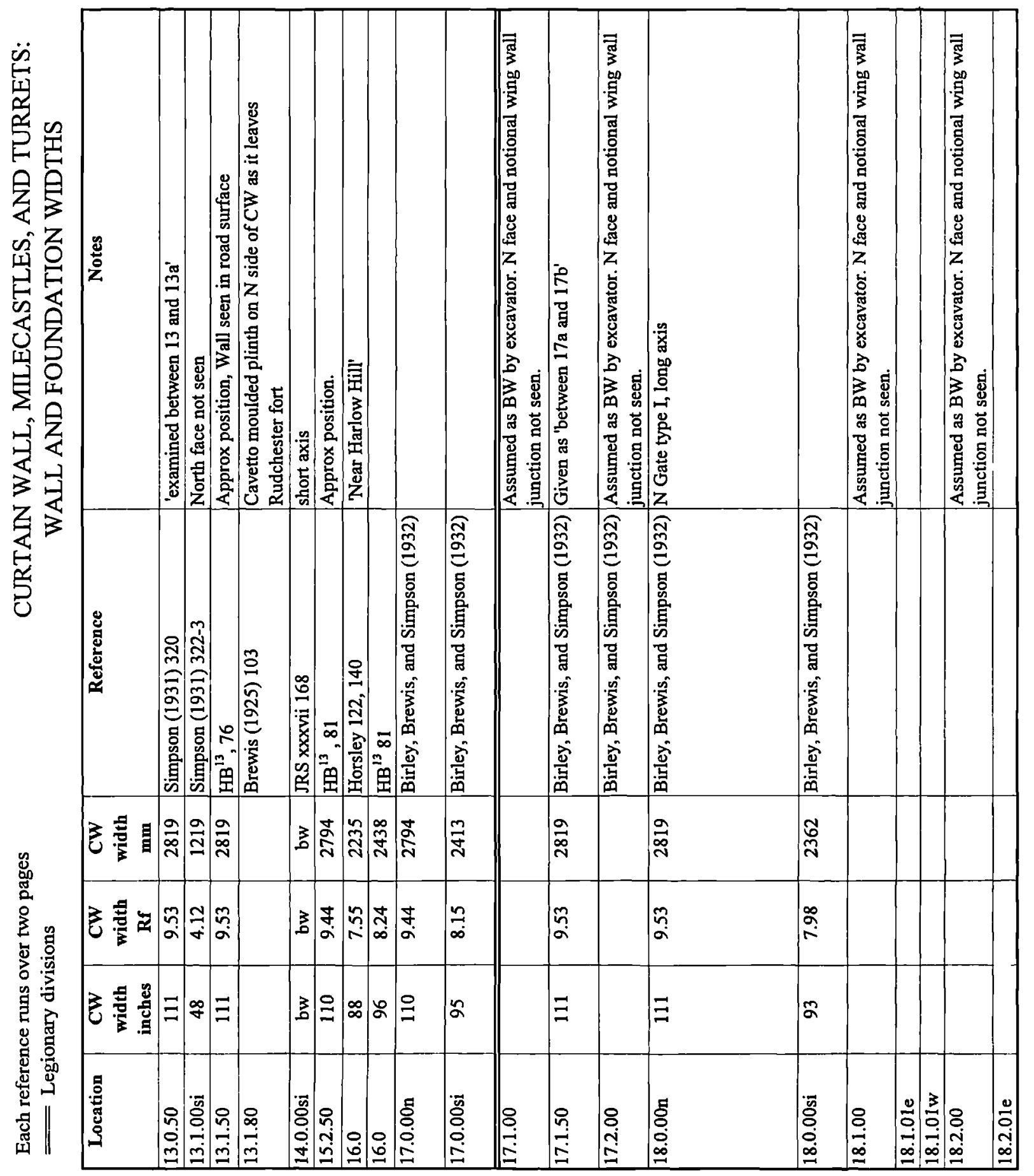




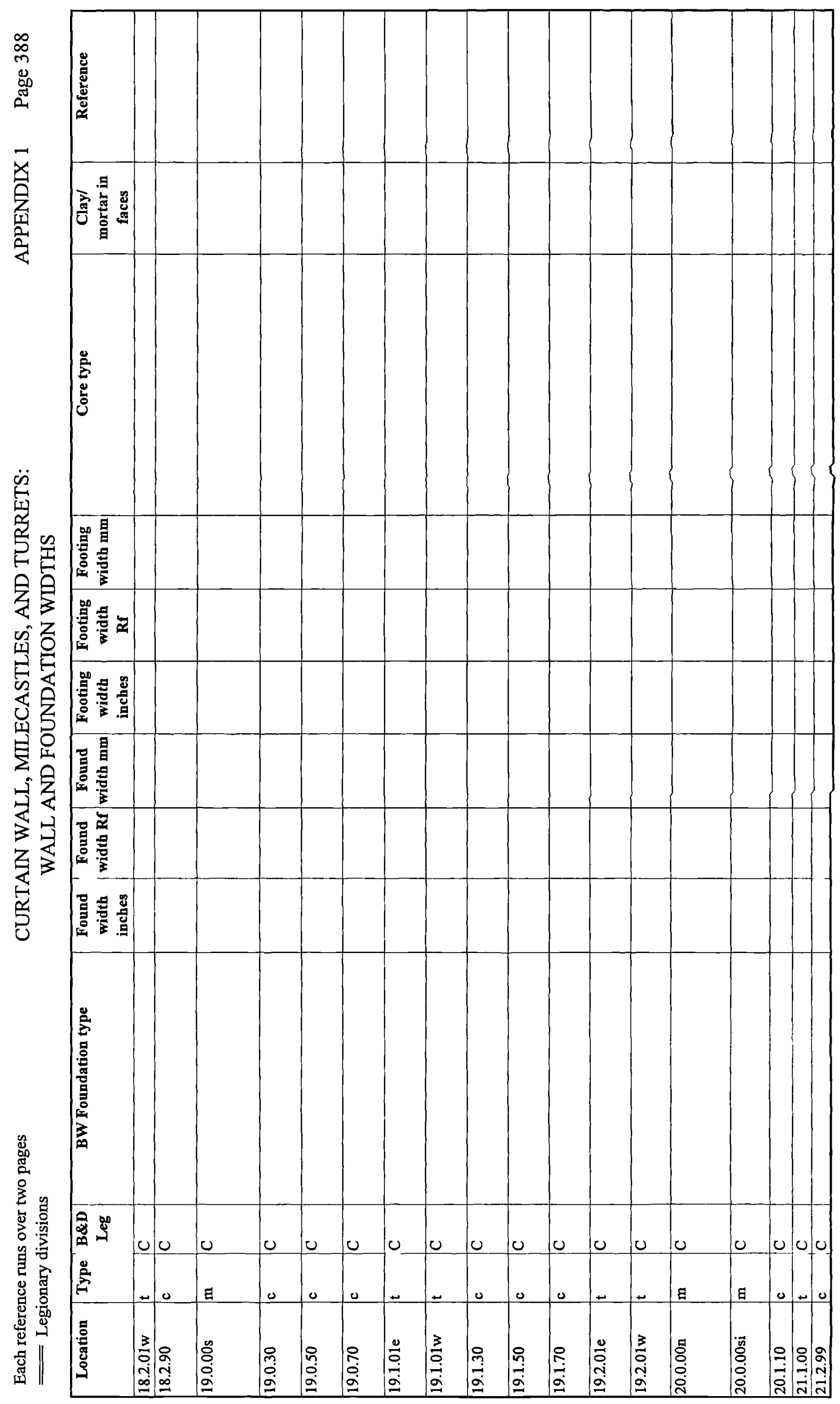


骨

遌

网

\begin{tabular}{|c|c|c|c|c|c|c|c|c|c|c|c|c|}
\hline & & 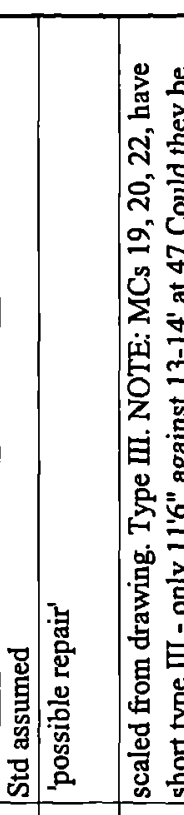 & 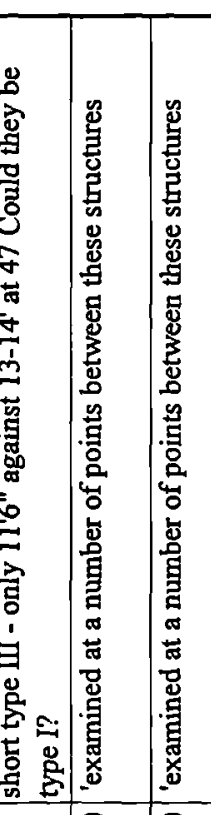 & 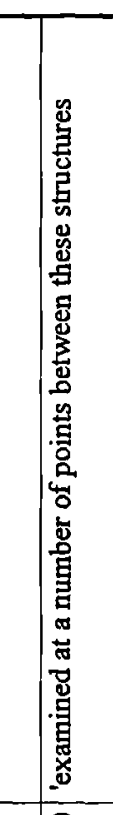 & & & & 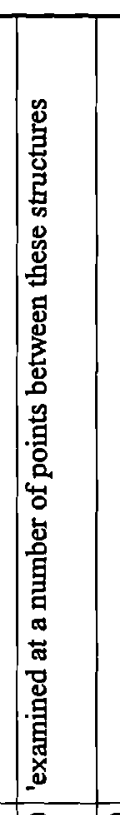 & & 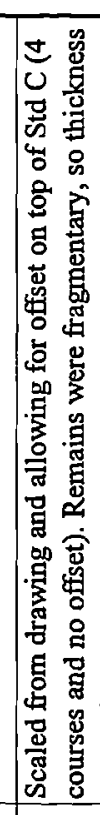 & & 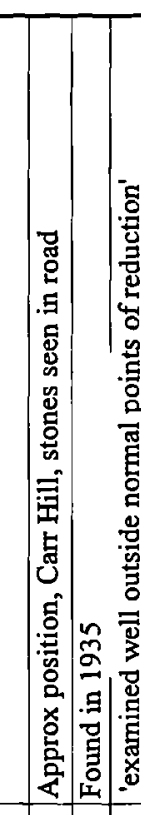 \\
\hline & & 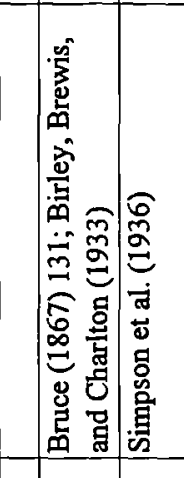 & 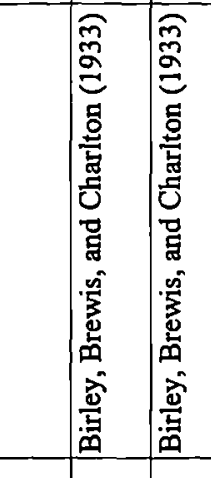 & 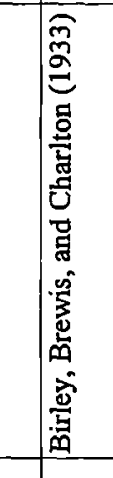 & & 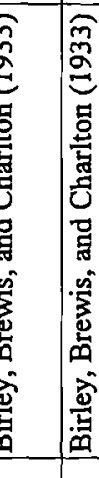 & & 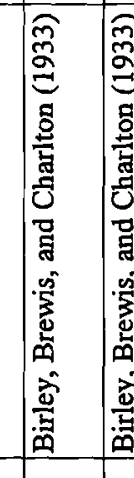 & 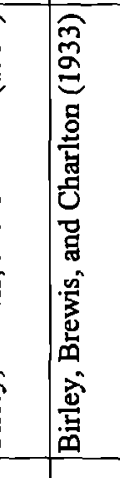 & & 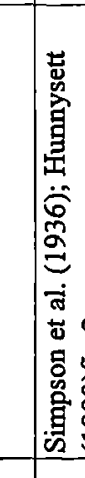 & 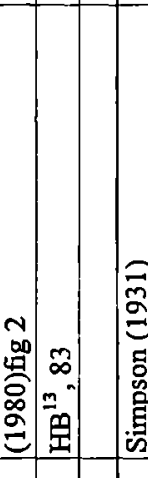 \\
\hline & 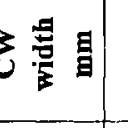 & 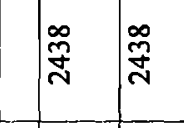 & 产 & $\stackrel{\circ}{\bar{\partial}}$ & & \% & & 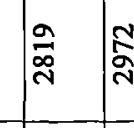 & 站 & 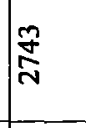 & & 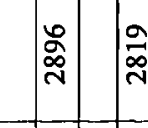 \\
\hline & 量 $z$ & 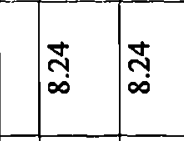 & $\begin{array}{lll}12 & 3 \\
2 & 2\end{array}$ & $\frac{1}{2}$ & 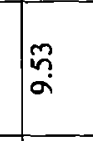 & 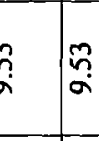 & & 2 & 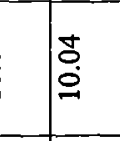 & $\approx$ & $\bar{\pi}$ & $:$ \\
\hline & 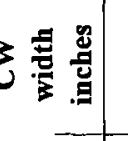 & $\therefore:$ & $\equiv \equiv$ & $\equiv$ & & & & & $\equiv$ & $\cong$ & 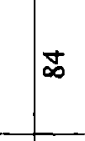 & \\
\hline & $\underline{\underline{d}}$ & 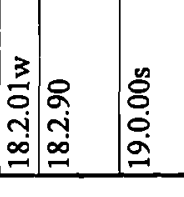 & 娄 & 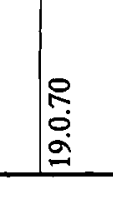 & & & & & & & & \\
\hline
\end{tabular}




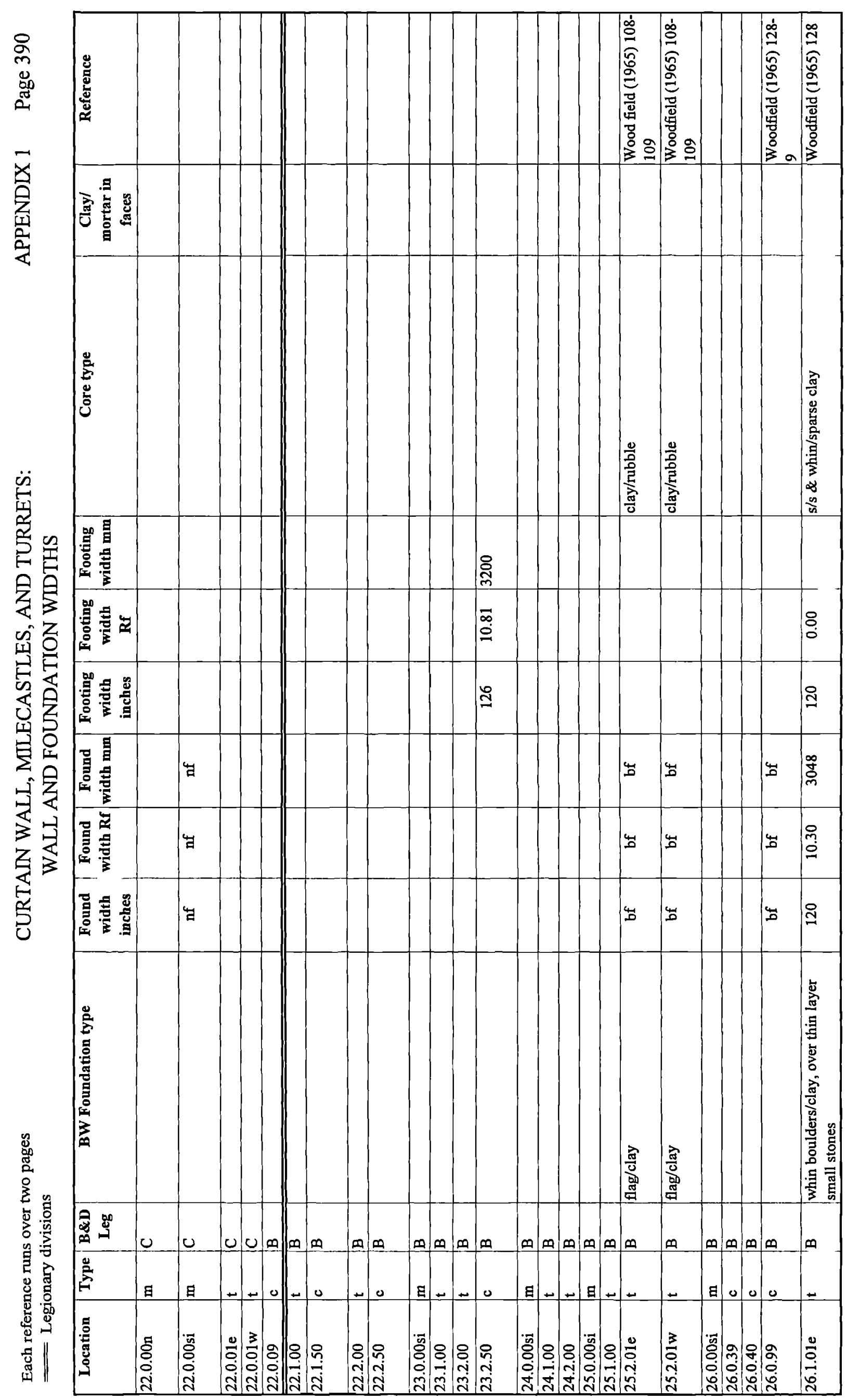




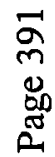

肴

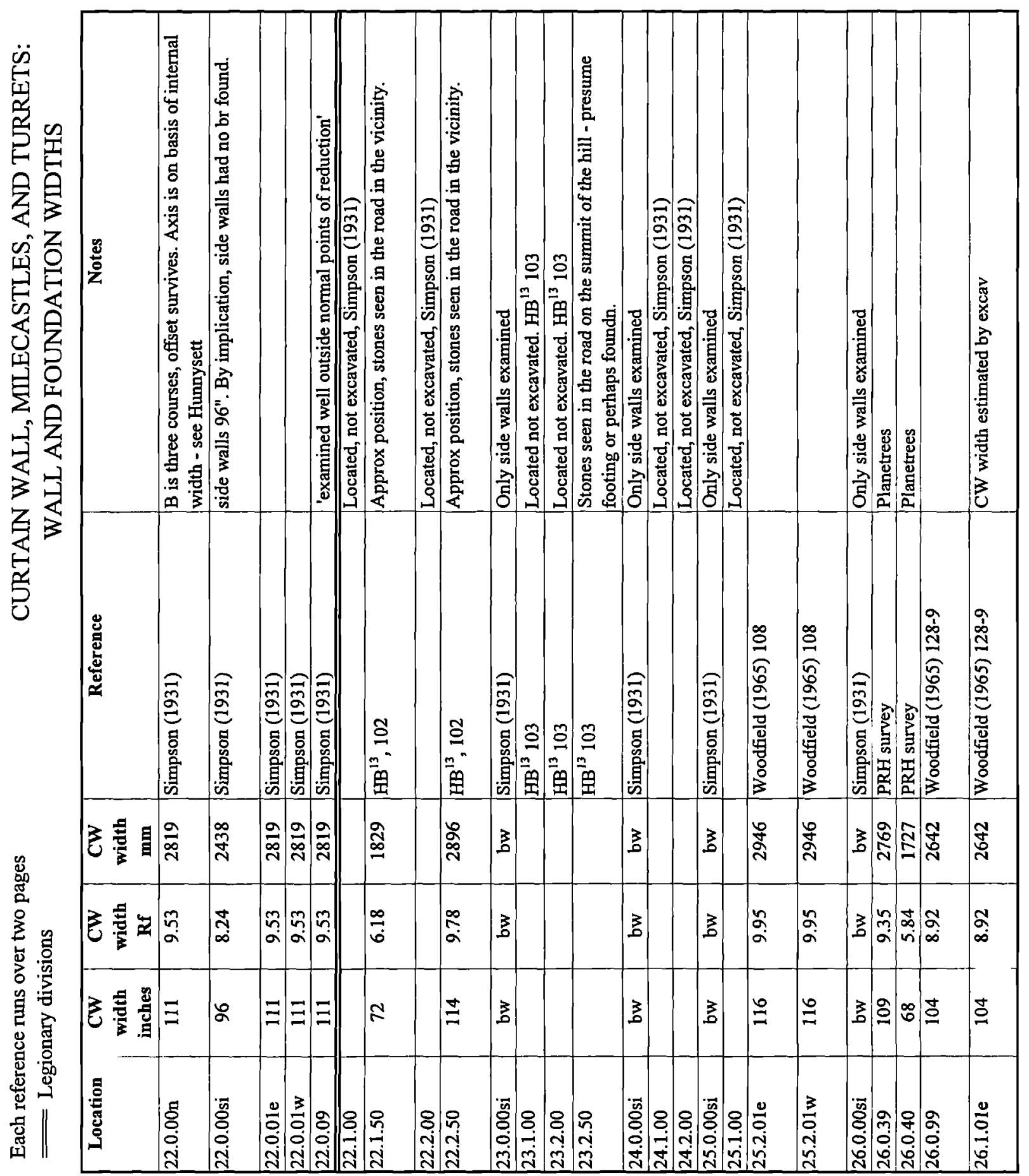




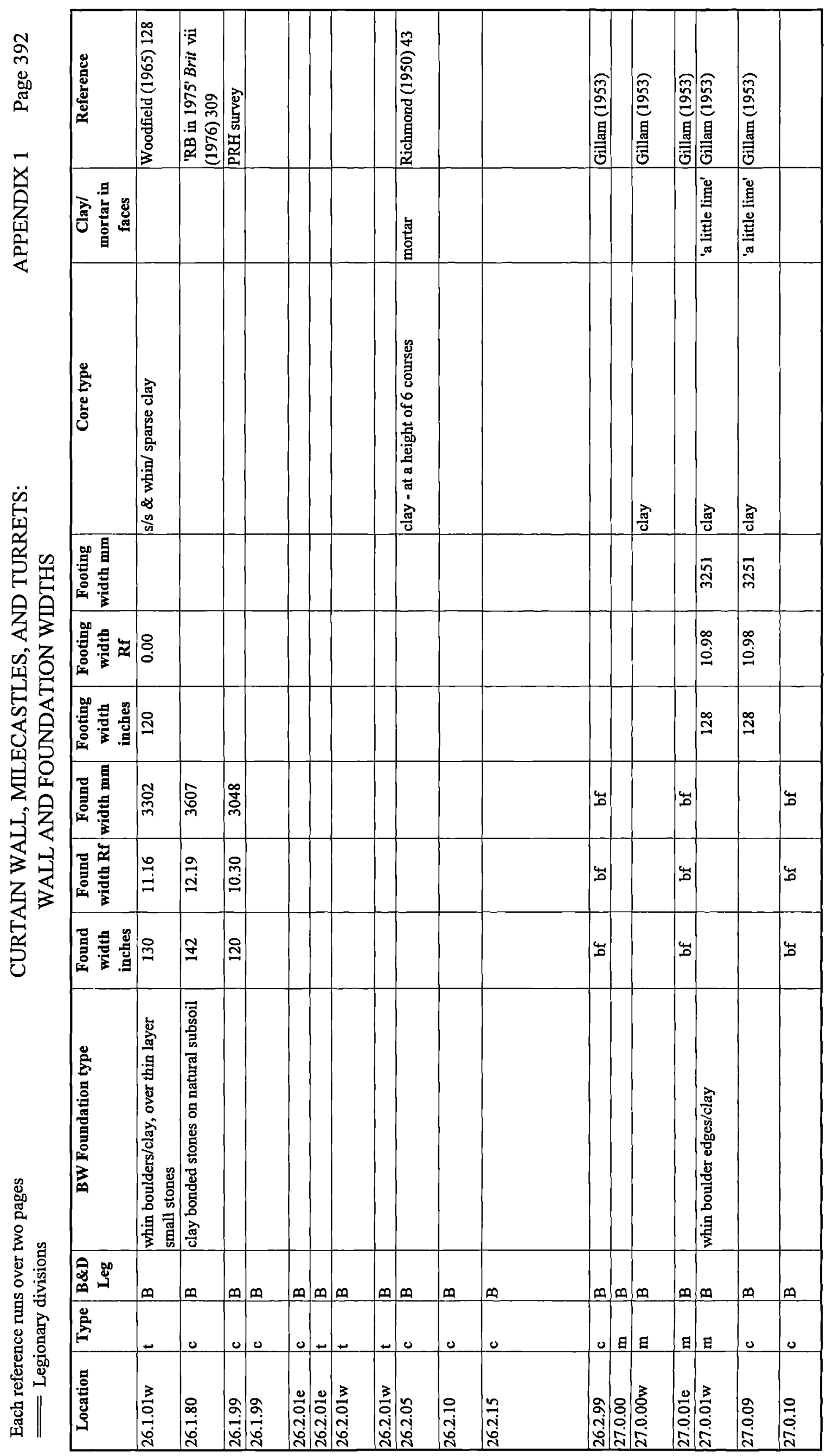




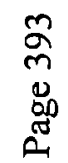

䒽

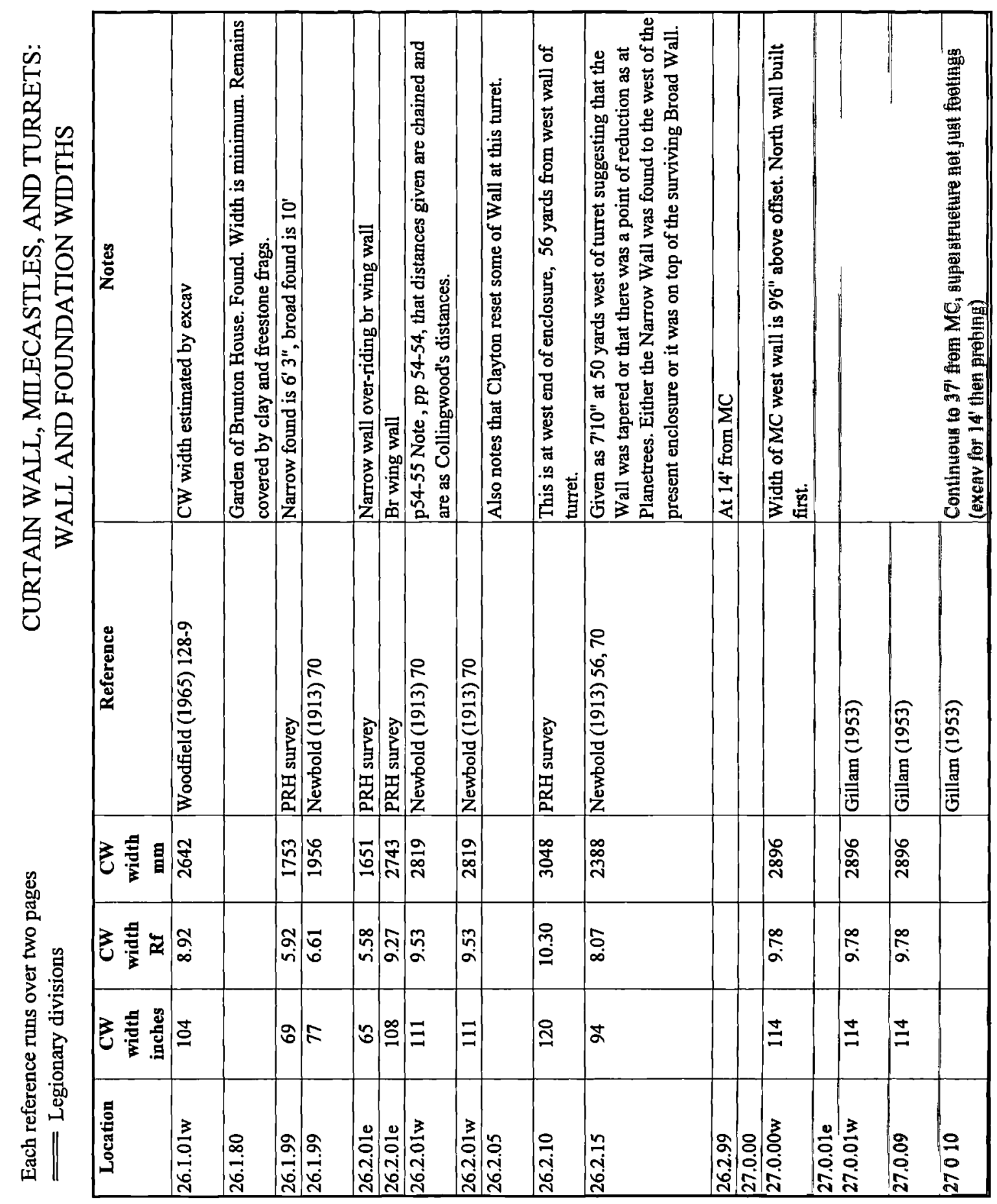




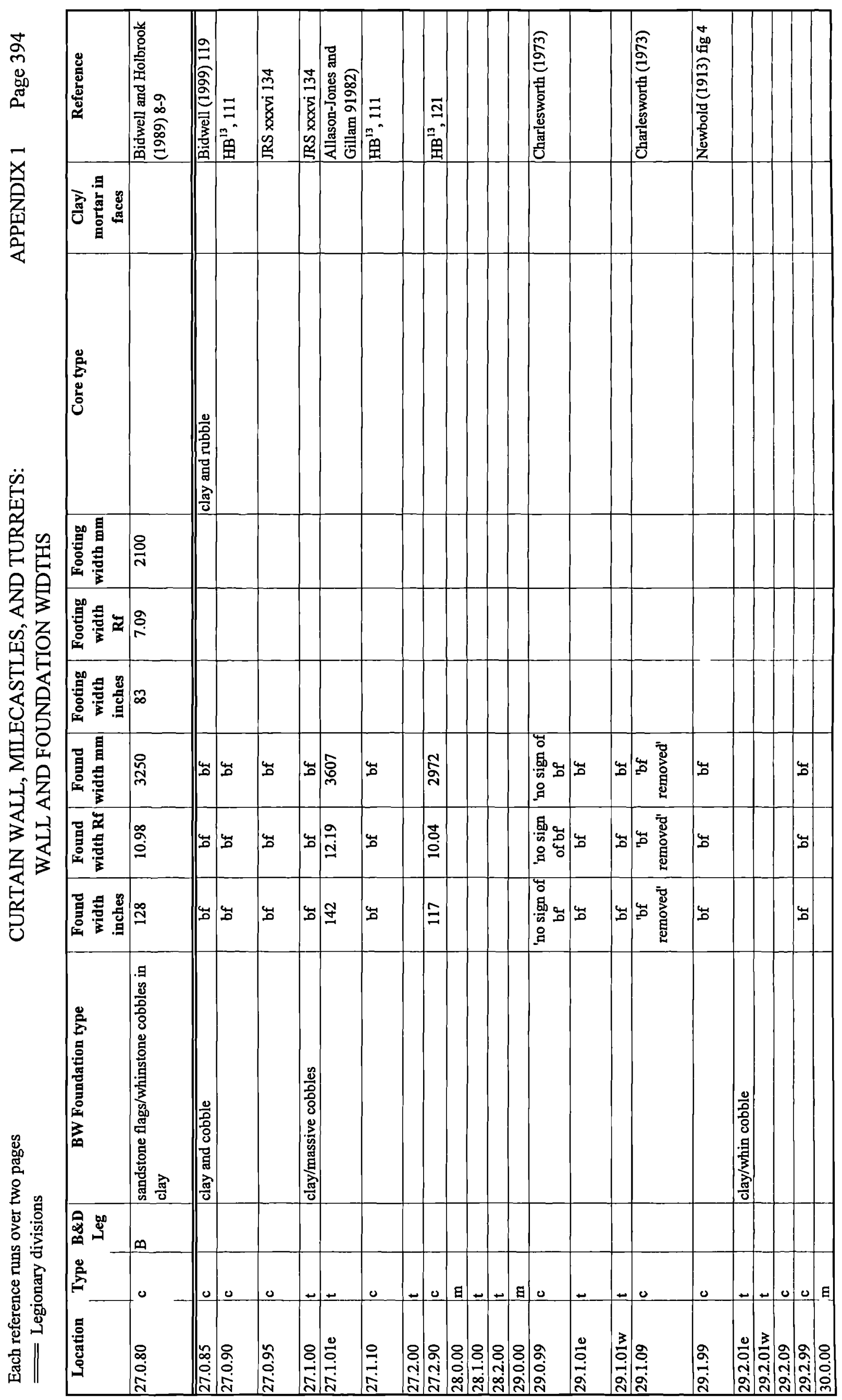




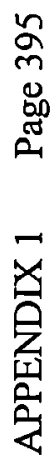

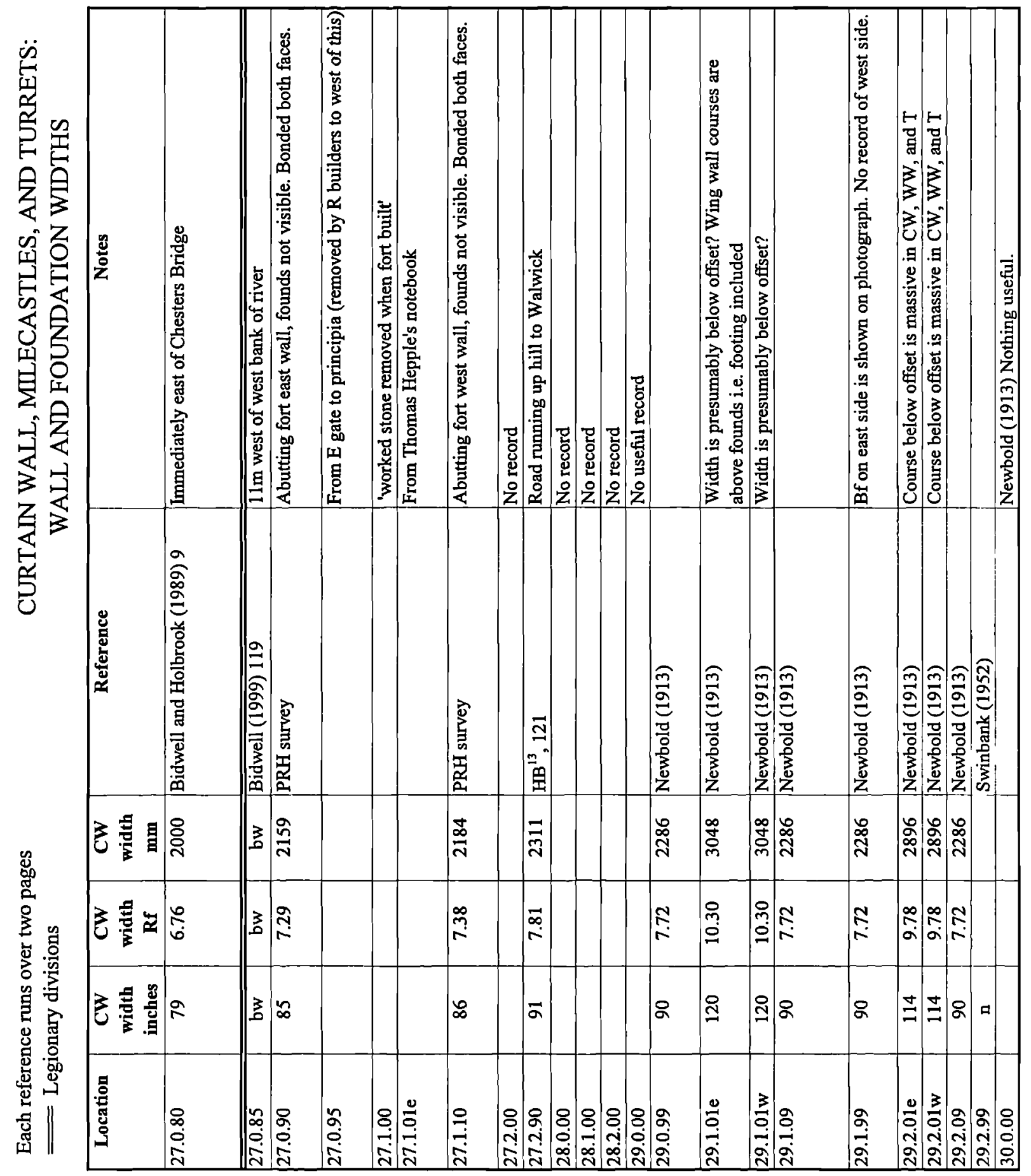



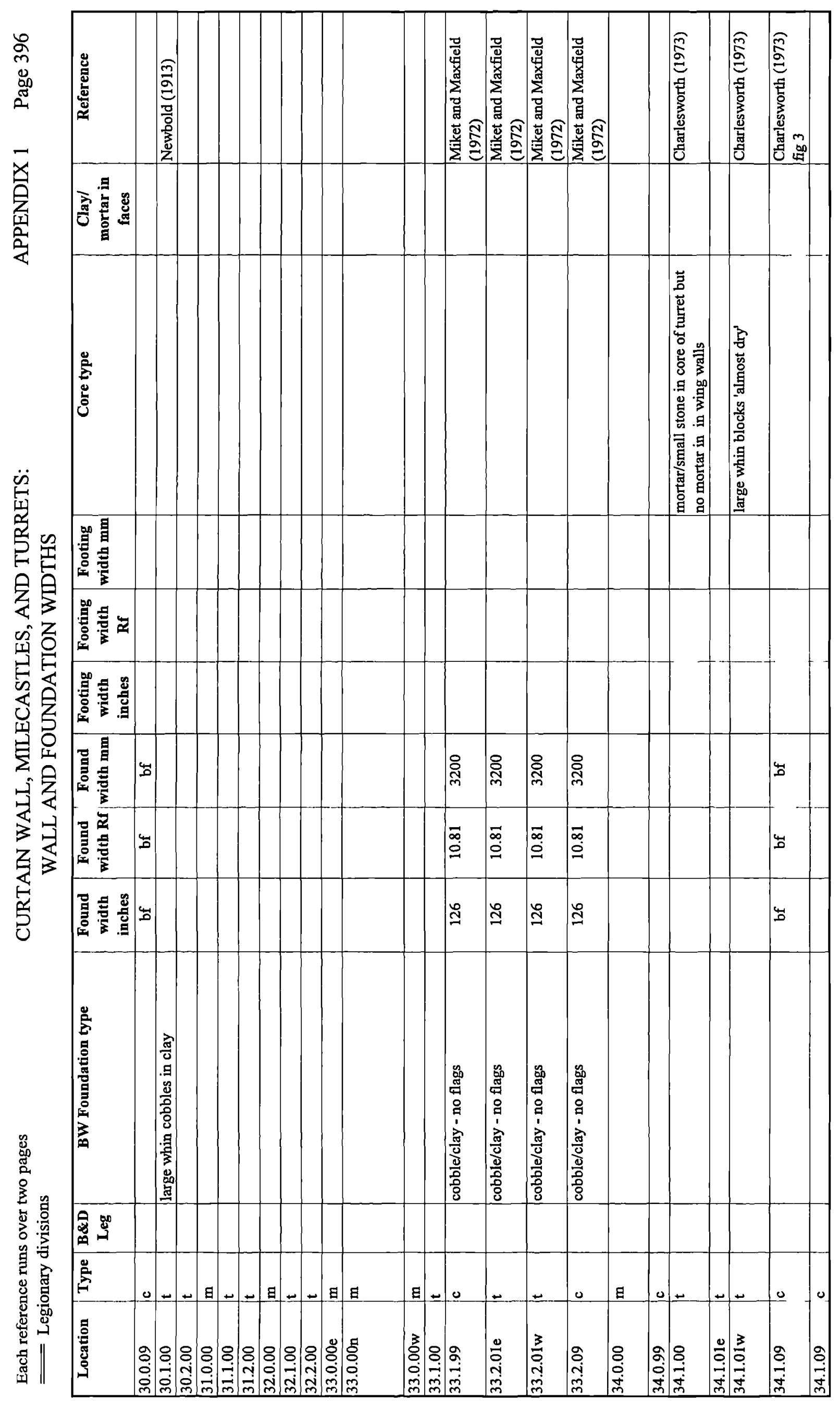
5
m
0
0
0
0
0

章

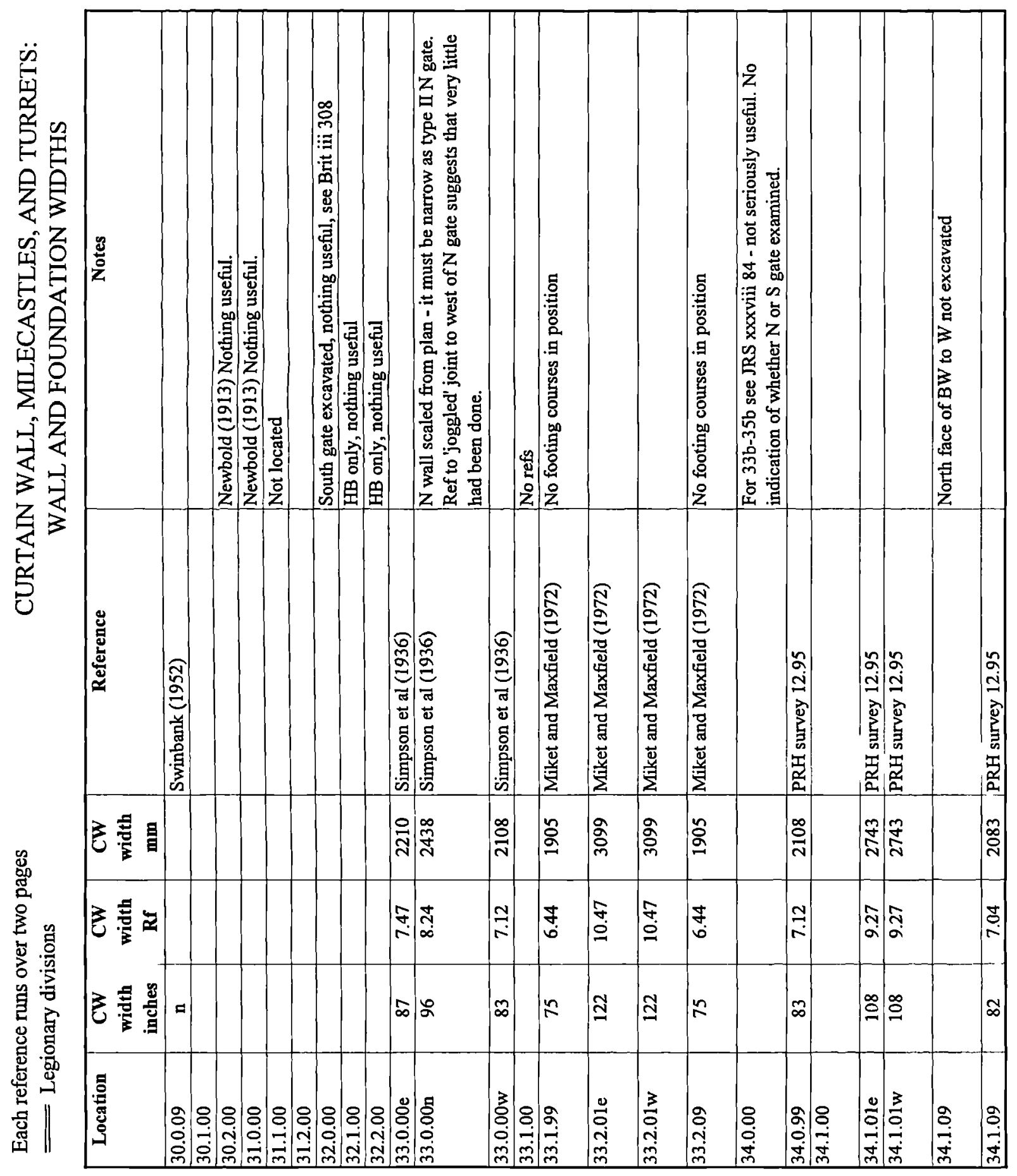




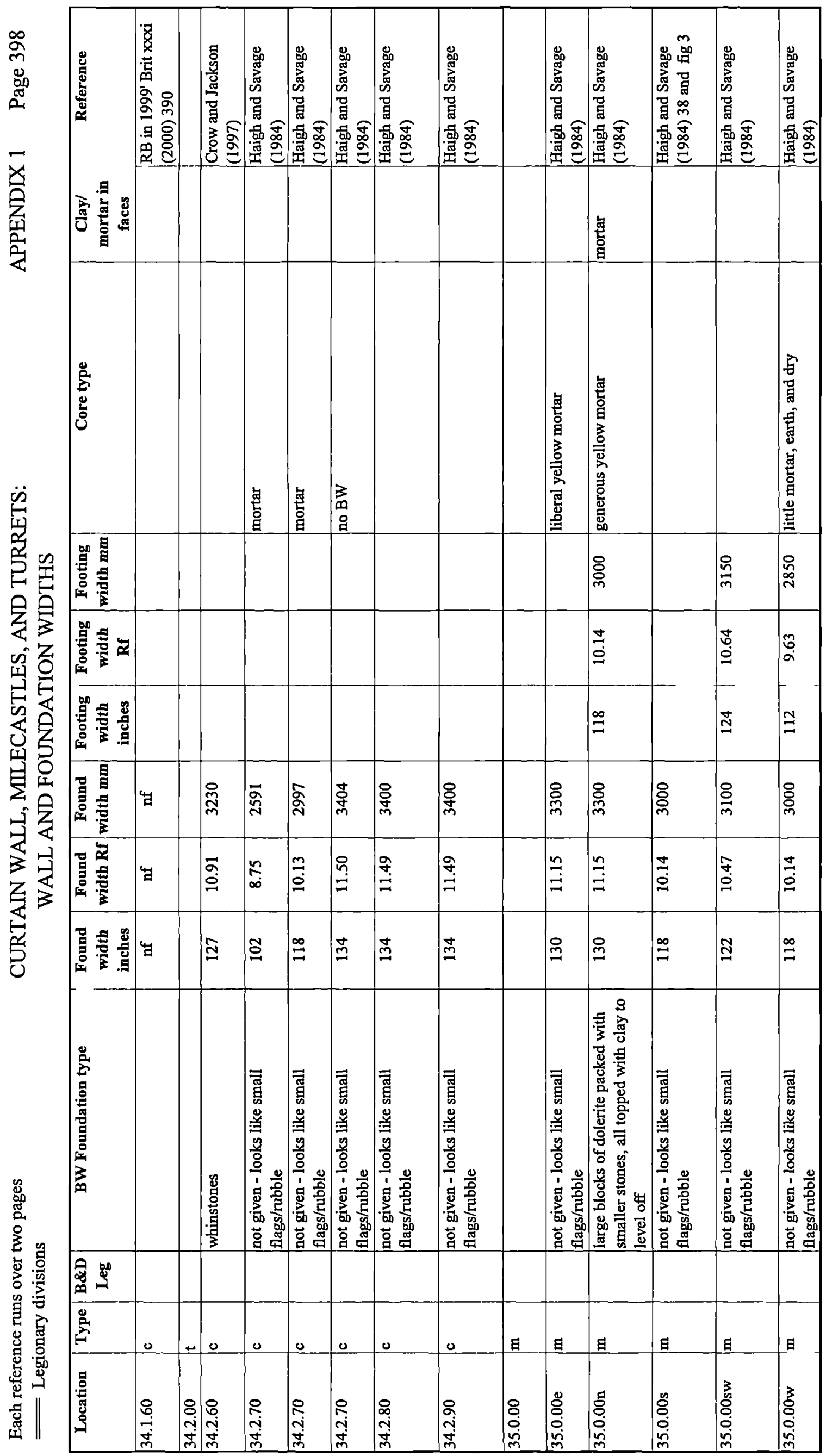




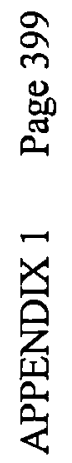

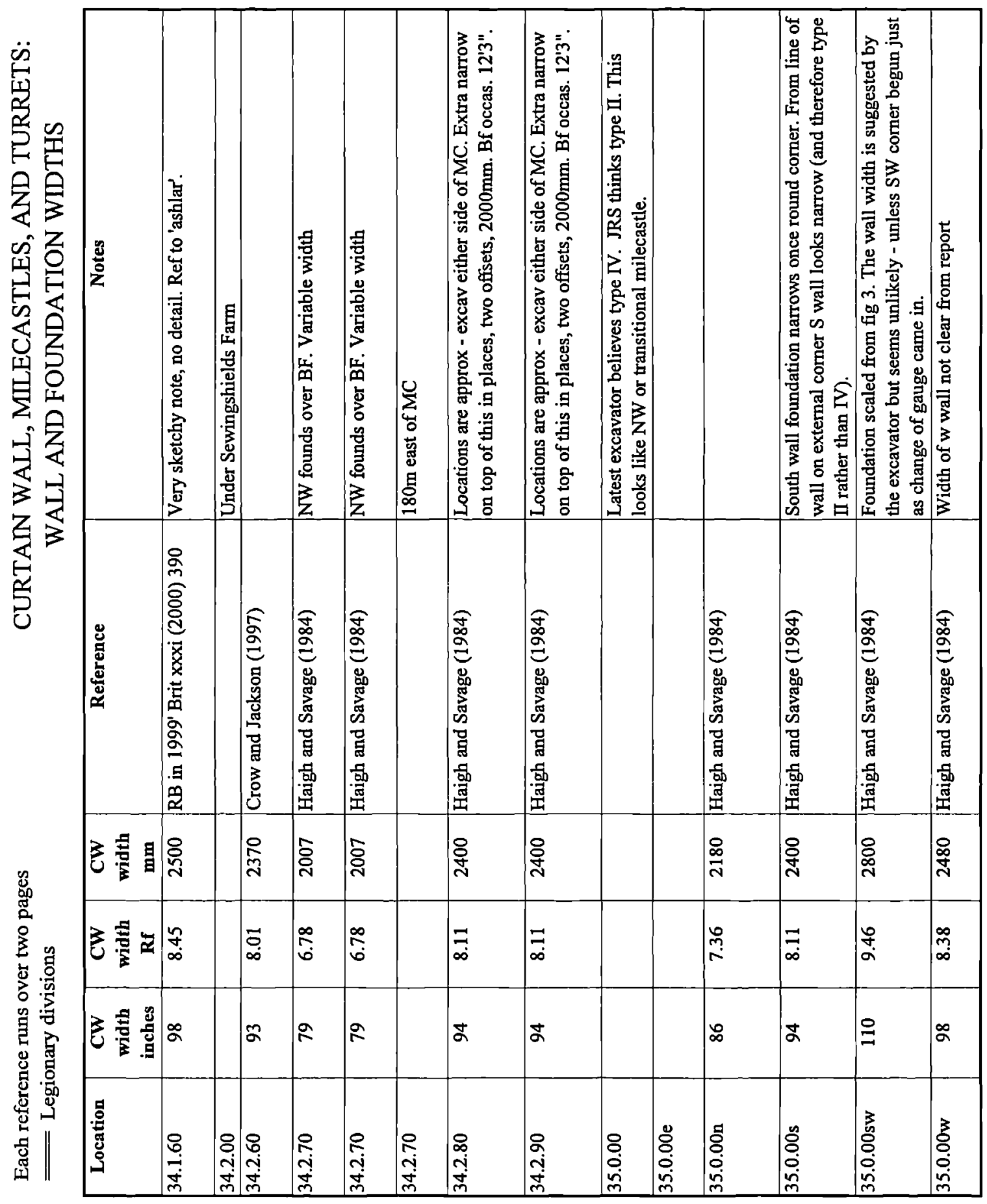




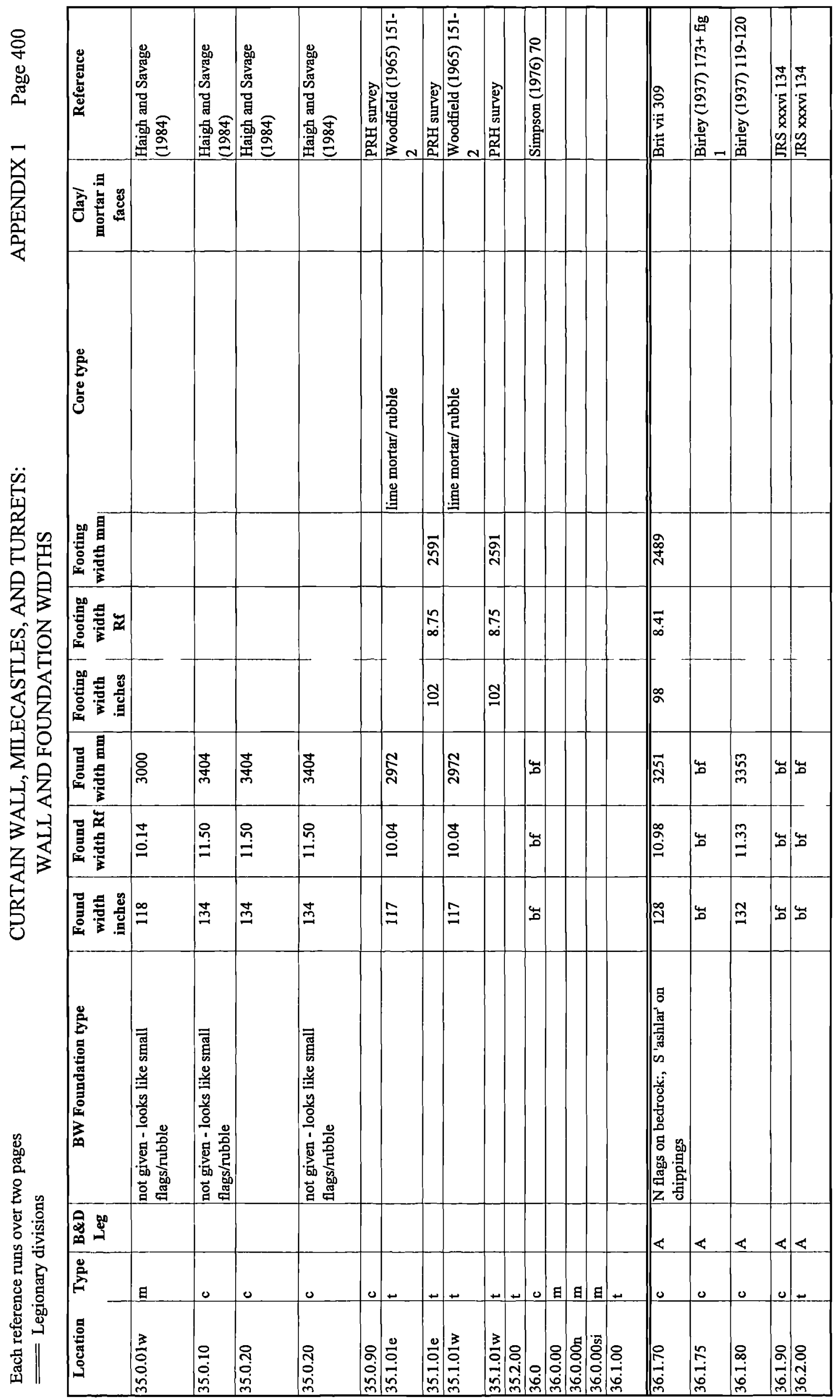




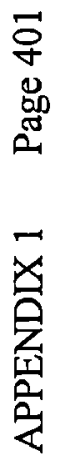

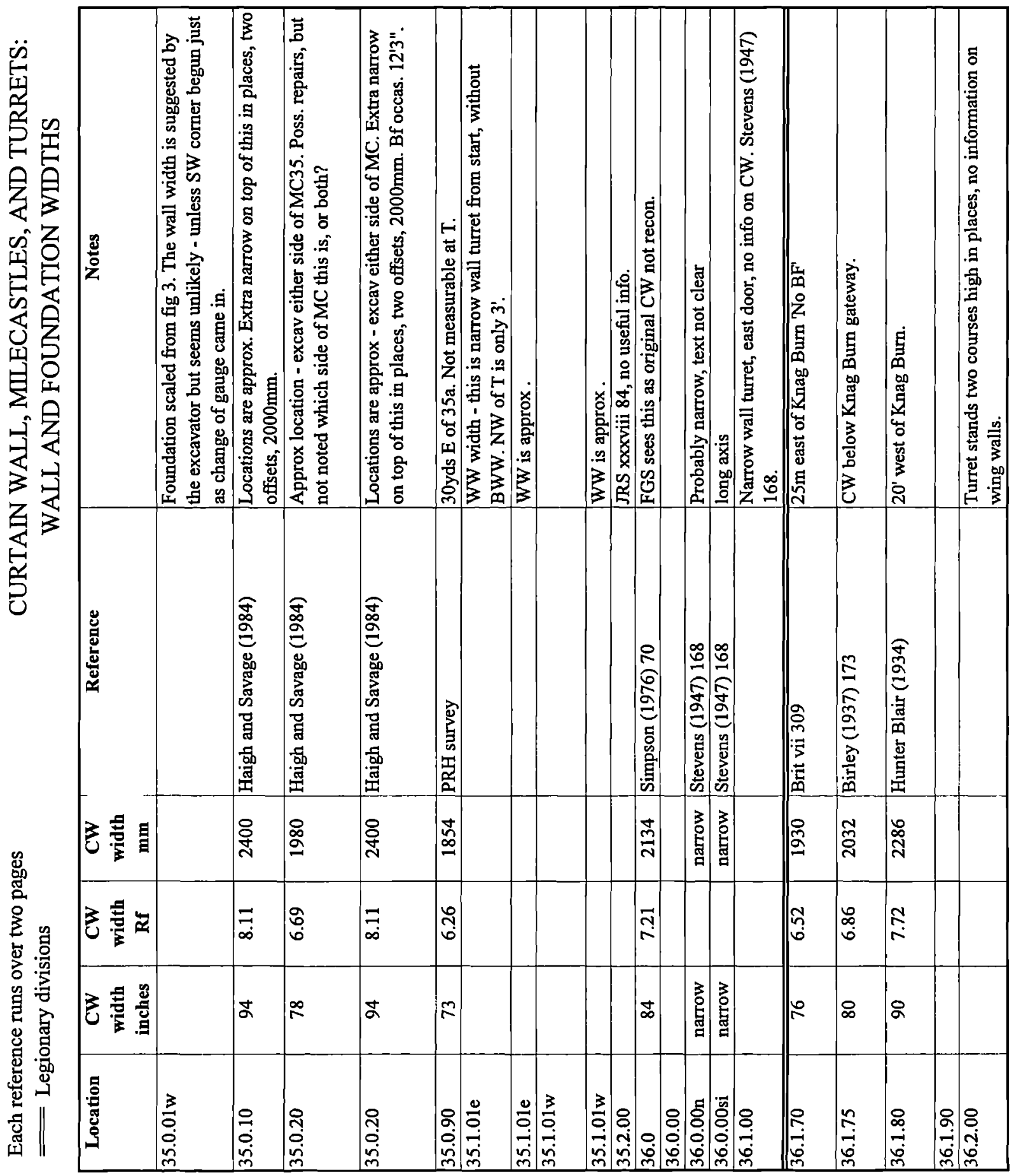




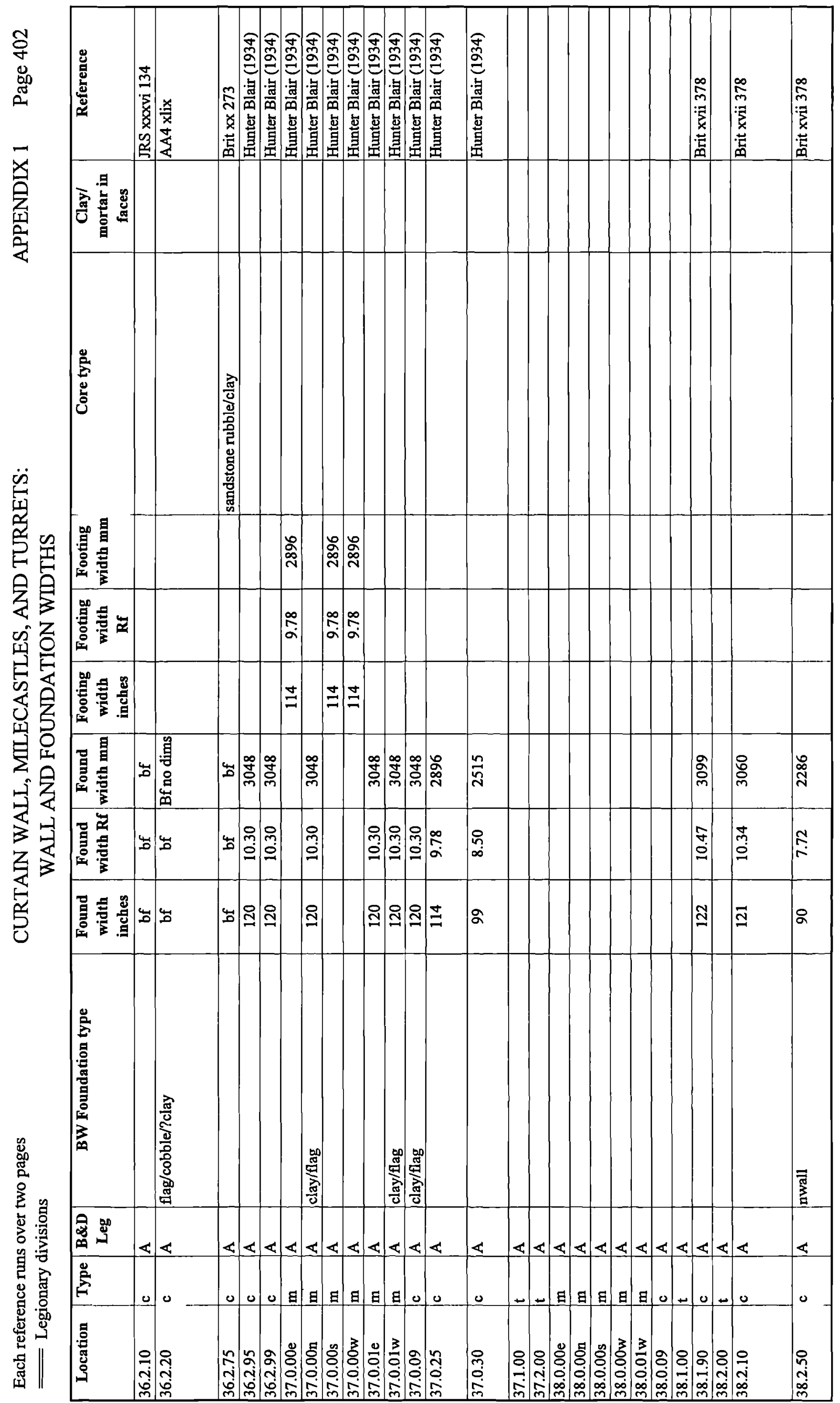




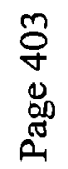

离

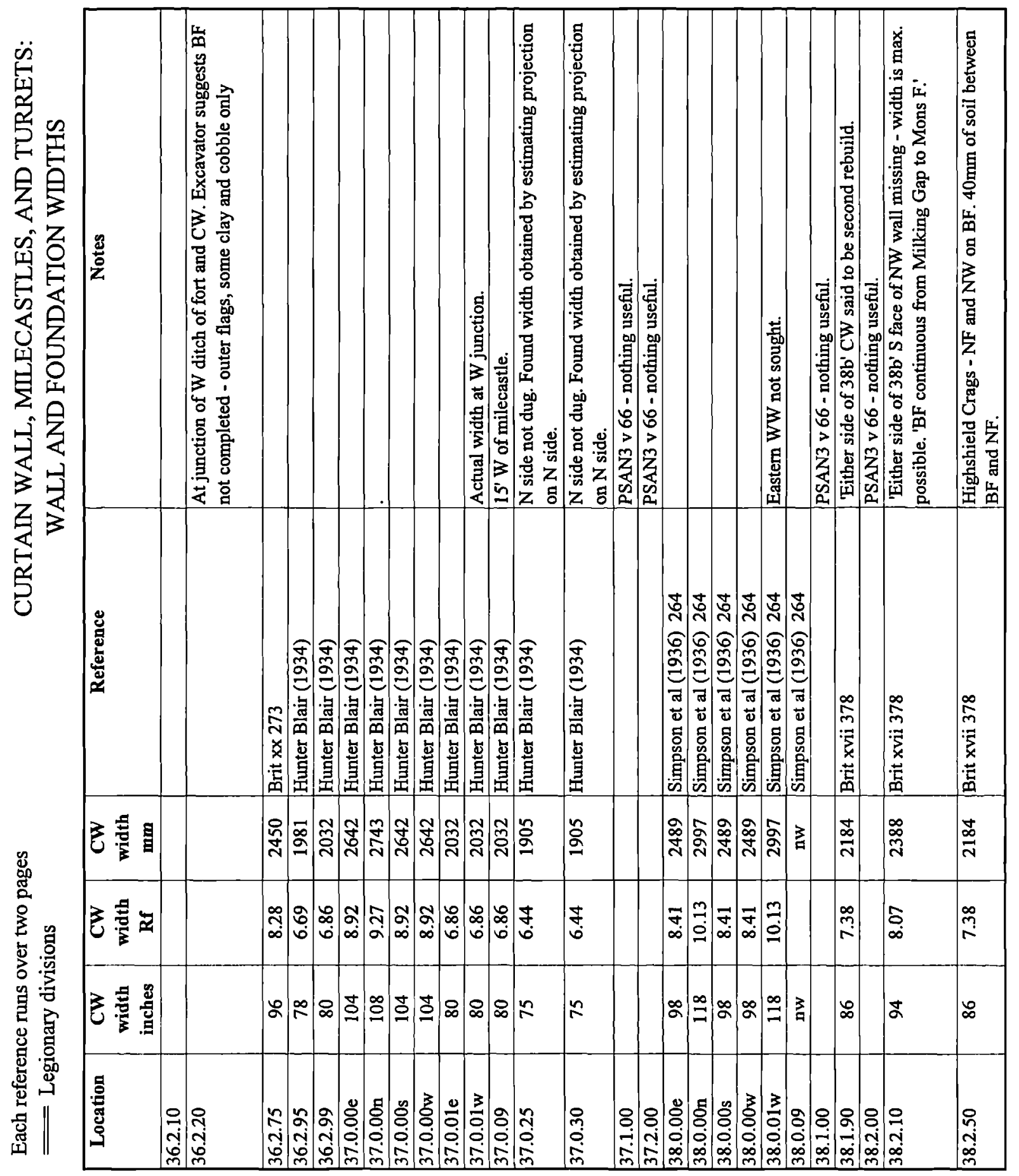




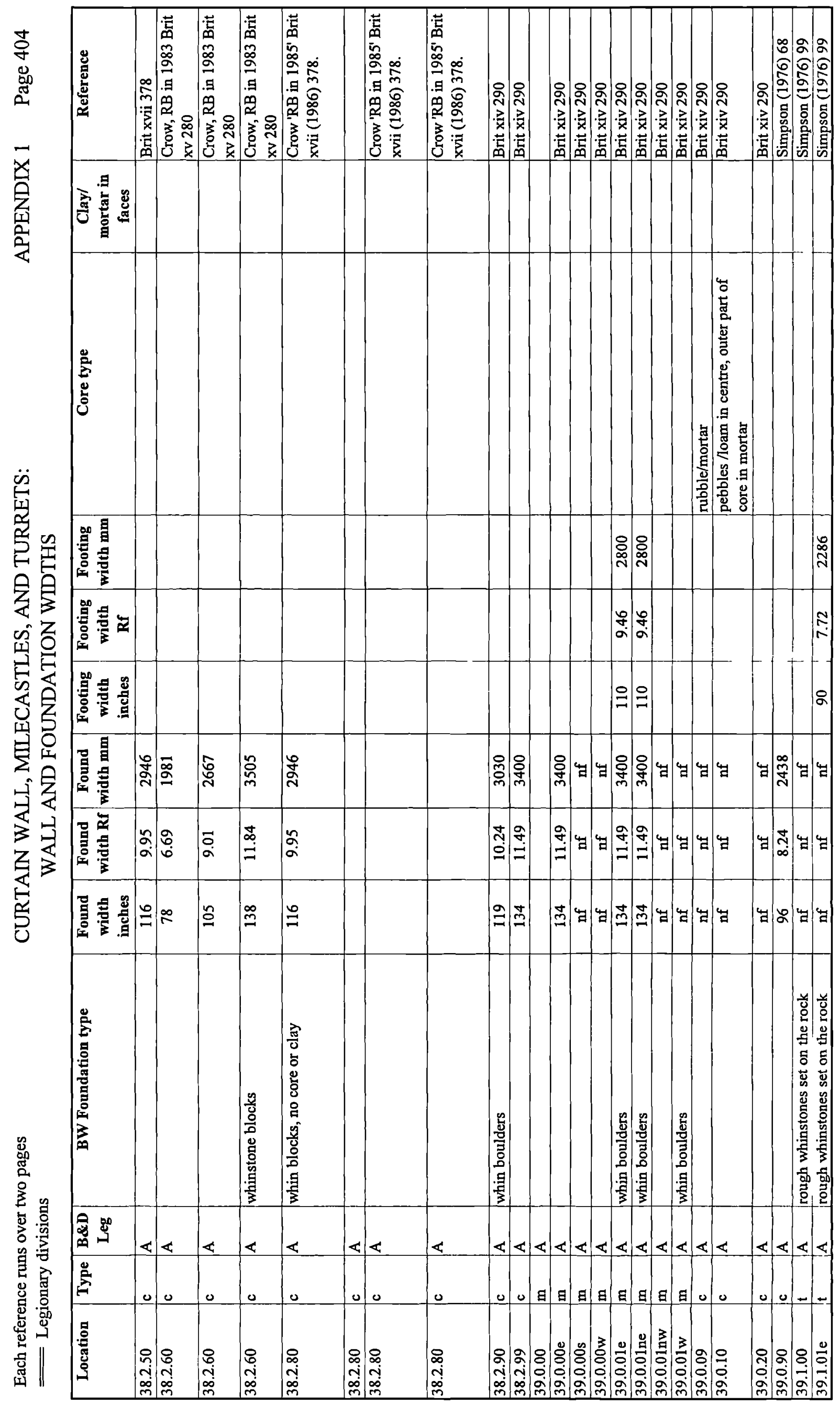




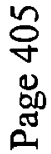

亘

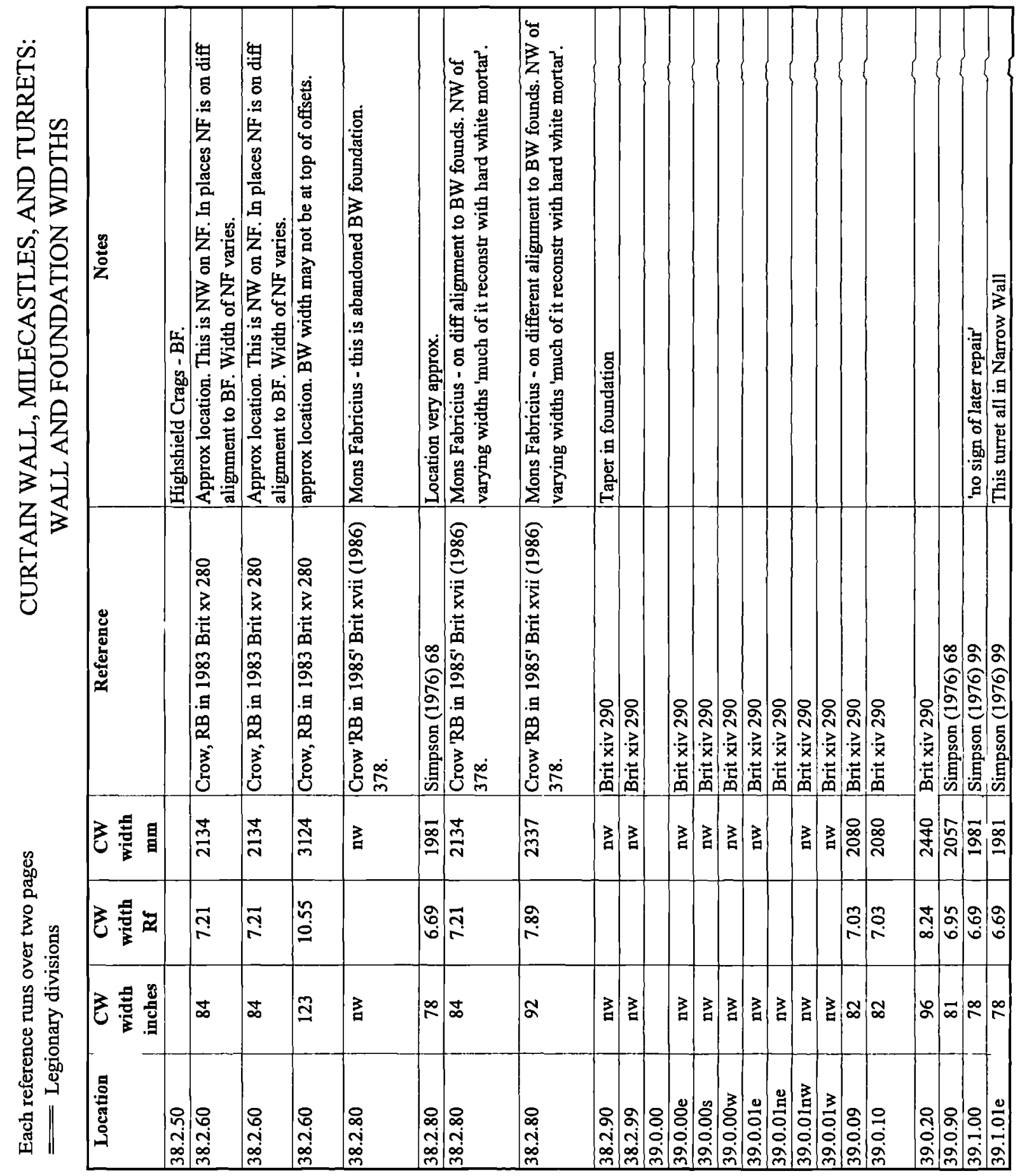




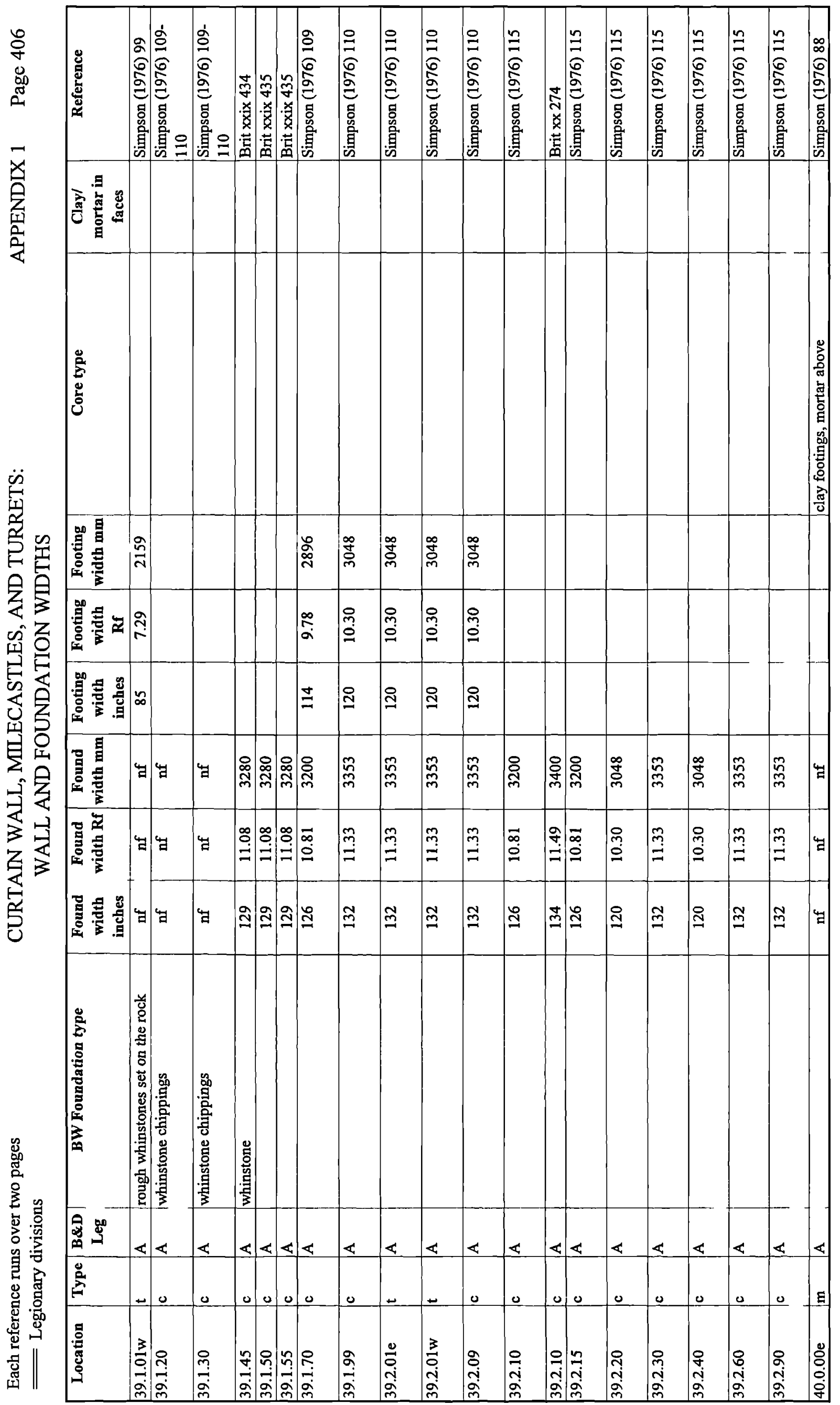




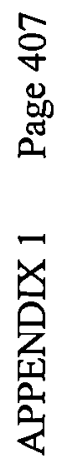

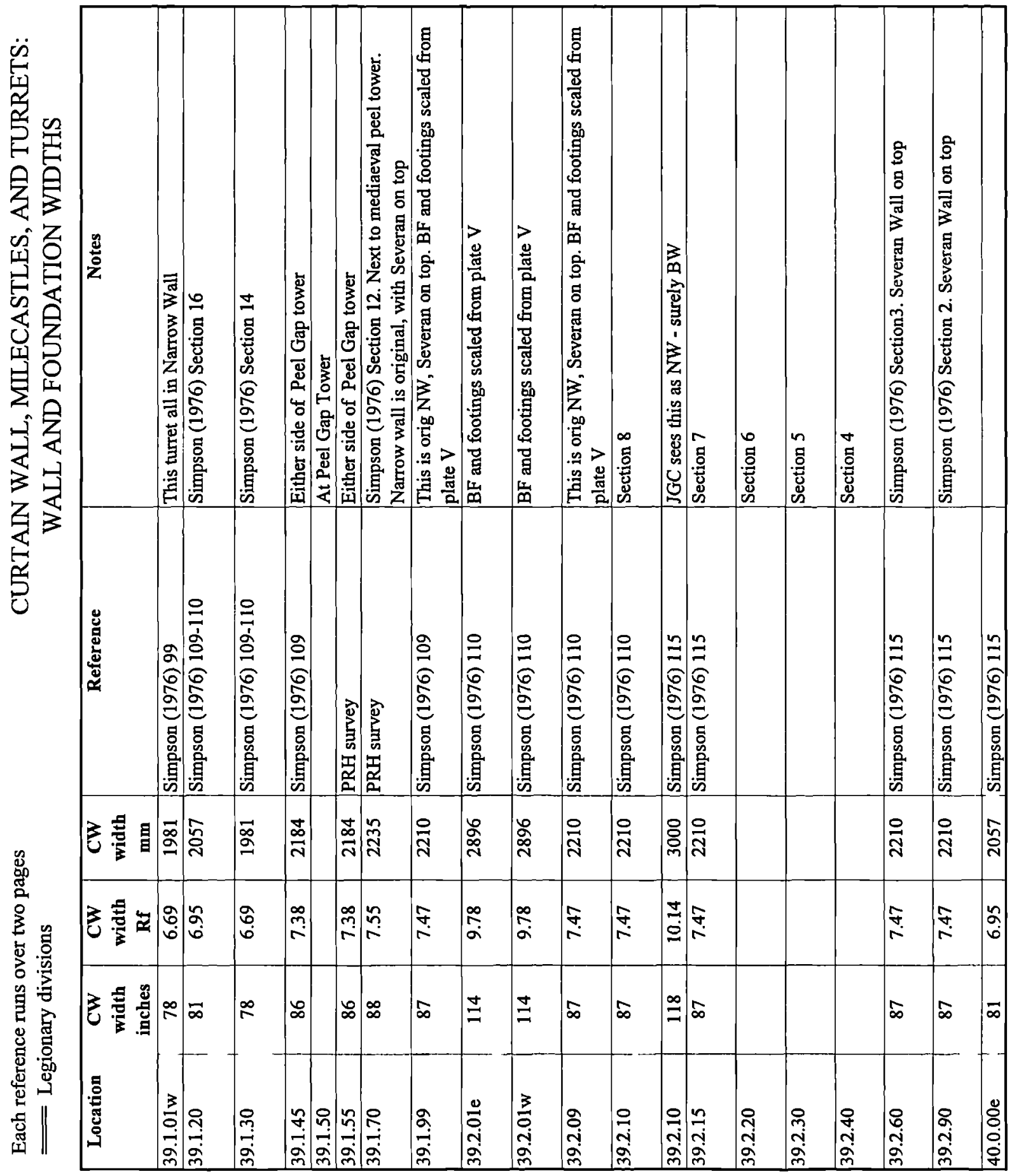




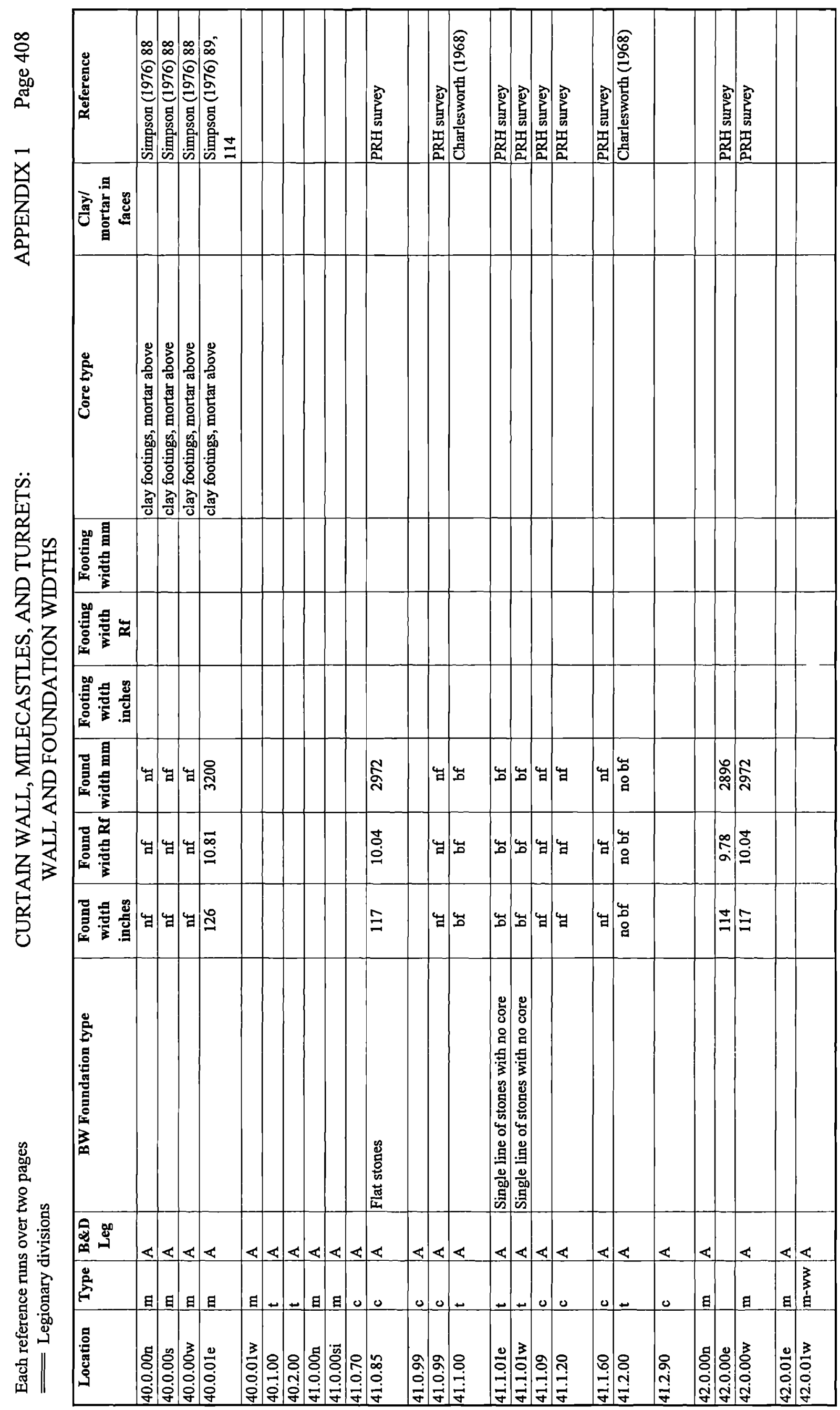




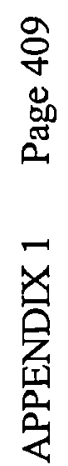

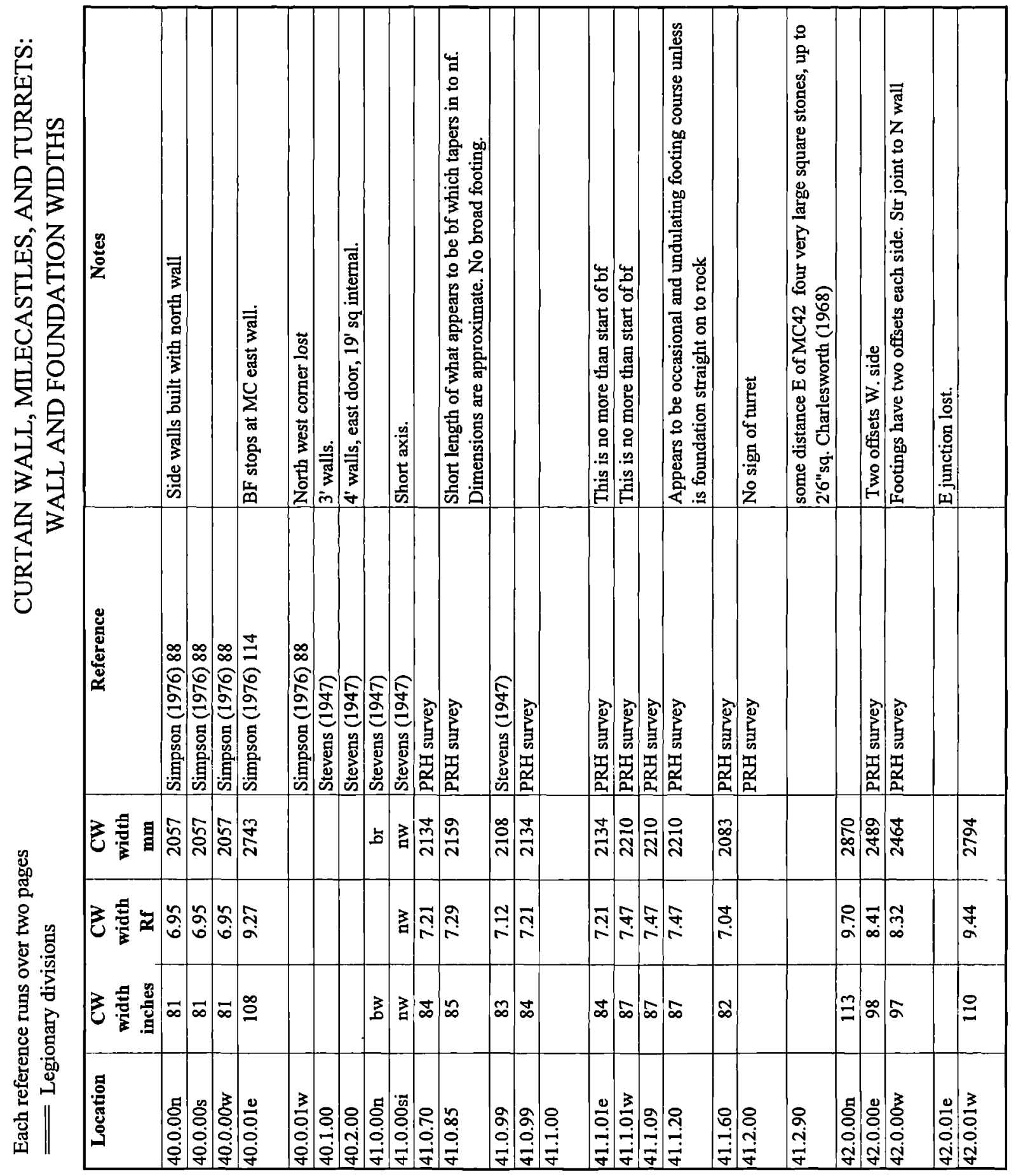




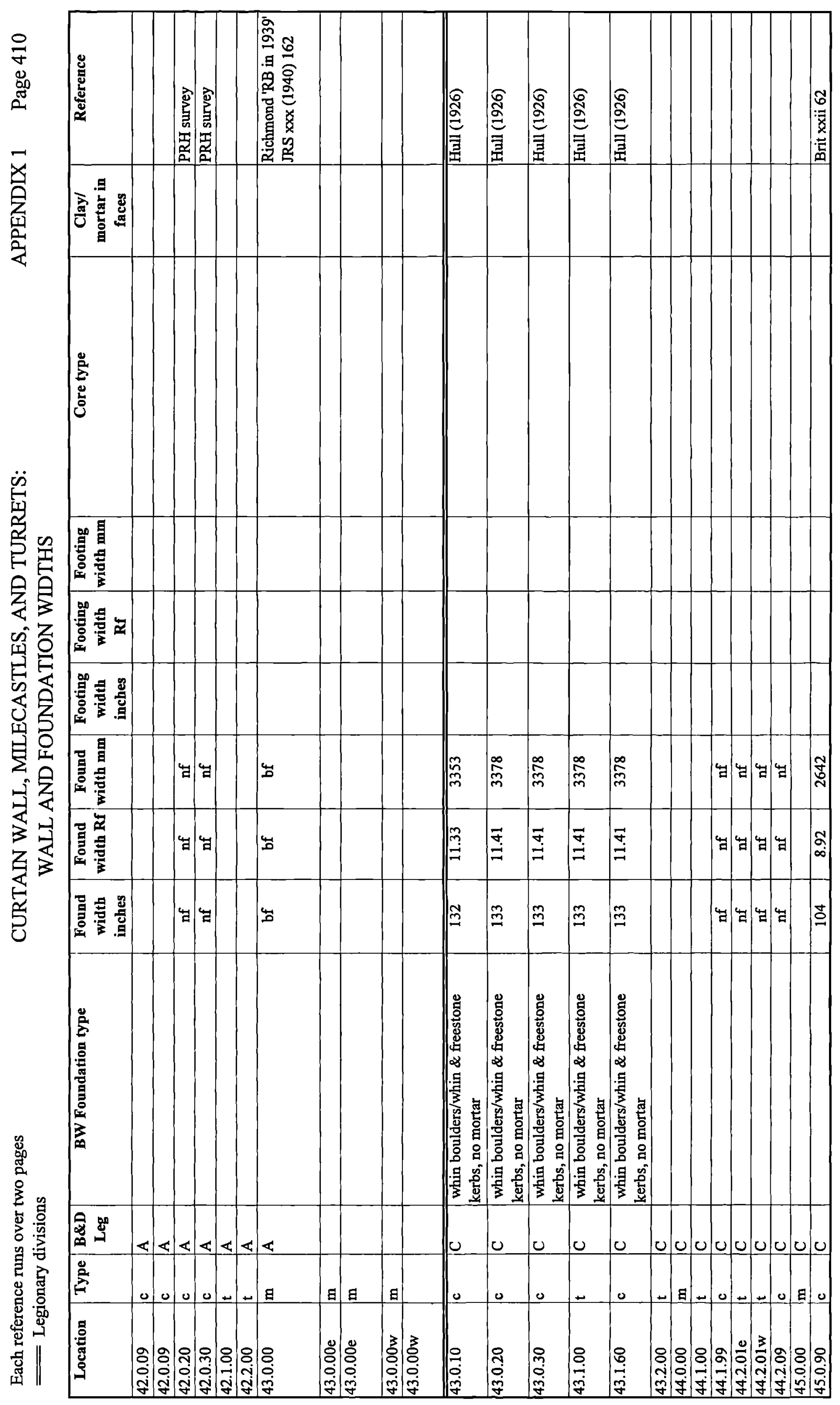


$\exists$
7
0
0
0
0

肴

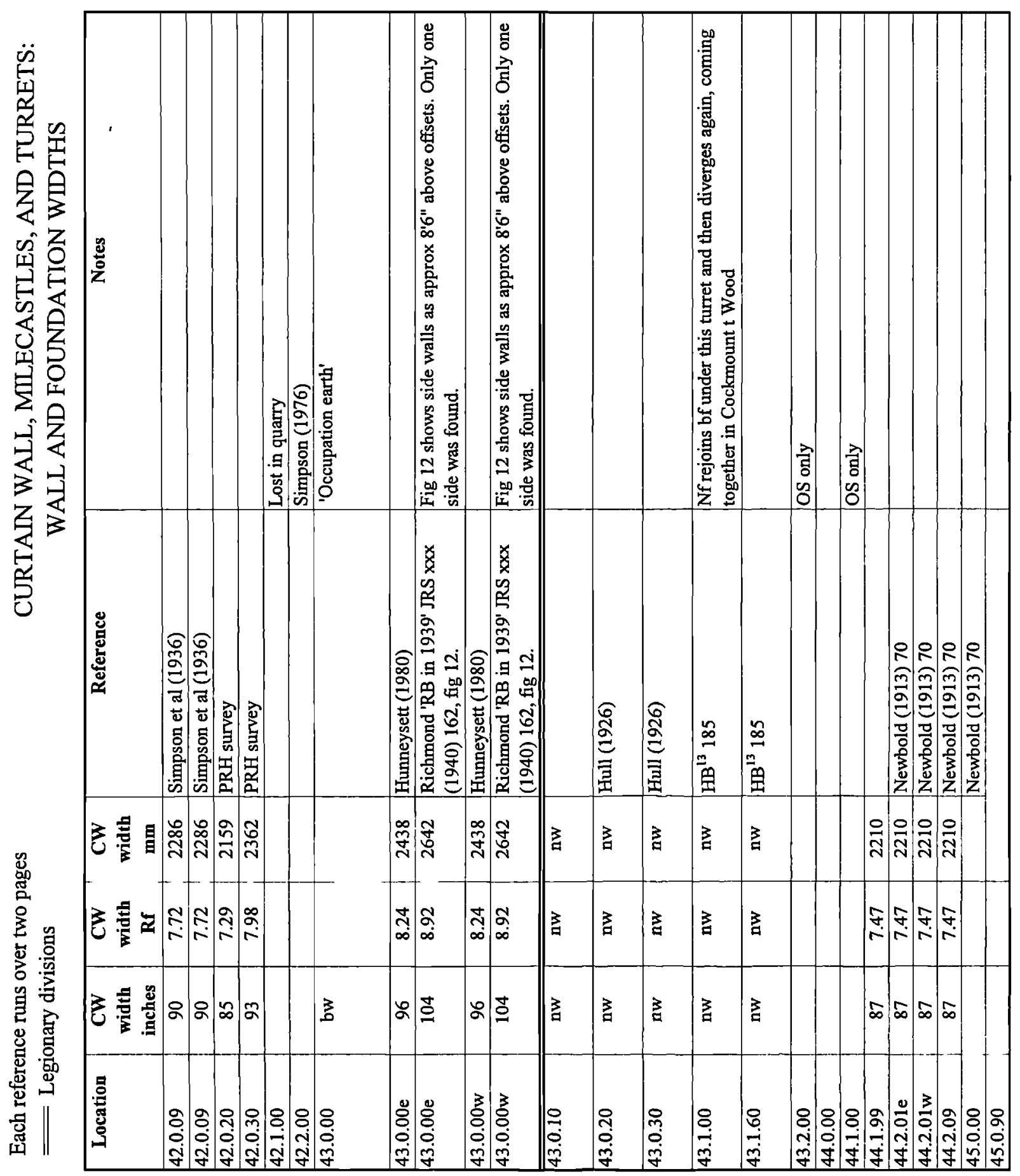




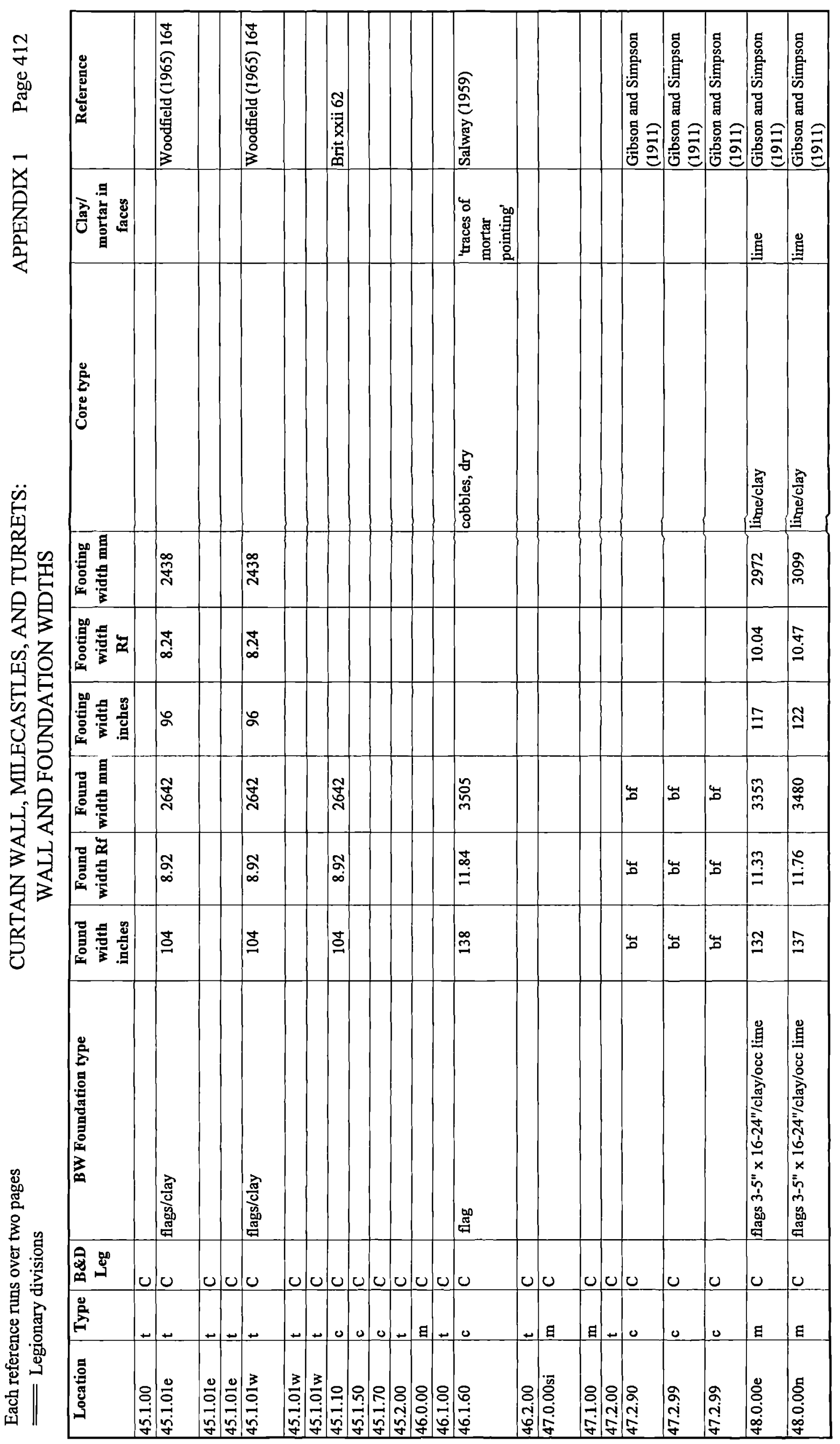




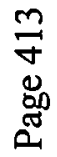

肴

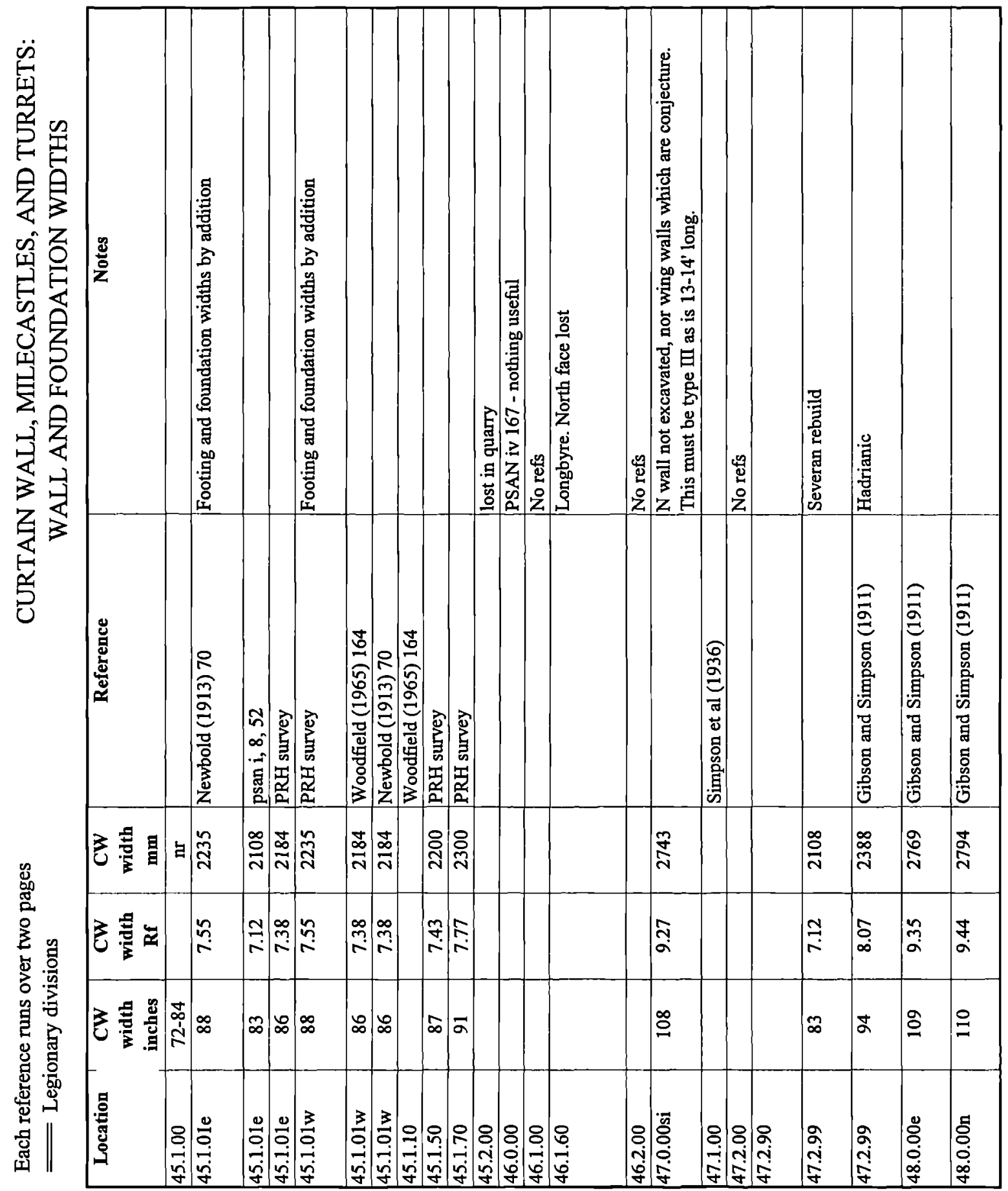




\begin{tabular}{|c|c|c|c|c|c|c|c|c|c|c|c|c|c|c|c|c|c|}
\hline 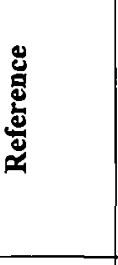 & 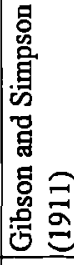 & 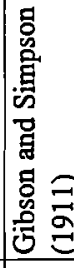 & 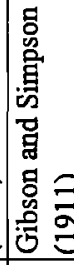 & $\frac{\Delta}{2}$ & 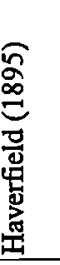 & 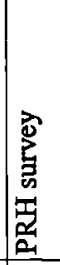 & $\mid$ & 空 & 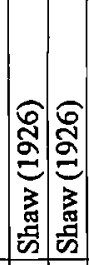 & 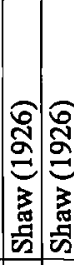 & 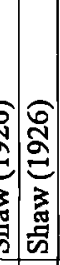 & 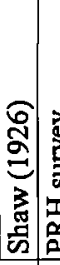 & 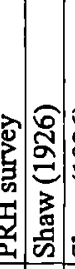 & 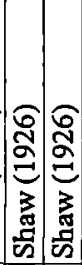 & 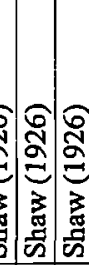 & 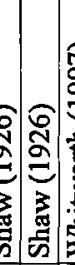 & 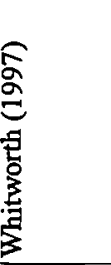 \\
\hline 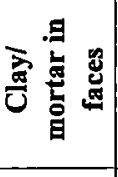 & 首 & 軍 & 首 & & & & & & & & & & & & & & \\
\hline 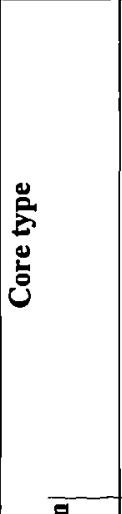 & 离 & 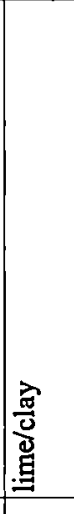 & & 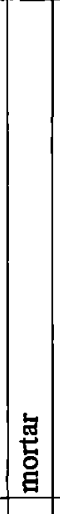 & & & & & & & & & & & & & 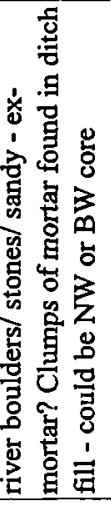 \\
\hline 昌昌 & 满 & స్ర్ల & ঐ̊ & & & $\overbrace{\vec{A}}$ & 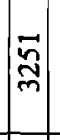 & & & & & & & & & & ర్లి \\
\hline 量害出 & $\stackrel{R}{R}$ & స్ & $\stackrel{\infty}{2}$ & & & $\frac{n}{\infty}$ & $\mid$\begin{tabular}{l}
$\infty$ \\
\hdashline \\
$\varrho$
\end{tabular} & & & & & & & & & & $\frac{\square}{9}$ \\
\hline 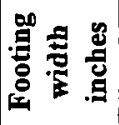 & $\Xi$ & $\exists$ & $\Xi$ & & & $\approx$ & $\underset{\mathbf{\Xi}}{\mathbf{\Xi}}$ & & & & & & & & & & 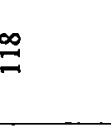 \\
\hline 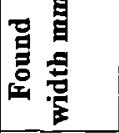 & $\overline{\check{n}}$ & 嘉 & స్ల & $\mid \begin{array}{l}5 \\
\end{array}$ & قد & & & $\begin{array}{l}\text { 岁 } \\
0 \\
0\end{array}$ & $\left|\begin{array}{l}5 \\
0\end{array}\right|$ & 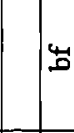 & 5 & 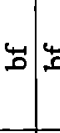 & 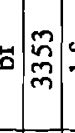 & 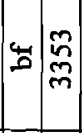 & 织 & $\hat{n}$ & స్ల్లి \\
\hline 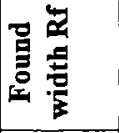 & 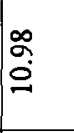 & $\stackrel{\mathscr{n}}{\equiv}$ & 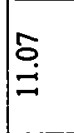 & 4 & 㸃 & & & $\begin{array}{l}\text { 岁 } \\
0 \\
0\end{array}$ & \begin{tabular}{l|l|l|}
5 & 4
\end{tabular} & 岁 & 5 & 4 & $\stackrel{0}{0}$ & 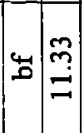 & 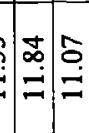 & 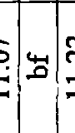 & $\stackrel{\Xi}{\Xi}$ \\
\hline 豆营兽 & $\stackrel{\infty}{\cong}$ & $\stackrel{m}{m}$ & స్తి & 4 & 4 & & & $\begin{array}{l}\text { 岁 } \\
\text { 品 }\end{array}$ & $\mid \begin{array}{ll}4 \\
\end{array}$ & 4 & 5 & 4 & $\Xi \approx$ & $\stackrel{4}{0} \approx$ & 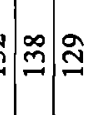 & 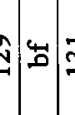 & $\vec{m}$ \\
\hline 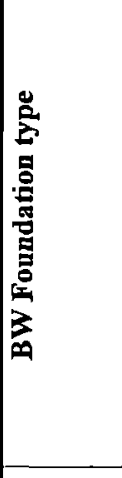 & 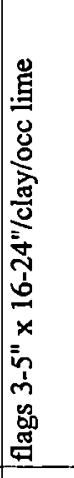 & 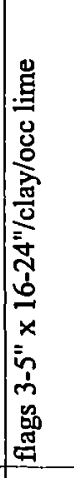 & 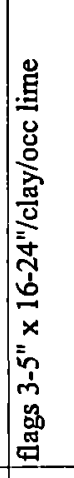 & & 嵌 & & & & & & & & & & & & 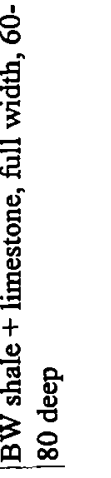 \\
\hline 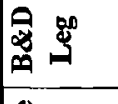 & 0 & 0 & 0 & 0 & 0 & 0 & 0 & U & \begin{tabular}{l|l}
0 & 0 \\
\end{tabular} & 0 & U & 0 & 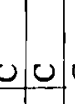 & 00 & 0 & c & 0 \\
\hline 总 & $E$ & $\mathbf{g}$ & 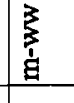 & 0 & 0 & 0 & 0 & 0 & 0 & ـ & -1 & 0 & 0.0 & - & -10 & 0 & 0 \\
\hline 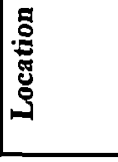 & \begin{tabular}{|l} 
\\
0 \\
0 \\
0 \\
$\infty$ \\
0 \\
\end{tabular} & \begin{tabular}{|l}
3 \\
0 \\
0 \\
0 \\
0 \\
0 \\
0 \\
0
\end{tabular} & \begin{tabular}{|l}
$\stackrel{0}{0}$ \\
0 \\
0 \\
$\infty$ \\
$\infty$ \\
\end{tabular} & 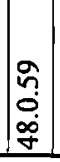 & 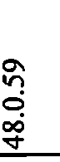 & 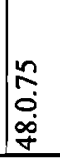 & $\begin{array}{c}2 \\
0 \\
0 \\
\infty \\
\sigma \\
\end{array}$ & & 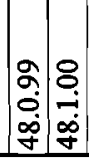 & 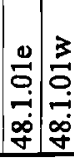 & 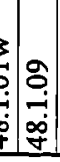 & 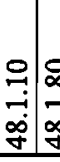 & 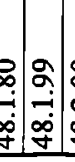 & 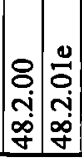 & 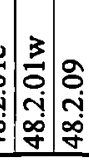 & 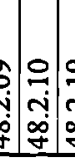 & 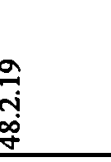 \\
\hline
\end{tabular}


$n$
$\forall$
0
0
0
0

肴

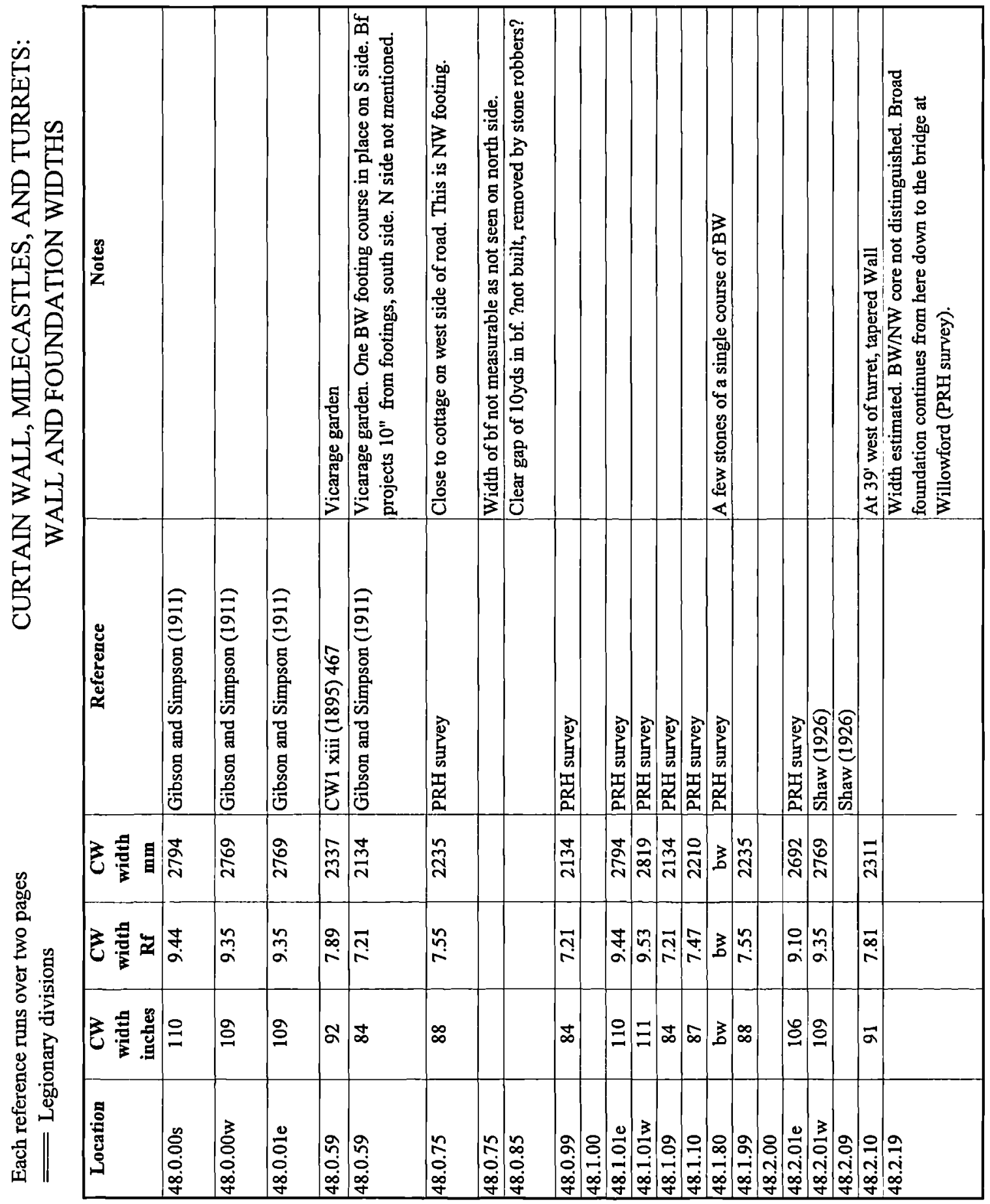




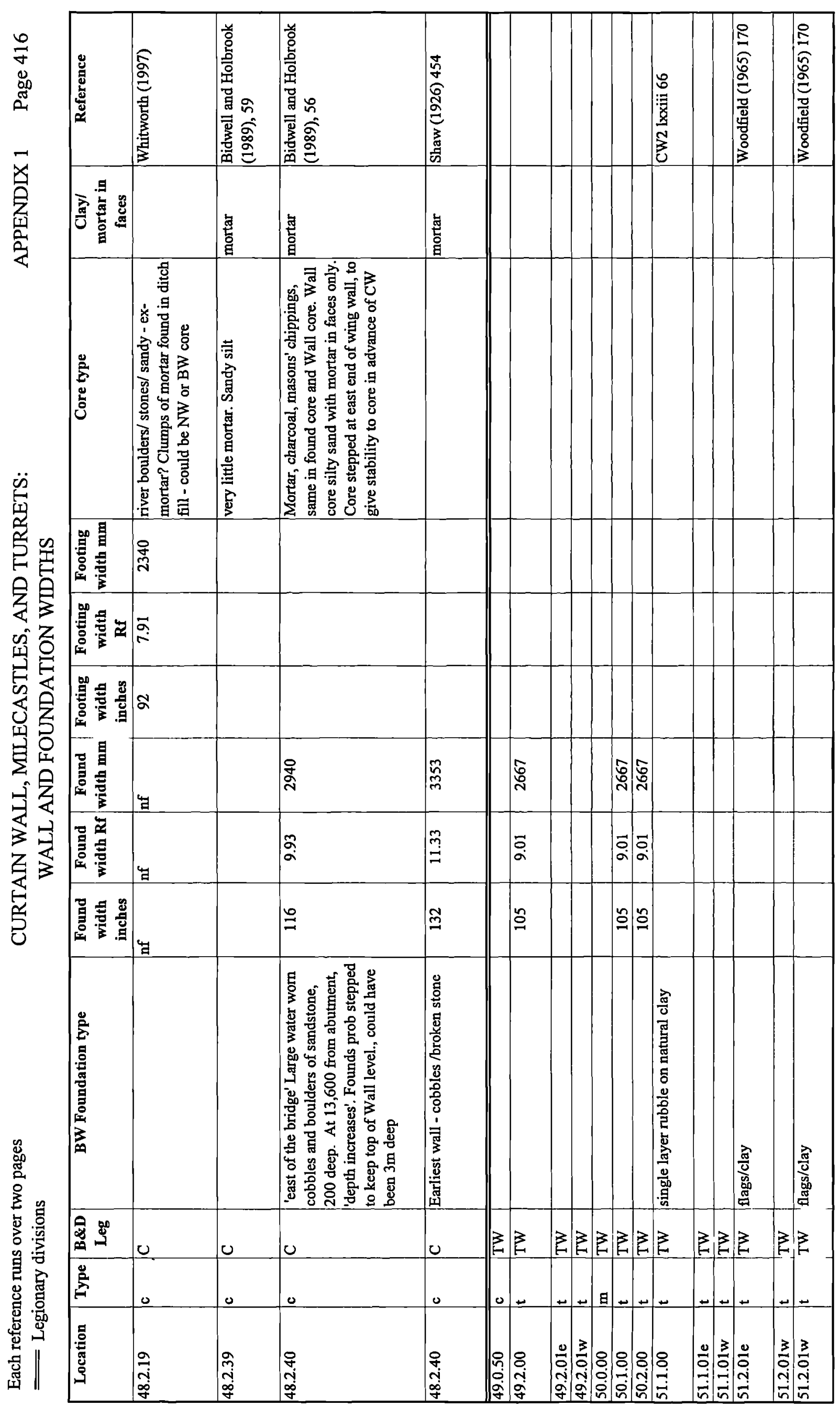


\begin{tabular}{l}
$\overline{7}$ \\
\multirow{8}{0}{} \\
\multirow{0}{*}{}
\end{tabular}

㿽

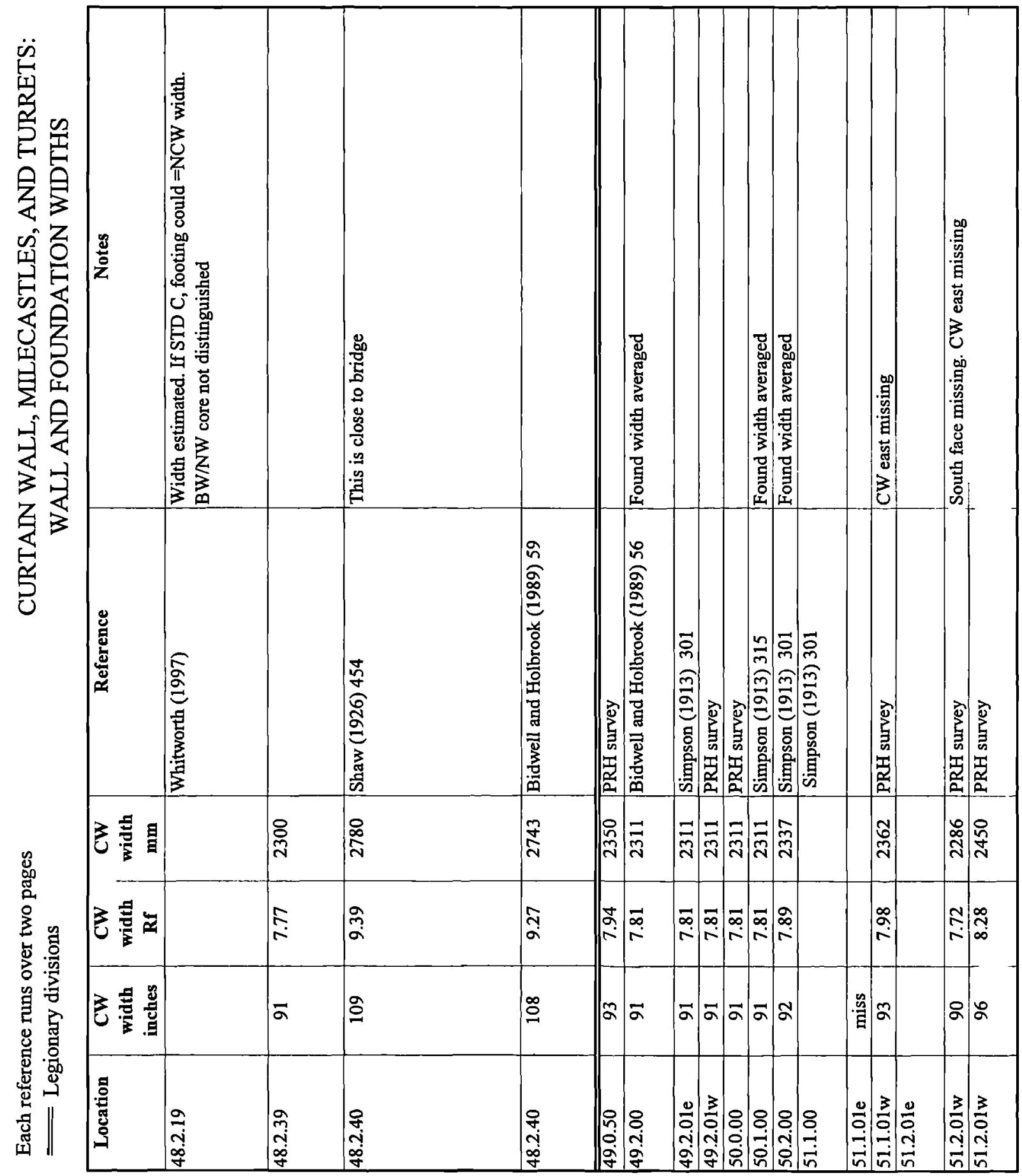




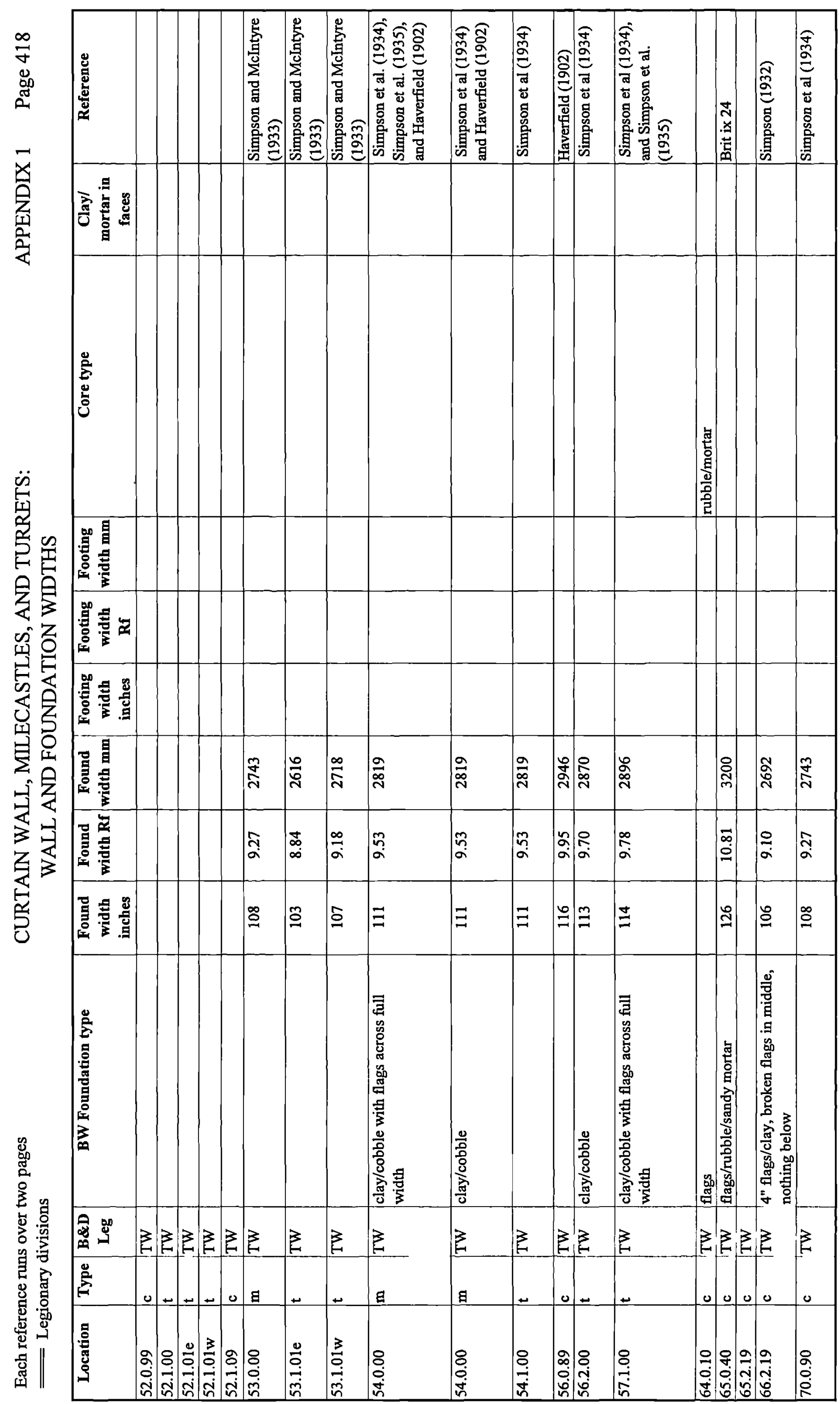




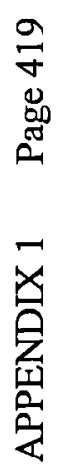

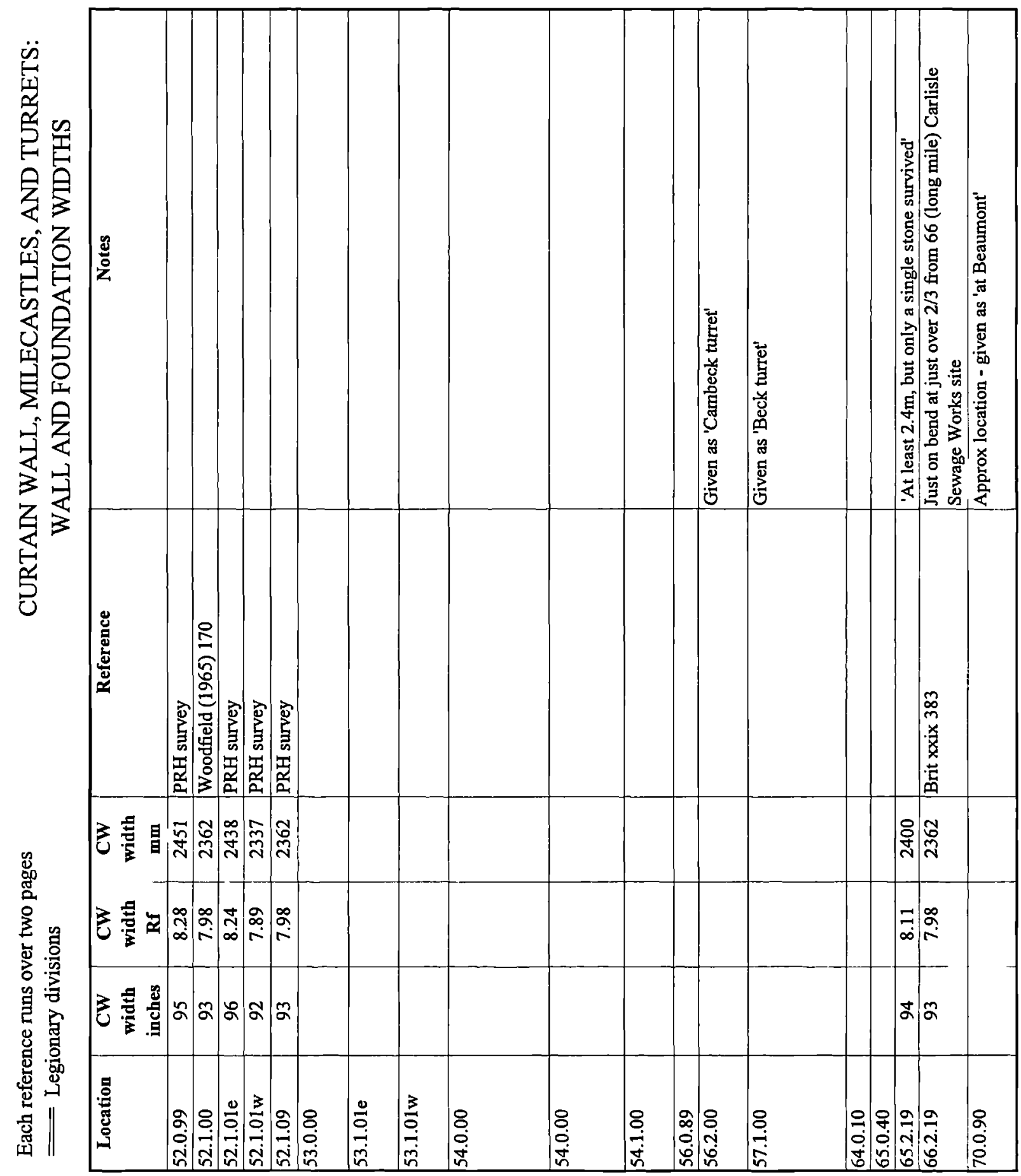




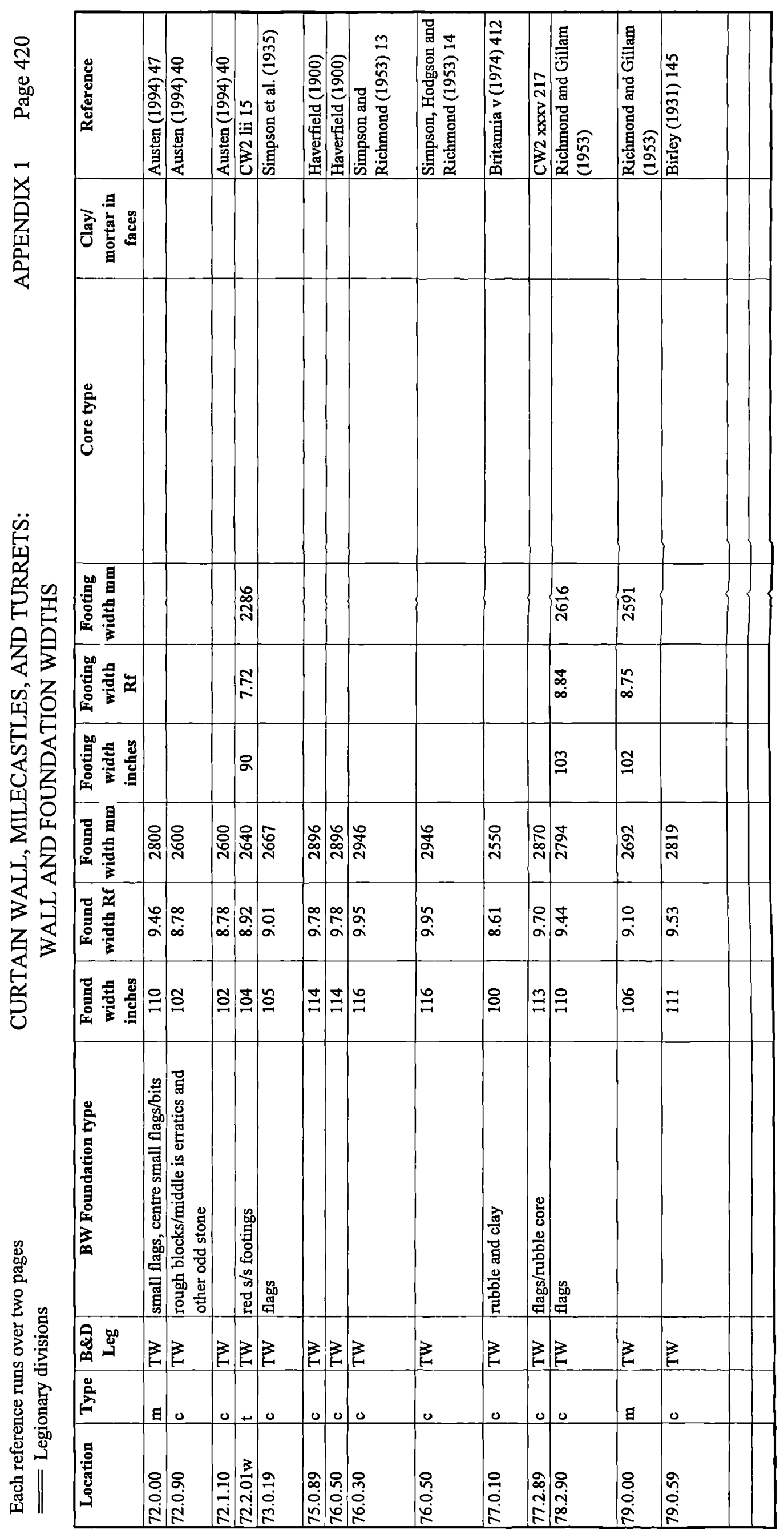




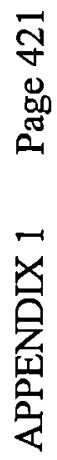

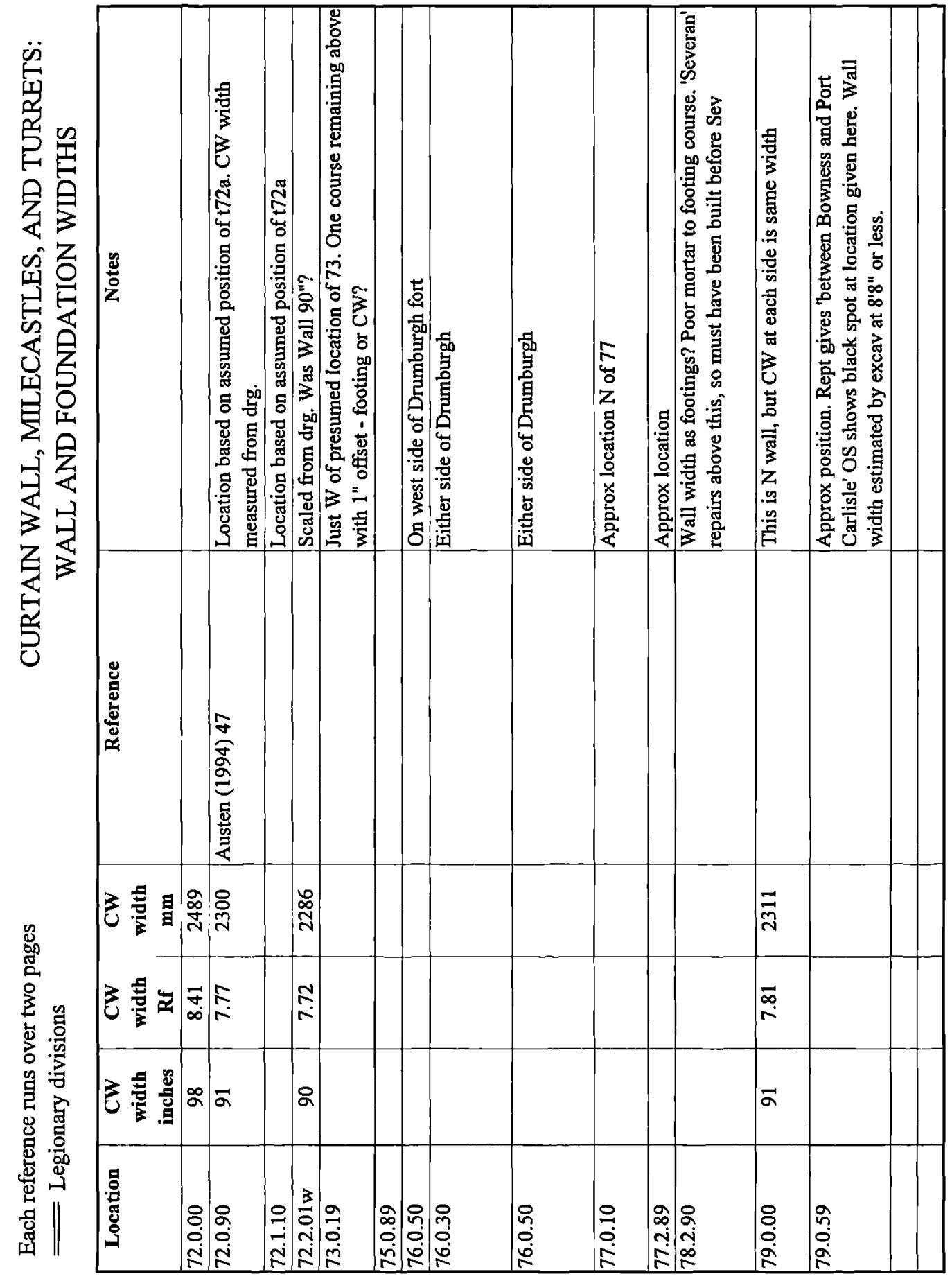




\begin{tabular}{|c|c|c|c|c|}
\hline & & & IMPERIAL & METRIC \\
\hline \multicolumn{5}{|l|}{ AVERAGE SIZE OF FACING STONES } \\
\hline Length inches/mm & & & 10.25 & 260 \\
\hline Depth inches $/ \mathrm{mm}$ & & & 15 & 381 \\
\hline Height inches/mm & & & 7 & 178 \\
\hline Taper on each vertical joint inches/mm & & & 3 & 76 \\
\hline Length at back inches $/ \mathrm{mm}$ & & & 4.25 & 108 \\
\hline Volume cubic feet/cubic metres & & & 0.44 & 0.012 \\
\hline Weight lbs per cubic foot/kg per cubic metre & & & 145 & 2325 \\
\hline Average weight of facing stone & & & 64 & 29 \\
\hline \multicolumn{5}{|l|}{ STONES PER SQ. YARD/SQ METRE } \\
\hline \multicolumn{5}{|c|}{$\begin{array}{l}\text { Stone size on face including joints inches } / \mathrm{mm} \text { (see below for mortar joint } \\
\text { thickness) }\end{array}$} \\
\hline Length inches/mm & & & 10.75 & 273 \\
\hline Height inches/mm & & & 7.25 & 184 \\
\hline Average number of stones per sq yd/sq.m & & & 17 & 20 \\
\hline \multicolumn{5}{|l|}{ BUILDING FACING STONES } \\
\hline Number of fixers (layers of stone) & 3 & men & & \\
\hline Walk $3 \mathrm{yds} / \mathrm{m}$ & 4 & seconds & & \\
\hline Lift stone from pile & 10 & seconds & & \\
\hline Walk $3 \mathrm{yds} / \mathrm{m}$ & 8 & seconds & & \\
\hline Place on bed and adjust & 20 & seconds & & \\
\hline Fill joint & 20 & seconds & & \\
\hline Point & 20 & seconds & & \\
\hline Spread new bed & 15 & seconds & & \\
\hline Seconds per stone & 97 & seconds & & \\
\hline Minutes to lay one sq. yd/sq. $\overline{\mathrm{m}}$. & & & $27 . \overline{5}$ & 32.2 \\
\hline Round to half hour & & & 30 & 32 \\
\hline \multicolumn{5}{|l|}{ CORE STONE } \\
\hline Average width of Broad Wall inches $/ \mathrm{mm}$ & & & 111 & 2819 \\
\hline Average depth of facing stones inches $/ \mathrm{mm}$ & & & 15 & 381 \\
\hline Width of core between facing stones & & & 81 & 2057.4 \\
\hline \multicolumn{5}{|l|}{ Following figures are for one side of Wall only } \\
\hline Volume of core in cu.ft.per sq. yd (cu.m per sq.m.) of face & & & 30.38 & 0.86 \\
\hline Weight of core in lbs. per cu ft/kg per cu.m. & & & 110 & 1764 \\
\hline Weight of core for 1 sq.yd/1 sq.m. of face, in $\mathrm{lbs} / \mathrm{kg}$ & & & 3341 & 1517 \\
\hline Man-carry basket or large stone weighing $\mathrm{lbs} / \mathrm{kg}$ & & & 50 & 22.7 \\
\hline No. of basketfulls to fill core & & & 67 & 67 \\
\hline Walk to heap $10 \mathrm{yds}$ & 10 & seconds & & \\
\hline Fill basket & 20 & seconds & & \\
\hline Walk to wall & 15 & seconds & & \\
\hline \multirow[t]{2}{*}{ Tip into wall } & 20 & seconds & & \\
\hline & 65 & seconds & & \\
\hline $\mathrm{Man} /$ minutes to lay core for 1 sq. $\mathrm{yd} / 1 \mathrm{sq} . \mathrm{m}$. & & & 72 & 72 \\
\hline To keep pace with fixers, number needed for tipping core is & 2.4 & men & & \\
\hline Total for core stone & 2.4 & men & & \\
\hline Round to whole number of men & 3 & men & & \\
\hline
\end{tabular}




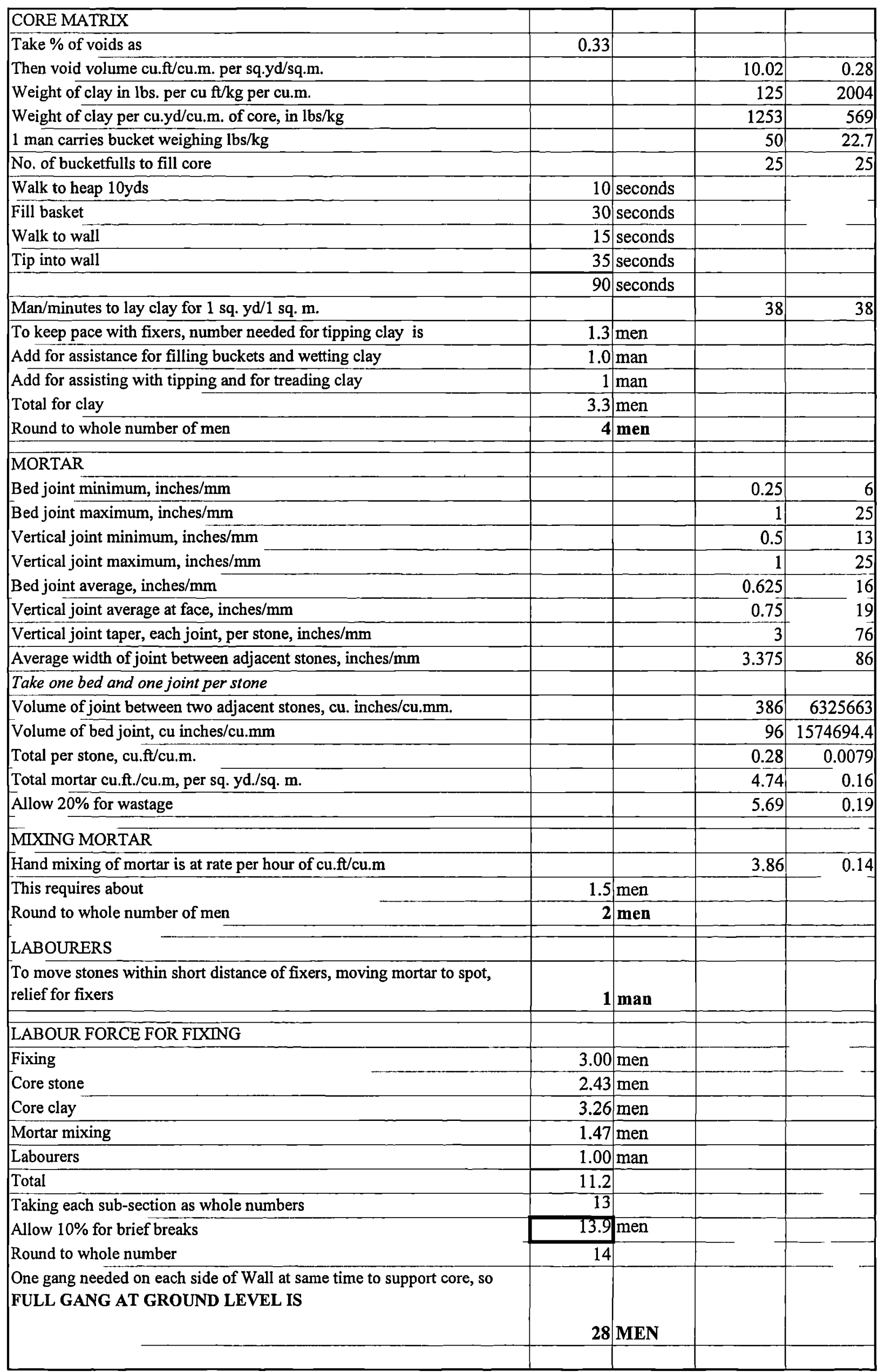




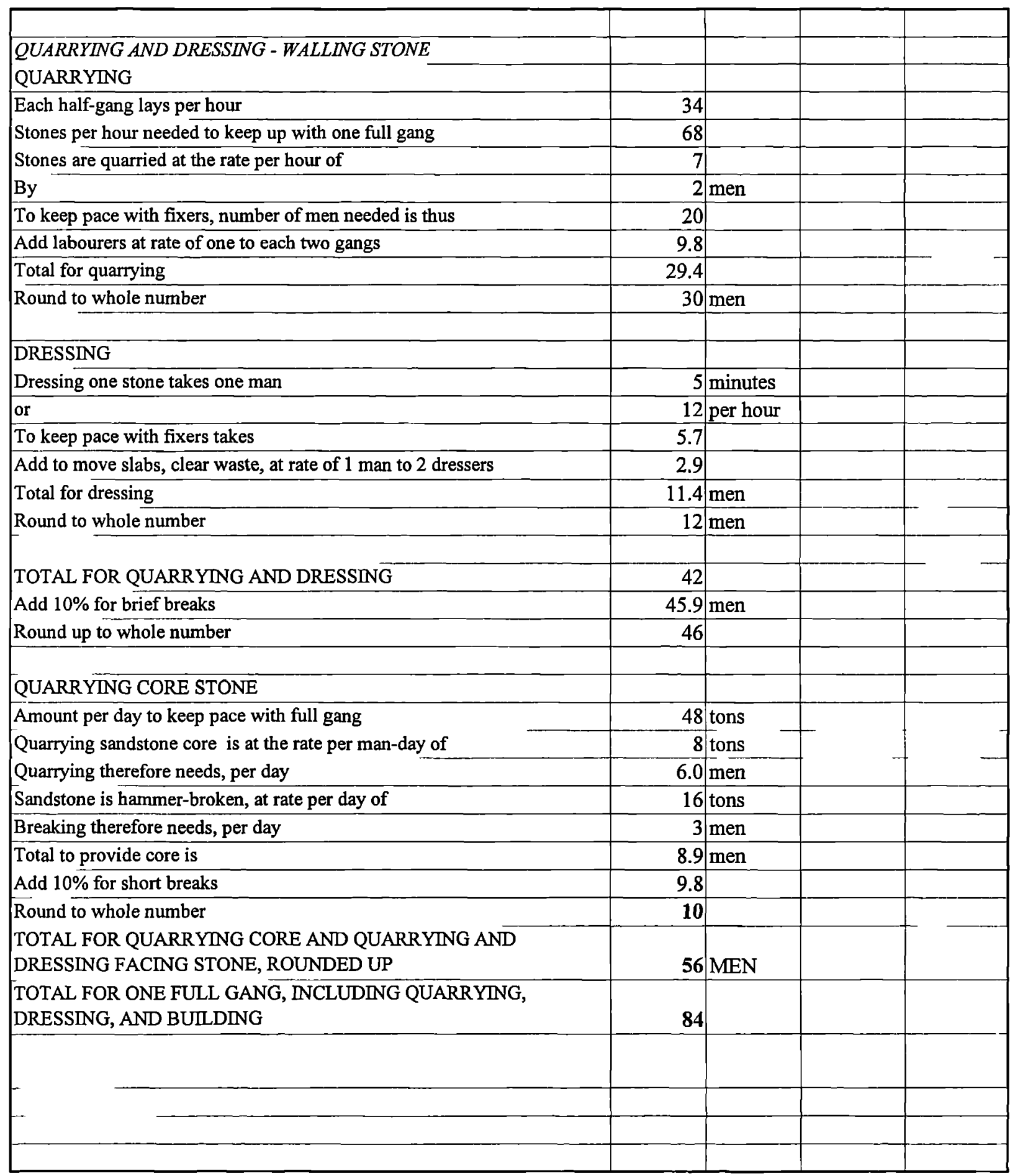




\section{BIBLIOGRAPHY}

\section{Ancient sources}

Bede Ecclesiastical History of the English People

Cato de agriculturi

M. Cetius Faventinus De Diversis Fabricis Architectonicae

Hero Mechanica.

Josephus Jewish Wars

Justinian The Digest

Livy History of Rome

Pliny Natural History.

Res Gestae Divi Augusti

Polybius Histories

Pseudo-Hyginus de munitionibus castrorum

Scriptores Historiae Augustae

Strabo The Geography

Suetonius The Twelve Caesars

Codex Theodosianus

Varro De Rustica

Vegetius Epitoma rei militaris

Marcus Vitruvius Pollio The Ten Books on Architecture

\section{Abbreviations}

$A A^{1.5} \quad$ Archaeologia Aeliana, 1st-5th Series

A.I The Archaeological Journal

CIL Corpus Inscriptionum Latinarum

AE Année Epigraphique

ANRW Aufsteig und Niedergang der Römischen Welt

$C W^{1-3} \quad$ Transactions of the Cumberland and Westmorland Antiquarian and Archaeological Society First to Third Series 


$\begin{array}{ll}\text { BAR } & \text { British Archeological Reports, British and International Series } \\ H B^{2 \cdot 13} & \text { J.C Bruce Handbook to the Roman Wall 2nd-13th edn, 1884-1978, first edition } \\ & \text { published as The Wallet Book } \\ \text { ILS } & \text { Inscriptiones Latinae Selectae Hermannus Dessau (ed.) 1892. } \\ N C H & \text { Northumberland County History } \\ \text { PSAN } & \text { Proceedings of the Society of Antiquaries of Newcastle upon Tyne, 1st-5th series } \\ \text { PSAS } & \text { Proceedings of the Society of Antiquaries of Scotland } \\ \text { ORL } & \text { Obergermanisch-raetische Limes des Römerreiches } \\ \text { RIB } & \text { Roman Inscriptions of Britain } \\ \text { RIC } & \text { Roman Imperial Coinage } \\ \text { 'RB in xxxx' } & \text { refers to annual summaries of work appearing in JRS up to and including } 1969 \\ & \text { and Britannia thereafter, normally published in the volume following the year } \\ & \text { referred to. }\end{array}$

\section{Modern sources}

Adam (1994)

Jean-Pierre Adam Roman Building: materials and techniques (1994).

Adlams (1993)

J.N. Adams 'The generic use of mula and the status and employment of female mules in the Roman world' Rheinisches Museum für Philologie Neue Folge 136. Band, Heft 1 (1993).

Admiralty (1932)

Manual of Seamanship Vol. II The Admiralty (1932).

Admiralty (1954)

Manual of Seamanship Vol. I The Admiralty (HMSO

Alberti (1775) 1951, reprinted 1954).

Leone Battista Alberti Ten books on architecture

Allason-Jones (1988) (facsimile reprint 1955, Ed. Joseph Rykwert).

Lindsay Allason-Jones "Small finds' from turrets on Hadrian's Wall' in Coulson (1988) 197-233.

Allason-Jones \& Gillam (1982)

Lindsay Allason-Jones and J.P. Gillam 'Roman pottery from Hadrian's Wall turret 27a' $A A^{5}$ x (1982)100-200. 
Allason-Jones, Bennett, and Welsby (1984)

Anderson (1992)

Andrews (1976)

M.R. Apted et al.

Arkell (1946)

Armitage and Chapman (1979)

Arnold (1991)

Audoin-Rouzeau (1991)

Aurenches (1981)

Austen (n.d)

Austen (1994)

Austen and Breeze (1979)

Balaam (1983)

Ball (1927)
Lindsay Allason-Jones, Julian Bennett, and Derek Welsby 'The finds from milecastle 54, Randylands' $A A^{5}$ xii (1984) 228-235.

James D. Anderson Roman Military Supply in North East England (BAR British Series 224, 1992).

Francis B. Andrews The Mediaeval Builder and his Methods (Wakefield, 1976).

M.R. Apted, R. Gilyard-Beer, and A.D. Saunders Ancient Monuments and their Interpretation (1977).

W.J. Arkell Oxford Stone (1946).

Philip Armitage and Hugh Chapman 'Roman Mules' London Archaeologist 3/13 (1979) 339-359.

Dieter Arnold Building in Egypt (New York, 1991).

Frédérique Audoin-Rouzeau La taille du boeuf domestique en Europe de l'antiquité aux temps modernes Fiches d'ostéologie animale pour l'archéologie, Série B:

Mammifères, № 2 (Juan-les-Pins, 1991)

Olivier Aurenches La maison orientale (Paris, 1981).

Paul S. Austen Bewcastle and Old Penrith Cumberland and Westmorland Research Series No.6 (Kendal, c.1991).

Paul S. Austen 'Recent Excavations on Hadrian's Wall at Burgh-by-Sands' $C W^{2}$ xciv (1994) 35-54.

Paul S. Austen and David J. Breeze 'A new inscription from Chesters on Hadrian's Wall' $A A^{4}$ vii (1979) 112 126.

Nicholas Balaam 'Pollen analysis' in Bennett and Turner (1983) 76-77.

Thomas Ball 'A section across Dere Street, near Swinburn, Northumberland' PSAN ${ }^{4}$ II (1927) 94-96. 
Balsdon (1969)

Baradez (1949)

Baradez (1967)

Barker et al. (1997)

Barrett et al. (1989)

Barton (1989)

Behn (1926)

Bellhouse (1955)

Bellhouse (1958)

Bellhouse (1963)

Bellhouse (1966)

Bellhouse (1969)

Bellhouse (1970)

Bellhouse (1981)
J.P.V.D. Balsdon 'Life and leisure' in J.P.V.D Balsdon (Ed.) Roman Civilization (1969) 253-263.

Jean Baradez Fossatum Africae (Paris, 1949).

Jean Baradez 'Compléments inédits au "Fossatum Africae"' in Studien zu den Militärgrenzen Roms (Köln, 1967).

Phillip Barker, Roger White, Kate Pretty, Heather Bird, and Mike Corbishley The Baths Basilica Wroxeter (1997).

John C. Barrett, Andrew P. Fitzpatrick, and Lesley Macinnes Barbarians and Romans in North-West Europe BAR British Series 471 (Oxford, 1989).

I.M. Barton (ed.) Roman Public Buildings (Exeter, 1989).

Friedrich Behn Steinindustrie des Altertums (Mainz, 1926).

R.L. Bellhouse 'Roman sites on the Cumberland coast $1954 C W^{2}$ lvi (1955) 28-55.

R.L. Bellhouse 'Roman sites on the Cumberland coast $1956 C W^{2}$ Ivii (1958) 18-24.

R.L. Bellhouse 'Roman sites on the Cumberland coast $1962 C W^{2}$ Ixiii (1963) 140-147.

R.L. Bellhouse 'Roman sites on the Cumberland coast 1962-3 CW2 lxvi (1966) 37-41.

R.L. Bellhouse 'Roman Sites on the Cumberland Coast, 1966-1967' $C W^{2}$ lxix (1969) 54-101.

R.L. Bellhouse 'Roman sites on the Cumberland Coast, 1968-1969' $C W^{2} \operatorname{Ixx}(1970)$ 9-47.

R.L. Bellhouse 'Roman sites on the Cumberland Coast:

Milefortlet 20 Low Mire' $C W^{2}$ lxxxi (1981) 7-13. 
Bellhouse (1984)

Bennett (1983)

Bennett (1986)

Bennett (1988)

Bennett (1990)

Bennett (1998)

Bennett \& Turner (1983)

Bidwell (1973)

Bidwell (1999)

Bidwell and Griffiths (1999)

Bidwell and Holbrook (1989)

Bidwell and Watson (1989)
R.L. Bellhouse 'Roman Sites on the Cumberland coast: the new tower on Rise How' $C W^{2}$ Ixxxiv (1984) 41-59. Julian Bennett 'The examination of turret $10 \mathrm{a}$ and the Wall and Vallum at Throckley' $A A^{5}$ xi (1983) 27-60. Julian Bennett 'Fort sizes as a guide to garrison type: a preliminary study of selected forts in the European provinces' in Studien zu den Militärgrenzen Roms III, Forschung und Berichte zu Vor- und Frühgeschichte in Baden-Württemburg 20 (Stuttgart, 1986) 707-16.

Julian Bennett 'The principal gateways of masonry forts on the Hadrianic frontier in England: aspects of their appearance, construction, planning and probable appearance' in Bidwell, Miket, and Ford (1988) 113-141. 'The setting, development, and function of the Hadrianic frontier in Britain' Unpublished PhD thesis, University of Newcastle upon Tyne (1990).

Julian Bennett 'The Roman Frontier from Wallsend to Rudchester Burn Reviewed' $A A^{5}$ xxvi (1998) 17-37.

Julian Bennett and Richard Turner 'The Vallum at Wallhouses' $A A^{5}$ xi (1983) 61-78.

Shelford Bidwell The Royal Horse Artillery (1973).

Paul Bidwell (ed.) Hadrian's Wall 1989-1999 (Carlisle, 1999).

P. Bidwell and W. Griffiths 'The Wall at Buddle Street' in Bidwell (1999) 95-6.

P.T. Bidwell and N. Holbrook Hadrian's Wall Bridges (1989).

P.T. Bidwell and Moira Watson 'A Trial Excavation on Hadrian's Wall at Buddle Street, Wallsend' $A A^{5}$ xvii (1989) 21-28. 
Bidwell and Watson (1996)

Bidwell et al. (1988)

Biggins and Taylor (1999)

Binns (n.d.)

Bird (1973)

Birley (1930)

Birley (1931)

Birley (1934)

Birley (1935)

Birley (1937)

Birley (1939)

Birley (1956)

Birley (1960)
P.T. Bidwell and M. Watson 'Excavations on Hadrian's Wall at Denton, Newcastle upon Tyne, 1986-89' $A A^{5}$ xxiv (1996) 1-56.

Paul Bidwell, Roger Miket, and Bill Ford (Eds) Portae cum Turribus BAR British Series 206 (Oxford, 1988).

J. Alan Biggins and David J.A. Taylor 'A survey of the Roman fort and settlement at Birdoswald, Cumbria' Britannia xxx (1999) 91-110.

A.M. Binns Unpublished excavation notes on Mains Rigg tower. Birley Archive, Dept. of Archaeology, University of Durham.

Anthony Bird Roads and Vehicles (1973).

E.B. Birley 'Excavations on Hadrian's Wall West of Newcastle upon Tyne in $1929^{\prime} A A^{4}$ vii (1930), 143-174.

Eric Birley 'Three notes on Roman Cumberland: Bewcastle, Bowness-on-Solway, Petrianae' $C W^{2}$ xxxi (1931) 137-147.

E. Birley 'On a copy of Bruce's Wallet Book' Durham University Journal xxix (1934) 26-31.

Eric Birley 'Excavations per lineam valli in 1934' Durham University Journal xxix No. 2 (March 1935) 9399.

Eric Birley 'Fifth report on excavations at Housesteads' $A A^{4}$ xiv (1937) 172-184.

Eric Birley 'Building records from Hadrian's Wall' $A A^{4}$ xvi (1939) 219-236.

Eric Birley 'Hadrianic frontier policy' Carnuntina iii (1956) 25-33.

Eric Birley 'Hadrian's Wall: some structural problems' $A A^{4}$ xxxviii (1960) 39-60. 
Birley (1961)

Birley (1971)

Birley (1977)

Birley (1981)

Birley (1994)

Birley (1997)

Birley et al. (1932)

Birley et al. (1933)

Birley et al. (1934)

Birley, Charlton, \& Hedley (1933)

Blake (1973)

Blake (1999)

Blagg (1976)
Eric Birley Research on Hadrian's Wall (Kendal, 1961). E.B. Birley 'The fate of the Ninth Legion' in Butler (1971) 71-80.

Robin Birley Vindolanda: a Roman frontier post on Hadrian's Wall (1977).

Eric Birley 'Hyginus and the First Cohort' Britannia xii (1981) 287.

Robin Birley The early wooden forts Vindolanda Research Reports, New Series, Vol. III (Bardon Mill, 1994).

A.R. Birley Hadrian: the restless emperor (1997).

Eric Birley, Parker Brewis, and F.G. Simpson 'Excavations on Hadrian's Wall between Heddon-on-theWall and North Tyne in 1931' $A A^{4}$ ix (1932) 255-259.

Eric Birley, Parker Brewis, and John Charlton 'Excavations on Hadrian's Wall between Matfen Piers and Halton Shields' $A A^{4} \times$ (1933) 97-101.

Eric Birley, Parker Brewis, and John Charlton 'Report for 1933 of the North of England Excavation Committee' $A A^{4}$ xi (1934) 176-184.

Eric Birley, John Charlton, and Percy Hedley 'Excavations at Housesteads in $1932^{\prime} A A^{4} \mathrm{x}$ (1933) 8296.

Marion Elizabeth Blake Roman Construction in Italy (Philadelphia, 1973).

Justin Blake The small finds Vindolanda Research Reports, New Series, Vol. IV, fascicule III The Tools (Greenhead, 1999).

T.F.C. Blagg 'Tools and Techniques of the Roman Stonemason in Britain' Britannia vii (1976) 152-172. 


\author{
Blagg (1990) \\ Blagrove (1906) \\ Bowden and Blood (1991)
}

Bowman (1994)

Bowman and Thomas (1994)

Brand (1789)

Brann (1985)

Breeze (1969)

Breeze (1972)

Breeze (1974)

Breeze (1985)

Breeze (1982)

Breeze (1997)

Breeze and Dobson (1969)

Breeze and Dobson (1972)

Breeze and Dobson (2000)
T.F.C. Blagg 'Building Stone in Roman Britain' in Parsons (1990) 33-50.

G.H. Blagrove Dangerous Structures (1906).

M.C.B Bowden and K. Blood 'The Roman fort at Rudchester' $A A^{4}$ xix (1991) 25-31.

Alan K. Bowman Life and Letters on the Roman Frontier (1994).

Alan K. Bowman and J. David Thomas Tabulae Vindolandensis II (1994).

John Brand History of Newcastle (1789).

M.L. Brann 'A survey of Walls Castle, Ravenglass, Cumbria' $C W^{2} \operatorname{lxxxv}(1985)$ 81-85.

David Breeze 'The organization of the legion: the first cohort and the equites legionis' JRS lix (1969) 50-55.

David J. Breeze 'Excavations at the Roman fort of Carraw burgh' $A A^{4} 1$ (1972) 81-144.

David J. Breeze 'The Roman fortlet at Barburgh Mill' Britannia v (1974) 130-162.

David J. Breeze 'Roman forces and native populations' PSAS 115 (1985) 223-238.

David J. Breeze The Northern Frontiers of Roman Britain (1982).

D.J. Breeze 'Regiments and frontiers: patterns of distribution on the rivers and artificial frontiers' in Groenman-van Waateringe et al. (1997) 73-74.

David Breeze and Brian Dobson 'Fort Types on Hadrian's Wall' $A A^{4}$ xlvii (1969) 15-32.

D.J. Breeze and B Dobson 'Hadrian's Wall: some problems' Britannia iii (1972) 182-208.

David. J. Breeze and Brian Dobson Hadrian's Wall 4th edn. (2000). 
Breeze and Hill (2001)

Breeze and Maxfield (1989)

Brereton (1976)

Brewis (1925)

Brewis (1927)

Brewis (1932)

Bristol Wagon (n.d.)

Bromehead (1956)

Bruce (1851)

Bruce (1863)

Bruce (1867)

Bruce (1871)

Bruce (1884)

Bruce (1885)

Budge (1903)
David J. Breeze and P.R. Hill 'Hadrian's Wall began here' $A A^{5}$ xxix (2001) 1-2.

David Breeze and Valerie A. Maxfield (eds) Service in the Roman Army (Edinburgh, 1989).

J.M. Brereton The Horse in War (Newton Abbot, 1976).

Parker Brewis 'Roman Rudchester. Report on excavations 1924' $A A^{4}$ i (1925) 93-120 with plates.

Parker Brewis 'Notes on the Roman Wall at Denton Bank, Great Hill and Heddon-on-the-Wall' $A A^{4}$ iv (1927) 109-121.

Parker Brewis, 'Conjectural Construction of Turret No. 18a on Hadrian's Wall' $A A^{4}$ ix (1932) 198-204 and plate xxiv.

Catalogue of the Bristol Wagon and Carriage Works Company, Limited (n.d., late nineteenth century).

C.N. Bromehead 'Mining and Quarrying to the seventeenth century' in Singer et al. (1956) Vol. II, 1-40.

J. Collingwood Bruce The Roman Wall (1851).

J. Collingwood Bruce The Wallet-Book of the Roman Wall (1863).

J. Collingwood Bruce The Roman Wall 3rd edn. (1867).

J. Collingwood Bruce The Story, partly sad and partly gay, of the Thorngrafton 'Find' (privately printed, 1871).

J. Collingwood Bruce The Handbook to the Roman Wall 2nd edn. (1884).

J. Collingwood Bruce 'Roman altar from Byker' PSAN' i (1885).

E.A.W. Budge An account of the Roman antiquities preserved in the museum at Chesters, Northumberland (1903). 
Burford (1960)

Butler (1971)

Cameron and Lucas (1973)

Caruana and Fane Gladwin (1980)

Casey (1987)

Charlesworth (1963)

Charlesworth (1968)

Charlesworth (1971)

Charlesworth (1973)

Charlesworth (1973a)

Charlesworth (1977)

Charlton and Day (1984)

Chevallier (1989)
A. Burford 'Heavy transport in classical antiquity' The Economic History Review, 2nd Series, xiii (1960) 1-18.

R.M. Butler (ed.) Soldier and civilian in Roman Yorkshire (Leicester, 1971).

H. Cameron and J. Lucas 'Tripontium, second interim report' Birmingham and Warwickshire Archaeological Society: Transactions for 1971-73 85 (1973) 93-144.

Ian Caruana and Col. P.F. Fane Gladwin 'Unpublished Excavations on the Line of the Roman Wall in Hadrian's Camp, Carlisle' $C W^{2}$ lxxx (1980) 17-22.

John Casey 'The coinage of Alexandria and the Chronology of Hadrian' in Huvelin, Christol, and Gautier (1987) 65-72.

Dorothy Charlesworth 'The Roman Wall at Cawfields' $A A^{4}$ xli (1963) 217-8.

Dorothy Charlesworth 'Recent work on Hadrian's Wall, Cawfields' $A A^{4}$ xlvi (1968) 69-74.

Dorothy Charlesworth 'Housesteads west ditch and its relationship to Hadrian's Wall' $A A^{4}$ xlix (1971) 95-99.

Dorothy Charlesworth 'A Re-examination of two turrets on Hadrian's Wall' $A A^{5}$ i (1973) 97-109.

Dorothy Charlesworth 'Hadrian's Wall, turret 51A (Piper Sike)' $C W^{2}$ lxxiii (1973) 67-78.

Dorothy Charlesworth 'The Turrets on Hadrian's Wall' in M.R. Apted et al. (1977) 13-26.

Beryl Charlton and John Day 'Henry MacLauchlan: field archaeologist and surveyor' in Miket and Burgess (1984) 4-37.

Raymond Chevallier Roman Roads revised edn (1989). 
Christison (1900-01)

Clayton (1859)

Clayton (1876a)

Clayton (1876)

Clifton-Taylor \& Ireson (1994)

Clutton-Brock (1992)

Collingwood (1928)

Collingwood (1929)

Collingwood (1930)

Collingwood (1931)

Collingwood (1931a)

Collingwood and Richmond (1969)

Connolly and Dodge (1998)

Constable (1983)
Dr. David Christison 'Excavation undertaken by the Society of Antiquaries of Scotland of earthworks adjoining the "Roman road" between Ardoch and Dupplin, Perthshire' PSAS xi (1900-1901) 15-43.

John Clayton 'The Thorngrafton Find' $A A^{2}$ iii (1859) 269-276.

John Clayton 'Notes on an excavation at Cilurnum' $A A^{2}$ vii (1876) 171-176.

John Clayton 'Notes of an excavation of a turret on the Roman Wall' $A A^{2}$ vii (1876) 256-260.

Alec Clifton-Taylor \& A.S. Ireson English Stone Building (1994).

Juliet Clutton-Brock Horse Power (1992).

R.G. Collingwood 'Hardknott Castle' $C W^{2}$ xxviii (1928) 314-352

R.G. Collingwood 'Roman Signal-Stations on and off Hadrian's Wall' $C W^{2}$ xxix (1929) 138-165.

R.G. Collingwood The Book of the Pilgrimage (Kendal, 1930).

R.G. Collingwood 'Hadrian's Wall. A system of numerical references' $P S A N^{4}$ iv (1931) 179-187.

R.G. Collingwood 'Ten Years' Work on Hadrian's Wall' $C W^{2} \operatorname{xxxi}(1931) 87-110$.

R.G. Collingwood and I.A. Richmond The Archaeology of Roman Britain (1969).

Peter Connolly and Hazel Dodge The Ancient City (Oxford, 1998).

Clive Constable 'The mule as a military animal, Part II' Exercitus 2, 6 (1983) 73-74. 
Conway (1906)

Coulson (1988)

Cowper (1998)

Crawford, Röder, et al. (1955)

Crofts (1967)

Crow (1988b)

Crow (1989)

Crow (1991a)

Crow (1991b)

Crow (forthcoming)

Crow and Jackson (1997)

Crummy (1983)

Cunliffe (1971)

Curle (1911)
R S. Conway Melandra Castle (Manchester, 1906).

J.C. Coulson, ed.) Military Equipment and the Identity of Roman Soldiers BAR, International Series 394 (1988).

A.D. Cowper Lime and Lime Mortars (first published 1927 for BRE, reprinted Donhead St. Mary, 1998).

O.G.S. Crawford in association with J. Röder and others 'The Quern-quarries of Mayen in the Eiffel' Antiquity xxix (1955) 68-76.

J. Crofts Packhorse, Waggon and Post (1967).

James Crow 'Notes on the North Gateway of Milecastle $39^{\prime}$ in Bidwell, Miket, and Ford (1988) 143-153.

J.G. Crow Housesteads Roman Fort (1989).

J.G. Crow 'Construction and reconstruction in the central sector of Hadrian's Wall' in Maxfield and Dobson (1991) 44-47.

J.G. Crow 'A review of current research on the Turrets and Curtain of Hadrian's Wall' Britannia xxii (1991) 5163.

J.G. Crow Excavation and Survey, Steel Rigg to Housesteads (forthcoming).

James Crow and Mark Jackson 'The Excavation of Hadrian's Wall at Sewingshields and the Discovery of a Long Cist Burial' $A A^{5}$ xxv (1997) 61-70.

Nina Crummy The Roman small finds from excavations in Colchester 1971-9 Colchester Archaeological Report 2 (Colchester, 1983).

Barry Cunliffe Excavations at Fishbourne 1961-1969 Reports of the Research Committee of the Society of Antiquaries of London (1971).

James Curle A Roman Frontier Post and it People (Glasgow, 1911). 
Garlick (1985)

Daniels (1959)

Daniels (1988)

Daniels (1989)

Dark and Dark (1997)

Davies (1989)

Davey (1971)

DAC (1997)

DeLaine (1997)

Dennis (1985)

Dent (1972)

Dessau (1892)

Dickinson and Hartley (1971)

Dilke (1971)
Tom Garlick Hardknott Castle Roman Fort 3rd edn. (Clapham (Lancaster), 1985).

C.M. Daniels 'The Roman bath house at Red House, Corbridge' $A A^{4}$ xxxvii (1959) 85-175.

Charles Daniels 'Africa' in Wacher (1988) 223-265.

Charles Daniels The Eleventh Pilgrimage of Hadrian's Wall (Newcastle upon Tyne, 1989).

Ken Dark and Petra Dark The Landscape of Roman Britain (Stroud, 1997).

Roy Davies (ed. David Breeze and Valerie Maxfield) Service in the Roman Army (Edinburgh, 1989).

Norman Davey 'Examination of the materials of construction from the Park Street Villa' in O'Neil (1971) 103-108.

Defence Animal Centre Training for Military Pack Transport Handlers (1997).

Janet DeLaine The baths of Caracalla Journal of Roman Archaeology, Supplementary Series No. 25) (Portsmouth (Rhode Island), 1997).

George T. Dennis Three Byzantine Military Treatises (Washington D.C., 1985).

Anthony Dent Donkey: the story of the Ass from East to West (1972).

Hermannus Dessau (ed.) Inscriptiones Latinae Selectae (1892).

B.M. Dickinson and K.F. Hartley "The evidence of potters' stamps on Samian ware and on mortaria for the trading connections of Roman York' in Butler (1971) 127-142.

O.A.W Dilke The Roman Land Surveyors (Newton Abbot, 1971). 
Dix (1982)

Dixon and Southern (1992)

Dobson (1986)

Dolenz (1955)

Domaszewski-Dobson (1967)

Drachman (1963)

van Driel-Murray et al. (1993)

Dumayne (1994)

Dworakowska (1983)

Dworakowska (1988)

Elton (1996)

Evetts (1948)

Essin (2000)
Brian Dix 'The manufacture of lime and its uses in the western Roman empire' Oxford Journal of archaeology 1(3) (1982) 331-343.

Karen R. Dixon and Pat Southern The Roman Cavalry (1992).

B. Dobson 'The Function of Hadrian's Wall' $A A^{5}$ xiv (1986) 1-30.

H. Dolenz Archäologische Mitteilungen aus Kärnten Carinthia I, CXLV (1955)

Alfred von Domaszewski Die Rangordnung des Römischen Heeres revised Brian Dobson (Köln, 1967).

A.G. Drachman The Mechanical Technology of Greek and Roman antiquity (1963).

Carol van Driel-Murray, John Peter Wild, Mark Seaward, and Jennifer Hallam The early wooden forts Vindolanda Research Report, New Series, Vol. III (Bardon Mill, 1993).

Lisa Dumayne 'The effect of the Roman Occupation on the Environment of Hadrian's Wall' Britannia xxv (1994) 217-224.

Angelina Dworakowska Quarries in Roman Provinces (Warsaw, 1983).

A Dworakowska 'Wooden Wedges in Ancient Quarrying Practice; Critical Examination of the State of Research' Archaeologia 38 (1988), 25-35.

Hugh Elton Frontiers of the Roman Empire (1996).

L.C. Evetts "The lettering of Romano-British inscribed stones' $A A^{4}$ XXVI (1948), 153-171.

Emmett M. Essin Shavetails and Bellsharps (Lincoln USA, 2000). 
Ewart (1911)

Fant (1988)

Fant (1989)

Febvre (1922)

Fentress (1979)

Ferguson (1881)

Fink (1971)

Fitchen (1986)

Forster and Knowles (1911)

Fowler (1982)

Frere (1972)

Frere (1980)

Frere (1984)

Frere (1984b)

Frere (1991)
J.C Ewart 'Animal remains' in Curle (1911) 362-377.

J. Clayton Fant (ed.) Ancient Marble Quarrying and Trade BAR International Series 453 (Oxford, 1988).

J. Clayton Fant Cavum antrum Phrygiae BAR International Series 482 (Oxford, 1989).

L. Febvre La terre et l'evolution humaine (Paris, 1922).

Elizabeth W.B. Fentress Numidia and the Roman Army BAR International Series 53 (1979).

R.S. Ferguson 'An attempt at a Survey of Roman Cumberland, continued, Part V. Risehow, near Flimby' $C W^{1}$ v (1881) 124-31.

Robert O. Fink Roman Military Records on Papyrus (Cleveland, Ohio, 1971).

John Fitchen Building Construction before Mechanization (1986).

R.H. Forster and W.H. Knowles 'Corstopitum: report on the excavations in 1910' $A A^{3}$ vii (1911) 143-267.

Daryl Fowler 'Temporary works, their construction and archaeology' in Drury (1982) 125-130.

Sheppard Frere Verulamium Excavations Vol. I Reports of the Research Committee of the Society of Antiquaries of London, No. XXVIII (1972).

S.S. Frere 'Hyginus and the First Cohort' Britannia xi (1980) 51-60.

Sheppard Frere Verulamium Excavations Vol. III Oxford Committee for Archaeology, Monograph No. 1 (1984).

S.S. Frere 'Roman Britain in 1983' Britannia (1984) 266332.

S.S. Frere 'Roman Britain in 1991' Britannia xxiii (1992) 256-308. 
Fox and Ravenhill (1966)

Frost and Boughton (1954)

Gibbons (1932)

Gibson (1903a)

Gibson (1903b)

Gibson and Simpson (1909)

Gibson and Simpson (1911)

Gillam (1953)

Gillam and Mann (1970)

Gillette (1904)

Gordon (c.1726)

Gordon \& Gordon (1977)

Gracie and Price (1979)

Greenwell and Elsden (1913)
Proceedings of the Devon Archaeological Exploration Society xxiv (1957) 3-39.

William Frost and R.V. Boughton Modern Practical Brickwork (1954).

Stella Gibbons Cold Comfort Farm (1932).

J.P. Gibson 'Mucklebank Wall Turret' $A A^{2}$ xxiv (1903) 13-18.

J.P. Gibson 'On excavations at Greatchesters (Aesica) in 1894, 1895, and 1897' $A A^{2}$ xxiv (1903) 19-64.

J. Pattison Gibson and F.G. Simpson 'The Roman fort on the Stanegate at Haltwhistle Burn' $A A^{3}$ v (1909), 213-285.

J.P. Gibson FSA and Gerald Simpson 'The Milecastle on the Wall of Hadrian at the Poltross Burn' $C W^{2}$ xi (1911) 390-461.

J.P. Gillam 'Excavations at Low Brunton Milecastle, No. 27, in 1952' $A A^{4}$ xxxi (1953)165-174 and plates xvixxii.

J.P. Gillam and J.C. Mann 'The northern British frontier from Antoninus Pius to Caracalla' $A A^{4}$ xlviii (1970) $1-44$.

H.P. Gillette Rock excavation, methods and cost (New York, 1904).

Alexander Gordon Itinerarium Septentrionale (c. 1726). Joyce S. and Arthur E. Gordon Contributions to the Palaeography of Latin Inscriptions (Milan, 1977).

H.S. Gracie and E.G. Price 'Frocester Court Roman villa: second report' Transactions of the Bristol and Gloucestershire Archaeological Society 97 (1979) 51-60. Allan Greenwell and J. Vincent Elsden Practical Stone Quarrying (1913). 
Groenman-van Waateringe et al. (1997)

Groves (1974)

Grundy (1930)

Haigh and Savage (1984)

Handbook

Hanson (1978)

Hanson (1989)

Hanson (1997)

Hanson et al. (1979)

Hanson and Maxwell (1983)

Harbottle et al. (1988)

Hargreaves (1996)

Hassall \& Ireland (1979)
W. Groenman-van Waateringe, B.L. Beek, W.J.H. Willems, and S.L. Wynia (eds) Roman Frontier Studies Oxbow Monograph 91 (Oxford, 1997).

Colin P. Groves Horses, Asses and Zebras in the Wild (1974).

R.F.B. Grundy Builders' Materials (1930).

David Haigh and Mark Savage 'Sewingshields' $A A^{5}$ xii (1984) 33-147.

J. Collingwood Bruce Handbook to the Roman Wall 13th

Edn Ed. Charles Daniels (Newcastle upon Tyne, 1978).

W.S. Hanson "The Organisation of Roman Military

Timber Supply' Britannia ix (1978) 293-305.

W.S. Hanson 'The nature and function of Roman frontiers' in Barrett et al. (1989) 5561.

W.S. Hanson 'Across the frontier: addressing the ambiguities' in Groenman-van Waateringe et al. (1997) 373-378.

W.S Hanson, C.M. Daniels, J.N. Dore, and J.P. Gillam 'The Agricolan supply base at Red House, Corbridge' $A A^{5}$ vii (1979) 1-98.

William Hanson and Gordon Maxwell Rome's North West Frontier (Edinburgh, 1983).

Barbara Harbottle, R. Fraser, and F.C. Burton 'The Westgate Road Milecastle, Newcastle upon Tyne' Britannia xix (1988) 153-162.

G.H. Hargreaves 'Roman surveying on continuous linear constructions' Unpublished $\mathrm{PhD}$ thesis, University of London, 1996.

Mark Hassall and Robert Ireland De rebus bellicis BAR International Series 63 (1979). 
Haselberger (1985)

Haselberger (1994)

Haselberger (1995)

Haverfield (1900)

Haverfield (1901)

Haverfield (1902)

Haverfield (1903)

Hebditch and Mellor (1973)

Heslop, Truman, and Vaughan (1994)

Heyman (1997)

Heywood (1965)

Hill (1981)

Hill (1989)
Lothar Haselberger "The Construction Plans for the Temple of Apollo at Didyma' Scientific American vol. 253 (December 1985) 114-122.

Lothar Haselberger 'Ein Giebeliss der Forehalle des Pantheon die Werkrisse vor dem Augustusmausoleum' Mitteilungen des Deutschen Archaeologischen Instituts, Roemische Abteilung 101 (Mainz, 1994) 280-308.

Lothar Haselberger 'Deciphering a Roman Blueprint' Scientific American vol. 272 (June 1995) 56-61.

F. Haverfield 'Report of the Cumberland Excavation Committee for $1899^{\prime} C W^{1}$ xvi (1900) 80-92.

F. Haverfield 'Report of the Cumberland Excavation Committee for 1900' $\mathrm{CW}^{2} \mathrm{i}$ (1901) 75-92.

F. Haverfield 'Report of the Cumberland Excavation Committee for 1901' $C W^{2}$ ii (1902) 381-392.

F. Haverfield 'Report of the Cumberland Excavation Committee for $1902^{\prime} C W^{2} 111$ (1903) 328-350.

Max Hebditch and Jean Mellor 'The Forum and Basilica of Roman Leicester' Britannia iv (1973) 1-83.

D.H. Heslop, L. Truman, and J.E. Vaughan 'Excavations on Westgate Road, Newcastle, 1991' $A A^{5}$ xxii (1994) 153-184.

Jaques Heyman Structural Theory of Masonry $\mathrm{Pb}$ edn. (Cambridge, 1997).

Brenda Heywood 'The Vallum - its problems restated' in Jarrett and Dobson (1965) 86-94.

P.R. Hill 'Stonework and the archaeologist: including a stonemason's view of Hadrian's Wall' $A A^{5}$ ix (1981), $1-21$.

Hill, P.R. 'Report on the north gate of Milecastle 37' unpublished report to the National Trust (1989). 
Hill (1991)

Hill (1992)

Hill (1995)

Hill (1997a)

Hill (1997b)

Hill (2000)

Hill (2001a)

Hill (2001b)

Hill (2001c)

Hill (2001d)
P.R. Hill 'Hadrian's Wall: some aspects of its execution' $A A^{5}$ xix (1991) 33-39.

P.R. Hill 'Survey of excavated and standing stone, Birdoswald Roman fort' unpublished report to English Heritage, 1992, in Birdoswald site archive; incorporated into Wilmott (1997).

P.R. Hill 'Housesteads Roman fort: technical assessment of gateways and other features' unpublished report to English Heritage (1995).

P.R. Hill 'Chesters Roman fort: technical assessment of the extant gateways' unpublished report to English Heritage (1997).

P.R. Hill 'The stone wall turrets of Hadrian's Wall' $A A^{5}$ $x x v(1997) 27-49$.

P.R. Hill 'Vindolanda Roman Fort: technical assessment of the the extant gateways and other stones' unpublished report to English Heritage (2000).

P.R. Hill 'Benwell Vallum Crossing: technical assessment of the pier and other stones' unpublished report to English Heritage (February 2001).

P.R. Hill 'Milecastle 42, Cawfields: technical assessment of the gateways' unpublished report to English Heritage (February 2001).

P.R. Hill 'Milecastle 48 Poltross Burn: a technical assessment of the gateways' unpublished report to English Heritage (March 2001).

P.R. Hill 'Hadrian's Wall from MCO to MC9' $A A^{5}$ xxix (2001) 3-18. 
Hill (2001e)

Hill (2001f)

Hill (2001g)

Hill (2002)

Hill (forthcoming)

Hill and David (1995)

Hill and Dobson (1992)

Hodges (1992)

Hodgson (1997)

Hodgson (1999)

Hodgson (2002)

Hogg (1950) et al.
P.R. Hill 'Milecastle 10, Walbottle Dene: technical assessment of the visible parts of the north gate' unpublished report to English Heritage (November 2001).

P.R. Hill ' The Burnfoot altar top: technical assessment and observations' unpublished report to English Heritage (November 2001).

P.R. Hill 'Pigeon Clint Written Rock: a brief overview of some quarry marks and other features' unpublished report to English Heritage (November 2001).

P.R. Hill 'The development of the Stanegate' in P.R. Hill (ed) Polybius to Vegetius (2002) 87-102.

P.R. Hill 'RIB 1445: a merlon stone from Hadrian's Wall?' (forthcoming).

P.R. Hill and J.C.E. David Practical Stone Masonry (1995).

P.R. Hill and B. Dobson 'The design of Hadrian's Wall and its implications' $A A^{5} \mathrm{xx}$ (1992) 27-52.

Henry Hodges Technology in the Ancient World (New York, 1992).

N. Hodgson 'Relationships between Roman frontiers and artificial frontiers' in Groenman-van Waatering et al. (1997) 61-66.

N. Hodgson 'Wallsend' in Bidwell (1999) 83-94.

N. Hodgson 'Book reviews' $A A^{5} \operatorname{xxx}$ (2002) 187-189.

Robert Hogg A. Holmes and H.F. Hanwood 'Age and Composition of the Whin Sill and the related dykes of the North of England' Mineralogy Magazine 28 (1928), 493-542. 
Holbrook and Speak (1994)

Holder (1982)

Holmes and Hanwood (1928)

Hooley and Breeze (1968)

Hörter et al. (1950)

Horsley (1732)

Hull (1926)

Hulme (1980)

Hunneysett (1980)

Hunter Blair (1934)

Huntley (1988)

Huntley (1999)
Neil Holbrook and Steve Speak 'Washingwells Roman fort: a transcription of the aerial photographs and an assessment of the evidence' The Arbeia Journal iii (1994) $33-45$.

P.A Holder The Roman Army in Britain (1982).

A. Holmes and H.F. Hanwood 'Age and Composition of the Whin Sill and the related dykes of the North of England' Mineralogy Magazine vol. 28 (1928), 493-542. Joyce Hooley and David Breeze 'The Building of Hadrian's Wall: a reconsideration', $A A^{4}$ xlvi (1968), 97114.

P. Hörter, F.X. Michels, and J. Röder Der Geschichte der Basaltlava-Industrie von Mayern und Niedermendig Jahrbuch für Geschischte und Kultur des Mittelrheins und seiner Nachbargebiete, 2-3 (1950) 1-32.

John Horsley Britannia Romana (1732).

M.R. Hull 'The excavations at Aesica, 1925 - Interim report' $A A^{4}$ ii (1926) 197-201.

Susan Hulme Native Ponies of the British Isles (Hindhead, 1980).

R. Hunneysett 'The Milecastles of Hadrian's Wall: an alternative identification' $A A^{5}$ viii (1980), 95-107.

Peter Hunter Blair 'Housesteads Milecastle' $A A^{4}$ xl (1934) 103-120 and plates.

J.P. Huntley 'Paleobotanical investigations' in Harbottle et. al. (1988) 160-162.

J.P. Huntley 'Environmental evidence from Hadrian's

Wall' in Bidwell (1999) 48-64. 
Huntley and Stallibrass (1995)

Huvelin, Christol, and Gautier (1987)

Hyland (1990)

Jackson (1973)

Jankovich (1971)

Jarrett (1976)

Jarrett and Dobson (1965)

Jennings (1959)

Jobey (1958)

Johnson (1997)

Johnson (1983)

Jones (1975)

Jones (1982)

Jones and Woolliscroft (2001)

Jorns (1959)
Jaqueline $\mathrm{P}$ Huntley and Sue Stallibrass Plant and vertebrate remains from archaeological sites in northern England Research Report No. 4, Architectural and Archaeological Society of Durham and Northumberland, (Durham, 1995).

Huvelin H., Christol M., and Gautier G. Mélange de Numismatique (Wetteren (Belgium), 1987).

Ann Hyland Equus: the horse in the Roman world (1990).

D.A. Jackson 'A Roman Lime Kiln at Weekley, Northants' Britannia iv (1973) 128-140.

M. Jankovich They Rode into Europe (1971).

Michael G. Jarrett 'An unnecessary war' Britannia vii (1976) 145-151.

Michael G. Jarrett and Brian Dobson (eds.) Britain and Rome (Kendal, 1965).

B. Jennings 'The lead mining industry in Swaledale' unpublished MA thesis, University of Leeds 1959.

George Jobey 'The Wall ditch, Bays Leap, Heddon on the Wall $A A^{4}$ xxxvi (1958) 55-60.

G.A.L. Johnson The Geology of Hadrian's Wall Geologists' Association Guide No. 59 (1997).

Anne Johnson Roman Forts (1983).

Michael J. Jones Roman fort defences to $A D 117$ BAR 175 (Oxford, 1975).

G.D.B. Jones (1982) 'The Solway Frontier: interim report 1976-81' Britannia xiii (1982) 283-297.

G.D.B. Jones and D.J. Woolliscroft Hadrian's Wall from the air (Stroud, 2001).

W. Jorns Der Felsberg im Odenwald (Kassel and Basel, 1959). 
Kendal (1996)

Kennedy (2000)

Kenyon (1948)

Keppie and Walker (1981)

Keppie and Walker (1985)

Kozelj (1988)

Körtüm (1998)

Lee (1946)

Lamb (1981)

Lamb (1995)

Lamprecht (1987)
Roger Kendal 'Transport Logistics Associated with the Building of Hadrian's Wall' Britannia xxvii (1996), 129 152.

D.L. Kennedy Archaeological Explorations on the Roman Frontier in North-East Jordan BAR International Series 134 (Oxford, 1982).

David Kennedy The Roman Army in Jordan (2000).

Kathleen M. Kenyon Excavations at the Jewry Wall Site, Leicester (1948).

L.J.F. Keppie and J.J. Walker 'Fortlets on the Antonine Wall at Seabegs Wood, Kinneil, and Cleddans' Britannia xii (1981) 143-162.

L.J.F. Keppie and J.J. Walker 'Auchendavy Roman Fort and Settlement' Britannia xvi (1985) 29-36.

Tony Kozelj 'Les carrières des époques Grecque, Romain et Byzantine: techniques et organisation' in Fant (1988) 3-79.

K. Körtüm 'Zur Datierung der Römischen Militäranlagen im obergermanisch-rätischen Limes gebiet, Chronologische Untersuchungen anhand der Münzfunde' Saalburg Jahrbuch 49 (1998) 5-65.

John Lee 'The last of the carrier Galloways' $P S A N^{4} \mathrm{x}$ (1946) 332-334.

H.H. Lamb 'Climate from $1000 \mathrm{BC}$ to $1000 \mathrm{AD}$ in M. Jones and G Dimbleby (eds.) The Environment of Man: the Iron Age to the Anglo-Saxon Period BAR 87 (1981).

H.H. Lamb Climate, History and the Modern World (1995).

Heinz-Otto Lamprecht Opus Caementitium (Düsseldorf, 1987). 
Landels (1978)

Lander (1984)

Leighton (1972)

Lepper and Frere (1988)

Lewis (1994)

Lewis (1995)

Ling (1985)

Lloyd (1954)

Lugard (1893)

Lugli (1957)

Lynch (1998a)

Lynch (1998b)

McCarthy (1986)
J.G. Landels Engineering in the Ancient World (Berkley and Los Angeles, 1978).

James Lander Roman Stone Fortifications BAR International Series 206 (Oxford, 1984).

Albert C. Leighton Transport and Communication in Early Mediaeval Europe AD500-1100 (Newton Abbot, 1972).

Frank Lepper and Sheppard Frere Trajan's Column (Gloucester, 1988).

M.J.T. Lewis 'The Origins of the Wheelbarrow' Technology and Culture 35(3) (July 1994) 453-475.

M.J.T. Lewis 'A Festuca from Chesters?' $A A^{5}$ xxiii (1995) 47-50.

Roger Ling 'The mechanics of the building trade' in F. Grew and B. Hobley (eds) Roman urban topography in Britain and the western empire CBA Research Report No 9 (1985).

Seton Lloyd 'Building in brick and stone' in Singer (1954) 456-494.

Captain F.D. Lugard The Rise of our East African Empire (1893).

G. Lugli La Tecnica Edilizia (Rome, 1957).

Gerard Lynch 'Lime Mortars - time for reappraisal?' Architects and Surveyors Institute Journal (March 1998) 26-7.

Gerard Lynch 'Lime Mortars for Brickwork: Traditional Practice and Modern Misconceptions - Part Two' Journal of Architectural Conservation 4(2) (July 1998) 7-19. M.R. McCarthy 'Woodland and Roman Forts' Britannia xvii (1986) 339-343. 
Macdonald (1932-3)

Macdonald and Curle (1929)

MacLauchlan (1858)

Mann (1974)

Mann (1979)

Mann (1990a)

Mann (1990b)

Mann and Breeze (1987)

Manning (1972)

Manning (1976)

Manning (1981)

Manning (1984)

Marshall (1796)
Sir George Macdonald 'Notes on the Roman forts at Rough Castle and Westerwood, with a postscript' PSAS v (1932-33), 243-296.

Sir George Macdonald and Alexander O. Curle 'The Roman fort at Mumrills' PSAS lxiii (1929) 396-575.

Henry MacLauchlan Memoir written during a survey of the Roman Wall (1858).

J.C. Mann 'The frontiers of the Principate' ANRW II. I (1974) 508-533.

J.C. Mann 'Power, force and the frontiers of the empire' JRS Ixix (1979) 175-183.

J.C. Mann 'The function of Hadrian's Wall' $A A 5$ xviii (1990), 51-54.

J.C. Mann 'Hadrian's Wall West of the Irthing: The Role of VI Victrix' Britannia xxi (1990) 289-292.

John C. Mann and David J. Breeze 'Ptolemy, Tacitus and the tribes of north Britain' PSAS 117 (1987) 85-91.

W.H. Manning 'The iron objects' in Frere (1972) 163195.

W.H. Manning Catalogue of Romano-British Ironwork in the Museum of Antiquities, Newcastle upon Tyne (Newcastle, 1976).

W.H. Manning Usk: The Fortress Excavations $1965-$ 1971 (Cardiff, 1981).

W.H. Manning 'The Iron Objects' in Frere (1984) 83106.

W. Marshall Rural Economy of the West of England (1796) 294. 
Matei (1997)

Mattingly (1995)

Maxfield (1988)

Maxfield (1990)

Maxfield and Dobson (1991)

Maxwell (1976)

Mayes (1994)

Meek and Gray (1911)

Meijer and van Nijf (1992)

Mendoza (1983)

Miket and Burgess (1984)

Miket and Maxfield (1972)

Miller (1922)

Mitchell (1922)
A.V. Matei 'Limes Porolissensis - a new defensive line (ditches, wall, and towers) discovered in front of the Roman military site of Porolissum, in Dacia' in Groenman-van Waateringe (1997) 93-100.

D.J. Mattingly Tripolitania (1995).

Valerie A. Maxfield 'Mainland Europe' in Wacher (1988) 139-195.

Valerie A. Maxfield 'Hadrian's Wall in its Imperial Setting' $A A^{5}$ xviii (1990) 1-27.

Valerie A. Maxfield and Michael J. Dobson (eds) Roman Frontier Studies 1989 (Exeter, 1991).

G.S. Maxwell 'A Roman Timber Tower at Beattock Summit, Lanarkshire' Britannia vii (1976) 33-38.

Bill Mayes 'The Reconstruction of a Leather Tent' Exercitus 2(10) (1994) 183-186.

Professor A. Meek M.Sc and R.A.H. Gray M.A, M.Sc 'Animal remains' in Forster and Knowles (1911) 220267.

Fik Meijer and Onno van Nijf Trade, Transport and Society in the Ancient World (1992).

A. Gomez Mendoza 'The Role of Horses in a Backward Economy: Spain in the Nineteenth Century' in Thompson (1983) 143-155.

Roger Miket and Colin Burgess (Eds) Between and Beyond the Walls (Edinburgh, 1984).

Roger Miket and Valerie Maxfield 'The excavations of turret 33B (Coesike)' $A A^{4}$ l (1972) 145-178.

S.N. Miller The Roman Fort at Balmuildy (Glasgow, 1922).

Charles F. Mitchell Building Construction (1922). 
Mitchell (1976)

Mócsy et al.(1983)

Molesworth (1910)

Monkhouse (1942)

Morgan (1996)

Natural Stone Directory (n.d.)

Nall (1883)

Nall (1886)

Nash-Williams (1931)

Newbold (1913a)

Newbold (1913b)

Newbold (1926)

Neuburger (1930)
Stephen Mitchell 'Requisitioned Transport in the Roman

Empire: a New Inscription from Pisidia' JRS lxvi (1976) 106-131.

Andreas Mócsy, Reinhardus Feldmann, Elisabetha Marton, Maria Szilágyi Nomenclator Dissertationes Pannonicae, Series III, Vol. I (Budapest, 1983).

Sir Guilford L. Molesworth K.C.I.E. Pocket-Book of Useful Formulae and memoranda (1910).

F.J. Monkhouse 'The transport of lead and silver from Langley Castle to Newcastle, 1768-1779' $P S A N^{4}$ ix (1942) 176-186.

G.C. Morgan 'Mortar analyses' in Bidwell and Watson (1996) 53-54.

Natural Stone Directory, bi-annual publication (Worthing, n.d. (c. 1998)).

Forster, Westgarth A treatise on the strata from Newcastle upon Tyne to Cross Fell 3rd Edn Revised by Revd. W. Nall (1883).

Rev. W. Nall 'Alston' $C W^{1}$ viii (1886) 7-39.

V.E. Nash-Williams FSA 'The Roman Legionary Fortress at Caerleon in Monmouthshire: Report on the excavations carried out in the Prysg Field, 1927-9' Archaeologia Cambrensis lxxxvi (1931) 99-157.

P. Newbold 'Excavations on the Roman Wall at Limestone Bank' $A A^{3}$ ix (1913) 54-74.

P. Newbold 'The pottery and the periods of occupation' in Simpson (1913) 339-346.

H.B. Newbold The Modern Carpenter and Joiner Three vols.(1926).

Albert Neuburger The technical arts and sciences of the ancients (1930). 
Noddle (1979)

O'Connor (1993)

O'Connor (1998)

O'Neil (1971)

Parsons (1990)

Peacock and Maxfield (1997)

Petrie (1930)

Pickering (1956)

Pitts (1989)

Pitts and St. Joseph (1985)

Plommer (1973)

Potter (1977)
B.A. Noddle 'The animal bones' in Gracie and Price (1979).

Colin O'Connor Roman Bridges (Cambridge, 1993).

M. O'Connor 'Lincoln Cathedral: the evolving perception and care in an historic masonry structure' unpublished PhD. thesis De Montfort University (1998).

Helen O'Neil The Roman villa at Park Street, near St. Albans, Herts. (Hertfordshire Archaeological Society, 1971).

David Parsons (ed.) Stone: Quarrying and Building in England AD 43-1525 (Chichester, 1990).

D.P.S. Peacock and V.A. Maxfield Mons Claudianus: survey and excavation Vol. 1 Topography and Quarries Institut Français d'Archéologie Orientale (Le Caire, 1997).

W.M.F. Petrie Ancient Egypt pt ii (1930) 33-39.

W.J. Pickering 'The masonry of the Roman Wall' PSAN i (1956) 361-2.

Lynn F. Pitts 'Relations between Rome and the German "kings" on the middle Danube in the first to fourth centuries AD' JRS lxxix (1989) 45-58.

Lynn F. Pitts and J.K. St. Joseph Inchtuthil: the Roman legionary fortress excavations 1952-65 Britannia Monograph Series No. 6 (1985).

Hugh Plommer Vitruvius and later Roman Building Manuals (Cambridge, 1973).

Timothy Potter 'The Biglands Milefortlet and the Cumberland Coast Defences' Britannia viii (1977) 149 183. 
Poulter (1998)

Purchase (1898)

Quartermaster General (1914)

Rackham (1986)

Rayment and Pettifer (1987)

RCHM (1962)

Rea (1902)

Reynolds \& Ward Perkins (1952)

Richmond (1929)

Richmond (1931)

Richmond (1933)

Richmond (1950)

Richmond (1950-51)

Richmond (1956)
John Poulter 'The date of the Stanegate, and a hypothesis about the manner and timing of the construction of Roman Roads in Britain' $A A^{5}$ xxvi (1998) 49-56.

W.R. Purchase Practical masonry (1898).

Army Service Corps Training, part II (1914).

Oliver Rackham The History of the Countryside (1986, pb edn 2000)

D.L Rayment and K. Pettifer 'Examination of durable mortar from Hadrian's Wall' Materials Science and Technology 3, (December 1987) 997-1004.

Eburacum: Roman York An Inventory of the Historical Monuments in the city of York 1 (1962).

J.T. Rea How to estimate, being the analysis of builders' prices (1902).

J.M. Reynolds and J.B. Ward Perkins The inscriptions of Roman Tripolitania (Rome and London, 1952).

I.A. Richmond 'Excavations on Hadrian's Wall in the Gilsland-Pike Hill Sector, $1928^{\prime} \mathrm{CW}^{2}$ xxix (1929) 303315.

I.A. Richmond 'Excavations on Hadrian's Wall in the Birdoswald-Pike Hill sector, $1930^{\prime} \mathrm{CW}^{2}$ xxxi (1931) 122-134.

I.A. Richmond 'The Tower at Gillalees Beacon, called Robin Hood's Butt' $C W^{2}$ xxxiii (1933) 241-245.

I.A. Richmond 'Hadrian's Wall 1939-49' JRS xl (1950) 43-56.

Ian A. Richmond 'Exploratory trenching at the Roman fort of Cappuck, Roxburghshire in 1949' PSAS lxxxv (1950-51) 138-145.

I.A. Richmond 'Excavations at Milecastle 49 (Harrow's Scar), 1953' CW'2 lvi (1956) 18-27. 
Richmond and Birley (1937)

Richmond and Child (1942)

Richmond and Gillam (1952)

Richmond and Keeney (1937)

Richmond and McIntyre (1934)

Rivet (1965)

Rivington (1897)

RNEC (1894)

Robertson (1990)

Röder (1959)

Roy (1793)

St. Joseph (1951)

Salway (1959)

Salzman (1952)

Schönberger (1969)
I. A. Richmond and E. Birley 'Centurial stones from the Vallum west of Denton Burn' $A A^{4}$ xiv (1937)227-242.

I.A. Richmond and F.A. Child 'Gateways of forts on Hadrian's Wall' $A A^{4}$ xx (1942) 134-154.

I.A. Richmond and J.P. Gillam 'Milecastle 79 (Solway)' $C W^{2}$ lii (1952), 17-40.

I.A. Richmond and G.S Keeney 'The Roman works at Chew Green, Coquetdalehead' $A A^{4}$ xiv (1937 129-150.

I.A Richmond and James McIntyre 'The Roman Camps at Reycross and Crackenthorpe' $C W^{2}$ xxxiv (1934) 5061.

A.L.F. Rivet 'Kaims Castle' $A J$ cxxi (for 1964) 196.

Rivington's Notes on Building Construction (1897).

(anon.) 'Report of the Northumberland Excavation Committee for 1894' $A A^{2}$ xvii (1895) xxii-xxxi.

Anne S. Robertson (revised Lawrence Keppie) The Antonine Wall (Glasgow 1990).

J. Röder 'Zur teknik der römischen Granitindustrie' in Jorns (1959) 17-38.

William Roy The Military Antiquities of the Romans in Britain (1793).

J.K. St. Joseph 'Brownhart Law' PSAN' xi (1951) 170174.

P. Salway 'Excavations at Longbyre (Haltwhistle Parish)' $A A^{4}$ xxxvii (1959) 211-215.

L.F. Salzman Building in England down to 1540 (Oxford, 1952).

H. Schönberger 'The Roman frontier in Germany: an archaeological survey' JRS lix (1969) 145-197. 
Schönberger (1985)

Schütte (1923)

Seaward (1976)

Seaward (1993)

Shaw (1926)

Shaw (1958)

Shaw (1982)

Shaw (1995)

Sherk (1974)

Sherlock (1978)

Shirley (2000)

Sim and Ridge (2002)
Hans Schönberger Die römischen Truppenlager der frühen und mittleren Kaiserzeit zwischen Nordsee und Inn Sonderdruck aus Bericht der Römisch-Germanischen Kommission 66 (Mainz, 1985) 321-49.

G. Schütte 'Der Römersteinbruch am Spitzelofen' 38 Jahresbericht des Stiftgymnasiums der Benediktiner zu St. Paul (Kärnten, 1923) 3-13.

Mark R.D. Seaward The Vindolanda Environment, (Haltwhistle, 1976).

Mark Seaward 'The environmental material' in van DrielMurray et al. (1993) 91-119.

R.C. Shaw 'Excavations at Willowford' CW' KKYi \{1926\} 429-506.

Noel Shaw 'Two iron rock wedges from Hadrian's Wall' $A A^{4}$ xxxvi (1958) 313-4 and plate xxxii.

Brent D. Shaw 'Fear and loathing: the nomad menace and Roman Africa' in Wells (Ottawa 1982) 25-46 (reprinted with same pagination in Brent D. Shaw Rulers, Nomads, and Christians in Roman North Africa (Aldershot 1995). Brent D. Shaw Rulers, Nomads, and Christians in North Africa (Aldershot, 1995).

Robert K. Sherk 'Roman geographical exploration and military maps' ANRW II (Berlin, 1974) 534-562.

David Sherlock 'Roll out the barrow' Building 22/29 (1978) 22-23.

Elizabeth Shirley The Construction of the Roman Legionary Fortress at Inchtuthil BAR British Series 298, (2000).

David Sim and Isabel Ridge Iron for the Eagles (Stroud, 2002). 
Simpson (1913)

Simpson (1923)

Simpson (1931)

Simpson (1932)

Simpson (1934)

Simpson (1974)

Simpson (1975)

Simpson (1976)

Simpson et al. (1934)

Simpson et al. (1935)

Simpson et al. (1936a)

Simpson et al. (1936b)
Frank Gerald Simpson 'Excavations on the line of the Roman Wall in Cumberland during the years 1909-1912' $C W^{2}$ xiii (1913) 297-397.

F.G. Simpson 'An excavation at Chesters in October, 1921' PSAN $^{3} \mathrm{x}$ (1923) 216-7.

F.G. Simpson 'Excavations on Hadrian's Wall between Heddon-on-the-Wall and North Tyne in 1930' $A A^{4}$ viii (1931) 305-327.

F.G. Simpson 'The Wall at the Sewage Disposal Works, Carlisle' $C W^{2}$ xxxii (1932) 149-151.

F.G. Simpson 'Boothby, Castle Hill' $C W^{2}$ xxxiv (1934) $154-5$.

Grace Simpson 'Haltwhistle Burn, Corstopitum and the Antonine Wall' Britannia v (1974) 317-339.

Grace Simpson "The moving milecastle: or how Turret $0 \mathrm{~b}$ came to be called Milecastle $1^{\prime} A A^{5}$ iii (1975) 105-115.

Grace Simpson (Ed.) Watermills and Military Works (Kendal, 1976).

F.G. Simpson, Miss K. Hodgson, and I.A. Richmond 'New turret sites on the line of the Turf Wall, and the type of stone wall associated with them' $C W^{2}$ xxxiv (1934) 130-137.

F.G. Simpson, I.A. Richmond, and James McIntyre 'The Stone Wall, Turf Wall, and Vallum west of Burgh-bySands' $C W^{2} \operatorname{xxxv}$ (1935) 213-220.

F.G. Simpson, I.A. Richmond, Eric Birley, G.S. Keeney and K.A. Steer 'Milecastles on Hadrian's Wall explored in $1935-6^{\prime} A A^{4}$ xiii (1936) 258-273.

F.G Simpson, I.A Richmond, Miss S.K. Hodgson, and K. St. Joseph 'The Stanegate' $C W^{2}$ xxxvi (1936) 182-191. 
Simpson and Hodgson (1948)

Simpson, Hodgson, and Richmond (1953)

Simpson and McIntyre (1932)

Simpson and McIntyre (1933a)

Simpson and McIntyre (1933b)

Simpson and Richmond (1936)

Simpson and Richmond (1935a)

Simpson and Richmond (1935b)

Simpson and Richmond (1935c)

Simpson and Richmond (1937a)

Simpson and Richmond (1937b)

Simpson and Richmond (1940)

Simpson and Richmond (1941)
F.G. Simpson and Miss K.S. Hodgson 'The Coastal Milefortlet at Cardurnock' $C W^{2}$ xlvii (1948) 78-127.

F.G. Simpson, Miss K.S. Hodgson, and I.A. Richmond 'Turrets and milecastles between Burgh-by-Sands and Bowness-on-Solway' $C W^{2}$ lii (1953) 14-16.

F.G. Simpson and James McIntyre 'Pike Hill' $C W^{2}$ xxxii (1932) 145-147.

F.G. Simpson and James McIntyre 'Banks Burn to Randylands' $C W^{2}$ xxxiii (1933) 262-270.

F.G. Simpson and James McIntyre 'Pike Hill' $C W^{2}$ xxxiii (1933) 271-275.

F.G. Simpson and I.A. Richmond "The Roman fort on the Stanegate, and other remains, at Old Church, Brampton' $C W^{2} x x x v i$ (1936) 172-182.

F.G. Simpson and I.A. Richmond 'Randylands Milecastles, 54' $C W^{2}$ xxxv (1935) 236-244.

F.G. Simpson and I.A. Richmond "The use of clay instead of turf at Randylands and Garthside' $C W^{2}$ xxxv (1935) 244-247.

F.G. Simpson and I.A. Richmond 'Bankshead Milecastle, $52^{\prime} C W^{2} \operatorname{xxxv}(1935) 247-256$.

F.G. Simpson and I.A. Richmond 'The Vallum at Milecastles 51, Wall Bowers, and 50TW High House' $C W^{2}$ xxxvii (1937) 157-177.

F.G. Simpson and I.A. Richmond 'The fort on Hadrian's Wall at Halton' $A A^{4}$ xiv (1937) 151-171.

F.G. Simpson and I.A. Richmond 'Roman Britain in 1939' JRS xxx (1940) 162-3.

F.G. Simpson and I.A. Richmond 'The Roman Fort on Hadrian's Wall at Benwell' $A A^{4}$ xix (1941) 1-43. 
Simpson and Richmond (1946)

Simpson and Richmond (1952)

Simpson, Richmond, and McIntyre (1934)

Simpson, Richmond, \& St. Joseph (1935)

Simpson and Shaw (1922)

Simpson and St. Joseph (1934)

Singer et al. (1956)

Smith (1946)

Smith (1978)

Sölter (1970)

Sprater (1948)

Spain and Simpson (1930)

Spain (1934)

Spruytte (1983)
F.G. Simpson and I.A Richmond 'Hadrian's Wall' in 'Roman Britain in 1945' JRS xxxvi (1946) 134-135.

F.G. Simpson and I.A. Richmond 'The Roman fort at Drumburgh' $C W^{2}$ lii (1952) 9-13.

F.G. Simpson, I A. Richmond, and James McIntyre 'Milecastles on the line of the Turf Wall' $C W^{2}$ xxxiv (1934) $144-8$.

F.G. Simpson, I.A. Richmond, and K. St. Joseph 'The Turf Wall milecastle at High House' $C W^{2}$ xxxv (1935) 220-229.

F.G. Simpson and R.C. Shaw 'The Purpose and Date of the Vallum and its Crossings' $C W^{2}$ xxii (1922) 353-433.

F.G. Simpson and Kenneth St. Joseph 'Nether Denton' $C W^{2}$ xxxiv (1934) 152-154.

Charles Singer, E.J. Holmyard, A.R. Hall, and Trevor Williams A history of technology (Oxford, 1956).

H.P. Smith B.Sc. (Eng.), M.I.Struct.E. Constructional Archwork (1946) .

G.H. Smith 'Excavations near Hadrian's Wall at Tarraby Lane 1976' Britannia ix (1978) 19-56.

W. Sölter Römische Kalkbrenner im Rheinland (Düsseldorf, 1970).

F. Sprater Limburg und Kriemhildenstuhl (Speyer, 1948).

G.R.B. Spain and F.G. Simpson 'The Wall from Wallsend to Newcastle upon Tyne' in Northumberland County History vol. xiii (1930) 493-501.

G.R.B. Spain 'The Roman Wall in Westgate, Newcastle upon Tyne' $A A^{4}$ xi (1934) 227-233.

J. Spruytte Early Harness systems (1983). 
Steer and Feachem (1954)

Stevens (1941)

Stevens (1947)

Stevens (1948)

Stevens $(1948 a)$

Stevens (1966)

Stone Federation (n.d.)

Stukeley (1776)

Sumpter and Coll (1977)

Susini (1973)

Swinbank (1952)

Swinbank and Spaul

Taylor (1997)

Taylor (1999)
K.A. Steer and R.W. Feachem 'The Roman Fort and Temporary Camp at Oakwood, Selkirkshire' PSAS 86 1951-2 (1954) 81-105.

C.E. Stevens "The British Sections of the 'Notitia Dignitatum" AJ xcvii (1941) 125-154.

C.E. Stevens 'Roman Britain in 1946' JRS xxxvii (1947) 168.

C.E. Stevens 'The Building of Hadrian's Wall' $A A^{4}$ xxvi (1948) 1-46.

C.E Stevens 'Roman Britain in 1947' JRS xxxviii (1948) 84.

C.E. Stevens The Building of Hadrian's Wall CW Extra Series XX (Kendal, 1966).

The Stone Federation Natural Stone Glossary (n.d.).

William Stukeley Itinerarium Curiosum Vol. II Iter Boreale (1776).

A.B. Sumpter and S Coll Interval Tower SW5 and the South-west Defences: Excavations 1972-75. The Archaeology of York 3/2 (1977).

Giancarlo Susini The Roman Stonecutter (Oxford 1973).

B. Swinbank 'Roman Britain in 1951' JRS xlii (1952) 89. Brenda Swinbank and J.E.H. Spaul "The spacing of forts on Hadrian's Wall' $A A^{4}$ xxix (1951) 221-238.

D.J.A. Taylor 'The Roman fort at Benwell: a reexamination of its size' Durham Archaeological Journal $13,61-64$.

David J.A. Taylor 'The forts on Hadrian's Wall: a comparative analysis of the form and construction of some buildings' Unpublished $\mathrm{PhD}$ thesis, University of Durham. 
Taylor (2000)

Thatcher (1907)

Thompson (1983)

Tomlin and Hassall (1998)

Turnbull (1998)

Van der Veen

Van Driel-Murray (1990)

Veterinary Department (1908)

Vicat (1837)

Wacher (1988)

Waelkens et al. (1988)

War Office (1935)

War Office (1936)

Warburton (1753)

Ward (1903)

Ward-Perkins (1971)
David J.A. Taylor The forts on Hadrian's Wall BAR British Series 305 (Oxford, 2000).

A.G.H. Thatcher Scaffolding (1907).

F.M.L. Thompson (Ed.) Horses in European Economic History (1983).

R.S. O Tomlin and M.W.C Hassall 'Roman Britain in 1997, II Inscriptions' Britannia xxix (1998).

Percival Turnbull 'Excavations at Milefortlet 21' $C W^{2}$ xcviii (1998) 61-106.

Marijke van der Veen Crop Husbandry Regimes Sheffield Archaeological Monographs 3 (Sheffield, 1992).

C. van Driel-Murray 'The Roman Army Tent' Exercitus vol. $2 / 8$ (1990) 137-144.

The Veterinary Department Animal Management (1908).

L.J. Vicat Mortars and Cements (facsimile reprint Donhead St. Mary, 1997).

John Wacher (ed.) The Roman World (1988).

M. Waelkens, P. De Pape and L. Moens 'Patterns of extraction and production in the white marble quarries of the Mediterranean: history, present problems and prospects' in Fant (1988) 81-116.

Military Engineering, Vol. V (War Office, 1935).

Military Engineering Vol. II (War Office, 1936).

John Warburton Vallum Romanum (1753).

J. Ward The Roman Fort of Gellygaer in the County of Glamorgan (1903).

J.B. Ward-Perkins, 'Quarrying in Antiquity; Technology, Tradition and Social Change', Proceedings of the British Academy lvii (1971). 
Ward-Perkins (1992)

Ward-Perkins (1993)

Warland (1929)

Walthew (1981)

Watson (1969)

Webster (1991)

Webster and Woodfield (1966)

Wells (1972)

Welsby (1985)

Wenham (1962)

Wessex (1983)

Whittaker (1994)

Whitworth (1994)

Whitworth (1997)
Hazel Dodge \& Bryan Ward-Perkins Marble in Antiquity. Collected papers of J.B. Ward Perkins (Rome, 1992).

J.B. Ward-Perkins The Severan Buildings of Lepcis Magna (Ed Philip Kenrick) Society for Libyan Studies, Monograph No. 2 (1993).

E.G. Warland Modern Practical Masonry (1929) (and shortened edition 1953).

C.V. Walthew 'Possible Standard Units of Measurement in Roman Military Planning' Britannia xii (1981) 15-35.

G.R. Watson The Roman Soldier (1969). Janet Webster 'The Bronze Head of a Mule from Great Llanmelin Farm, Gwent' Britannia xxii (1991) 219-220 and pl.XXIV.

Graham Webster and Paul Woodfield ' The Old Work' at the Public Baths at Wroxeter' $A J$ xlv1 (1966) 229-239.

C.M. Wells The German Policy of Augustus (Oxford, 1972).

D.A. Welsby "The Pottery from the Two Turrets at Garthside on Hadrian's Wall' $C W^{2} \operatorname{lxxxv}(1985)$ 72-76. Peter Wenham 'Excavations and discoveries within the legionary fortress in Davygate, York, 1955-8' YAJ xl (1962) 507-587.

Wessex Comprehensive Building Price Book 1983/4 (Beaminster, 1983).

C.R. Whittaker Frontiers of the Roman Empire: a social and economic study (Baltimore and London 1994).

Alan Whitworth 'Recording the Roman Wall' $A A^{5}$ xxii (1994) 67-78.

Alan Whitworth 'Recording of Hadrian's Wall at Willowford Farm' $C W^{2}$ xcvii (1997) 57-61. 
Williams (1968)

Wilmott (1997)

Wilmott (1999)

Wiltshire (1997)

Woodfield (1965)

Woolliscroft (1989)

Woolliscroft (1999)

Woolliscroft (2001)

Woolliscroft (2002)

Wright (1977)

Wright (1985)
John H. Williams 'Stone building materials in Roman Britain' unpublished M.A. thesis University of Manchester 1968. .

Tony Wilmott Birdoswald: Excavations of a Roman fort on Hadrian's Wall and its successor settlements: 1987-92 English Heritage Archaeological Report 14 (1997).

T. Wilmott 'Black Carts' in Bidwell (1999) 120-122.

Patricia J.E. Wiltshire 'The pre-Roman environment' in Wilmott et al (1997), 25-40.

Charmian Woodfield 'Six turrets on Hadrian's Wall' $A A^{4}$ xliii (1965) 87-200.

David J. Woolliscroft 'Signalling and the design of Hadrian's Wall' $A A^{5}$ xvii (1989), 5-19.

D.J. Woolliscroft 'More thoughts on the Vallum' $C W^{2}$ xcix (1999) 53-65.

D.J. Woolliscroft Roman Signalling (Stroud, 2001).

D.J. Woolliscroft The Roman Frontier on the Gask Ridge Perth and Kinross BAR British Series 335 (Oxford, 2002).

R.P. Wright 'A Roman Veterinary Physician from the Thames Valley' Britannia viii (1977) 279-282.

R.P. Wright 'The locating of Roman structures along the line of Hadrian's Wall between Wallsend (Segedunum) and Milecastle $2^{\prime} A A^{5}$ xiii (1985) 231-214. 